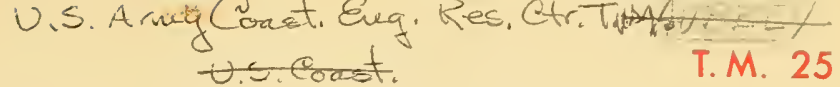

THE TSUNAMI

of the

Alaskan Earthquake, 1964 :

Engineering Evaluation

by

Basil W. Wilson

and

Alf Tørum

TECHNICAL MEMORANDUM NO. 25

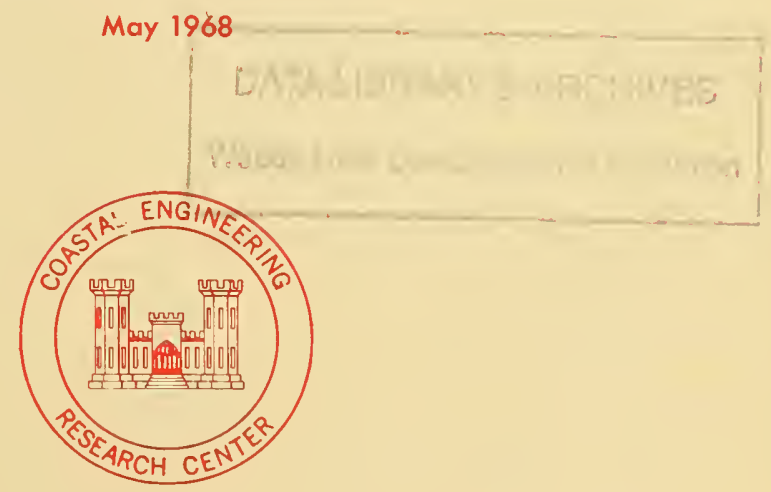

\author{
U. S. ARMY \\ CORPS OF ENGINEERS
}

COASTAL ENGINEERING RESEARCH CENTER 
All uncredited original material in this report is public property and not subject to copyright.

Material in this report from outside sources has been used with the knowledge and permission of the authors, contributors and/or publishers. Credit has been given in the text at the point of use. Full identification of works referred to is given in LITERATURE CITED beginning on page 385, including notice of copyright where requested by the source. It is possible that other material for which no such notice was requested is also subject to copyright. Anyone wishing to make further use of any of this outside source material, by itself and apart from the context in which herein presented, should seek necessary permissions direct from such sources.

Reprint or re-publication which includes any of the uncredited original material in this report should identify this report, the authors, and the Coastal Engineering Research Center. If the reprint or republication additionally includes credited material from outside sources the statements on this page should be referenced thereto. 


\section{THE TSUNAMI of the}

Alaskan Earthquake, 1964:

Engineering Evaluation

by

Basil W. Wilson and Alf Tørum

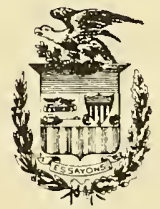

U. S. ARMY

CORPS OF ENGINEERS

COASTAL ENGINEERING RESEARCH CENTER 



\section{ABSTRAC'T}

The purpose of this study is to evaluate the tsunami of Good Friday 1964. The evaluation is directed to an engineering view of the causes, effects, and future protective measures. A secondary purpose is to evaluate the oceanographic and geophysical nature of tsunami generation. Based on the literature of earlier investigators and on field investigation by the authors, the study gives a picture of what occurred. Analyses by the authors also suggest an explanation of how it occurred.

Started nearly two years after the event, the study had the advantage of collecting data from a great number of sources - sources that would not have been available much closer to the event. A disadvantage was that vital engineering evidence concerning structural damage was lost during cleanup and reconstruction.

Nature of the earth dislocation is described and related to the generation, propagation, and dispersion of the main tsunami waves. It is inferred that this earthquake (as perhaps many great earthquakes) was triggered by the lunisolar forces on the earth's crust at syzygy and by the moment-arm forces of local spring tide differentials. The complex tectonic movements may, for simplification, be imagined as a gigantic wave-paddle that pushed an initial wave 10 to 20 meters high along a front of 650 kilometers. Propagation of this enormous wave is followed to Canada, Washington, Oregon, and California, to Hawaii, Russia, Japan, and New Zealand, even to Tierra del Fuego and Antarctica.

Detailed studies of the main tsunami and local seismic sea waves are given for damaged areas in Alaska, especially those in Prince William Sound. Similar studies are presented for areas in Canada, Washington, Oregon and California. In addition to the wave analysis for each place, an engineering evaluation is presented for severely damaged areas. Included are marigrams of component waves and oscillations for many places reached by the tsunami, based on a subjective analysis of tide gage records. These analyses relate the tsunami waves to local bay and shelf oscillations, and to the local tides.

For convenience, the study is summarized in Section VII, and conclusions are presented in sections VIII and IX.

\section{FOREWORD}

Although large tsunamis are relatively rare occurrences, they cause major damage when they do occur. The Alaskan tsunami of March 1964 generated a great deal of interest in the scientific community as a whole, and in various Federal agencies concerned with tsunami warning and protection, including the U. S. Army Corps of Engineers which is particularly involved in the planning and design of protective structures to prevent or mitigate damage in harbors and along shores. This general scientific interest was also stimulated by the establishment of a National Academy of Sciences Committee on the Alaska Earthquake. Two panels of that Committee, the 
Panel on Engineering and the Panel on Oceanography, were particularly interested in the tsunami aspects of the earthquake. Their interest, together with that of the Corps of Engineers, resulted in the U. S. Army Coastal Engineering Research Center initiating a contract with Science Engineering Associates to make an engineering study of the effects of this tsunami, and from these to derive conclusions as to engineering applications and approaches for preventing or mitigating tsunami damage. This contract was sponsored by the Coastal Engineering Research Center, and administered through its Research Division.

This report is a final report on this study, and was prepared by Dr. Basil W. Wilson (Director of Engineering Oceanography, Science Engineering Associates) and Mr. Alf T $\phi r u m$, then with Science Engineering Associates, but now returned to his former affiliation with the River and Harbor Research Laboratory at the Technical University of Norway, Trondheim.

The authors would like to express their appreciation for the help of Messrs. Takashi Umehara and George Zwior who, in addition to much of the drafting work, undertook much painstaking research and detailed measurements from photographs and other sources in the compilation of the damage maps of Kodiak, Seward, and Valdez. The authors also have greatly appreciated the personal interest and encouragement of Dr. George Housner (Chairman of the Panel on Engineering of the NAS Committee on the Alaska Earthquake), Mr. Doak Cox (Chairman of the Panel on Oceanography of that Committee) and the members of their respective panels, as also of Dr. Konrad Krauskopf and Mr. William Petrie, respectively Chairman and Executive Secretary of that Committee: also the personal interest and help of Thorndike Saville, Jr., Chief, Research Division and Richard H. Allen, Chief, Publications Branch, both of the Coastal Engineering Research Center. The authors state their recognition that it is impossible to make individual acknowledgment to all of the many people, authors, and agencies that have contributed either verbal information or written and photographic material; however, as far as possible, their contributions have been acknowledged in the text or in the figures. The authors have greatly appreciated the cooperation of all of these.

At the time of publication Joseph M. Caldwell was Acting Director of the Coastal Engineering Research Center.

NOTE: Comments on this publication are invited. Discussion will be published in the next issue of the CERC Bulletin.

This report is published under authority of Public Law 166, 79th Congress, approved July 31, 1945, as supplemented by Public Law 172, 88 th Congress, approved November $7,1963$. 
Section I. INTRODUCTION . . . . . . . . . . . . . . . . . I

Section II. THE NATURE OF EARTH DISLOCATION AND MOVEMENT • . . . 3

1. The Geological Character of Faults in Alaska . . . . . . 3

2. Historical Distribution of Earthquakes in Alaska . . . . 5

3. Vertical Earth Movement During the Alaskan Earthquake . . 9

4. Horizontal Earth Movement During the Alaskan Earthquake . 20

5. Seismic Evidence for Fault-Plane Mechanism . . . . . . . 24

6. Character of the Source Inferred from Tsunami Waves . . . 28

7. Speculation on the Cause of the Earthquake and the

Earthquake Mechanism . . . . . . . . . . . 39

Section III. GENERATION, PROPAGATION, AND DISPERSION OF THE MAIN TSUNAMI . . . . . . . . . . . . 49

1. The Inferred Mechanism of Tsunami Generation . . . . . 49

2. The Heights of Tsunamis Near Their Source . . . . . . . . 49

3. Progression and Dispersion of the Tsunami Across the

4. Height Characteristics of the Main Tsunami . . . . . . . . .

4. Height Characteristics of the Main Tsunami . . . •. •. • 98

5. Period Characteristics of the Main Tsunami . ... . . . . 103

6. The Transfer of Tsunami Energy to Higher Frequencies . . 106

7. The Relationship of Runup to Coastal Resonance . . . . . 114

8. Sub-Harmonic Effects of the Alaskan Tsunami . . . . . . . 115

9. Heights of Runup Along the North American Coast . . . . . 118

10. Heights of Runup Along the Hawaiian Islands . . . . . . 132

Section IV. EFFECTS OF THE MAIN TSUNAMI AND OF LOCAL SEISMIC SEA WAVES IN ALASKA . . . . . . . . . . . 137

1. Tsunami at Kodiak City, Kodiak . . . . . . . . . . . 137

2. Tsunami Damage at Kodiak City . . . . . . . . . . . 147

3. Tsunami Damage at the U. S. Naval Station, Kodiak . . . . 164

4. Tsunami Damage at Other Coastal Communities on Kodiak and Neighboring Islands . . . . . . . . . . . . 189

5. Seismic Sea Waves in Cook Inlet . . . . . . . . . . . . 198

6. The Tsunami in Resurrection Bay, Kenai Peninsula . . . . 204

7. Tsunami Damage at Seward, Alaska . . . . . . . . . 231

Section V. EFFECTS OF THE MAIN TSUNAMI AND OF LOCAL SEISMIC SEA WAVES IN PRINCE WILLIAM SOUND . . . . . . . 247

1. The Gross Picture of Behavior of Prince William Sound . . 247

2. Tsunami Waves in Port Valdez, Prince William Sound . . . 254

3. Tsunami Damage at Valdez, Alaska . . . . . . . . . . 284

4. Tsunami Waves at Whittier, Prince William Sound . . . . . 292

5. Tsunami Damage at Whittier,Alaska . . . . . . . . . . 297

6. Tsunami Waves and Damage at Cordova, Prince William Sound 3.1 
CONTENTS

Page

Section VI. EFFECTS OF MAIN TSUNAMI ON NORTH AMERICAN SEABOARD . .

1. Tsunami Damage Along the Canadian Pacific Coast . . . .

2. Tsunami Damage at Port Alberni, Vancouver Island, Canada.

3. Tsunami Damage Along the Washington-Oregon Coasts, United States . . . . . . . . . . . . . . . . .

4. Tsunami Damage Along the California Coastline . . . . .

5. Tsunami Damage at Crescent City, California . . . . . 328

Section VII. SUMMARY . . . . . . . . . . . . . . 347

1. Introduction ................ . . 347

2. The Nature of Earth Dislocation and Movement . . . . . . 347

3. Generation, Propagation and Dispersion of the Main Tsunami Waves ................... 350

4. Effects of the Main Tsunami and of Local Seismic Sea Waves in Alaska . . . . . . . . . . . . . 354

5. Effects of the Main Tsunami and of Local Seismic Sea Waves in Prince William Sound . . . . . . . . . . 358

6. Effects of the Main Tsunami Along the North American Seaboard ................... 361

Section VIII. CONCLUSIONS . . . . . . . . . . . . 363

1. Introduction ................ . . 363

2. Water Particle Velocities and Pressure Forces from Tsunamis

3. The Ability of Structures to Withstand Tsunamis . . . . 366

4. Harbor Structures: Their Damage and Protection . . . . . 367

5. Damage from Scour . . . . . . . . . . . . . 369

6. Protective Measures for Ships and Boats in Harbors . . . . 369

7. Economic Aspects of Protective Measures . . . . . . . . . 371

Section IX. SUMMARIZED CONCLUSIONS . . . . . . . . . . . . 373

1. Earthquake and Tsunami Generation Characteristics . . . 373

2. Tsunami Propagation Characteristics . . . . . . . 374

3. Features of Tsunami Damage . . . . . . . . . . . 375

4. General Design Criteria for Tsunami Protection . . . . 377

Section X. LIST OF SYMBOLS . . . . . . . . . . . . . 381

LITERATURE CITED . . . . . . . . . . . . . . . . 385

Appendix A U. S. Fleet Weather Central, Kodiak, Alaska . . . . . A-1

Appendix B Tables B-1 to B-5 . . . . . . . . . . . . . . B-I

Appendix C Tsunami Characteristics and Runup . . . . . . . . . C-1

Appendix D The Flow and Force Field of Tsunami Waves . . . . . . D-l

Appendix E Estimates of Damage Caused by the Alaskan Tsunami . . E-I 


\section{ILLUSTRATIONS}

Figure

Page

1 General map of south-central Alaska covering the area most affected by the Earthquake . . . . . . . . . . 2

2 (a) Major physiographic Divisions of Alaska........ . 4

(b) Areal extent of the effects of the Earthquake . . . . . 4

3 Epicenters of Major Alaskan Earthquakes . . . . . . . 6

4 Alaskan Earthquake energy release (ergs per unit area, $\left.2^{\circ} \mathrm{EW}-4^{\circ} \mathrm{NS}\right) 1904-1964$. . . . . . . . . . . . 7

5 Mean annual occurrence of shallow focus earthquake shocks . 8

6 Map and sections of the Kurile-Kamchatka segment of the circum-Pacific arc. . . . . . . . . . . . . 10

7 Zones of disturbance in the Alaskan Earthquake . . . . . 11

8 Tectonic uplift and subsidence in south-central Alaska . . 12

9 Contours of tectonic land-level change in Prince William Sound (levels in feet) ................. 14

10 Contours of tectonic land-level change in Prince William Sound ....................... .

11 Tectonic land-level change (in meters) and faulting in the Montague Island Region . . . . . . . . . . . .

12 Tectonic sea-bottom change (in feet) southwest of Montague Island . . . . . . . . . . . . . . . . 17

13 Bathymetric cross sections southwest of Montague Island . . 18

14 Schematic cross sections across the Aleutian Arc showing land-level changes . . . . . . . . . . . . .

15 Apparent horizontal displacement of south-central Alaska.

16 Magnitude and direction of apparent horizontal land displacement

17 Trend of dependence of maximum resultant ground displacement on earthquake magnitude . . . . . . . . . . . . 23

18 Epicenter locations of earthquake of March 27-28, 1964, and aftershocks through December 31, 1965. 


\section{ILLUSTRATIONS}

Figure

19 Theoretical models of vertical movements associated with

Alaskan Earthquake on a section normal to belt of epicenters .

20 Equal-area projection of the focal mechanism solution based on first motion of $\mathrm{P}$ waves . . . . . . . . . . . . . . 29

21 Mechanism diagrams (stereographic projection of earthquakes) in Prince William Sound Region and Kodiak Island Region . . . 29

22 Tectonic displacements of the free surface . . . . . . . . 31

23 Relationship of major fault length to earthquake magnitude . . 33

24 Microbarograph record from La Jolla showing atmospheric "tsunami" from Alaskan earthquake. . . . . . . . . . 34

25 (a) Projection of imaginary wavefronts from observation stations back towards the tsunami source . . . . . . 35

(b) Hypothetical model of the tsunami source, showing negative and positive wave fronts... . . . . . 35

26 (a) Inferred generating area of the Alaskan Tsunami . . . . 36

(b) Apparent generating area of the Alaskan Tsunami . . . . 37

27 Approximate locations of Tsunami Wave front at one-hour intervals (GMT) in the Pacific Ocean ......... 38

28 Relationship of diameter of tsunami source region to Earthquake magnitude... . . . . . . . . . . . . 41

29 Pictorial view of relative positions of earth, moon, and sun on occasions of notable great earthquakes . . . . . 42

30 Schematic diagram of the earth, moon, and sun relationship at the time of the Alaskan earthquake . . . . . . . 42

31 Tide elevations with reference to mean sea level at the time of the Alaskan earthquake . . . . . . . . . 44

32 Oscillations of water level in the Gulf of Mexico, related to the Alaskan earthquake ............. 45

33 General Bathymetry of the Continental Shelf, Gulf of Alaska, Prince William Sound and Cook Inlet

34 Inferred mechanism of tsunami generation between Montague and Middleton Islands, Gulf of Alaska 


\section{ILLUSTRATIONS}

Figure

Page

35 Observed tsunami wave activity at Cape Yakataga . . . . . . . 55

36 Inferred mechanism of tsunami generation on the Continental Shelf off the Kenai Peninsula, Alaska . . . . . . . . . 56

37 Inferred mechanism of tsunami generation on the Continental Shelf off Kodiak, Alaska . . . . . . . . . . . . 57

38 Water level fluctuations in Womens Bay, Kodiak, based on observations of Lt. C. R. Barney, U. S. Naval Station, Kodiak . 58

39 Theoretical wave forms generated by radially symmetric model of sudden water surface disturbance . . . . . . . . . . 60

40 Observed tsunami runup along the coasts of Kodiak and Afognak Islands . . . . . . . . . . . . . . . . .

41 Heights of tsunamis to be expected at a coast from submarine earthquakes of varying magnitude within a 500-mile range .

42 Schematic representation of the progression of the Alaskan tsunami in the first hour following the earthquake . . . . .

43 Subjective analysis of marigram for Yakutat, Alaska . . . . 66

44 Subjective analysis of marigram for Juneau, Alaska . . . . . 67

45 Subjective analysis of marigram for Sitka, Alaska . . . . . 68

46 Subjective analysis of marigram for Prince Rupert, Canada . . 69

47 Subjective analysis of marigram for Port Alberni, Canada . . 70

48 Subjective analysis of marigram for Victoria, Canada . . . . 71

49 Subjective analysis of marigram for Crescent City, California 72

50 Subjective analysis of marigram for San Francisco, California 73

51 Subjective analysis of marigram for Rincon Island, California 74

52 Subjective analysis of marigram for San Diego, California . . 75

53 Subjective analysis of marigram for Talcahuano, Chile . . . 76

54 Subjective analysis of marigram for Corral, Chile . . . . . 77 


\section{ILLUSTRATIONS}

Figure

55 Subjective analysis of marigram for Ushuaia, Tierra Del

Fuego, Argentina . . . . . . . . . . . . . . . . .

56 Subjective analysis of marigram for Argentine Island,

Palmer Peninsula, Antarctica . . . . . . . . . . . .

57 Subjective analysis of marigram for Midway Islands, Hawaii . .

58 Subjective analysis of marigram for Mokuoloe Island, Oahu, Hawaii.

59 Subjective analysis of marigram for Hilo, Hawaii . . . . . .

60 Subjective analysis of marigram for Lyttelton, New Zealand. .

61 Subjective analysis of marigram for Moen Island, Truk, Caroline Islands

62 Subjective analysis of marigram for Massacre Bay, Attu, Aleutian Islands . . . . . . . . . . . . . . . . .

63 Subjective analysis of marigram for Poronaysk, Sakhalin Island

64 Subjective analysis of marigram for Yuzhno, Kurilsk, Kuril Islands

65 Subjective analysis of marigram for Hanasaki, Japan

66 Subjective analysis of marigram for Ofunato, Japan . . . . . .

67 Time changes in wave energy spectra for the tsunami, March 1964, at Hilo and Honolulu, Hawaii

68 Map of Vancouver Island, Canada, showing location of Port Alberni at the head of Alberni Inlet .

69 Location of Lyttelton, New Zealand, in relation to the Inlet of Port Lyttelton

70 Height decay with distance for the primary tsunami waves . . .

71 Relationship of primary tsunami period to earthquake magnitude 105

72 Oscilıating characteristics of Hilo Bay, Hawaii . . . . . . 109

73 Oscillating characteristics of Continental Shelf off Crescent City 


\section{ILLUSTRATIONS}

Figure

Page

74 Wave energy spectrum for tide-gage marigram at Crescent City, registered at the time of the Chile tsunami, May 1960 . . . . 113

75 Wave crest elevation above still water as a function of relative water depth and wave steepness.......... . 116

76 Influence of resonance on wave runup on uniformly sloping Continental Shelves . . . . . . . . . . . . . . . . .

77 Maximum heights of tsunami waves recorded at tide stations along the North American seaboard from Alaska to Vancouver Island . . . . . . . . . . . . . . . 119

78 Maximum heights of tsunami waves recorded at tide stations or river gaging stations in the Vancouver Island Region, Canada . . . . . . . . . . . . . . . . I20

79 Maximum heights of tsunami waves recorded along the Washington-Oregon coastline . . . . . . . . . . . . 122

80 Sample tide gage records from stations along the Columbia River . . . . . . . . . . . . . . . 123

81 Analysis of tsunami wave propagation up the Columbia River, Washington-Oregon . . . . . . . . . . . . . 124

82 Maximum runup heights of tsunami waves observed along the north-central California coast . . . . . . . . . . . 127

83 Geometrical analogy of Monterey Bay to the quadrant of a circular basin . . . . . . . . . . . . . . . . 129

84 Possible modes of oscillation for Monterey Bay as a circular quadrant basin of uniform depth . . . . . . . . 130

85 Marigrams recording the tsunami in Southern California waters . 133

86 Maximum runup heights of tsunami waves (referred to MLLW) measured along the coasts of the Hawaiian Islands . . . . . . . 135

87 Bathymetry of coastal region adjacent to Kodiak City, Kodiak . 139

88 Location of the Kodiak Naval Station and the City of Kodiak . . 140

89 Map of Kodiak City and Harbor with details of the breakwaters. 141

90 Hypothetical marigrams for Kodiak City based on eyewitness observations 


\section{ILLUSTRATIONS}

Figure

91 View along Marine Way at Kodiak City during the rise of the second tsunami wave............. . . 148

92 View of Kodiak City waterfront and boat harbor at about 1836 (AST) March 27, 1964 . . . . . . . . . 149

93 View from the Elks Club Bowling Alley showing the wave still rising at Kodiak City at about 1838 (AST) March 27, 1964 . . 150

94 View of Kodiak City boat harbor at approximately 1841 (AST) March 27, 1964

95 View (south-southwest) of the boat harbor at Kodiak City at approximately 1845 (AST) March 27, 1964. . . . . . . .

96 Map of Kodiak City and boat harbor as existing prior to the earthquake

97 Subjective analysis of the inferred marigram for Kodiak City 154

98 Aerial view of St. Pauls Harbor and Kodiak . . . . . . . . 155

99 Laboratory-produced surge waves believed to be similar to the tsunami surges in Near Island Channel, Kodiak City . . . 157

100 Kodiak before the earthquake . . . . . . . . . . . 158

101 (a) Skeleton-like timber pilings mark former site of cannery in this view northeast along Near Island Channel 160

(b) Pre-earthquake view of Near Island Channel and Harbor facilities, Kodiak City . . . . . . . . . . .

102 Southwest breakwater at Kodiak shortly after the earthquake with some of the battered remains of the King Crab Cannery.

103 Map of Kodiak City, boat harbor and inner anchorage after the earthquake and tsunami . . . . . . . . . . 166

104 Tsunami damage in downtown Kodiak . . . . . . . . . . 168

105 Tsunami damage in downtown Kodiak. Some cleanup has been done 169

106 View of part of Kodiak City showing destruction wrought by the tsunami

107 Kodiak City at high tide on March 28, 1964 after the earthquake 171 


\section{ILLUSTRATIONS}

Figure

108 (a) Waterfront of Kodiak on the day following the earthquake and tsunami . . . . . . . . . . . 172

(b) Pre-earthquake view of the waterfront at Kodiak City . . . 173

109 Map of Shahafka Cove area, Kodiak, showing damage, area of inundation, and direction of initial seismic sea waves . . . 174

110 View seaward showing tsunami damage at Potato Patch Lake . . 175

11 View of the inundation from the first tsunami wave at the head of Womens Bay, Kodiak, at about 1835 (AST) March 27, 1964176

112 View (northwest) of inundation from the first tsunami wave in Womens Bay, Kodiak, at about 1835 (AST) March 27, 1964 . 177

113 Area of maximum inundation by seismic sea waves and structures damaged at Kodiak Naval Station . . . . . . . . . 178

114 Partial recession of the first tsunami wave at the Navy Air Terminal, Womens Bay, Kodiak . . . . . . . . . . . 179

115 Damaged cargo dock at the Naval Station, Kodiak; view northeast

116 The Fuel Pier at the Naval Station, Kodiak, inundated by postquake high tide... . . . . . . . . . . . . 182

11 Hobby Shop Boat Repair House at the Naval Station, Kodiak . 183

118 Damaged Hobby Shop at the Naval Station, Kodiak . . . . . . . 184

119 The Ground Electronics Building at Kodiak Naval Station . . . 185

120 Mooring buoy washed ashore by seismic sea waves, Kodiak Naval Station . . . . . . . . . . . . . 187

121 Evidence of settlement of backfill material below pavement level, adjacent to the foundation of a hangar at Kodiak Naval Station

122 Roadbed eroded at the tip of the Nyman Peninsula . . . . . . . 190

123 Damaged road on the deltaic area at the southwest head of Womens Bay . . . . . . . . . . . . . . . . . . 191

124 Damaged road bridge on the deltaic area at the southwest head of Womens Bay. 


\section{ILUUSTRATIONS}

Figure

125 Close-up view of damaged road bridge on the deltaic area of the southwest head of Womens Bay . . . . . . . . . . 193

126 Planimetric sketch-map of Afognak showing approximate

limits of inundation by seismic sea waves . . . . . . . . . 194

127 Tsunami inundation of Uzinki, Spruce Island . . . . . . . . 196

128 Bathymetry of portion of southeast coast of Kodiak Island . . 200

129 T'sunami inundation of Old Harbor, Kodiak Island . . . . . . 201

130 Bathymetry of the Continental Shelf at mouth of Cook Inlet . 202

131 Comparison of the high-water line along Homer Spit before and after the earthquake and submergence of March 27, 1964 . . . 205

132 Bathymetry of Seldovia Bay in the region of Port of Seldovia . 206

133 (a) Inferred mechanism of tsunami generation of the Continental Shelf athwart and including Resurrection Bay . . . . . 207

(b) Schematic representation of Resurrection Bay as a chain system of basins . . . . . . . . . . 207

134 Bathymetry of Resurrection Bay, Kenai Peninsula and the location of Seward... . . . . . . . . . . . 208

135 Seward before the earthquake . . . . . . . . . . . . . 211

136 Plan of Seward as existing prior to the earthquake . . . . . 212

137 Inferred Marigram for Seward, Alaska . . . . . . . . . . 216

138 Remains of the Alaska Railroad Docks at the south end of Seward after the earthquake and seismic sea waves . . . . . 217

139 Schematic representation of submarine slide near south end of Seward giving rise to first seismic sea wave to devastate the waterfront... . . . . . . . . . . . 219

140 Deck of the tanker "Alaska Standard" with wreckage from the Standard Oil Company of California Dock at Seward . . . . . . 220

141 View of the Texaco Tank Farm and debris still burning along the waterfront on the day following the earthquake at Seward . 221 


\section{ILLUSTRATIONS}

Figure

142 (a) View looking southeast at Seward from location A . . . 222

(b) View looking east-northeast from location A . . . . . 223

(c) View looking east shows later wave crest illuminated by burning oil, at about 2120, March 27, 1964 . . . . 224

143 (a) View of the first seismic sea wave advancing southward along the coast from Seward towards Lowell Point . . . . 227

(b) View of the first seismic sea wave advancing southward along the coast from Seward toward Lowell Point . . . . 228

144 Map of the northern part of Resurrection Bay including Seward 229

145 Plan of Seward after the earthquake . . . . . . . . . . 232

146 View of the Alaska Railroad switchyard and engine roundhouse after the earthquake and seismic sea waves . . . . . . . . 234

147 Wave damage in the Alaska Railroad marshalling yard - view looking northeast .. . . . . . . . . . . 236

148 Wave damage in the Alaska Railroad marshalling yard . . . . . 237

149 Part of the Alaska Railroad freight yard showing tracks stripped of their rails . . . . . . . . . . . . . 238

150 115-ton switching locomotive No. 7107 transported and overturned . . . . . . . . . . . . . . 239

151 125-ton locomotive transported and overturned by waves . . . . 240

152 Approximate calculation of water velocities to overturn locomotive No. 7107 . . . . . . . . . . . 241

153 Engine "Roundhouse" near the Alaska Railroad marshalling yards 242

154 Wreckage of houses and boats carried into the lagoon by waves 243

155 The chaos of wreckage left by the seismic sea waves at the northwest end of the head of Resurrection Bay . . . . . . . . 245

156 Remains of 6-ton truck at Lowell Point near Seward . . . . . 246

157 Bathymetry of Prince William Sound and its approximation as a triangular basin 


\section{ILLUSTRATIONS}

Figure

Page

158 Generalized distribution of larger destructive local waves and known subaqueous slides in Prince William Sound and part of the Kenai Peninsula . . . . . . . . . . . 250

159 Inferred marigrams at five locations in Prince William Sound . 251

160 Bathymetry of Port Valdez and Valdez Arm, Prince William Sound 256

161 Seismic reflection profiles along the axis of Valdez Arm and Port Valdez, showing basement structure and sediments . . . 257

162 Plan of Valdez, Alaska, as existing prior to the earthquake . 258

163 Aerial view of the waterfront at Valdez photographed several years before the earthquake . . . . . . . . . . . 259

164 Valdez after the earthquake . . . . . . . . . . . . 261

165 Inferred marigram for Valdez based on accounts of eyewitnesses 262

166 Inferred path of the SS Chena from an initial position at the North Arm dock, Valdez Harbor, during and after the earthquake

167 Sequence of schematic diagrams illustrating the movements of the SS Chena and the destruction of the harbor at Valdez . . 266

168 View of the first seismic sea wave engulfing the cannery on the North Arm of Valdez Harbor . . . . . . . . . . 267

169 View of first seismic sea wave destroying the cannery of the North Arm of Valdez Harbor . . . . . . . . . . . . 270

170 Momentary quiet in the ruins of the boat harbor at Valdez . . 271

171 View from the Chena while being swept southwestward along coast off Valdez . . . . . . . . . . . . . . . 272

172 Panoramic composite view from the Chena, south of the harbor of Valdez showing water draining from the coast under the effects of the submarine slide. . . . . . . . . . . 273

173 Panoramic composite telephoto view from the Chena of chasm formed by the submarine slide south of the harbor at valdez. . 274

174 Aerial view of the devastation of the waterfront at Valdez in the vicinity of the Standard Oil Company tank farm 


\section{ILLUSTRATIONS}

Figure

175 Pre- and Postquake soundings at Valdez . . . . . . . . . 276

176 Profiles of the seabed near Valdez before and after the earthquake ... . . . . . . . . . . . . .

177 Heights and inferred directions of local waves in the western part of Port Valdez, Prince William Sound . . . . . .

178 Concrete pylon of the navigation light located at the entrance to Port Valdez . . . . . . . . . . . . .

179 Plan of Valdez, Alaska, as existing after the earthquake and tsunami of March 27, 1964 . . . . . . . . . . . .

180 Composite view of the small-boat harbor and docks at Valdez just a day or two before the earthquake . . . . . . . . . .

181 Aerial view of the Valdez waterfront after the earthquake

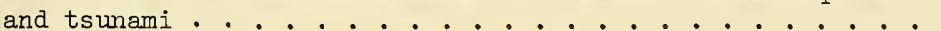

182 Looking east along Alaska Avenue . . . . . . . . . . .

183 The eroded approach ramp to the North dock . . . . . . . . 290

184 Cannery roof and truck on mud flats east of harbor . . . . . 291

185 Map of Port Valdez showing the area contaminated by asphalt from damaged oil tank farm . . . . . . . . . .

186 Looking east on Alaska Avenue before cleanup . . . . . . . .

187 Looking south on Water Street . . . . . . . . . . . . .

188 Bathymetry of Port Wells and tributary fjords including Passage Canal and Whittier, Prince William Sound . . . . . 298

189 Map of Whittier and Head of Passage Canal, Prince William Sound . . . . . . . . . . . . . . . . . .

190 Aerial view of Whittier, Prince William Sound, as existing prior to the earthquake

191 Map of Whittier with particulars of submarine slides and sea waves 


\section{ILLUSTRATIONS}

Figure

Page

193 Map of Whittier showing waterfront details before and after the earthquake and tsunami

194 Aerial view of Whittier after the earthquake showing the devastation of the waterfront

195 Fire and seismic sea wave damage to the Union Oil Company Tank Farm at Whittier . . . . . . . . . . . . . . .

196 Aerial view of the west end of Whittier looking north . . . .

197 Damaged car-barge slips at Whittier . . . . . . . . . . 308

198 Damaged slip tower at Whittier . . . . . . . . . . 309

199 View looking southeast of the Alaska Railroad Depot . . . . 310

200 Bathymetry of Orca Bay and Orca Inlet including Cordova . • . 313

201 Cordova Harbor and Waterfront area . . . . . . . . . . . 314

202 Inferred marigram for Cordova . . . . . . . . . . . . . 315

203 Comparative profiles before and after earthquake . . . . . 316

204 Postearthquake soundings of the U. S. Coast and Geodetic Survey superimposed on old chart show approximate pattern of deposition . . . . . . . . . . . . . . . . .

205 Part of the Harbor Facilities at Cordova showing the effect of regional uplift of the area exposing previous tidal flats.

206 The Cities of Alberni and Port Alberni

207 Inundation suffered by Seaside, Oregon, from the tsunami

208 Plan of Santa Cruz Harbor with high water marks left by the Alaskan tsunami of 1964 .

209 Map of Crescent City, California, showing limit of inundation by the tsunami . . . . . . . . . . . . .

210 (a) Map of Crescent City Harbor, California, with details of breakwater construction . . . . . . . .

(b) Map of downtown Crescent City showing the depth of the maximum tsunami wave overrunning the land 


\section{ILLUSTRATIONS}

Figure

Page

211 Aerial view of northwest side of Crescent City Harbor showing wreckage left by the tsunami . . . . . . . . . .

212 Coast south of Crescent City with piles of logs and debris

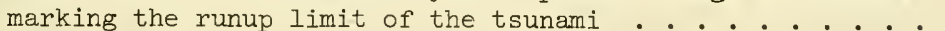

213 Typical section of Citizens Dock at Crescent City . . . . . .

214 Aerial view of Crescent City Harbor after the tsunami, looking north... . . . . . . . . . . . . . .

215 Lumber barge alongside damaged Citizens Dock at Crescent City

216 Cross-section of Citizens Dock showing lumber barge elevated by the maximum tsunami wave . . . . . . . . .

217 Plan of Citizens Dock showing moored lumber barge and pier.

218 Fish shacks nailed to decking jolted from original positions

219 Approach to the Citizens Dock showing tsunami damage . . . . 342

220 Approach to the Citizens Dock damaged by the tsunami . . . 343

221 Typical scene of destruction in the downtown area of Crescent City . . . . . . . . . . . . . . . .

222 Calculation of wave force required to bend a light box normal to the plane of the diagram . . . . . . . . .

B-I Tide stations listed in Tables B-I and B-2 . . . . . . . . B-5

C-l Experimental observations on wave runup . . . . . . . . . C-3

D-1 Schematic diagram of impulsive force of a tsunami surge on a wall. . . . . . . . . . . . . . . . . D Dll 


\section{ILLUSTRATIONS}

Table

I Characteristics of the Alaskan Earthquake of March 1964 . . . 30

II Computed Amplification Effects in Port Lyttelton, N. Z. . . . 97

II Summarized Results of Subjective Analyses of Marigrams from Selected Tide Stations, Pacific Ocean . . . . . . . . 100

IV Apparent Periods of Oscillation of Monterey Bay Stimulated by Alaskan Tsunami of March 1964 . . . . . . . . . . . . 131

V Structures in Kodiak City which Resisted Displacement by Tsunami Waves .................. 163

VI Dimensions of Interconnecting Rectangular Basins Simulating Resurrection Bay . . . . . . . . . . . . . . . 209

VII Eyewitness Account upon which the Marigram (Figure 137) is Based . . . . . . . . . . . . . . . . 214

VIII Dimensions of Interconnecting Rectangular Basins Simulating Valdez Arm and Port Valdez . . . . . . . . . . . 254

IX Identifiable Structures in Valdez Destroyed or Damaged in the Earthquake . . . . . . . . . . . . . . 287

X Water Velocity at Front of Tsunami Surge . . . . . . . . . . 364

B-1 The Tsunami of March 28, 1964 as Recorded by Tide Gages . . . B-1

B-2 Seiche Action Caused by the Prince William Sound Earthquake of March 28, 1964 as Recorded by Tide Gages . . . . . . . . . B-4

B-3 Maximum Crest Levels of the Tsunami Along the Canadian Coast B-6 B-4 Water Levels and Damage Along Pacific Coast of Washington . . B-7 B-5 Summary of Recent Tsunamis Along Northern California Coast. . B- 8 E-1 Tsunami Damage at Kodiak City, Alaska . . . . . . . . . . E-1 E-2 Intensity of Damage to Boats at Kodiak and Vicinity . . . . E-2 E-3 Description and Cost of Restoration or Replacement of Facilities at Kodiak Naval Station Damaged by the Earthquake or Tsunami

E-4 Losses of Property and Income in Communities on Kodiak Island and Nearby Islands E-4 


\section{ILLUSTRATIONS}

Table

Page

E-5 List of Casualities and Major Damage due to the Tsunami. . E-5

E-6 Casualties and Damage from the Tsunami of March 28, 1964 Along the Oregon Coast . . . . . . . . . . . . . E-7

E-7 Casualties and Damage from the Tsunami of March 28, 1964 at Crescent City, California . . . . . . . . . . . E-8 

At 5:36 p.m. local time on Good Friday, March 27, 1964, Alaska was rocked by a great earthquake with an estimated magnitude $M \cong 8.4$ to 8.6 on the Richter Scale. The strain energy released was more than half as much again as that released by the earthquake of 1906 at San Francisco $(M \simeq 8.3)$ or a quarter more than that released by the Chile earthquake of $1960(M \simeq 8.4)$.

The epicenter of the Alaskan earthquake occurred apparently in the remote Chugach Mountains at latitude $61.1^{\circ} \mathrm{N}$. , longitude $147.7^{\circ} \mathrm{W} ., \pm 15$ kilometers (Hansen, et al, 1966), but, according to this definition, it could have occurred as easily in Unakwik Inlet, or on tributary arms of Unakwik Inlet, or the neighboring College Fjord to the west of Prince William Sound (Figure 1). Main particulars of the epicenter location of the earthquake focal depth, magnitude, and orientation are contained in Table I, from which it is evident that estimates of longitude reported by various authorities vary from $147.5^{\circ}$ to $147.8^{\circ}$, a difference latitudinally of about 9 nautical miles.

The focal depth of the earthquake appears to have been comparatively shallow (20-50 kilometers) and for the earthquake magnitude this conforms to the statistical trend reported by Gutenberg and Richter (1954), and as summarized by Wilson, et al (1962). The hypocenter has evidence of being at or near the elbow point of an almost right-angled faulting system that characterizes the geological structure of the Alaskan landmass. An immense movement of the land, horizontally and vertically, resulted, covering a large extent of south central Alaska and the Continental Shelf offshore.

The impact of this movement on the sea was registered in many ways. The total movement along a front of about 800 kilometers, within the short time of 4 or 5 minutes, triggered a train of tsunami waves that swept to the far reaches of the Pacific Ocean. Locally, in Prince William Sound and in the complex fjord-like indentations of the coast, seiches were set in motion by the tilting of the sea bed, and devastating waves were generated by submarine slumping of unstable glacial deltas and by landslides from the steep sides of the fjords into the sounds.

Inside Prince William Sound the violent local commotion of water in the maze of gulfs and bays that encompass the Sound in an almost landlocked circuit completely razed the waterfronts of Valdez and Whittier and virtually wiped out the Indian village of Chenaga. Cordova on the southeast side of the Sound was spared a far worse fate by the uplifting of the land.

Outside Prince William Sound the tsunami assailed Seward on the southwest side of the Kenai Peninsula and destroyed part of Kodiak City and its residential environs. The great waves raced on to the west coast of Canada and the United States and demolished parts of Port Alberni, Canada, and Crescent City, California. They reached the Hawaiian Islands 


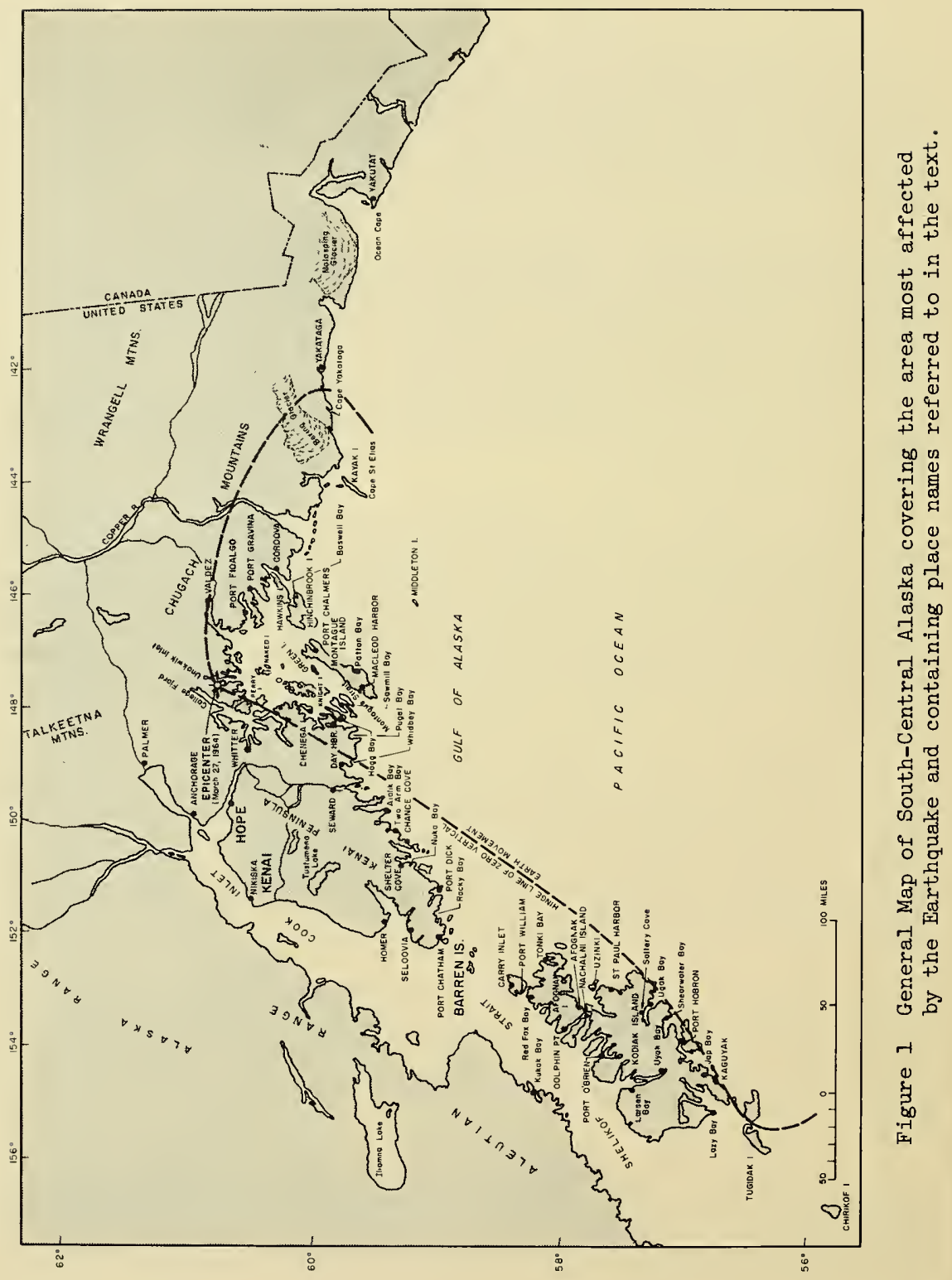


and went on to be recorded at the Argentine Islands on the west side of the Palmer Peninsula of Antarctica, on the east coasts of New Zealand and Australia, on the eastern seaboard of Japan and even on Sakhalin Island in the Sea of Okhotsk.

Mercifully, the earthquake occurred at a period of low tide; also in most of Prince William Sound the land was raised 4 to 10 feet in elevation and mitigated the full damage potential of the first waves. Fortunately too, Alaska's indented coastline is sparsely populated so that the dissipation of wave energy occurred with far less loss of life and property than would have occurred on a well-populated coastline. Nevertheless, Valdez, Whittier, Seward, and Kodiak were tragically inundated and suffered severe damage (Life Magazine, April 10, 1964; National Geographic Magazine, July 1964; Grantz, Plafker and Kachadoorian, 1964 ; U. S. Coast and Geodetic Survey, 1964; Brown, 1964).

The earthquake also stimulated remote seiche and wave effects in the Gulf of Mexico and various parts of the United States. These effects were completed dissociated from the Pacific Ocean tsunamis, yet in their own right may be logically called seismic sea waves or seismic seiches.

This study is an attempt to assemble and assimilate the work of many investigators who in one way or another have been concerned with the task of recording what happened, specifically as regards the effects of the tsunami. More importantly it seeks to reconstruct the mechanisms whereby the tsunamis were generated, to identify the nature and propagation of the waves, and to determine the damage they caused. We shall take the liberty of injecting some new ideas and considerations that may or may not be in agreement with the explanations advanced by others.

\section{Section II. THE NATURE OF EARTH DISLOCATION AND MOVEMENT}

\section{The Geological Character of Faults in Alaska}

The geological structure of Alaska has been discussed in detail in the now voluminous literature dealing with the Alaskan Earthquake (cf. Wood, et al, 1966; Hansen, et al, 1966; Marlette, et al, 1965) so that we shall dwell only on those features pertinent to our theme.

The State of Alaska may be broadly divided into four physiographic regions which band the area in a approximate east-west direction (Figure 2a). In the south, the Pacific Mountain system forms an arcuate belt of rugged terrain and encompasses the system of faults within which the earthquake epicenter was located. The region is typified by a serration of geanticlines and geosynclines which roughly parallel the coast and penetrate laterally into the next northerly region of intermontane plateaus and beyond. North of this is another mountainous region, a continuation of the continental Rocky Mountain System. Still further north is a comparatively narrow Arctic Coastal Plain. 
ARCTIC OCEAN

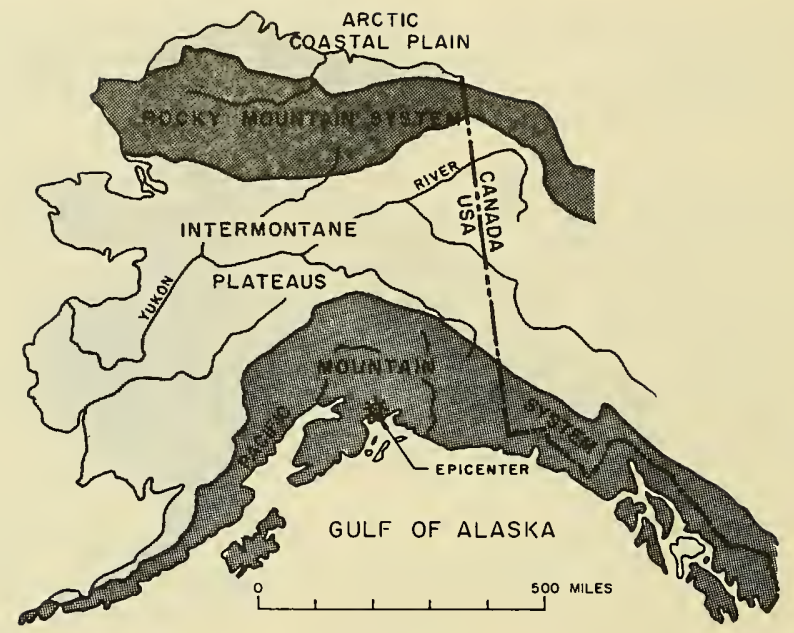

Figure 2 (a) Major Physiographic Divisions of Alaska (from Hansen, et al, 1966)

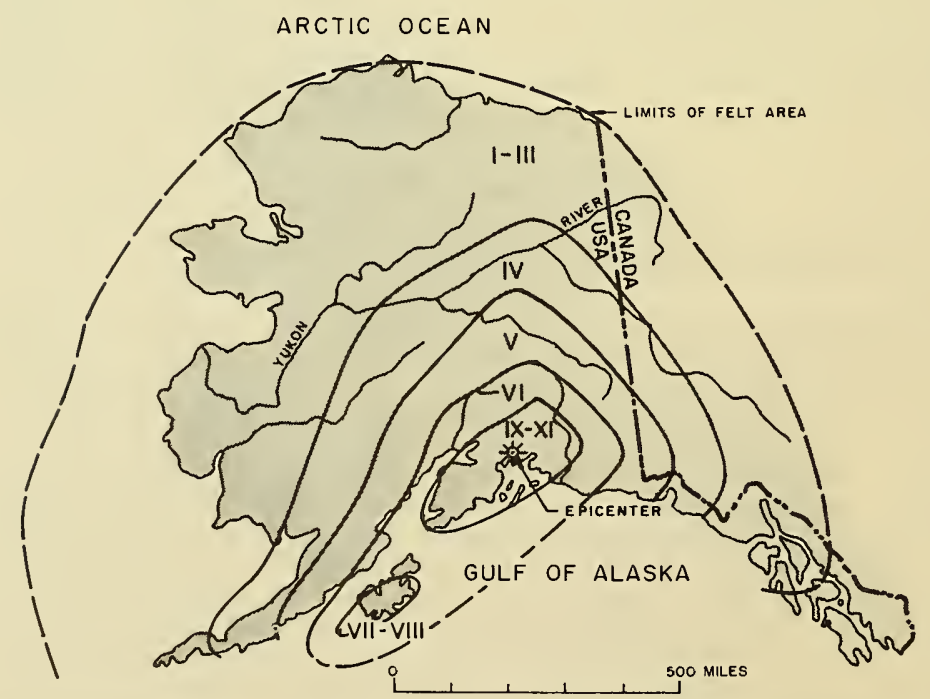

Figure 2 (b) Areal Extent of the Effects of the Earthquake of March 27, 1964, contoured to intensities of the modified Mercalli Scale. (from Berg, 1964) 
The earthquake had its main effects in the Pacific Mountain region in the south central area and the spread of perceptible effects from the source throughout Alaska is illustrated in Figure $2 \mathrm{~b}$ ( $\mathrm{cf}$. Townshend and Cloud, 1964). The substructure of the coastal area mainly affected is underlain by cretaceous sediments of graywacke which have been folded and warped into the system of geanticlines and geosynclines already mentioned. Within this system lies a series of arcuate faults which parallel the structural features of the region, as also the coast and the well-known Aleutian Trench (Figure 3). Of the faults shown, only the ChugachSt. Elias fault appears to comprise a boundary between radically different rock types. The dip and sense of movement along the faults is not yet well established. (Wood, et al, 1966), nor are all the faults fully recognized or located. As we shall see, the seismic evidence suggests that the fault planes giving rise to the Alaskan earthquake are apparently buried and have no intersections with the free surface. Certain localized faults, however, notably the Hanning Bay and Patton Bay faults on Montague Island, became visible during the earthquake, but these apparently have only secondary connection with the submerged faults already mentioned (Plafker, 1965).

\section{Historical Distribution of Earthquakes in Alaska}

The South Alaskan seaboard is one of the most active seismic regions in the world. It forms part of the circum-Pacific belt of seismicity that gives a well-defined geographical distribution to the occurrence of earthquakes and volcanic eruptions in the Pacific arena.

The positions of the epicenters of major Alaskan earthquakes occurring in the interval from 1898 to 1961 are shown in Figure 3 (from Hansen, et $a 1,1966)$. These epicenters are scattered along the island arc of the Aleutian Islands and concentrated in Cook Inlet, on Kenai Peninsula, and at the head of Prince William Sound. A corresponding distribution for strain-energy release covering the period 1904-1964 and incorporating the 1964 earthquake (Berg, 1964), is shown by the contours in Figure 4, which indicate that Prince William Sound has now become one of the focal areas of high energy concentration.

A detailed listing of earthquakes in the Alaskan region from 1786 to 1964 has been compiled by Wood, et al (1966). From data such as these, Berg (1964) has plotted the frequency of occurrence of Alaskan earthquakes versus their magnitude M. Compared with Japanese and World data (Figure 5), the trend is found to be similar and the mean annual number of earthquakes $\mathrm{N}_{\mathrm{a}}$ for Alaska is somewhat higher than for Japan. According to this, an earthquake of magnitude $M=8.5$, as that of March 1964, has about a 1-in30 year frequency of occurrence within the Alaskan Aleutian arc region. . An empirical equation relating $\mathrm{N}_{a}$ and $\mathrm{M}$, of the form used by Gutenberg and Richter (1954), is

$$
\log _{10} \mathrm{~N}_{\mathrm{a}}=0.99(8-\mathrm{M})-1.0
$$

and is essentially that given by Berg (1964).

Text resumes on page 9 


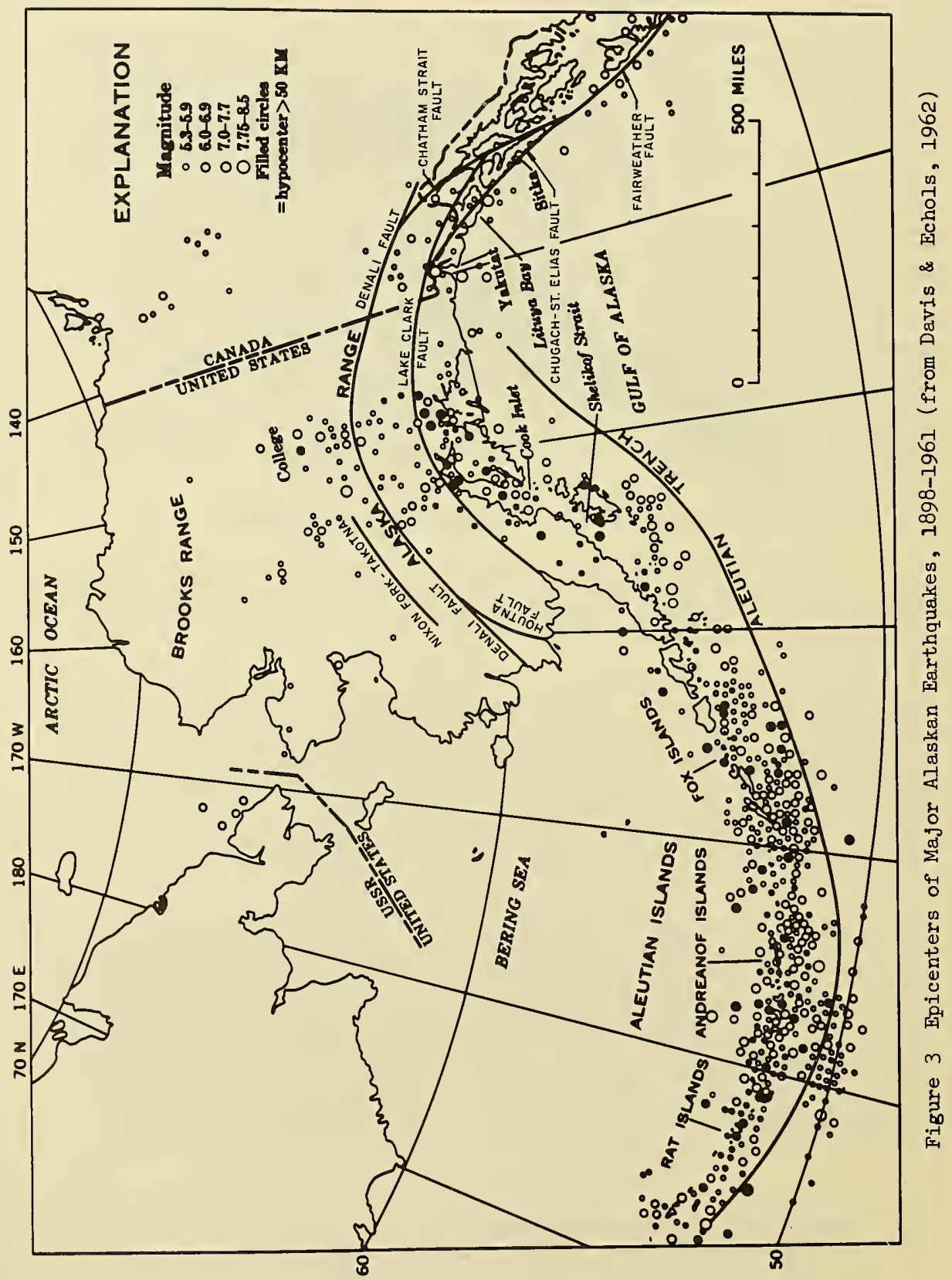




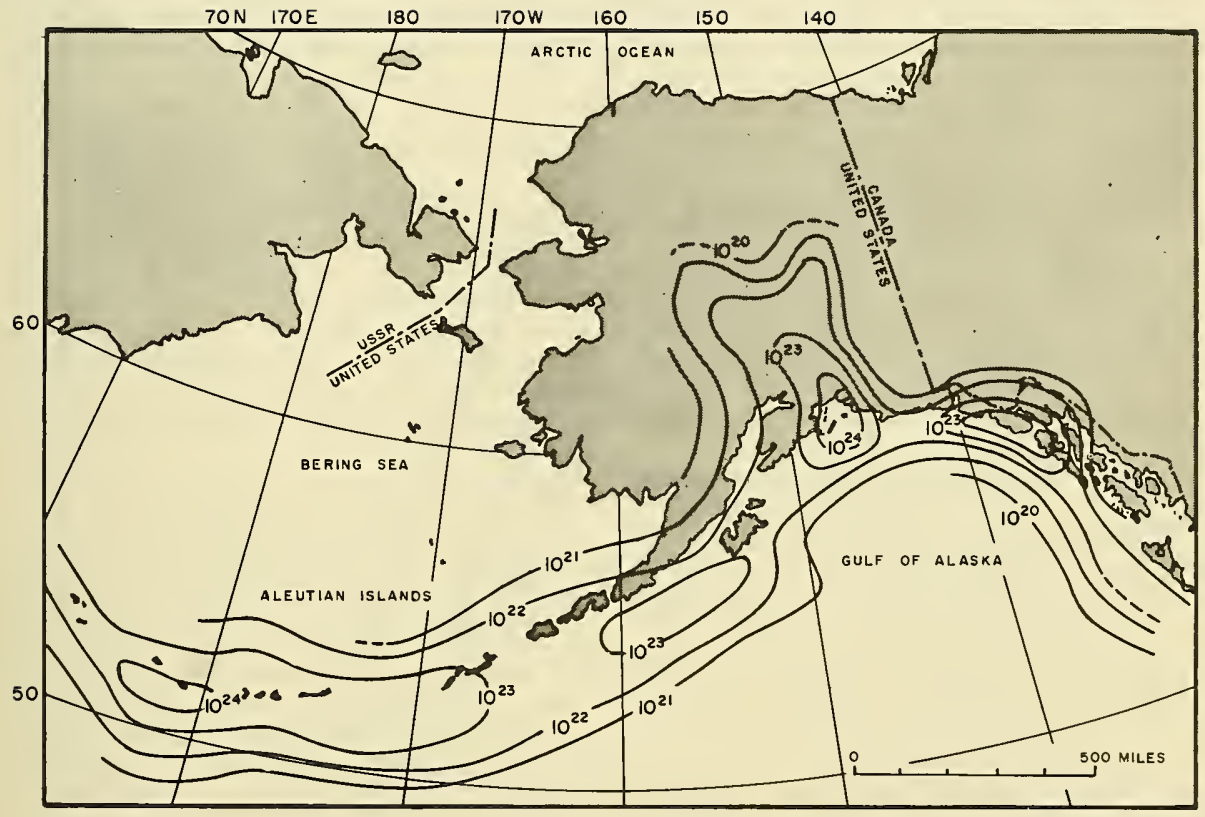

Figure 4 Alaskan Earthquake Energy Release (ergs per unit area, $2^{\circ} \mathrm{EW}-4^{\circ} \mathrm{NS}$ ) 1904-1964 (adapted from Berg; .1964) 


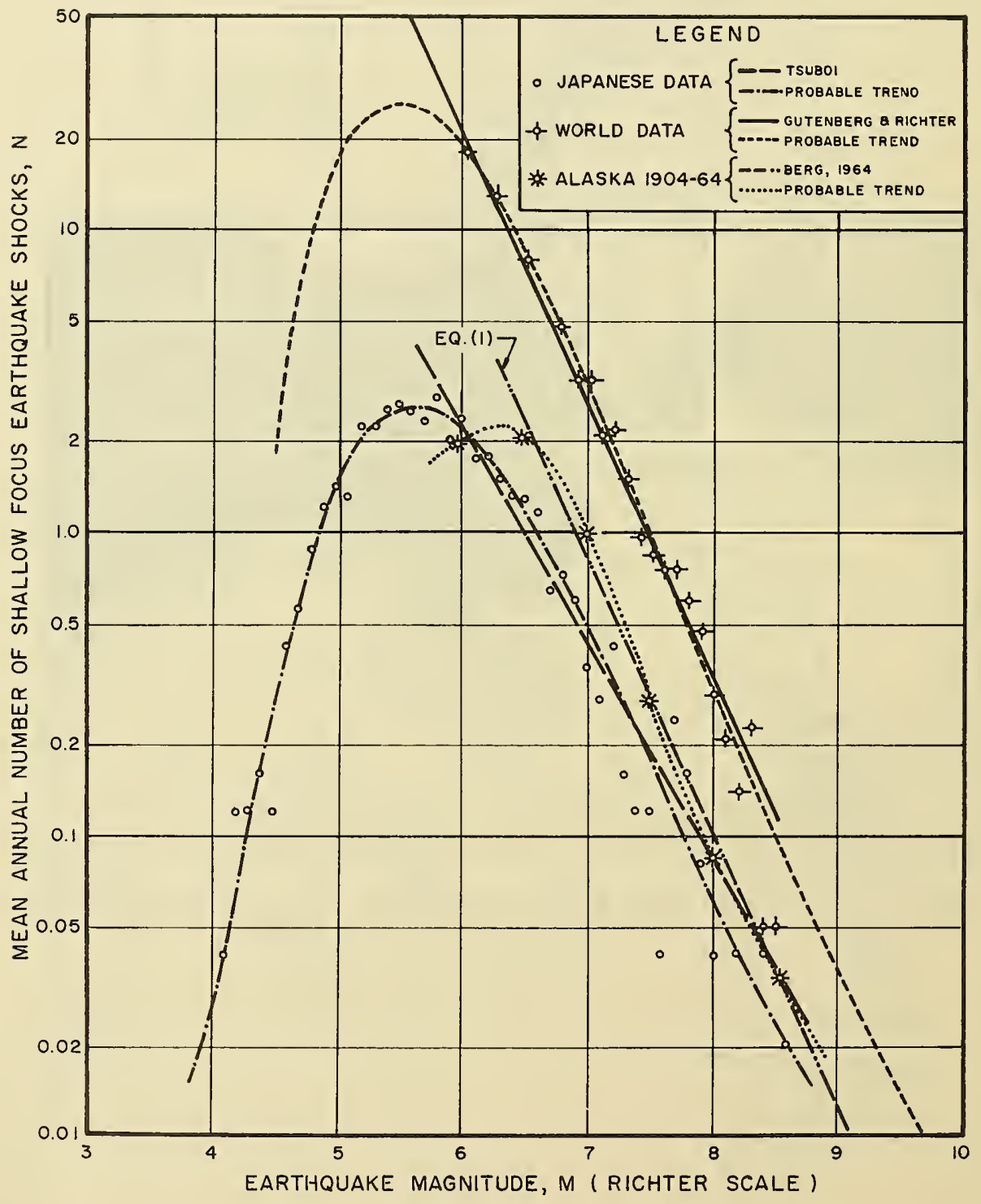

Figure 5 Mean Annual Occurrence of Shallow Focus Earthquake Shocks of Particular Magnitudes Felt Beyond a Radius of $200 \mathrm{~km}$ from the Epicenters 
The reason for the active seismicity of the circum-Pacific belt is still not clearly understood but the area may be considered a zone of structural weakness resulting from some tremendous upheaval of the earth in the remote past. The deeper-focus earthquakes of the Alaskan region have a tendency to occur beneath or behind the island arc or the coast; the shallower-focus earthquakes towards the Aleutian Trench (Figure 3) (see also Tobin and Sykes, 1966). This accords with similar trends elsewhere in the circum-Pacific seismic belt. Milne and Lee (1939) held that this was manifestation of a vast inclined fault plane extending downward from the ocean trenches into the mantle below the island or continental land masses. An example of this zone of weakness in the Kurile-Kamchatka segment of the circum-Pacific arc is illustrated in Figure 6. Benioff (1964), however, notes that deep earthquakes are essentially missing from the Aleutian segment in this type of formation.

Besides compressional thrusting in a vertical sense along this fault zone, there is rotational movement counter-clockwise of the entire area within the circum-Pacific belt (Marlette, et al, 1965). Worth noting is a long-term secular trend of land emergence from sea level in evidence for much of the Alaskan coastline and probably attributable, at least in part, to deglaciation (Twenhofel, 1952; Plafker, 1965; Hicks and Shofnos, 1965). This emergence would also signify some of the forces at work in building up strain within the earth crust in that region.

\section{Vertical Earth Movement during the Alaskan Earthquake}

Perhaps the most notable aspect of the Alaskan earthquake was the great extent and amount of the changes in land level that accompanied it. From the epicenter in northern Prince William Sound, the zone of surface deformation (Figure 7) extends for 500 miles roughly parallel to the trends of the Aleutian volcanic arc and trench and the coast of the Gulf of Alaska. As shown in Figure 7, and in greater detail in Figure 8, an uplift of the land and sea bed has occurred on the seaward side of a hinge line paralleling the Aleutian volcanic arc and passing through the epicenter of the earthquake. On the northwest or landward side of this hingeline the land level has dropped. Thus most of Prince William Sound has been raised above its former level while much of the Kenai Peninsula and the Kodiak Island group has sunk below the former level.

This picture of continental change has now been widely reported by Grantz, et al (1964), Plafker, et al (1964), Bruder (1964), Plafker (1965), U. S. Coast and Geodetic Survey (1964, 1965), and others. The vertical tectonic movement in Prince William Sound was determined by the U. S. Geological Survey, mainly by making more than 800 measurements of displacement of intertidal sessile marine organisms along the long intricate embayed coast. These measurements were supplemented at the tidal bench marks by coupled pre- and post-earthquake tide-gage readings made by U. S. Coast and Geodetic Survey and by numerous estimates of relative changes in tide levels by local residents. The amount and distribution of the vertical tectonic movement inland from the coast were defined along the highways connecting the cities of Seward, Anchorage, Valdez and 

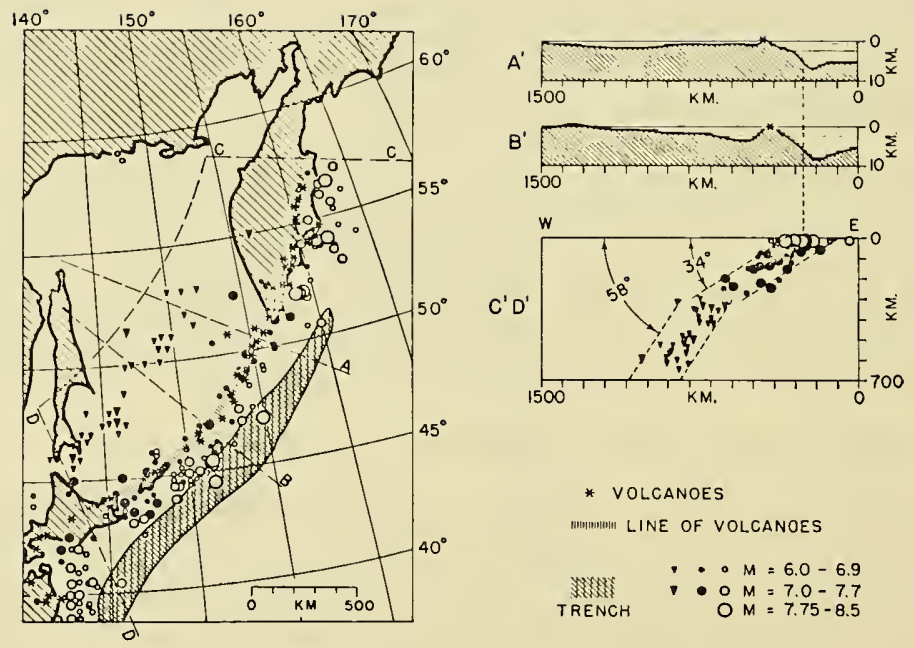

* volcanoes

HMHUH LINE OF VOLCANOES

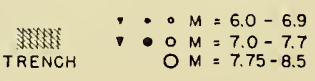

Figure 6 Map and Sections of the Kurile-Kamchatka Segment of the Circum-Pacific Arc, showing Earthquake Epicenters, Projected Foci, and Magnitudes (from Benioff, 1964) 


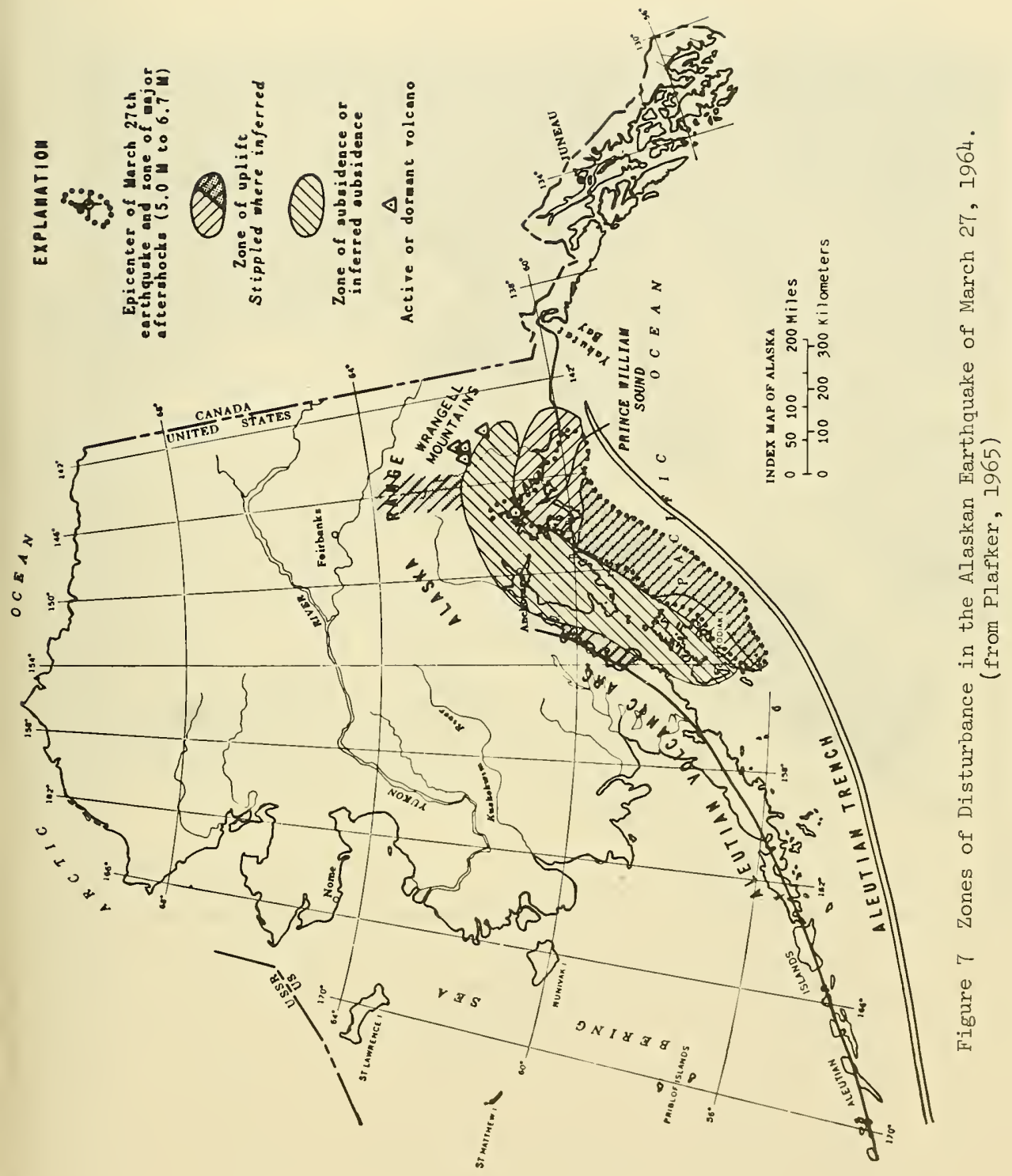




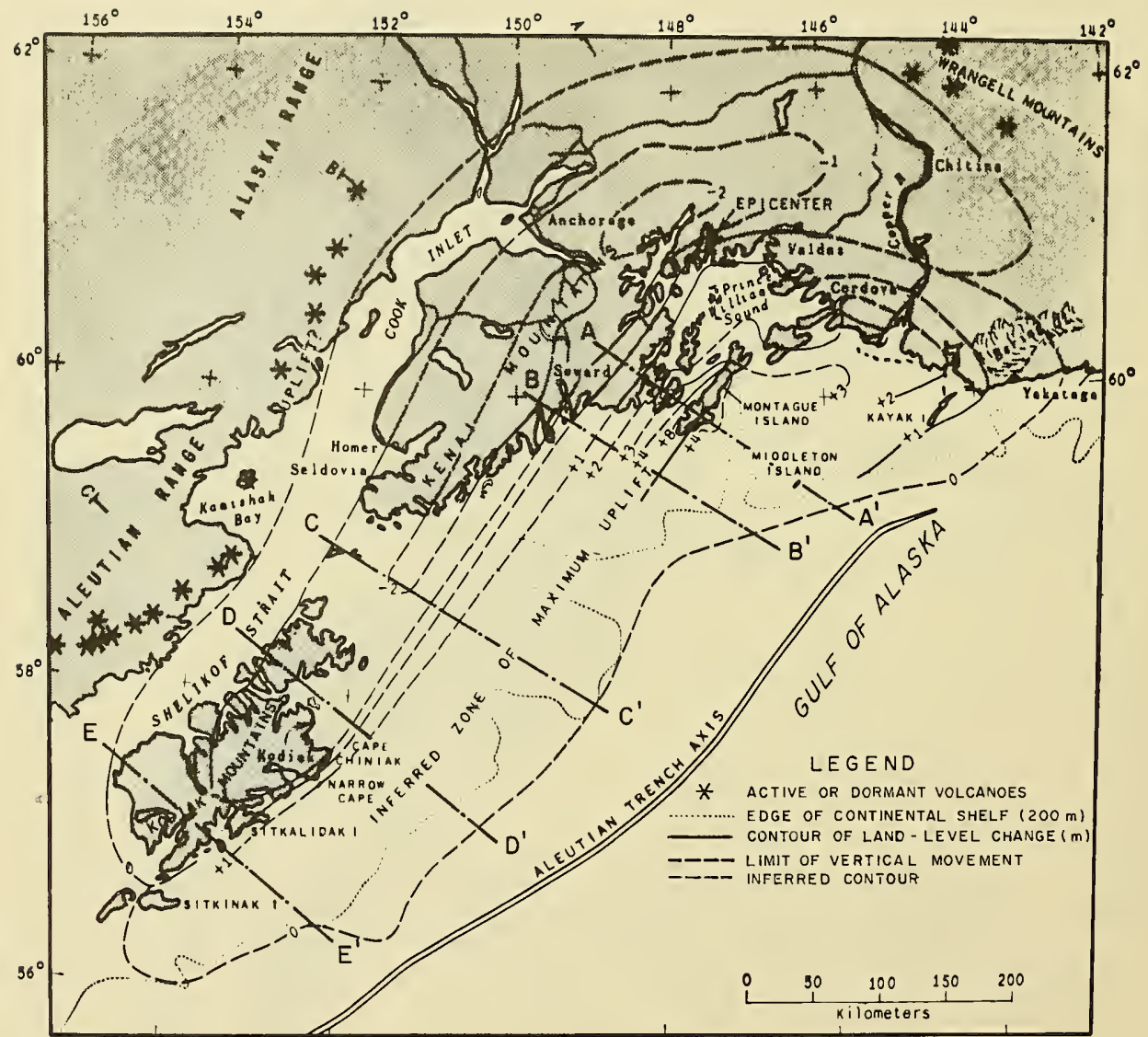

Figure 8 Tectonic uplift and subsidence in South-Central Alaska. (from Plafker, 1965) 
Fairbanks by releveling the previously surveyed first order level lines tied to tidal bench marks at Seward, Anchorage, and Valdez (Plafker, 1965; Smal1, 1966). This work was done by the U. S. Coast and Geodetic Survey. The result of an initial survey of a U. S. Geological Survey team is illustrated in Figure 9 and shows that Montague Island, at the mouth of Prince William Sound, experienced the greatest uplift on land (about 33 feet). The interpretation of Figure 9 (from Plafker and Mayo, 1965; Plafker, 1965) differs only in minor detail from that of the U. S. Coast and Geodetic Survey (1966), Figure 10, which relied heavily on the original isobase contouring and measurements provided by Plafker (see also Plafker, 1967).

The only visible faulting that occurred anywhere during the earthquake, other than local fissures and grabens, was on Montague Island, Figure 11. Here vertical displacements of 12 to 17 feet mark the Hanning Bay and Patton Bay faults (see inset cross-sections, Figure 11).

Although the U. S. Coast and Geodetic Survey has been engaged on a massive program of resurveying the marine areas affected by the earthquake (cf. U. S. Coast and Geodetic Survey, 1965; Wood, et al, 1966), the only positive results available to us at this time (apart from numerous chartlets that have been issued as revisions to U. S. Coast and Geodetic Survey hydrographic charts) are those reported by Malloy (1964, 1965, 1966) and by Malloy and Merrill (1967) mainly for the area southwest of Montague Island. The essence of these is shown in Figure 10 and in greater detail in Figure 12 which shows that several localized areas have sustained uplifts in excess of 50 feet. Comparison here is made between hydrographic data collected in 1927 and fathograms recorded in 1964. The equipment used in 1927 for making the soundings was a submarine sonic fathometer which had been adequately checked against lead-line soundings. The data are therefore unusually good. Also, this area is free from sediments, which indicates that the measured differences are not affected by scouring or sedimentation. Figure 13 shows typical vertical cross-sections along the lines A, B, C, ... H, I (Figure 12); all exhibit a remarkable consistency of general profile, which alone suggests reliable data.

The hinge line of zero movement was established from known movements along the coastline (see Figure 8). The hinge line runs from Sitkinak Island along the southeast coast of Kodiak Island to the mouth of Resurrection Bay and further on toward the epicenter, thence bending eastward toward Valdez. The general nature of land-level change is illustrated in Figure 14 (Plafker, 1965). Here the individual profiles $\mathrm{AA}^{\prime}, \mathrm{BB}^{\prime}$ and $\mathrm{CC}^{\prime}$ should be referenced to their locations in Figure 8. Maximum subsidence of the land is seen to be about 7 feet on the Kenai Peninsula. It is not known whether uplift in the deeper water over the shelf between Montague Island and Kodiak Island has occurred of a magnitude comparable with, or greater than, the 50 feet measured in the proximity of Montague Island (cf. Malloy, 1966), but when the evidence for tsunami generation is considered, the inference must be that there probably has been uplift of comparable magnitude. 


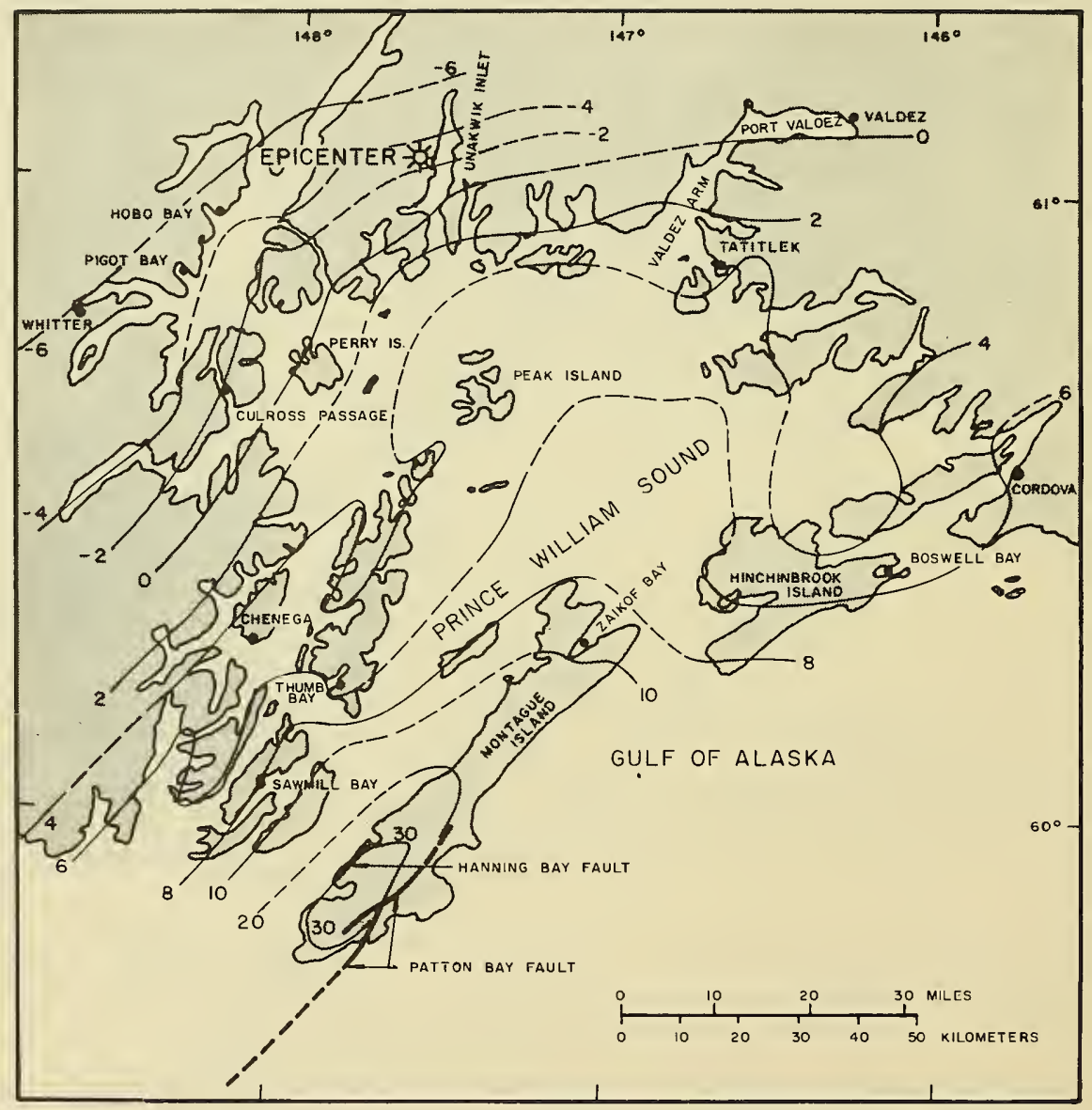

Figure 9 Contours of Tectonic Land-Level Change in Prince William Sound (levels in feet) (from Plafker and Mayo, 1965) 


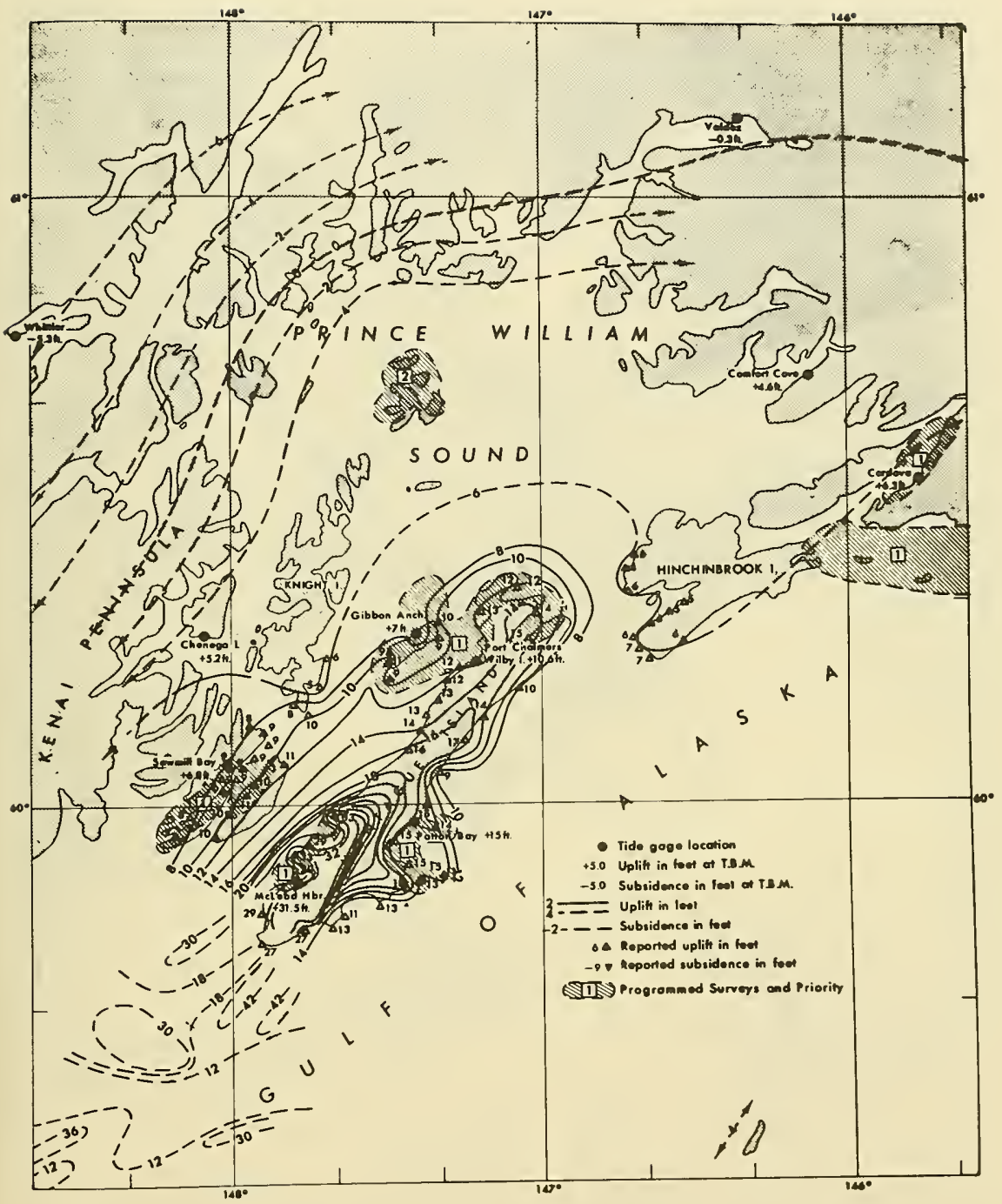

Figure 10 Contours of Tectonic Land-Level Change in Prince William Sound (from Coast \& Geodetic Survey, 1964; Wood, et al, 1966) 


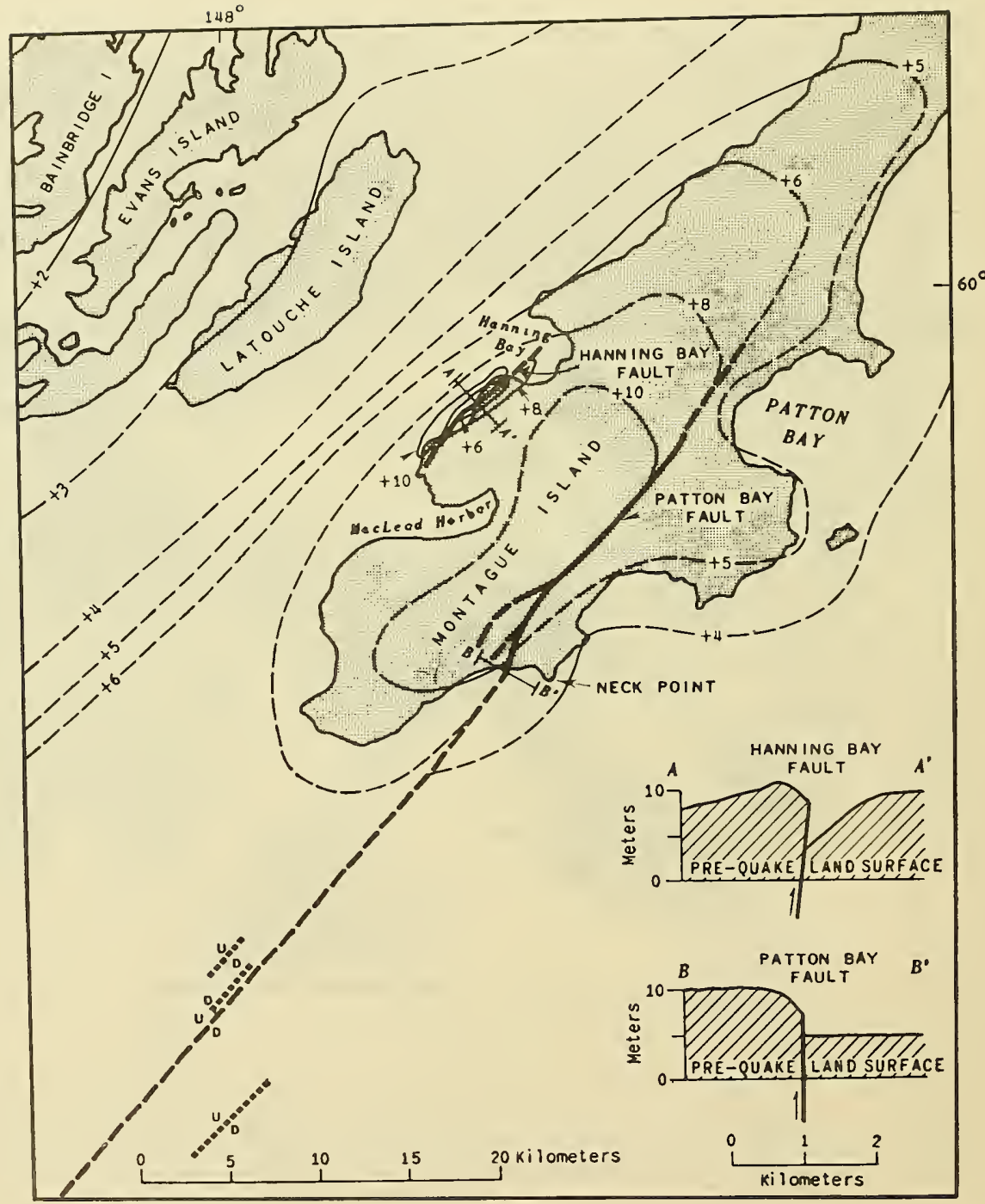

Figure 11 Tectonic Land-Level change (in meters) and faulting in the Montague Island Region (from Plafker, 1965) 


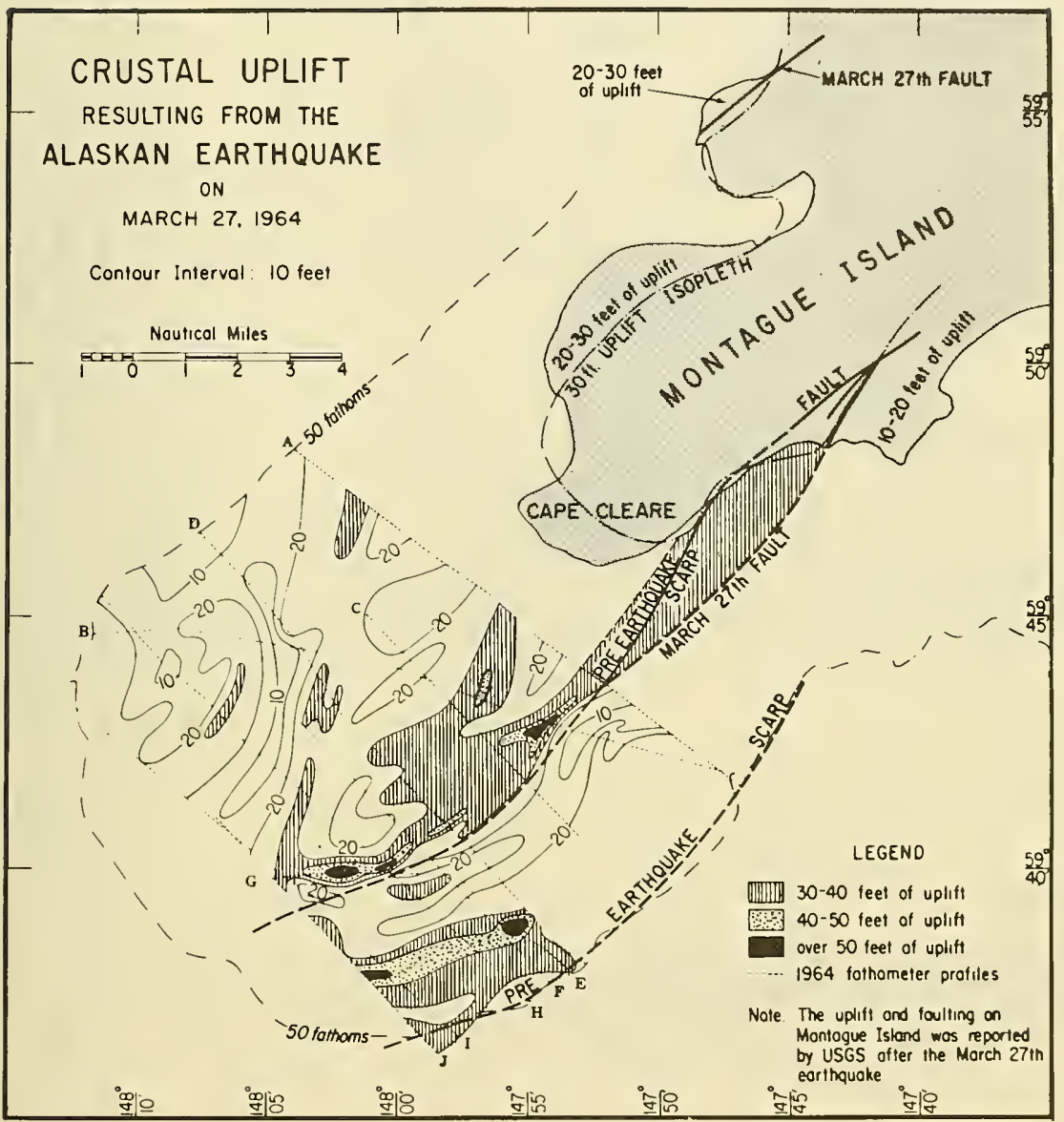

Figure 12 Tectonic Sea-bottom Change (in feet) Southwest of Montague Island (from Malloy, 1964; Wood, et al, 1966) 


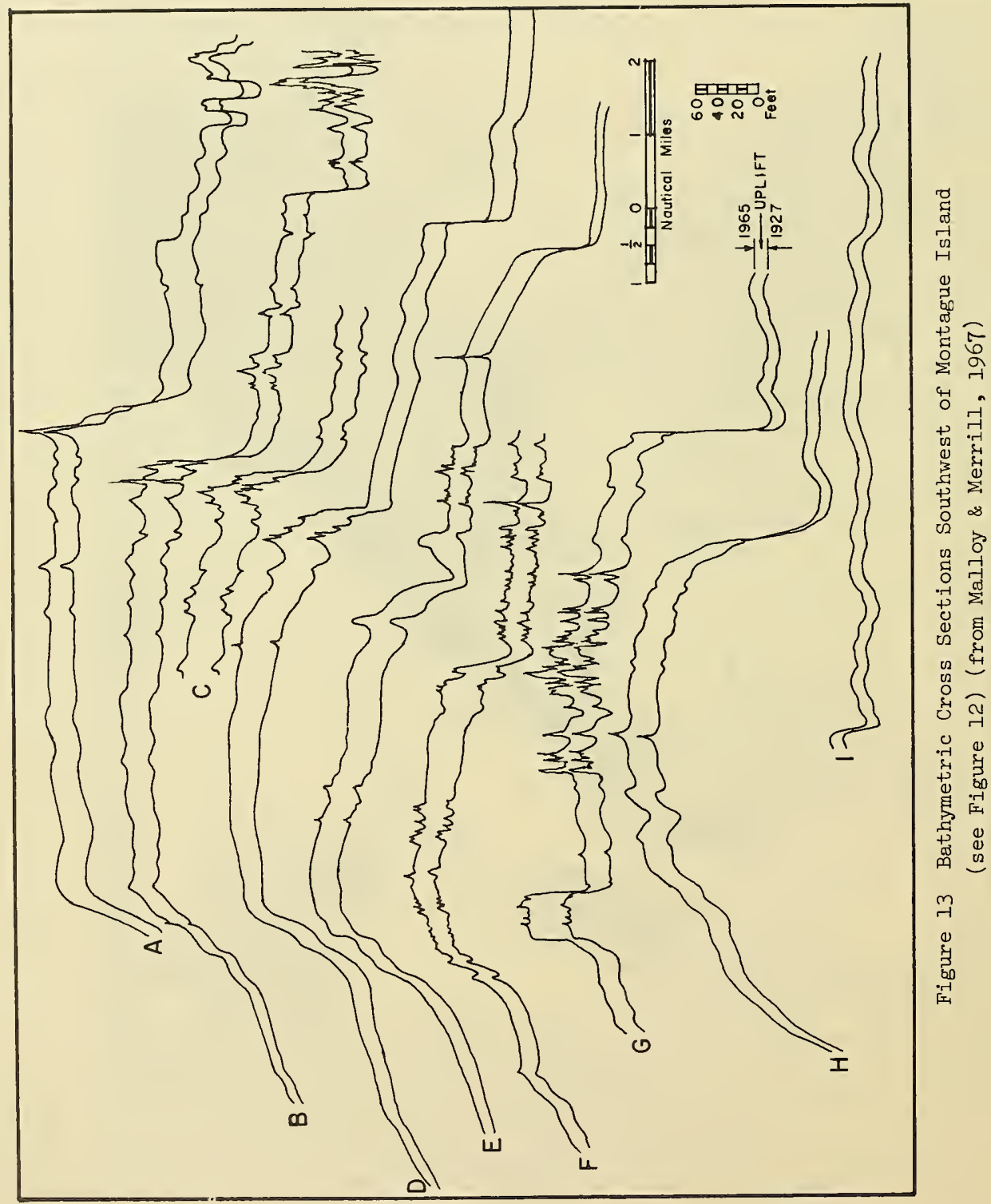




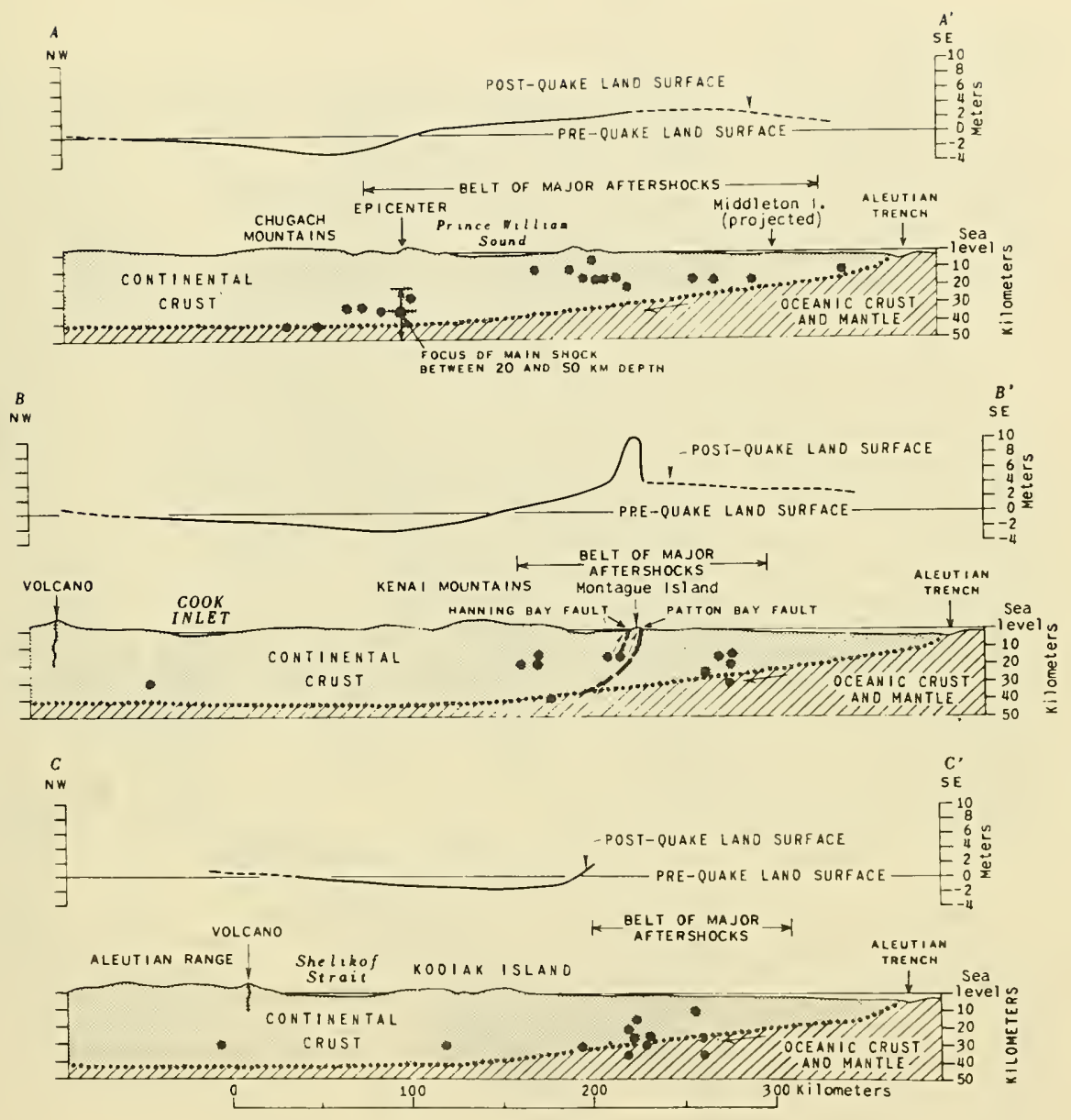

Figure 14 Schematic Cross Sections Across the Aleutian Arc Showing Approximate (solid) and Inferred (dashed) Land-Level Changes, Aftershock Distribution, and Geologic Interpretations. Heavy Dots are Aftershock Hypocenters within $30 \mathrm{~km}$ of Section Lines (Section Locations Shown in Figure 8) (from Plafker, 1965). 


\section{Horizontal Earth Movement during the Alaskan Earthquake}

In addition to subsidence and uplift, substantial horizontal movement of the land in the earthquake area has been reported ( $c f$. Parkin, 1966). The U. S. Coast and Geodetic Survey has undertaken an extensive postquake triangulation survey encompassing a large area of south central Alaska. The Survey has compared these measurements with prequake triangulations on the assumption that station FISHHOOK, about 45 miles northeast of Anchorage near Palmer (Figure 1), suffered no horizontal displacements. This base of reference appears justified because results show the station to be on an axis of zero horizontal movement, roughly in line with the Knik Arm of Cook Inlet, north of which displacements were tending to the northwest, and south of which displacements were to the south-southeast.

The essential outcome of the triangulation is given in Figure 15 (Parkin, 1966) from which contours of horizontal movement and streamlines of flow have been developed in Figure 16 for purposes of this study. A reading for Middleton Island, near the edge of the Continental Shelf, permits a useful degree of extrapolation over the shelf southwest of Montague Island. This extrapolation suggests that horizontal movements as great as 80 feet may have developed in a narrow area approximately along the axis of maximum uplift and that here the thrust was directed south-southwest. Montague Island shifted horizontally a distance of 40 to 50 feet. The contours on Figure 16 show that whereas the northwest side of Montague Island displaced horizontally through 50 feet, La Touche Island to the northwest (Figure II) moved from 60 to 70 feet, thus narrowing the straits by some 10 to 20 feet. A comparison of surveys made in 1933 and 1964 shows the straits to have become shorter by 15 to 20 feet (Parkin, 1966). A typical cross-section AA (Figure 16) normal to the hinge line for vertical movement shows the vectors of horizontal displacement, and suggests that a dilatation of the crust occurred on the northwest side of the hinge line and acompression on the southeast side.

Parkin (1966) has pointed out that most of the triangulation stations occupied in the survey were on peaks at elevations of 1,500 to 3,000 feet above sea level. Because of this and the possibilities of earth tilt, the apparent horizontal displacements may not be entirely meaningful since a tilt of one degree in a block of the earth's crust containing a peak could yield a differential horizontal movement of 50 feet between peak and sea level. However, since the crustal tilt over most of the area surveyed would favor sea level displacements in excess of those found, we must conclude that the recorded horizontal movements are minimal.

Assuming a conservative figure for maximum horizontal ground movement of say $\xi=70$ feet and a maximum value of vertical movement of $\zeta=50$ feet, the resultant maximum ground displacement $\Delta\left(=\sqrt{\xi^{2}+\zeta^{2}}\right)$ is found to be 86 feet or 26 meters. Plotted against earthquake magnitude $M$ in Figure 17, this value suggests that the statistical relationship between $\Delta$ and $M$ needs some revision from that formerly given by Wilson (1964). The fact that data for other large earthquakes now underlie the 


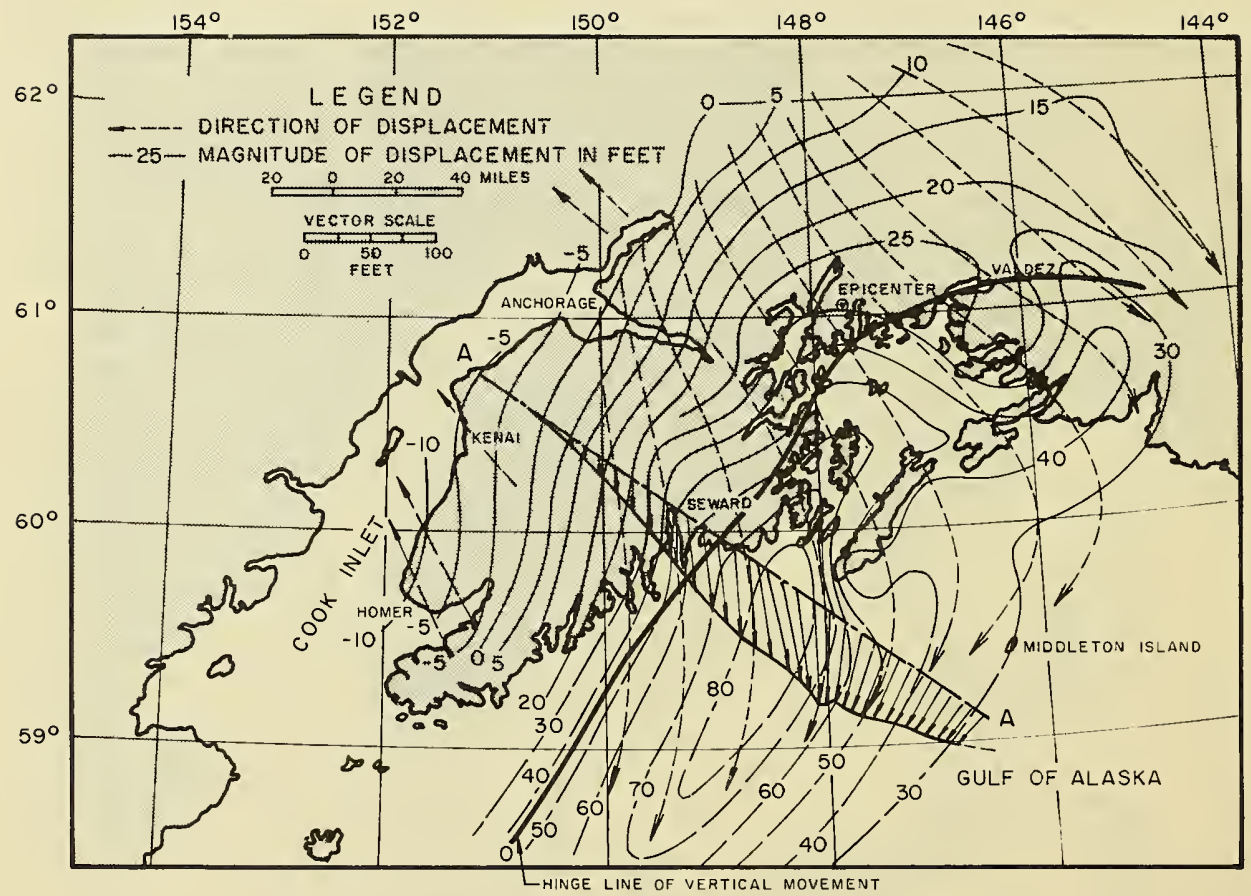

Figure 16 Magnitude and Direction of Apparent Horizontal Land Displacement (based on Figure 15) 


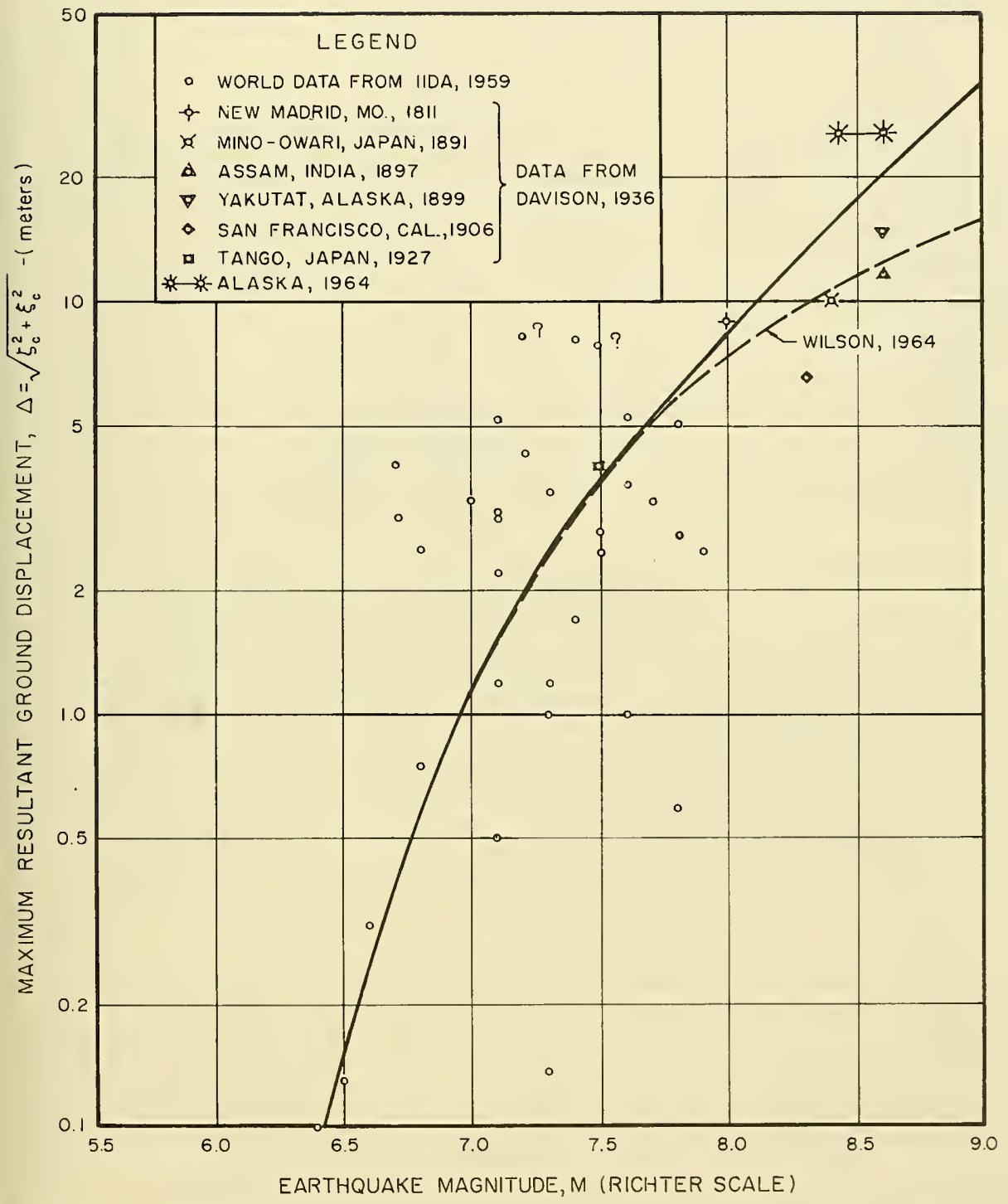

Figure 17 Trend of Dependence of Maximum Resultant Ground Displacement on Earthquake Magnitude 
new trend is perhaps not surprising since previous data are probably incomplete and do not incorporate, in particular, accurate information on horizontal components of displacement.

\section{Seismic Evidence for Fault-Plane Mechanism}

The zone of aftershocks following the main quake of March 27 is indicated in Figure 7 and in much greater detail in Figure 18 . More than 7,500 aftershocks were detected instrumentally; they covered a belt about $800 \mathrm{kilometers} \mathrm{long} \mathrm{and} 250 \mathrm{kilometers} \mathrm{wide} \mathrm{(Press,} \mathrm{1965).} \mathrm{This} \mathrm{shot-}$ scatter of aftershocks following a great earthquake provides significant information on the general extent of the faulting, which usually runs along the long axis of the approximately elliptical area covered by the aftershocks. On this basis alone the fault can be prescribed as being approximately 800 kilometers long (Press and Jackson, 1965).

The average focal depth for some 200 aftershocks for which determinations were made was found to be about 20 kilometers (Press, 1965). The deepest quake of these occurred at 60 kilometers. However, according to Press, specially sensitive seismographs were subsequently installed in Alaska and measured hundreds of aftershocks, some of which occurred to depths as great as 200 kilometers.

Investigators, using some of the latest tools of seismology ( $\mathrm{f}$. Stauder, 1962; Hodgson and Stevens, 1964), have employed seismic P-wave and $S$-wave data for the determination of the fault-plane mechanism. Essentially, the methods determine two possible fault planes at right angles to each other, one of which is auxiliary to the other. However, which of the two planes is actually the fault plane is not uniquely determined unless both $\mathrm{P}$ - and $\mathrm{S}$-wave data are used in the analysis. Most recording seismographs at suitable range were rendered inoperative after arrival of the P-waves from the main shock of March 27, 1964. As a result there is a difference of opinions as to which of the two fault planes found was responsible for the earthquake. Berg (1964) and Algermissen (1966), respectively, find one well-defined plane with a strike $\mathbb{N} 72^{\circ} \mathrm{E}$ (N $\left.61^{\circ} \mathrm{E}\right)$ and a dip of $89^{\circ} \mathrm{NW}\left(82^{\circ} \mathrm{SE}\right)$, which is close to being vertical and in the general direction of the hinge axis of zero movement (Figure 7 ).

Press and Jackson (1965) and Press (1965) reported the results of applying dislocation theory, assuming the fault to be a vertical rectangular dislocation sheet in a half-space. The vertical surface displacements calculated for their three models are shown in Figure 19a, which plots also measured vertical displacements across a section normal to the belt of epicenters. These authors favor Model 3 (with a vertical dip slip $\Delta \mathrm{u}=9 \mathrm{~m}$, fault length $\mathrm{L}=800 \mathrm{kilometers,}$, and a dislocation between depths 16 kilometers and $200 \mathrm{kilometers)}$ as being in reasonable accord with the measurements. This fault model is one without an intersection at the surface. 


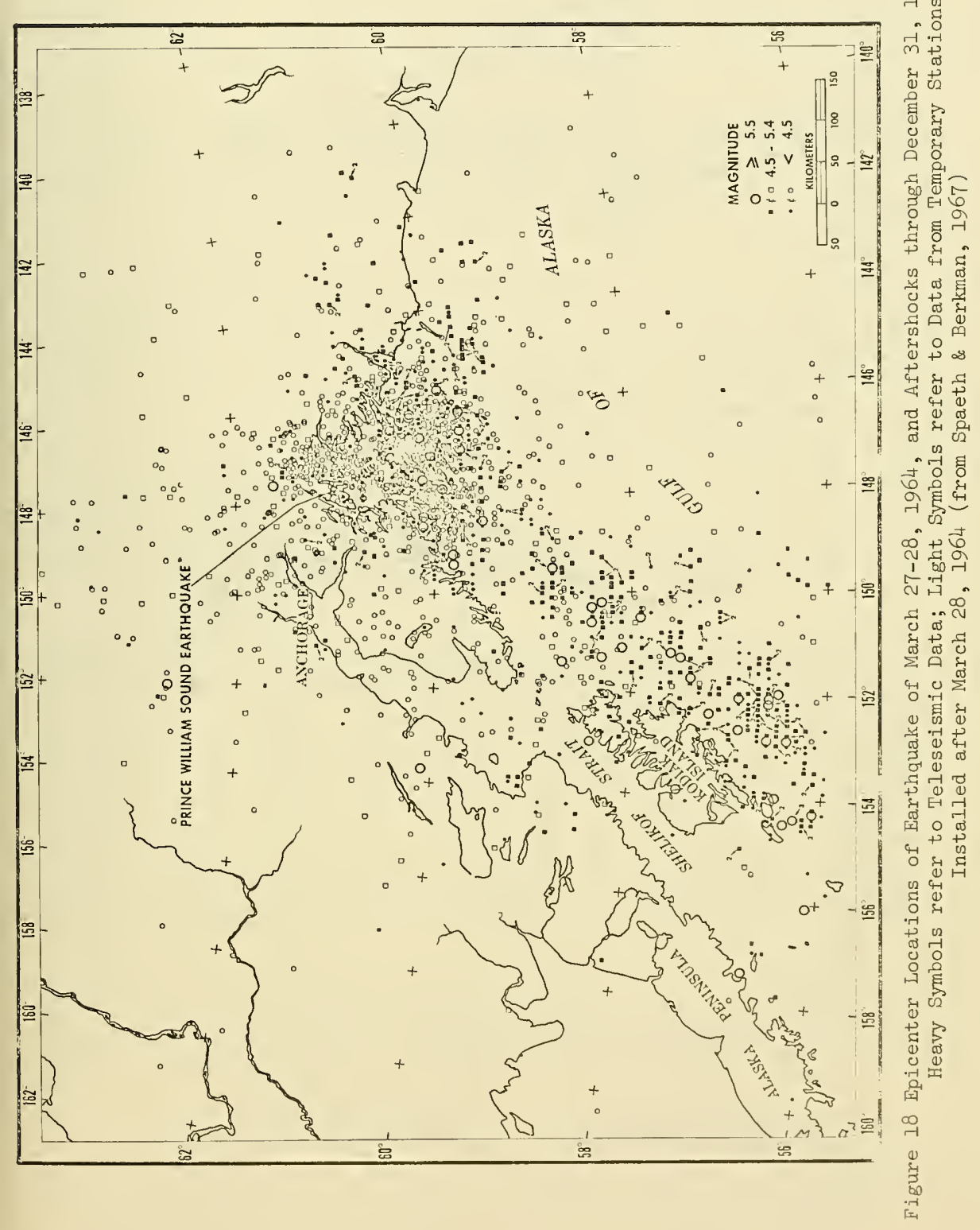




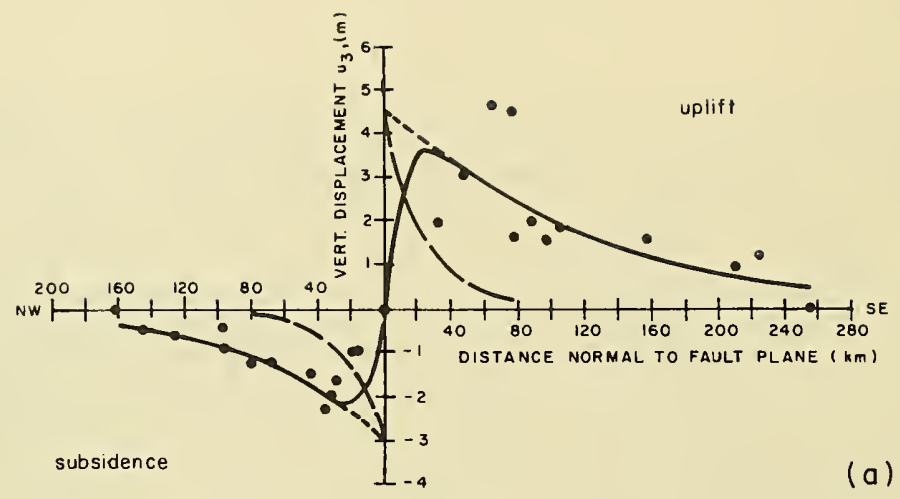

LEGEND

- MODEL I, $d=0, D=40 \mathrm{~km}, \Delta u=6 \mathrm{~m}$

- MODEL 2, $d=0, D=0.136 \mathrm{~km}, \Delta \nu=6 \mathrm{~m}$

MODEL $3, d=16 \mathrm{~km}, D=200 \mathrm{~km}, \Delta u=9 \mathrm{~m}$
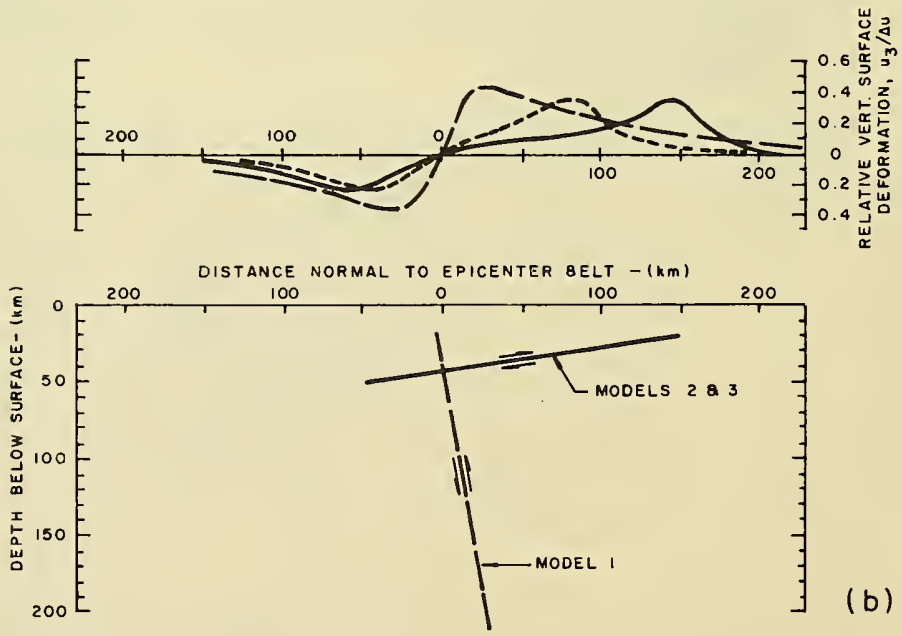

(b)

LEGEND

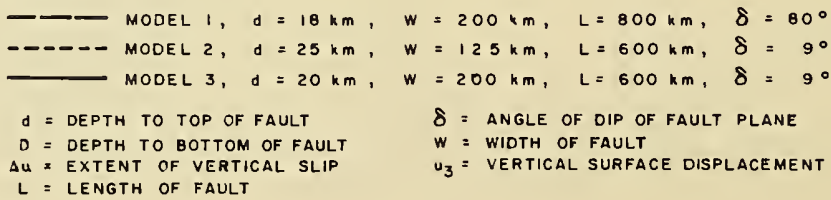

Figure 19 Theoretical Models of Vertical Movements Associated with Alaskan Earthquake on a Section Normal to Belt of Epicenters.

(a) from Press \& Jackson, 1965; (b) from Savage \& Hastie, 1966. 
Plafker (1965), on the basis of field observation and qualitative arguments, proposed a low-angle plane with predominantly thrust motion as accountable for the earthquake deformation (see Figure 14). These apparently conflicting results have been discussed further by Savage and Hastie (1966) and by Stauder and Bollinger (1966). The first pair of authors apply the theory of Maruyama (1964) to determine the surface deformation for a dislocation model of thrust faulting. The results of their calculations for three such models are shown in Figure 19b. Model I tends to be comparable with that obtained by Press and Jackson (1965). Model 3, however, yields results much more akin to the actual surface deformation shown in Figure 14. Savage and Hastie therefore tend to the view that thrust faulting was the more likely cause of the earthquake.

\section{Stauder and Bollinger proceed to show that fault-plane solutions} based on the main shock of the earthquake and numerous subsequent shocks are consistent with both interpretations of thrust faulting and dip-slip faulting. Their equal-area projection of the focal mechanism solution based on seismic $P$-wave data is shown in Figure 20 , and indicates a fault plane with a strike $N 66^{\circ} \mathrm{E}$ and a dip $85^{\circ} \mathrm{SE}$, in close agreement with Berg (1964) and Algermissen (1966). Their fault plane solutions based on various aftershocks in the Prince William Sound and Kodiak Island regions are shown in Figure 21 a and $b$. Besides the dominant, almost vertical plane lying along the axis of the epicenter belt, these authors found the second plane to have a strike bearing mainly to the northeast and a dip between about $5^{\circ}$ to $15^{\circ}$ northwest. Such a plane would be consistent with that envisioned by Plafker (1965), Figure 14.

Stauder and Bollinger then advanced the work of Savage and Hastie by applying the Maruyama theory to the second (thrust) fault plane on the supposition that a differential slip occurs along it, as shown in Figure $22 \mathrm{~b}$. Their computed vertical and horizontal deformations of the earth's surface are in remarkably good accord with some of the latest measured data provided by Plafker (Figure 22a). A refinement of their calculation, allowing for some vertical thrusting at the locations corresponding to the Hanning Bay and Patton Bay faults on Montague Island even simulates the discontinuities of profile found there (Figure 22c). Stauder and Bollinger favor the thrust plane mechanism for the earthquake, so ably argued by Plafker (1965). The present writers concur with this view in the main, particularly insofar as the thrust plane mechanism also offers an explanation for the horizontal displacements already noted in Figure 16.

However, the tendency of the flow lines of thrust to bear south and southwest (Figure 16) suggests that a degree of strike-slip and dip-slip may also have occurred on a near vertical fault plane and that the total earthquake phenomenon may have been a complex combination of the mechanisms envisioned by Press and Plafker.

It should be recorded that Furumoto (1965), using the "directivity function" method of Ben-Menahem (1961) and the data of the seismograph station at Kipapa, Hawaii, arrived at a rupture length of 800 kilometers for the Alaskan Earthquake, a rupture velocity of 3 kilometers/second, 
and a direction of the line of rupture, S $30^{\circ} \mathrm{W}$. This direction of rupture he finds to be some $5^{\circ}$ at variance from the hinge line of zero deformation - a difference he considers to be within the limits of error. Ben-Menahem and Toksoz previously had concluded on the same basis (see Press, 1965) that the fault length was 650 kilometers and that the near vertical fault-plane was uniquely determined.

It was shown by Benioff, Press, and Smith (1961), and by Press, BenMenahem, and Toksoz (196I) that the main shock of an earthquake represents the rupture that starts at the hypocenter and runs the length of the fault at the rate of about 3 to $3.5 \mathrm{kilometers/second,} \mathrm{the} \mathrm{speed} \mathrm{of} \mathrm{shear} \mathrm{waves}$ in crustal rock. Since most observers' estimates of the duration time for the main Alaskan earthquake range from $21 / 2$ to 8 minutes and average about 5 minutes ( $f f$. Chance, 1966), the fault length may be estimated on this basis to have been as much as 900 kilometers. We favor the fault length $\mathrm{L}=800 \mathrm{kilometers} \mathrm{proposed} \mathrm{by} \mathrm{Press} \mathrm{and} \mathrm{Jackson} \mathrm{(1965);} \mathrm{Press}$ (1965); and Furumoto (1965) over the shorter lengths of 600 and 650 kilometers proposed by some seismologists. Fault length data for the Alaskan earthquake are found to be in reasonable accord with a statistical relationship proposed by Tocher (1963), (see also Press and Brace, 1966), connecting length $L$ with earthquake magnitude $M$. This relationship

$$
M=6.6+\log _{10} I
$$

(for $\mathrm{L}$ in kilometers) is shown in Figure 23. The data and curve fitting of Iida (1959) included in Figure 23 yield a rather different relationship, which clearly overestimates the fault length for large earthquake magnitudes. Tocher's result must be considered to supersede a result given by Wilson, et al (1962), Wilson (1964) which was based only on Iida's data.

For convenience we summarize now in Table I some of the essential characteristics of the earthquake as cited by various authorities.

\section{Character of the Source Inferred from Tsunami Waves}

The Alaskan earthquake initiated trains of seismic sea waves or tsunamis which lashed the shores adjacent to the generation area and penetrated to every part of the Pacific Ocean. A discerning study of the source mechanism of the tsunami has been made by Van Dorn (1964, 1965) who reasoned that the entire vertical earth motions (Figure \&) occurred within the time (2-6 minutes) of ground shaking during the main shock of the earthquake. The essential dipole character of earth movement, revealed in Figures 14 and 22, was recognized by Van Dorn as being responsible also for an initial dipole surface disturbance of the sea and of the atmosphere; the latter was clearly registered as a pressure disturbance on a microbarograph at La Jolla, California (Figure 24). A similar trace was recorded on a microbarograph at Rice University, Houston, Texas, soon after the earthquake was registered there (Houston Chronicle, March 29, 1964), and other traces may have been recorded elsewhere. 

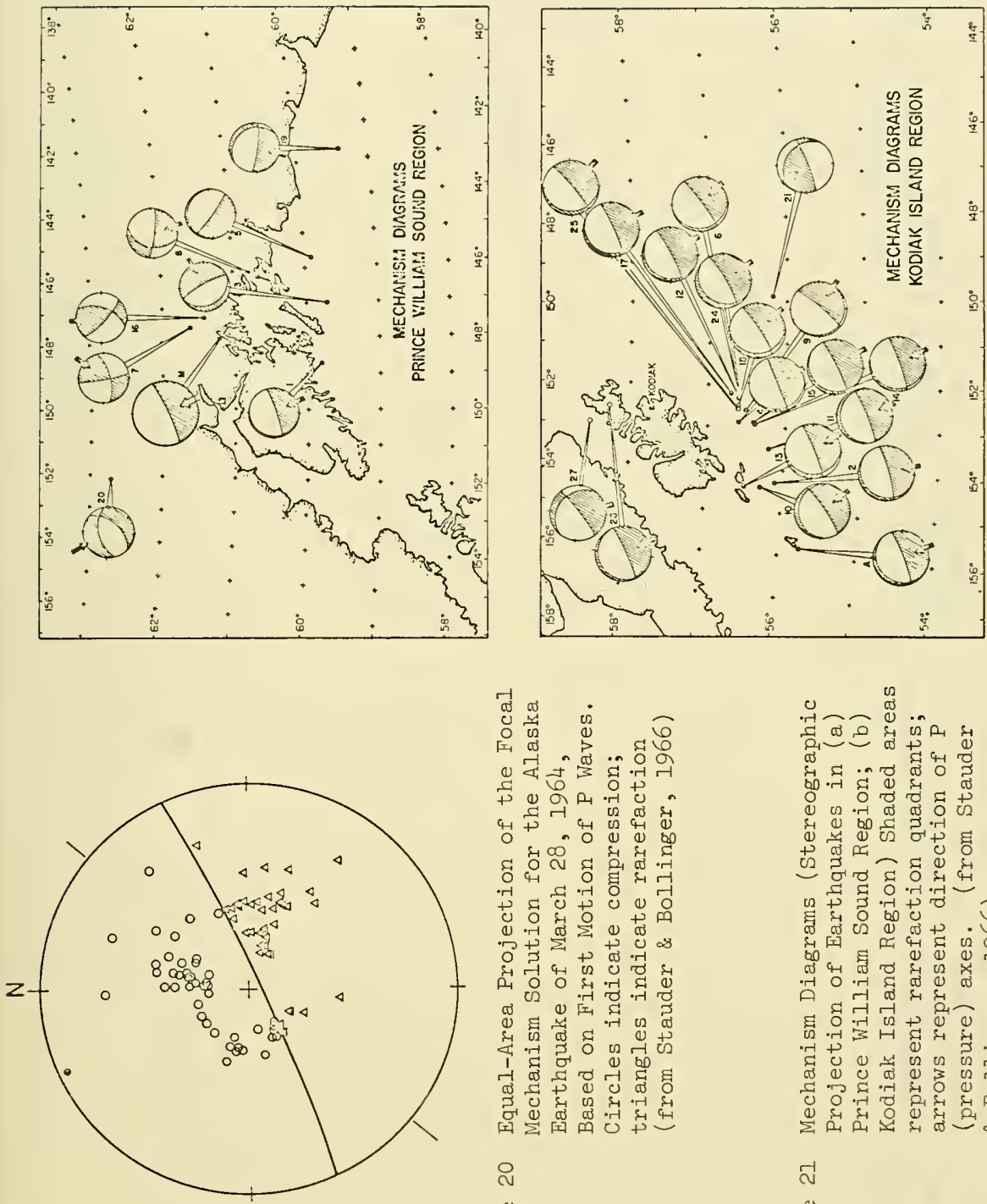

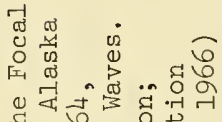

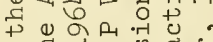

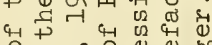
म 0 ० 0 \& द्व

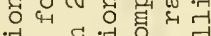
† द्व पु i) ब

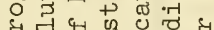
मि तु

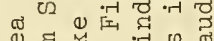

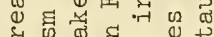

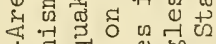

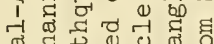
बु

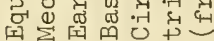

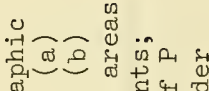

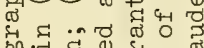

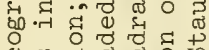
(1) \& 100 है (1) 1 ए जि हु

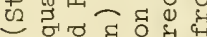

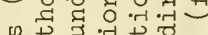
है 0 की है क 4 乐

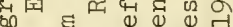

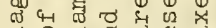

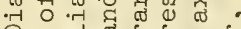

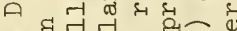

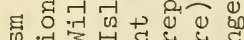

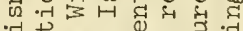

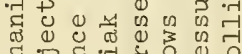

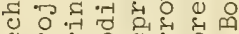

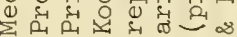

ก

त्र

เै

है 


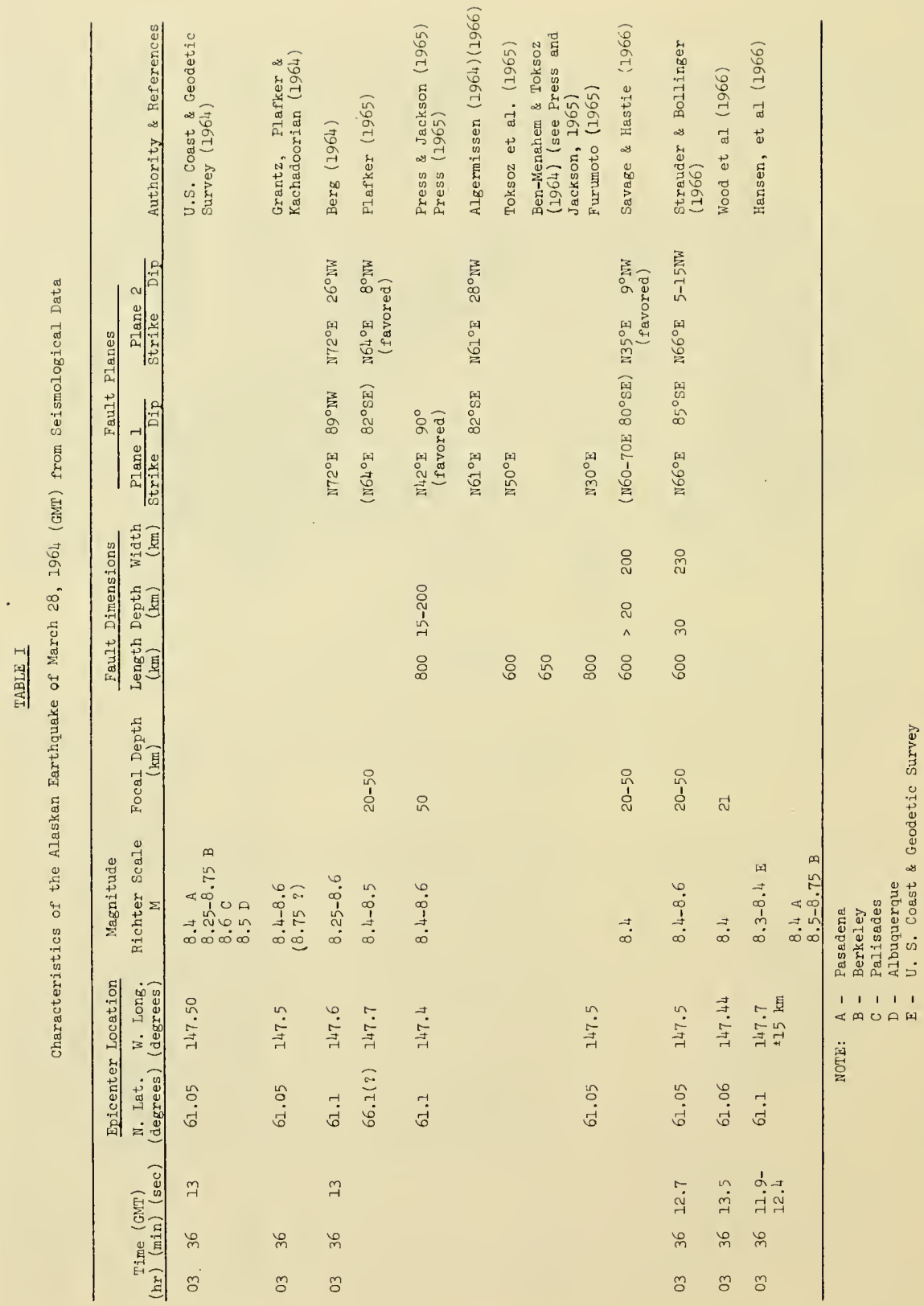



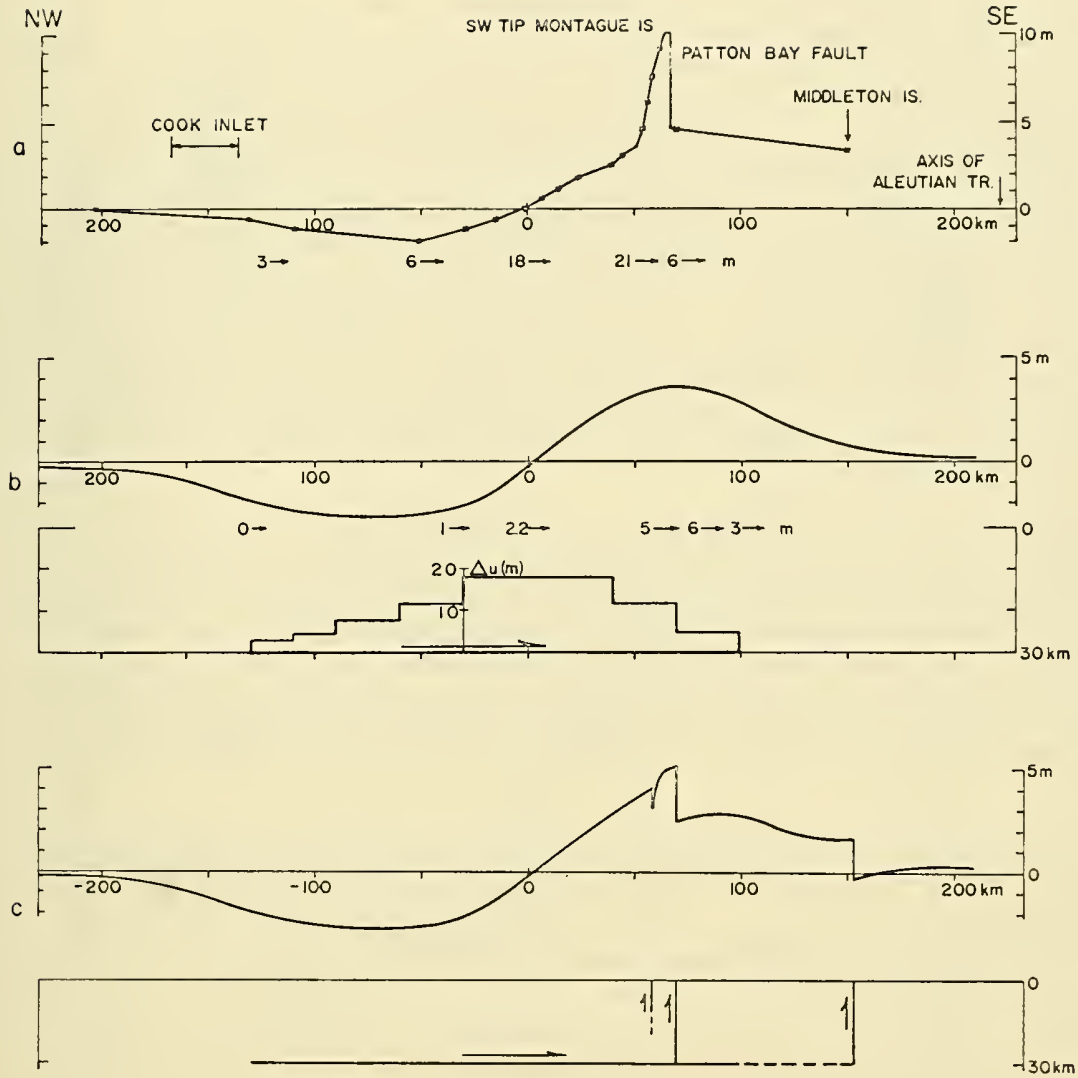

Figure 22 Tectonic Displacement of the Free Surface. (a) Revised profile (Plafker, personal communication) of observed uplift and subsidence; (b) Computed vertical surface motion $\mathrm{u}_{3}$ for differential slip $\Delta u$ for model indicated below profile: Horizontal fault, $\mathrm{d}=30 \mathrm{~km}, \mathrm{~W}=230 \mathrm{~km}, \mathrm{~L}=600 \mathrm{~km}$. Arrows beneath the profile represent the horizontal surface motion; (c) Superposition on $22 \mathrm{~b}$ of vertical surface motion due to vertical faults, as indicated on the model below the profile. (from Stauder and Bollinger, 1966) 
Van Dorn's interpretation of the tsunami-generation mechanism is additionally based on the initial wave types arriving at recording stations around the Gulf of Alaska and on a long-practiced Japanese technique of establishing the tsunami source by refracting waves backward from the stations out to deeper water over travel times equivalent to the intervals between the time of occurrence of the earthquake and the arrivals of first waves at each station (Figure 25a). In Figure 25b Van Dorn has reconstructed possible initial wave fronts which accord with the previous figure. He hypothesizes that the extent of surface uplift of the seabed reached as far as the Aleutian Trench with a ridge of maximum uplift along an arc extension of the uplift crest through Montague Island, roughly parallel to the hinge line of zero ground elevation. This concept is generally supported by Plafker and Mayo (1965), whose picturization is shown in Figure 26a. Pararas-Carayannis (1965), in a wave refraction study somewhat similar to Van Dorn's, arrives at the tsunami source region shown in Figure $26 \mathrm{~b}$.

Figures 25 and 26 agree in the main, although Pararas-Carayannis ' initial wave front is a considerable distance landward of the Aleutian Trench axis and thus differs from Van Dorn's interpretation. A possible weakness of both investigations lies in attempting to define the major wave front on the open sea side from such oblique station data. Also, it seems that no consideration has been given to the fact (largely because it was not then known to the authors) that the entire Continental Shelf suffered a horizontal thrust in a south and south-southwest direction (Figures 15 and 16).

The initial velocity communicated to the water from this thrust would help to throw a great deal more energy toward the southwest than might otherwise be the case. It would also promote more rapid elevation of the tsunami crest seaward of the ridge of maximum crustal uplift. It would not otherwise affect the speed of tsunami propagation.

We have considered it important and desirable to examine the propagation of the tsunami across the entire Pacific Ocean and have therefore prepared a plot of the continuous wave fronts at one-hour intervals from their source to their destinations at tide gage stations throughout the Pacific arena (Figure 27). In developing this chart on Mercator projection, the wave fronts have been drawn to be consistent with the arrival times tabulated by Spaeth and Berkman (1968) (see Table B-l, Appendix B) and the travel rates in different depth $d$ of water at the velocity of long waves $c=\sqrt{\mathrm{gd}}, \mathrm{g}$ being the acceleration due to gravity. The distorted scale of Mercator projection causes the map distance-intervals between wave fronts to appear larger at high latitudes than at low latitudes. Nevertheless, a consistent picture is established which accomodates all the observational data and the varying velocity of travel with depth. In a few cases station arrival times in parentheses have been used in preference to those (unbracketed) given by Spaeth and Berkman. These adjustments are based on careful examination of the tide gage records and will be reported in the next section. 


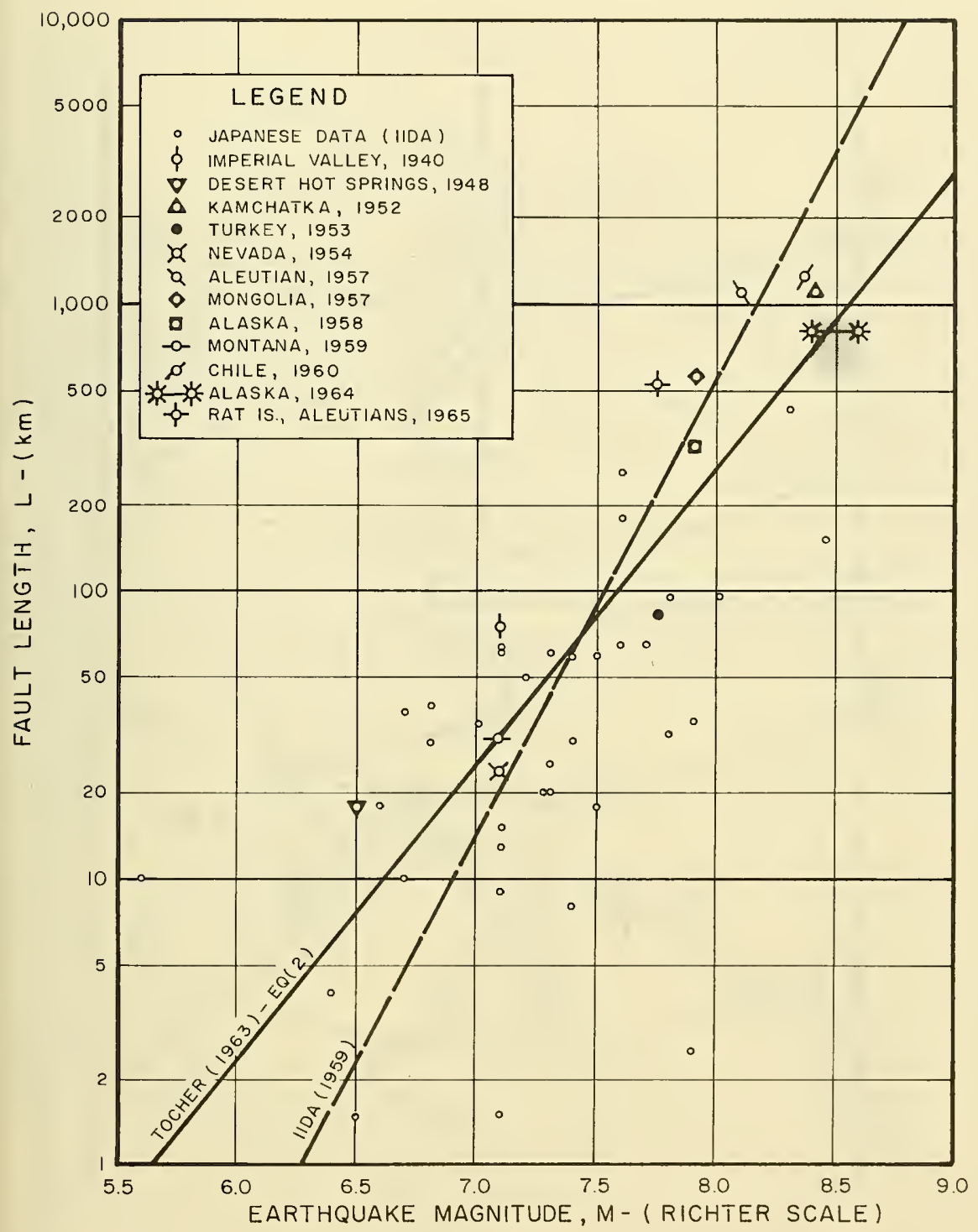

Figure 23 Relationship of Major Fault Length to Earthquake Magnitude (Richter scale) 


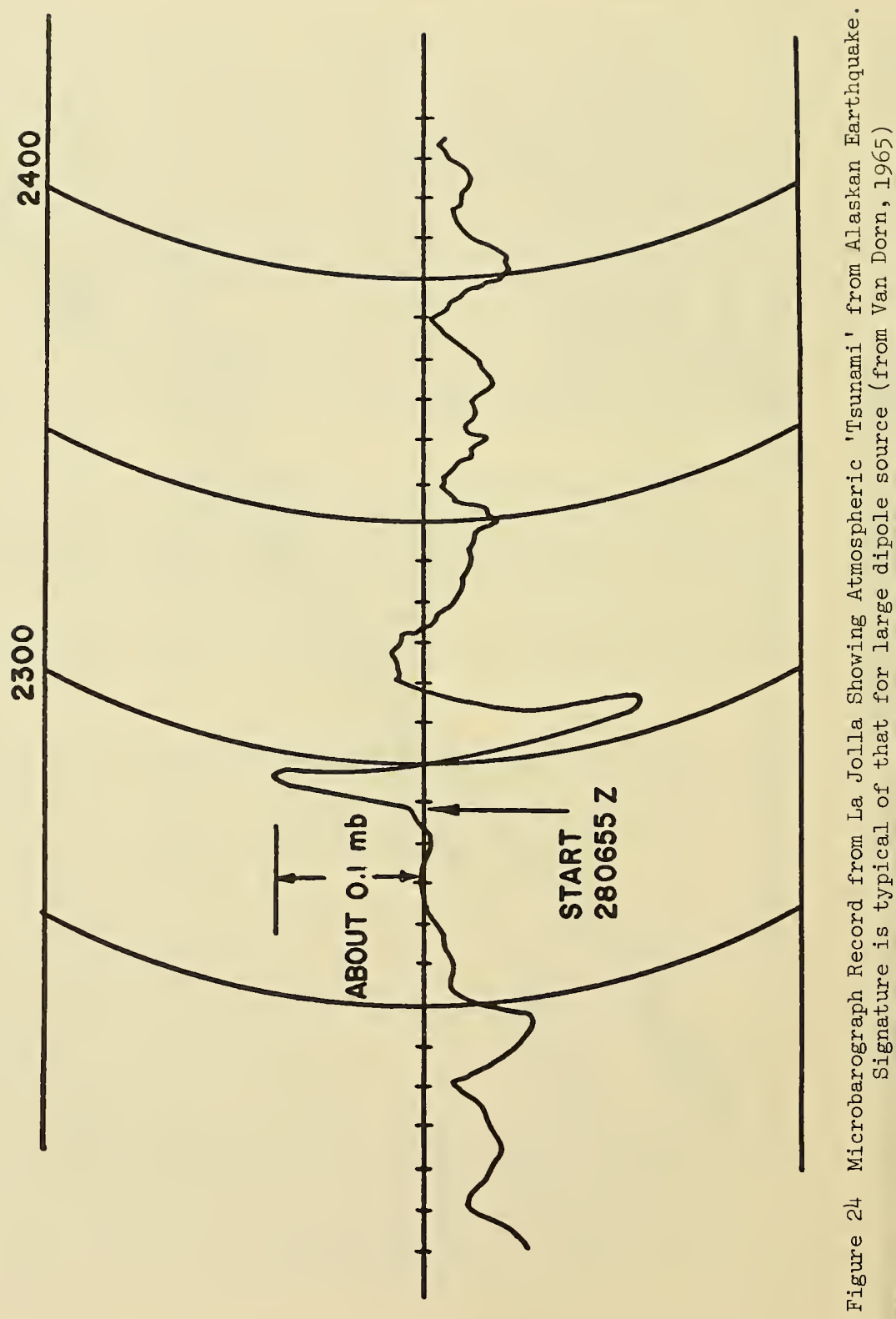




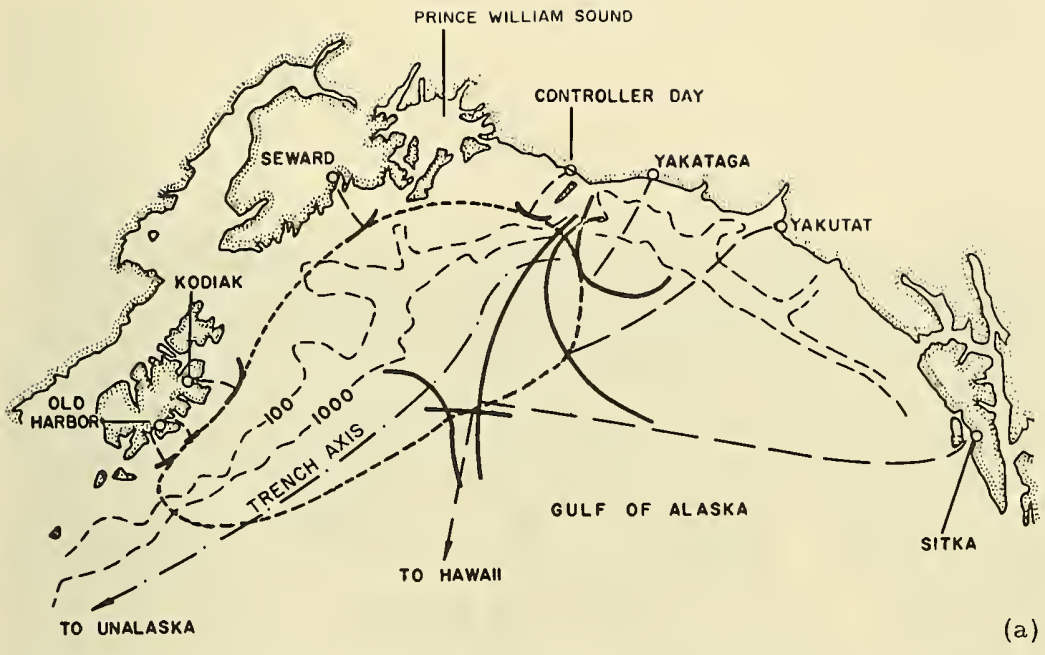

Figure 25 (a) Projection of Imaginary Wavefronts from Observation Stations back towards the Tsunami Source. The presumed source lies within the region circumscribed by the heavy curves and dotted line (from Van Dorn, 1965)

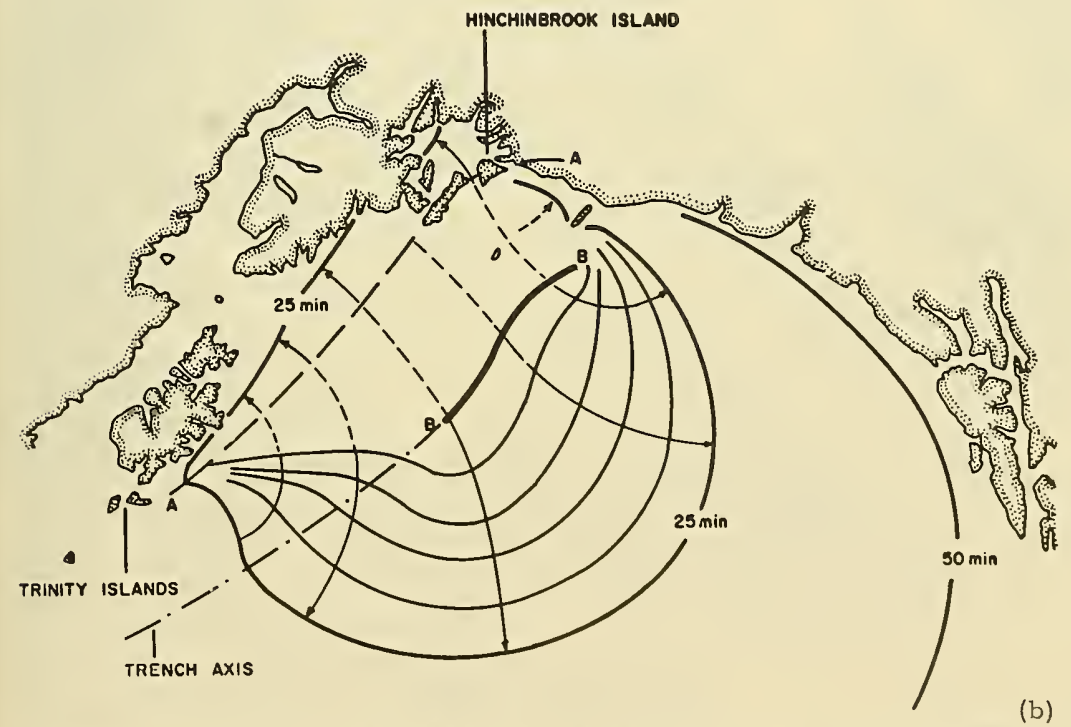

Figure 25 (b) Hypothetical Model of the Tsunami Source, Showing Negative Wave Front Radiating towards Northwest, and Positive Front Spreading out over Gulf of Alaska (from Van Dorn, 1965) 


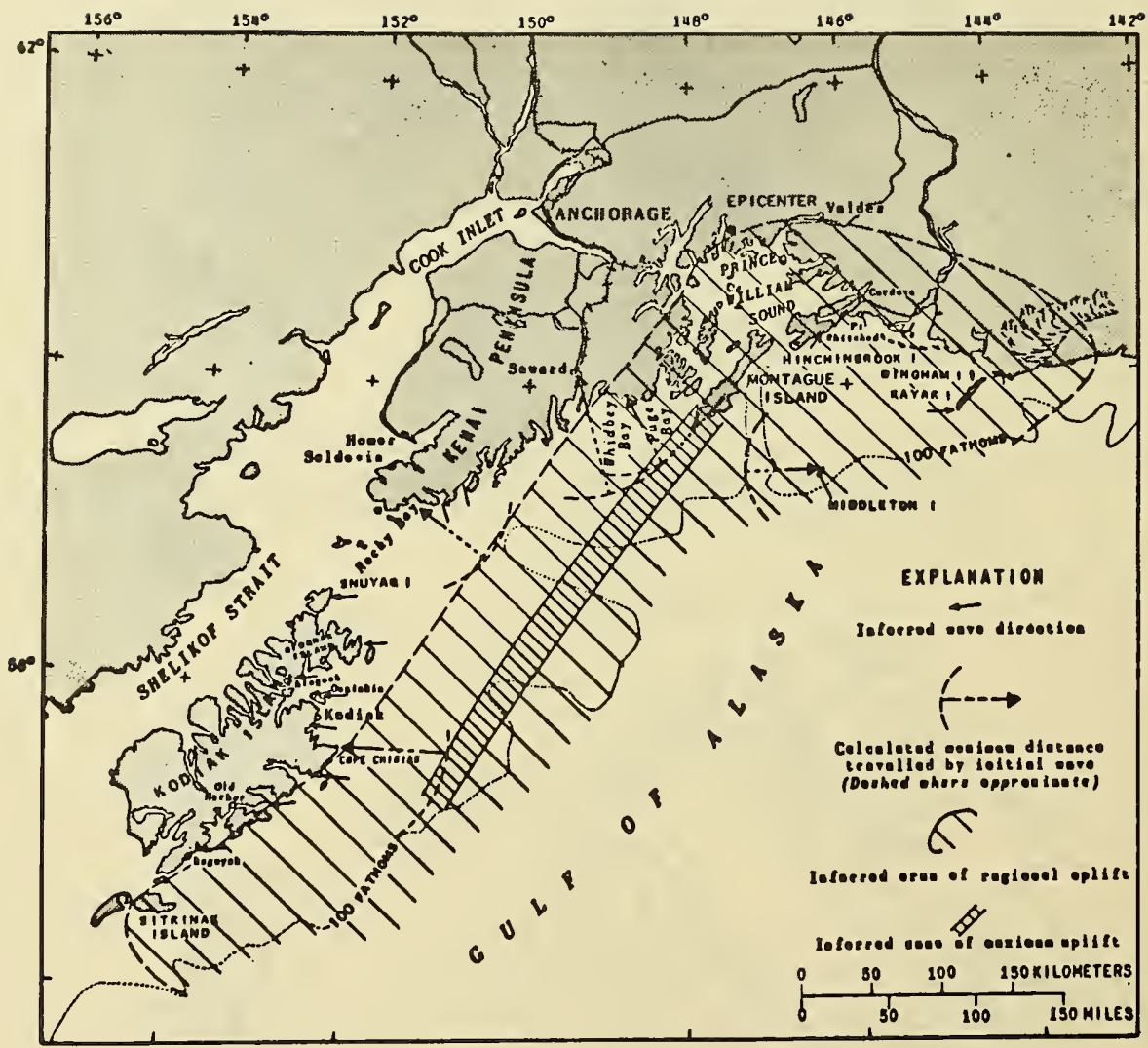

Figure 26 (a) Inferred Generating Area of the Alaskan Tsunami (from Plafker \& Mayo, 1965) 


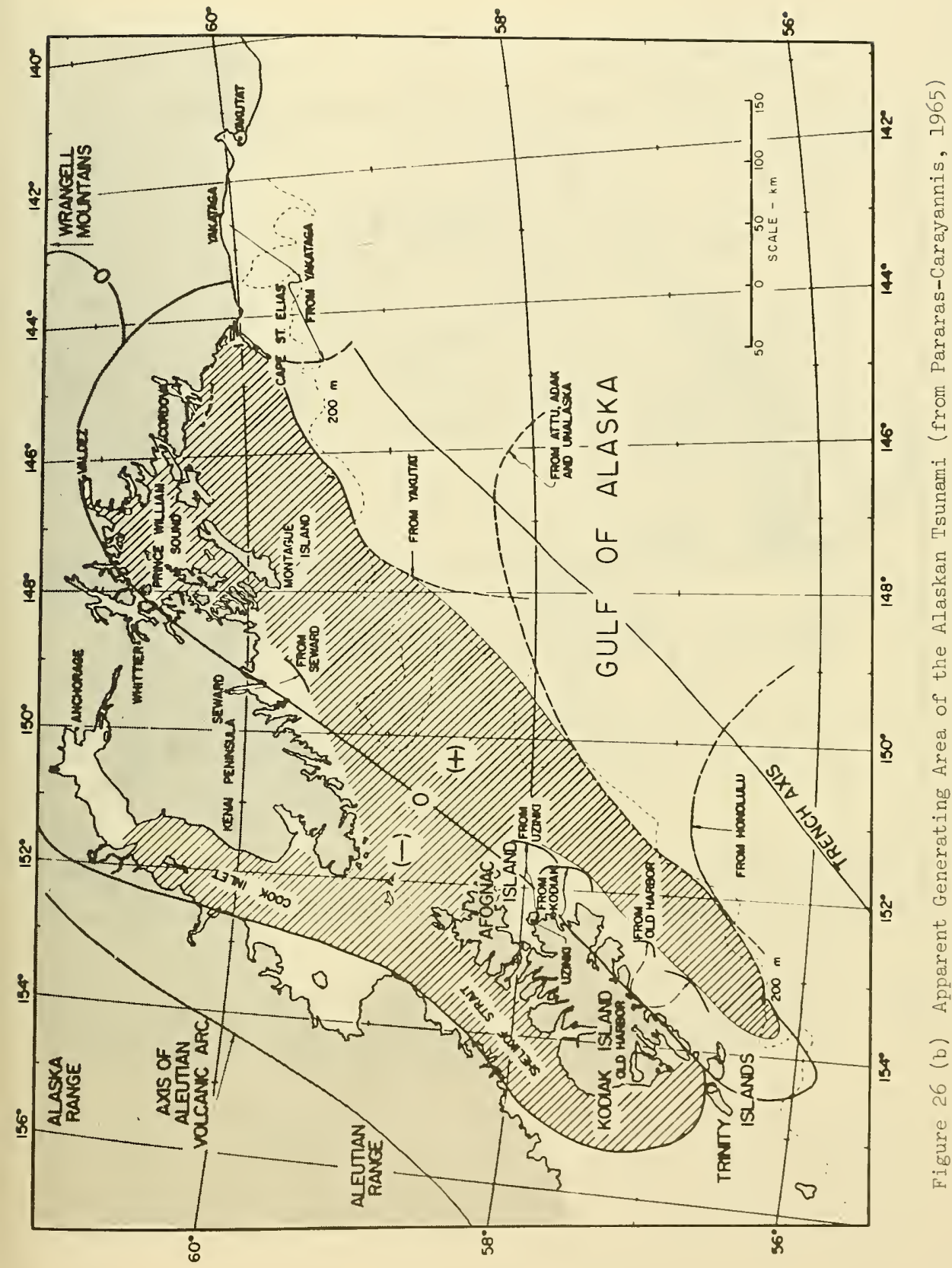




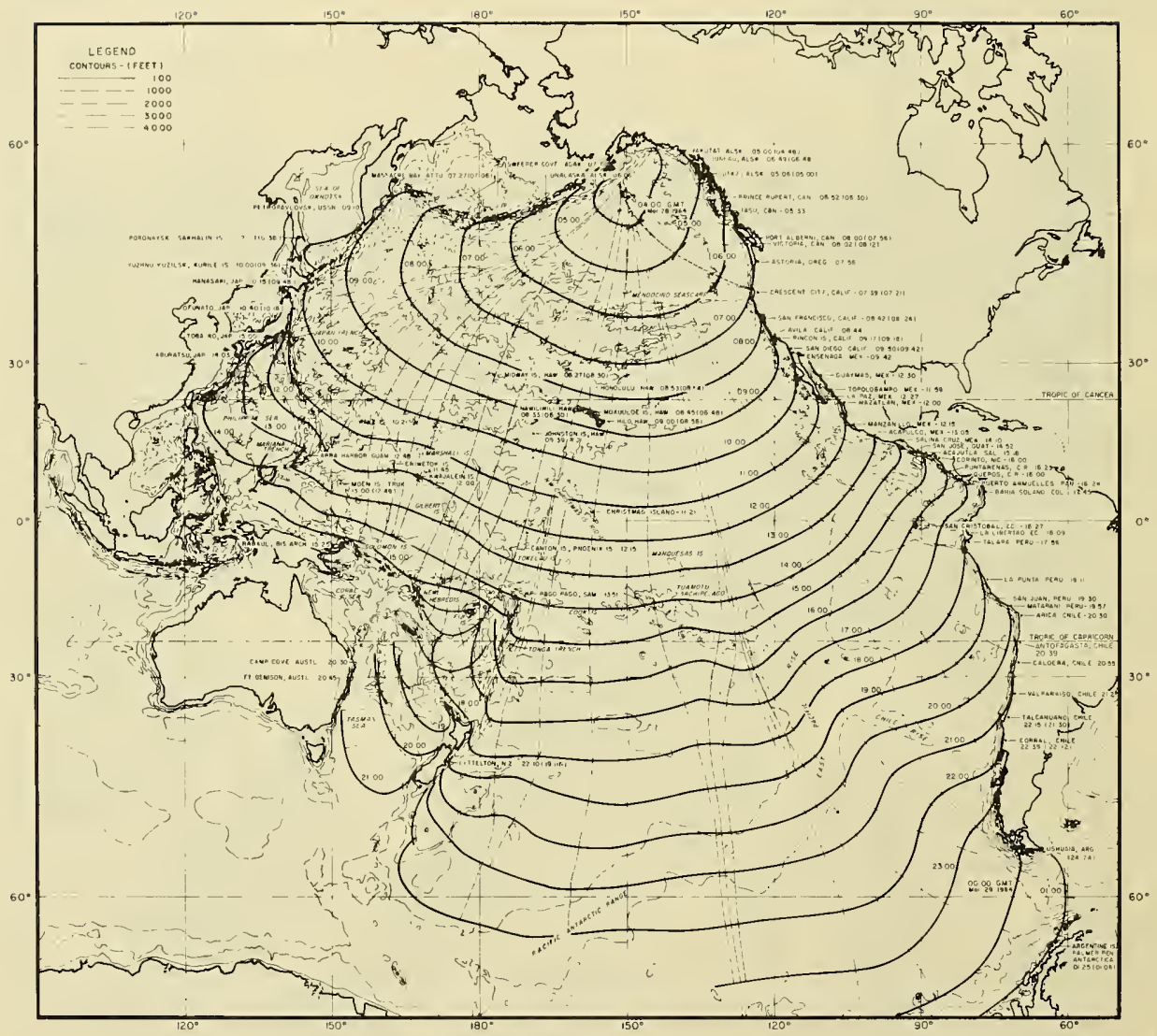

Figure 27 Approximate Locations of Tsunami Wave Front at One-hour Intervals (GMT) in the Pacific Ocean (based on arrival times of Tsunami at tide stations and refraction of waves by water depths) 
Figure 27 tends to place the flanking wave at the origin almost exactly along the line of the Aleutian Trench as found by Van Dorn. On the other hand, it suggests a strong concentration of energy emanating from what must be considered the end of the fault along the line of the Aleutian Trench at a point approximately due southeast of the southwestern tip of Kodiak Island near the Trinity Islands. In regard to the southwestern extremity, this is in fair agreement with PararasCarayannis (Figure 26b), and would suggest that the total fault length $I \simeq 800$ kilometers proposed by Press and Jackson, and Furumoto is not unreasonable, assuming its penetration as far as Valdez.

From Figures 25, 26, and 27 we infer that the tsunami source area was roughly rectangular and about 700 kilometers long by 200 kilometers wide. The corresponding source diameter $S$ yielding the same area is about 425 kilometers. Plotted against earthquake magnitude in Figure 28 , this is found to be in reasonable accord with Japanese data of Iida (1958) and of Watanabe (1964). An empirical relationship which would provide a reasonable fit to these data is

$$
\log _{10} S=(2 / 3) M-3
$$

for $\mathrm{S}$ in kilometers and is similar to the relationship proposed by Wilson, et al, (1962).

\section{Speculation on the Cause of the Earthquake and the Earthquake Mechanism}

In the Introduction we remarked that the earthquake occurred "mercifully" at low tide and that this fact, together with the uplift of the land over a vast area greatly mitigated the damage potential of the tsunami. We shall now advance the concept that this interrelationship necessarily had to occur as it did.

In all the literature about the Alaskan earthquake, we have found nothing to suggest that it was remarkable that the earthquake occurred on Good Friday and at a time close to sunset. We shall suggest that these facts also were part of the interlocked relationship. In advancing the concepts that follow, the first author (Wilson) does so somewhat diffidently, knowing that he trespasses in an area of uncertain knowledge. If the ideas lack substance, he trusts that he will be forgiven for letting a spirit of enquiry outrun the formal bounds of study. But, if some element of truth is found, the implications could have value in furthering the prediction of earthquakes and of tsunamis.

That the earthquake occurred on Good Friday, March 27, 1964, establishes that the moon was at the full; that the earth, sun and moon were in conjunction; that the oceanic tides were at the spring or greatest range and that the earth tides were at their strongest. Moreover, the earth had just passed the vernal equinox (March 20) on its orbital path in the plane of the ecliptic (Figure 29). We are tempted to ask whether 
all this was merely coincidental or whether a reason for it can be found.

At once the question arises: Have other great earthquakes shown any relationship to the phases of the moon and sun? The answer appears to be in the affirmative. Figure 29, which is a pictorial representation of the plane of the ecliptic and the orbit of the earth around the sun, shows the relative positions of earth, moon and sun on the occasion of seven of the largest earthquakes the earth has known. In four of these cases (Lisbon, November 1, 1755; Mino-Owari, Japan, October 28, 1891; San Francisco, April 18, 1906; Alaska, March 27, 1964), the moon was in opposition, at syzygy (opposite side of the earth from the sun). Of the remaining three (Assam, India, June 12, 1897; Chile, May 22, 1960; Yakutat, Alaska, September 10, 1899), the first two were on occasions of new moon with the moon in conjunction, at syzygy. Of the limited number of cases thus examined the single exception to the syzygy position of the moon at the time of earthquake was the occasion of Yakutat, Alaska, September 10, 1899, but even here the moon is only about three days past its syzygy position of conjunction. Moreover, this $M \simeq 8.6$ earthquake was preceded by one of magnitude $M=8.3$ in almost the same area, just six days earlier on September 4, 1899, when the moon would have been about three days ahead of its syzygy position. One might suppose that the approach to syzygy of the moon triggered the first quake and relieved enough of the strain to delay the second and prevent what might otherwise have been a monstrous earthquake when the moon was exactly in conjunction.

This sampling of cases implies that earth tides are indeed a factor in the causation of earthquakes. * Zetler (1966) has briefly discussed this question, and referred to the work of Allen (1936) and Knopoff (1964). Knopoff failed to find any significant correlation between times of earthquake occurrence in California and earth tidal potential. Allen, however, had warned of the inefficacy of correlations of global events that paid no attention to the local nature of faults and earth stresses. Zetler appears to concede that insufficient attention has really been given to the horizontal component of the tide-producing force in work of this kind.

We ourselves (Wilson, et al, 1962), had drawn attention to an observation of the Japanese, as reported by Davison (1936), that the highest frequencies of occurrence of aftershocks following the great earthquake of Mino-Owari, in 1891, were timed at new and full moon, resulting in notable recurrence periods of 24 hours, 14.8 days and 29.6 days. Davison (1936) also remarked that a similar effect on aftershock activity had followed the Calabrian earthquake of 1783, in Italy. Clearly in these cases, lunisolar tide-generating forces must have been instrumental in promoting strain-release in the aftershock adjustments.

Recently, Ryall, Van Wormer and Jones (1967) have established a definitive correlation between aftershock activity (following the Truckee, California, earthquake of September 12, 1966), and earth tide cycles of about 24 and $121 / 2$ hours, so that the question of lunisolar influence upon earthquakes no longer appears in doubt.

* See note on Figure 29, page 42. 


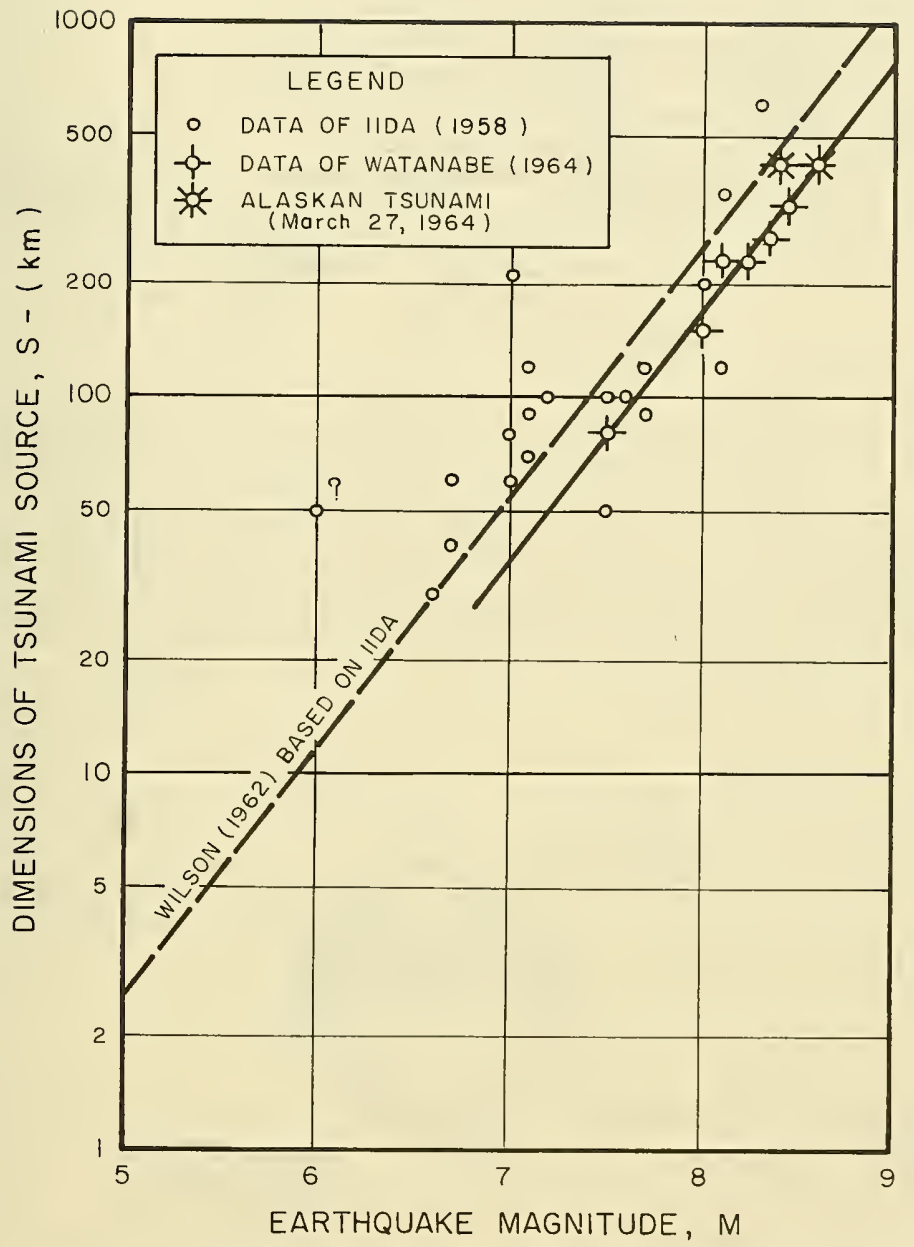

Figure 28 Relationship of Diameter of Tsunami Source Region to Earthquake Magnitude 


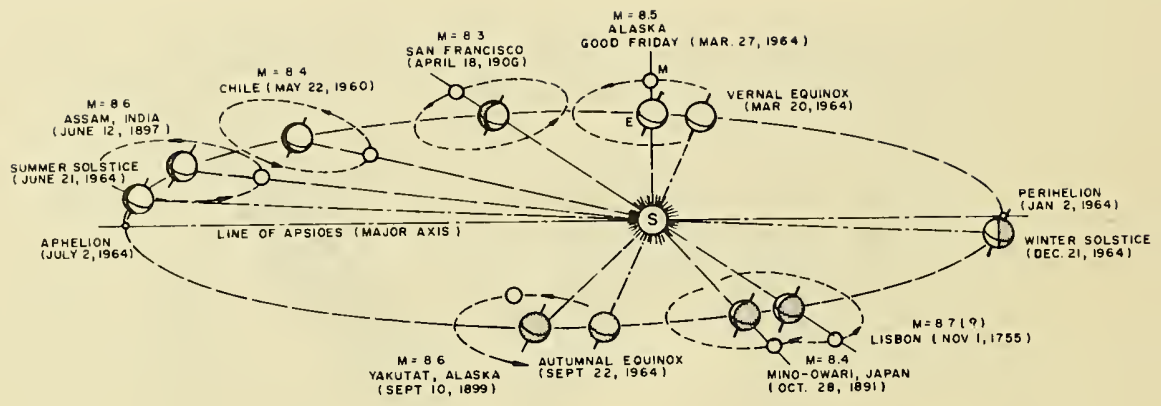

Figure 29 Pictorial View of Relative Positions of Earth, Moon, and Sun on Occasions of Notable Great Earthquakes.

Editor's note: Later investigation (12 May 1968) appears to indicate that this figure is not wholly accurate and that the arguments expressed regarding "syzygy triggering" may not be tenable. The Coastal Engineering Research Center, however, feels that the concept is worthy of consideration.

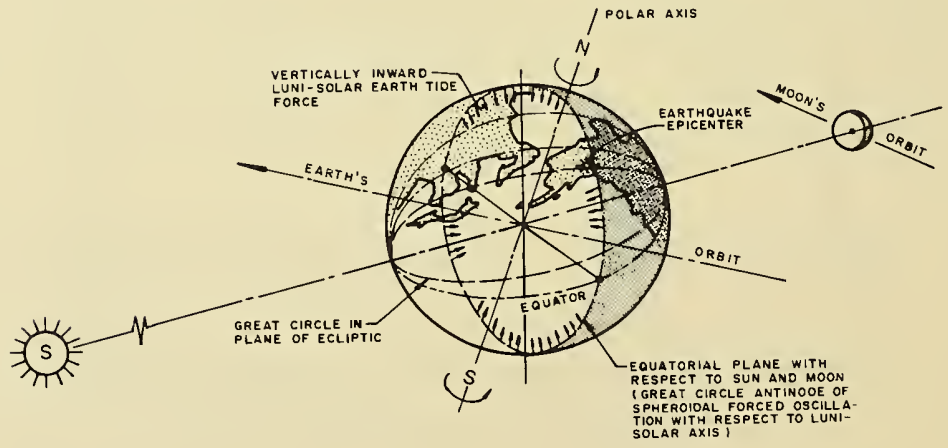

Figure 30 Schematic Diagram of the Earth, Moon, and Sun Relationship at the Time of the Alaskan Earthquake of March 27, 1964. 
We return then to a consideration of the circumstances of the Alaskan earthquake of March 27, 1964. In Figure 30 the lunisolar relationship is shown in greater detail at the time(5:36 AST), close to sunset, when the earthquake occurred. Because of the earth's position, just beyond the vernal equinox, the earth's axis was almost coplanar with the great circle normal to the line joining the sun and the moon. Consequently at $5: 36$ p.m. the hypocenter or the earthquake moved into a position on this plane where the crust became subject to the maximum vertical inward squeeze of the earth tide that can result at any time from both the sun and moon, acting in unison. Within the crust, this squeeze would have produced a ring-type tangential compressive stress in an almost due north-south direction, which presumably was a sufficient increment of stress in the right direction to trigger the earthquake and cause a massive release of rock strain.

It is worthy of note that besides the earth tide effect, there would have occurred an additional triggering load from the oceanic tides. Figure 31 shows the tidal situation at the time of the earthquake. The tides in Prince William Sound are in rhythmic opposition to the tides at the head of Cook Inlet. At the moment of the earthquake, the tide in the Inlet was at its highest (about +18 feet above MSL) and at its lowest in Prince William Sound (about -7.5 feet below MSL).

The weight of water impounded above MSL in Cook Inlet was about $2.7 \times 1010$ short tons. On the opposite side of Kenai Peninsula, approximately $9.3 \times 1010$ tons of water had been drained (with reference to MSL) from the roughly triangular area of Prince William Sound, out to the boundaries of no vertical earthquake ground motion (Figure 31). The centers of mass of these water bodies occur in the locations shown at a moment-arm distance of about 131 miles. This moment arm is seen to be approximately normal to the hinge axis of no vertical ground movement. The tilting moment of the entire water mass, which thus favored vertical ground motion in the manner in which it occurred, amounted to about $4 \times 1016$ foot-tons. It seems almost certain that this moment must have been an aditional factor in triggering the rupture that caused the earthquake. It is of general interest that the centroid of negative water load lies on the axis of highest uplift through Montague Island.

There remains one other remarkable feature of the Alaskan earthquake which warrants attention. The earthquake caused many remote effects in the form of seismic seiches and disturbances in lakes, ponds, canals, and waterways over a large part of the United States (cf. Vorhis, 1967; McGarr and Vorhis, 1967; Spaeth and Berkman, 1967). The maximum concentration of these effects occurred along the U. S. Gulf of Mexico coastline. Examples of the effects registered on the tide gages in the old Brazos River channel at Freeport, Texas, and at Pensacola, Florida, are reproduced in Figure 32. What is remarkable in Figure 32 is that in addition to the obvious disturbances triggered at Freeport and Pensacola about 25 minutes after the earthquake, there occurred also on the tide record at Pensacola, similar type vibrations of the water surface at regular intervals preceding by several hours the occurrence of the Alaskan earthquake of March 27, 1964. 


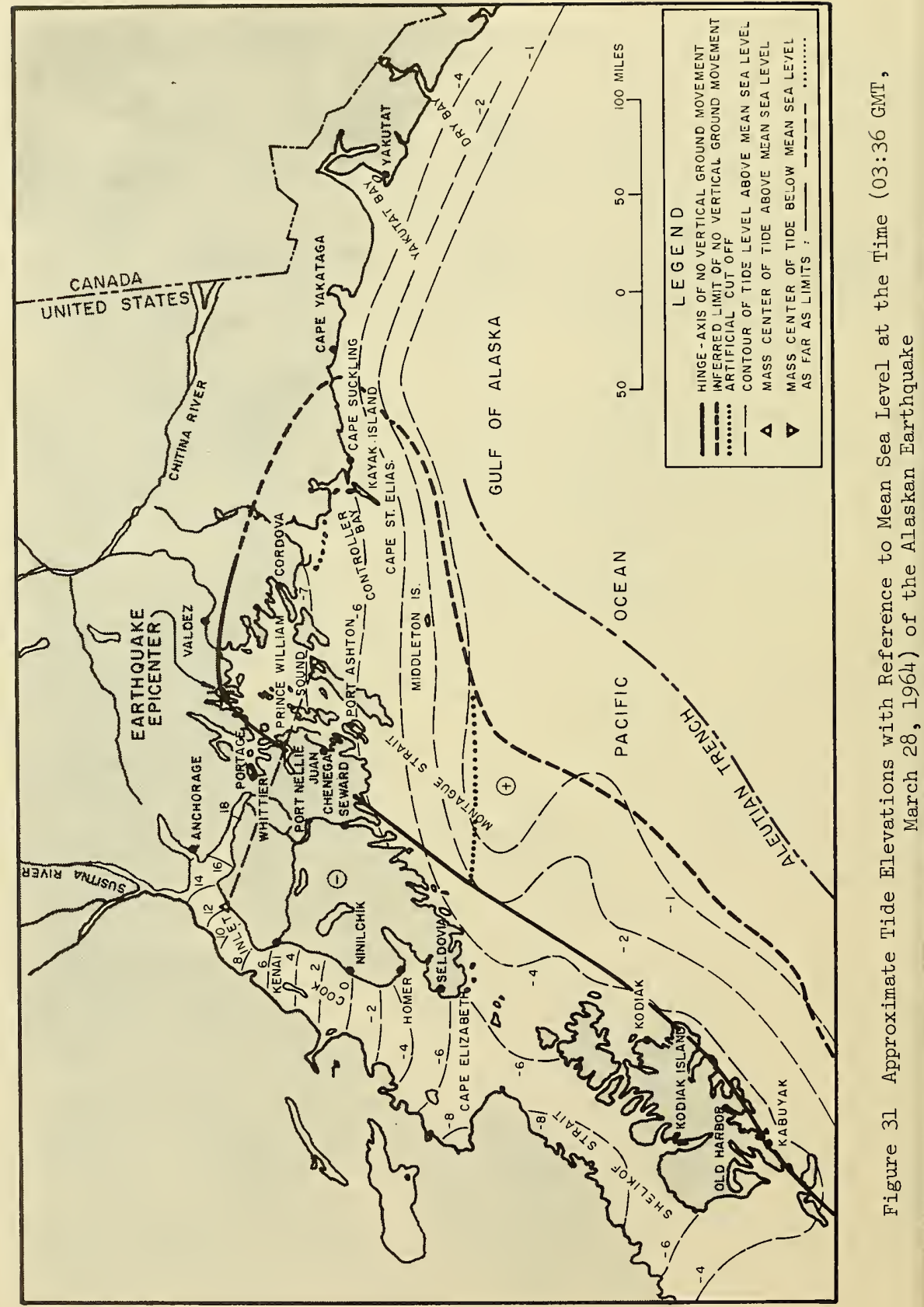


The fact emerges (assuming the record itself to be accurate as to time) that the vibrations start at intervals of about 50 minutes, with the last and biggest group of evanescent oscillations starting almost exactly 25 minutes after the Alaskan earthquake. These oscillations are so obviously unlike any that would be ascribed to normal wave action (being of impulsive, evanescent type) that some association with the imminent earthquake mechanism seems implied.

At Freeport, Texas, there is an equivalent interval of about $25 \mathrm{~min}-$ utes between the time of occurrence of the earthquake and the development of the water disturbance in the canal. Donn (1964) has remarked on this case and indicated that the natural periods of transverse oscillation across the channel are of the same order as the periods of Love $(Q)$ and Rayleigh $(R)$ waves. McGarr (1965) has investigated this case more closely and evolved a very suggestive mechanism for explaining the disturbances by the transverse vibration of the channel bed at the frequency of the Love and Rayleigh waves. deBremaecker (Donn, 1964) had pointed out that the Rayleigh waves would have had a period of about 16 seconds and double amplitude of 15 centimeters. Donn remarks that the arrival time of these $\mathrm{R}$-waves corresponded to the development of the channel water oscillation. On close examination of the Freeport record we find, however, that there is evidence for underlying $2.25,1.75$, and 1.5 minute oscillations of impulsive type which are not fully accounted for in McGarr's otherwise admirable analysis. The explanation for these longer oscillations, if real, is not immediately apparent.

Even at Freeport there is a suggestion of an impulse at almost exactly 50 minutes prior to these disturbances, or 25 minutes prior to the earthquake. Though we have diligently searched other readily available records of seismic seiches, (cf. Spaeth and Berkman, 1967; McGarr and Vorhis, 196T) no other similar antecedent effect can be detected.

The 25-minute interval between disturbances at Freeport, Texas and Pensacola, Florida, and the curious occurrence of these oscillations earlier than the earthquake suggests strongly that the earth was in its second (football) mode of spheroidal oscillation (natural period 54 minutes - Press, 1964) with respect to the lunisolar axis, forced by the lunisolar earth tide of 12.4 hours, whose 15 th harmonic would be about 50 minutes. At the time ( $01.30 \mathrm{GMT}$; March 28, 1964) that the water oscillations start at Pensacola, the position of Pensacola in relation to such a spheroidal earth oscillation would have been close to the nodal circle on the moon side of the earth (Figure 30). Consequently, if the spheroidal forced oscillation actually existed, the ocean water in Pensacola Bay would have been subject to the maximum horizontal accelerations across the node.

This raises the point, that, had the earth been in such a spheroidal (football) mode of oscillation with respect to the lunisolar axis, then at the time the earthquake occurred, the hypocenter, moving with the rotation of the earth on its axis, would have just reached the antinodal position of maximum vertical acceleration (Figure 30). Further, since 
Pensacola lies on a small circle that would be nodal with respect to an antinode at the epicenter of the earthquake, in a second-mode (football) free spheroidal oscillation engendered by the earthquake (Nowroozi, 1965; Smith, 1966) it would be in a uniquely favorable position to record a resonance effect of earth-shaking after the earthquake. It is suggested that a mechanism of this type if within the bounds of credence, might also possibly explain the high density of seismic seiches found by McGarr and Vorhis (1967) in the region of the U. S. Gulf of Mexico coastline. 

Section III. GENERATION, PROPAGATION, AND DISPERSION OF THE MAIN TSUNAMI

\section{The Inferred Mechanism of Tsunami Generation}

In Section II, paragraph 6, we considered some of the inferences that could be drawn from tsunami evidence regarding the character of the seabed disturbance resulting from the earthquake. Along with seismic evidence and the measured horizontal and vertical displacements of land in the meizoseismal area, the emergent picture is that of a skew thrust in a south and southwesterly direction (see Figure 16), of the earth's crust over a slightly dipping fault plane that probably intersects the earth's surface deep in the Aleutian Trench. It is possible that the skewness of the thrust was partly the result of a strike and dip slip along a nearly vertical fault that has no intersection with the earth's surface. The vertical ground deformations have been shown to be compatible with both forms of faulting, although the evidence strongly favors thrust faulting on a low angle plane as being the primary mechanism of the earthquake.

The dipole character of the vertical ground movement led Van Dorn (1964, 1965) to conclude that the corresponding initial form of seasurface disturbance must also have been of this form. This conclusion may be substantiated also on theoretical grounds (Wilson, et al, 1962; Kajiura, 1963; Van Dorn, 1965) which show that the initial surface effect from a sudden bottom disturbance tends to he a smoothed representation of the bed displacement. In this picture the new element, whose effect has no background of mathematical exploration, is the horizontal displacement of the seabed, occurring simultaneously with the vertical uplift. Hinchinbrook Island, Montague Island, and the entire emerging ridge to the southwest moved forward through 40 or more feet and thus functioned as a gigantic wave-generating paddle (Figure 16). Further, if the extrapolations of Figure 16 are correct to any degree, the thrust from this movement was increasingly skew toward the southwest, implying that near the end of the fault, off Kodiak and the Trinity Islands, its direction was almost entirely southwest.

\section{The Heights of Tsunamis Near Their Source}

Tide gage records of the seismic sea waves, outside the immediate earthquake area on the Pacific Ocean side, show an initial rise of water indicating a positive sea wave resulting from the upward (and forward) motion of the seabed (Coast and Geodetic Survey, 1964; Brown, 1964; Spaeth and Berkman, 1965). The initial water movement within the Gulf of Alaska and along its coast is not so well known because no tide gages were operating between Yakutat and Kodiak or in Prince William Sound.

In the region of uplift, immediate water withdrawals were reported at Boswell Bay (Hinchinbrook Island), Cape St. Elias, and Middleton Island (Van Dorn, 1964), and also at Cape Yakataga (Berg, et al, 1964; Brown, 1964; Chance, 1968); - see Figure 1 for locations. 
Middleton Island on the edge of the Continental Shelf (see Figure 33 for bathymetric details) occupies a unique position in relation to the tsunami-generating area. According to Brown (1964), the initial regression of the sea there was observed to last about 15 to 20 minutes, and to drop about 2 to 3 feet (Chance, 1968). A wave arrived some 20 minutes after the quake but rose no higher than the tectonically elevated higher high-water line (Chance, 1968). St. Amand's observation, on the other hand, found swash marks at an elevation 10 feet above the latter level (Brown, 1964).

In Figure 34, we place these facts within a visual framework which shows a cross-section of the Continental Shelf between Middleton Island and Montague Island, normal to the hinge line of earth movement (section $\mathrm{AA}^{\prime}$ in Figures 8 and 33). The vertical uplift of the land and seabed in this region, as inferred from Figures 8 to 1l, is shown, together with an estimated initial elevation of the sea surface, whose crest is displaced somewhat to the right (southeast toward Middleton Island) because of the horizontal thrust of the land during the earthquake. Although the water would have risen at once about 1.7 meters (ab) at Middleton Island, the greater uplift of abnut 2.5 meters (ac) of Middleton Island itself caused the water actually to drain from around the Island. This regression would have lasted about 20 minutes until the point $f$ on the tsunami front advanced to the elevation c (Figure 34). Although St. Amand's observation e might suggest extremely high waves, it is probable that the swash marks are the result of the runup in a concave embayment and thus reflect an amplification of the true wave height. Brown (1964) records that two consecutive waves approached Middleton Island about an hour after the earthquake; these were about three feet high and separated by about half a mile of distance and one minute in time. Undoubtedly these waves were secondary to the main tsunami and were probably parasitic.

Figure 34 suggests that the crest elevation (above normal sea level) of the tsunami at its source near Montague Island, may have been about 5 meters (15-16 feet). This crest elevation implies a nominal wave height of 30 feet. Southwest of Montague Island the larger vertical uplift (>50 feet) and horizontal land thrust ( $>60$ feet) probably would have created waves about twice as high.

At Cape Yakataga, Charles Bilderback recorded the arrival of the waves and noted their levels with reference to landmarks, and so was able to assess their runup height (cf. Berg, et al, 1964; Pararas-Carayannis, 1965; Chance, 1968). Figure 35, a plot of Bilderback's observations, suggests that the underlying dominant wave had a period of about 1.5 hours and a height of about 8 meters (26 feet). This plot shows that in the period range from 5 to 20 minutes, local oscillations increased the height by almost 2 meters. As we shall see later, these and other wave periods are a common feature of tide gage records of the tsunami.

At Puget Bay and Whidbey Bay on Kenai Peninsula (Figure 1), close to the hinge line of zero vertical earth movement, waves up to 35 feet 
in height (runup) rolled in about 18 to 20 minutes after the earthquake (Chance, 1968). The lack of recession of the water here may be attributed to the probability that both land and water were uplifted about the same extent in the same time (see lefthand side of Figure 34). Further to the southwest, along the greatly indented southeast coast of Kenai Peninsula, on the subsidence side of the hinge line, initial withdrawals of water were reported for Rocky Bay and Nuka Bay (Van Dorn, 1964; Chance, 1968). These initial withdrawals were more probably produced by the differential stretch of the land caused by the horizontal earth movement in a southerly direction (see Figure 16) resulting in an immediate drop of sea level, than by any relative effect of the subsidence of the land itself (see Figure 36).

Seward, at the head of Resurrection Bay, experienced remarkable effects referred to briefly here, but due for critical examination later in this report. A massive horizontal shear of the seabed occurred along the axis of Resurrection Bay. This was intimated brief'ly to the authors by Captain Watkins of the Coast \& Geodetic Survey ship Hodgson and was confirmed in a verbal communication from Rusnak of the U. S. Geological Survey in 1967. The shear is almost presaged by the natural folding of the contours along the flow lines of horizontal earth movement along the axis of Resurrection Bay in the gross picture of Figure 16. Although details of this bottom movement were not available to us and were apparently unknown to Lemke (1967), we may speculate that the initial counter-clockwise wave effects recorded at Seward (cf. Grantz, et al, 1964; Brown, 1964; Berg, et al, 1964; Plafker and Mayo, 1965; Chance, 1968; Lemke, 1967) were a direct consequence of this shear. The first wave of the main tsunami, however, rolled in on Seward about 25 minutes after the earthquake, according to Lemke (1967), and was estimated to be 30 to 40 feet high as it neared the bay-head. An antecedent withdrawal of water probably occurred in this area (Figure 36a).

To the southwest, in the Kodiak Island region (Figure 1), initial drawdown of the water table was reported for Port Williams, Afognak Village, and Uzinki (Berg, et al, 1964); drawdown occurred also at Homer, on Kenai Peninsula within Cook Inlet (Berg, et al, 1964). No initial regression of water seems to have occurred, on the other hand, along the southeast coast of Kodiak Island at such places as Saltery Cove, Old Harbor, and Kaguyak (Berg, et al, 1964). An attempt to explain these situations in terms of the inferred tectonic deformations taking place over the Continental Shelf is shown in Figure 37.

A detailed account of wave sequence and wave height at Kodiak is available, thanks to the log kept by Lt. C. R. Barney of the U. S. Fleet Weather Central at the Naval Base, Womens Bay, some 7 miles southwest of Kodiak City. Lt. Barney's log, recorded here in Appendix A, is now well documented (cf. Brown, 1964; Berg, et al, 1964; Tudor, 1964; Chance, 1968; Pararas-Carayannis, 1965; Plafker and Kachadoorian, 1966; Kachadoorian and Plafker, 1967; Spaeth and Berkman, 1967). This $\log$ is the only such detailed account for the earthquake area. Various plots of Barney's data have been made, notably by Brown (1964), Tudor (1964), Pararas-Carayannis (1965); and Kachadoorian and Plafker (1967). These all tend to disagree on certain 
details, whenever different interpretations have been applied to parts of the data that seem ambiguous. We have studied these interpretations rather carefully, and evolved our own record of Barney's data in Figure 38, indicative of the postquake fluctuations of sea level in Womens Bay.

Figure 38 is based on the premise that mean lower low water (MLLW) at Kodiak, as a tide level, referenced to mean sea level (MSL), has remained unaffected by the earthquake. The only way in which MLLW could be affected would be through a complete change of tidal range in the area, which by all accounts has not occurred. Since astronomical tide level is presumed unaffected at the time of the earthquake, the record must show the essential continuity of the tide in regard to mean water level at any time. Barney's readings were referenced to a tide staff zero, which from later observation (Bryant, April 6, 1964) is related to sea level as indicated in Figure 38 a.

Barney's data make no reference to any initial recession of the sea from Womens Bay, yet at the time of the earthquake (5:36 p.m. AST, March 27) the land level is known to have dropped by 5.5 feet (Bryant, 1964 ). Barney first noted the water rising rapidly at $6: 20 \mathrm{p} . \mathrm{m}$. AST, about 40 minutes after the cessation of the main shock, but since no relative land-sea change had drawn his attention, sea level must have dropped with the land through an approximately equal amount. Accordingly, Figure 38a shows the sudden drop of sea level through 5.5 feet followed by a small hypothetical recession, relative to land, of about 1.5 feet, before the observed rapid rise at $6: 20$ p.m. AST.

Figure 38a has question-mark indicators wherever the water level was not definitely established. However, one criterion binding on all the data is that mean sea level at any time must lie at (or close to) the level of predicted tide. By a subjective analysis, we have found it possible to break down the complicated record of Figure 38 a into separate components considered to be: Figure $38 \mathrm{~b}$, the astronomical tide, Figure $38 \mathrm{c}$, the main tsunami, and Figure 38d, the local oscillations. A modulated wave system evolves in Figure $38 \mathrm{c}$ with the fantastic wave period of about 2.5 hours, upon which is superimposed another beat-system of waves with a period of about 1.3 hours (Figure 38d).

The first wave system may be shown to correspond to the tsunami envisioned in Figure 37a, which applies to the area under consideration. From Figure $37 \mathrm{a}$ the half-length $(\lambda / 2)$ of the water wave measures approximately 60 nautical miles and the average water depth d about 260 feet. Using the Lagrangian equation for wave velocity

$$
c=\sqrt{g d}
$$

where $\mathrm{g}$ is the acceleration due to gravity, the period of the tsunami is found to be

$$
T=\lambda / \mathrm{c}=2.22 \text { hours }
$$

which is in approximate agreement with Figure $38 \mathrm{c}$. 


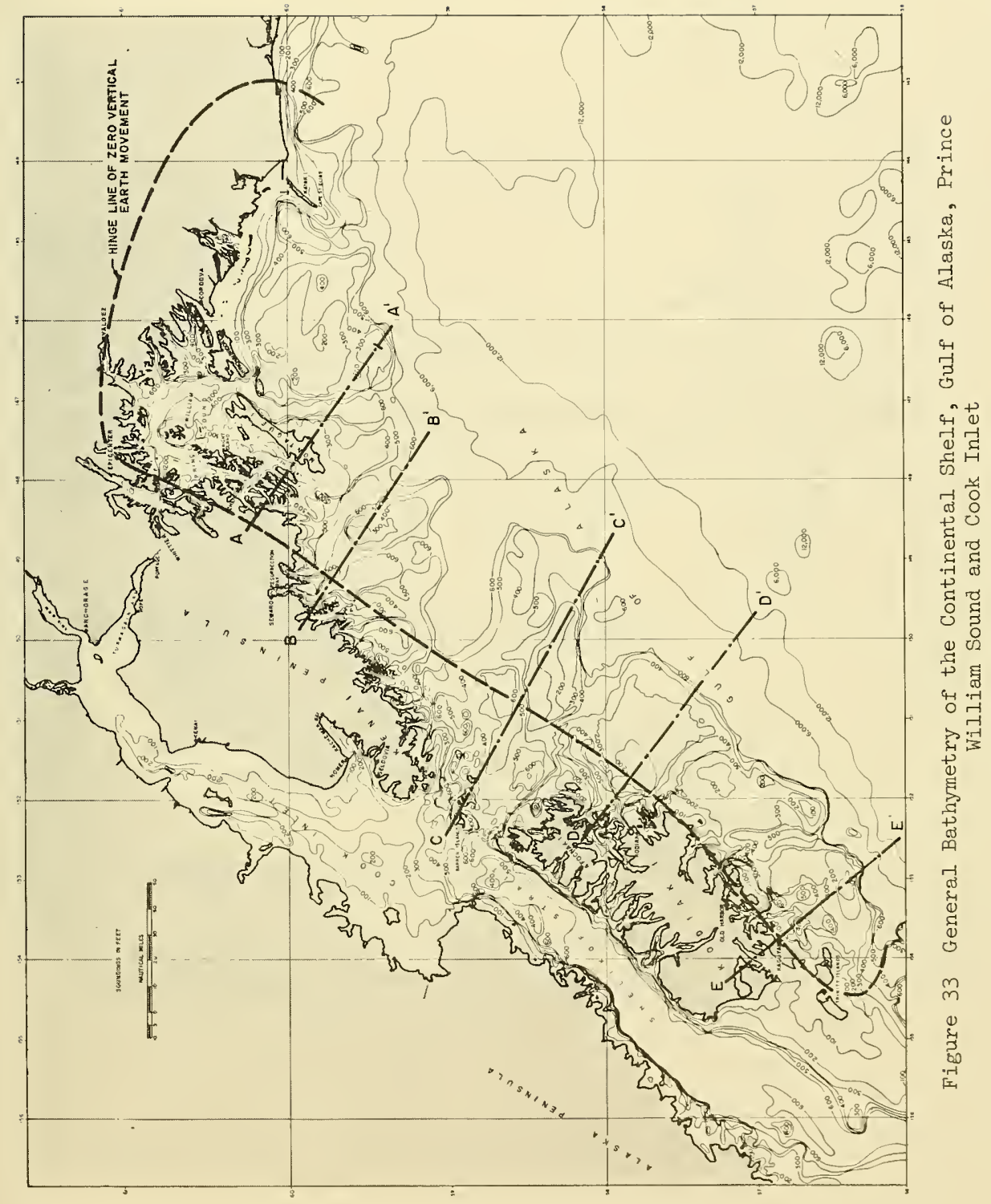




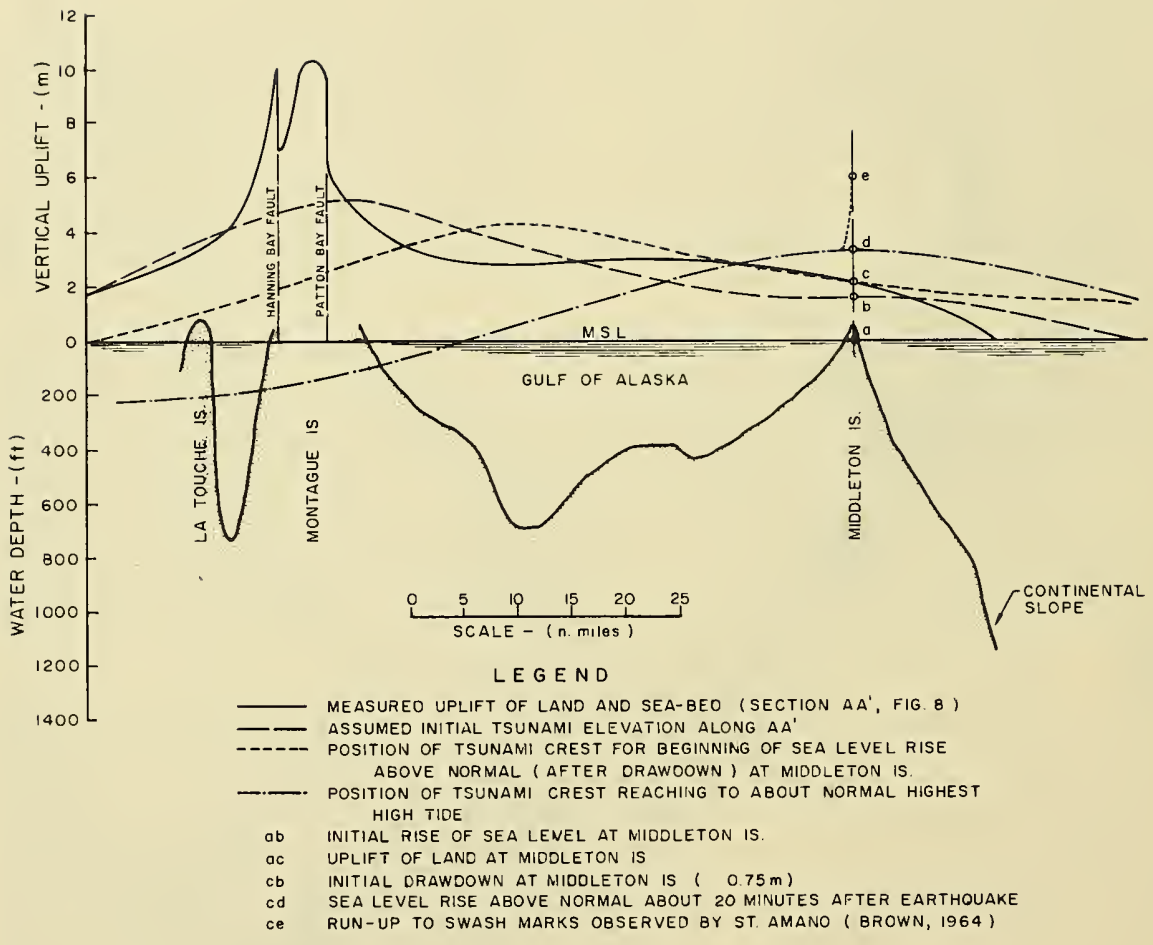

Figure 34 Inferred Mechanism of Tsunami Generation between Montague and Middleton Islands, Gulf of Alaska (section line AA', Figure 8) 


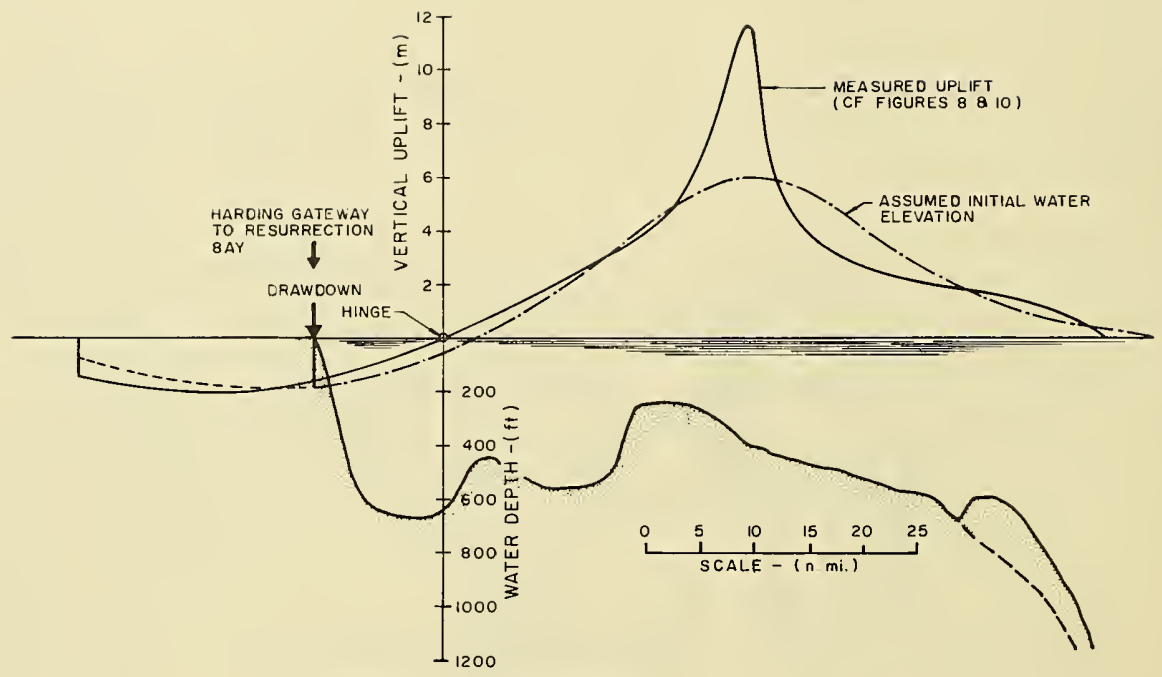

(a) PROFILE OF SECTION BB'

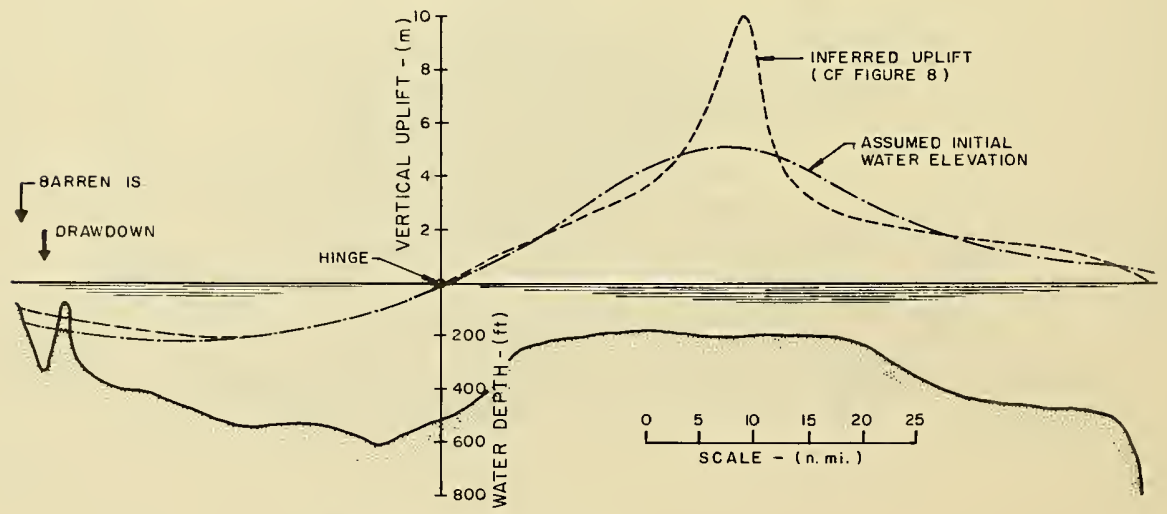

(b) PROFILE OF SECTION CC'

Figure 36 Inferred Mechanism of Tsunami Generation on the Continental Shelf off the Kenai Peninsula, Alaska. (a) along section line $\mathrm{BB}^{\prime} ;(\mathrm{b})$ along section line $\mathrm{CC}^{\prime}$ (Figure 8 ) 


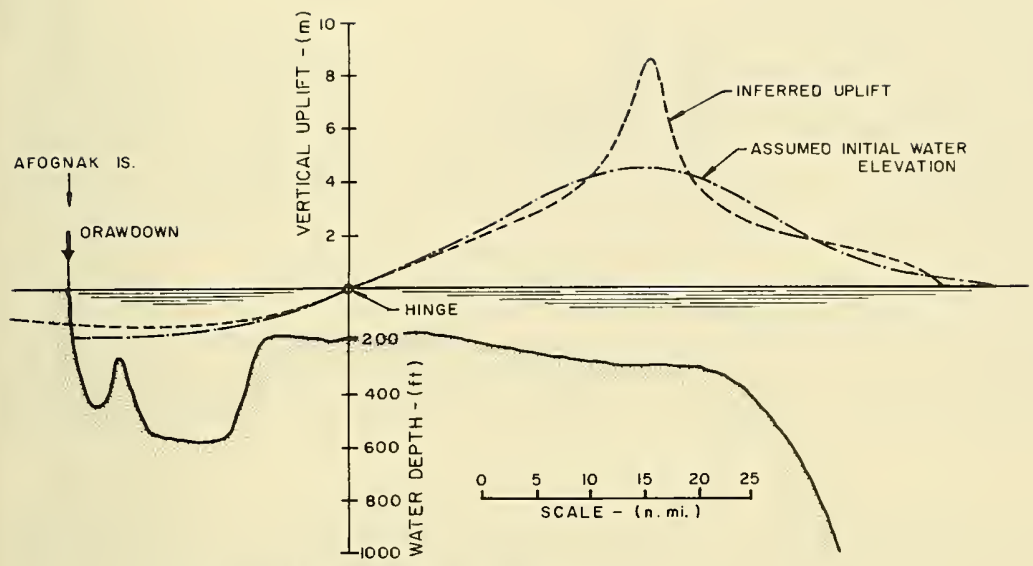

(a) PROFILE OF SECTION DD'

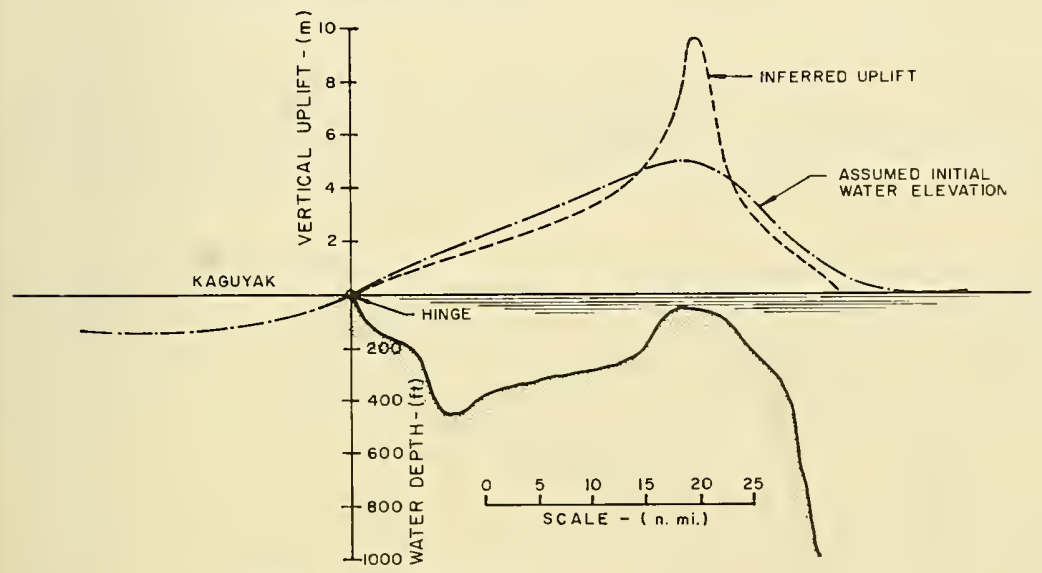

(b) PROFILE OF SECTION EE'

Figure 37 Inferred Mechanism of Tsunami Generation on the Continental Shelf of Kodiak, Alaska. (a) along section line DD', (b) along section line EE' (Figure 8) 


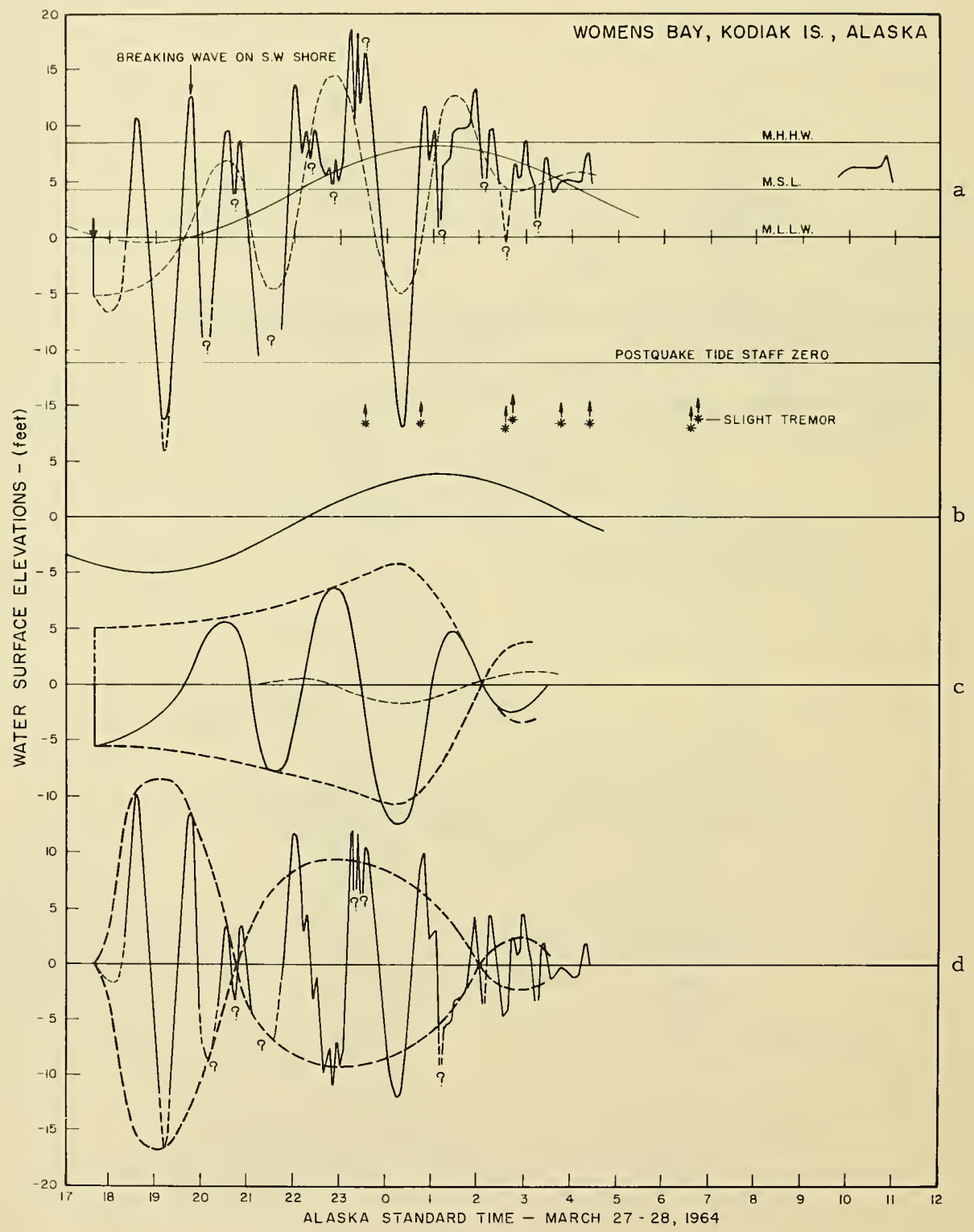

Figure 38 Water Level Fluctuations in Womens Bay, Kodiak, based on onserrations of Lt. C. R. Barney, U. S. Naval Station, Kodiak. (a) reconstructed marigram; (b), (c), (d), subjective analysis of (a) for identification of principal wave systems.

58 
The nature of the modulated waves of the second wave system in Figure 38d strongly suggests they represent a second mode oscillation. of the free oscillation of the Continental Shelf, forced initially by a second harmonic of the main tsunami. The free oscillation of the Continental Shelf for the profile DD' of Figure 37a may be calculated by using the impedance principle adopted by Neumann (1948) for investigating the eigenfrequencies of coupled basins. The profile of section DD' is best approximated by considering the shelf as comprising two coupled basins with horizontal beds, one 17 nautical miles long and 450 feet deep, and the second 50 nautical miles long and 260 feet deep. The shallow basin is considered to be open at both ends and the deep basin to be closed at one end. The calculation yields a fundamental mode oscillation of period $\mathrm{T}_{7}=300$ minutes or 5 hours and a second mode of period $\mathrm{T}_{2}=99.5$ minutes. These periods could reasonably be reduced somewhat because of the shorter overall length of the shelf off Kodiak as compared with profile DD' of Figure 37 a.

The main tsunami in Figure $38 \mathrm{c}$ also reveals a much longer period interference with wave crests 5 hours apart. It seems reasonable to adduce that this represents the development of a fundamental shelf oscillation, attaining maximum amplitude at the time the tsunami oscillation attained its maximum amplitude in the beat.

The approximate parallel of Figures $38 \mathrm{c}$ and $38 \mathrm{~d}$ with the theoretical examples of impulsive water upheaval calculated by Kranzer and Keller (1959) - see Figure 39 - is notable and suggests that the mechanism envisioned by Van Dorn (1964) and further exemplified here in Figures 34,36 , and 37 is a likely representation of what occurred.

It appears to have been fortunate for the Naval Station at Womens Bay, Kodiak, that the phasing of the primary and secondary wave systems of Figure 38 was toward producing ultralow rather than ultrahigh water. That Kodiak City was slightly less fortunate in this respect will be shown later. We merely note here that while Womens Bay reported a highest runup level of 18.8 feet above MLLW (Figure 38a), Kodiak City experienced a maximum runup to 21 feet above MLLW.

At various places along the coast in the earthquake zone, accounts have indicated runup heights of waves to 60 or 80 feet ( 58 feet west of Narrow Cape, Kodiak; 80 feet Aialik Bay, Kenai Peninsula) (Berg, et al, 1964; Chance, 1968). These accounts are not too well established, and they may refer to swash marks left by slide-generated waves or later seismic sea waves that occurred on the high tide. On Kodiak Island coast between Cape Chiniak and Narrow Cape, however, it is fairly well documented (see Berg, et al, 1964; Plafker and Mayo, 1965; Chance, 1968; Plafker and Kachadoorian, 1966) that waves reached 30 to 40 feet above the low tide level soon after the earthquake (Figure 40). If we anticipate a conclusion to be presented later that the runup $R$ of such longperiod tsunamis on the coast invoked only a modest amplification factor of about 1.5 on the wave height $H$, a nominal wave height near the coast might be considered to be of the order of 26 feet ( 8 meters). At the generation point we have already inferred wave heights of the order of 
(a)

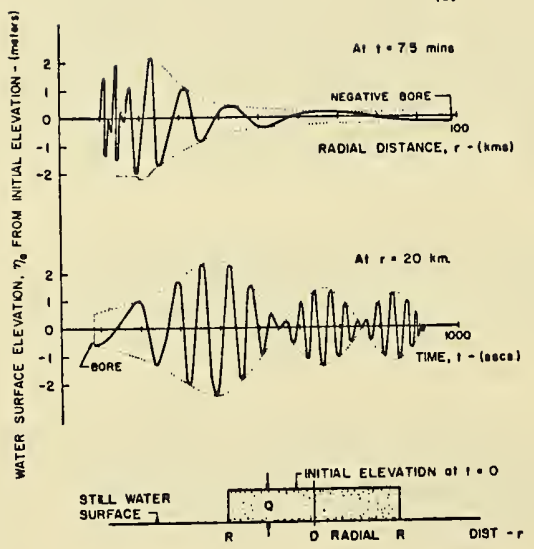

(b)

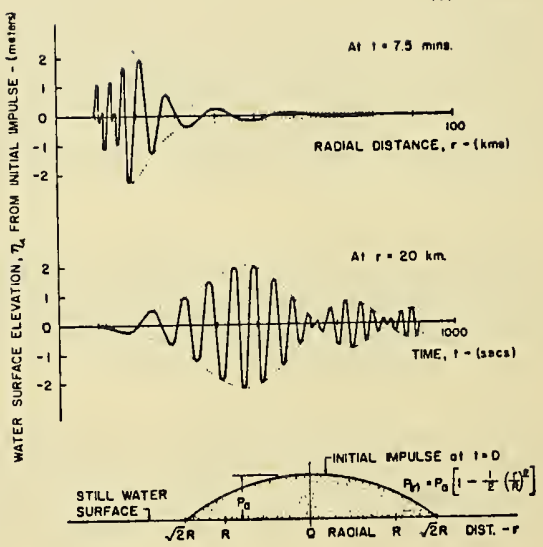

Figure 39 Theoretical wave forms generated by radially symmetric model of sudden water surface disturbance. (a) piston-like upheaval $(\mathrm{Q}=28 \mathrm{~m}, \mathrm{R}=2 \mathrm{~km}$, water depth $\mathrm{d}=5 \mathrm{~km}) ;(\mathrm{b})$ paraboloidal pressure impulse $\left(P_{0}=5 \times 107\right.$ dyne-sec $/ \mathrm{cm}^{2}, R=1.43 \mathrm{~km}$, $\mathrm{d}=5 \mathrm{~km}$ (from Kranzer and Keller, 1959) 
LE GE N D

- INDICATED DIRECTIDN OF GROUND MOTION

$14 \mathrm{~B}(+)$ FIGURES GIVE HIGMEST LEVEL OF RUN UP PRESUMED TO HAVE OCCURRED AT ONE OF THE FOLLOWING TIDE STAGES

LOW TIDE- $-(-)$

INTERMED TIOE - (?)

OATA FROM - (1) KACHADOORIAN \& PLAFKER (1966)

(2) BERG, et ol $\{1964\}$

REPRESENTS EVIOENCE OF RUN-UP
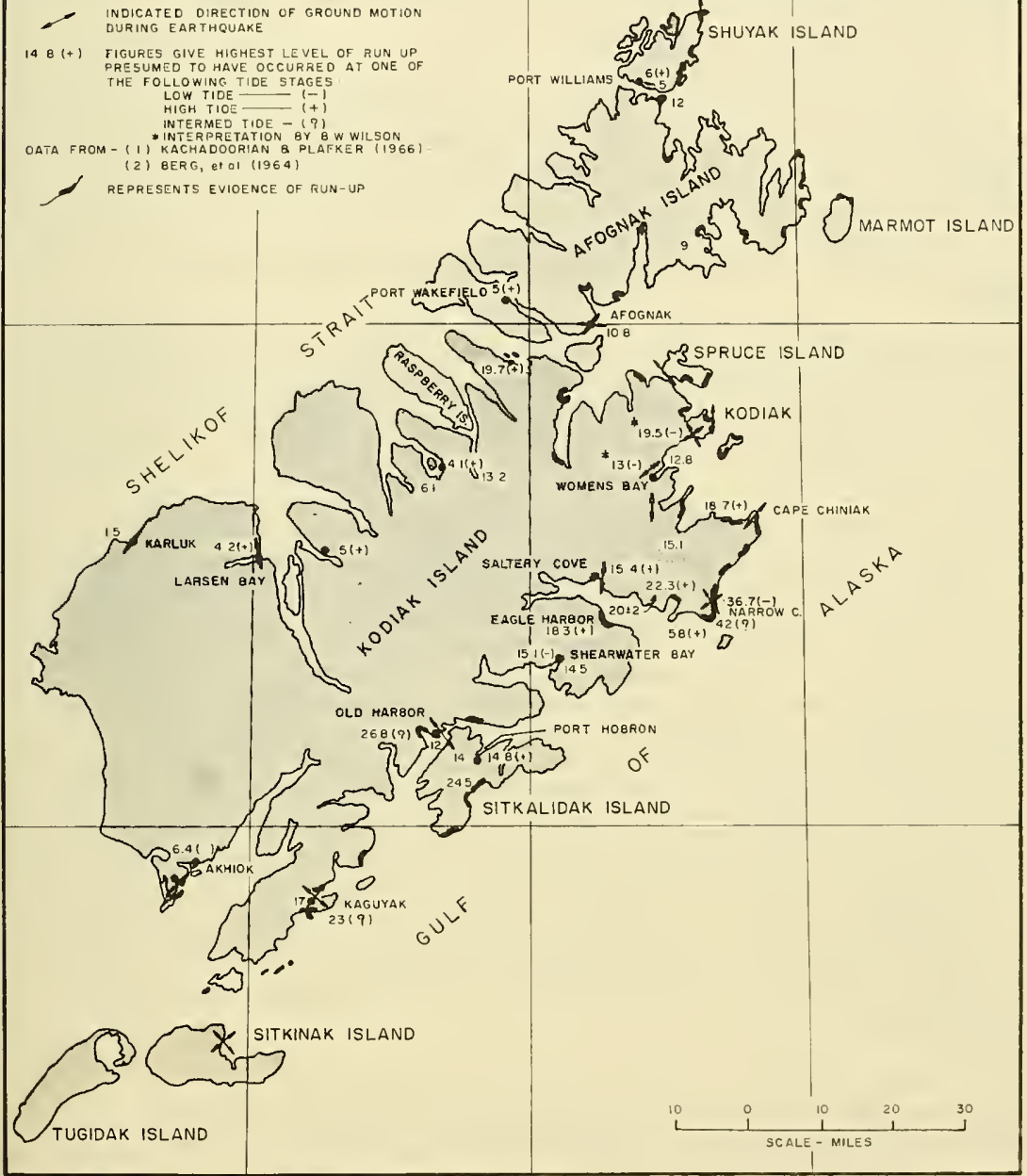

Figure 40 Observed Tsunami runup along the Coasts of Kodiak and Afognak Islands (based on data of Plafker \& Kachadoorian, 1966 and Berg, et al, 1964) 
10 to 20 meters (Figures 34,36 and 37). The range of wave height $H$, plotted against earthquake magnitude $\mathrm{M}$ in Figure 41 , appears to accord with the trend of Japanese data, and with an empirical relationship established in earlier studies (Wilson, et al, 1962; Wilson, 1964). This relationship is

$$
\log _{10} \mathrm{H}=0.75 \mathrm{M}-5.0
$$

and may be expected to give a rough idea of tsunami heights expected from an earthquake of given magnitude within a range of 500 miles of a coastline.

\section{Progression and Dispersion of the Tsunami Across the Pacific Ocean}

We may briefly enquire into the immediate development following the upheaval of the water surface over the Continental Shelf (Figure $42 a$ ). Under the effects of gravity, and with the energy communicated from the uplift and thrust of the land, the positive wave will start to separate in two as shown in Figure $42 \mathrm{~b}$.

Propagation landward of the negative wave will start a negative reflection from the coast with some loss of energy from entrapment, scattering, and absorption in the greatly indented coastline, as well as leakage into Cook Inlet and Prince William Sound (cf. discussion of this subject by Munk, 1961). The positive wave propagating seaward over the shelf into deep water loses some energy at once to a negative reflection which propagates back toward the coast ( $c f$. Lamb, 1932; Johnson, et al, 1951; LeMehaute, 1960; Dean, 1964). The progress of these reflections in the early moments of tsunami transmission is shown schematically in Figure 42. In this process a little-understood mechanism of energy transfer to higher frequencies takes place, and amplification results through sympathetic resonance at the natural frequencies of shelf oscillation. The interference of the coast and shelf-edge reflections with each other probably accounts for the beat oscillation revealed in Figure $38 \mathrm{c}$. The oscillation is essentially of the "leaky" mode type discussed by Snodgrass, Munk, and Miller (1962), and by Munk (1962), because the direction of propagation of the reflections in the gross sense is normal to the coast and to the shelf edge.

The main tsunami meanwhile emerges from the Continental Shelf and spreads across the Pacific Ocean in the manner inferred from Figure 27. Its energy will be supplemented by small additional amounts of energy continuously transmitted to deep water from the shelf oscillation.

The tsunami was recorded at tide gage stations throughout the Pacific arena and facsimile reproductions of marigrams, together with arrival times, have been published by the U. S. Coast \& Geodetic Survey (C\&GS, 1964 ; Spaeth and Berkman, 1965, 1967). A selection from these are reproduced here in diagrams (a) of Figures 43 to 66 , which refer to stations encompassing most of the peripheral boundary of the Pacific Ocean. 
In general, these marigrams are characterized by large and sometimes pseudo-regular, sometimes highly irregular oscillations, announcing the arrival of the tsunami. The extraordinary variety of effects recorded is eloquent testimony to the profound changes that a tsunami is subject to when propagating from deep water to the shallow-water locations of most gaging stations. One logically wonders what aspects there are in common, if any, between records such as those, say, of Prince Rupert, Canada (Figure 46a), San Francisco, California (Figure 50a), and Hilo, Hawaii (Figure 59a). The resemblances appear to be small, and possibly they might be explained away on the grounds that these three receiving stations are very far apart. However, when comparison is made between Figures $58 \mathrm{a}$ and $59 \mathrm{a}$ for two stations close together in the Hawaiian Islands, the differences are not so easily disregarded.

Wave energy spectra might be expected to reveal certain fundamental resemblances between marigrams, but except in the case of the records for Honolulu and Hilo, Hawaii (Loomis, 1966), few comparisons of wave spectra for the Alaskan tsunami have come to our attention. Figures $67 \mathrm{a}$ and $67 \mathrm{~b}$ present the results of Loomis' analyses, but the frequency resolution at low frequencies is rather poor so that the existence of any waves having periods of the order of two hours is not revealed. The best that can be said of the two spectra for the early stages of the tsunami ( 0 to 8.3 hours) is that periods around $33.3,18.0$ to 20.8 , and 12.1 to 13.0 minutes are prominent in both records and that the dominance of the periods changes with time at the two places and becomes different in both.

Spectral analysis, however, has the limitation of requiring a specified time sequence of record for its elaboration, and that in that time sequence changes in the dispersive wave system are continually taking place. It can therefore never give a completely true picture of the composition of a tsunami at any given time, even though in the very nature of an impulsive wave system the particular wave dominant at any time is actually the resultant of a spectrum of frequencies (cf. Wilson, et al, 1962; Van Dorn, 1965). The computed spectrum can reveal a prominent, often broad, frequency band, but it cannot usually identify whether, or how, frequencies in the band may be interfering to form beats. Moreover, in the range of frequencies covered in Figure 67, the obvious prominences are likely to be characteristic of the oscillating modes of the locality rather than the fundamental nature of the tsunami (cf. Munk, et al, 1959).

To discover more about the tsunami itself, the first author (Wilson) has applied the same kind of subjective analysis employed in Figure 38 to the marigrams of Figures 43 to 66 . This process is a matter of judgment and experience; perhaps something of an art. At present (1967), a purely objective mathematical treatment of the data to achieve comparable results has not been developed. The subjective analyses given in Figures 43 to 66 are subject to the human errors of interpretation and of drafting, but the overall consistency of results in identifying characteristic signatures of the tsunami is most encouraging. 


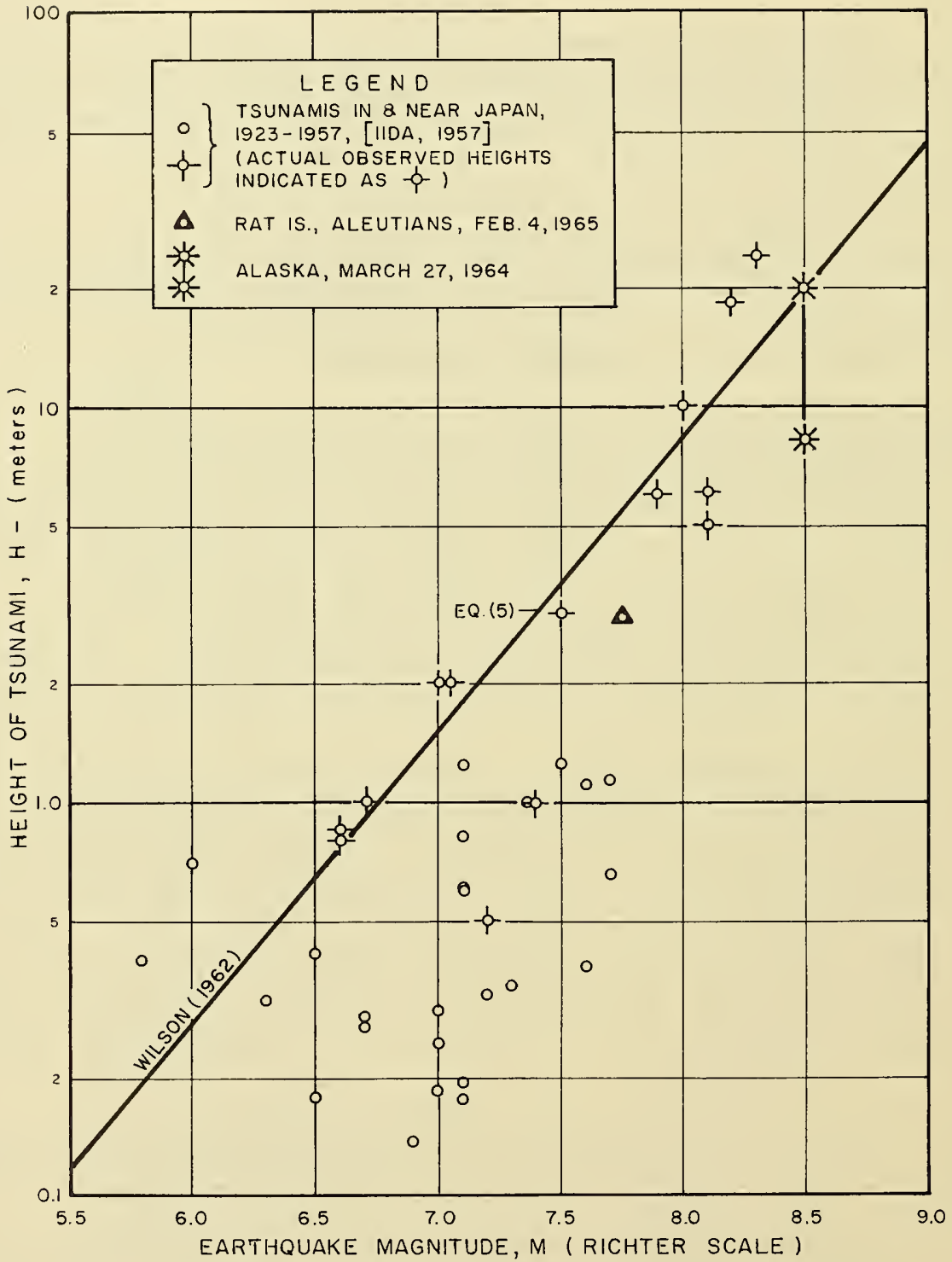

Figure 41 Heights of Tsunamis to be expected at a Coast from Submarine Earthquakes of varying magnitude within a range of about 500 miles (adapted from Wilson, 1964) 


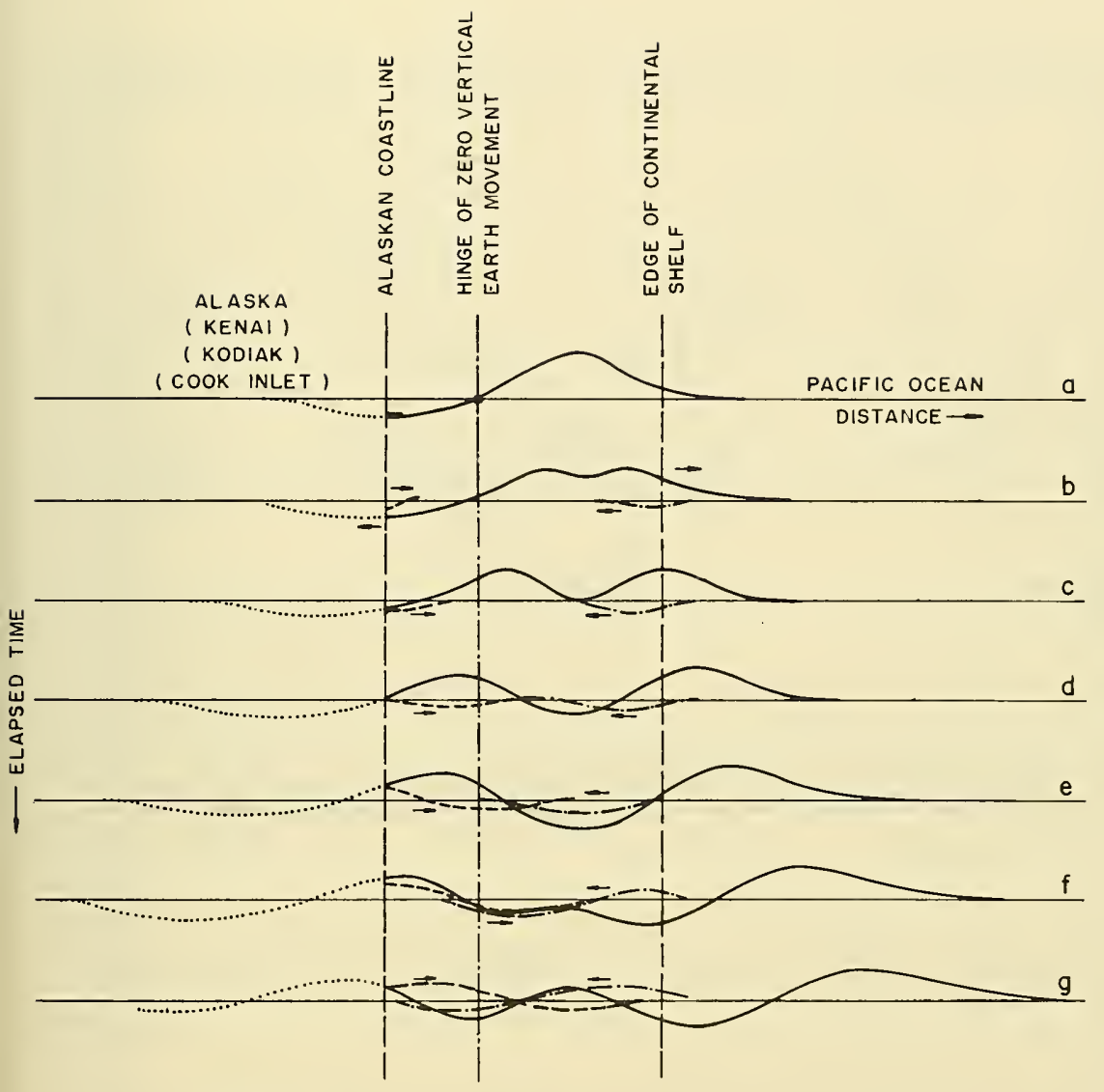

LE GEN D

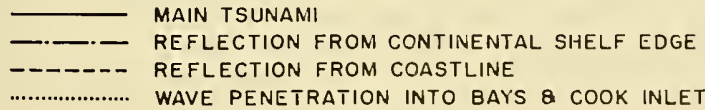

Figure 42 Schematic Representation of the Progression of the Alaskan Tsunami in the first hour following the Earthquake 


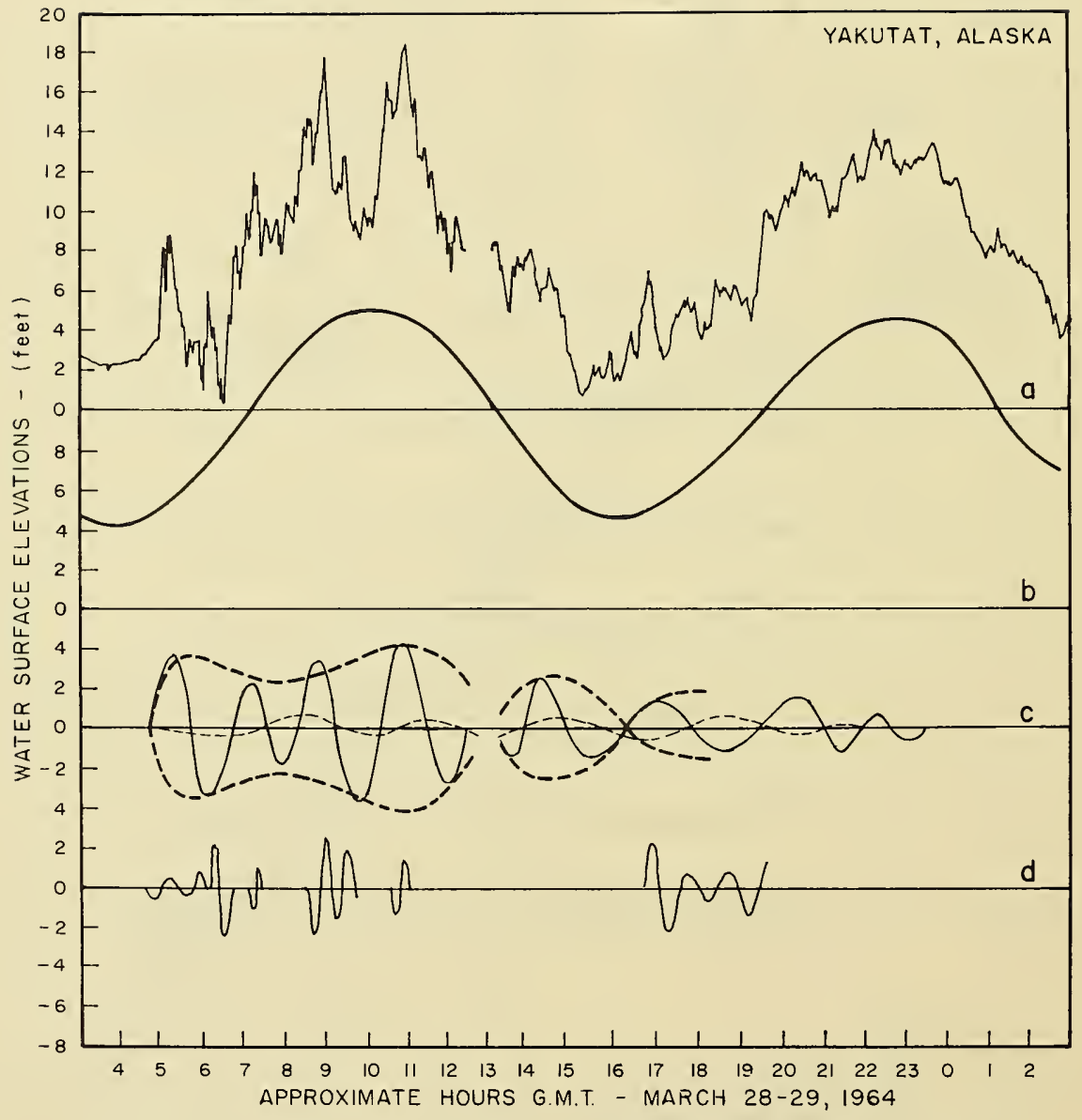

Figure 43 Subjective Analysis of Marigram for Yakutat, Alaska 


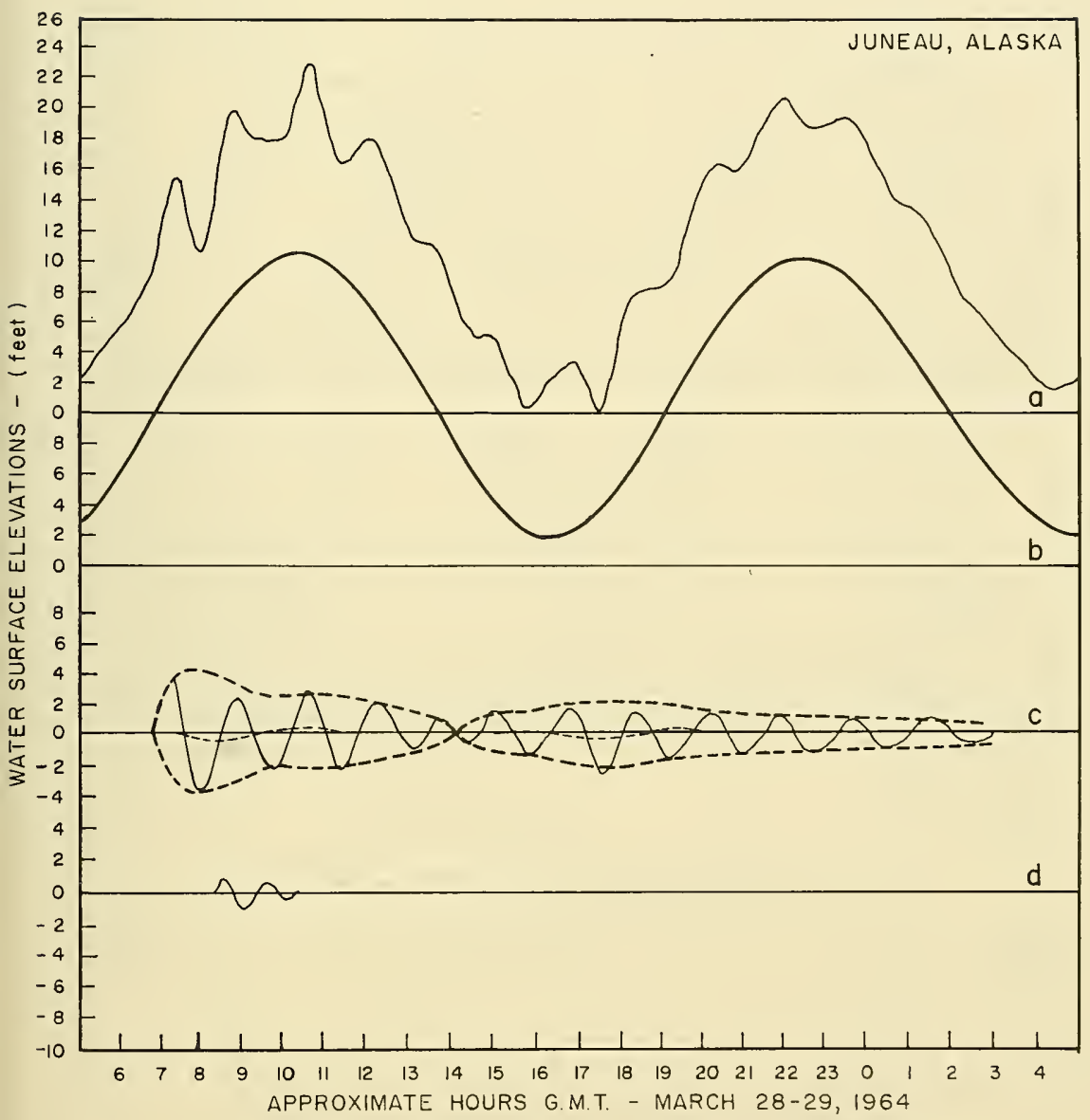

Figure 44 Subjective Analysis of Marigram for Juneau, Alaska 


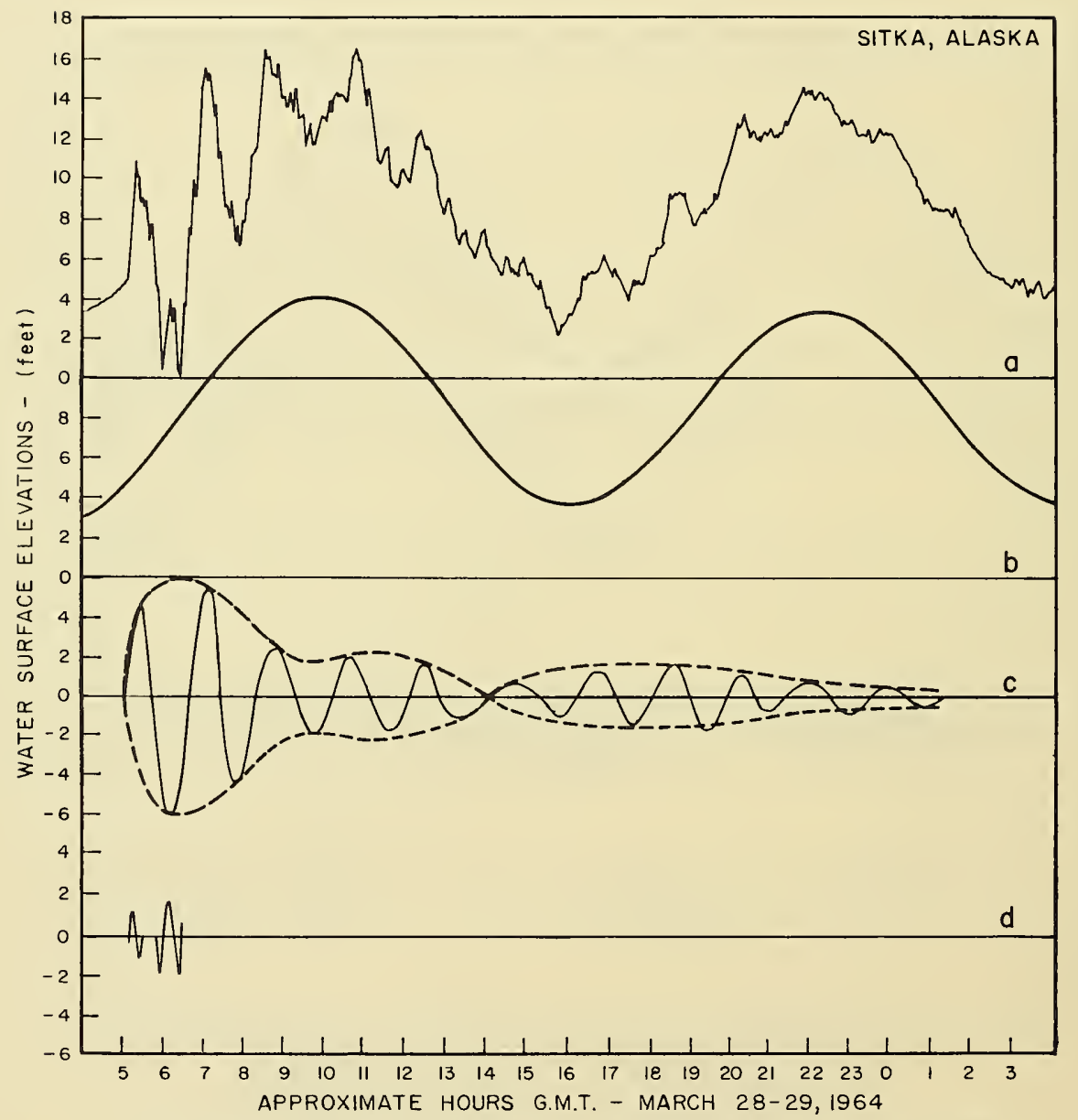

Figure 45 Subjective Analysis of Marigram for Sitka, Alaska 


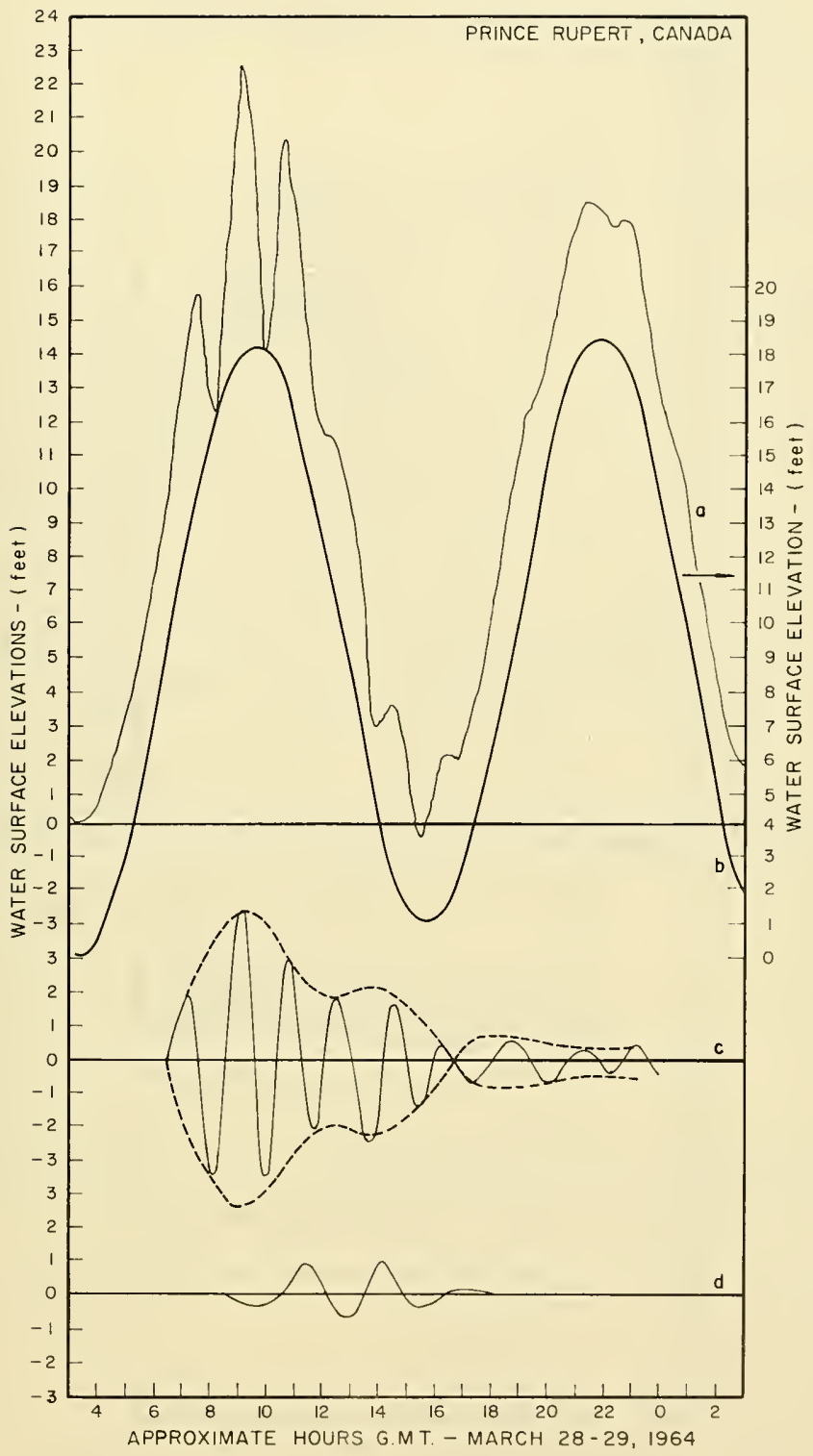

Figure 46 Subjective Analysis of Marigram for Prince Rupert, Canada 


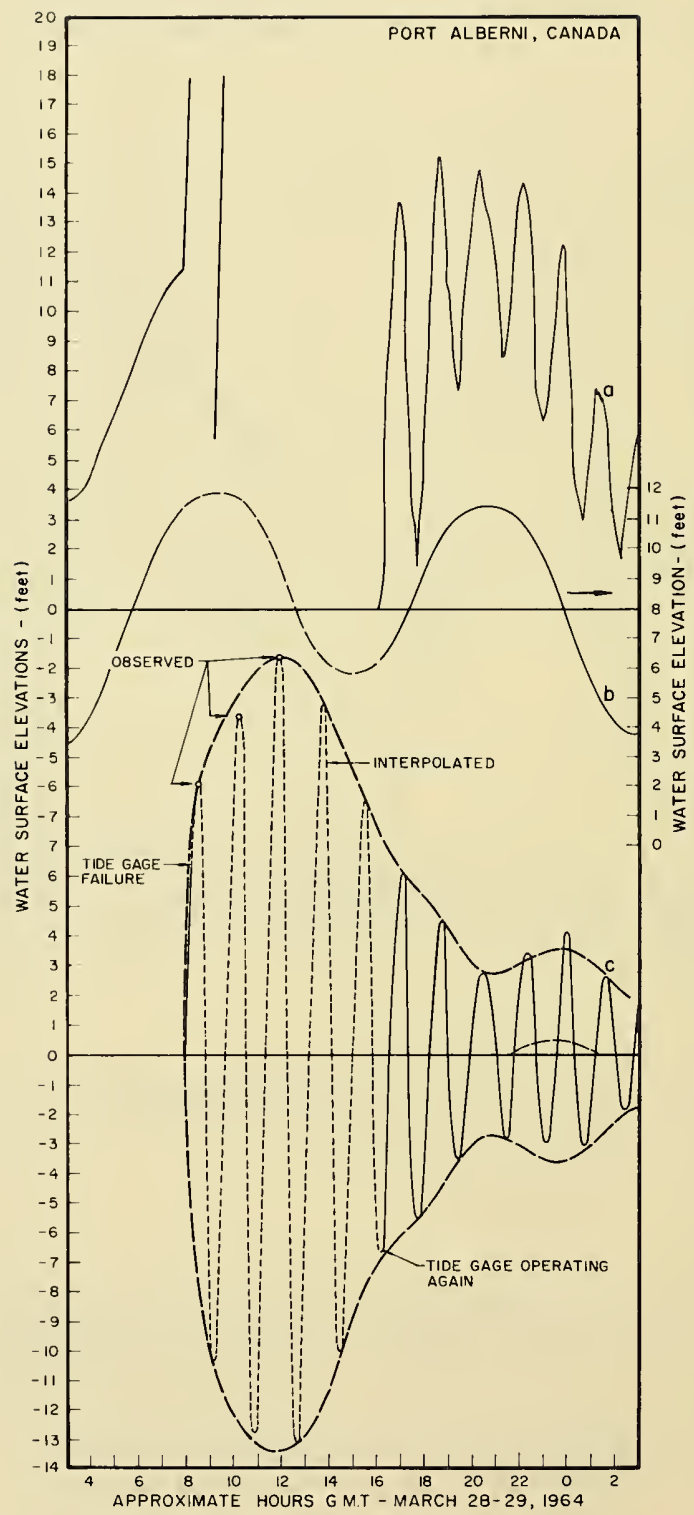

Figure 47 Subjective Analysis of Marigram for Port Alberni, Canada 


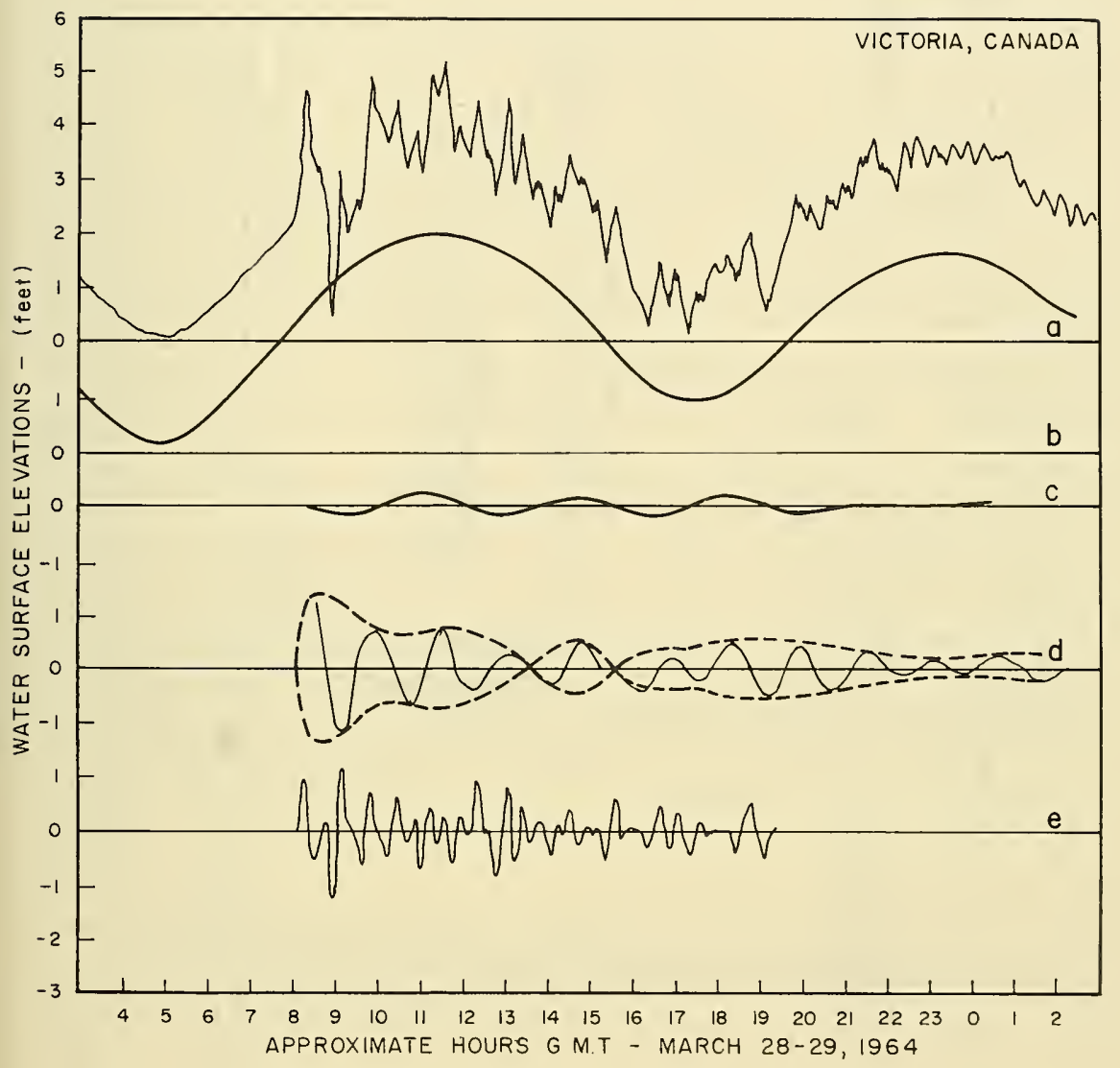

Figure 48 Subjective Analysis of Marigram for Victoria, Canada

71 


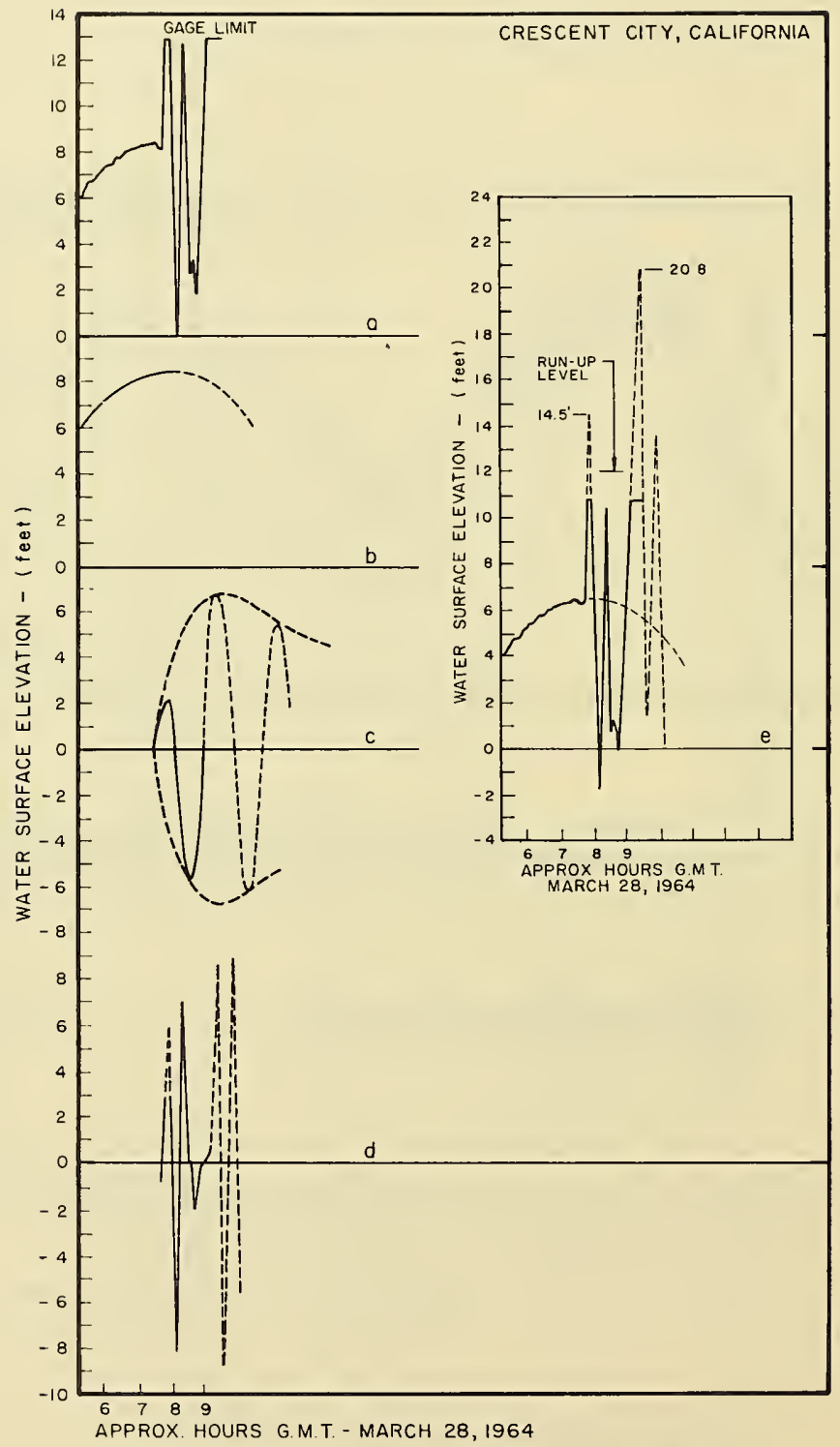

Figure 49 Subjective Analysis of Marigram for Crescent City, California 


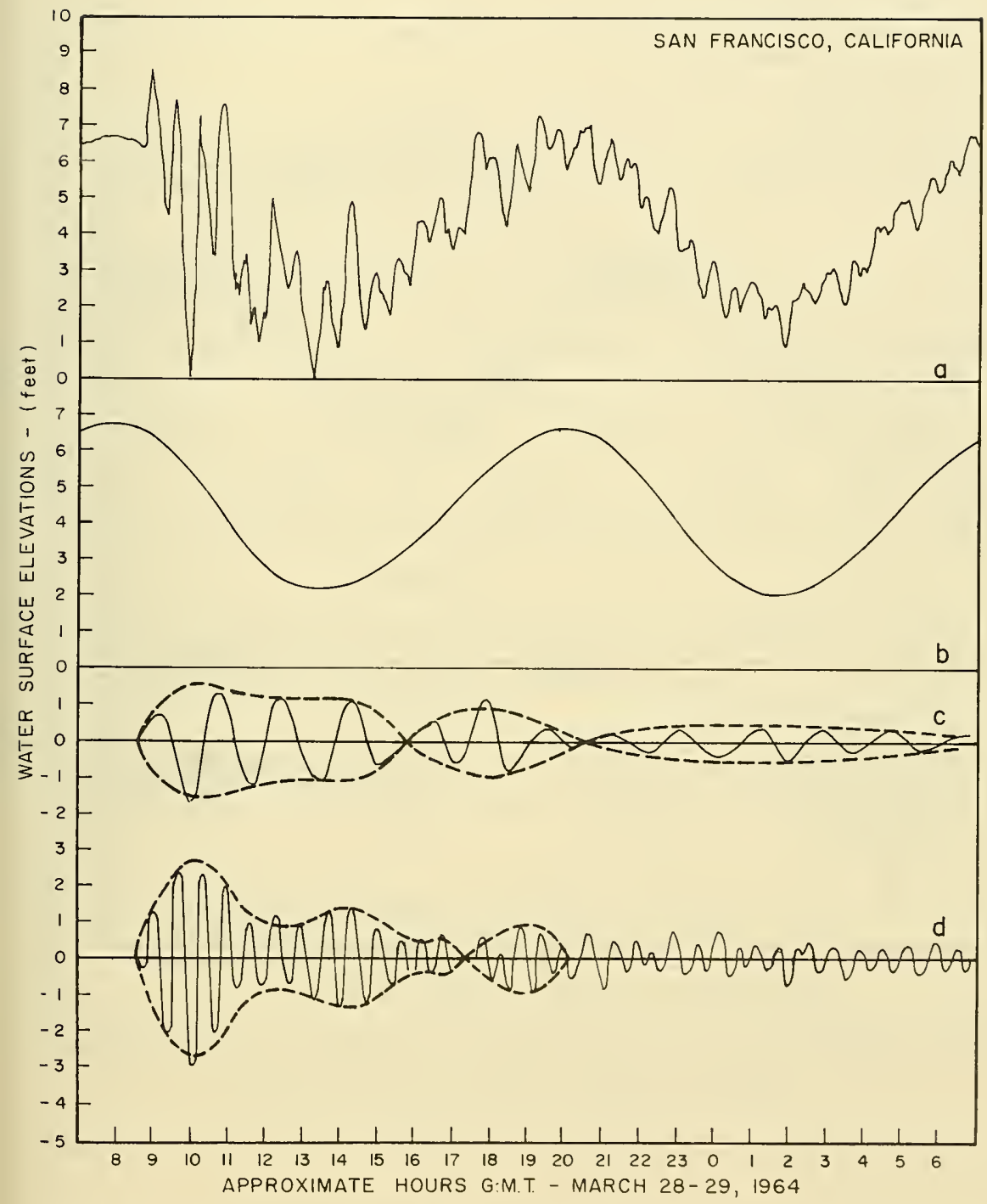

Figure 50 Subjective Analysis of Marigram for San Francisco, California 


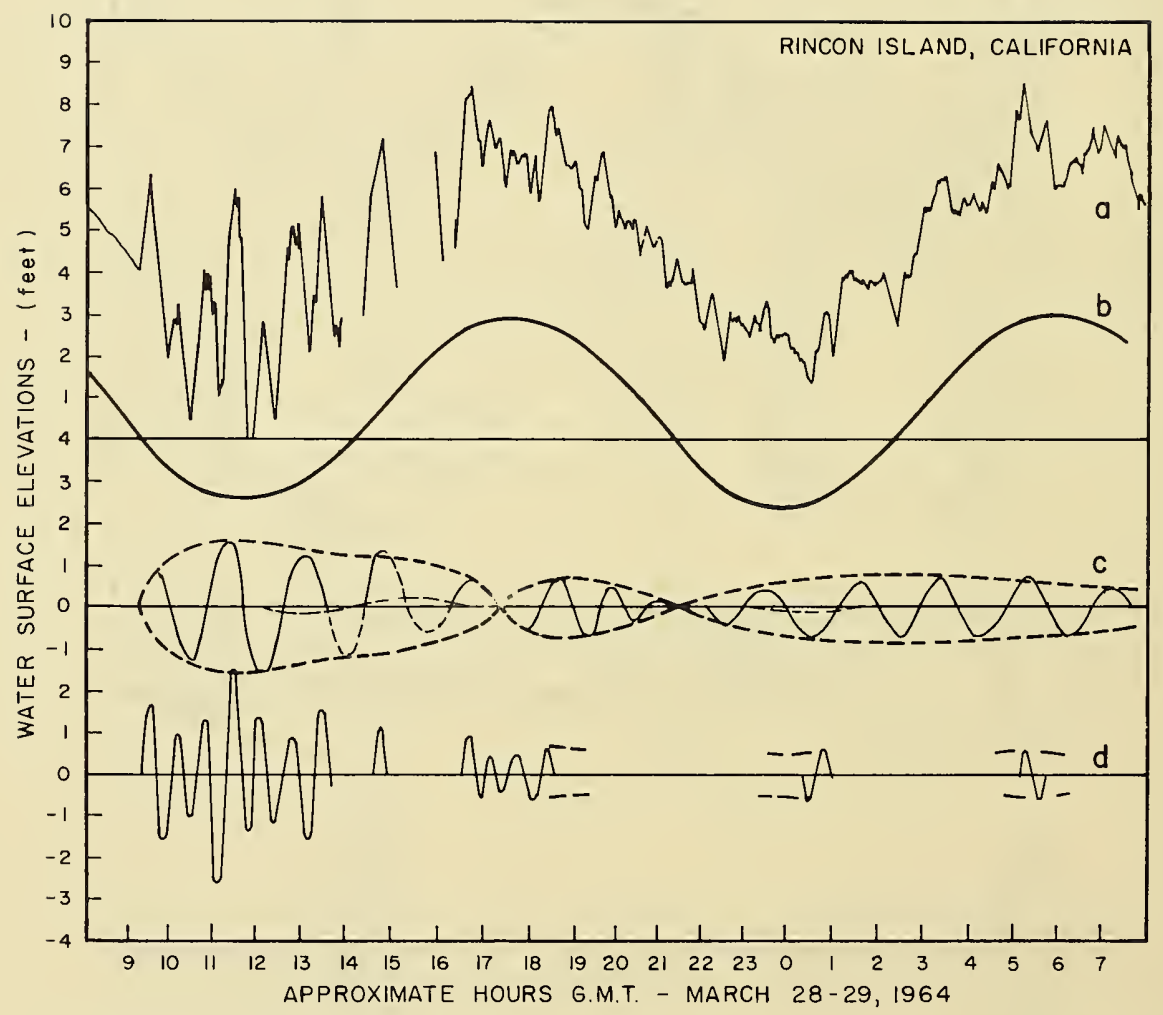

Figure 51 Subjective Analysis of Marigram for Rincon Island, California 


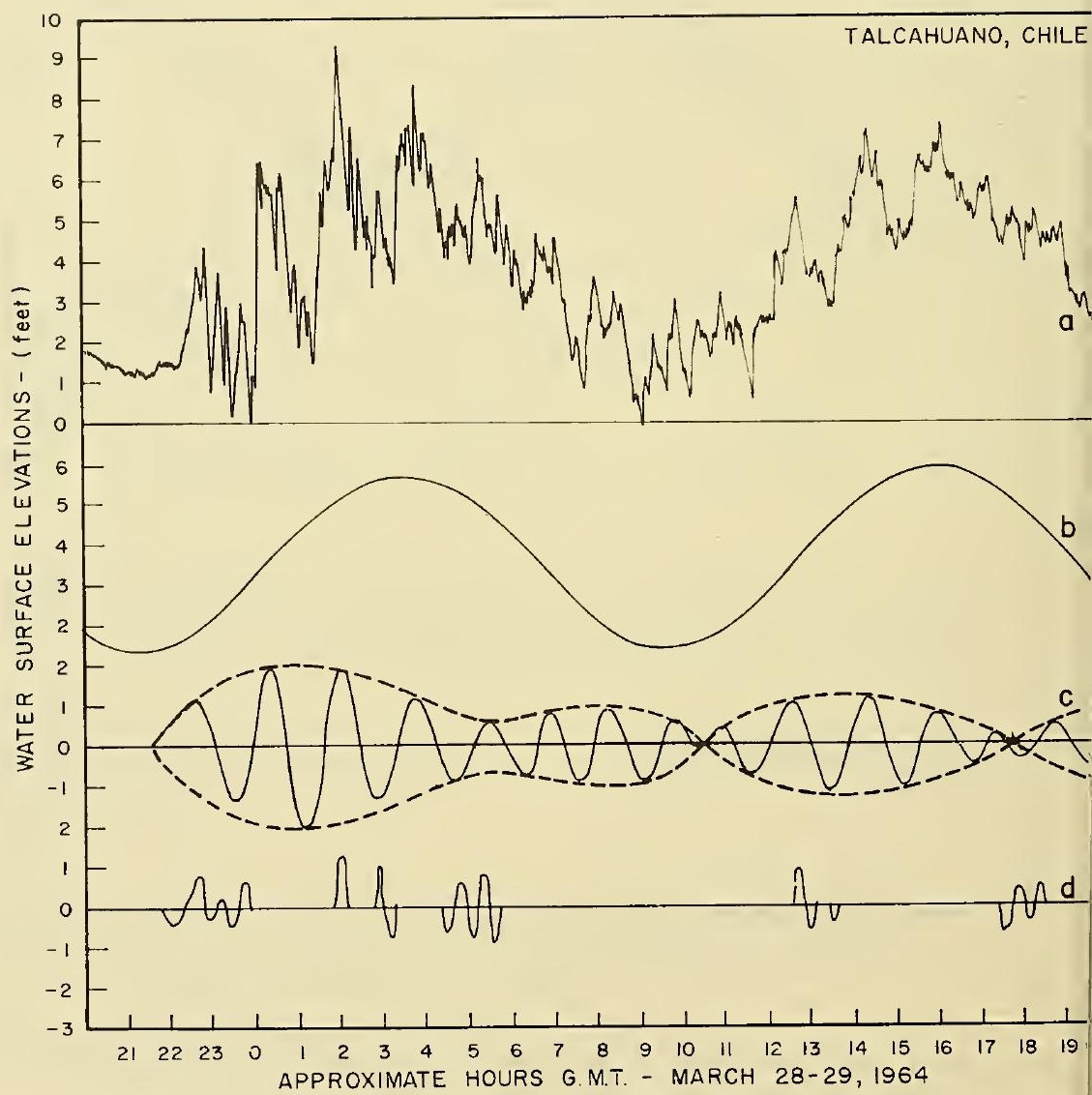

Figure 53 Subjective Analysis of Marigram for Talcahuano, Chile 


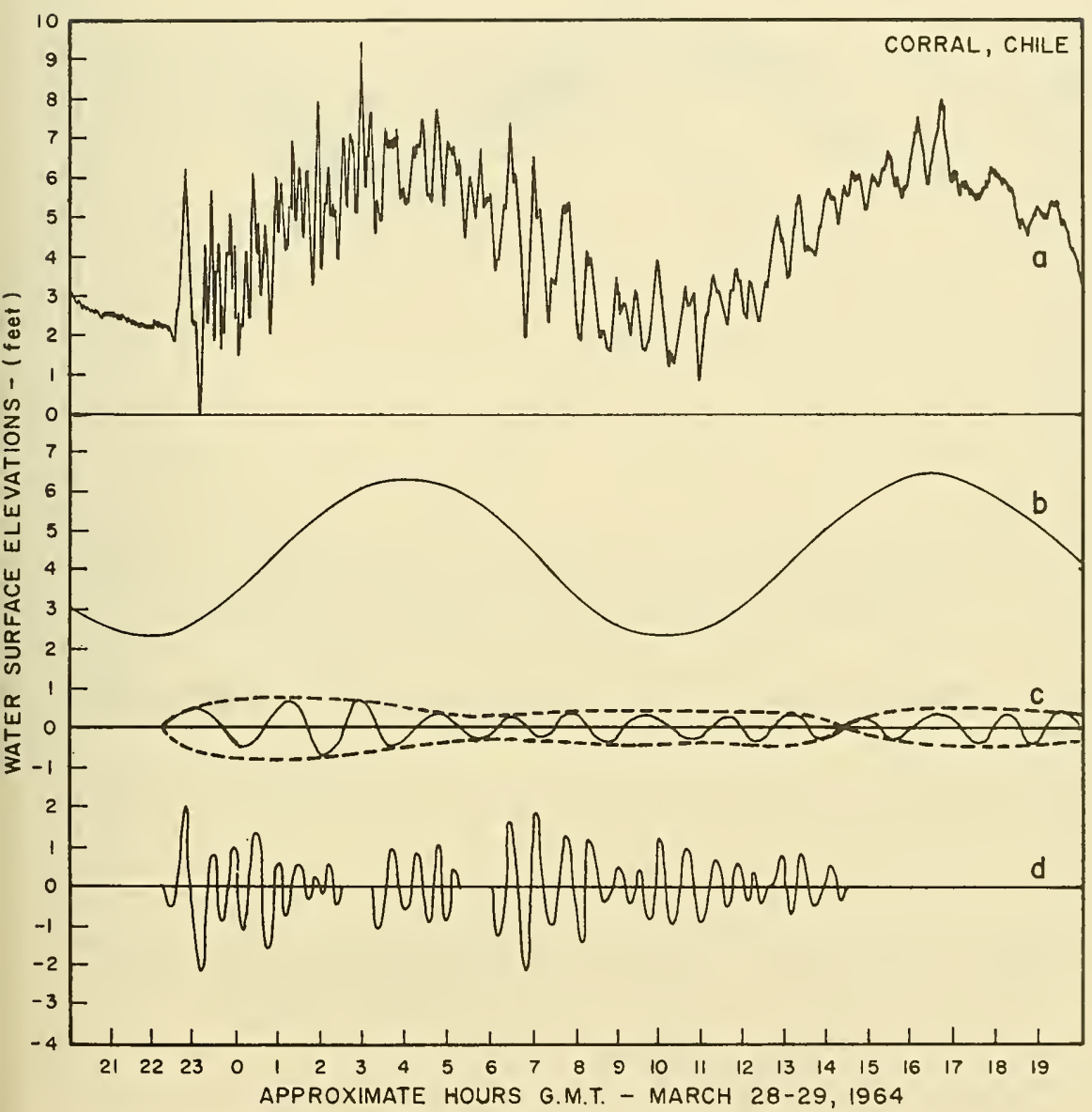

Figure 54 Subjective Analysis of Marigram for Corral, Chile 


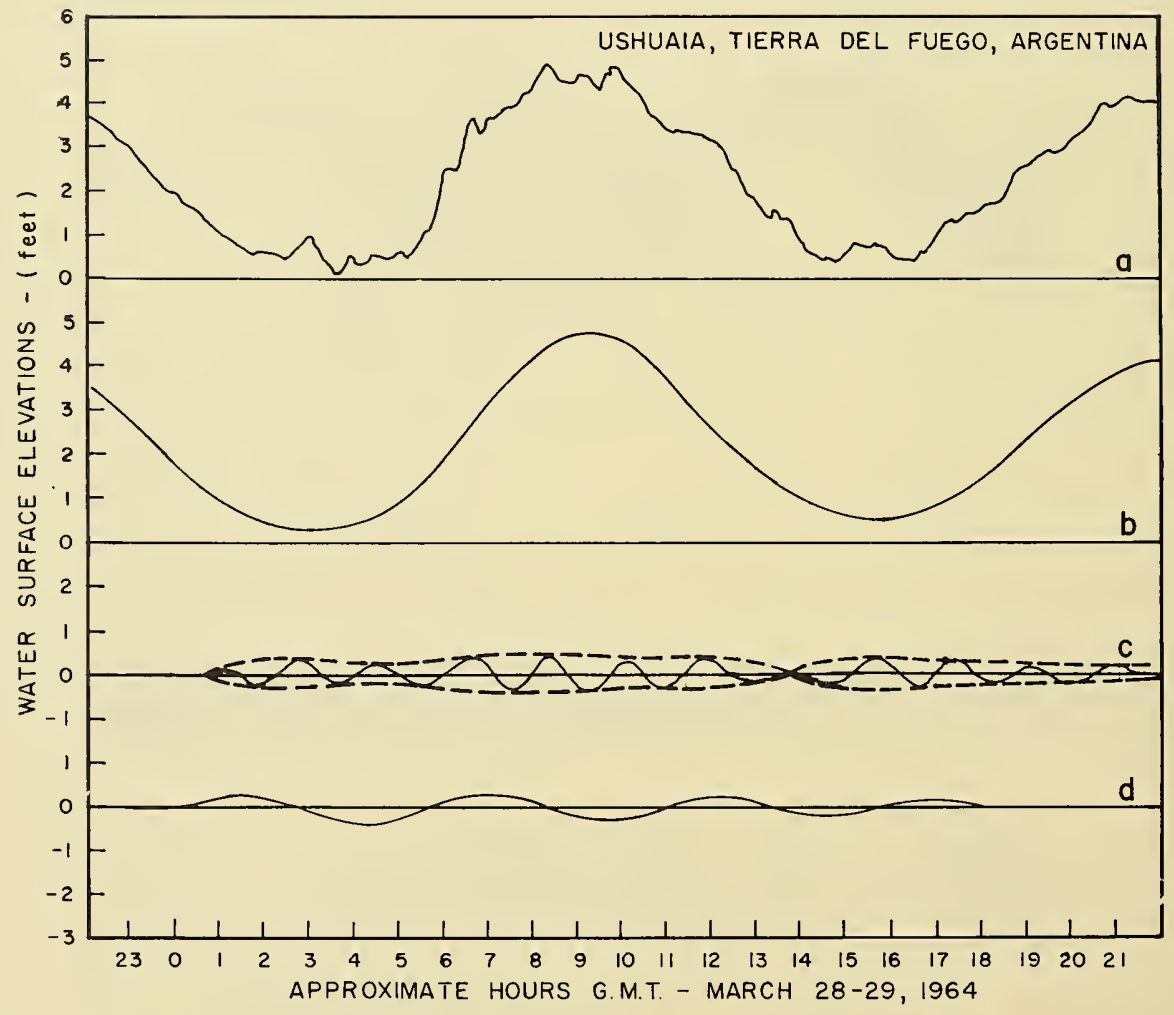

Figure 55 Subjective Analysis of Marigram for Ushuaia, Tierra Del Fuego, Argentina 


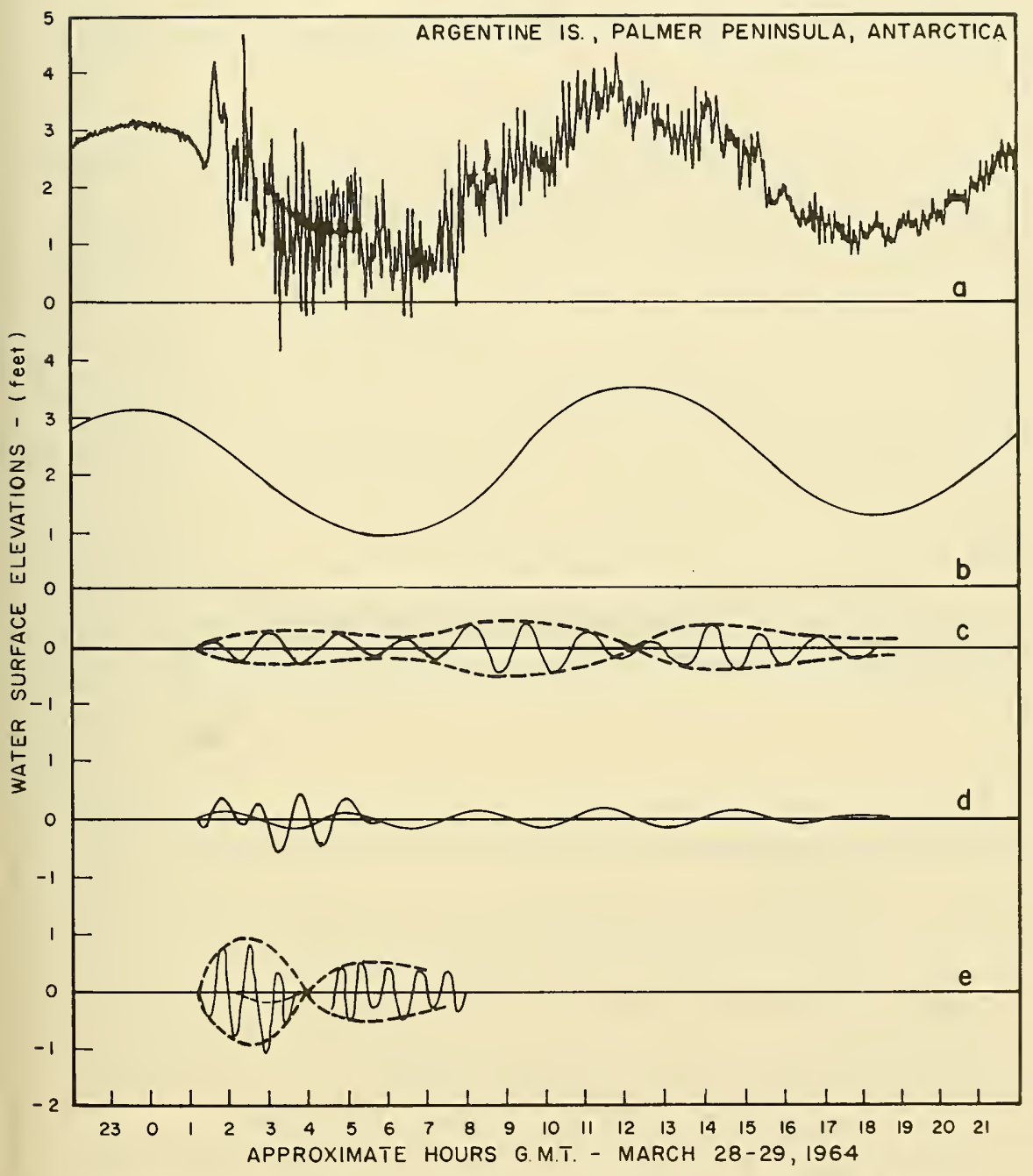

Figure 56 Subjective Analysis of Marigram for Argentine Island, Palmer Peninsula, Antarctica 


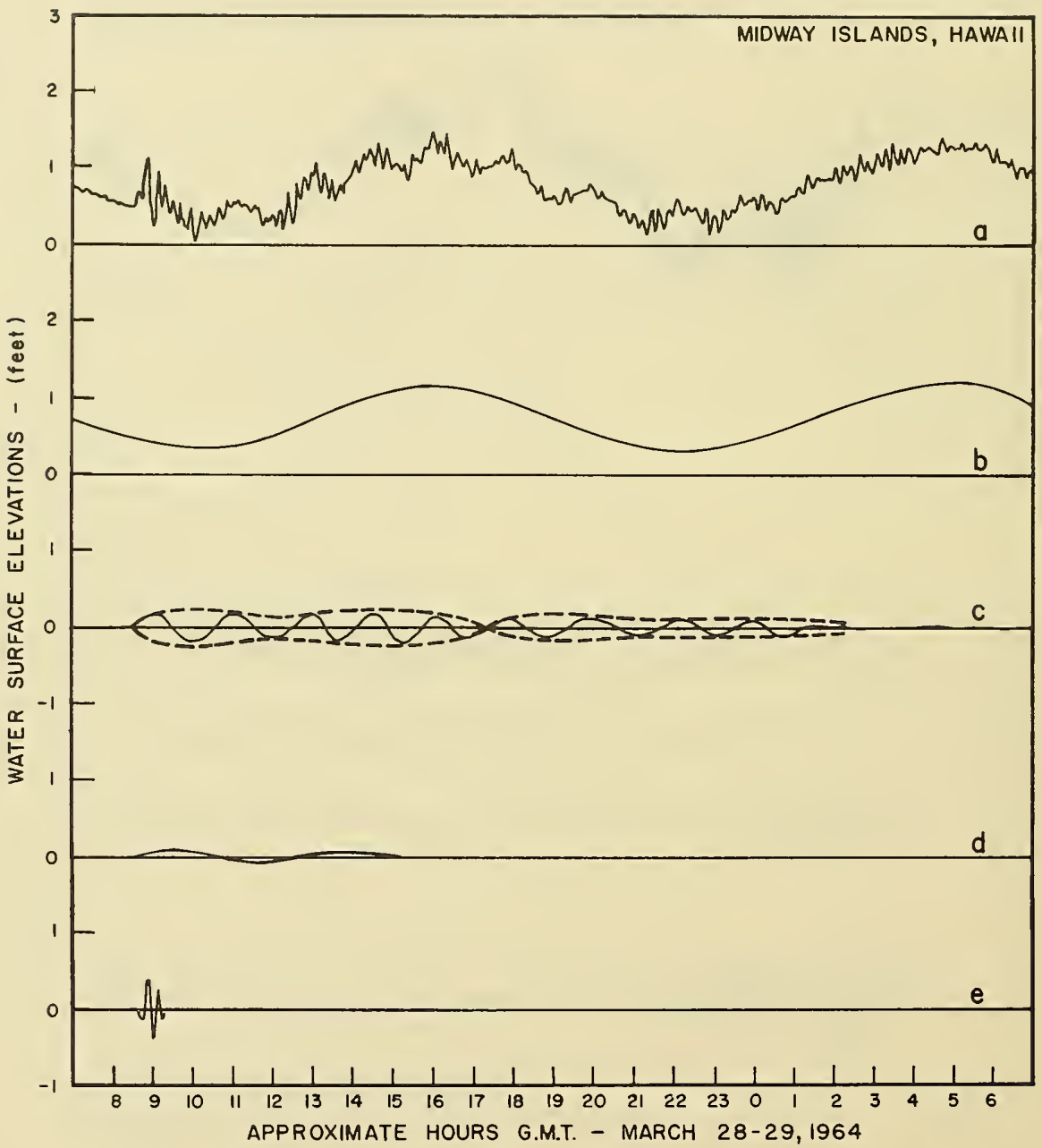

Figure 57 Subjective Analysis of Marigram for Midway Islands, Hawaii 


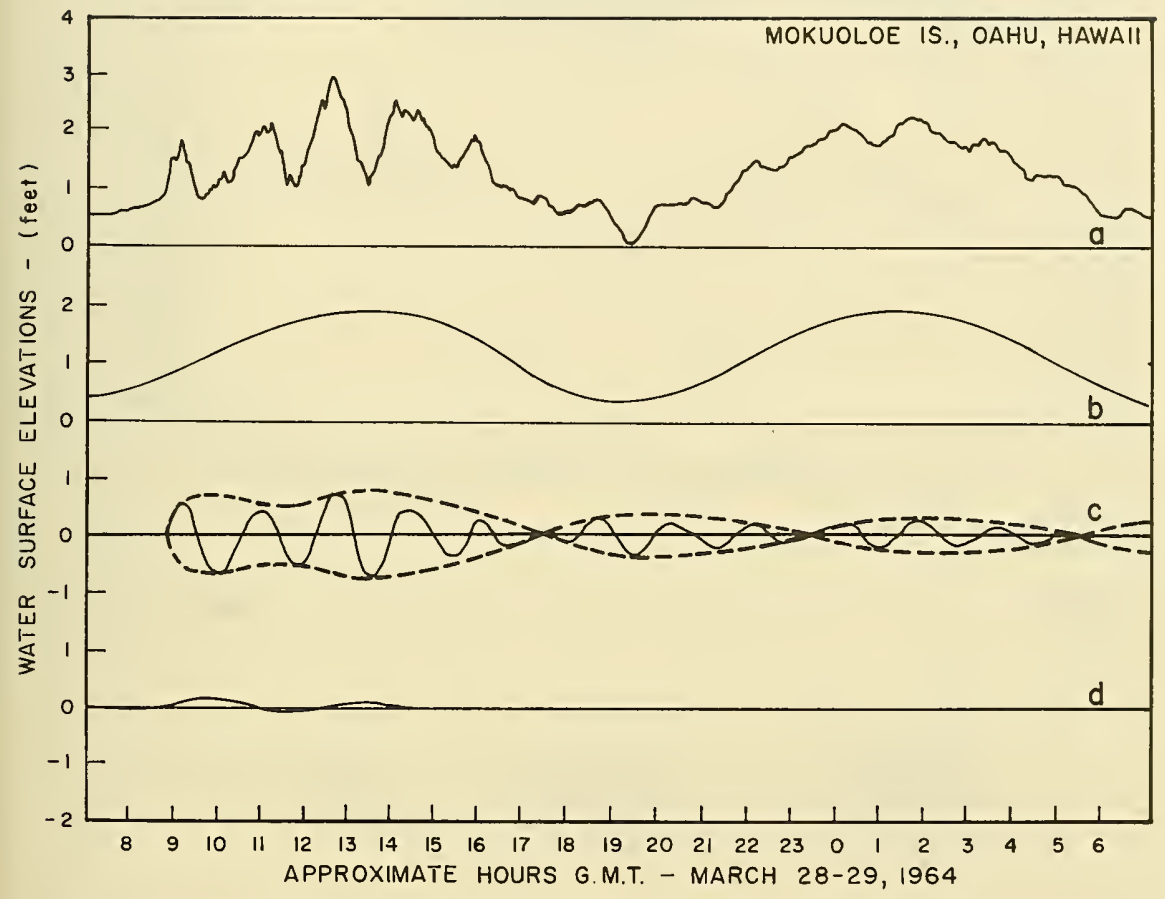

Figure 58 Subjective Analysis of Marigram for Mokuoloe Island, Oahu, Hawaii 


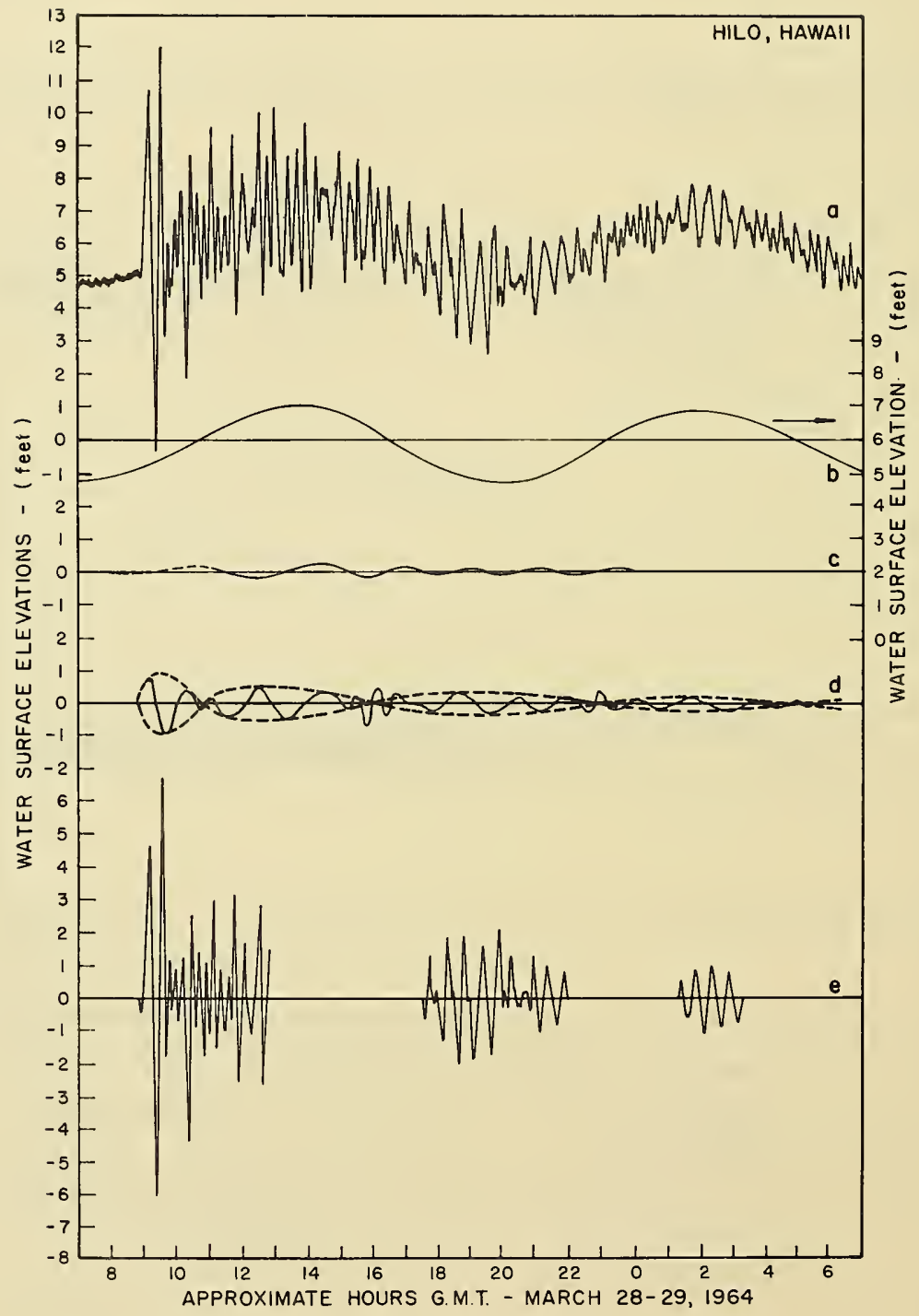

Figure 59 Subjective Analysis of Marigram for Hilo, Hawaii 


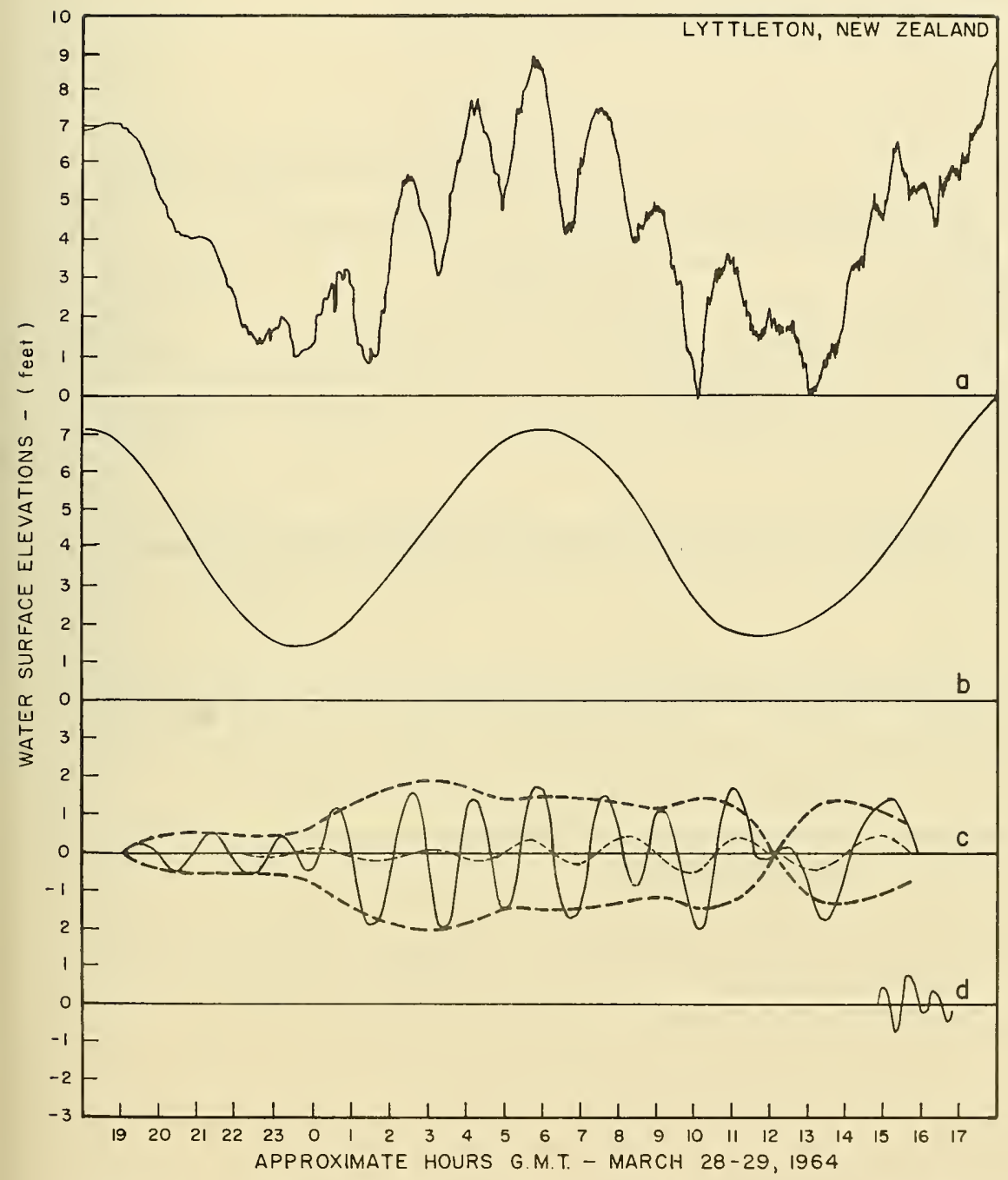

Figure 60 Subjective Analysis of Marigram for Lyttelton, New Zealand 


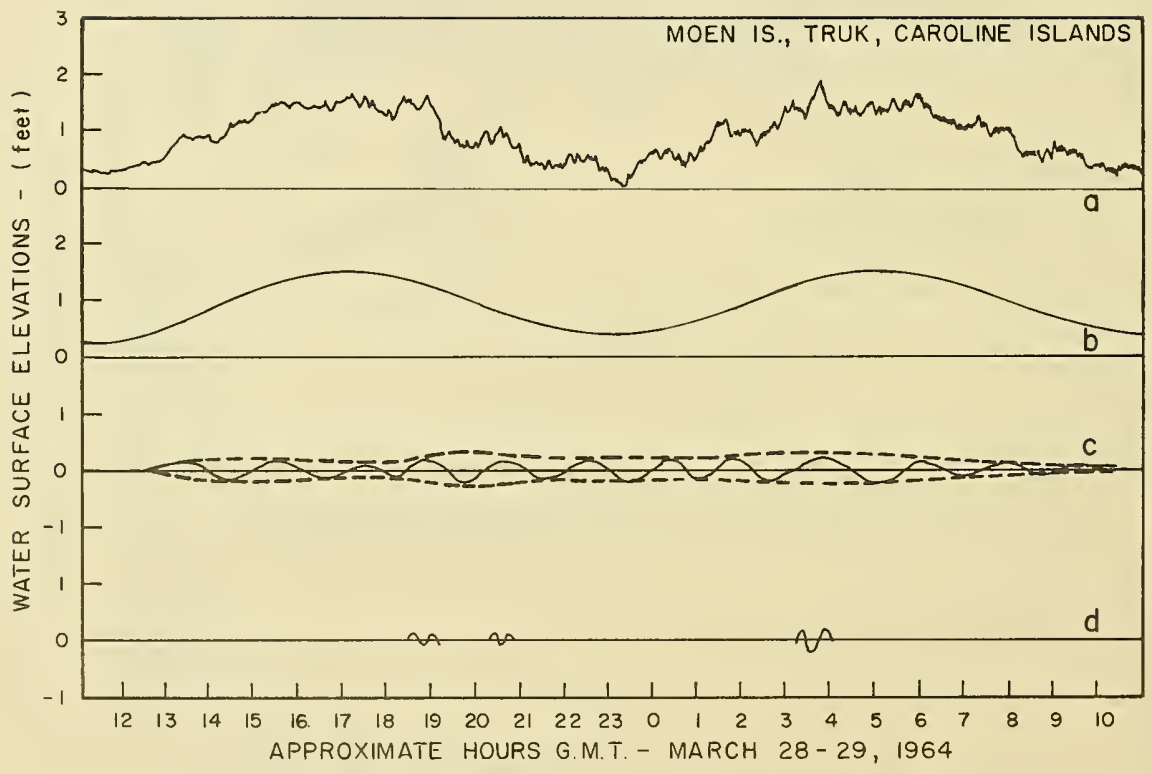

Figure 61 Subjective Analysis of Marigram for Moen Island, Truk, Caroline Islands 


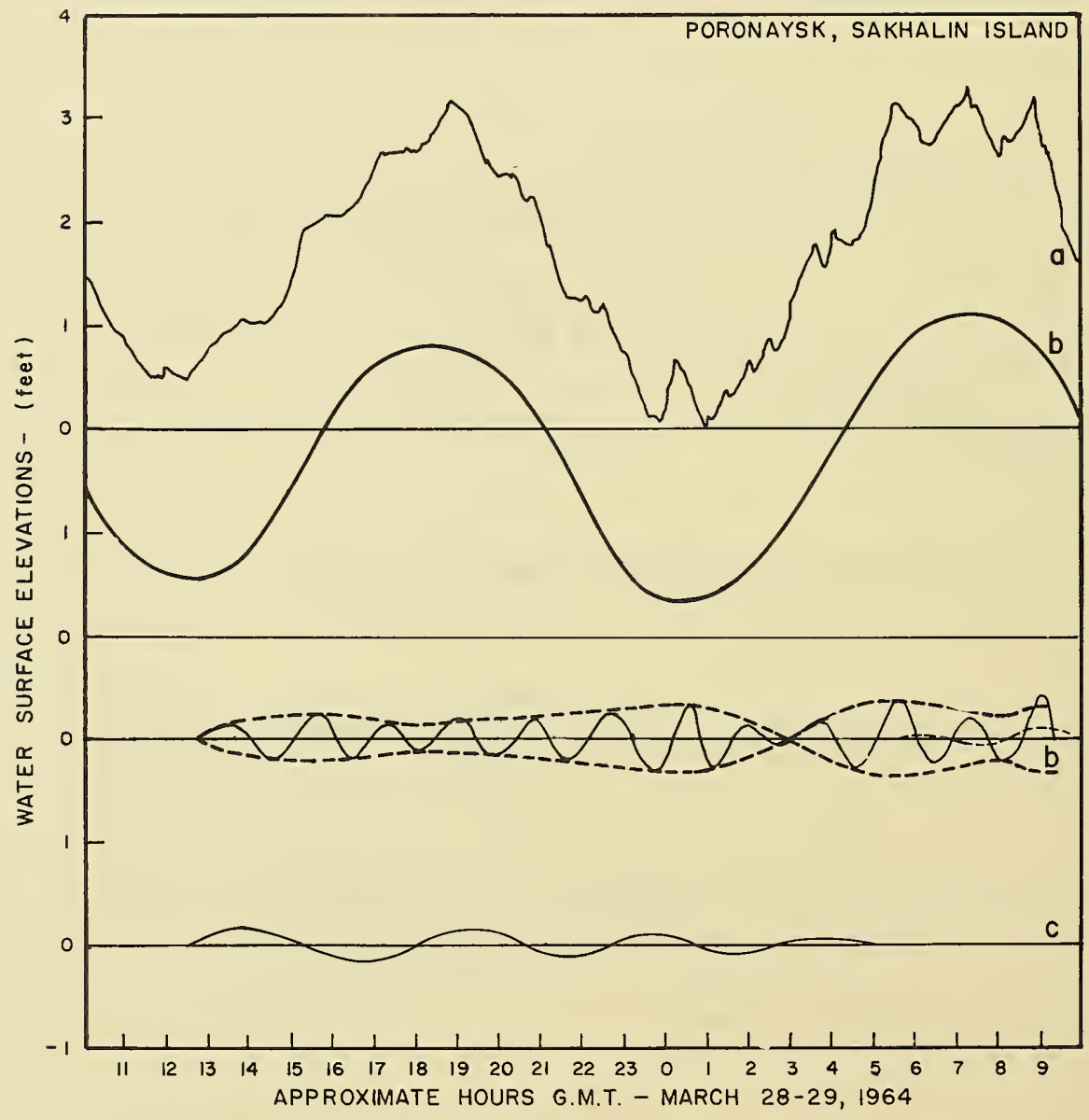

Figure 63 Subjective Analysis of Marigram for Poronaysk, Sakhalin Island 


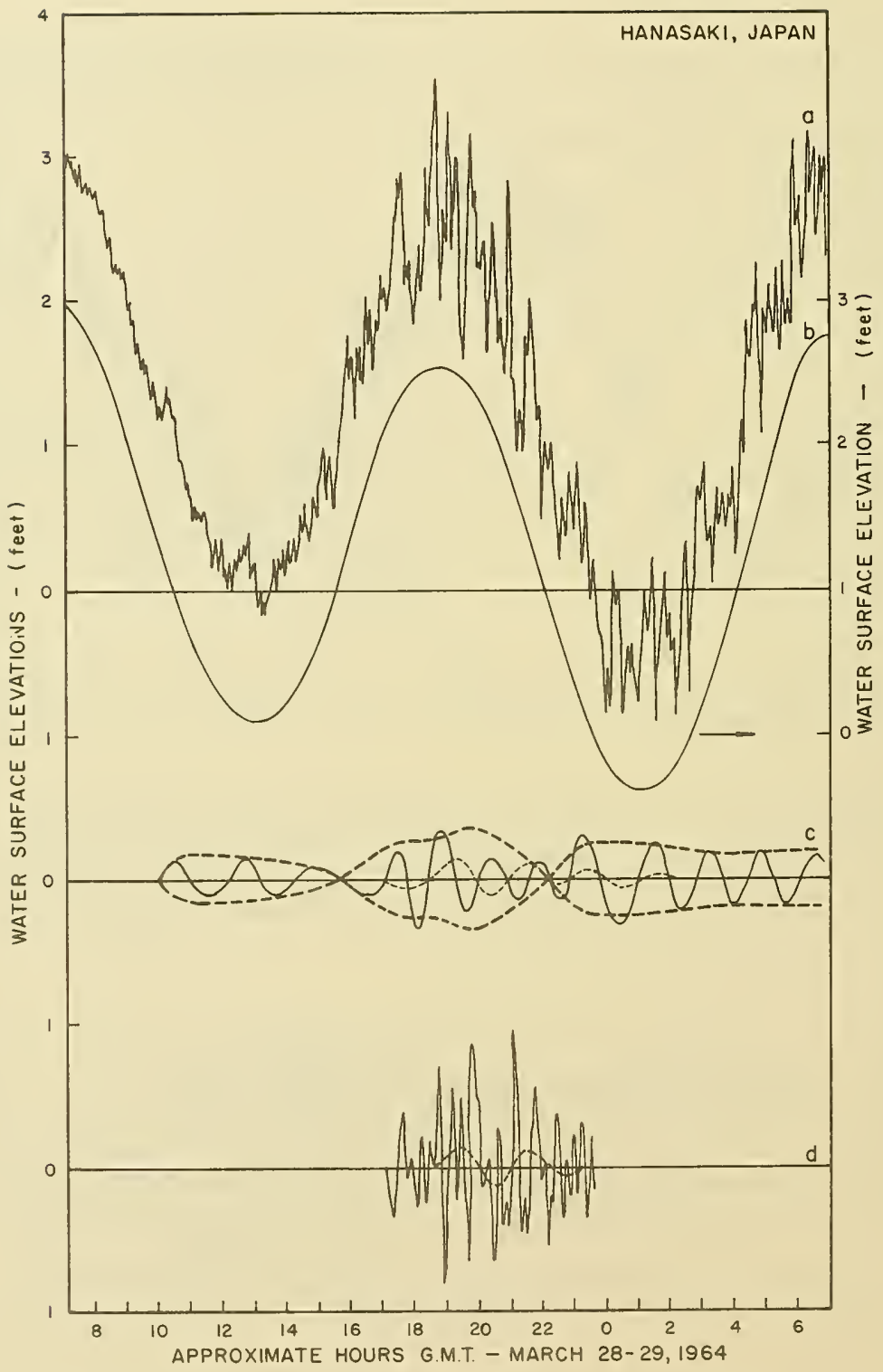

Figure 65 Subjective Analysis of Marigram for Hanasaki, Japan 


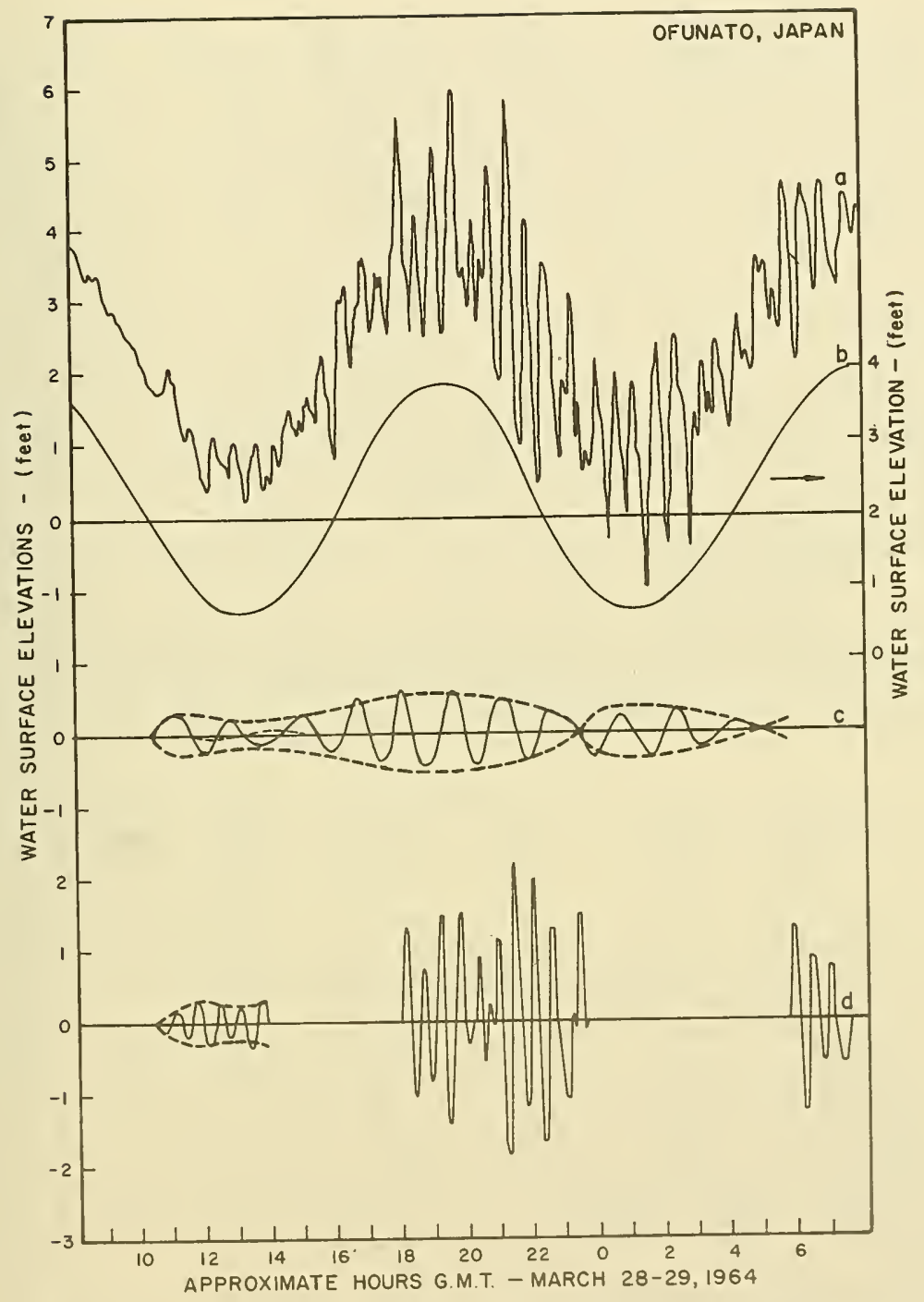

Figure 66 Subjective Analysis of Marigram for Ofunato, Japan 


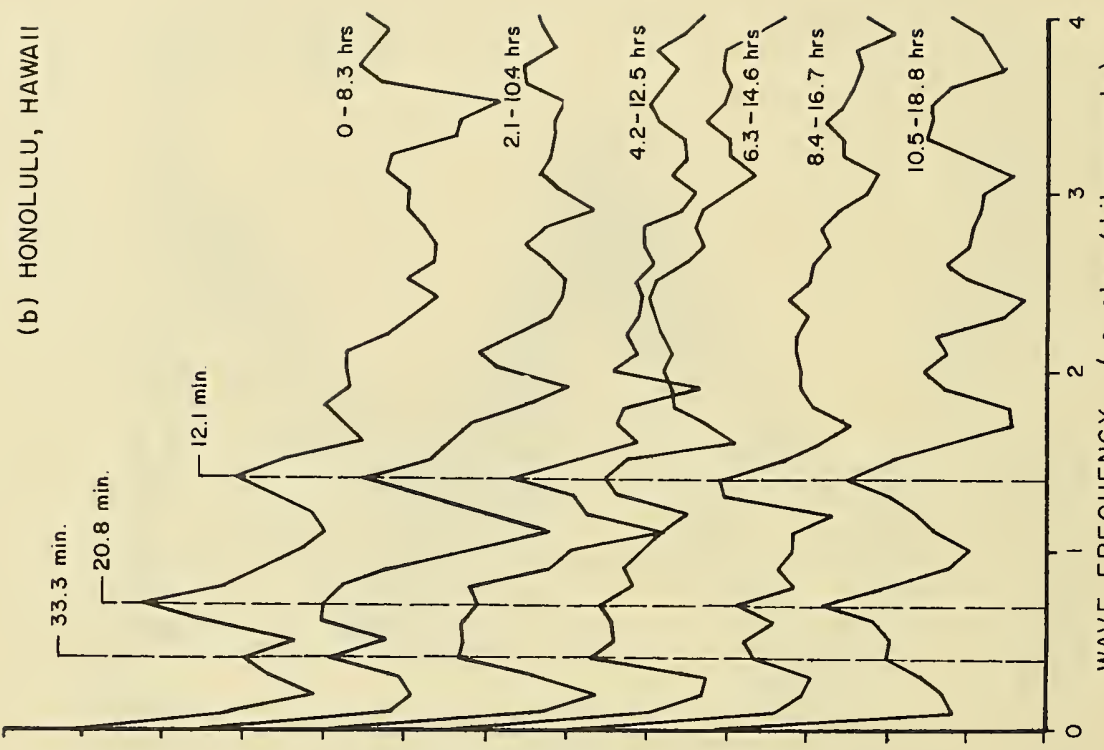

ซี

-6

๙

نे

ฮี.

$\sum$

4

- $\rightarrow$ \&

छ요

वै

००

व

4 o

山 岳

$\geqslant$

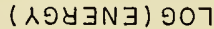

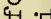

क

4

บ

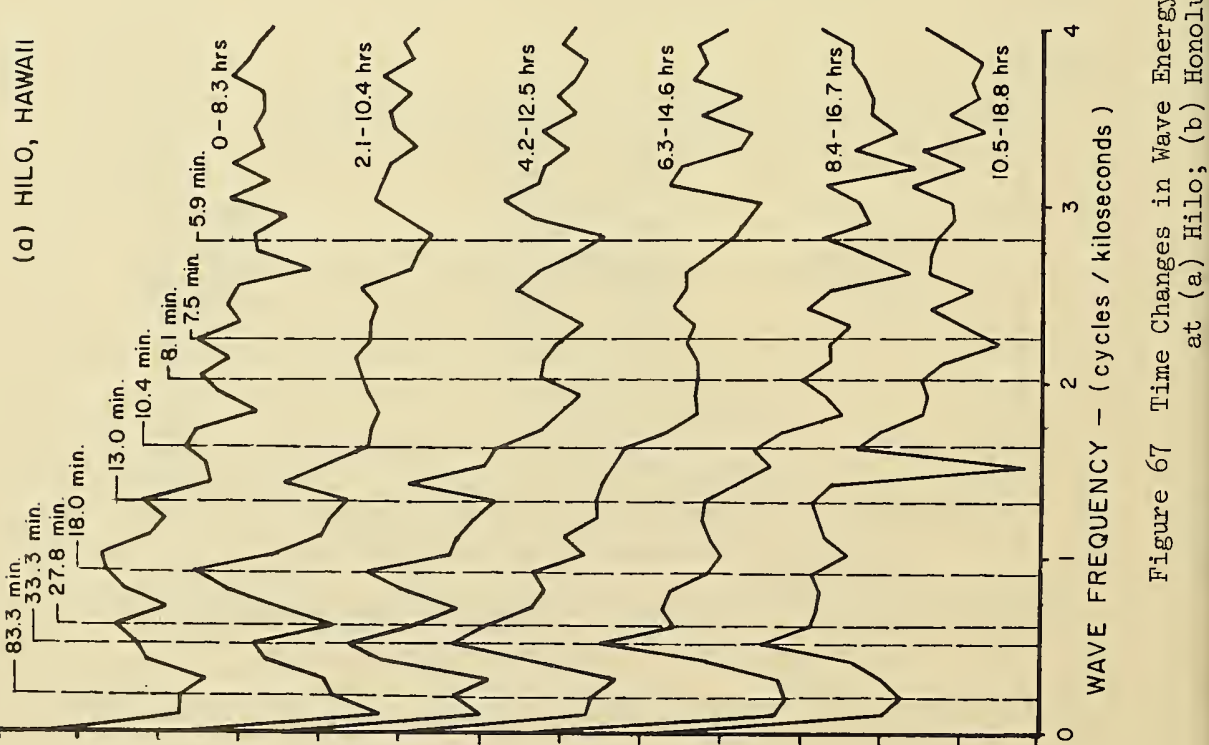

( ᄉอปヨNヨ) э0า 
The procedure, first used in an earlier work (Wilson, et al, 1962; Wilson, 1964), depends on visually identifying the underlying wave systems, and on separating them from each other and the background of the astronomical tide. As an example, Figure 44a, the marigram for Juneau, may be separated into curves (b), (c), and (d), of which (b) may be considered the characteristic signature of the tsunami and (d) a minor oscillation related to the locality. The signature shows a beat system of waves with periods close to 1.7 hours. The first beat has five waves, the largest of which is a negative wave near the front of the beat.

Referring back to Figure 27, the main flanking attack of the tsunami on the North American coastline took place between Yakutat and Crescent City. Analyses covering stations along this coast (Figures 43 to 49) show the first five waves in a rather pear-shaped beat with the largest modulation near the front. The shape of the beat modulation undoubtedly relates to the shape of the source, and generally confirms the interpretations of seabed disturbance in Figures 19, 34, 36, and 37. Figure 27 shows that the waves striking Yakutat originated from a generating area off Hinchinbrook Island, where the seabed deformation had the same dumbbell shape as the beat of waves reaching Yakutat (Figure 9).

The waves reaching Sitka came from the generating area just southwest of Montague Island (Figure 27) where highest known uplift occurred (Figure 12). Figure 45c shows an apparently corresponding prominence of the forefront of the beat of waves of about 1.7 hours period. The maximum envelope height of waves for Sitka was 12 feet.

Further south, Prince Rupert, Canada, was hit by 7 -foot waves (maximum envelope height), Figure 46c. Figure 27 shows that these waves originated off the southern end of Kenai Peninsula (Figure 36b).

Port Alberni is of special interest. According to the analysis of Figure 47c, which attempts to infer what the tide gage would have recorded had it not failed during the first waves, the maximum envelope wave height may have been as much as 27 feet. Port Alberni suffered severe damage from the tsunami ( $c f$. Wigen and White, 1964; White, 1966; Abernethy, et al, 1964). Water levels for the first three waves were established by observation, thus permitting some definition of the wave system by interpolation between these observations and the later marigram (Figure 47a). The waves approximate 1.72 hours in period and clearly must have gained their extraordinary height through some near-resonance local phenomenon since the corresponding maximum waves at Victoria (Figure 48d), only a short distance southeast along Vancouver Island, were only 3 feet high.

Port Alberni lies at the head of a long inlet, about 40 miles from the mouth of Barkley Sound on the west coast of Vancouver Island. (Figure 68). The inlet, a narrow channel, varies in width from $1 / 2$ to $I$ mile and in depth from about 100 fathoms at the mouth to less than 30 fathoms at the head (White, 1966). The approximate natural period of oscillation of such a canal may be calculated by assuming that the depth profile along the length is parabolic. Thus from Lamb (1932) (see also Wilson, 1966), 


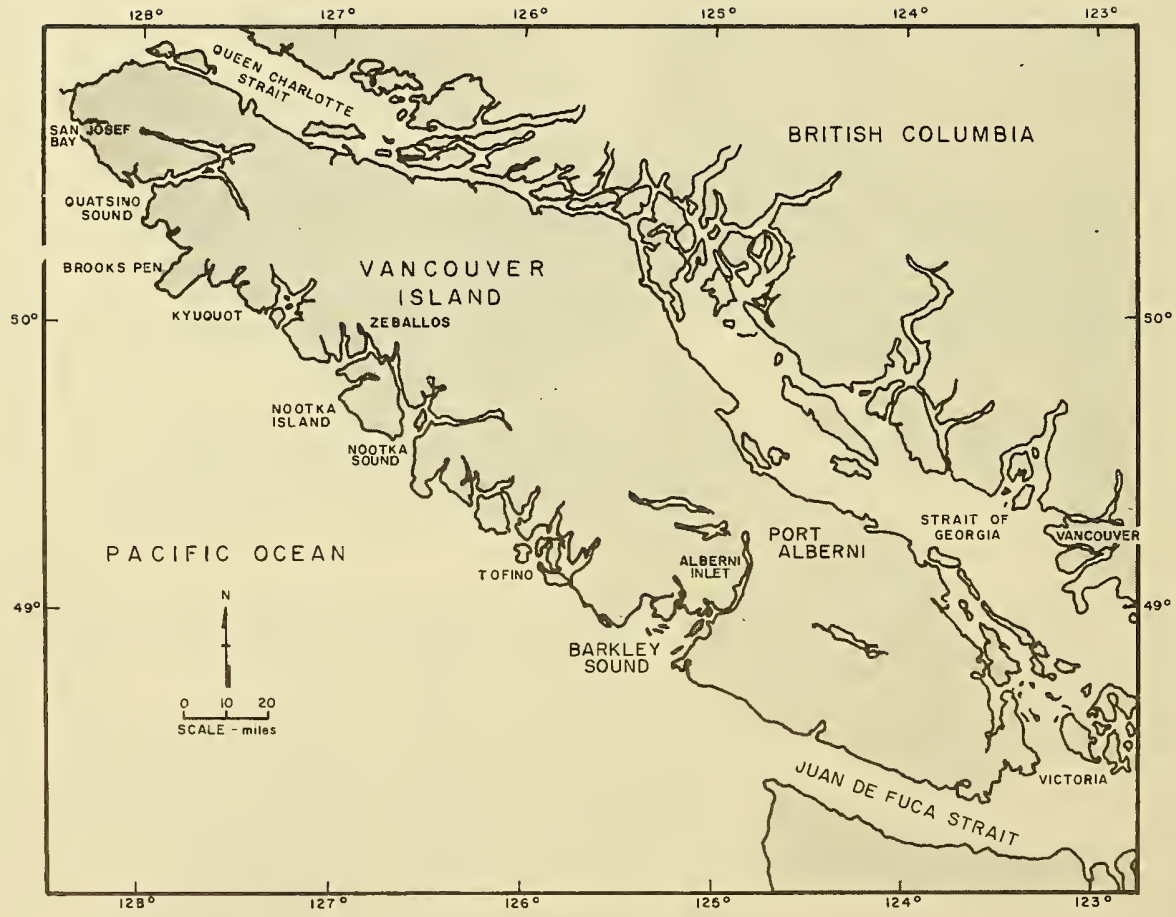

Figure 68 Map of Vancouver Island, Canada, Showing Location of Port Alberni at the Head of Alberni Inlet 
the fundamental period is:

$$
\mathrm{T}_{1}=4.44 \mathrm{~L} / \sqrt{\mathrm{gd}_{1}}
$$

in which $L$ is the length of the channel from the mouth and $d$ the depth at the mouth. For $\mathrm{L}=40$ miles, $d_{1}=600$ feet, $T_{1}$ is 1.85 hours, which clearly suggests that pseudo-resonance occurred.

Assuming a uniformly sloping channel bed, which is still a fair approximation, an estimate of the amount of amplification $\alpha$ of the waves between the mouth and the head of Alberni Inlet may be obtained (Lamb, 1932), without consideration of friction.

$$
\alpha=\frac{\text { Amplitude at head }}{\text { Amplitude at mouth }} \simeq\left(1+\frac{K L}{2}\right)^{2}
$$

in which $\mathrm{K}$ is a wave number defined by

$$
K=\sigma^{2} \mathrm{~L} / \mathrm{gd}_{1}
$$

and $\sigma$ is the angular frequency of the incident waves. For the 1.7-hour waves of Figure 47c, $\alpha$ is about 10, suggesting that the tsunami waves entering Barkley Sound (Figure 68) were about 2.7 feet high and therefore of the same order as the waves reaching Victoria (Figure 48d).

We shall confine our attention here to what are considered the essential tsunami signatures in Figures 43 to 66 and reserve comment on secondary features (such as the wave systems (c) and (e) in Figure 48, for example) for a later stage.

Analysis of the limited data for Crescent City suggests that the second principal wave (Figure 49c), of 1.8 hours period and 13 feet effective wave height, made the tide gage inoperative and caused the great destruction and tragedy (Griffin, et al, 1964). This wave was assisted by a local oscillation with an effective height of 17.5 feet and a period of about 30 minutes exactly phased to occur on the crest of the monster 1.8-hour wave. In addition, these waves rolled in on the high spring tide just as at Prince Rupert and Port Alberni, Canada. (see Figures 46 and 47 ).

The waves reaching Crescent City came from the southwest extremity of the source region near Kodiak Island (Figure 27). A paper recently received (von Huene, et al, 1967) indicates that this part of the source region had the highest concentration of strain-energy release over the period March 27 through May 1, 1964 of any area tectonically affected by the earthquake. The wave rays of Figure 27 suggest that energy from that region was spreading through overlapping wave systems, presumably as a result of the vertical uplift and the horizontal thrust of the seabed or from some other cause. The line of progression of the "caustic" or intersection of the slightly oblique wave systems has the appearance of bearing directly on Crescent City and might account for the large 
magnitude of the tsunami signature in Figure 49c. The degree of accuracy of Figure 27 limits an explanation of this kind to little more than suggestion, but one aspect that is possibly substantiative concerns what happened on either side of Crescent City. Thus at Victoria, Canada (Figure 48d) and at San Francisco, California (Figure 50c), the leading modulation has been shortened by an interference effect, yielding a short intermediate beat not found in the tsunami signatures north of Victoria, nor even in the signatures south of Rincon Island, California (compare Figures $51 \mathrm{c}$ and $53 \mathrm{c}$ ).

Causes for the high waves at Crescent City have been sought by others, notably Foley (1964), Tudor (1964), Roberts and Chien (1965), Wiegel (1965), Kent (1965) and Raudio (1965), but with no positive conclusions. Roberts and Chien impute the concentration of wave energy on Crescent City to the refractive effect of a distant sea mount in deep water. We are not convinced of this argument because of the small size of these topographical features, relative to the great length and period of the tsunami. Nevertheless, the caustic formations envisioned by Roberts and Chien would at least enhance any larger caustic accumulation of energy coming from the source.

The possibility that continental-shelf resonance amplified the wave effect at Crescent City will be discussed later. However, Crescent City has been peculiarly subject to high wave effects from numerous great tsunamis (Magoon, 1962; Wiegel, 1965; Raudio, 1965), though this tsunami was the greatest of them all.

The wave rays of Figure 27 indicate that the energy distributed along the South American coastline originated from a very small sector of the southwest extremity of the source region. Nevertheless, Figure $53 c$ for Talcahuano, Chile, shows waves 4 feet high of 1.75 hours period in a fish-shaped beat; the largest amplitude is carried by the second trough, and 8 waves occur in the beat. At Corral, Chile, about 180 nautical miles south, the primary waves were 2 feet high and about 1.9 hours in period; 9 waves are found in a similar fish-shaped beat (Figure 54c).

The effect of the East Pacific Rise on the tsunami is apparent in Figure 27 by the refraction of the wave fronts and the focusing of wave energy toward the southern tip of South America. At Ushuaia, Tierra del Fuego, Argentina, the tsunami signature is still characteristically a beat of long waves 1 foot high with a period of about 1.9 hours (Figure $55 \mathrm{c}$ ), but the highest waves are now further removed from the front.

The natural refractive process allows little wave energy leakage through the Drake Passage, which forms a window to the South Atlantic Ocean (Figure 27), while considerable spreading of energy also occurs along most of the Antarctic continental boundary to the Pacific Ocean. Despite this, enough energy reached Palmer Peninsula in Antarctica to register the tsunami signature and a variety of superimposed oscillations (Figure 56c). 
In the Pacific-Antarctic area near Iongitude $130^{\circ} \mathrm{W}$, Figure 27 suggests a strong focusing of wave rays, and pronounced tsunami effects probably resulted if the tsunami remained relatively unaffected by the screen of islands in the Tuamotu Archipelago and nearby island clusters. That the tsunami did breach the island barriers without sensible loss of its identity is shown by the sequence of analyses in Figures 57 through 60.

For Midway Island; Mokuoloe Island, Oahu, and Hilo, Hawaii; represented by Figures 57 through 59, the primary signatures are similar and comprise a leading beat of about five waves of 1.8 hours period with a maximum beat-height at Hilo of 1.8 feet.

Lyttelton, New Zealand, has an elongated rocket-shaped beat of 10 waves with periods of 1.8 to 1.5 hours and a maximum height of 3.8 feet (Figure 60). The waves reaching Lyttelton had to penetrate the Hawaiian Islands, cross the Christmas Island Ridge, and then follow a ray parallel to the Tonga Trench (Figure 27). Their emergence in such pure form and high amplitude (Figure $60 \mathrm{c}$ ), even after radial spreading caused by the Tonga Trench bathymetry, indicates not only that the island barriers were ineffective scatterers of the large waves, but that the signal strength was significant to excite so large a response.

This raises the interesting question whether Lyttelton provided appropriate conditions for pseudoresonance of the tsunami. Lyttelton lies about half-way up a 16-mile long inlet (Port Lyttelton) on the east coast of South Island, New Zealand. This inlet (Figure 69) is about 1 mile wide along most of its length and shelves almost uniformly from a depth of about 7 fathoms at the mouth. We use the eigenperiod formulas for a uniformly sloping rectangular open-mouthed basin (cf. Wilson, 1966).

$$
\begin{aligned}
& \text { (i) } \mathrm{T}_{1}=5.236 \mathrm{~L} / \sqrt{\mathrm{gd}_{1}} \\
& \text { (ii) } \mathrm{T}_{2}=0.435 \mathrm{~T}_{1}
\end{aligned}
$$

where $T_{1}$ and $T_{2}$ are the first and second mode periods of free oscillation of the inlet, $L$ is its length and $d_{l}$ its depth at the mouth. For $L \simeq 16$ miles, $d_{1}=42$ feet; $T_{1}$ is 3.35 and $T_{2}$ is 1.46 hours. It is thus inferred that the tsunami would have excited a near-resonant response from the second mode of the free oscillation.

We now enquire into the amplification that could be expected of waves entering the inlet with periods of 1.8 and 1.6 hours. We require the generalized formula for wave height amplification a at a specified distance $x$ from the head of the inlet. This formula developed from Lamb (1932) and akin to Equation (8) is:

$$
\alpha=\left(1-\frac{K x}{2}\right)^{2}\left(1+\frac{K L}{2}\right)^{2}
$$

in which $\mathrm{K}$, a wave number, has the same definition as given in Equation ( 9 ). 


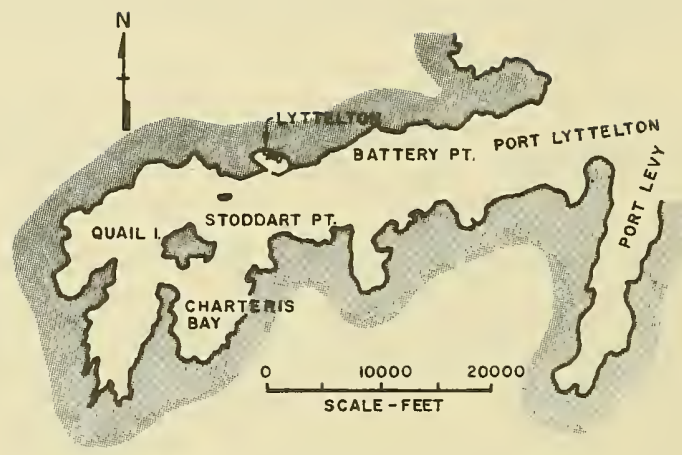

PLAN OF PORT LYTTELTON

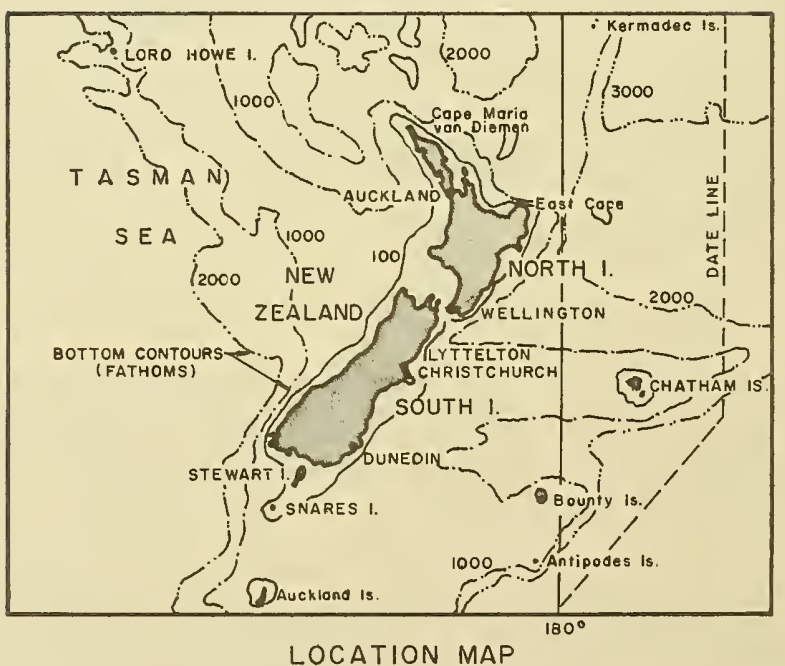

Figure 69 Location of Iyttelton, New Zealand, in Relation to the Inlet of Port Lyttelton 
Taking the Lyttelton position in the inlet as $x=8$ miles, we derive the results listed in Table II.

\section{TABLE II}

Computed Amplification Effects in Port Lyttelton, New Zealand

\begin{tabular}{|c|c|c|c|}
\hline $\begin{array}{l}\text { Period of Tsunami } \\
\text { Excitation }\end{array}$ & $\begin{array}{c}\text { Amplification } \\
\text { Factor }\end{array}$ & $\begin{array}{l}\text { Observed } \\
\text { Wave Height } \\
\text { at Lyttelton }\end{array}$ & $\begin{array}{l}\text { Inferred } \\
\text { Wave Height at } \\
\text { Mouth of Inlet }\end{array}$ \\
\hline $\mathrm{T}$ & $\alpha$ & $\mathrm{H}$ & $\mathrm{H}_{1}$ \\
\hline (hours) & & (feet) & (feet) \\
\hline 1.8 & 0.84 & 1.0 & 1.2 \\
\hline 1.6 & 6.3 & 3.8 & 0.6 \\
\hline
\end{tabular}

The inference drawn from Table II is that the beat-shape of tsunami waves entering Port Lyttelton was quite different from the rocket-shape of Figure 60c. The later waves in the beat would have been less prominent in relation to the leading waves, and the beat-shape at the mouth may have been more in accord with Figure 6lc, applicable to Moen Island, Truk, in the Caroline Islands.

West of the Tonga Trench the tsunami had to filter through much thicker island clusters whose strength in depth prevented much penetration of energy into the Tasman Sea, despite a focusing tendency brought about by wave refraction (Figure 27). The waves reaching Fort Denison and Camp Cove, Australia, were about 1.2 feet high (Spaeth and Berkman, 1967).

The analyses of Figures 62 to 66 relate to the tsunamis that emanated from the extreme southwest end of the source region (Figure 27). In five cases covering a boundary spread from the Aleutian Islands to Japan, the tsunami signal is still characteristically a long bullet-shaped beat comprising 6 to 8 waves with periods of about 1.9 hours. The complexity of the records in most of these cases made their analysis a considerable challenge. For example, in the records for Japan, the presence of the primary waves is not readily apparent (Figures 65 and 66). Nevertheless, strong similarities found in primary wave systems for Poronaysk (Sakhalin Island), Yuzhno, Kurilsk (Kuril Islands), Hanasaki and Ofunato, Japan, indicate the same origin. (Figures $63 c, 64 c, 65 c, 66 c$ )

Table III summarizes some of the salient features evolved from the analyses of the marigrams in Figures 43 through 66. 


\section{Height Characteristics of the Main Tsunami}

Table III lists maximum envelope heights $\mathrm{H}_{1}$ and average periods $T_{1}$ of the first three waves in the leading beat of the primary wave systems. It also gives heights and periods of secondary wave systems. Travel times $t$ are based on arrival times of the waves from Figures 43 through 66. In many cases these differ somewhat from the arrival times of Spaeth and Berkman (1968), see Figure 27. For the first six stations in the table the distance $r$ is the length of the refracted wave ray connecting the source and the station as evolved in Figure 27 . For all other stations, the distance $r$ is the great circle distance of wave travel given by Spaeth and Berkman.

Equation ( 4 ) is invoked to calculate the mean depth along the total distance to each station from the relationship

$$
\mathrm{d}=(r / t)^{2} / g
$$

Relative distance is then the ratio $r / d$.

An assumed wave height $\mathrm{H}_{\mathrm{O}}$ at the source has been adopted according to the arguments presented in Figures 34, 36, and 37. Because of the finding of von Huene, et al (1967), that a very high center of strain release existed near the southwest end of the inferred tsunami source region, we have adopted $\mathrm{H}_{\mathrm{O}}=60$ feet for all stations beyond the first six. Figure 27 suggests that nearby stations received most of the wave energy spread laterally from the source length, whereas the distant stations received wave energy predominantly from the radial expansion of the southwest end disturbance. These wave heights at the sources, although speculative, provide a comparative basis for investigating some properties of wave decay.

The inference seems clear that the tsunami that traversed the Pacific Ocean comprised packets of extremely long waves with periods of about 1.8 hours. At insular and continental shelves, some of the energy of the waves was reflected and scattered and some transferred to high frequencies so that the residual energy remaining to the fundamental waves, as represented in the height $\mathrm{H}_{I}$, has in many cases been much depleted. Nevertheless, even the height $\mathrm{H}_{l}$ is nominally greater than the height $H$ the long waves would have at the shelf-edge, because of the height enhancement from shoaling. Rating this enhancement as 50\% on average, the deepwater height ratio $\mathrm{H} / \mathrm{H}_{\mathrm{O}}$ is taken as $2 / 3\left(\mathrm{H}_{1} / \mathrm{H}_{0}\right)$.

Values of $\mathrm{H} / \mathrm{H}_{\mathrm{O}}$ have been plotted against relative distance $\mathrm{r} / \mathrm{d}$ in Figure 70. The range of values of $\mathrm{r} / \mathrm{d}$ from all these data is limited so that it is difficult to establish trends. However, if we assume that for a value of $r / d=1$, the ratio of $H / H_{O}$ would have to be unity, we may perhaps draw some conclusions. We are assuming that $r / d=1$ effectively represents the fringe of the initial wave at the source, at or near the continental slope of the Aleutian Trench. 


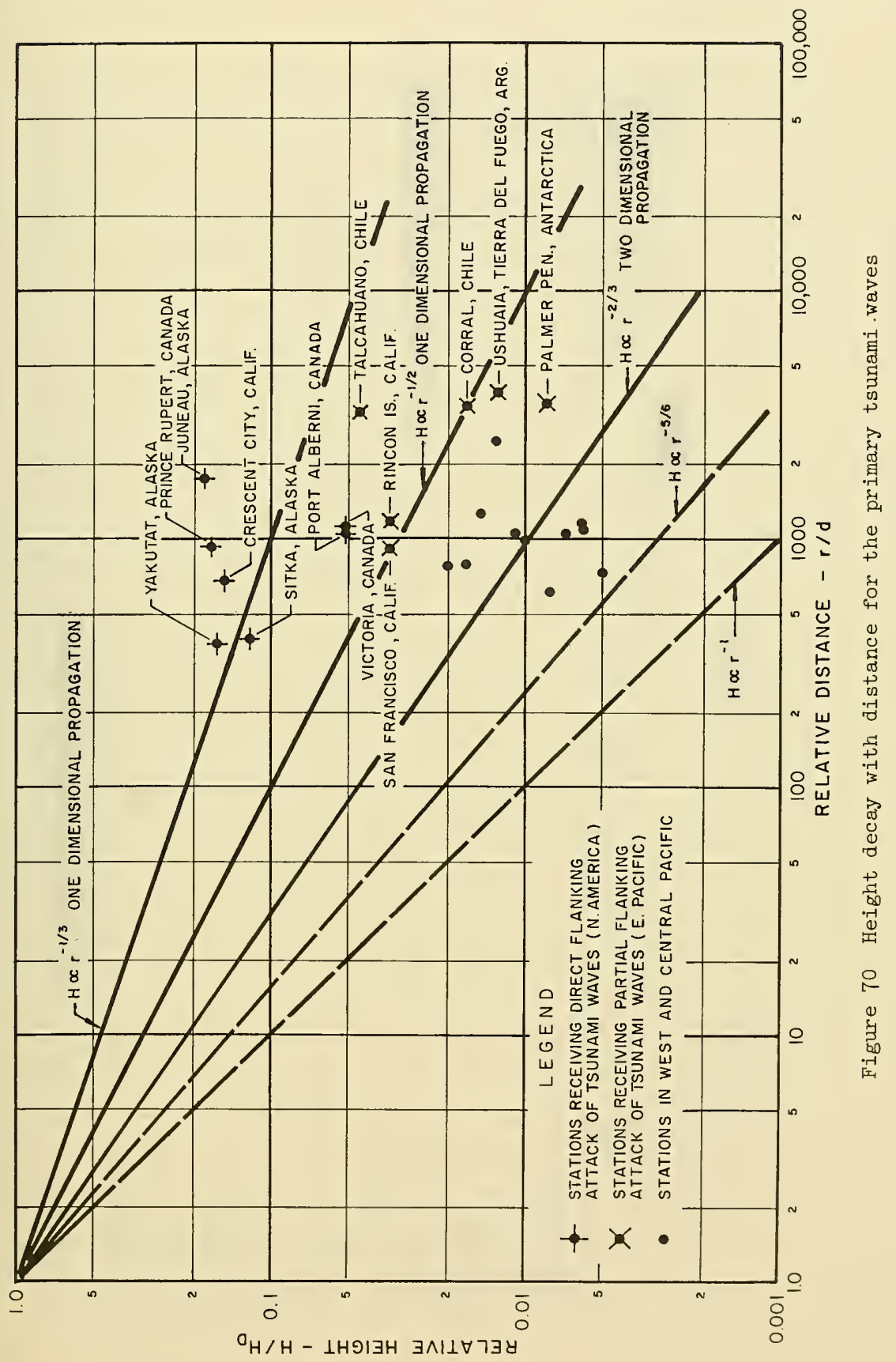




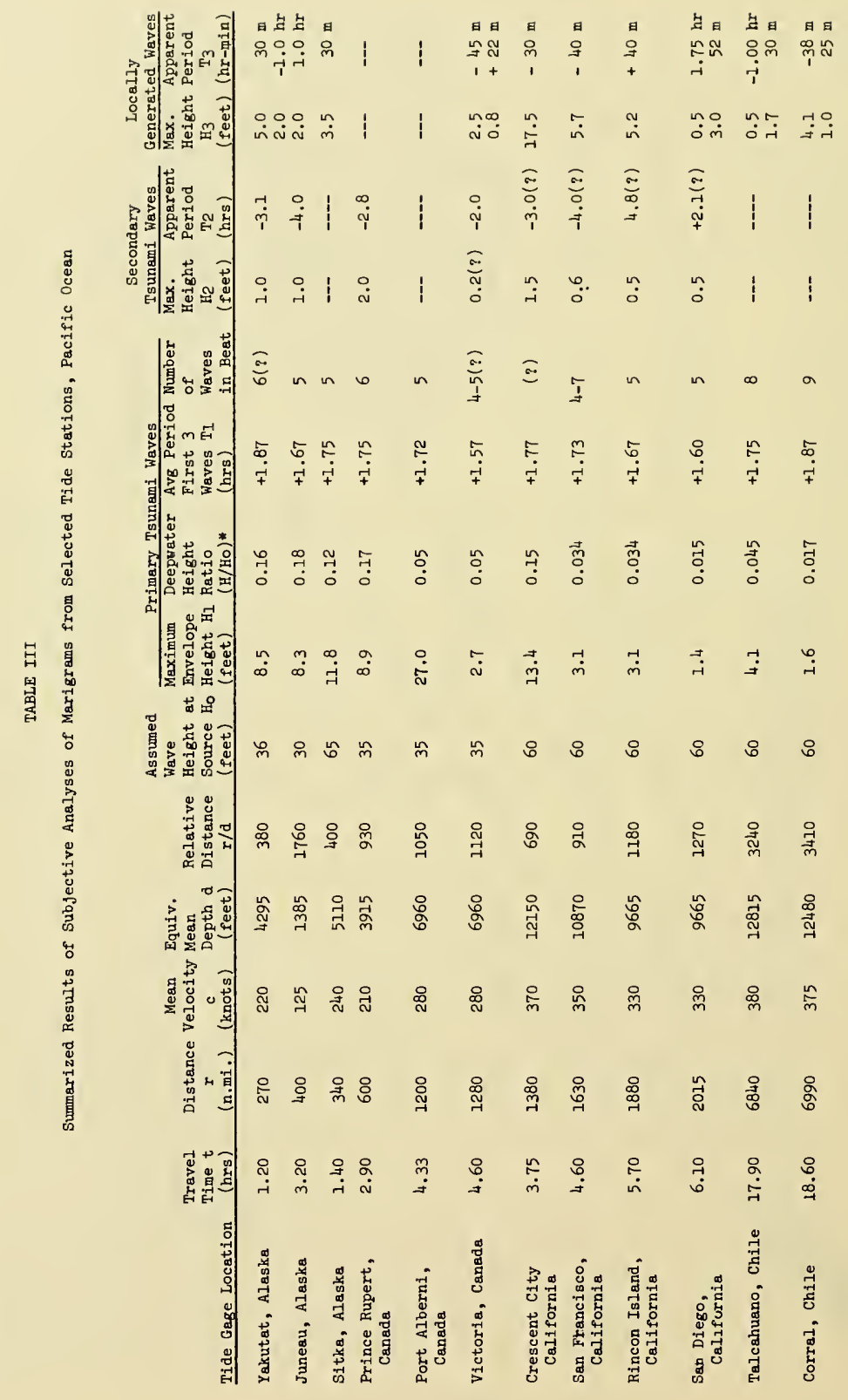




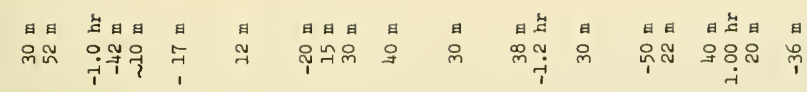

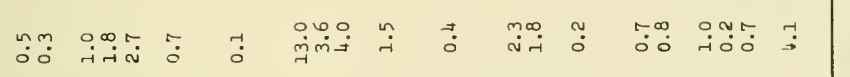

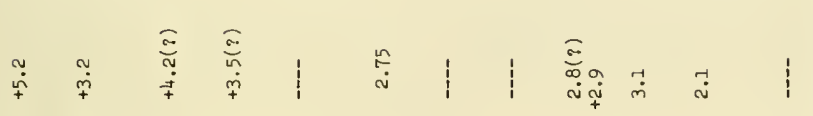

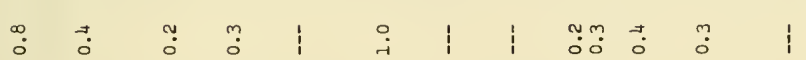

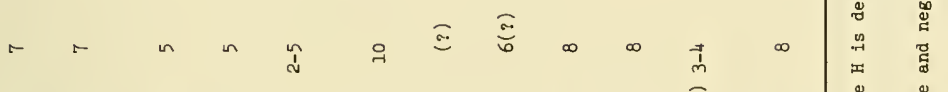

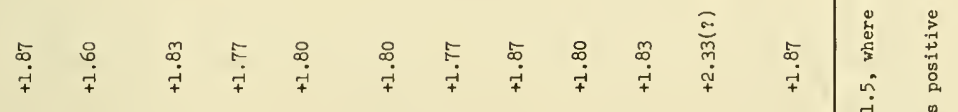

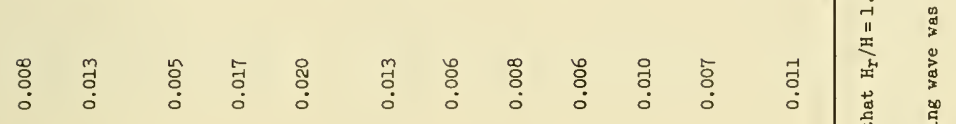

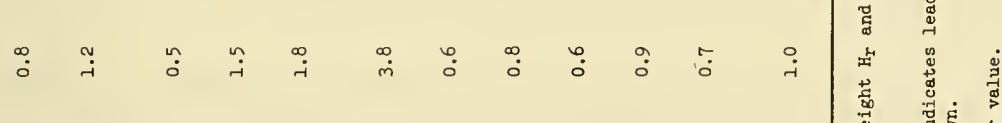

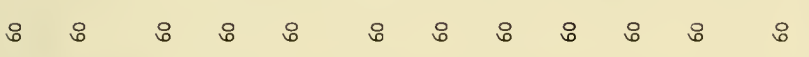

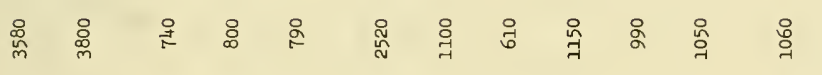

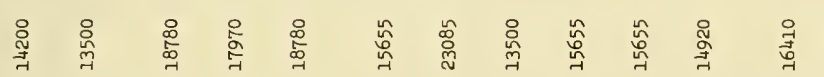

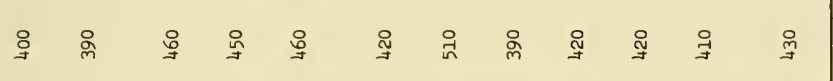

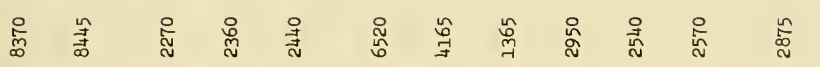

ㅇํㄹ

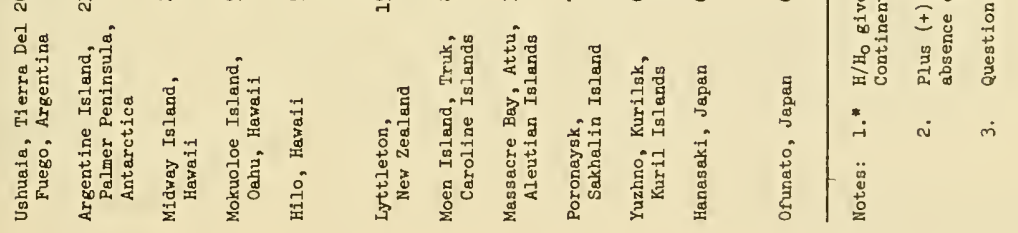


From the point $\left(H / H_{0}=1 ; r / d=1\right)$ in Figure 70 , lines have been drawn which represent proportionalities, $H \propto r^{-n}$, for the values $n=1 / 3$, $1 / 2,2 / 3,5 / 6,1$. Theoretical studies of decay of impulsively generated waves have variously shown that one or another of these laws may be involved. As summarized by Wilson, et al (1962), Wilson (1964), onedimensional ( $x$, horizontal) dispersive waves decay according to the law $\mathrm{x}^{-1 / 2}$ in the body of the waves and as $\mathrm{x}^{-1 / 3}$ at the wave front. Kajuira (1963) confirms the latter result for the leading wave of a tsunami provided that

$$
(\mathrm{b} / \mathrm{d})(6 \sqrt{\mathrm{d} / g} / \mathrm{t})^{1 / 3}<1
$$

where $b$ is the half-breadth of a rectangular source area and wave propagation is in the direction of the breadth (see also Van Dorn, 1965).

It must be assumed that, at least for the first six stations listed in Table III, and possibly for the first twelve, the tsunami advanced on the American seaboard with a one-dimensional propagation. We find that the data points for stations along the Americas show a certain disposition to accord in the mean with the laws $H \propto r^{-1 / 3}$ and $H \propto r^{-1 / 2}$. Further, those that seem to accord with the first law represent data drawn largely from high waves at the front of the beats for situations in which energy lost to other frequency excitations was fairly low.

Of the data points that seem to accord better with the $\mathrm{H} \propto \mathrm{r}^{-1 / 2}$ law, there was considerable loss of energy to higher frequencies. Had this loss not occurred, they would place higher in Figure 70. San Francisco and Rincon Island, for example, might qualify then for the $H \propto r^{-1 / 3}$ law, particularly as the highest waves are close to the front of the beat (see Figures 50, 51). Also, the data points for Ushuaia, Tierra del Fuego, and the Palmer Peninsula, Antarctica, drawn from wave heights deep in the body of the beat (Figures 55, 56), would then conform better to the law of $\mathrm{H} \propto \mathrm{r}^{-1 / 2}$.

Since the data of Table III for the North American coastline appear to obey the $\mathrm{H} \propto \mathrm{r}^{-1 / 3}$ law, we may use Kajuira's condition, Equation (13), to place a bound on the half-breadth of the tsunami source region. If we take an approximately median value for the data represented by the upper set of points (Figure 70 ) as $r / d=1000$ and note that time $t$ in Equation (13) can be expressed in terms of $r$ via Equation (12), then Equation (13) resolves to

$$
\mathrm{b} / \mathrm{a}<(r / 6 \mathrm{a})^{1 / 3}
$$

Using $r / d=1000$ and adopting $d=5000$ feet for the first seven data points, we find

$$
\mathrm{b}<10 \mathrm{~km}
$$

In terms of what we know about the actual source region, this condition appears unduly restrictive. 
In the matter of two-dimensional ( $r$, radial) propagation of dispersive waves, Wilson, et al (1962), Wilson (1964), had concluded that height decays as $r^{-1}$ in the body of the waves and as $r-5 / 6$ near the wave front. Some experimental evidence seemed to support those conclusions at that time, particularly the experiments of Takahasi (1961) and the field results reported by Van Dorn (1961). However, Kajuira (1963), using more rigorous theory, has shown the amplitude decay of the leading wave of a tsunami will conform to the law $\mathrm{H} \propto \mathrm{r}^{-2 / 3}$ in two-dimensional propagation from a rectangular source, provided

$$
(a / d)(6 \sqrt{d / g} / t)^{1 / 3}>3
$$

where a is the half-length of the major axis and propagation is in the direction of that axis (see also Van Dorn, 1965).

Data represented by the third group of points in Figure 70, which apply to stations west and southwest of the tsunami source region, are clearly representative of two-dimensional (radial) wave propagation. Their scatter appears to be centered around the line $\mathrm{H} \propto \mathrm{r}^{-2 / 3}$ near a value of $r / d \simeq 1,000$. Kajiura's condition would then require

$$
a / d>3(r / 6 d)^{1 / 3}
$$

For a depth $\mathrm{d} \simeq 15,000$ feet, Equation (17) stipulates that

$$
\text { a }>75 \mathrm{~km}
$$

In this condition Equation (18) is well satisfied by the inferred dimensions of the tsunami source region.

\section{Period Characteristics of the Main Tsunami}

Table III shows that the periods $T_{1}$, the average of the first three waves in the beat of the primary wave system, are remarkably uniform. This suggests that these large waves were, in effect, nondispersive.

Because of the smallness of the relative depth $k d$, where $k(=2 \pi / \lambda)$ is the wave number, and $\lambda$ the wave length, the group velocity of the wave envelopes would not be sensibly different from the phase velocity of the individual waves in the beats. Thus $k d$ is normally less than $1 / 60$ for waves of 2 hours approximate period in an ocean 12,000 feet deep. Over a travel distance as long as 10,000 nautical miles the waves would outpace the envelope by only about 10 seconds. This implies that the beat structure of the main tsunami should remain largely unchanged. The stations from Yakutat to San Diego, Figures 43 to 52, suggest that this was generally true, and the earth movement along the fault length must have been of a rather uniform character, probably well symbolized by Figures 34,36 and 37. 
Table III shows five waves in the leading envelope for North American stations south to San Diego. Variations from this number are explained as interference effects of merging wave trains.

The number of waves in the leading envelope increases to 8 and 9 along the South American coast, but again this development is found to be incipient in the two leading envelopes for San Francisco and Rincon Island, California (Figures 50 and 51), and again the explanation is an interference effect of competing wave trains of the basic type ( 5 waves per beat). The 5-waves-per-beat character of the tsunami is still retained in the waves reaching the Hawaiian Islands (Figures 57 to 59), but is then lost to much longer envelopes in the records for the more distant stations in the West Pacific. Tsunami signatures shown in Figures 61 to 66 have about 8 waves in the leading envelopes, but since these tsunamis originated from a restricted part of the source region at the southwest end, they may have been of fundamentally different shape at the outset.

The periods $T_{1}$ of Table III range from 1.57 to 2.33 hours and average 1.79 hours (108 minutes). When this information is plotted in Figure 71 , which is adapted from original data of Takahasi (1961) supplemented by other data (Wilson et al, 1962; Wilson, 1964), a best fit curve to the total data yields the relationship

$$
\log _{10} \mathrm{~T}=(5 / 8) \mathrm{M}-3.31
$$

where $T$ is the tsunami period in minutes and $M$ the earthquake magnitude.

Equations (3) and (19), empirically derived from statistical data, suggest a relationship between the tsunami period and the effective source diameter $S$. Elimination of $M$ between these equations, gives

$$
\mathrm{T} \simeq 0.316 \mathrm{~s}^{15 / 16}
$$

for $\mathrm{T}$ in minutes and $\mathrm{S}$ in kilometers.

This result clearly implies that the tsunami period is directly proportional to the source diameter, a relationship which can be shown to have some theoretical support. It was shown, for instance, by Wilson, et al (1962), Wilson (1964) that Kranzer and Keller's (1959) result for the surface disturbance $n$ at a great distance $r$ from an arbitrary radially symmetric initial surface elevation $Q(r)$ of the water surface, centered at a source $(r=0)$, could be expressed (in the case of shallow water) as

$$
n=[H(k) / r d] \cos (k r-\sigma t)
$$

in which $\mathrm{H}(\mathrm{k})$ is the Hankel transform in the variable $\mathrm{k}$ of the function $\mathrm{Q}(r)$.

For the case of a supposed cylindrical rise of water level at the 


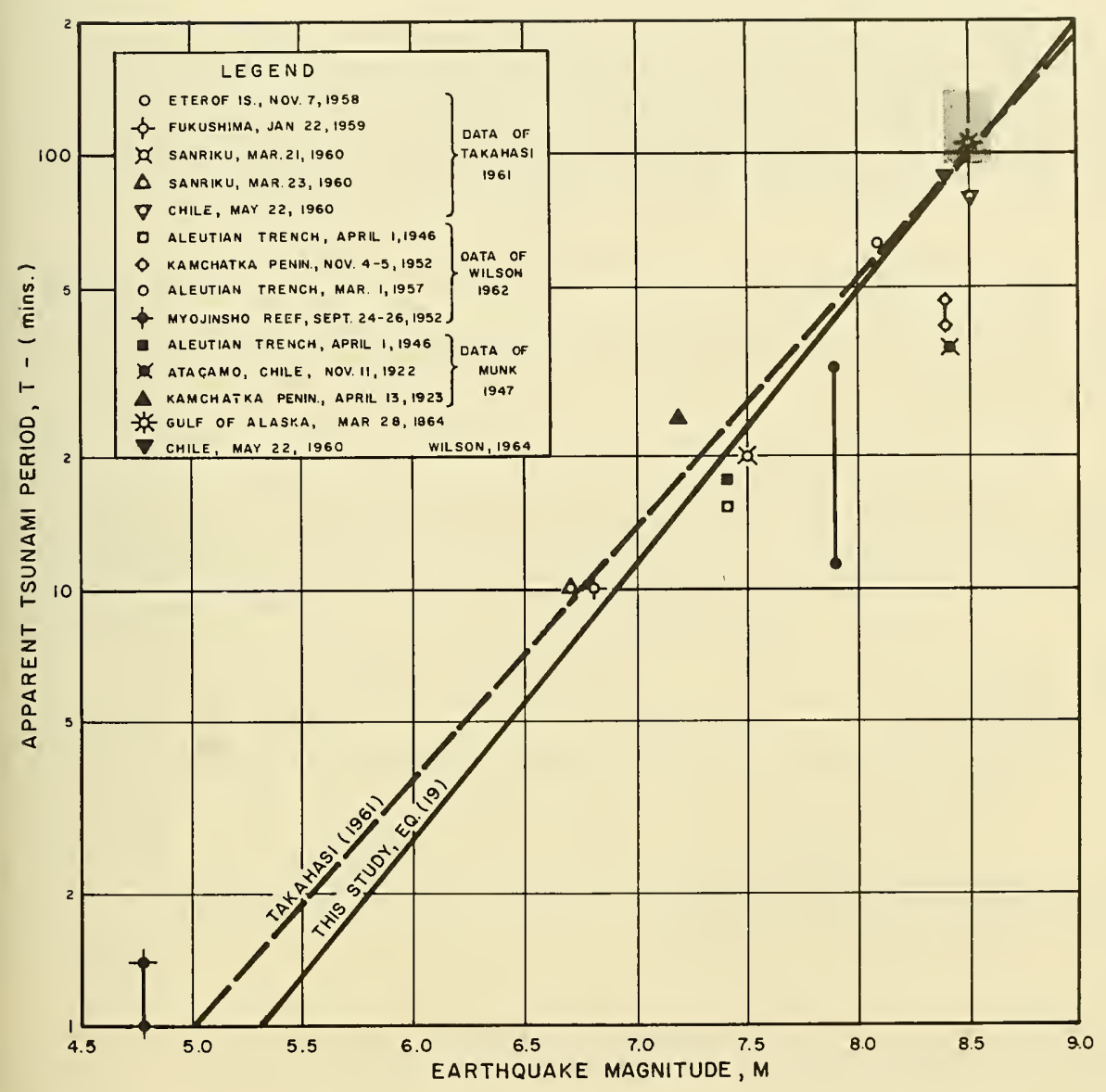

Figure 71 Relationship of Primary Tsunami Period to Earthquake Magnitude (adapted from Wilson, 1964). 
source for which $Q(r)=Q, r \leq R ; Q=0, r>R$, the Hankel transform is found to be

$$
\mathrm{H}(\mathrm{k})=\mathrm{QR} \mathrm{J}_{1}(\mathrm{kR}) / \mathrm{k}
$$

wherein $J_{1}(k R)$ is the first order Bessel function of the variable (kR). This Bessel function provides the modulation to the wave system expressed by Equation (2l) and thus effectively defines the beat. Nominally it could be said that the leading beat length would be defined by the first finite value of $k R$ for which the Bessel function $J_{l}(k R)$ is zero, namely $\mathrm{kR}=3.832$. In the more general case for which $\mathrm{Q}(r)$ is some unknown function we should expect $k R$ to have some unknown value $\beta$, that is,

$$
\mathrm{kR}=\beta
$$

where $\mathrm{R}$, in this case, would represent some nominal radial limit to the equivalent initial circular disturbance. Thus $2 \mathrm{R}=\mathrm{S}$ and Equation (23) may be replaced by

$$
k S=2 \beta
$$

Because the waves of the Alaskan tsunami have been shown to be effectively nondispersive, we invoke Equations (4) and (5) to express Equation (24) in the form

$$
\text { T } \sqrt{g / d}=(\pi / \beta)(S / d)
$$

which immediately shows that $T \propto S$ as predicted by the empirical result, Equation (20).

If Equations (20) and (25) are combined, the value of $\beta$ is found to be

$$
\beta=107.6 / \sqrt{d}
$$

for d in feet. From Equation (25) we should now expect that the wave periods generated would be given by

$$
\mathrm{T}=(\pi / 107.6 \sqrt{\mathrm{g}}) \mathrm{S}
$$

for $T$ in seconds and $S$ in feet. Resorting to the value of $S=425 \mathrm{~km}$ (Figure 28), the wave period from Equation (27) is found to be

$$
\mathrm{T}=1.99 \text { hours }
$$

which is in quite good agreement with the values of $\mathrm{T}_{1}$ given in Table III.

\section{The Transfer of Tsunami Energy to Higher Frequencies}

Aerial photographs of waves reaching a discontinuity, (such as a breakwater end), or passing over a submerged obstruction (such as a rocky outcrop) frequently show odd harmonics of the incident waves in the 
leeward waves. The same phenomenon is found in waves reflected from promontories or headlands, and has been observed and demonstrated in model experiments. Theoretical understanding of thị phenomenon, however, appears to be meager. The only studies known to us are those of Biesel (1966), but the subject is far from being fully explored. Munk and his collaborators (cf. Munk, et al 1959; Snodgrass, et al, 1962; Munk, 1962) have shown from analyses of long period wave spectra that the Continental Shelf plays a great part in trapping long-wave energy over the shelf and in promoting local oscillations. All of the subjective analyses in Figures 43 to 66 indicate that seismic waves, incident on a coastline, tend to induce instantaneous response in a wide variety of frequencies.

\section{a. San Francisco Bay. A good example is at San Francisco,} California where a regular oscillation of average period (38.5 minutes) developed instantaneously with the tsunami, and appeared to be modulated by the same modulating influences governing the primary waves (Figure 50d). The period 38.5 minutes is close to being the third harmonic of the 1.73-hour period of the main tsunami. However, one of the free periods of oscillation for San Francisco Bay is in the range 34-4I minutes and the bay's fundamental free period is 1.90 hours (cf. Wilson, 1966; Thornton, 1946; Honda, Terada and Isitani, 1908). Not only then were the tsunami waves near-resonant for San Francisco Bay, but their third harmonic, developing no doubt from the entrance constriction, as a process of energy transfer at an obstruction, also was enabled to resonate on its own. Thus, large effects developed in San Francisco Bay despite its very protected location and narrow entrance.

b. Hilo Bay, Hawaii. Fxplanations of this kind are not so readily made for the local oscillations at other places, because knowledge of the inherent oscillating characteristics is largely lacking. Hilo, Hawai, is one exception. Hilo Bay, with reference to a base line drawn across the mouth, has the approximate shape of an acute-angled triangle (Figure 72a). Schematically it may be idealized to the shape of the isosceles triangle shown in Figure 72c. The bed of the bay can be considered a uniformly inclined plane (Figure $72 \mathrm{~b}$ ), although some departure from a linear depth profile takes place near the mouth. In general the bay is a good case for the application of the geometrical analogy shown in Figures $72 \mathrm{c}$ and $\mathrm{d}$.

The natural periods $\mathrm{T}_{\mathrm{n}}$ of oscillation for a triangular bay with a uniformly sloping bed, from hydrodynamic theory (Lamb, 1932; Wilson, 1966) are:

$$
T_{n} \quad \sqrt{g_{d}} / L=3.306 ; 1.786 ; 1.237 ; 0.936 ; . . .
$$

where $n(=1,2,3 \ldots)$ is an integer defining the mode number, $L$ is the length of the bay and $d_{l}$ its depth at the mouth. For an axial length $L=30,400$ feet and depth $d_{l}=200$ feet, the first four modal periods are

$$
\mathrm{T}_{\mathrm{n}}=20.9 ; 11.3 ; 7.8 ; 5.9 \text { minutes }
$$


However, the slight truncation of the vertex of the triangle by land (Figure $72 \mathrm{~b}$ ), reduces these periods by the factor 0.92 , to

$$
\mathrm{T}_{1}=19.2, \mathrm{~T}_{2}=10.4, \mathrm{~T}_{3}=7.2 \text {, and } \mathrm{T}_{4}=5.4 \text { minutes }
$$

Further, assuming partial truncation of the bay due to the breakwater of Hilo Harbor (Figures 72 a and $\mathrm{b}$ ), the fundamental period $\mathrm{T}_{\mathrm{I}}$ is reduced (cf. Keulegan, 1962) to

$$
\mathrm{T}_{1}=14.5 \text { minutes }
$$

For each of the modes of oscillation a node occurs across the mouth of the bay and the number of nodes is represented by the integer $n$. (Figures $72 \mathrm{c}$ and d). Thus for the second mode oscillation $\left(\mathrm{T}_{2}=10.4\right.$ minutes) there are two nodes, one located at $0.293 \mathrm{~L}$ or 8200 feet from the head of the bay, almost exactly at the position of Hilo Harbor breakwater.

From our subjective analysis of the Hilo marigram (Figure 59) it appears that there was immediate development of an oscillation 13 feet high of about 20 minutes period which drained energy from the main tsunami (Table III). The fifth harmonic of the main tsunami period of 1.8 hours is 21.6 minutes, so that the natural tendency for the tsunami to develop odd harmonics through its convergence in Hilo Bay apparently found a sympathetic response from the fundamental eigenperiod for the bay. The enormous wave of 20-minute period was clearly a resonance effect. The effect, however, was rapidly broken by interference from other oscillations of about 15 minutes and 30 minutes period (Table III), the shorter oscillation probably associated with the truncation effect of the breakwater (Equation (3I)).

For a more exacting examination of the responses we refer to the wave energy spectra of Figure $67 \mathrm{a}$. In the first 8 hours, the tsunami apparently excited pseudo-resonant responses from all four of the modes suggested by Equation (30). However, it drew a large response from a 33-minute oscillation (which is close to being the third harmonic of the fundamental tsunami period). A free oscillation of this period must represent the coupled bay-shelf oscillation for that area, for it is noted from Figure 72 a that the insular shelf has a peculiar convex shape that would help to trap energy between the continental slope and the bay-head. The spectra of Figure 67 a show that the peak at 33 minutes tends to become dominant with time as the other oscillations damp out.

Hilo Bay then appears peculiarly attuned to resonance effects from great tsunamis. Since we conclude from Figure 71 that a great earthquake of magnitude $M=8.5$ always will tend to develop a tsunami of period approximating 1.8 hours, Hilo will always respond in the same way, regardless of the origin of the earthquake. Differences, of course, would be expected on the basis of direction. The lesser effects experienced at Hilo from the Alaskan tsunami, as compared with the Chilean tsunami of May, 1960, or the Aleutian tsunami of April, 1946, are 

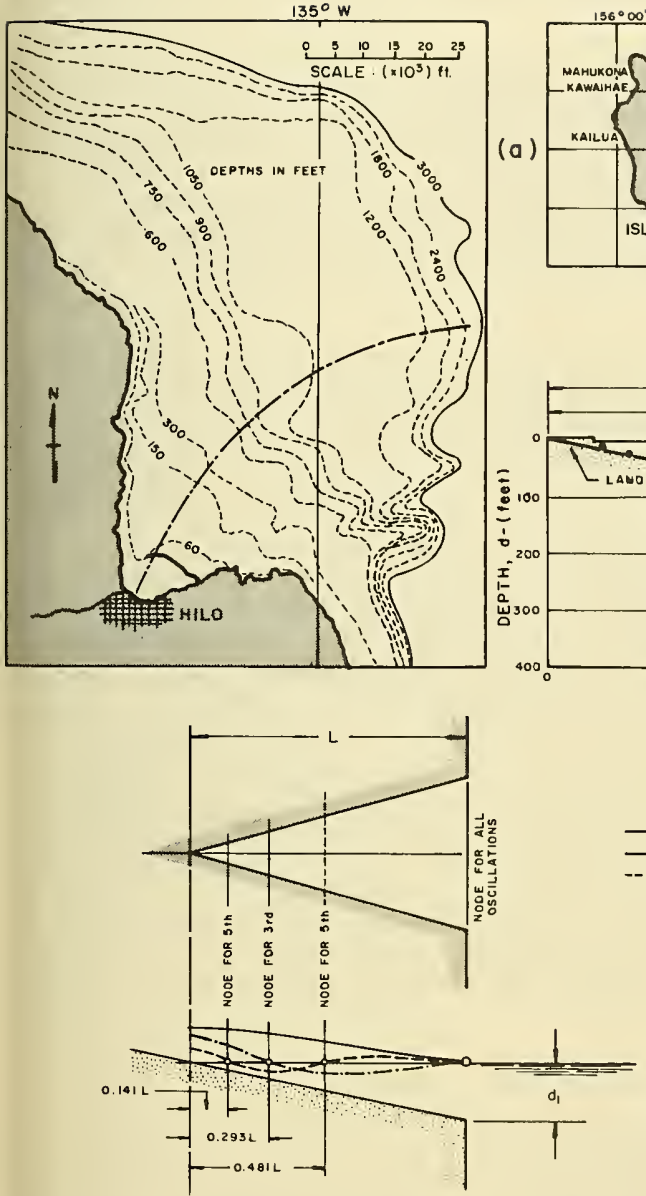

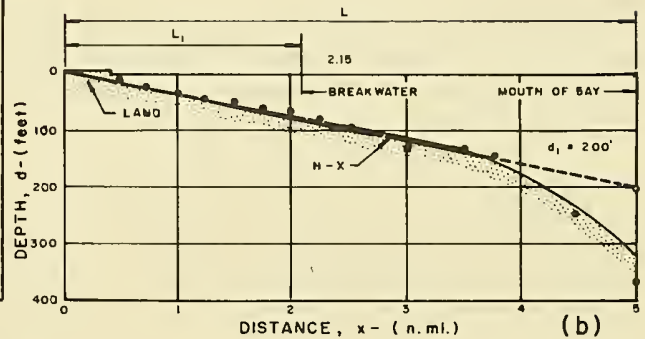

(b)

Pigure 72 Oscillating Characteristics of Hilo Bay, Hawaii (a) Location and Bathymetry of the Bay; (b) Depth Profile along Centerline of Bay; (c) Schematic Representation of the Bay and its lowest Modes of Oscillation. 
ascribed to the lesser amount of tsunami energy focused toward Hilo from the Gulf of Alaska. The exception to this generalization might be a large earthquake causing little or no vertical ground motion, as seems to have occurred at San Francisco in 1906.

c. Crescent City. Returning to Crescent City, our subjective analysis of Figure 49 has suggested large amplitude (30 to 35-minute period) oscillations occurring on top of the 13.4 feet high tsunami waves with a 1.77-hour period (Table III). We note at once that the 30 to 35minute oscillations would accord with the third harmonic of the incident tsunami waves. That this frequency could have gained such large response suggests that some topographical feature of the region must provide resonant conditions.

Crescent City occupies a position on a concave coastline southeast of Point St. George, from which a submerged reef extends seaward in a continuation of the coastal area (Figure $73 \mathrm{a}$ ). Moreover, at the two extremities of the arc, off Point St. George and off Rocky or Patrick's Point (at the southern end), the Continental Shelf width narrows appreciably. The coast and shelf markedly conform to a semi-elliptic basin, open-mouthed along its major axis at the edge of the shelf (Figure 73a). The dimensions of this basin are such that the ratio of the half-lengths of the major and minor axes is close to 4/3; the half-length $L$ of the minor axis is 17.25 nautical miles. The depth profile along the minor axis is approximated very closely by a parabola, and the trend of the depth contours indicates that the entire shelf in the area is pseudoellipsoidal to a maximum depth $\mathrm{d}_{1}$ of 300 feet (Figures $73 \mathrm{a}$ and $\mathrm{b}$ ).

The approximation of the shelf and coast to a geometrical form that can be described mathematically makes possible some conclusions regarding oscillating characteristics. For this we adapt the work of Goldsbrough (1930) to the situation of an open-mouth basin (cf. Wilson, 1966). For this particular shape of elliptic basin, extrapolation from previous calculations (Wilson, 1966), suggests that the Continental Shelf off Crescent City has the following natural periods of oscillation, $\mathrm{T}_{\mathrm{m}}$ :

$$
\frac{T_{m} \sqrt{g d_{1}}}{L}=4.444 ; 3.528 ; 2.930 ; 2.340 ; 1.785 ; . . .
$$

The subscript $m$ is an arbitrary integer $(m=1,2,3 \ldots)$ to describe the mode order in terms of period value or frequency. All these modes require that a node of the free oscillation shall lie along the major axis at the mouth of the basin (or the edge of the shelf). The fundamental mode represented by $\mathrm{m}=1$ ( $\mathrm{T}_{1}=79.1$ minutes) would be a simple uninodal oscillation about the major axis. The second mode ( $T_{2}=62.8$ minutes) would represent a binodal oscillation with nodes along both axes of the semi-ellipse. Another binodal oscillation ( $\mathrm{T}_{3}=52.1$ minutes) would involve a hyperbola as the second node, symmetrical with respect to the minor axis, and intersecting the coast probably near Point St. George and Patrick's Point. The fourth mode ( $\mathrm{T}_{4}=41.6$ minutes) effectively would be trinodal for the bay, with two nodal hyperbolas, each symmetrical 
with respect to the minor axis and intersecting the coast. The nodes in this case would approximate to radial lines from the center of the major axis and the type of oscillation would effectively constitute edge waves.

The fifth mode yielding a period $\mathrm{T}_{5}=31.7$ minutes is actually a binodal oscillation of a different type which involves a semi-ellipse as the second node (see Figure $73 \mathrm{c}$ and $\mathrm{d}$ ). Since this mode would conform well to the coastal configuration, it would seem to be the resonating medium for stimulating the third harmonic of the tsunami excitation. None of the other modes of shelf oscillation had periods in conformity with the tsunami period and its odd harmonics. The third mode $\left(\mathrm{T}_{3}=52.1\right.$ minutes) would have been in good accord with the second harmonic of the tsunami, but the implication of Figure 49 is that it was not excited.

However, the fundamental eigenperiod for the shelf off Crescent City $(T \simeq 79$ minutes $)$ is sufficiently close to the main tsunami wave period $(T \simeq 108$ minutes) to have provided a degree of amplification through partial resonance, as seems to have been the case more completely, however, at Port Alberni, Canada, and Lyttelton, New Zealand.

The tsunami of May 23, 1960, generated by the Chilean earthquake $(M=8.4)$, also drew a strong response at Crescent City at a period of 32 minutes. Figure 74 , reproduced from Wiegel (1965), shows the response and presents the energy spectrum for the waves calculated from the tide record. Wiegel, seeking an explanation for the 32-minute peak as a possible shelf oscillation, investigated wave travel times from the edge of the Continental Shelf, but found this approach unrewarding. The travel time over the distance $\mathrm{L}$ of Figure $73 \mathrm{~b}$ was about 21.2 minutes. Four times this value would yield the approximate period of the fundamental shelf oscillation, $\mathrm{T}_{1}=84.8$ minutes, which compares favorably with our result of $\mathrm{T}_{I}=79.1$ minutes. This period, according to Takahasi's data in Figure $7 \bar{I}$, should have favored resonance of the main waves propagated from the Chilean earthquake; Figure 74 , however, does not show the resonance, although the accuracy of the spectrum at very low frequencies is suspect. It should be noted that the harbor at Crescent City cannot support resonance of tsunamis at periods greater than about 10 minutes.

We conclude then that Crescent City's susceptibility to large wave response from major tsunamis is, by its very name, related to its crescent-shaped coast and bowl-shaped Continental Shelf. Because of its dimensions, it will forever be a responsive echo-chamber for great tsunamis since their periods will be always capable of exciting full or partial resonances.

We mentioned previously that the mechanism for transfer of energy of long waves to higher frequencies when negotiating depth changes that are sudden with respect to the wave length, is not yet fully understood. Dean (1964) may have uncovered the main elements of such changes by drawing attention to the fact that the wave form, if resolved into its Fourier constituents, would yield different amplifications and phase changes for the components in their propagation over the continental slope. Long 


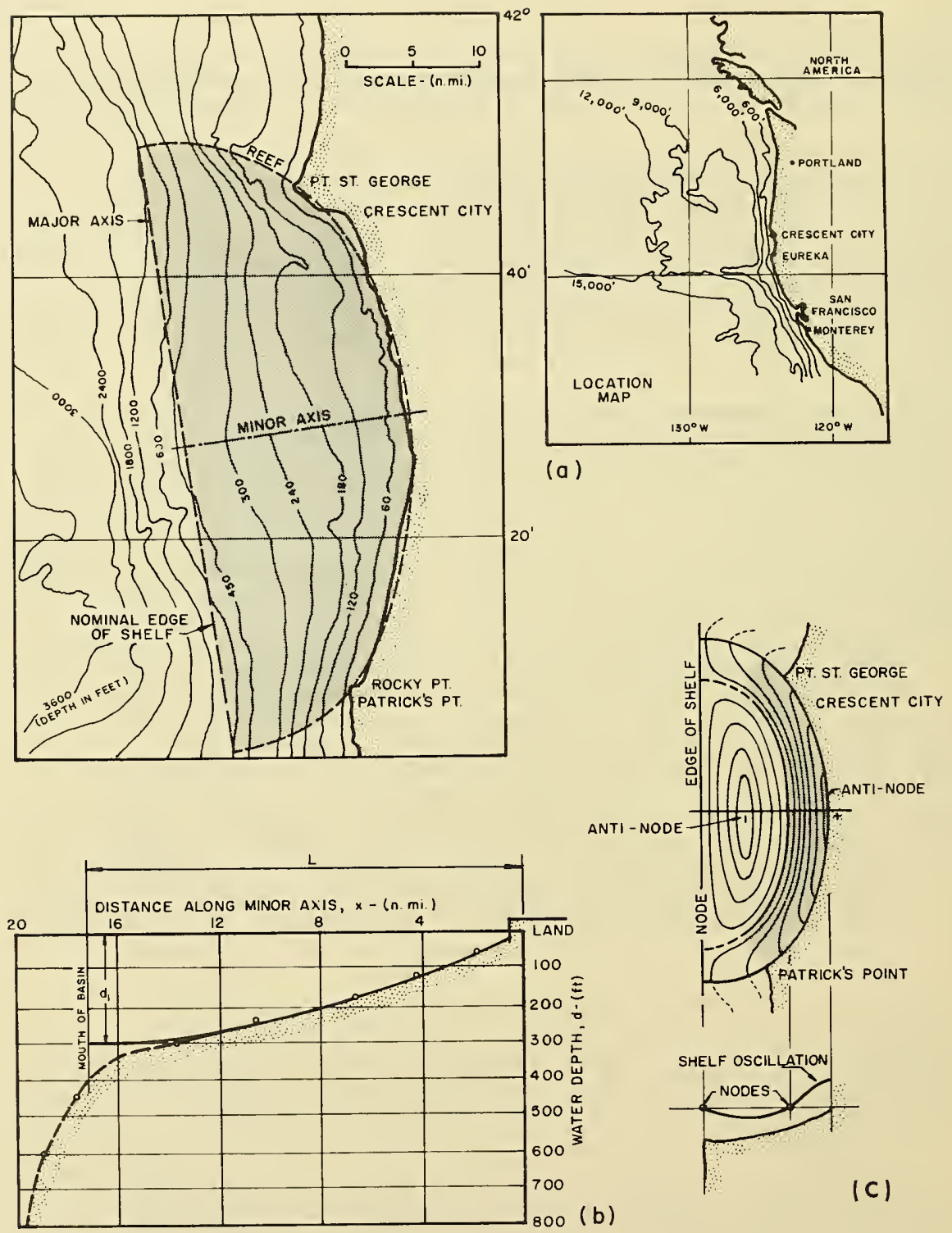

Figure 73 Oscillating Characteristics of Continental Shelf off Crescent City. (a) Location and Bathymetry of Shelf; (b) Depth Profile Along Minor Axis; (c) Binodal Mode of Shelf Oscillation. 


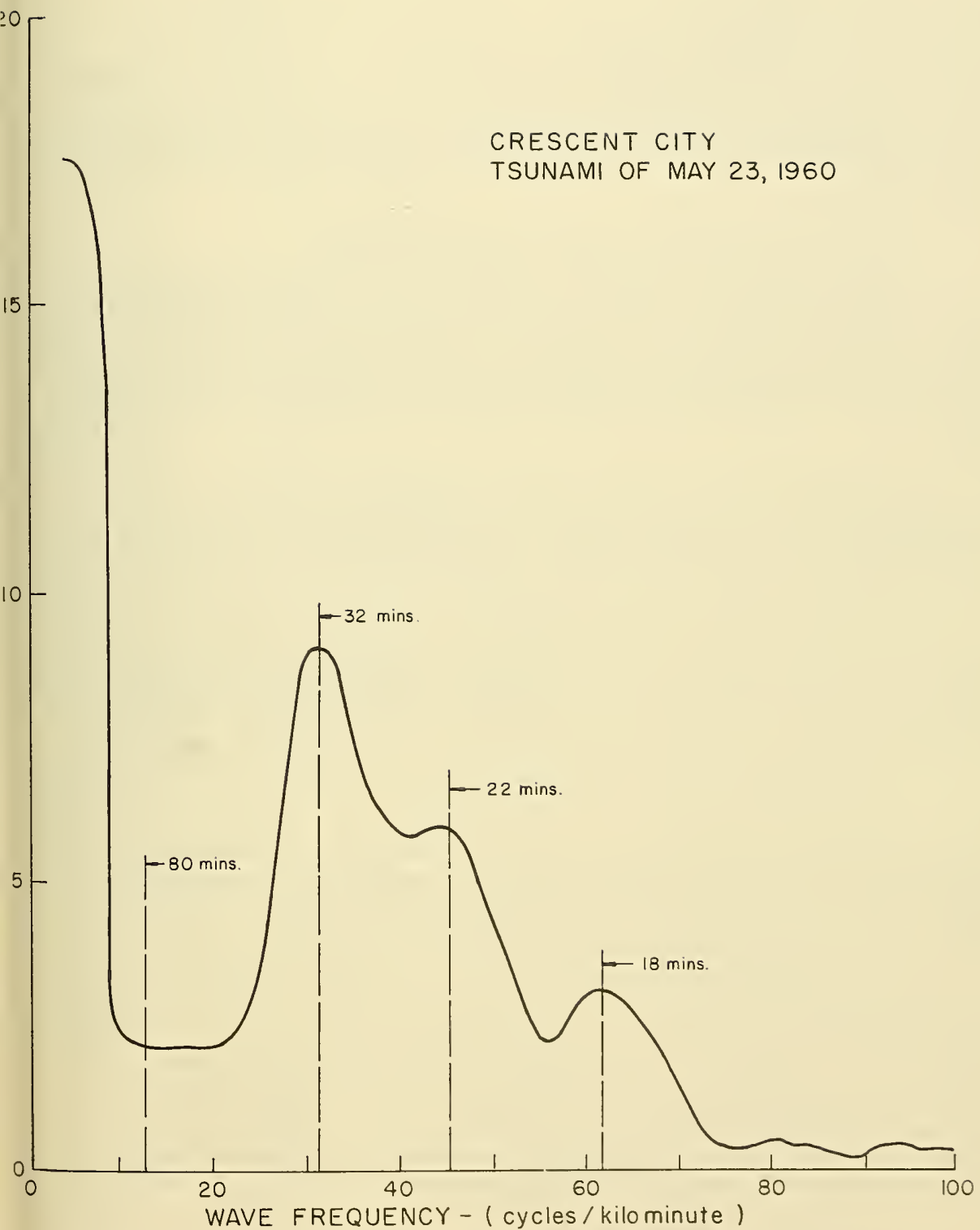

Figure 74 Wave Energy Spectrum for Tide Gage Marigram at Crescent City, Registered at the Time of the Chile Tsunami of May 23, 1960 (from Wiegel, 1965) 
waves, whose amplitude is not small compared with the mean depth, have an inherent tendency to propagate by developing harmonics, even in a channel of uniform depth. Airy first drew attention to this (cf. Lamb, 1932, § 188), and the phenomenon is a feature of the propagation of tides in narrow channels. The reason for the suppression of ever harmonics, in situations of sudden change, is not known at this time. Recently, Groves and Harvey (1967) have made enquiry into nonlinear effects of transformation.

\section{The Relationship of Runup to Coastal Resonance}

Even a perfectly straight coastline with a uniformly sloping (inclined plane) shelf can provide a resonating platform for normally incident wave trains of the right period. In this case the shelf responds as a broad canal similar to Port Alberni Inlet or the Inlet of Port Lyttelton. The problem has been treated by Lamb (1932) (cf. Wilson, 1966) with the same result, for wave amplification, already stated in Equation (11).

An important factor in this form of resonance is the value of the term $\mathrm{KL}$ of which $\mathrm{K}$ is a wave number expressed by Equation (9) and $\mathrm{L}$ is the length of the shelf from its edge to the coastline. It is readily shown that

$$
K \amalg=\left(4 \pi^{2} / g\right)\left(d_{l} / T^{2}\right)\left(I / s^{2}\right)
$$

where $d_{l}$ is the depth at the shelf edge, $T$ the period of the incident wave train and $s=\left(d_{l} / L\right)$ the shelf slope. Consequently the critical parameter governing amplification is the value of the quantity $\left(\mathrm{d}_{l} / \mathrm{gT}^{2} \mathrm{~s}^{2}\right)$ or simply $\left(d_{1} / T^{2}\right) / s^{2}$ and the amplification $\alpha$ at the shore may be written as

$$
\alpha=H_{r} / H=f\left[\left(d_{l} / T^{2}\right) / s^{2}\right]
$$

where $\mathrm{H}_{r}$ is the wave height at the coastal boundary, $\mathrm{H}$ the wave height (assumed sinusoidal) at the shelf edge and $f$ symbolizes a function 7 he latter involves a zero-order Bessel function of the variable $\left(2 \mathrm{~K}^{1 / 2} \mathrm{~L}^{172}\right)$, which in turn, through Equation (33), involves the variable $\left(d_{l} / T^{2}\right) / s^{2}$.

Although Equation (34) is based strictly on linear, long-wave theory (cf. Lamb, 1932, §185), we may stretch a point and derive the amplification for a range of wave situations in which it is known that $n_{r} / H_{r}>0.5$ where $\eta_{r}$ is the crest height of the waves above still water at the shore. For example, it is known that for a solitary wave $n_{r} / H_{r}=1.0$ and that for an Airy, small-amplitude, sinusoidal wave $n_{r} / H_{r}=0.5$. A whole range of intermediate values is thus possible according to the prevailing relative depth $\left(\mathrm{d}_{I} / \mathrm{T}^{2}\right)$ and wave steepness $\left(\mathrm{H} / \mathrm{T}^{2}\right)$ of the waves at the shelf edge. If then we allow for this contingency by writing

$$
n_{r} / H_{r}=\gamma
$$

we have from Equations (34) and (35) 


$$
\frac{n_{r}}{H}=\gamma f\left[\left(d_{1} / T^{2}\right) / s^{2}\right]
$$

which expresses the runup $n_{r}$ in terms of the initial wave height $H$.

Values of $\gamma$ are available from various wave theories and are summarized in Figure 75, revised from Wilson, et al (1962), while the value of the function $f$ is given by

$$
f=I / J_{0}\left(2 K^{I / 2} L^{I / 2}\right)
$$

in which $J_{0}$ is the zero-order Bessel function of the variable $\left(2 K^{1 / 2} L^{1 / 2}\right)$. The relationship in Equation (36) has been calculated, and is plotted in Figure 76. Results all lie within the shaded band which exhibits the first, second and third modes of this form of shelf resonance. Because of friction (not allowed for in the simple theory), the cusps of Figure 76 could expect to be severely flattened, so that the runup, as a ratio of wave height at the toe of the slope, may perhaps seldom exceed a value of about 4 .

Some data of Granthem (1953), the only experimental work on moderately long wave runup that provides the information needed for plotting in Figure 76 , are included in the figure. They show some degree of accord without, however, exhibiting any evidence of runup becoming especially enhanced at the predicted critical mode values of $\left(d / T^{2}\right) / s^{2}$. There is, however, an escalation of runup values in the range of $\left(d / T^{2}\right) / s^{2}$ between 0.02 and 2.0 , in keeping with the prediction, if the damping at the critical modes were severe enough to erase the cusps entirely, as well as the higher mode effects shown in Figure 76.

The subject of runup of waves on coasts is in itself so involved, and the literature so extensive, that we hesitate to penetrate more deeply into the question at this time. Appendix C gives merely a brief review of some aspects of the problem. We may use Figure 76 to answer a general question as to what runup would be caused by waves of the Alaskan tsunami approaching normally on a uniformly sloping Continental Shelf. Taking $T \simeq 2$ hours, $d_{1}=600$ feet and $s=0.01$, we find $\left(d_{1} / T^{2}\right) / s^{2}=0.12$ feet $/$ second $2^{2}$ and from Figure $76, \eta_{r} / H \simeq 0.6$ to 1.2 . On a flatter slope $s=1 / 200,\left(\mathrm{~d}_{1} / \mathrm{T}^{2}\right) / \mathrm{s}^{2} \simeq 0.5 \mathrm{feet} / \mathrm{second}^{2}$ and the range of runup lies between $\eta_{r} / H \simeq 1.1$ to 2.2. Adopting $n_{r} / H_{r} \simeq 0.5$ and a value of $\eta_{r} / H \simeq 0.75$ we obtain $H_{r} / H=1.5$, the value used in Table III.

\section{Sub-Harmonic Effects of the Alaskan Tsunami}

The subjective analyses of Figures 43 to 66 have disclosed at some places low-amplitude waves of much longer period than the main tsunami waves. In Table III, these are listed as secondary waves, because it is not known whether they represent a wave system that propagated from the source, or whether they are locally generated through some nonlinear mechanism of the coastal boundary.

The effects are particularly strong at some of the most distant places like Lyttelton, New Zealand (Figure 60c), Poronaysk, Sakhalin 


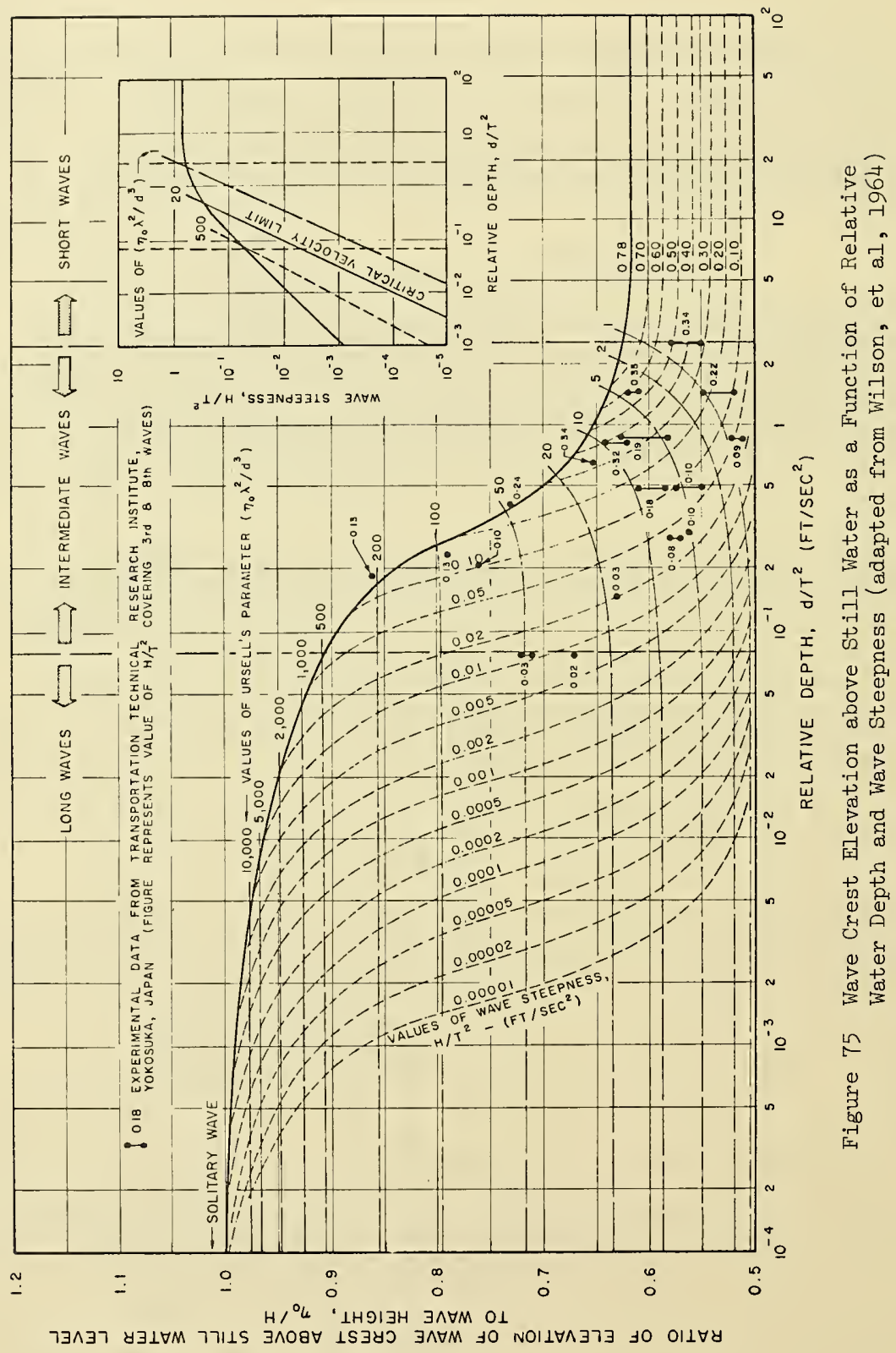




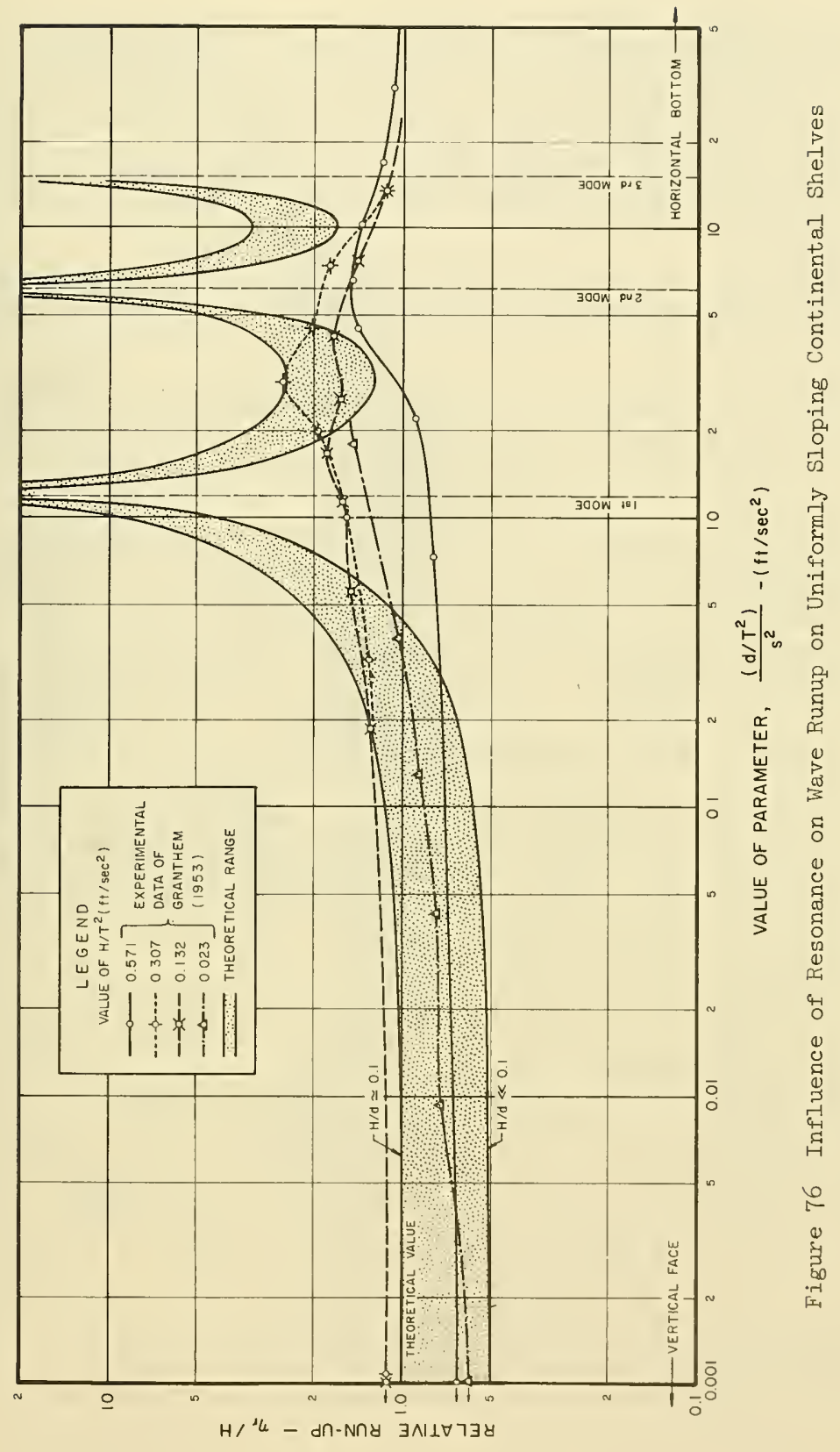


Island (Figure 63d), Yuzhno, Kuril Islands (Figure 64c) and Hanasaki, Japan (Figure 65c). At Lyttleton there is an amplitude increase of these long waves toward the end of the beat suggesting that energy was being accumulated at the period of about 2.75 hours. Since the natural period of oscillation of the inlet of Port Lyttelton is about 3.35 hours, it is possible that sufficient energy was being stored by the incoming waves at or near this frequency to produce resonance in the fundamental mode of the inlet.

At Hanasaki, Japan, the effect is similar (Figure 65c) but details of Hanasaki Bay on Kokkaido Island, Japan, are unknown. Similar responses are found also at Yuzhno, Kurilsk (Figure 64c).

At Poronaysk, Sakhalin Island, the long waves of 4.9 hours period are dominant from the moment of arrival of the tsunami and show all the features of a dispersive, evanescent wave system. At Hilo, Hawaii, a decaying, strongly dispersive long-wave system of initial period $\mathrm{T} \simeq 3.5$ hours is apparent in the record (Figure 59c).

This feature occurs too frequently in the subjective analyses to be considered an error of interpretation. We believe that these long-wave systems are real and may have relation to the horizontal thrust of the Alaskan landmass in the earthquake region. They were obviously of very low amplitude and therefore required some degree of resonance to be recorded at remote stations. The possibility that the waves are a nonlinear subharmonic derivation from the main tsunami cannot be overlooked.

\section{Heights of Runup Along the North American Coast}

Here we use the final column of figures in Table B-l of Appendix $B$ to define the maximum height of the wave derived either as a rise or fall above tide level of the time to give an idea of runup along the North American seaboard. Table B-2 gives some particulars of effects recorded at remote stations outside the Pacific Theater. The locations of the stations for both these tables are shown in Figure B-l.

The maximum recorded wave heights along the U. S. and Canadian coastline from Alaska to Vancouver Island are shown in greater detail in Figure 77. Figure 78 provides added detail in the Vancouver Island region. The data are derived from Spaeth and Berkman (1967), Wigen and White (1964) and from White (1966). In general, Figures 77 and 78 show that the tsunami penetrated deeply into the farthest reaches of the fjord-like coastline, even to Pitt Lake, about 135 nautical miles from the mouth of the Juan de Fuca Strait at the south end of Vancouver Island. On the seaward side of Vancouver Island wave height 9 registered from 8 to 17 feet according to location. Port Alberni, along with Shields Bay in Queen Charlotte Islands, suffered the highest waves.

Figure 77 shows the approximate positions on the hour reached by the tsunami front and the approximate positions on the hour of the crest of the spring tide sweeping in toward the Gulf of Alaska. The tsunami front reached the shore between Prince Rupert and Vancouver 


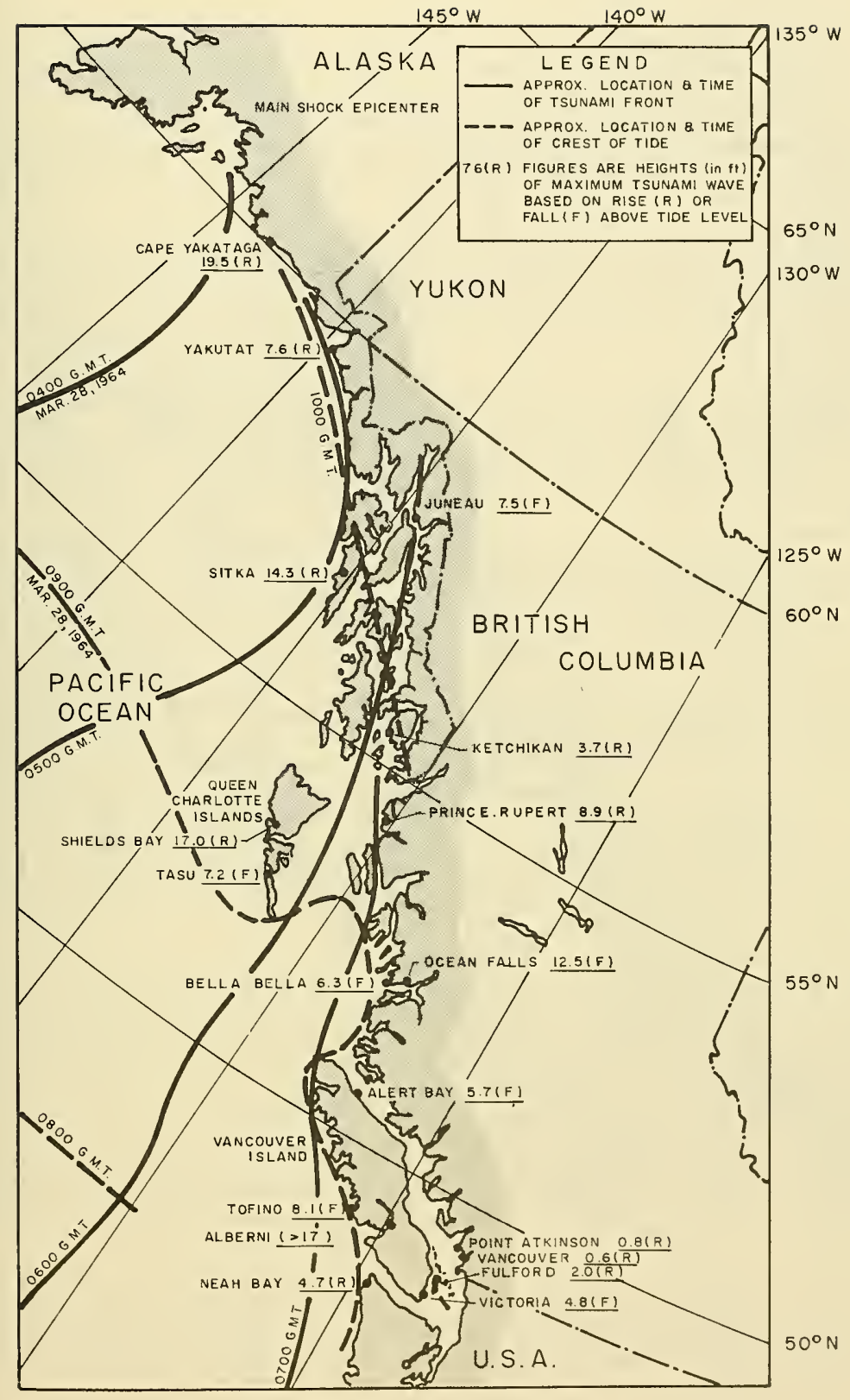

Figure 77 Maximum Heights of Tsunami Waves Recorded at Tide Stations along the North American Seaboard from Alaska to Vancouver Island. 


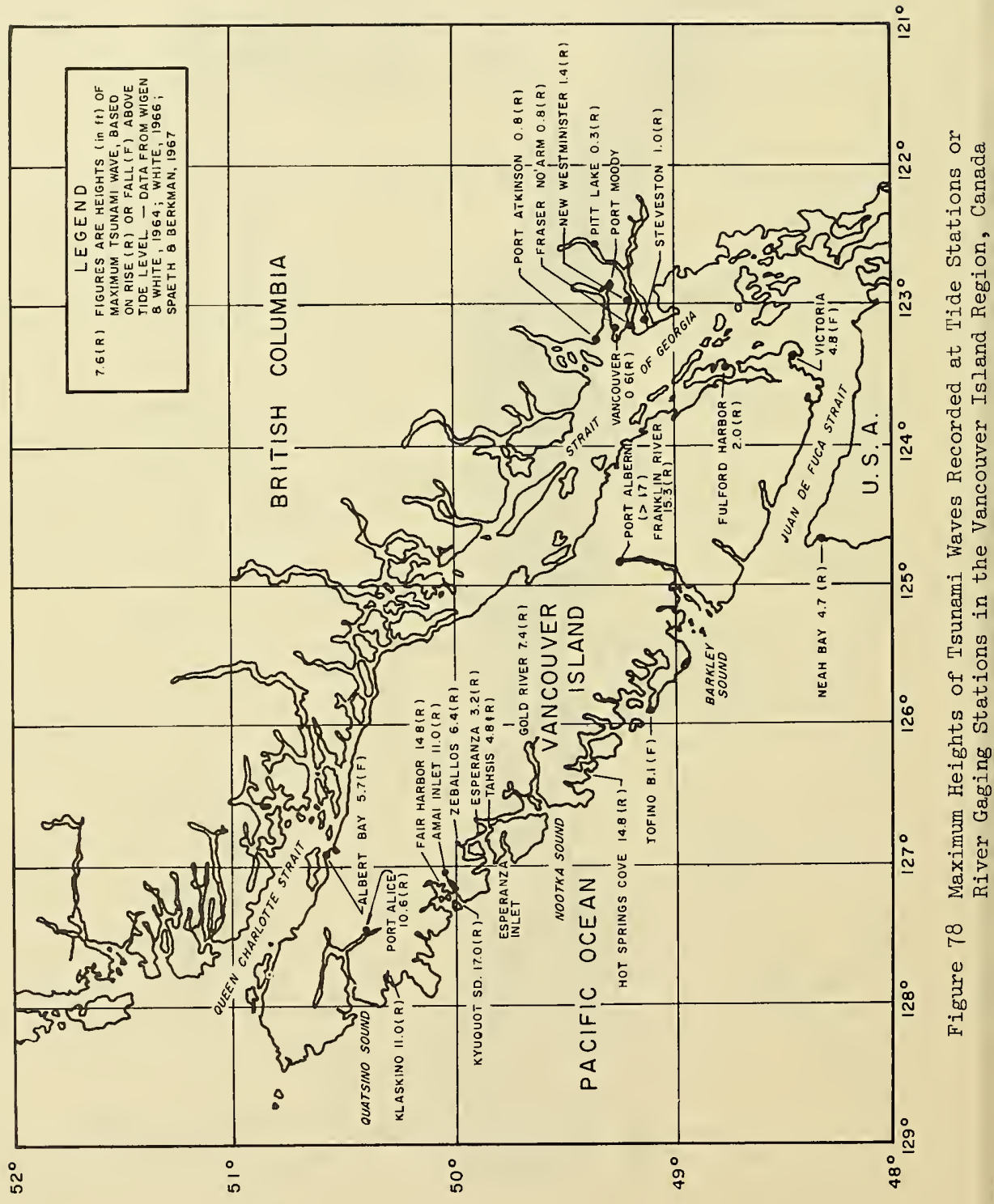


Island at about 07 hours GMT of March 28, 1964. The crest of the high tide reached the same area two hours later at 09 hours GMT. Since the tsunami period may be considered nominally 2 hours, the first tsunami crest would occupy the frontal position ( 07 hours) at about 08 GMT, or very near the peak of the high astronomical tide, and the first few high waves would effectively ride the tide wave and cause the high runup in the area.

Farther south below the Canada-U.S.A. border the tsunami, as also the tide wave, rolled in practically normal to the coastline (Figure 79). Here the concurrence of high seismic sea waves with high spring tide again caused runup of serious proportions.

The tide wave and the tsunami ran up the Columbia River with the tsunami front preceding the tide crest by about 1.5 hours. The vast size of the tide wave ensured that the leading waves of the tsunami rode on the top of the tide wave, and propagated upriver in this virtually interlocked fashion.

The effects, recorded at tide-gage stations spaced along the 90 nautical miles of estuary, make possible the derivation of important conclusions regarding the tsunami. Three samples of the estuary marigrams (Figure 80 ) reveal the development of the tide wave as an unsymmetrical wave effectively made up of harmonics of the tide riding the fundamental wave as already noted (cf. Section II-7). Beaver Tide Gage in particular, shows that, other than the tsunami waves riding the tide crest, the intermediate waves have lost their identity and hardly register at the low tide, though later waves are again found on the succeeding high tide. This absence of tsunami waves (other than the first three) on the rear slope of the tide wave would have been promoted by the tsunami beat interference effect evident in the fourth, fifth and sixth waves of Figure 48d for Victoria, Canada, even if frictional damping of the waves at low tide were not the major cause.

The data from the Columbia River tide gages permit us to derive some quantitative information about the tsunami and the tide propagation up river. Figure 81 a shows a space-time plot of the progression of the first, second and third tsunami crests on the first tide crest and of two other tsunami crests riding the subsequent tide crest. At the mouth the leading tsunami waves show a period $\mathrm{T} \simeq 1.75$ hours, in good agreement with Table III, but the period changes and increases with distance because the wave velocities differ, in accordance with Equation (4), with the depth of water provided by the tide wave and the river water. By the time the third wave loses identity at about 70 nautical miles from the mouth, its effective period is 2.2 hours.

In the first 50 nautical miles the tide crests advance more rapidy than the tsunami, but then slow rapidly, presumably as a result of shallow water and increasing tidal friction. The tsunami crests, less susceptible to friction, then outrun and advance through the tide crest. The reason for the initially greater speed of the tide may be surmised 


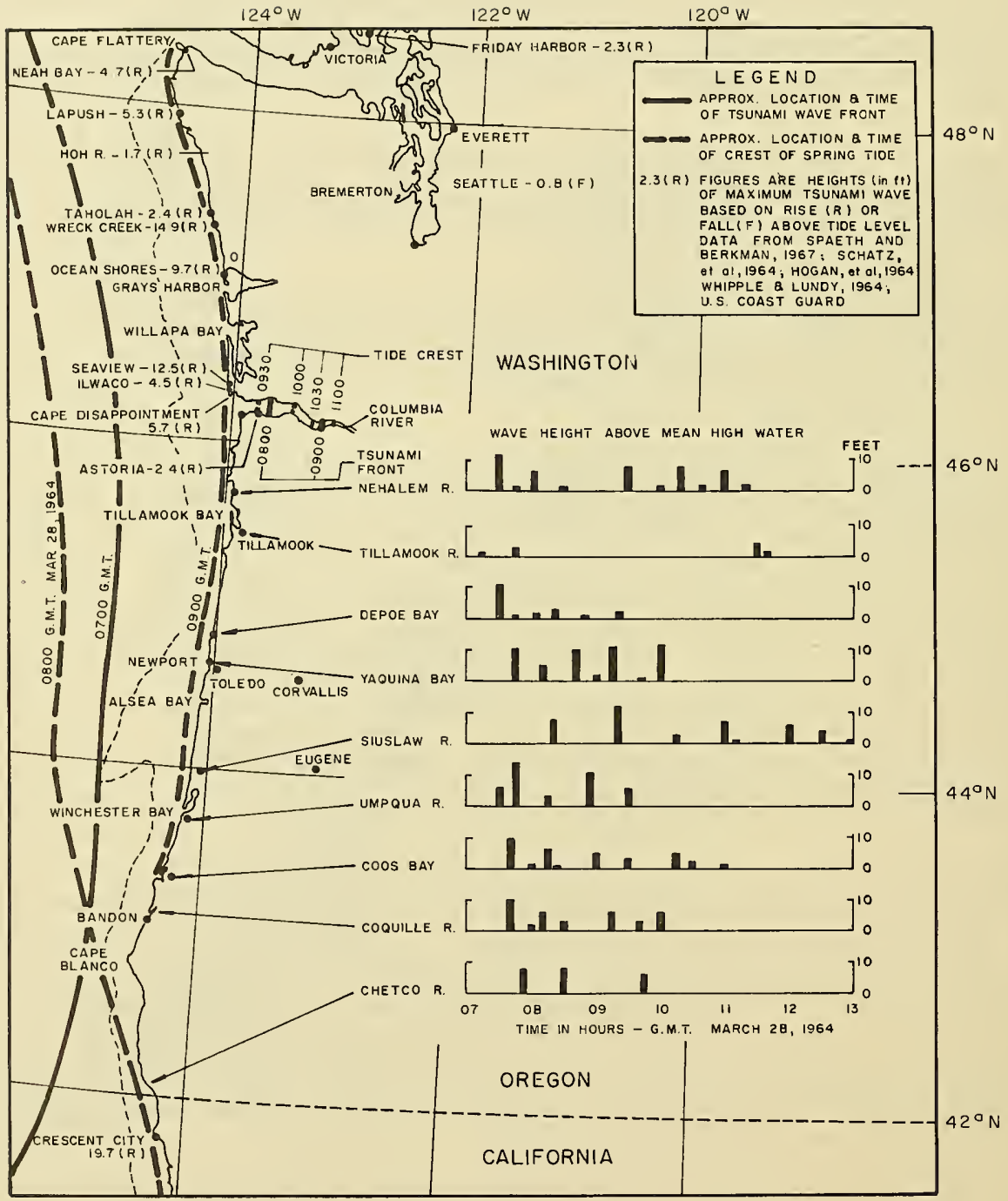

Figure 79 Maximum Heights of Tsunami Waves Recorded at Tide Stations or by Observation along the Washington-Oregon Coastline 
(tb) $-(038 y 3 \pm N I)$

HId 30 \& $3 \perp \forall M$ N $\forall \exists W$

응ㅇㅇㅇㅇㅇㅇㅇㅇㅇㅇ

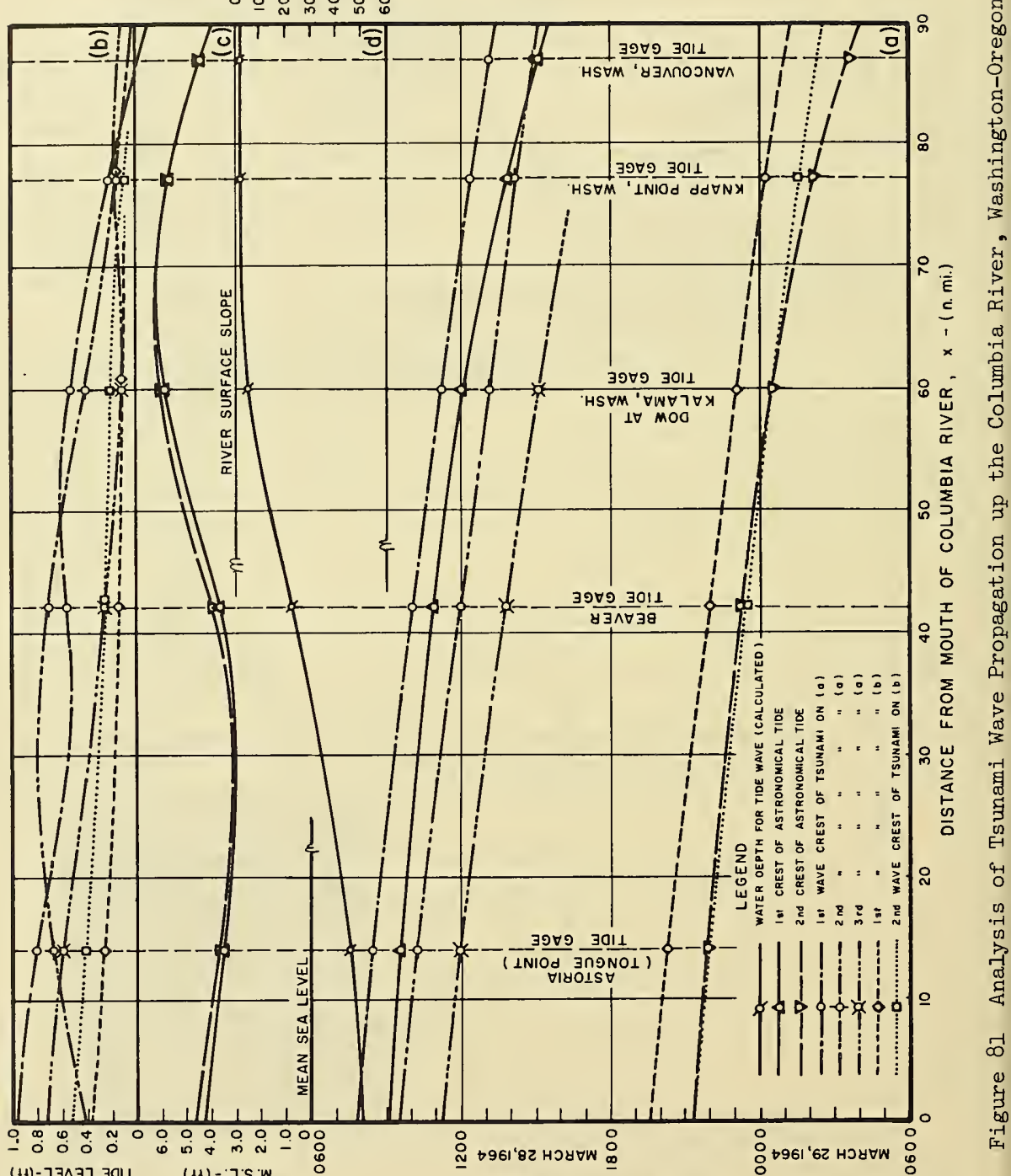

(4) $-7 \exists \wedge \exists 73011$

(tt) - . 7 's $w$ $(\operatorname{sino4})-(1 \mathrm{~N} 9) \quad \exists$ WI 
as being related to the effect of tide height. Lamb (1932) has shown that finite-amplitude long waves, whose elevation above stillwater of depth $d$ is $n$, will propagate at the velocity

$$
c=\sqrt{g d}\left[3(1+n / d)^{1 / 2}-2\right]
$$

which is in excess of Equation (4) when $n$ is positive. The steepening of the tide wave front is inherently related to the fact that the crest speed ( $n$ positive) exceeds the trough speed ( $n$ negative).

The essentially nondispersive nature of the tsunami is verified by the fact that the period between the waves riding the second tide crest is also found to be about 1.75 hours near the mouth of the Columbia River (the same as the leading waves). This period decreases to 1.4 hours at the Vancouver tide gage ( 87 nautical miles from the river mouth), because the second tsunami crest, having advanced through the tide crest, is favored by a greater depth of water and therefore a faster speed relative to the antecedent wave.

Figures $81 \mathrm{~b}$ and $\mathrm{c}$ show the crest elevations above tide level of all five tsunami waves and the tide crest elevations above MSL. At the mouth of the Columbia River, Figure 81 a shows that the leading tsunami crest is highest and the third crest higher than the second. The beat pattern of the waves for Victoria, Canada, shows this same characteristic (Figure 48d). The relative prominence of the first and second waves, however, reverses three times as they progress up the Columbia River. The crossing points of reversal occur at about 19, 49 and 79 nautical miles from the mouth, or intervals of exactly 30 nautical miles. The significance of this will be discussed after commenting on the behavior of the tide waves.

The elevation of the tide crest first declines and then enhances as the tide runs upriver (Figure 8lc). A pseudo-resonance effect seems to cause this, and merits further attention. From Figure 80 we surmise that the hydraulic gradient for the Columbia River would place normal river level about 3.5 feet above MSL at 90 nautical miles from the mouth. Tide elevations relative to normal river level are then obtained from Figure 81 c to provide values of $n$ for use in Equation (38) to calculate the mean river depth d. From Figure 81 a the gradients of the space-time propagation line for the first tide crest yield values of velocity $c$, so that Equation (38) can be solved for d. Results are shown in Figure 8ld and indicate that at 65 nautical miles from the mouth, the mean depth (from the tide point of view) is small. The depth profile from the mouth, in fact, is closely parabolic over a length $L \simeq 65$ nautical miles, with a mouth depth of $d_{1} \simeq 50$ feet. The Columbia River, then, acts as a closed-end canal with the closure about 65 nautical miles upriver.

We now use Equation ( 7 ), as for Port Alberni, to calculate the fundamental period of oscillation for this system. The result is startling:

$$
\mathrm{T}_{1}=12.14 \text { hours }
$$


in almost exact agreement with the semi-diurnal astronomical tide period. The peak tidal oscillation at mileage 65 (Figure 8lc) is immediately explained. That it declines beyond this, is the result of the leak effect to the higher river reaches. The low tide crest height, found at mileage 30, effectively defines a quasi-node.

We return to a consideration of the fluctuations of height of the two leading waves of the tsunami. Figure 8la shows the tide wave takes 3.6 hours to propagate from the river mouth to mileage 65 . Also, the third mode of oscillation for the river, as a closed-end open-mouth canal of parabolic bed (cf. Wilson, 1966), is

$$
\mathrm{T}_{3}=0.259 \mathrm{~T}_{1}=3.64 \text { hours }
$$

It follows then that a tidal induced oscillation of this period could have positive antinodes at the mouth and at mileage 65 (Figure $81 \mathrm{~b}$ ), and a negative antinode at about mileage 33 . Just 1.8 hours later the signs of the antinodes could reverse. Since the leading waves are about 1.8 hours apart in time, they would become enhanced or reduced in height by this canal oscillation, accordingly as they rode the positive or the negative antinode. The nodes of the canal's third mode of oscillation are thus revealed by the crossing points of the crest height lines for the two leading waves in Figure 81b. The usual requirement that a node for an open-mouth basin oscillation be located at the mouth is waived in this case since the leakage effect to the upper river reaches beyond mileage 65.

A similar effect may actually be present with the tsunami waves riding the second tide crest but the effects are obviously severely damped. There is some justification for believing that the 3.6-hour Columbia River oscillation is a direct subharmonic effect of the tsunami itself.

South of the Columbia River along the Oregon coast no well-established pattern of wave arrivals can be determined from the data of Schatz et al (1964), shown in Figure 79. The approximate tsunami front and tide crest positions and times show that the leading waves of the tsunami would have occurred everywhere along this shore on the top of the high spring tide. Runup 10 to 15 feet above the high tide line (Figure 79) was confirmed in August 1966 by one of the authors (Wilson), who observed long, debris lines on this entire stretch of coast at about this level.

Other data in Figure 79 were obtained from the Corps of Engineers Office, Seattle (Hogan et al, 1964; Whipple and Lundy, 1964).

The north-central portion of the California coastline is shown in Figure 82. The data here are from the extensive survey of the Corps of Engineers, San Francisco (Magoon, 1965), and indicate that runup along this part (south of Crescent City) was generally much less than farther north. Magoon's data are all referred to mean lower low water (MLLW) datum. To make them camparative with data given in Figures 77 to 79 , 
the tide level prevailing at the time of the highest wave or waves of the tsunami must be subtracted. Figure 82 suggests that south of Crescent City and Fort Bragg the tsunami waves arrived on a falling tide 1 to 2 or more hours after high tide, which caused a natural lessening of the runup potential. The approximate tidal ranges from Monterey to Crescent City are shown on the cotidal lines in Figure 82. Supporting data for Figure 82 (from Magoon, 1965) are included in Table B-5 of Appendix B.

The behavior of San Francisco Bay has already been discussed in Section II-6. Particulars of the attenuation of the tsunami waves in the bay in relation to unit amplitude at the Golden Gate (cf. Magoon, 1965) are in the inset to Figure 82.

In Monterey Bay, about 60 nautical miles south of San Francisco, the tsunami produced widely different effects at the north and south extremities at Santa Cruz and Monterey. Santa Cruz experienced a runup almost twice that at Monterey despite the apparently protected setting of Santa Cruz in relation to the approach direction of the tsunami. The reason may perhaps be ascribed to the deep and narrow canyon that virtually bisects the bay (Figure 83) and favors refraction of wave energy entering the bay more toward the north than toward the south (Wilson, et al, 1965).

Monterey Bay provides another case for assessing the effects of the tsunami in stimulating local resonances. The peculiar planform of the bay andits bathymetry (Figure 83) discounting the canyon, is well approximated by a circular quadrant basin with a paraboloidal bed (or even a conical bottom). Using this geometrical analogy, the solutions for applicable modes of oscillation of the bay can be deduced from Lamb (1932) (cf. Wilson, et al, 1965, Wilson, 1966) and are illustrated in the sequence of Figure 84, which applies to a quadrant basin of 240 feet uniform depth and 100,000 -foot radius (Figure 83 ). Figure $84 d$ may be considered to approximate the fundamental-mode oscillation for the Continental Shelf and bay with a node at the edge of the Continental Shelf. However, to a good approximation also, Figure 84 a could be considered fundamental to the bay; and its Continental shelf, to the edge of the deep canyon. The two cases yield widely different periods, the first about 65 minutes, the second about 31 minutes. The other modes of oscillation in Figure 84 involve nodal circles or nodal diameters or combinations of both. All of the nodes might be considered realizable as possible ways in which Monterey Bay could respond to excitation at its lowest frequencies.

That the bay did appear to oscillate in some of these modes is evident from Table IV, which compares observational deductions with theory. This table includes spectral analyses of the tsunami records at three locations in Monterey Harbor (Marine Advisers, 1964). In the lowest modes these show noticeable peaks at 33.3 and 16.7 minutes. The resolution, however, was poor at low frequencies and failed to show longer period effects. For comparison in Table IV, results are drawn 


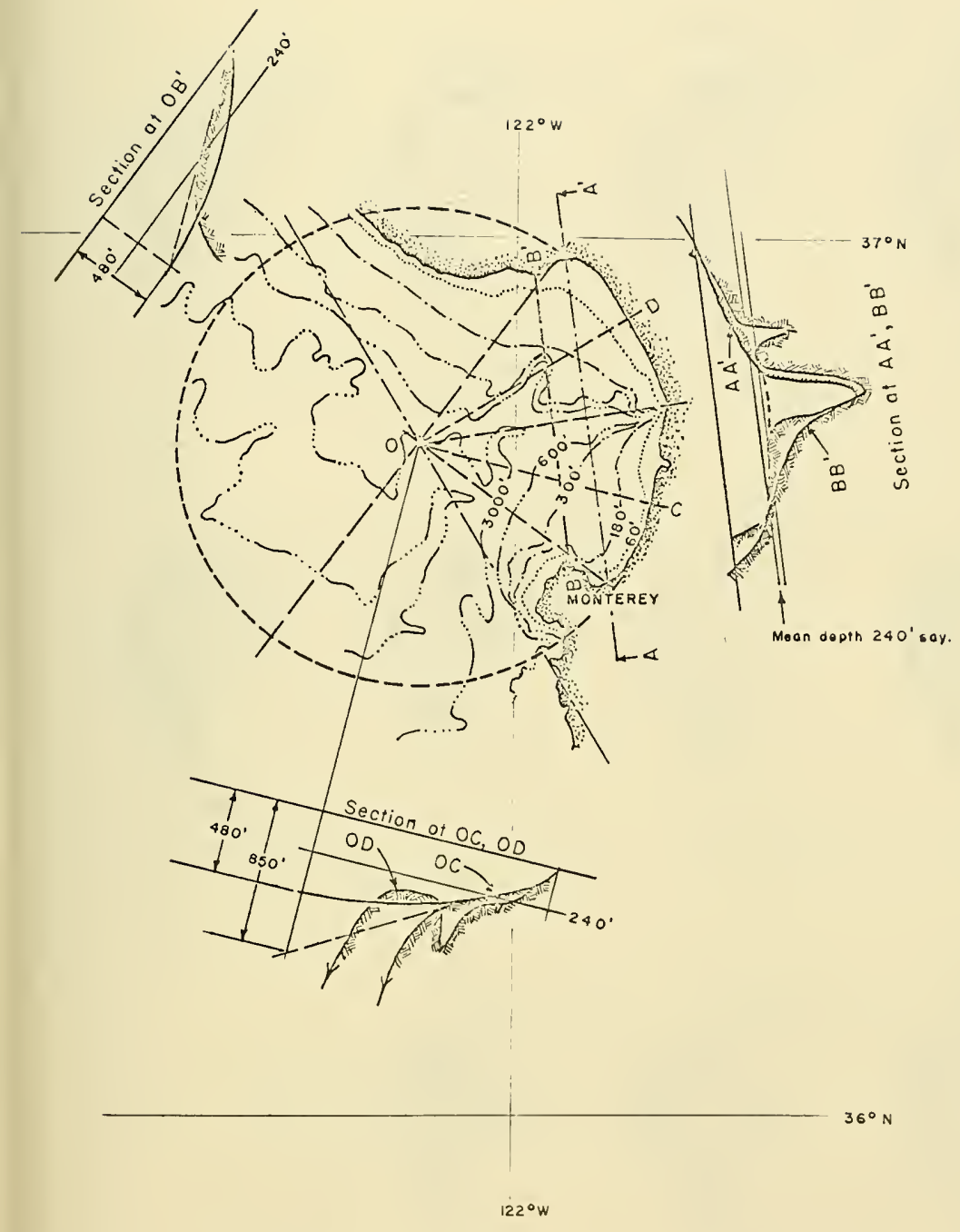

Figure 83 Geometrical Analogy of Monterey Bay to the Quadrant of a Circular Basin (from Wilson, et al, 1965) 


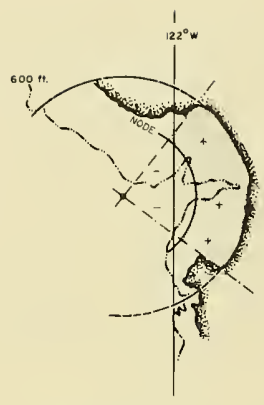

(a) Symmetrucal Mode $(0,1)$ $T_{0,1}=31.1$ mins. $(x / R=0.628)$

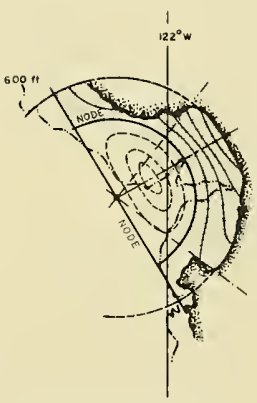

C) Unsymmetrical Mode $(1,1)$

$T_{1,1}=22.3$ mins. $(5 / R=0,66$

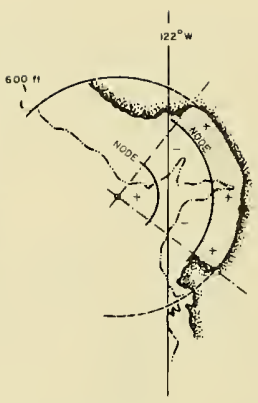

(b) Symmetrical Mode $(0,2)$

$T_{0,2}=17.0$ mins.

(r) $/ R=0.343,0.787$ )

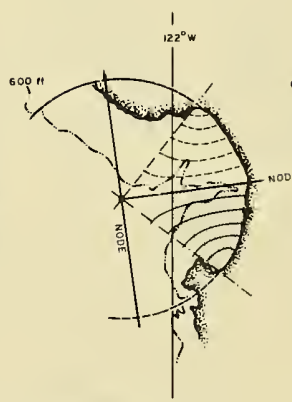

(f) Unsymmetrical Mode $(2,0)$

$\mathrm{T}_{2,0}=38,4$ mins

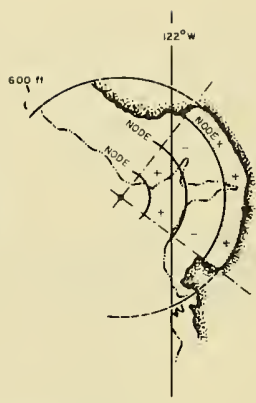

(c) Symmetrical Mode $(0,3)$

$\mathrm{T}_{0,3}=11.7 \mathrm{mins}$

$(\mathbf{r} / \mathbf{R}=0.236,0.542,0.850)$

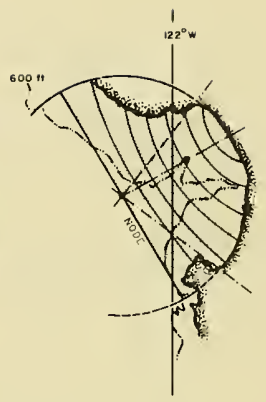

(d) Unsymmetrical Mode $(1,0)$

$T_{1,0}=64.7$ mins.

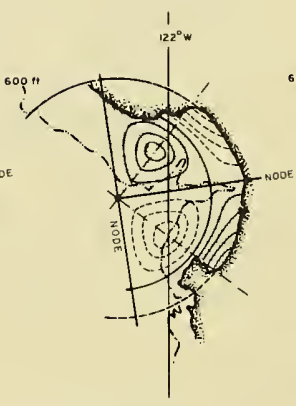

(g) Unsymmetrical Mode $(2,1)$ $T_{2,1}=17.8$ mins $(r / R=0.78$ )

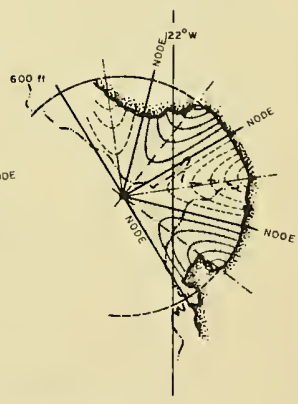

(h) Unsymmetrical Mode $(4,0)$ $\mathrm{T}_{4,0}=22.5 \mathrm{mins}$

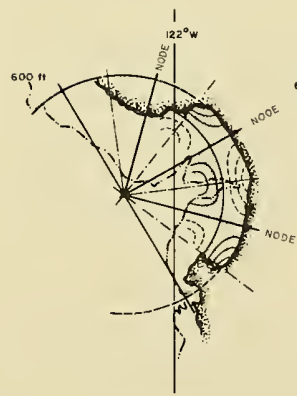

(i) Unsymmetrical Mode $\{4,1\}$ $\mathrm{T}_{4,1}=12.8 \mathrm{mins}$. $(\mathbf{r} / \mathrm{R}=0.83)$

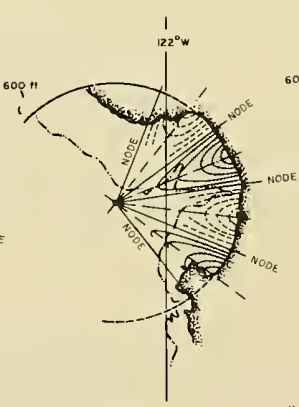

(j) Unsymmetrical Made $(6,0)$ $T_{6,0}=15.9$ mins.

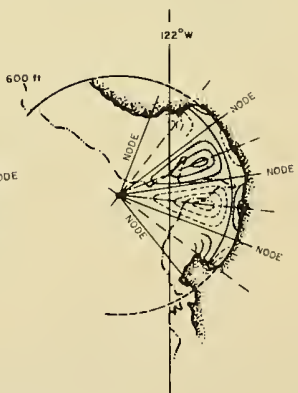

(k) Unsymmetrical Mode (6, 1$)$

$T_{b, 1}=10.1$ mins.

$(r / R=0.93)$

Figure 84 Possible Modes of Oscillation for Monterey Bay as a Circular Quadrant Basin of Uniform Depth (from Wilson, et al, 1965) 


\begin{tabular}{|c|c|c|c|c|c|c|c|c|}
\hline \multirow{15}{*}{ 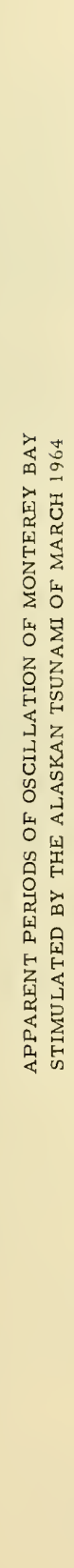 } & 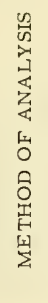 & 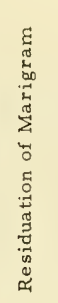 & 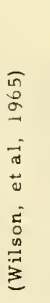 & 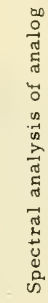 & 胫 & 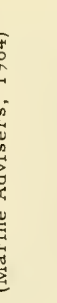 & 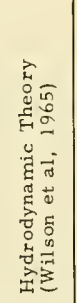 & 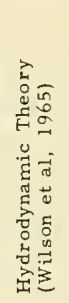 \\
\hline & & & & $\stackrel{\circ}{\text { i }}$ & $\stackrel{m}{i}$ & $\vec{i}$ & & \\
\hline & & & & $\stackrel{+}{\text { N }}$ & $\stackrel{\text { in }}{\text { in }}$ & $\stackrel{+}{a}$ & & \\
\hline & $\dot{0}$ & & & $\stackrel{N}{m}$ & $\dot{m}$ & $\ddot{i n}$ & & \\
\hline & $\begin{array}{l}\stackrel{5}{\circ} \\
\dot{0} \\
\dot{5}\end{array}$ & & & $\stackrel{m}{\dot{r}}$ & $\ddot{4}$ & $\stackrel{m}{\dot{m}}$ & & \\
\hline & $\begin{array}{l}z \\
1 \\
0\end{array}$ & in & in & $\begin{array}{l}\infty \\
\text { in }\end{array}$ & in. & $\overrightarrow{0}$ & & \\
\hline & 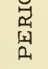 & $\begin{array}{l}\infty \\
\infty\end{array}$ & m. & $\stackrel{m}{\infty}$ & $\stackrel{m}{\infty}$ & & & \\
\hline & 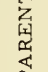 & $\begin{array}{l}0 \\
\dot{n}\end{array}$ & 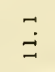 & & & in & 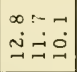 & $\begin{array}{l}0 \sim N \\
-\sim \sim N \\
-\sim \sim N\end{array}$ \\
\hline & $\begin{array}{l}\text { 岕 } \\
\end{array}$ & & $\stackrel{m}{\check{m}}$ & & 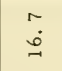 & $\ddot{\sim}$ & 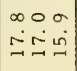 & $\begin{array}{l}\infty N \\
\infty \\
\infty \\
\sim\end{array}$ \\
\hline & 息 & $\begin{array}{l}0 \\
\text { N }\end{array}$ & $\ddot{g}$ & & & & 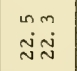 & $\begin{array}{l}m \sim n \\
\dot{N} N \\
\text { N }\end{array}$ \\
\hline & $\begin{array}{l}\text { a } \\
\text { 娄 } \\
\omega\end{array}$ & $\begin{array}{l}m \\
\dot{m}\end{array}$ & $\begin{array}{l}\sim m \\
\dot{m} \sim \tilde{m}\end{array}$ & $\dot{m}$ & $\dot{m}$ & $\dot{m}$ & $\stackrel{\dot{m}}{\dot{m} \bar{m}}$ & $\underset{\sim}{\sim} \stackrel{\infty}{\sim}$ \\
\hline & & ఠ̊ & $\stackrel{8}{0}$ & $c-$ & $c$ & $\sigma$ & تु & $\begin{array}{l}\dot{0} \\
\dot{\infty} \\
\dot{n}\end{array}$ \\
\hline & 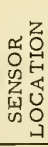 & 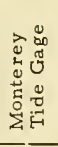 & 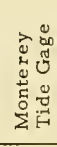 & 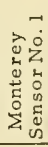 & 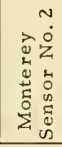 & 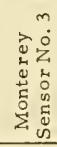 & & \\
\hline & 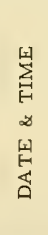 & 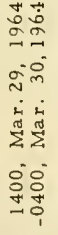 & 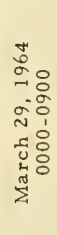 & 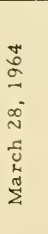 & & & 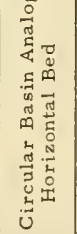 & 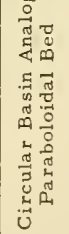 \\
\hline & & & NOI & $\Lambda$ 거 & & & XYO & H.L.L \\
\hline
\end{tabular}


from the residuation analyses made by Wilson, et al (1965) for a part of the Monterey tide gage marigram, scribed long after the arrival of the first waves of the tsunami. These suggest that more of the lower modes of oscillation were excited at that stage and that the systems denoted by Figures 84 a and $d$, in particular, were probably operative. It seems reasonable to conclude that the tsunami excited the circularnode shelf-oscillation (Figure 84a) immediately on its arrival, probably through the stimulus of its third harmonic, as seemed to be the case at Crescent City.

Runup of the tsunami along the California coast south of Monterey appears undocumented. Figure 85, from Spaeth and Berkman (1967), however, shows that the tsunami, although drawing powerful response from such places as Santa Monica, was now arriving on the low spring tide and therefore failed to reach higher than the normal range of tide.

\section{Heights of Runup Along the Hawaiian Islands}

Information about the Hawaiian Islands has been furnished by H. G. Loomis (1967) of the Environmental Science Services Administration, Honolulu, Hawaii, and is incorporated with minor change in the following.

The tsunami caused no loss of life and no serious structural damage in the Hawaiian Islands. The highest water levels reported were generally about 10 feet above MLLW on the northern shores of Maui and Oahu and in Hilo Bay. High water marks of 15 feet and 16 feet were observed at isolated places on the northern shore of Oahu. The highest water level measured at Kahului, Maui, was 12 feet; on Kauai, 6 feet. There was little intrusion of water beyond the usual limits of high water and occasional high seas at these places. In Hilo, the floors of several restaurants and houses at the water's edge were flooded. The tsunamis of 1946, 1952, 1957, and 1960 had washed out vulnerable areas at Hilo and those parts most severely damaged in 1946 and 1960 had been mostly cleared of buildings by March 1964. The highest wave of 1964 did not even come over the road into that part of town.

Teams from the University of Hawaii made runup measurements at most places on the islands of Hawaii, Maui, Oahu, and Kauai where waves left a measurable high water mark. As it happened, most of the staff of the Tsunami Research Program at the University were out of the State at the time of the tsunami and so the runup measurements were made two or three days later. The heights of the water marks were measured by surveyor's staff and hand level in some cases, and estimated in others. Some information was obtained by questioning people about their observations during and immediately after the tsunami. Runup heights are shown in Figure 86.

The highest water levels occurred, as expected, on the north sides of the islands. The C\&GS tide gage records of the tsunami (Spaeth and Berkman, 1965, 1967) show the following features. The record from Mokuoloe Island, Oahu (Figure 58a) appears to show a low-pass filter 

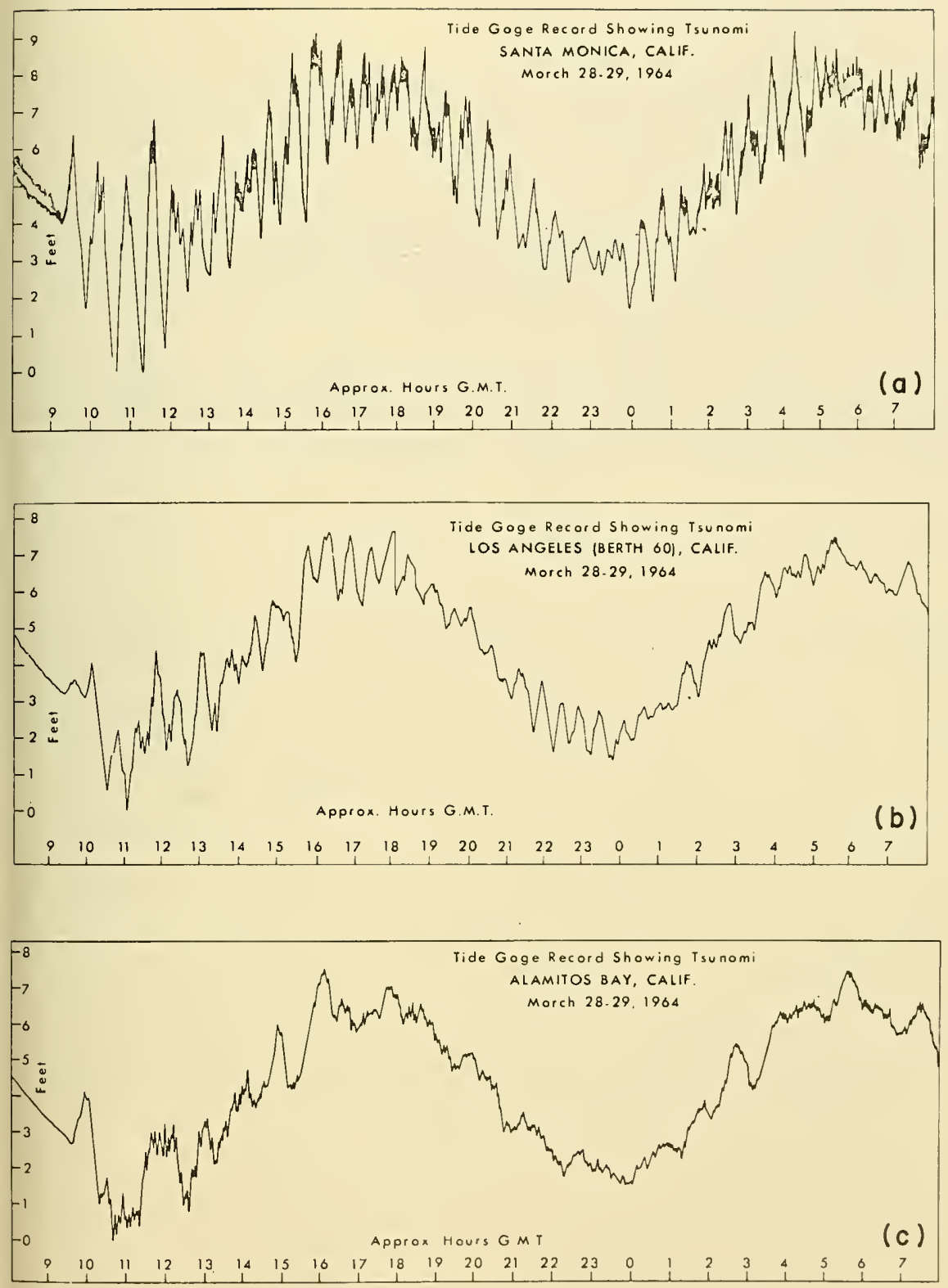

Figure 85 Marigrams Recording the Tsunami in Southern California Waters. (a) Santa Monica; (b) Los Angeles; (c) Alamitos Bay (from Spaeth \& Berkman, 1967) 
effect produced by the large shallow lagoon between the island and its encircling reef. This record shows five large waves with crests separated by about one hour and forty minutes as noted in Table III. The records from Hilo, Honolulu, and Kahului all begin with wave crests 23 minutes apart. At Kahului, this appears to be near to a natural resonance and three large crests occurred before an incoming crest and cycle of a natural mode of oscillation were out of phase and destructive interference occurred. The case for Hilo has already been discussed in Section II-6 and will not be further referred to here except to note that a greater interference effect at Hilo seems to account for the greater amplification at Kahului than at Hilo.

The tidal range in the Hawaiian Islands is normally less than 2 feet (cf. Figures 57b, 58b, 59b). The initial resonance at Hilo caused by the tsunami occurred on fairly low tide. Had it occurred on the high tide, maximum elevations would have been increased about 1.5 feet. 

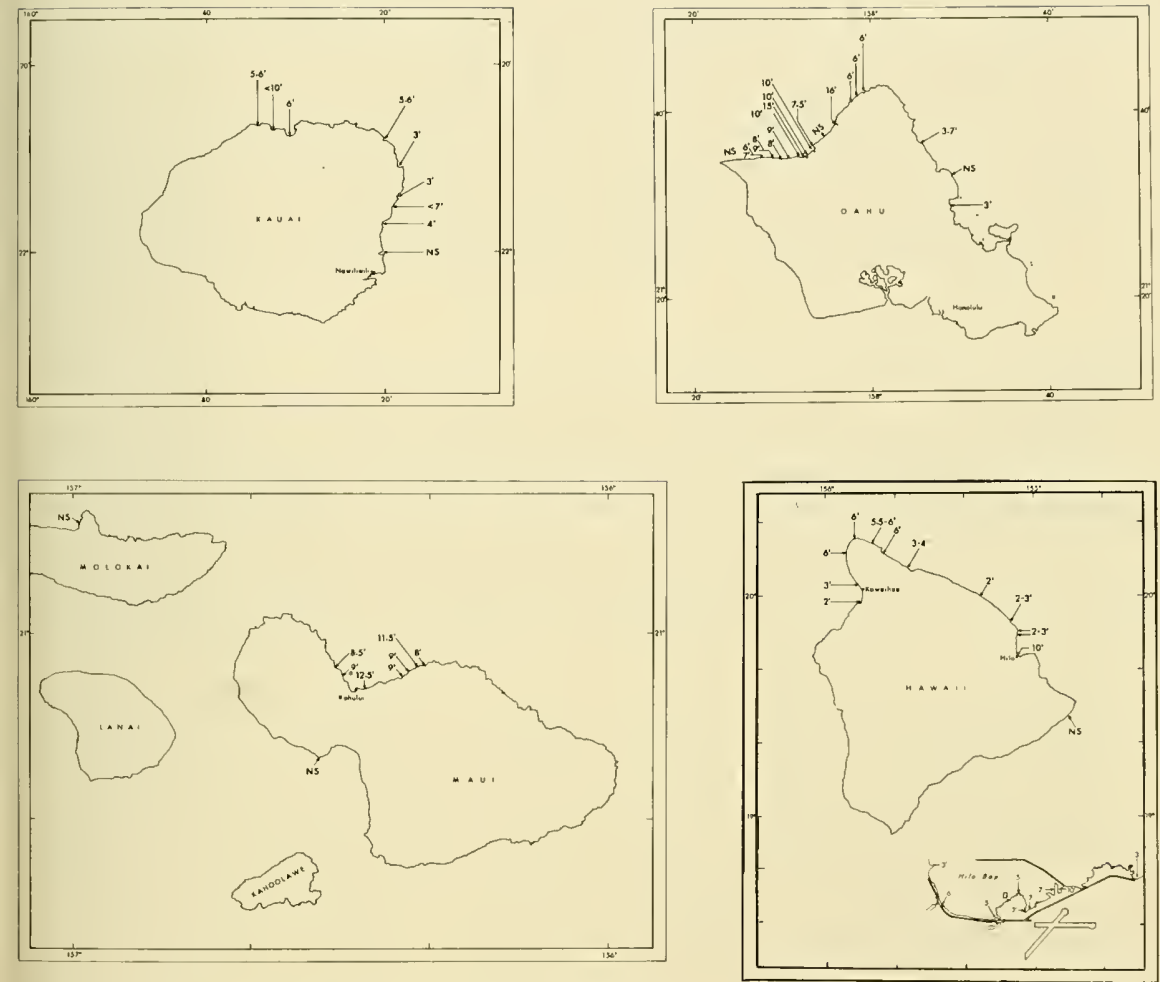

Figure 86 Maximum Runup Heights of Tsunami Waves (referred to MLLW) Measured along the Coasts of the Hawaiian Islands (from Loomis, 1967) 

Section IV. EFFECTS OF THE MAIN TSUNAMI AND OF

LOCAL SEISMIC SEA WAVES IN ALASKA

\section{Tsunami at Kodiak City, Kodiak}

We return to consider the effects of the tsunami on the coastal communities of Alaska commencing with Kodiak in particular. We have seen in Section III-2 that the Kodiak Island group was assailed by gigantic waves of about 2.5 hours period (Figure $38 \mathrm{c}$ ), whose first effect was negative, according to location, and resulted in a relative withdrawal of water in the initial stages of arrival. This withdrawal was not evident in some cases, particularly at Womens Bay, apparently because the land sank, and with it the sea. The extent of this subsidence has been given as 5.5 to 5.8 feet (Brown, 1964; Plafker and Kachadoorian, 1966; Kachadoorian and Plafker, 1967; Bryant, 1964). The U. S. Coast and Geodetic Survey and the U. S. Army Corps of Engineers have accepted 5.8 feet.

The general topography of the region suggests that the direct path of the tsunami toward Womens Bay and Kodiak would have been via Chiniak Bay, with the wave front initially parallel to the hinge line of zero vertical earth movement (Figures 87 and 88 ). In the absence of longwave refraction diagrams, it is difficult to determine exactly how such long waves would have reached Kodiak City. We may infer, however, that the deep channel running between Woody Island and Near Island (Figure $87 \mathrm{~b}$ ) would have favored the waves reaching Kodiak first from the northeast via the channel between Near Island and Kodiak City.

At Kodiak City, only about 5 nautical miles (in direct line) from Kodiak Naval Station (about 10 nautical miles in terms of wave distance via Womens Bay) (see Figure 87), there were conflicting opinions about how the water behaved immediately after the earthquake (Chance, 1968; Plafker and Kachadoorian, 1966; Kachadoorian and Plafker, 1967). Many claim that the first wave was a fast-rising tide noticeable at about 6:10 p.m., AST, or about $1 / 2$ hour after the earthquake, which would accord with what Lt. Barney had logged for Womens Bay (Figure 38). A few have contended that the first wave came much earlier - within 10 minutes of the earthquake. The most convincing evidence for this early wave comes from Jerry Tilley, a crewman on the shrimpboat Fortress, which was tied at the city dock, Kodiak (Figure 89). What happened, according to Tilley, reproduced from Kachadoorian and Plafker (1967), follows:

$5: 35$ or 5:36 p.m. - Shock felt aboard boat. Boil of reeking black water arose from beneath boat.

5:45 p.m. - Approximately 13-foot tide at dock when predicted tide should have been +0.5 feet. (The 13 -foot level is prequake elevation above MLLW. Since land level dropped 5.5 to 5.8 feet postquake elevation above MLLW would be 7.2 to 7.5 feet.)

5:50 p.m. - Cut loose from dock as water began to recede. 
$5: 50-6: 10$ p.m. - Water receding.

6:10 p.m. - Water at lowest level, approximately at 10 feet below MLLW. (Owing to land subsidence, this level would be 15.2 to 15.8 feet below MLLW.)

6:15 p.m. - Wave moved in from south as large swell.

$6: 15$ - $6: 20$ p.m. - Water rising at initial rate of about 15 feet in 5 seconds.

$6: 20$ p.m. - Wave crested.

The times are estimates, and comments in parentheses are partly ours and partly Kachadoorian's. Tilley's observations, plotted in Figure 90, are only qualitatively supported by the evidence of Chuck Powell and Commander Miller (Chance, 1968) and that of Fred Brechan (Norton and Haas, 1966).

Discussing Tilley's observation of a 13-foot tide at the city dock at $5: 45 \mathrm{p} . \mathrm{m}$. (effectively a 7.2 to 7.5 -foot tide in relation to water level before the quake), Kachadoorian and Plafker (1967) and Plafker and Kachadoorian (1966) speculate on the reality of the tide and its possible relation to a submarine slide or to seiching. The black boil of water reported by Tilley might suggest a submarine landslide, but this may reasonably be discounted on the basis that the water was too shallow and the sediments too thin to sustain so large and gentle an effect on the sea. The wave could be explained possibly as a phenomenon of seismic seiching, related to the tilting of the land by tectonic subsidence and regional horizontal displacement. The black boil could have resulted from the sudden upwelling of water containing mud and debris from the floor of St. Paul Harbor (Figure 89). The horizontal thrust of the land in the Kodiak Island region was probably almost southwest, in a direction parallel to the coast of St. Paul Harbor and thus, through the inertia of the water, would have favored a piling of water to the northeast. This explanation, however, encounters the difficulty that the water must inevitably have drained from Womens Bay, even though, inside of the Nyman Peninsula (Figure 88), it would also have been heaped to some extent toward the Naval Station. It is possible that these effects were selfcompensating in Womens Bay to the extent of causing only a minor drop of water level as shown in Figure 38.

Whether this first wave was real or not is of more than casual interest. If a reality, it would show that a great many people in that time of stress and anxiety were unaware of what was really happening around them. Mayor Peter Deveau left the cannery of King Crab, Inc. shortly after the earthquake in expectation of a tsunami. He travelled the road toward Kodiak, overlooking the Inner Anchorage and Boat Harbor (presumably Shelikoff Street or South Benson Avenue, Figure 89) (Norton and Haas (1966). That he failed to notice such an unmistakable sign of imminent seismic sea waves as the rapid draining of water from the boat harbor is particularly puzzling. 


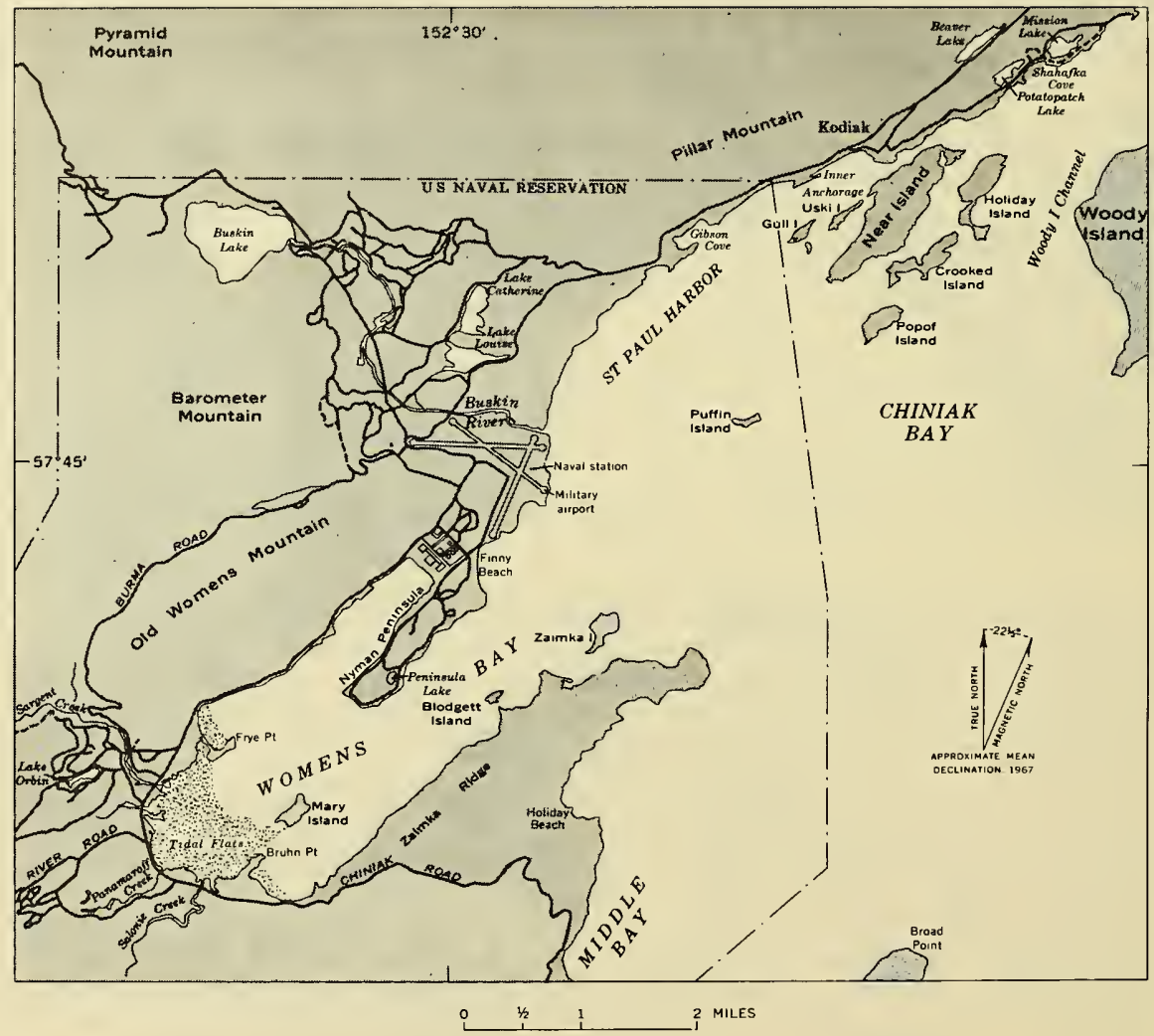

Figure 88 Location of the Kodiak Naval Station and the City of Kodiak (from Kachadoorian \& Plafker, 1967) 


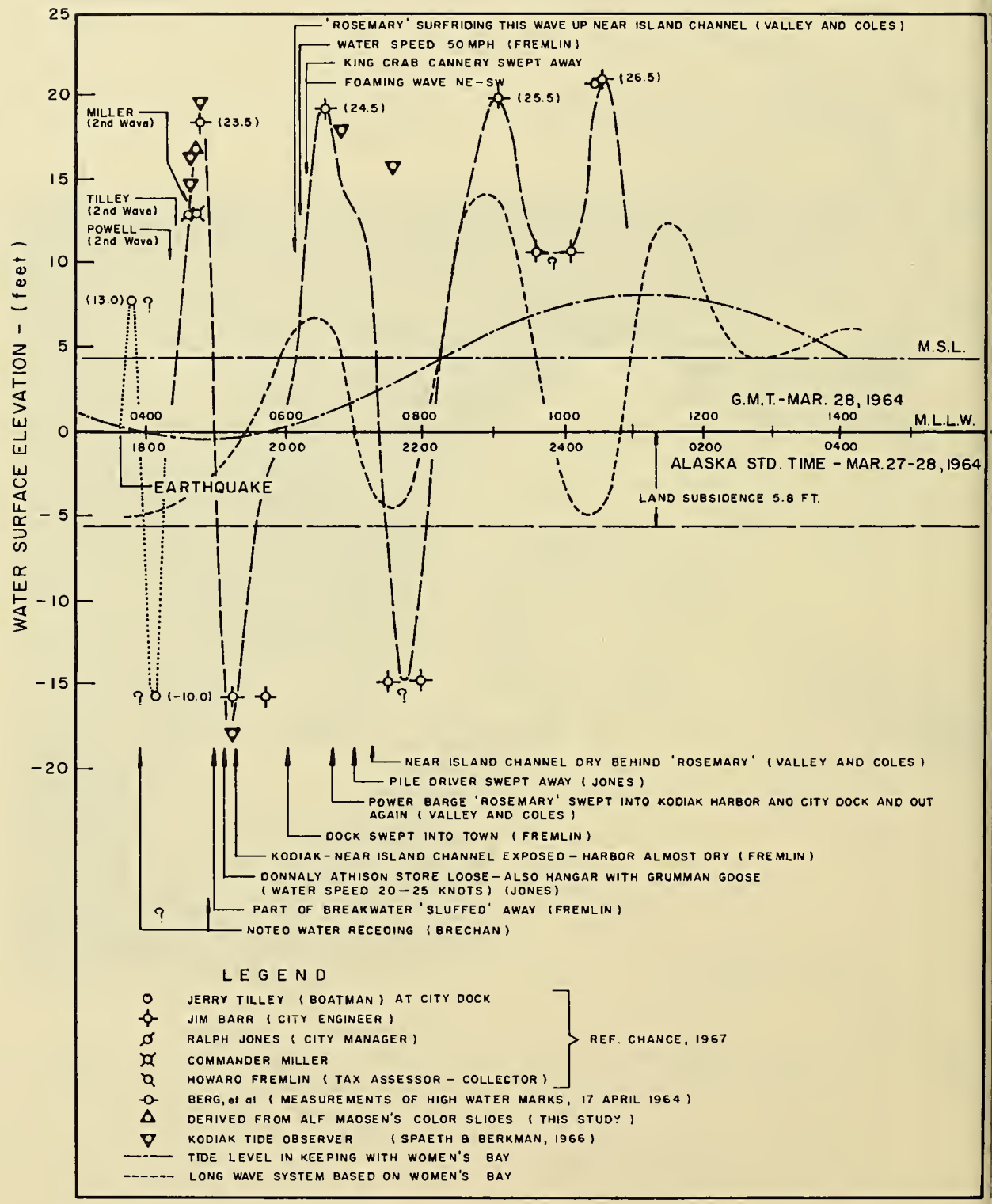

Figure 90 Hypothetical Marigrams for Kodiak City Based on Eye-Witness Observations 
There is also the conflict of view that, whereas City Manager Ralph Jones observed the first wave at $5: 45 \mathrm{p} . \mathrm{m}$., according to Chance (1968), Norton and Haas (1966) report the following incident took place after $6: 00$ p.m.

\begin{abstract}
"Mayor Deveau reached the municipal building shortly after 6:00 p.m. along with several off-duty policemen, who checked in with Chief Jack Rhines. Although he still had no direct knowledge, Deveau reported to Rhines and to City Manager Ralph Jones his conviction that there would be a tidal wave. Deveau wanted to sound a siren alarm. There was a large Civil Defense siren on the hill but it was tied into the long-distance phone lines warning system, and was out of commission. Deveau urged sounding of the fire siren over the fire station. Jones was inclined to agree, but Rhines wasn't convinced that this was a wise procedure, as they had no evidence to substantiate Deveau's conviction. However, the mayor's view prevailed and the siren was sounded."
\end{abstract}

The italies in the quotation are ours.

There is factual evidence that sheds further light on events because the first (or second) wave was photographed by Alf Madsen (professional photographer and hunter) as shown in the sequence of photographs, Figures 91 to 95 , reproduced from his color slides. It is possible to identify the exact locations from which these photographs were taken, and the directions and angles of view. These are indicated in Figure 96, a preearthquake map of Kodiak City and harbor with land levels as they were before the subsidence.

In photographing Figures 91 and 92, Madsen occupied a corner position of the concrete-slab, ground floor of the Elks Club bowling alley (under construction) (location A in Figure 96). From the position of cars and trucks, from their extent of submergence, and from distant water level looking down Marine Way, the water is judged to be about 12 feet above MLLW (an unchanged reference datum). In Figure 93, Madsen had withdrawn to position B on the floor slab. Wall-reinforcing bars show in the foreground. Water level at this time had risen about one foot higher, as judged from car submergence and levels against the flatroofed waterfront structure (Harbormaster's office). Clearly the rise of water is gentle, almost peaceful. However, the water was on the verge of surrounding the Elks Club, and Madsen retreated to higher ground on the opposite side of Mill Bay Road at position C (Figure 96). Here he apparently found time to fit his camera with a wider-angle lens to secure the photograph of Figure 94. The Elks Club structure now shows in the right center with some indication that water has lapped over one corner of it. Water level may here be judged at about 16 or 17 feet above MLLW. In the final photograph, Figure 95, taken from Location D (Figure 96) the water has begun to drain away as judged by the hydraulicjump formations appearing as bow-wave patterns relative to fixed structures on either side of the road. In this view, the piledriver barge is 
in the right center-distance, but the breakwaters are completely submerged. From Figure 89 we infer that prequake levels, allowing for land subsidence of 5.8 feet, would have been such as to ensure submergence at this time.

We refer now to Figure 90. Clearly the photographic evidence produced here would not relate to the time of 5:45 p.m. A flooding so extensive would have been apparent to all, whereas the level of the first wave cited by Tilley, Jones and Fremlin (according to Chance), could not have been much higher than the high spring tide. Our observation of about 17 feet is therefore plotted on the 'second' wave, according to Tilley, and also Chuck Powell and Commander Miller (Chance, 1968). According to Madsen, whom the writers interviewed at Kodiak in 1966, this was the first wave, rising gently from a situation of no prior recession, and causing the first damage only on withdrawal. It is inconceivable that Madsen could have equipped himself with camera and lenses and gained a vantage point for his photography at $5: 45 \mathrm{p} . \mathrm{m}$. so that what he photographed was definitely the wave that crested at about $6: 30 \mathrm{p} . \mathrm{m}$. according to the evidence of City Engineer Jim Barr and Commander Miller (Chance, 1968). We note too that the color slide of Figure 95 clearly shows a sunset light in the clouds on the righthand side. Since the view was south, this would have been light from the west. Sunset at the latitude of Kodiak would have been at $6: 30$ p.m. on March 27, 1964 (Nautical Almanac for 1964).

It now becomes clear that the times reported by Jones (cf. Chance, 1968) must be in error and would account for the anomaly already mentioned. Chance says that Jones reported the first rise in water was " "like a high tide - about 10 feet higher than it should have been"", (therefore about 13 feet above MLLW), at about 5:45 p.m. (probably 6:20 p.m.). "Then", quoting Chance (1968), "the water receded 'way far out', (7:20 p.m., according to Figure 90) and a wave struck 'with much force, tossing buildings and boats around - making a complete mess of the waterfront' ", (presumably at about 8:30 p.m., according to other evidence in Figure 90). Comments in parentheses are ours.

Confusion also stems from the evidence of $\mathrm{Mr}$. and Mrs. Fremlin (Chance, 1968). Quoting Chance,

"Mr. and Mrs. Fremlin watched the water rising rapidly in the small boat harbor immediately after the quake. The water rose to the top of the pilings, fouling the lines of boats tied to the dock. The water rose so fast most of the boats were unable to cut loose in time to escape. Part of the breakwater sluffed away and 'the whole thing went dock and all - and swept into town'. The water then began receding rapidly - 'it was just sucking right out of the harbor' - until it was almost dry."

Since the photographic evidence of Figures 91 through 95 now timed for 6:20 - 6:30 p.m. clearly disproves that the dock swept into town at $6: 30$ p.m., the Fremlins must have been talking of the wave of about 
8:30 p.m. (Figure 90). In elaborating on this (latter) wave, Mrs. Fremlin described it as a "big foaming wave" before it struck the outlying islands. Quoting Chance's interview with $\mathrm{Mr}$. and Mrs. Fremlin:

"It then struck Mission Road and surged around the shoreline and into the channel and small boat harbor where it 'foamed and boiled and bubbled." Mr. Fremlin described it as looking like a 'swift-water river that foams and boils and bubbles' but it 'seemed to dissipate' as it swept by the outlying islands and appeared to be 'a rapid surge upward, rather than a wave' as it swept into town 'carrying houses and boats and planes at a speed of about 50 miles an hour' .... The water swept in the back doors of bars along the waterfront, lifting the buildings as people ran out the front. Some people were wading waistdeep and some were swimming. One man who saw the wave approaching ran into the Elks Club on the waterfront and warned the members of the Women's League who were bowling in the basement. The water rushed down the stairway as the women ran up to get out of the building".

The Fremlins were on or near the top of Pillar Mountain (Figure 88) when they saw all this, but several points emerge which suggest further confusion. From Figure 90 we infer that the wave of $8: 30 \mathrm{p} . \mathrm{m}$. would have been visible to them in the fashion described at about 8:00 p.m., by which time, with the overcast, it would have been getting rather dark. One questions, therefore, whether they could have noted the incident of the Elks Club at that time. Surely the wave of $6: 30 \mathrm{p} . \mathrm{m}$. which flooded around the Elks Club (Figure 94) must have disrupted the bowling game in the basement at that time.

According to Chance (1968), Dell Valley and Will Coles, respectively skipper and engineer on the crab boat Rosemary, surf-rode a wave through the channel between Near Island and Kodiak (Figure 87b) into the harbor. This boat was about 25 miles from Kodiak when the earthquake occurred. According to Chance, "about a half-hour after the quake, their boat was entering the channel when it was caught by a swift, incoming wave." The channel entrance, however, is not more than 2 nautical miles from Kodiak, and since it would be impossible for a crab boat to negotiate, say 20 miles in $1 / 2$ hour, we conclude that Valley and Coles were actually surf-riding the $8: 30 \mathrm{p} . \mathrm{m}$. wave (Figure 90). This would agree with the Fremlins' evidence that they saw a boat surf-riding up the channel from northeast on the wave we have already adduced tc be the 8:30 p.m. crest.

Quoting Chance again:

"Valley said that riding atop the wave it was impossible to know it was a wave because 'it wasn't breaking at all - couldn't even tell if there was any height to it' ...... Coles said, 'it was a real fast tide and this thing went like a motor boat.' The Rosemary was swept through the area where the small boat harbor had been and into the city dock (see Figure 89). The water then 
began to recede immediately taking the dock out with it and they turned the Rosemary around to ride out of the channel with the tide. Valley said the only indication he had that it was a wave they were riding was when it approached the shallow land of $f$ Spruce Cape (Figure 87b) and the water curved upward along the shorelines. 'It ran up on Spruce Cape, and as it came up in a shoal it kept building up higher and higher until it was a big comber. And it just rolled right over the land. I thought probably the Loran Station would go, but it didn't. And the same thing happened on Woody Island - it ran up into the trees. But as far as the center of the wave was concerned you couldn't tell it was a wave'."

With the adjustments made in timing, the evidence of Jones, the Fremlins, Powell, Miller and Barr, as plotted in Figure 90, become coherent. Also shown in Figure 90 are the water levels cited by Kodiak Tide Observer (KTO) in messages transmitted to the Honolulu Observatory of the U. S. Coast and Geodetic Survey (Spaeth and Berkman, 1966), which appear to agree fairly well in all but the last observation at 1l:15 p.m. It is not known whether these data are based on Kodiak City or Womens Bay.

We return to consider Tilley's observation, now largely unsupported except in the qualitative sense that Miller and Powell acknowledged a "first" wave prior to the tide wave of $6: 30 \mathrm{p} . \mathrm{m}$. However, Tilley's observation of an abnormally low. tide at $6: 10 \mathrm{p} . \mathrm{m}$. is also unconfirmed except in a qualitative way by Brechan (Norton and Haas, 1966). Despite the apparent confusion of time in the evidence of others, we are inclined to give Tilley the benefit of the doubt by conceding that there was such a first wave with an effective period of 40 minutes (Figure 90). We may show, too, that the natural period of oscillation of the quasibasin between Womens Bay and Kodiak is of this order and favors his observation.

Figure $87 \mathrm{~b}$ shows that the quasi-basin from Womens Bay to Kodiak can be approximated by a basin, oriented NE-SW, with a bed sloping uniformly from zero depth off the point of Nyman Peninsula to a maximum of 70 feet at the Kodiak breakwater (at low tide). For such a triangular depth profile, the fundamental eigenperiod (cf. Wilson, 1966) is

$$
\mathrm{T}_{1}=3.28 \mathrm{~L} / \sqrt{\mathrm{gd}_{1}}
$$

where $L$ ( $\simeq 6$ nautical miles) is the length of the quasi-basin and $\mathrm{d}_{1}$ ( $\simeq 70$ feet) its maximum depth. For these values, $\mathrm{T}_{1}$ is 42 minutes. We conclude that Tilley was correct in his observations, and that two further aspects of this oscillation may explain why it would not have been very noticeable in Womens Bay and at Kodiak City. The location of the city dock in St. Paul Harbor (see Figure 89) would agree approximately with maximum depth of the quasi-basin envisioned. From the city dock to Kodiak, water depth decreases considerably. At the opposite 
extreme, in Womens Bay, the depth shelves to zero on the tidal flats (see Figure 88). Hence any free oscillation of the basin would have rather small amplitude in Womens Bay, maximum amplitude at City Dock, and reduced amplitude at Kodiak City. We believe the enigma is thus explained, and that the oscillation Tilley observed was the direct result of the jolt of land movement in the southwest direction occurring during the earthquake. Figure 40 shows that many observations of ground motion from NE to SW were reported throughout the region.

In Figure 90 we have superimposed upon our hypothetical marigram the large tsunami system that seemed apparent in Figure 38c. In Figure 97 we apply the subjective analysis technique to find the residual oscillations. Thus, Figure 97c suggests the nature of the wave system riding on the main tsunami system. The accuracy of Figures 90 and 97 after about 11:00 p.m. is doubtful. Prior to that time, however, we suspect that the oscillation shown is a combination of the Continental Shelf oscillation (Figure 97c) noted in Figure 38c and the oscillation in St. Pauls Harbor (Figure 97d).

\section{Tsunami Damage at Kodiak City}

The picture we now have of the tsunami (Figure 90) suggests that the "second" wave, after Tilley's first wave, had an amplitude of some 20 feet or a height of about 40 feet. This wave is presumed to be dominantly the result of a shelf oscillation such as discussed in Section III-2, with a second mode period of approximately 100 minutes. The interval of time between the "second" wave, or first crest on Figure 97c, and the next crest (Figure 97c) is about 2 hours, however.

In Figure 97d we have assumed the amplitude of the first oscillation in St. Pauls Harbor, as it might have occurred at Kodiak City, to be somewhat less than Tilley's observation. The second wave of Figure 90 is now seen to comprise a 10-foot amplitude shelf oscillation apparently combined (slightly out of phase) with a 15-foot amplitude oscillation of St. Pauls Harbor. Most of the water for the antinodal resultant of these waves at Kodiak City would have been drawn locally from St. Pauls Harbor accounting for the fact that velocities of horizontal flow during the rise of the wave at Kodiak were small (at the antinode of a seiche they are nominally zero). However, after the "second" wave (Figure 90), the shelf oscillation went to work in draining water from the entire area. Figure 97c suggests that it would have done this to the extent of a drop in water level of about 20 feet over the entire area of St. Pauls Harbor. An extra drop in level at Kodiak City of another 20 feet would have been occasioned by the local oscillation (Figure 97d).

This total drop of water level of nearly 40 feet in 35 minutes (Figure 90) would have occurred over the entire area of the Inner Anchorage and boat harbor which, as Figure 98 shows, are contained between the island string (Gull, Uski and Near Islands) and the mainland. 


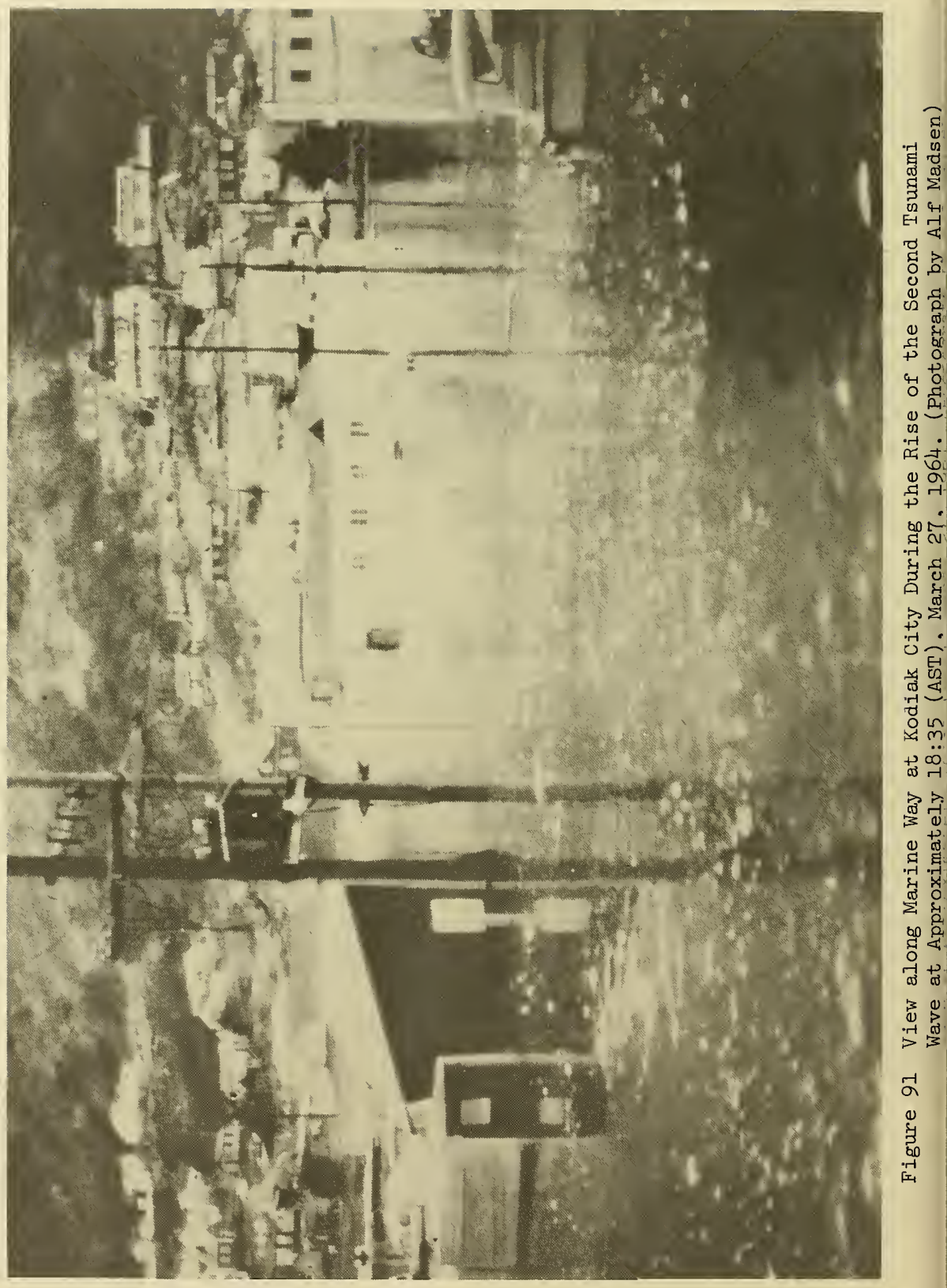




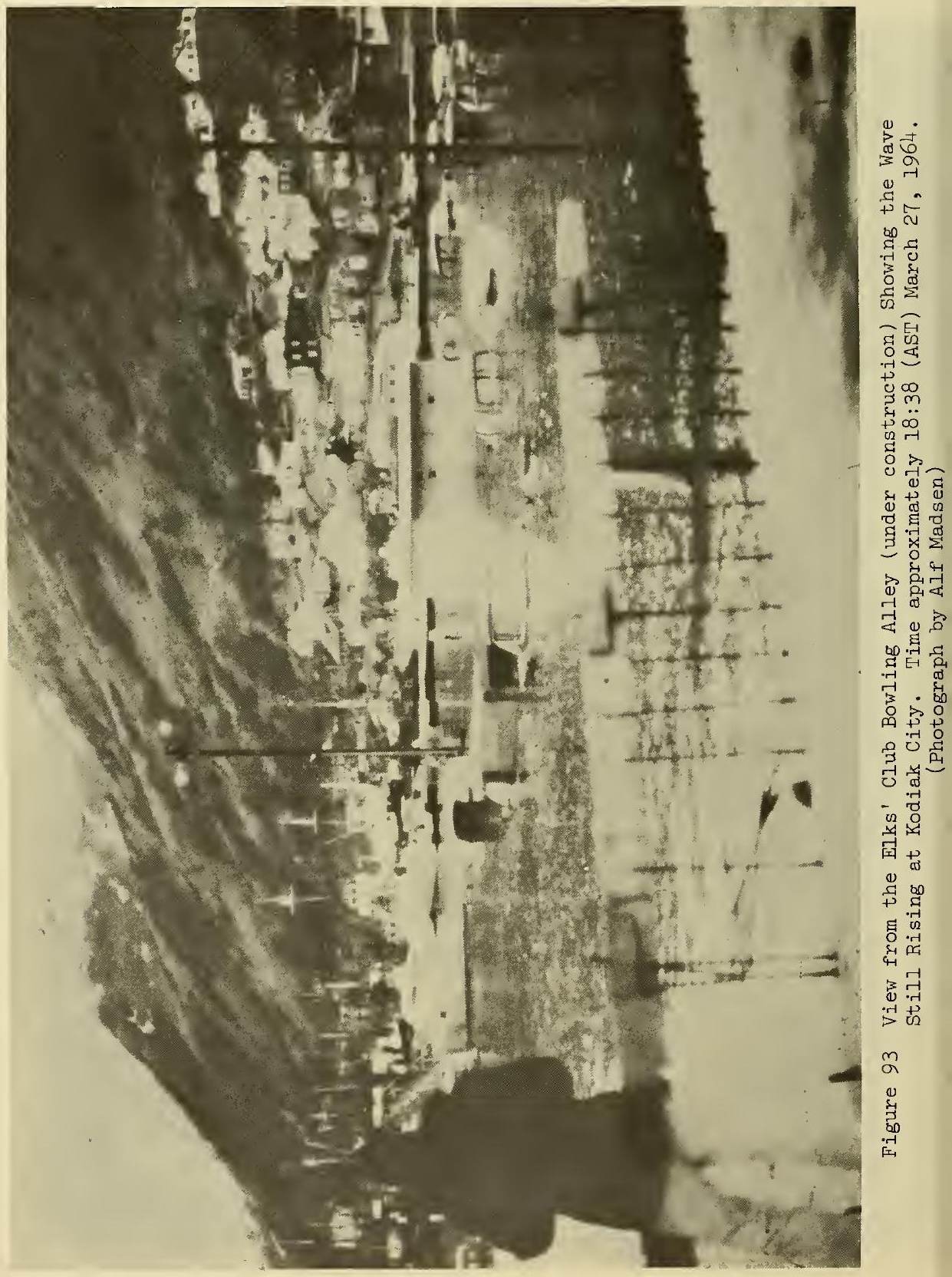




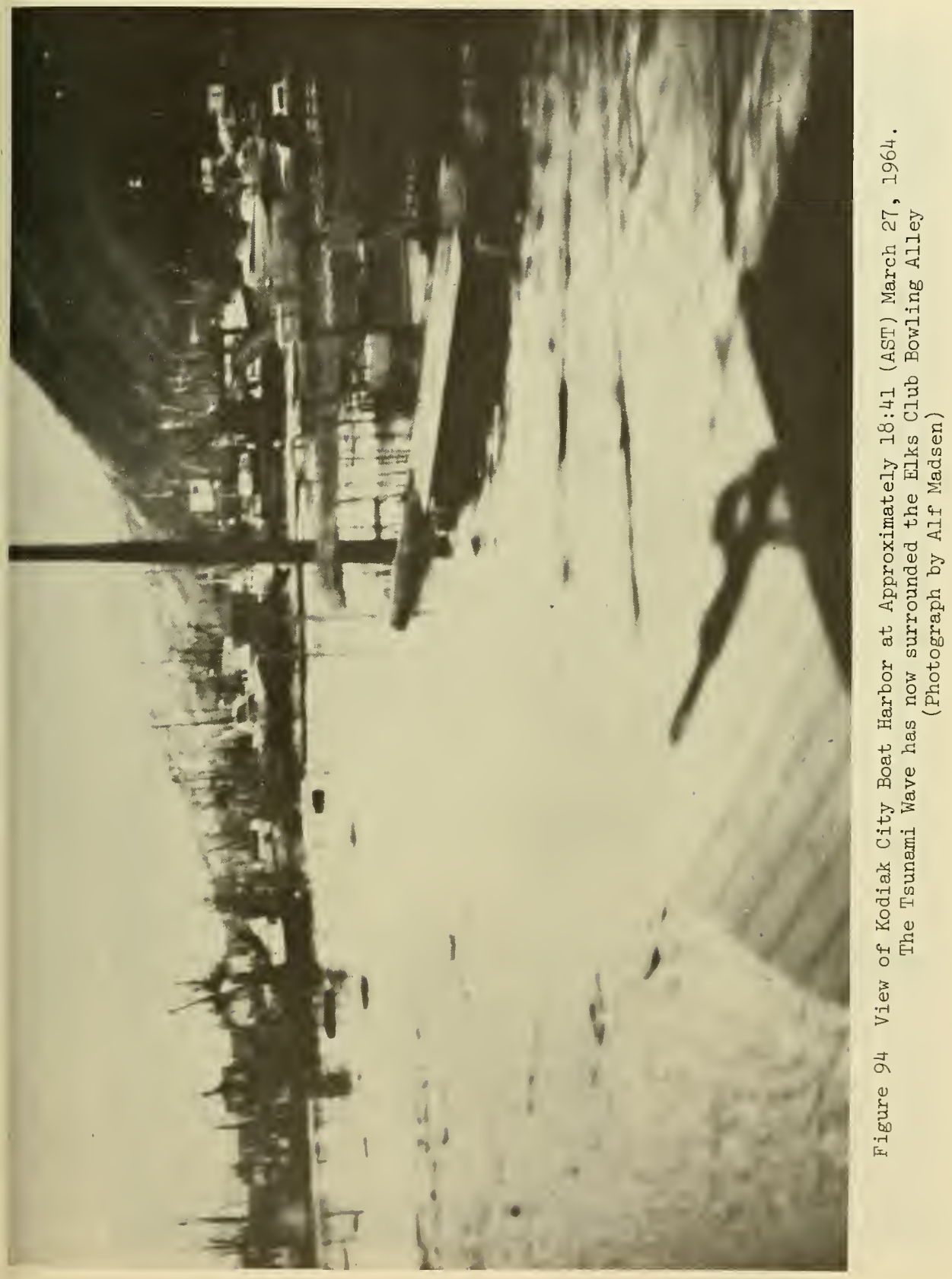




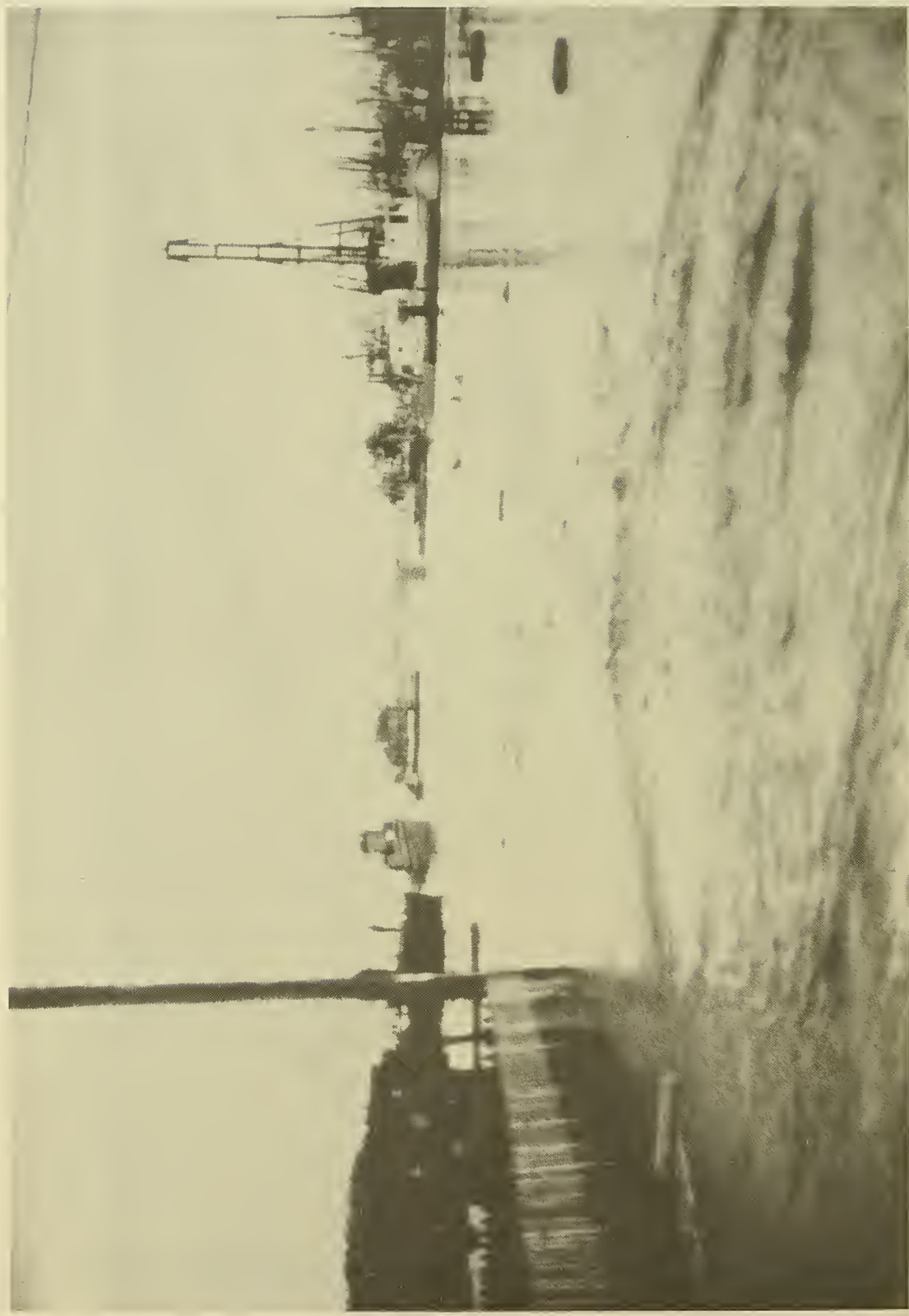

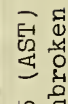

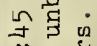
$\ddot{\infty}$ का क्षे $\rightarrow 03$ (1) ट्ञ त ${ }_{0}^{\infty}$ 青 장 엉 岸 近霡 + स - 0 U응 तै \&

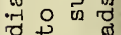
O

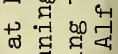
. क्षि० \&े का

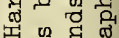
出 + 0 年 कृ 0 की ต $>$

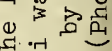
के 켱 4 ⿷匚 0 is के is d r है 近 ํㅕ कै เ ตै क्ष है तो 苛 롱 วิ ह 3 है त (1) $i^{-1} \sum^{\infty}$ กิ 艺 . 穴 
प्म

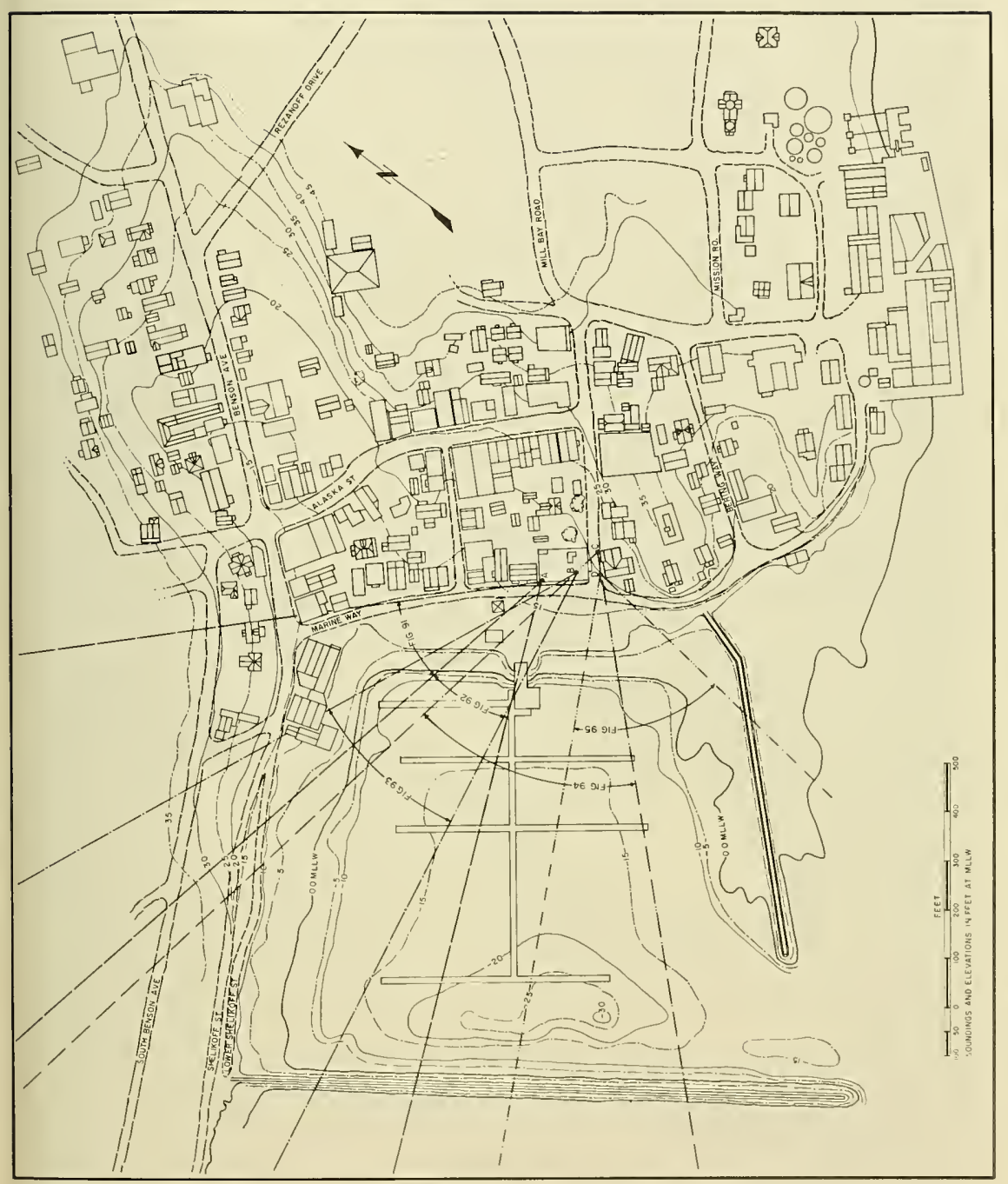

\begin{tabular}{l}
0 \\
8 \\
0 \\
\hline
\end{tabular}

i)

ฮี

당

मे का

西

(1)

है

온

\&

0

क्ष

है क

it

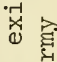

业

\&

\& 20

है

江

$+0$

ต थ

त्ठ

ฮี थ

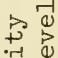

ठㄷ

क्ष त्व

न्-

9

4-1

敢

ด

1
3
80
.0
.1 


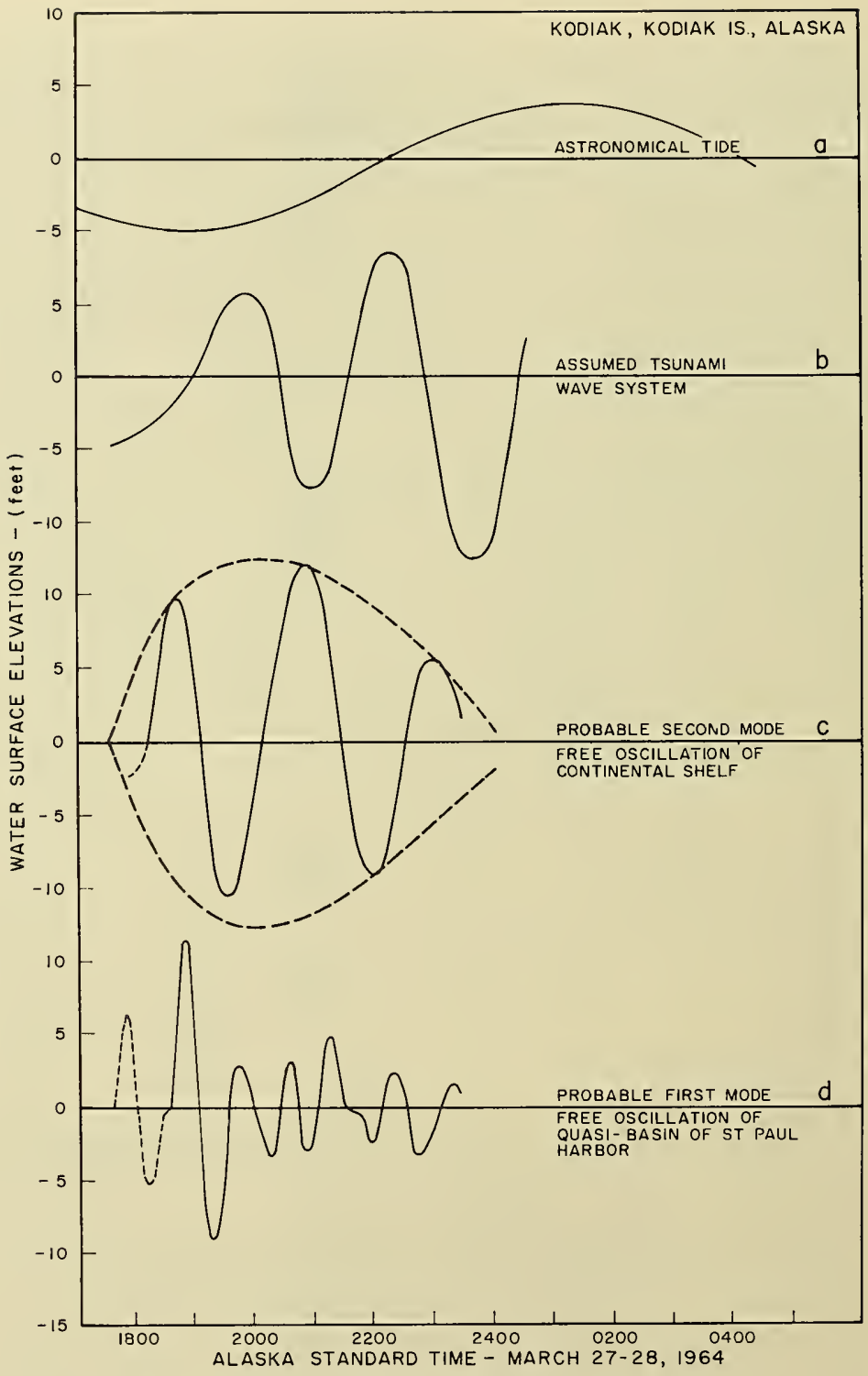

Figure 97 Subjective Analysis of the Inferred Marigram for Kodiak City (see Figure 90) 


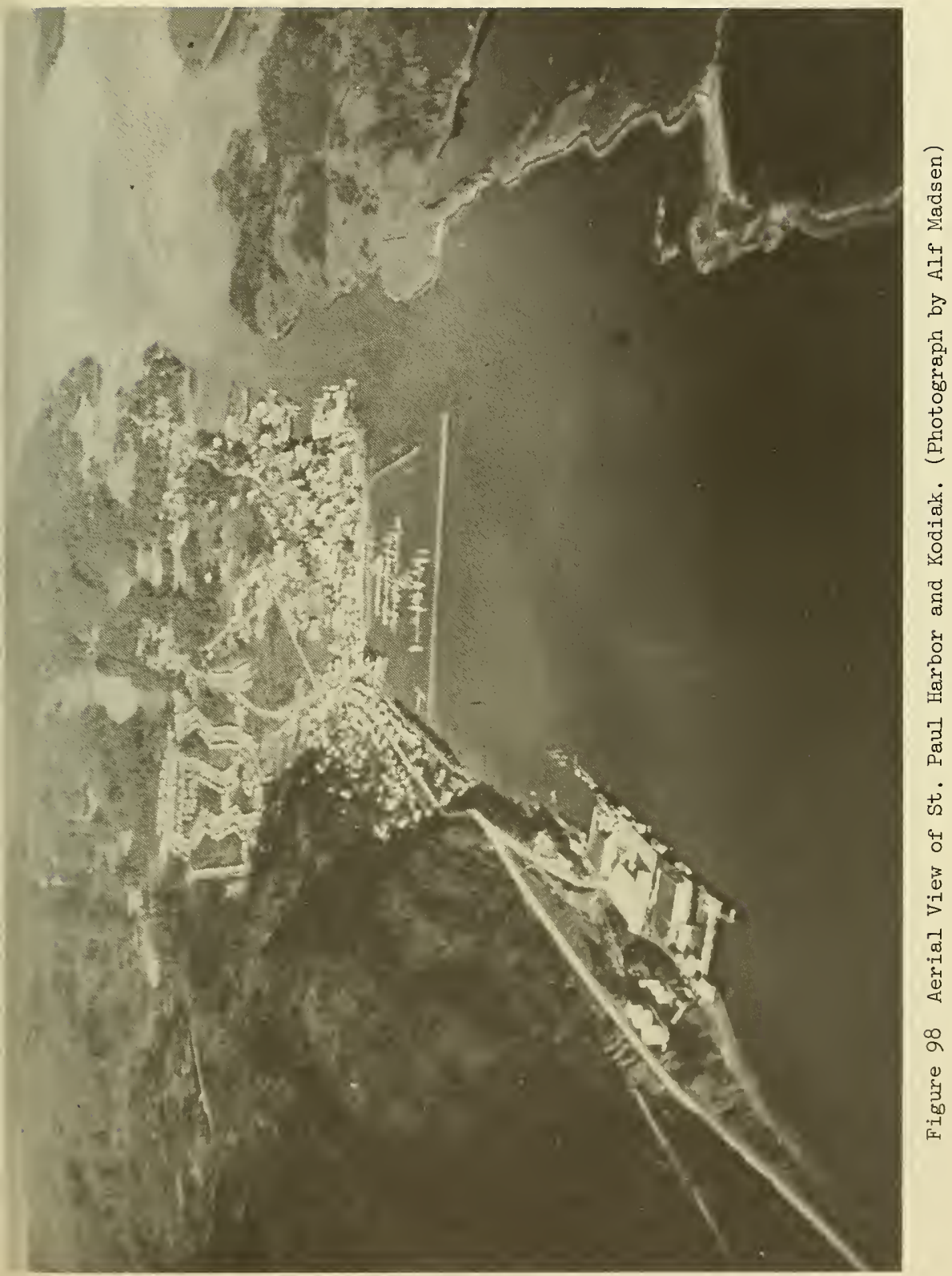


Computation shows that the area of the Inner Anchorage (Figure 88) between the southwest end of Gull Island and Kodiak City is about 0.5 nautical square mile and that the volume of water to be drained in about 35 minutes would have been roughly $3.6 \times 10^{8}$ cubic feet. Available outlets were the southwest entrance to the Inner Anchorage and the Near Island channel. The latter has such small capacity that most of the drainage would have had to take place via the Gull Island entrance. For a cross-sectional area of this entrance of $1.2 \times 10^{5}$ square feet, taken on average over the drop of water level, the average velocity of outflow is calculated to be about 9 feet per second. The maximum velocity, according to a sinusoidal rate of level drop, would be about $9 \pi$ or 28 feet per second (19 miles per hour). With some margin for error, this estimate is in reasonably good accord with Jones' estimate of water speed of 20-25 miles per hour (Figure 90).

This outflow of impounded water apparently sucked out part of the southwest breakwater of the boat harbor, and tore loose the Donnally Atchison store and an aircraft hangar on the Near Island channel. But the real damage came with the next two waves.

Figure 90 shows that the next (third) wave was composite of the first progressive wave crest of the tsunami, overlaid by the second wave of the shelf oscillation and additional local oscillations (Figure 97c and d). This monstrous wave, 35 to 40 feet high over a vast wave length, moved into the area via the fastest route, up the Woody Island channel (Figure 88) into the Near Island channel, already almost completely denuded of water. This was the wave upon which the crab boat Rosemary surf-rode up the channel. At its immediate front it had some of the features of a foaming bore, but as Valley and Coles imply, it was mainly a sloping front in the body of the wave crest. Such a wave configuration would conform to the surge waves studied experimentally by Cross (1966) and illustrated in Figure 99.

In Appendix D we give some discussion of water particle motions and induced forces in tsunamis of surge type. The formula for the surge velocity $u_{S}$

$$
u_{\mathrm{s}}=2 \sqrt{g d_{S}}
$$

is reasonably supported by theory and experiment, and may be considered to apply when the depth of water in front of the surge is small compared to the total depth $d_{S}$ of the surge. Adopting $d_{s} \simeq 37$ feet, $u_{s}$ is calculated to be 69 feet per second or 47 miles per hour. The Fremlins had estimated the water speed in the Near Island channel as 50 miles per hour (Chance, 1968).

This wave came roaring up the channel from the northeast. It washed away the channel docks and canneries, like the Alaska Packers Association cannery shown in Figure 100. Figure 101 shows that only a few of the supporting piles for this cannery remained (Tudor, 1964). An old stone wall (Figure 10la), built by Russian settlers before the year 1800, survived the tsunami. Inspection of this structure by the authors 


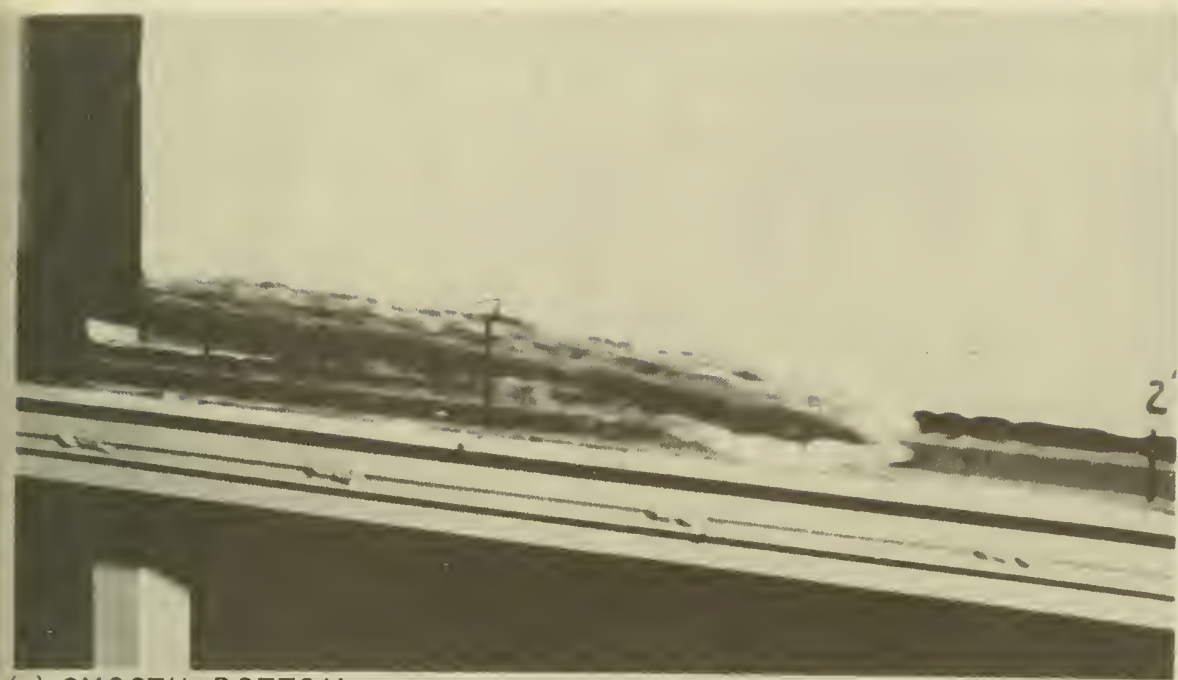

(a) SMOOTH BOTTOM

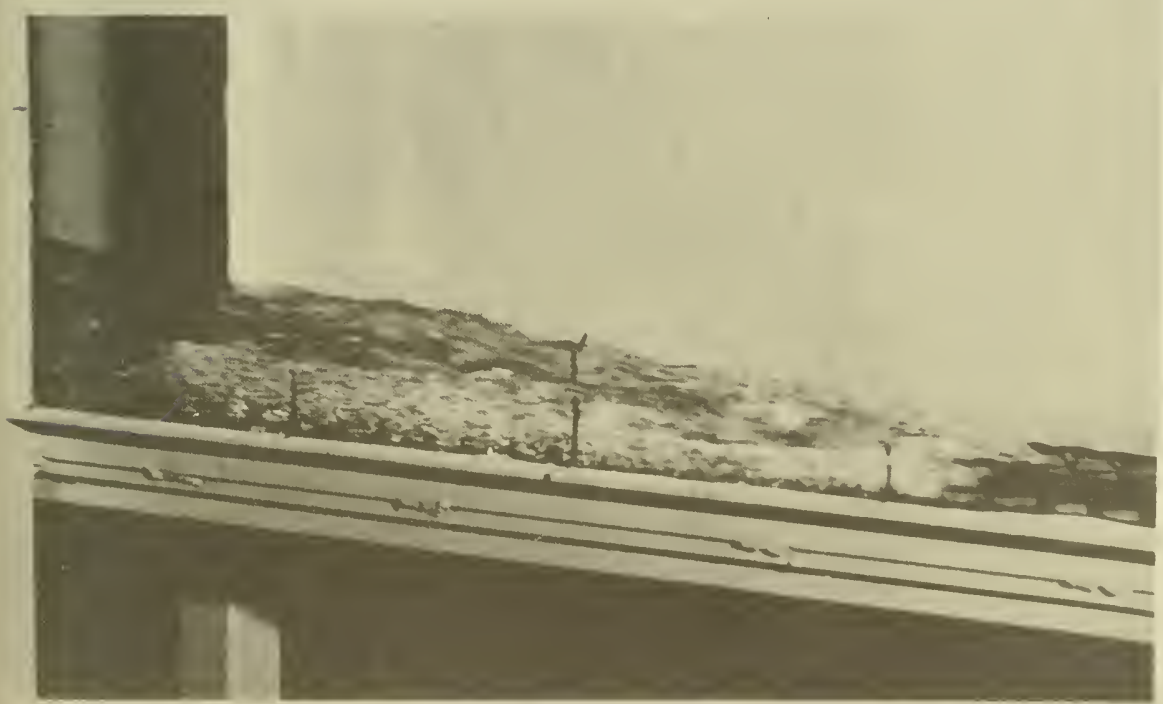

(b) ROUGH BOTTOM

Figure 99 Laboratory-Produced Surge Waves believed to be similar to the Tsunami Surges in Near Island Channel, Kodiak City (from Ralph Cross, 1966) 


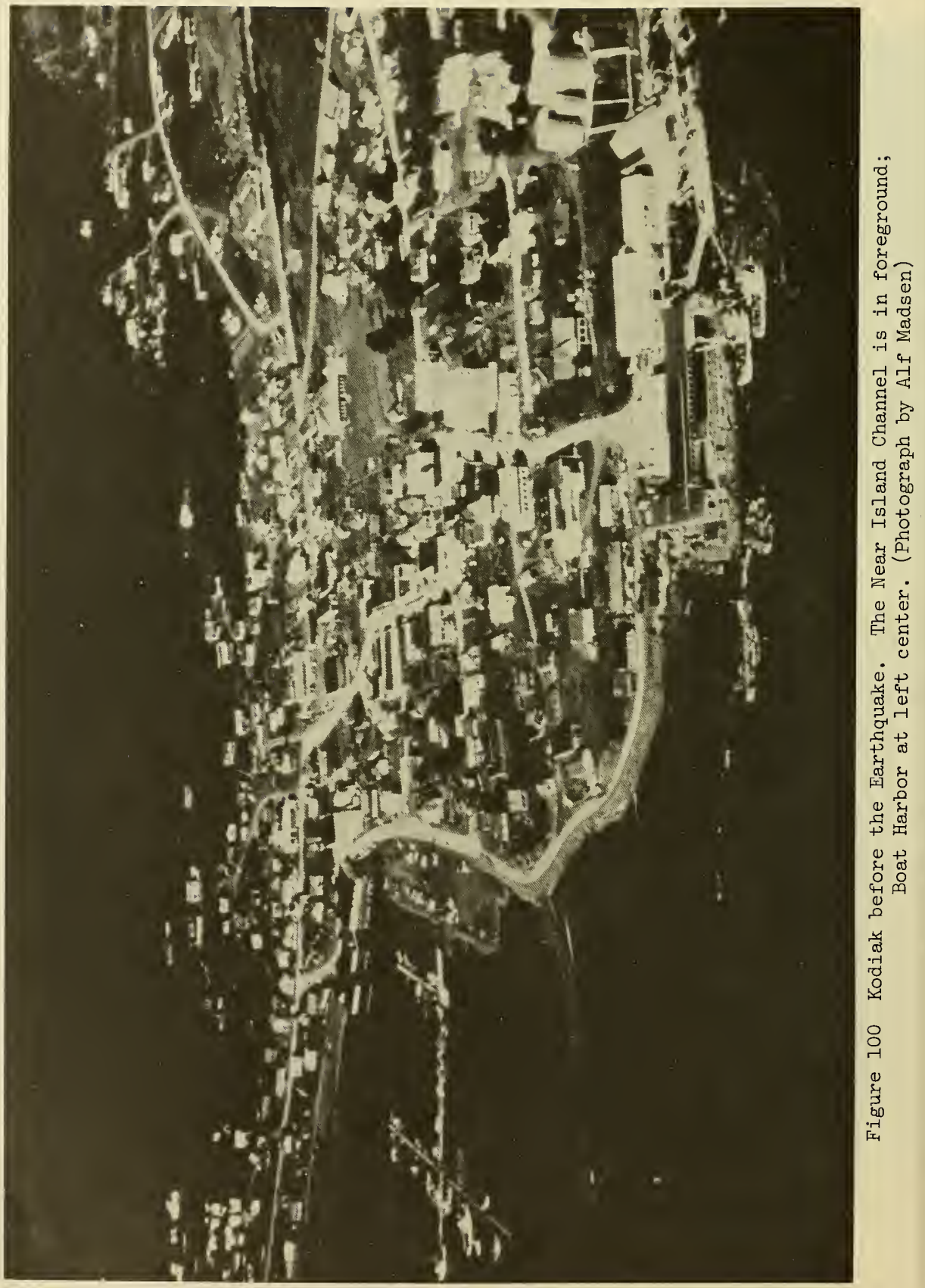


in 1966 showed that it was heavily buttressed in cellular (plan) formation as if specially built to withstand strong tidal surging.

The hangar of Kodiak Airways wasthed away and was still floating 30 miles offshore about one month after the quake. Lill's Cafe on Mission Road floated away and ultimately wound up in a lagoon on Near Island (Armstrong, 1964).

Boats that were left dry on the channel bottom and in the boat harbor were toppled and rolled; some became waterlogged and sank (Chance, 1968). All the markers and mooring buoys in the channel were washed away by this "third" wave. It is probable that this wave or its counterpart coming into the Inner Anchorage via the Gull Island entrance lifted the Alaska King Crab cannery off its piles (Tudor, 1964) on the northwest side of the Inner Anchorage. It floated until it lodged on the southwest breakwater (Figure 102).

The conflict of the waves reaching Kodiak via the Near Island channel and the Gull Island entrance probably caused a maelstrom of writhing water in and over the boat harbor which effectively destroyed the harbor and carried surviving boats and flotsam into the low-lying area of Kodiak City. Figure 103, a reconstruction of Kodiak after the tsunami, shows contours of land level as they would have been after the earthquake and before the arrival of the tsunami (dashline). It also shows (solid line) contours of level marking the depredations of the tsunami as derived from U. S. Army Corps of Engineers soundings. Hypothetical streamlines of flow on this map suggest how the waves may have acted in the boat harbor. The contour changes in the neighborhood of the breakwaters show the leeward deposits from the main outpourings of the impounded water.

Figure 103 shows also the probable paths of buildings in Kodiak which were either lifted off their foundations by this "third" wave or were battered to pieces by the ramming effect of boats and flotsam. Because most people left the town after the "second" wave, and because of darkness, little is known in detail about the damage done downtown by the third and succeeding waves except the evidence found next morning. As Figure 90 shows and Figure $38 \mathrm{a}$ indicates, the highest wave was yet to come. This wave, probably the "fourth", was a composite of the second tsunami crest (Figure 38c), the third shelf oscillation, sundry local oscillations and the rising high tide. The effect was undoubtedly similar to that of the "third" wave, and whatever had been weakened by the "third" became prey for the "fourth". The torrents of water in the channel made roaring and sucking noises, and horrible grinding sounds accompanied the attrition of buildings and structures during the night (Norton and Haas, 1966; Chance, 1968).

James Barr, consulting engineer, Kodiak, surveyed the damage for the Office of Civil Defense shortly after the quake; his rough results are corrected and incorporated in Figure 103. The excellent photographs of Alf Madsen have greatly assisted the preparation of this map. 


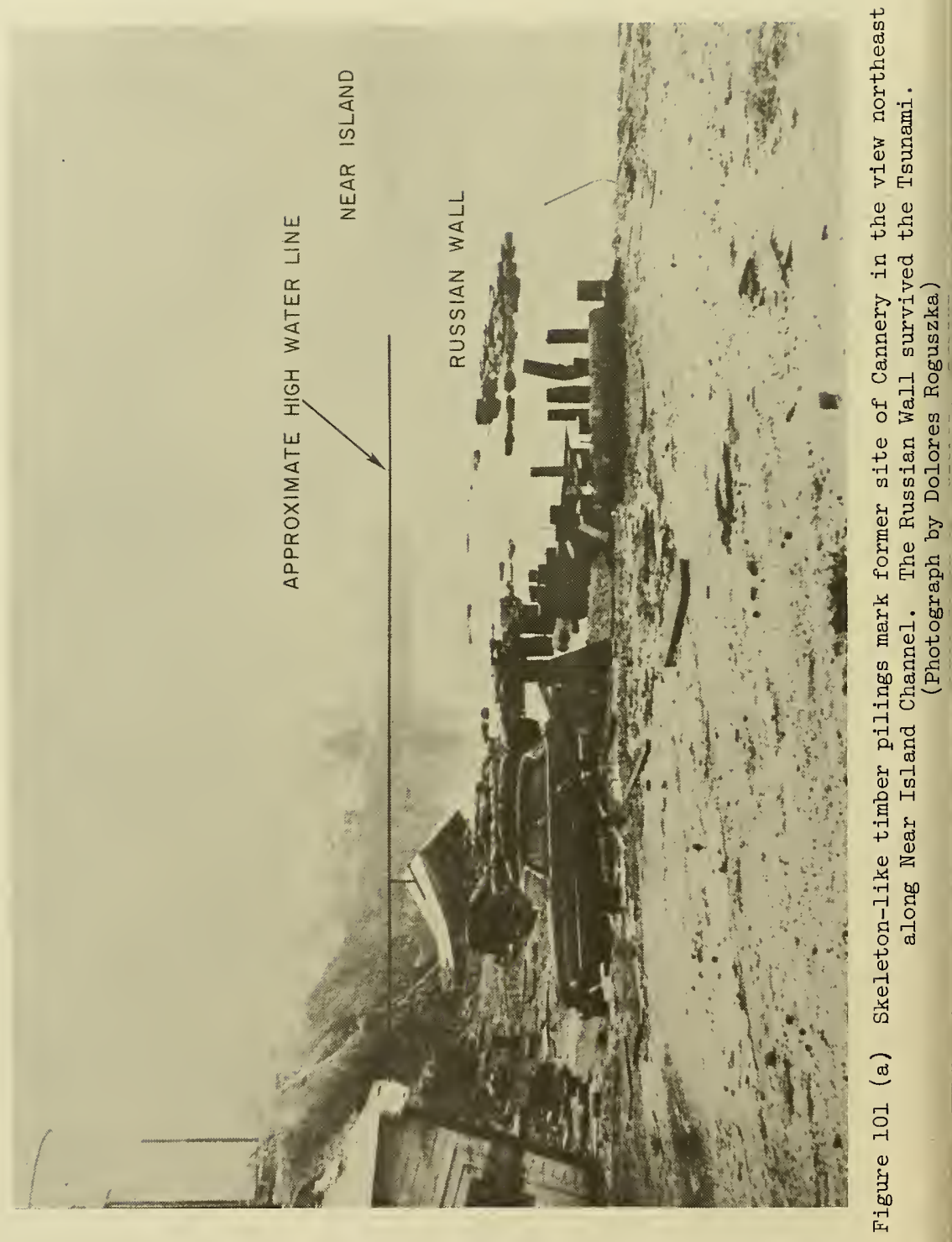




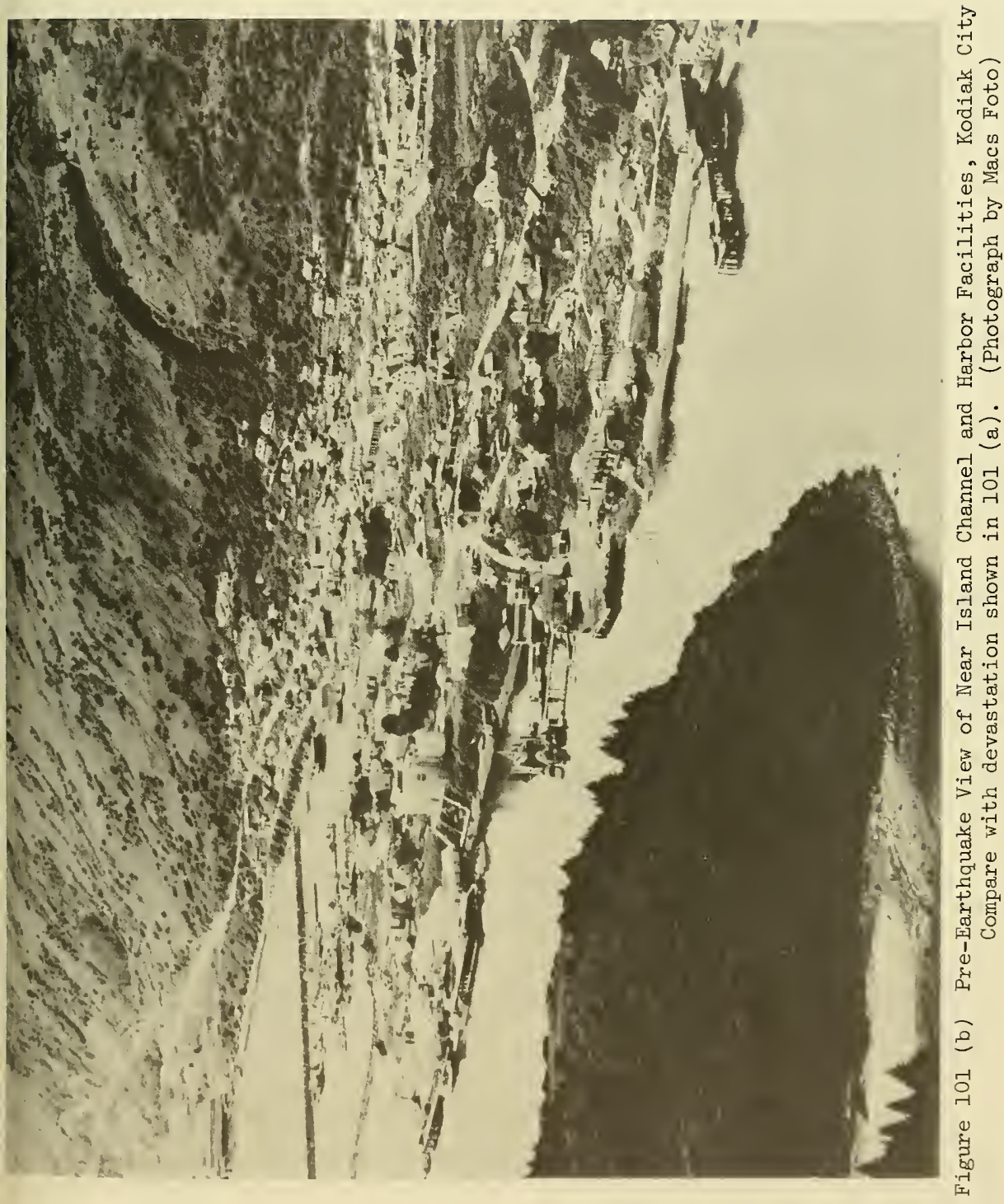


Most houses downtown were old buildings. In fact, prior to the quake, plans had been made for urban renewal of this section. These old light wooden frame buildings, generally were inadequately connected to their foundations. Many were floated away and damaged by the flowing water. They were also damaged by impacts when they stranded, or by impacts from other houses, boats and other floating objects. Many of the houses, affected by the waves but still remaining on their foundations, were partly damaged by impacts from floating objects, and all had damage due to inundation.

Damage in the downtown area is shown in the series of photographs, Figures 104 to 106. On these and on the map (Figure 103), several buildings are marked with identifying numbers $I$ to $X$. These buildings, although lying in the path of the tsunami, were unmoved, but all suffered damage and some were unsalvable. The type of structure in these buildings and the extent of damage are summarized in Table $V$. The waves caused minor erosion of roads and sidewalks downtown.

Serious scour occurred in the channel between Kodiak and Near Island where, in some places, 10 feet of sediment was washed away. This presented a major postquake construction problem because no sediment foundation remained for the piles of new waterfront structures (Kachadoorian and Plafker, 1967).

All boat floats in the small boat harbor were totally damaged. The boat floats were held in place by approximately 100 guide piles, all of which were broken. Estimating pile diameter at 12 inches and water depth at 12 feet, the ultimate lateral load capacity of one pile is calculated to be 2.5 tons, assuming the load is applied 2 feet above stillwater level. Acting in unison, the piles would have had an effective load capacity of 250 tons. If water moved through this array at 25 feet per second, the drag force alone would have been of the order of 700 tons. Failure of the system is thus easily explained, particularly since water velocities may have been higher, and pressure and inertia forces from the wave slope may have been additional to drag.

Damage to the breakwaters was partly due to compaction settlement caused by the tremors and partly due to the tsunami. Figure 89 shows typical sections of the breakwaters as they were measured after the quake, as well as cross sections of the rebuilt breakwaters (U. S. Army Corps of Engineers, Anchorage, Alaska). The exact weight of the cover-layer stones and the core material of the breakwater are not known. However, to judge from Figure 102, the armor stones were too light to resist any great degree of overtopping.

At the City Dock (Figure 89), submergence from the "second" wave of some 6 to 8 feet apparently buoyed the decking off the pile caps, because the deck stringers were merely driftpinned to the pile caps. Subsequent vertical motion accompanied by lateral movement destroyed the decking. When the bulkhead and about 25 piles at the approach to City Dock were destroyed, presumably with the third wave, the approach decking floated away (Tudor, 1964). 


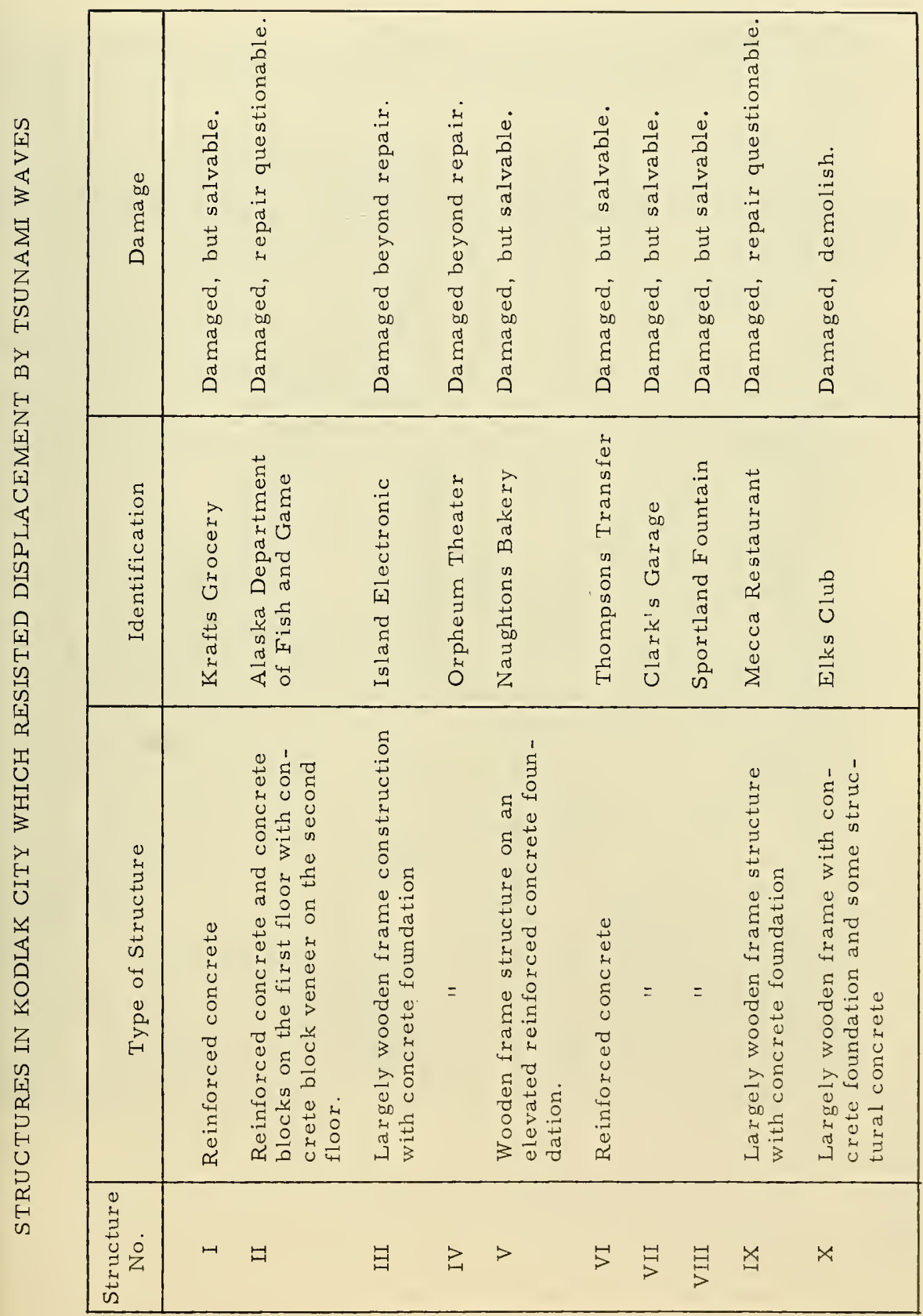


The appalling scene of destruction presented to the world on the day following the earthquake is shown in Figures 107 and 108. The entire waterfront was inundated by the high tide owing to the scour and general subsidence of the land (Figure 107).

North of Kodiak City the coast had to withstand the full brunt of the tsunami inrush from the two sides of Woody Island. At Potato Patch Lake the tsunami flooded into the lake (Figure 109). Many of the residences on the barrier between Shahafca Cove and the lake were washed into the lake (Figure 110). As a result of the severe land erosion and general subsidence, the lake is now a saltwater lagoon.

Eight people died at Kodiak City during the tsunami. The economy of the area was severely crippled. Total estimated property damage according to the Office of Civil Defense was $\$ 31,279,000$ (Tudor, 1964). Harbor facilities suffered to the extent of $\$ 2,165,000$; industry and commerce lost $\$ 19,346,000$; public property, $\$ 5,400,000$; the fishing fleet, $\$ 2,440,000$; and private dwellings, $\$ 1,928,000$. Nearly 100 vessels were lost or damaged. Appendix E contains tabular information, giving further details of these losses.

\section{Tsunami Damage at the U. S. Naval Station, Kodiak}

The U. S. Naval Station is about five miles southwest of Kodiak City. Fortunately, considering 3,000 people were on the base at the time of the quake, few were injured and only three died. The casualties may well have been far higher had it not been for the tsunami warning received from Cape Chiniak and broadcast on television and radio, allowing people time to flee to higher ground.

Figure $87 \mathrm{~b}$ shows that the tsunami approach to Womens Bay from Chiniak Bay would have been through comparatively shallow water. Nevertheless, the arrival time $(8: 35 \mathrm{p.m}$.$) of the first high wave (Figure 35 \mathrm{a}$ and Appendix A) was ostensibly the same as that of the "second" wave at Kodiak City. The reason for an earlier wave at Kodiak City and none at Womens Bay has already been imputed to a northeast-southwest oscillation of the quasi-basin forming st. Pauls Harbor.

As at Kodiak City, the first large wave occurred as a fast-rising tide, effectively the result of gradual flooding from a previous situation of only minor withdrawal if any. The first wave was photographed in the sunset light and the extent of flooding is shown in Figures 111 and 112. These photographs show inundation at the head of Womens Bay around the hangars of the Navy air terminal (Figure 113). In Figure 114 partial recession of the wave has taken place: leaving deposits of flotsam on the seaplane ramps. Figure 113, based on an original drawing of the Nyman Peninsula by the U. S. Navy, Kodiak (Kachadoorian and Plafker, 1967) shows the general extent of flooding of the Navy Base area. The locations at which the photographs of Figures 111, 112, and 114 were taken, as well as the locations of other photographs to which we shall refer, are also shown. 


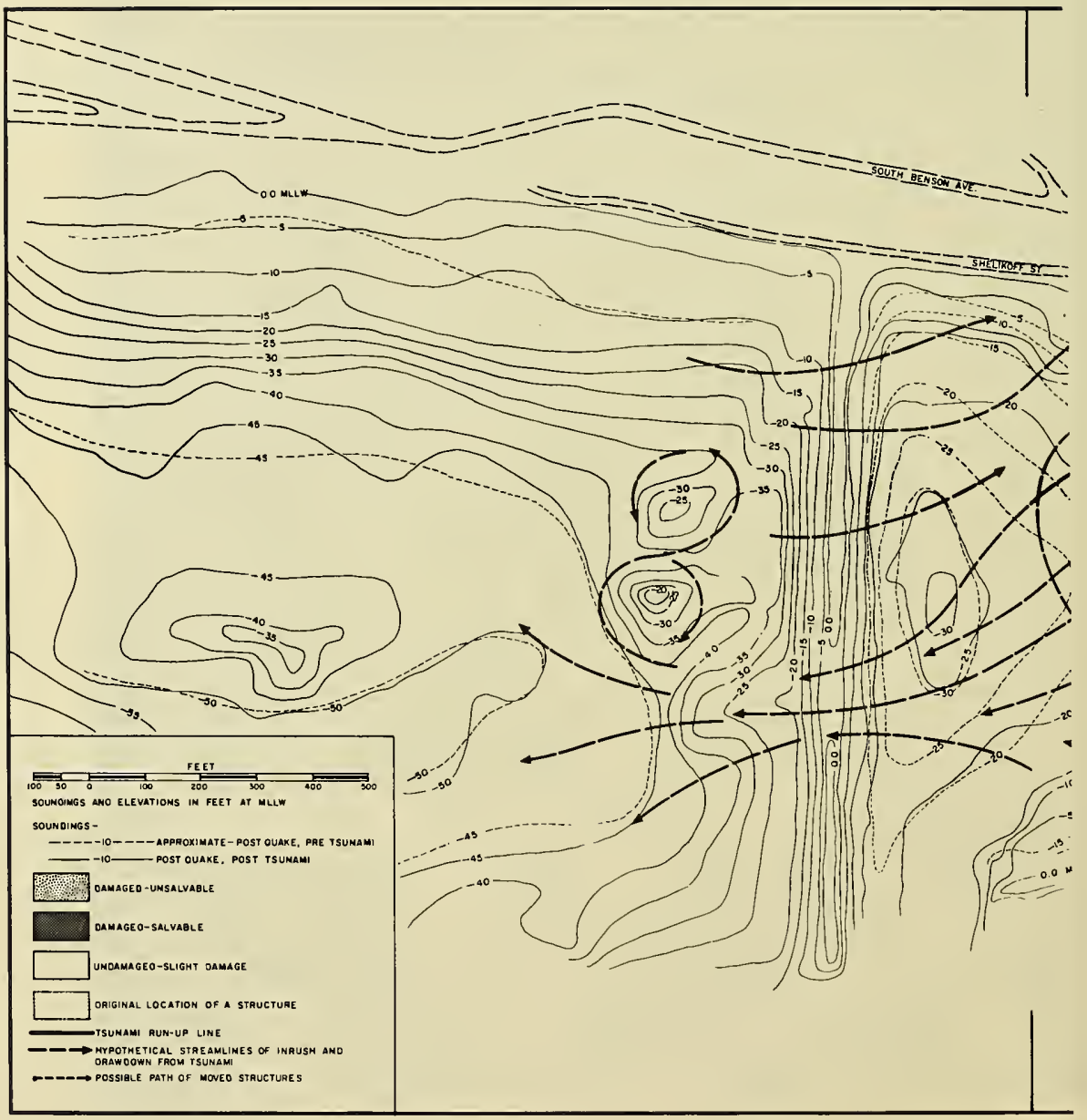




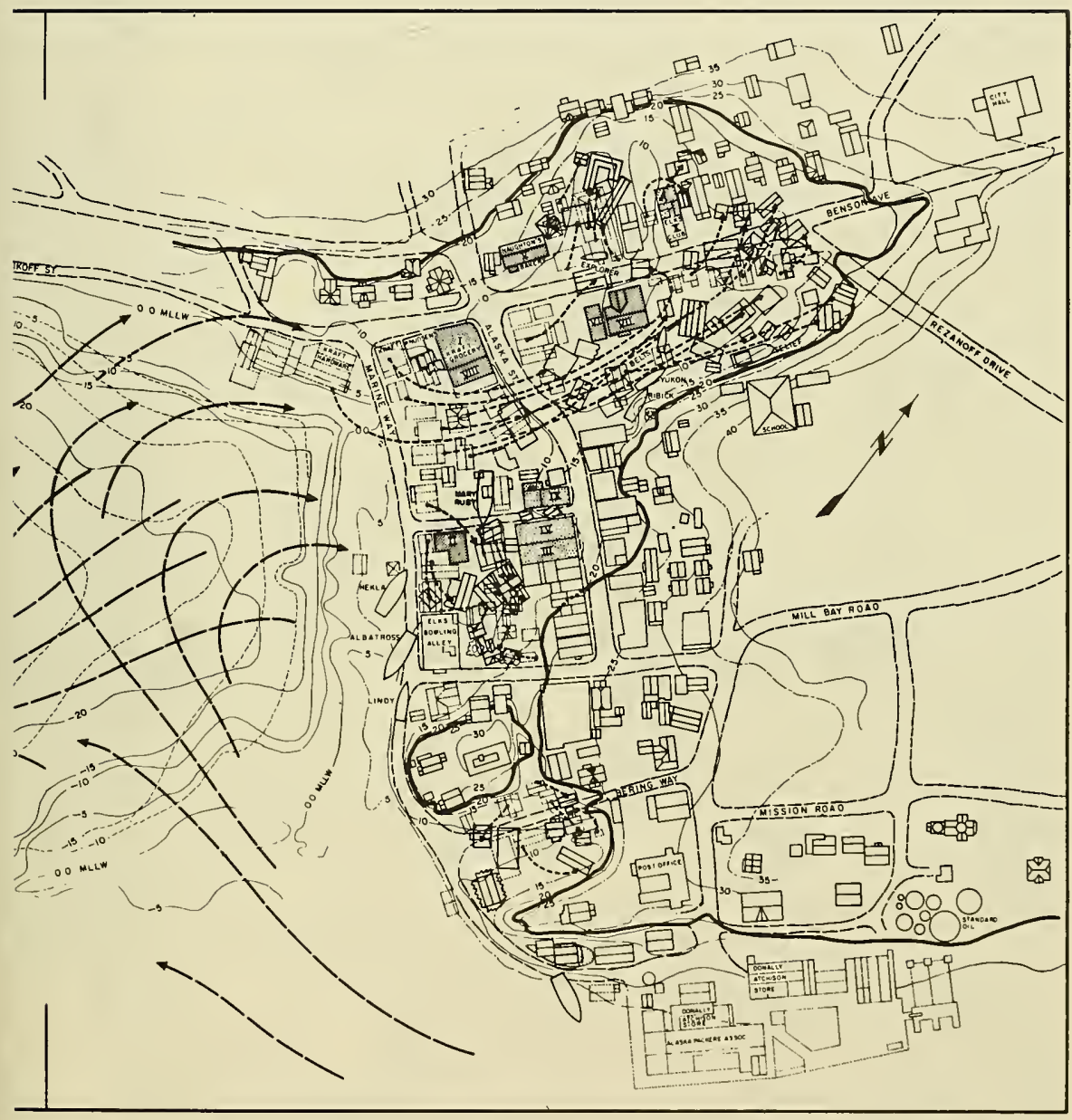

Figure 103 Map of Kodiak City, Boat Harbor and Inner Anchorage after the Earthquake and Tsunami. (Based on data from J. Barr, Kodiak; U. S. Army Corps of Engineers, Anchorage; photographs of Alf Madsen, Kodiak; and U. S. Navy Station, Kodiak) 


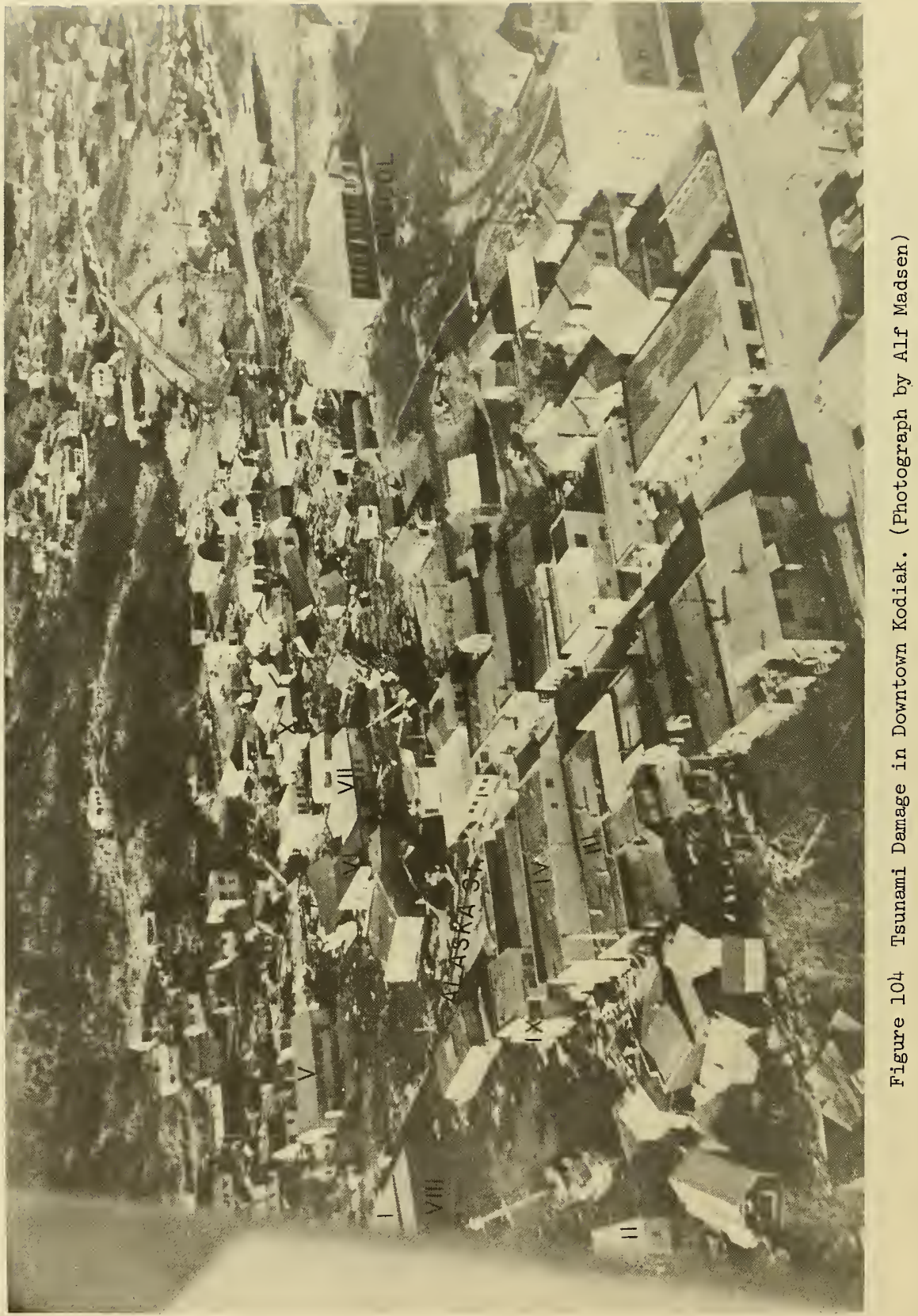




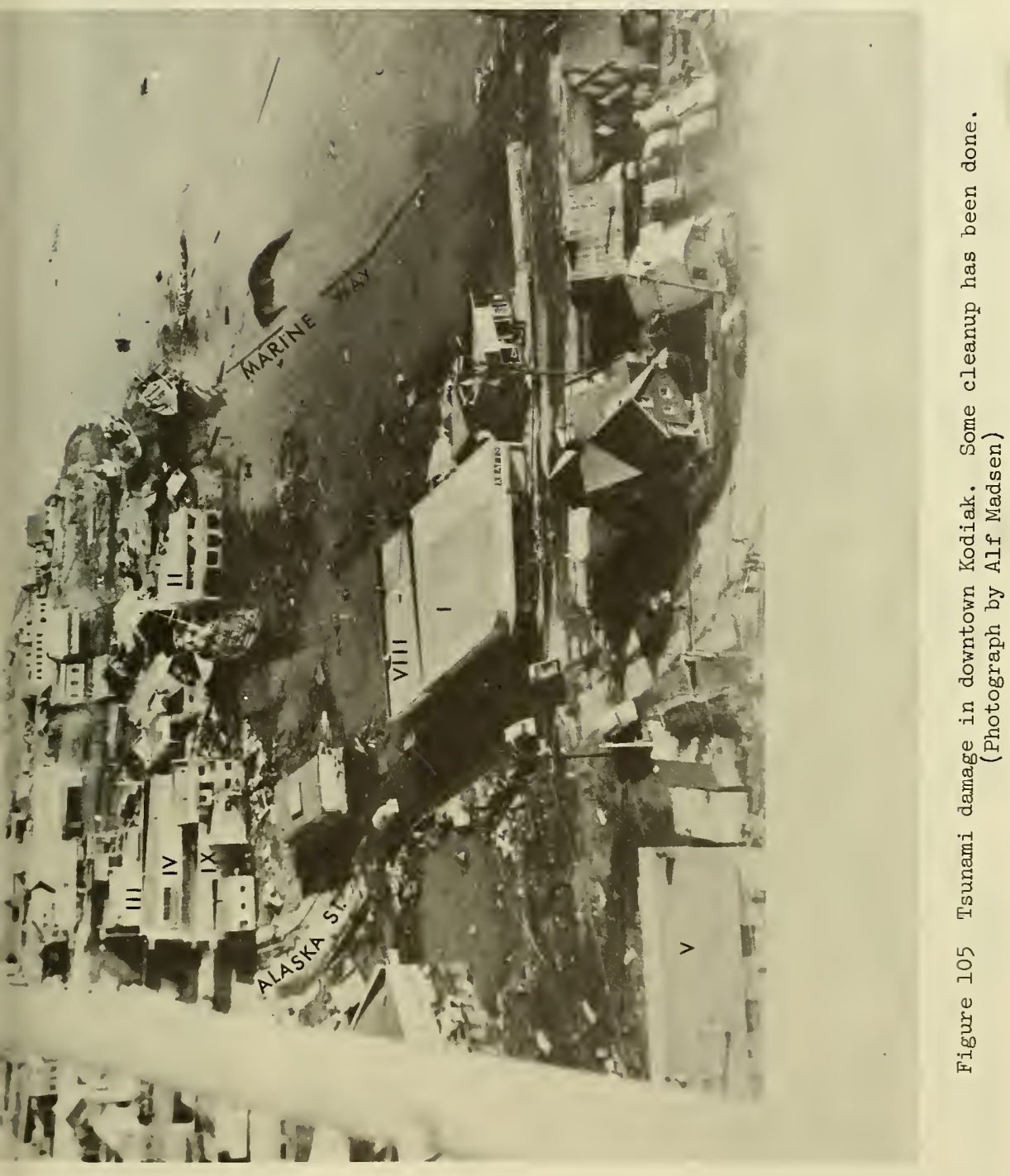




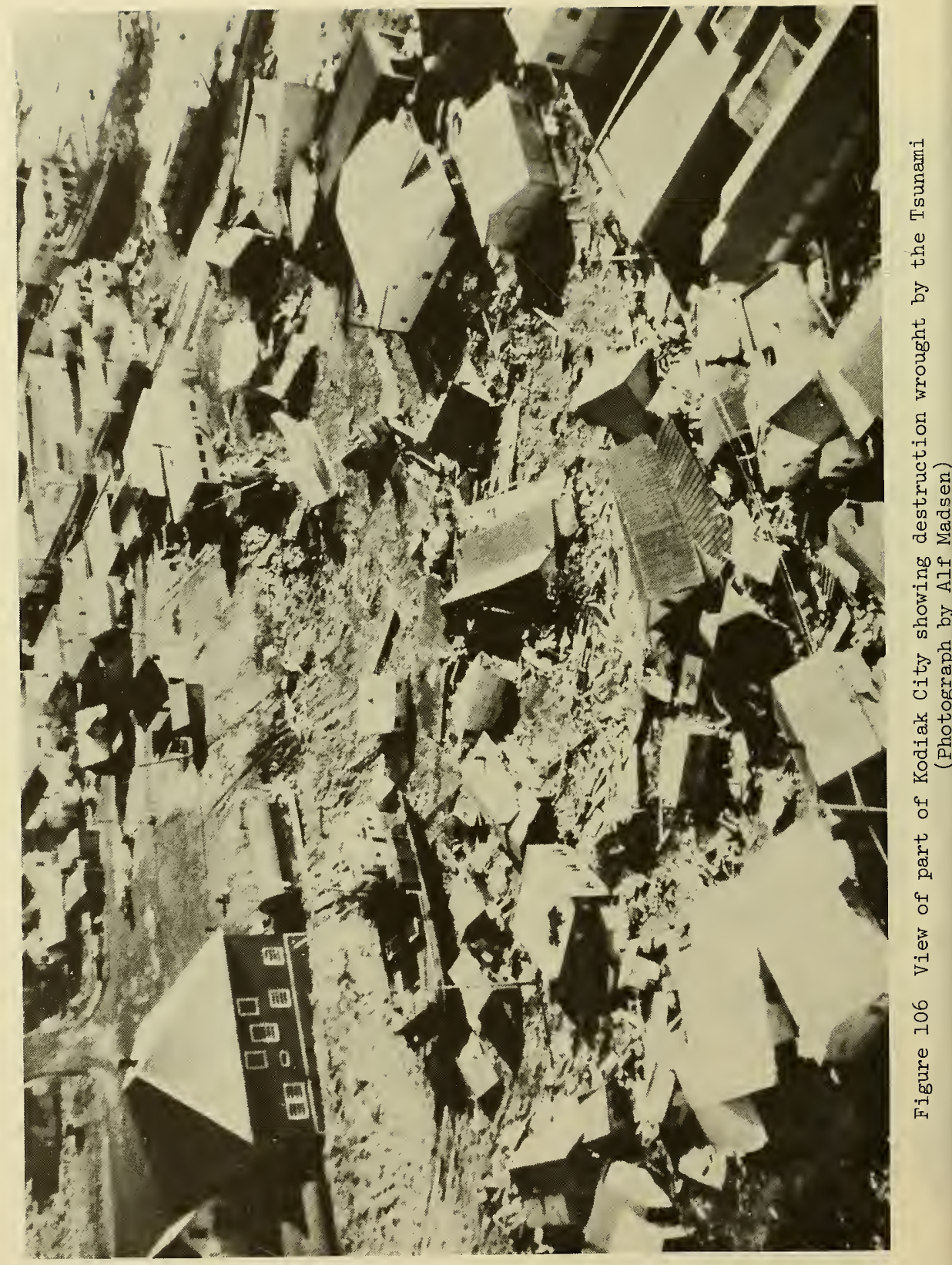




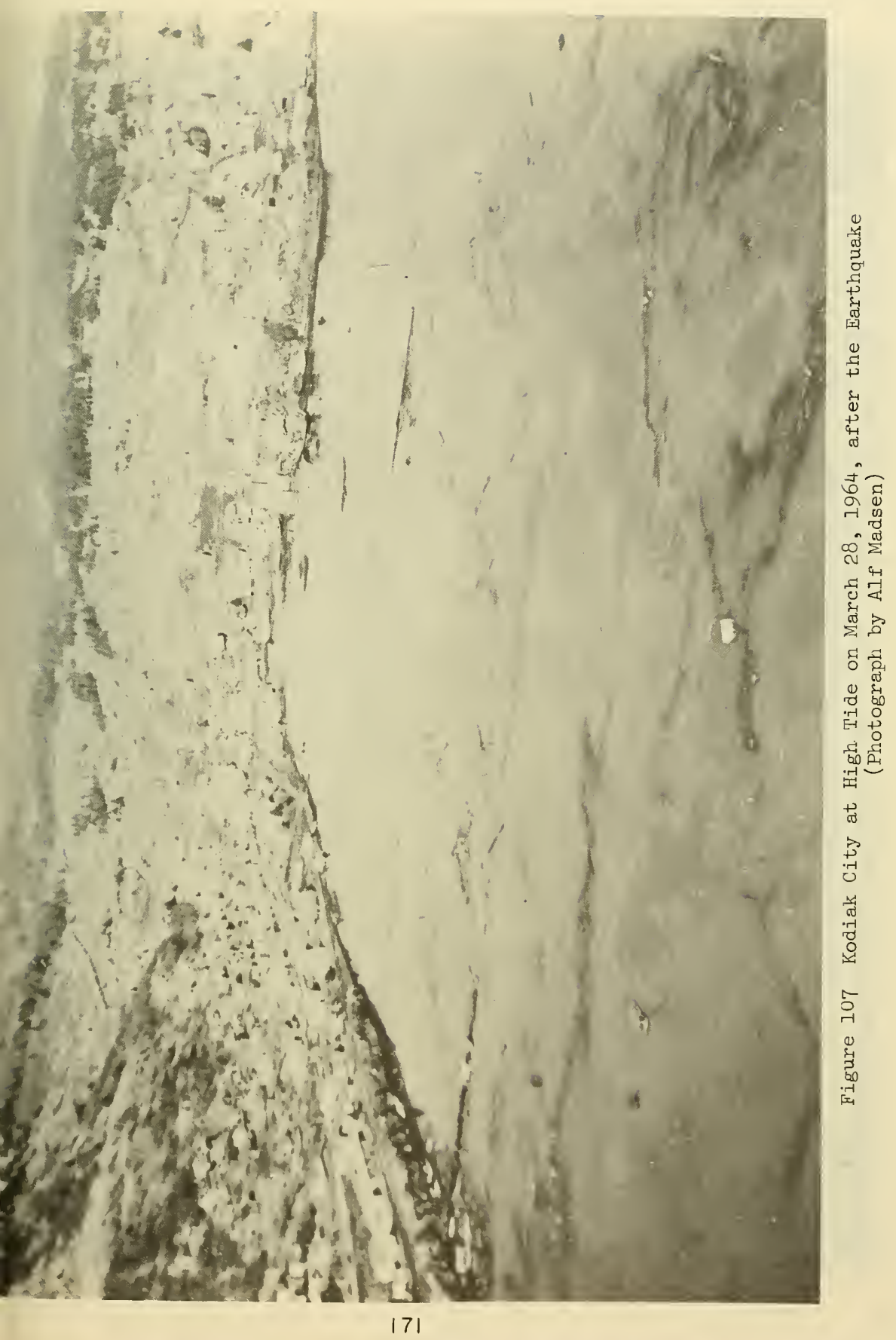




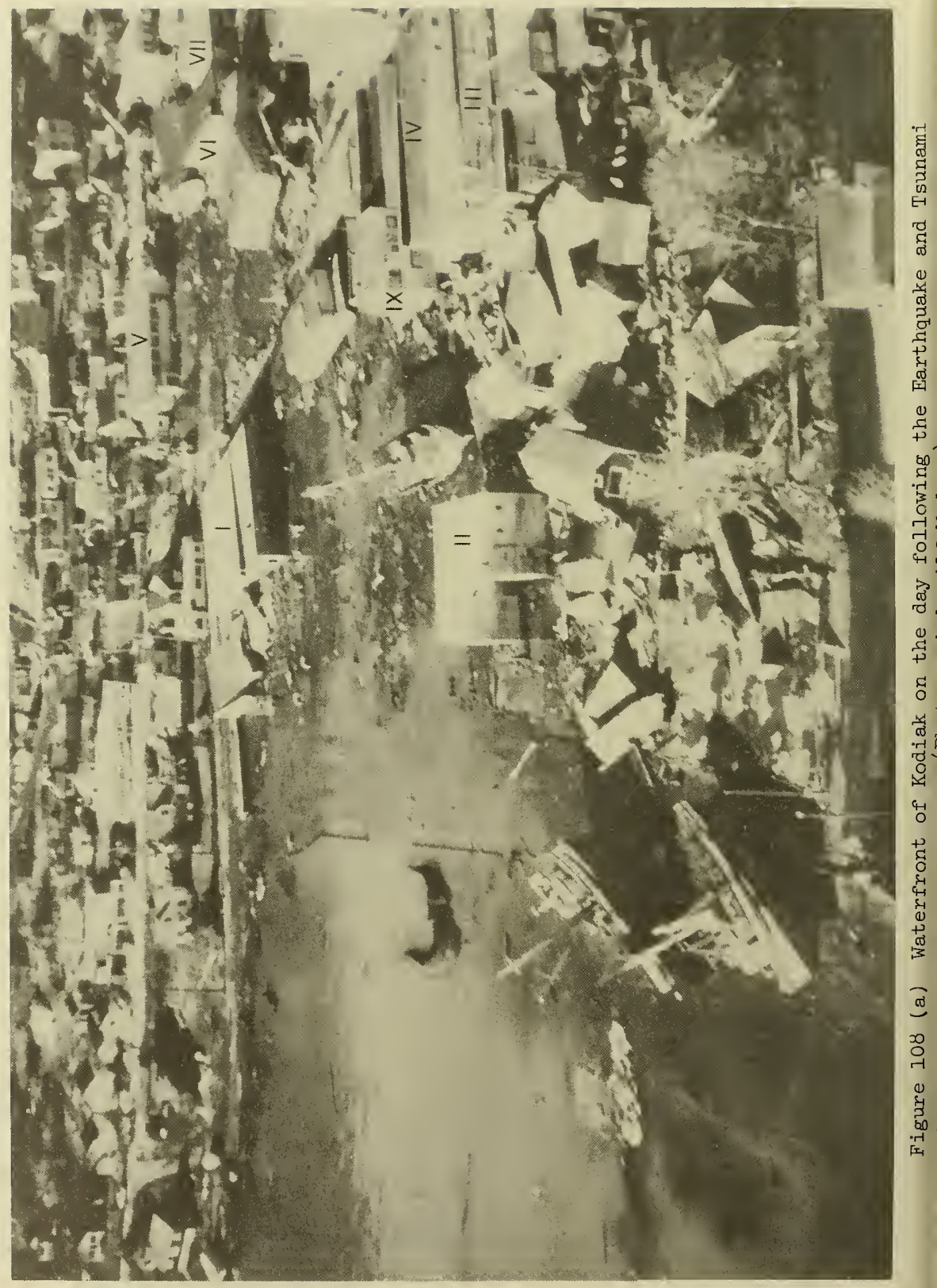


Piv

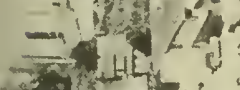

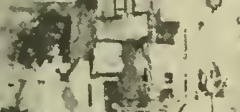 \\ rit in}

is 1
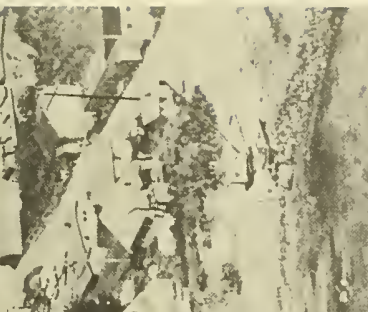

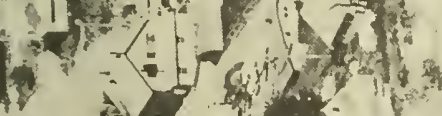

$3=$

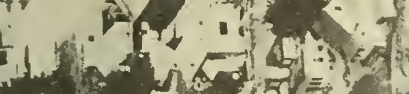

ग $5=0$ w

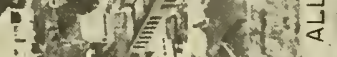

is

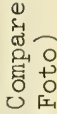

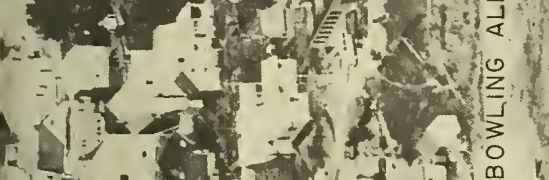

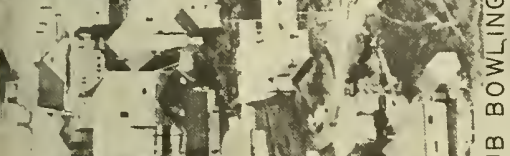
(3-7)

set

(5)

ii

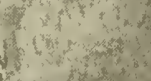

$211]+\cdots v^{2}$

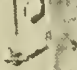

. U

iे

年

तै द्ध

개 ๘

वै 0

$-13$

范 苟

苨䓃

०.

क्ष

घ1

$+$

; 0

$-$

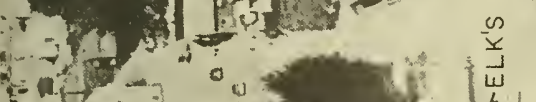

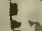

.

(it)

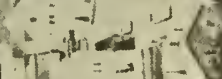

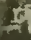

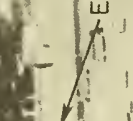

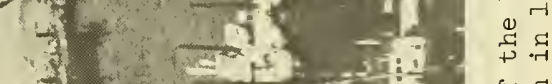

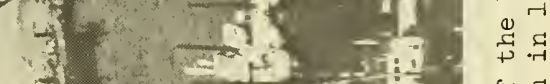

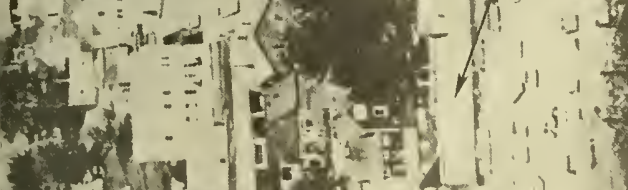

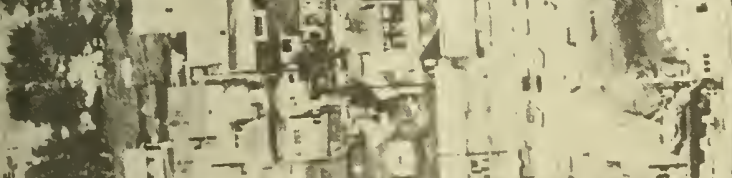

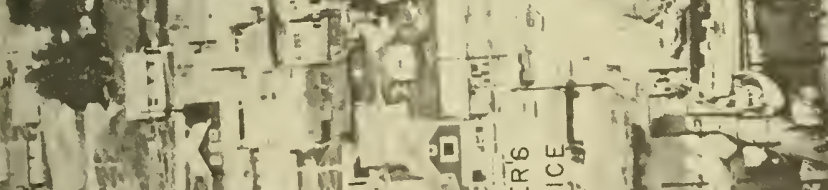

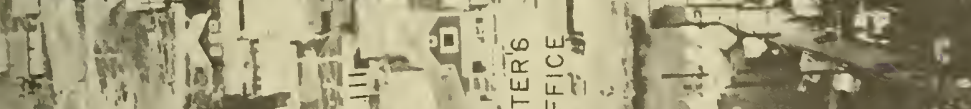

.

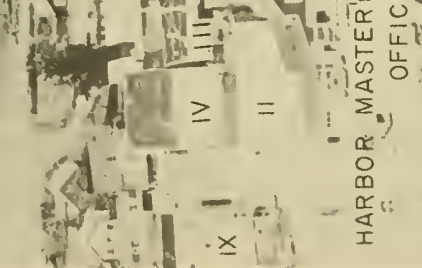



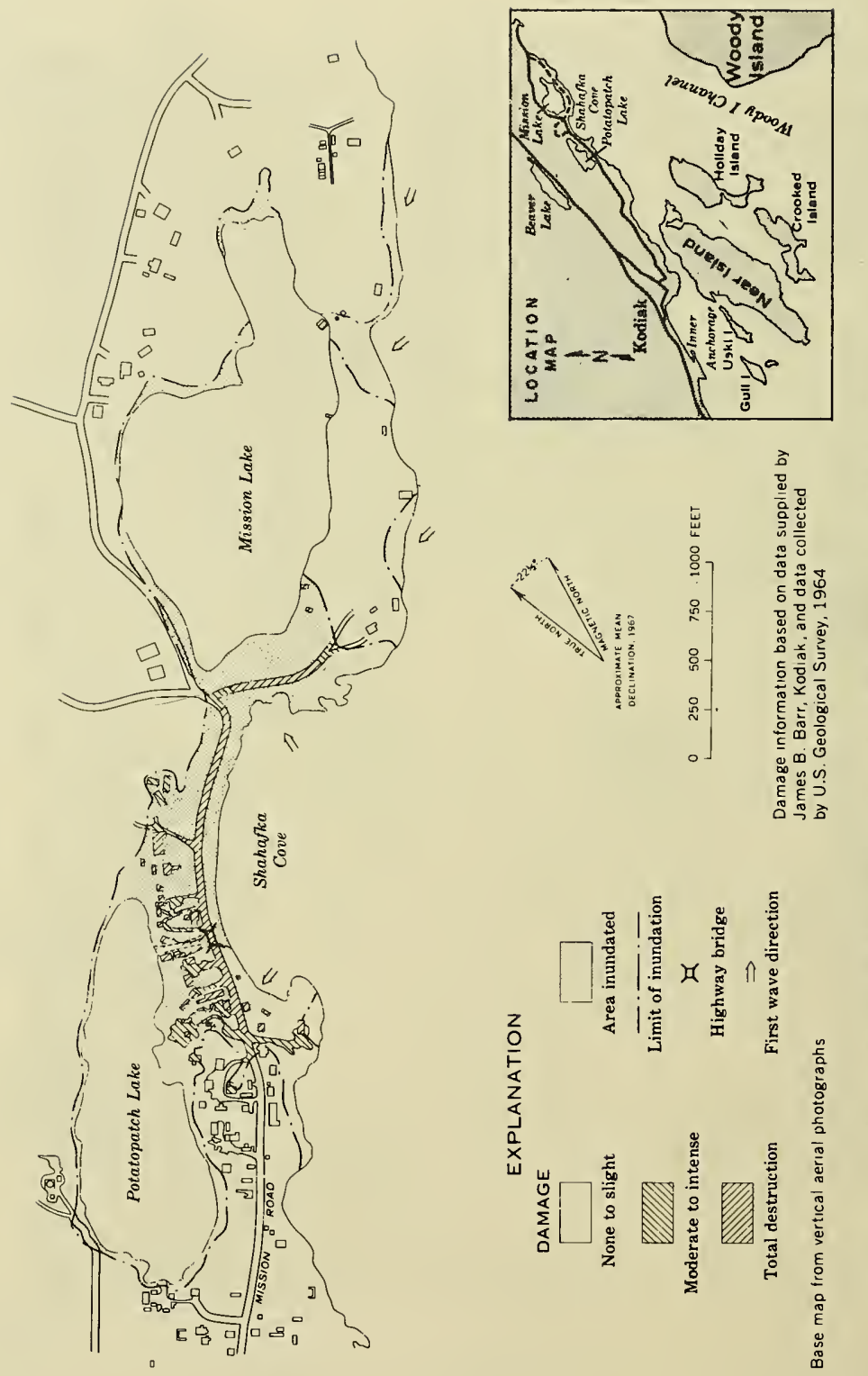

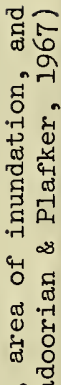

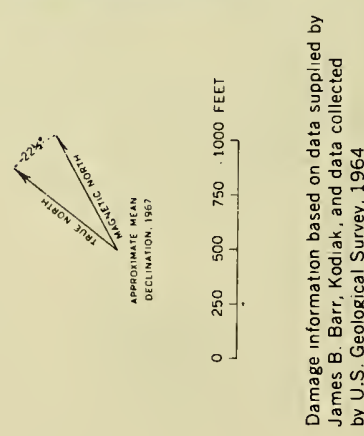

i 율

赵

悬

영

\&ᄋ क्ष

3

है

年

สี่

न-

O

a 0

(ึ)

๘ै ญ

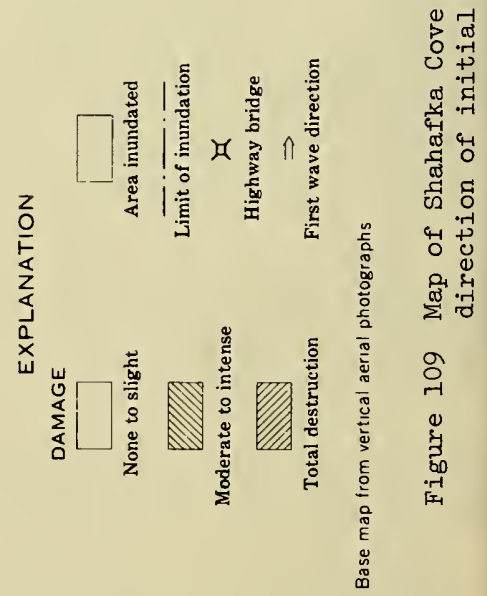




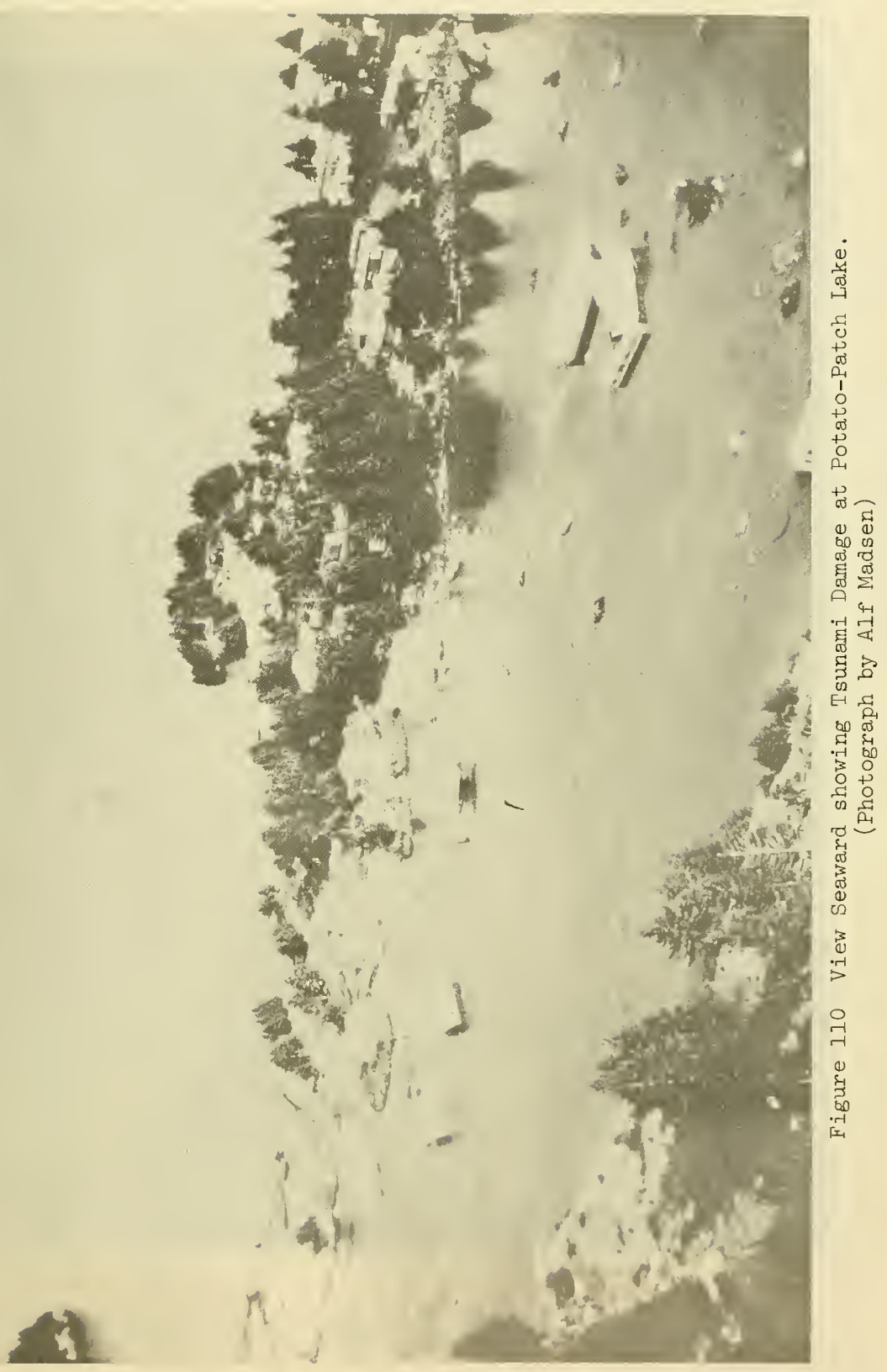




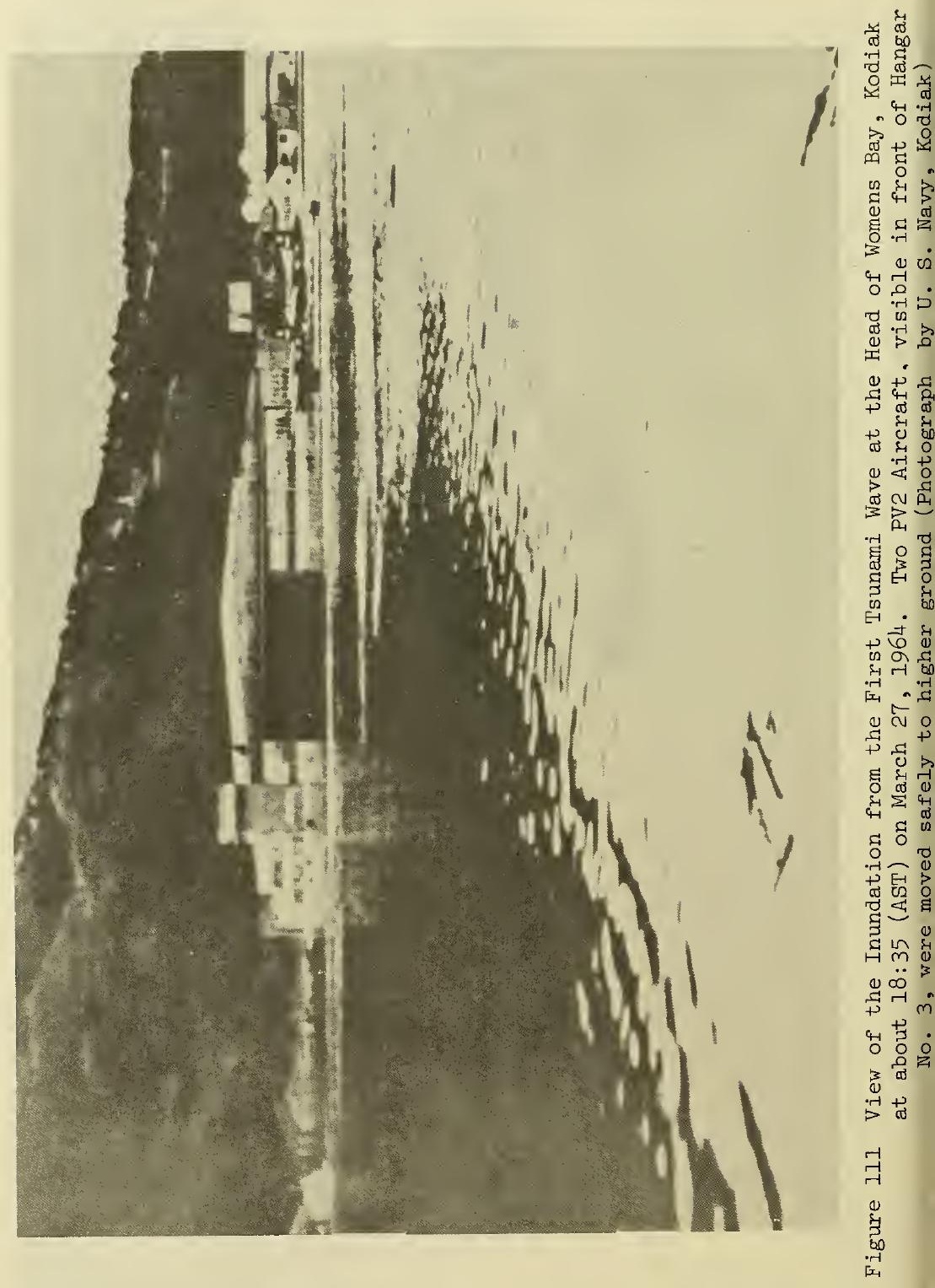




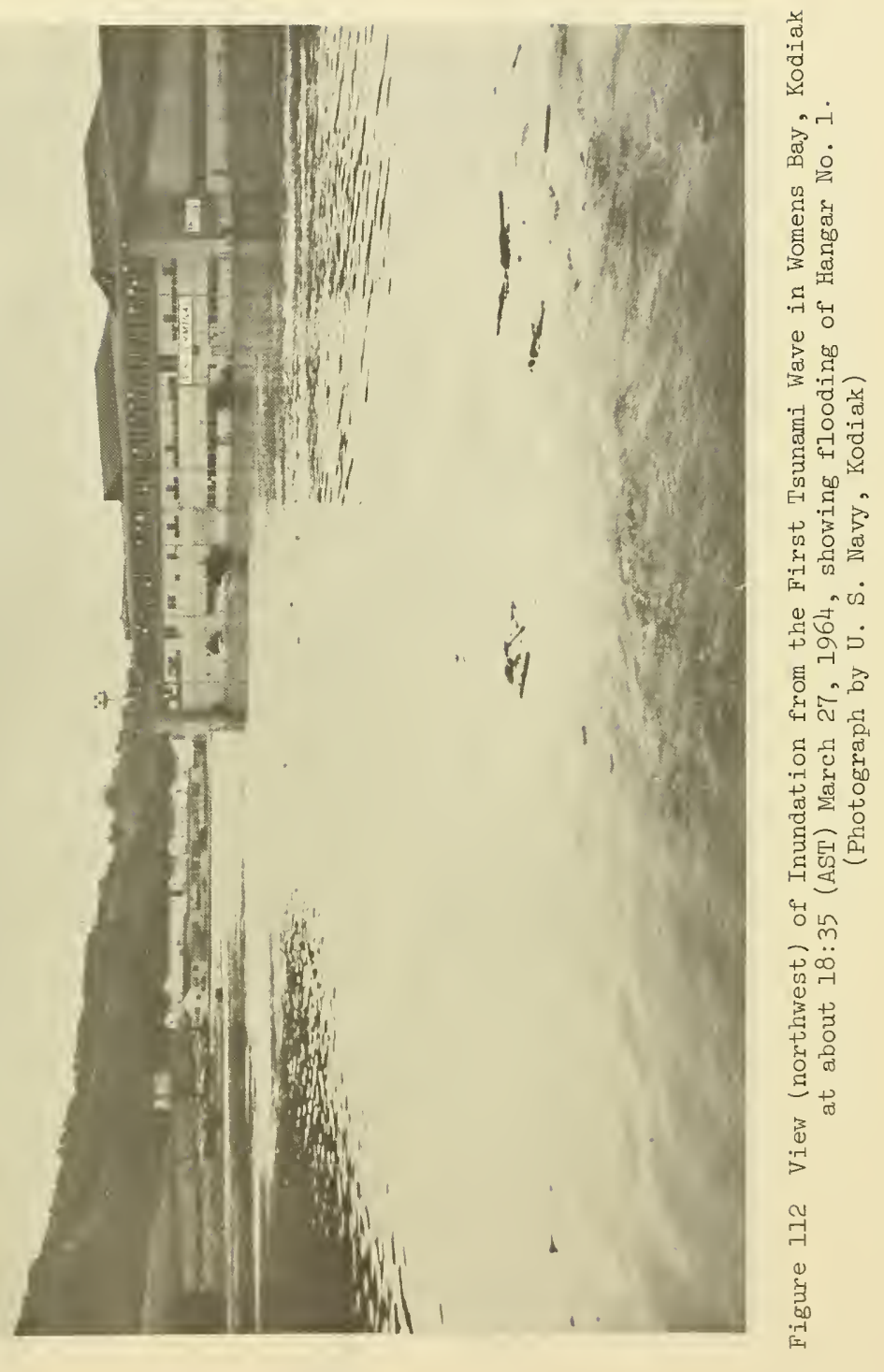




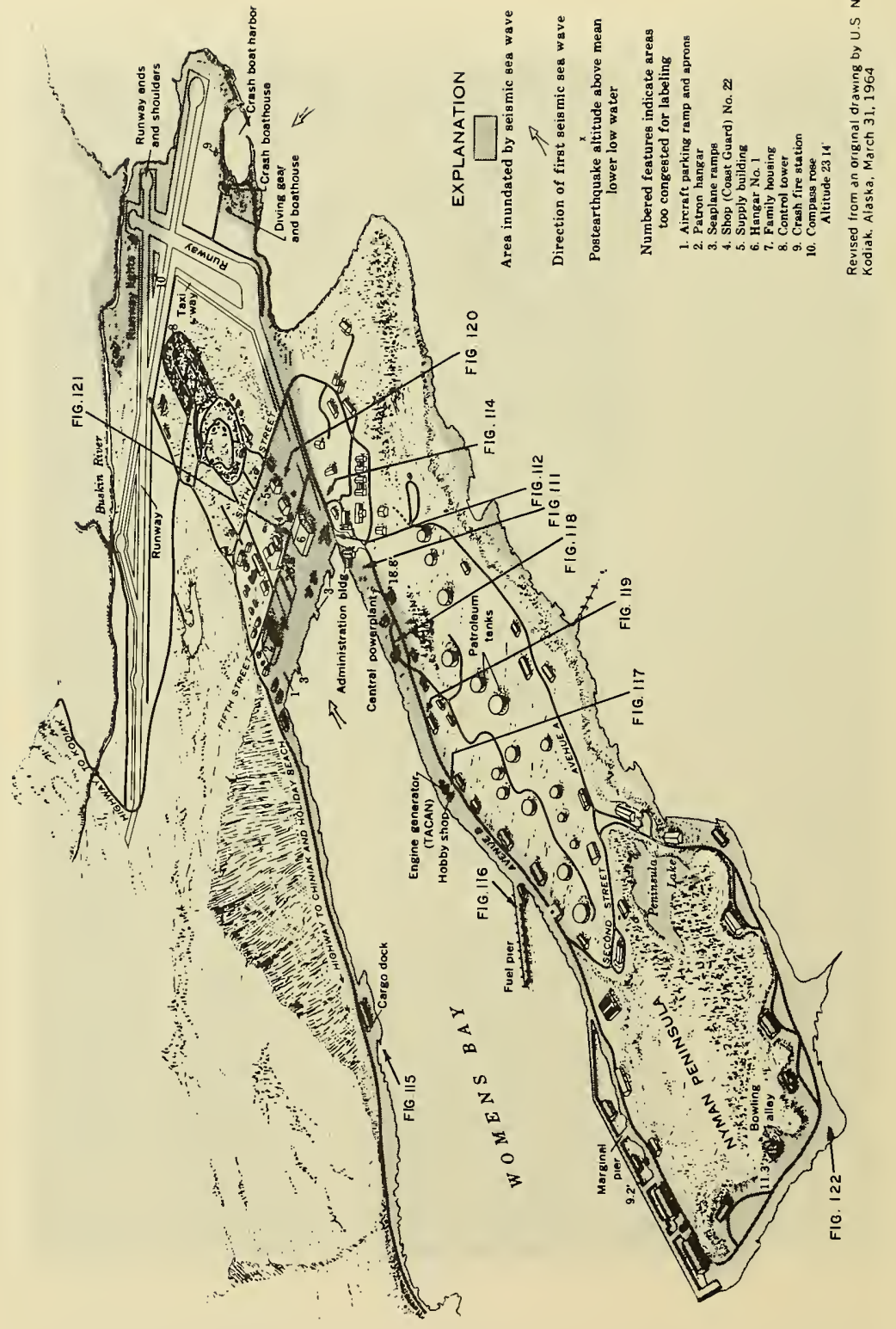

สิ

on

है बे

을

究

范

总

os

$\stackrel{5}{5}$

क

ฮె

थ

०)

目

(1) ్ㅣ

क है

s

:

.

త

걱

म

园

羊

$x$

$\sum^{\infty}$

㟧

घै

$m$
न1
0
0
0
0
$0-1$
[. 


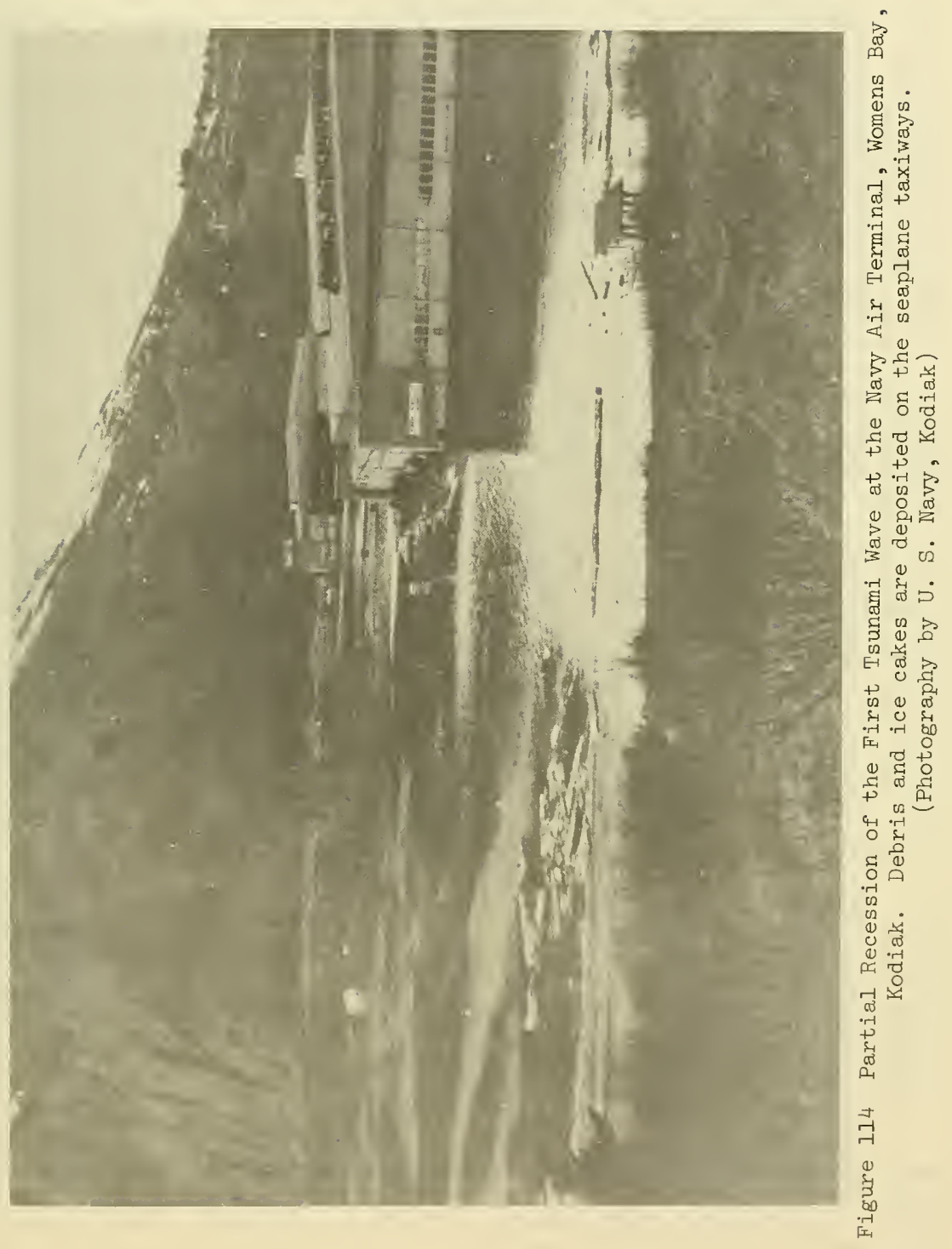


Eyewitnesses have reported that the second damaging wave which struck at $7: 40 \mathrm{p} . \mathrm{m}$. (Figure $38 \mathrm{a}$ and Appendix A) was a breaking wave along the southwest shoreline of Womens Bay (Kachadoorian and Plafker, 1967). This is not surprising in view of the extremely flat slope of the tidal flats in this region (Figure 88) and the fact that the withdrawal of the previous wave would have exposed the seabed near the hairpin bend of the bay. Additional information on this wave comes from Mr. and Mrs. Louis Schultz (Kachadoorian and Plafker, 1967), who were on the Chiniak Road Figure 88), presumably near Womens Bay, when the wave struck. It rolled in rapidly as a wall of water about 3 feet high and was followed immediately by a series of surges. Each surge raised the water level by jumps. This is typical of a bore or large wave running up a flat beach gradient. The darkness of the night precluded further observation of later waves, and no reports are available other than the measurements logged at the Fleet Weather Central (Appendix A).

The total damage to buildings, materials and equipment at the Naval Station, resulting from the earthquake, was said to be in excess of $\$ 10,000,000$ (Tudor, 1964). Most of this damage can be attributed to the tsunami. A listing of damaged structures and estimates for their restoration or replacement is found in Table E-3 (Appendix E).

The Cargo Dock on the north shore of Womens Bay (Figure 113), already deteriorated, was completely destroyed (Figure 115). According to Tudor (1964), the tsunami violently moved a moored ship which lifted the bollards and damaged some fendering. The elevated water buoyed sections of the pier decking off the pilings and moved them laterally, thus causing failure of many framing and bracing members. Several piles were pulled from their pile holes intact along with the elevated decking. The reason for this is that great trouble had been experienced originally in driving the piles into the rocky bottom on the northside of Womens Bay, and in some instances pile holes had to be augered. When the flood water receded, the buoyed decking and extracted piles crumpled the dock as shown in Figure 115.

The Marginal Pier and the Tanker and Fender Pier (fuel pier, Figure 113), suffered only minor damage. At the Marginal Pier, a moored barge, under tsunami action, loosened a bollard and some of the decking (Tudor, 1964). The pier had to be loaded down with anchor chains after the earthquake to prevent flotation on the high tides which, after the earthquake, reached to higher levels than previously owing to a 5.6-foot subsidence of the land (Figure 116). Because of this complete rebuilding of the Marginal Pier had to be undertaken later.

Two small, waterfront structures, the Hobby Shop Boat Repair House and the Engine Generator Building (Figure 113), were completely swept from their foundation pilings. Figure 117 shows the Boat Repair House after the earthquake right alongside of its own pilings. The Hobby Shop itself was moved and broken in two pieces (Figure 118). The Ground Electronics building was damaged as shown in Figure 119. Here a side wall apparently failed under hydrostatic pressure of water at a level 


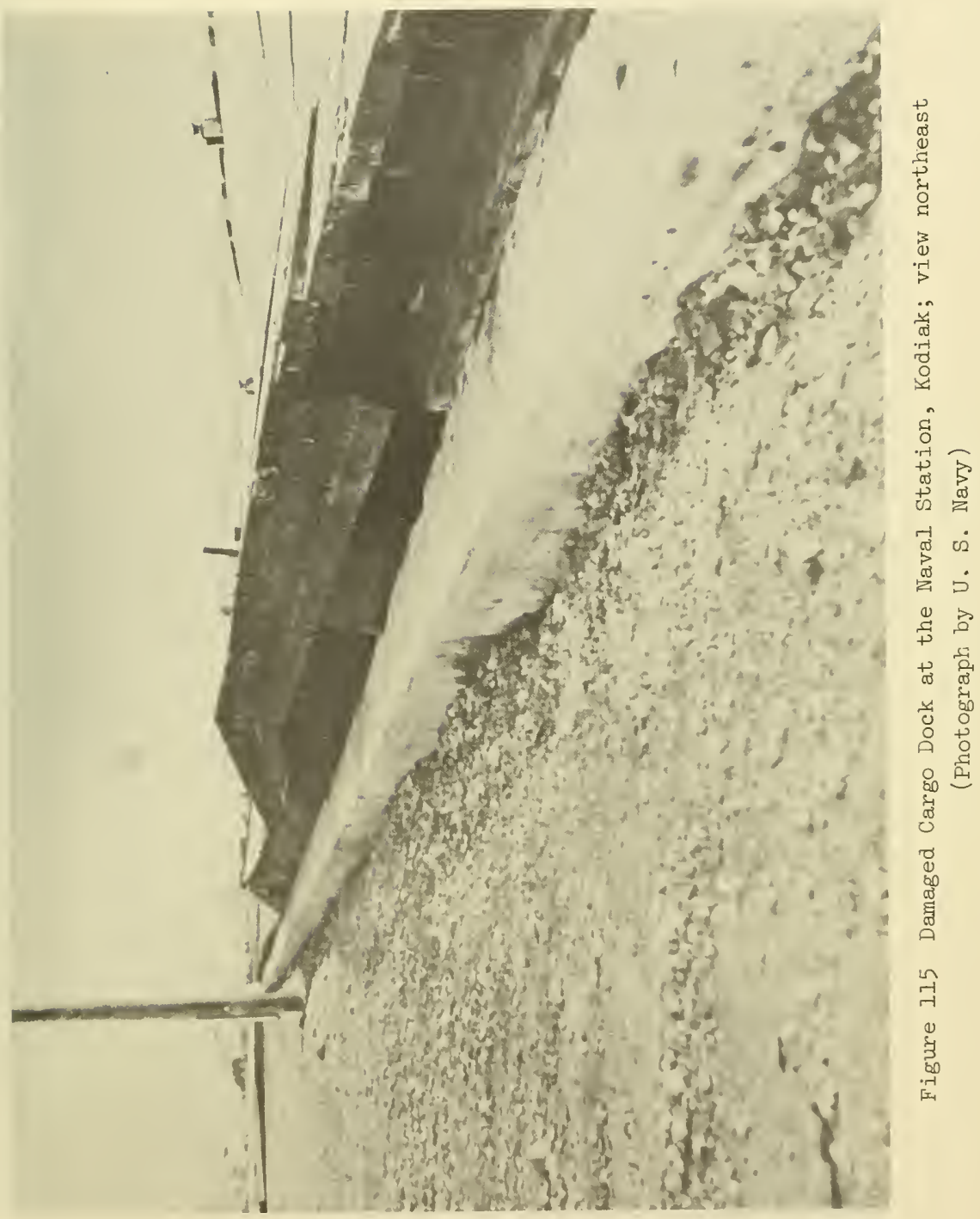




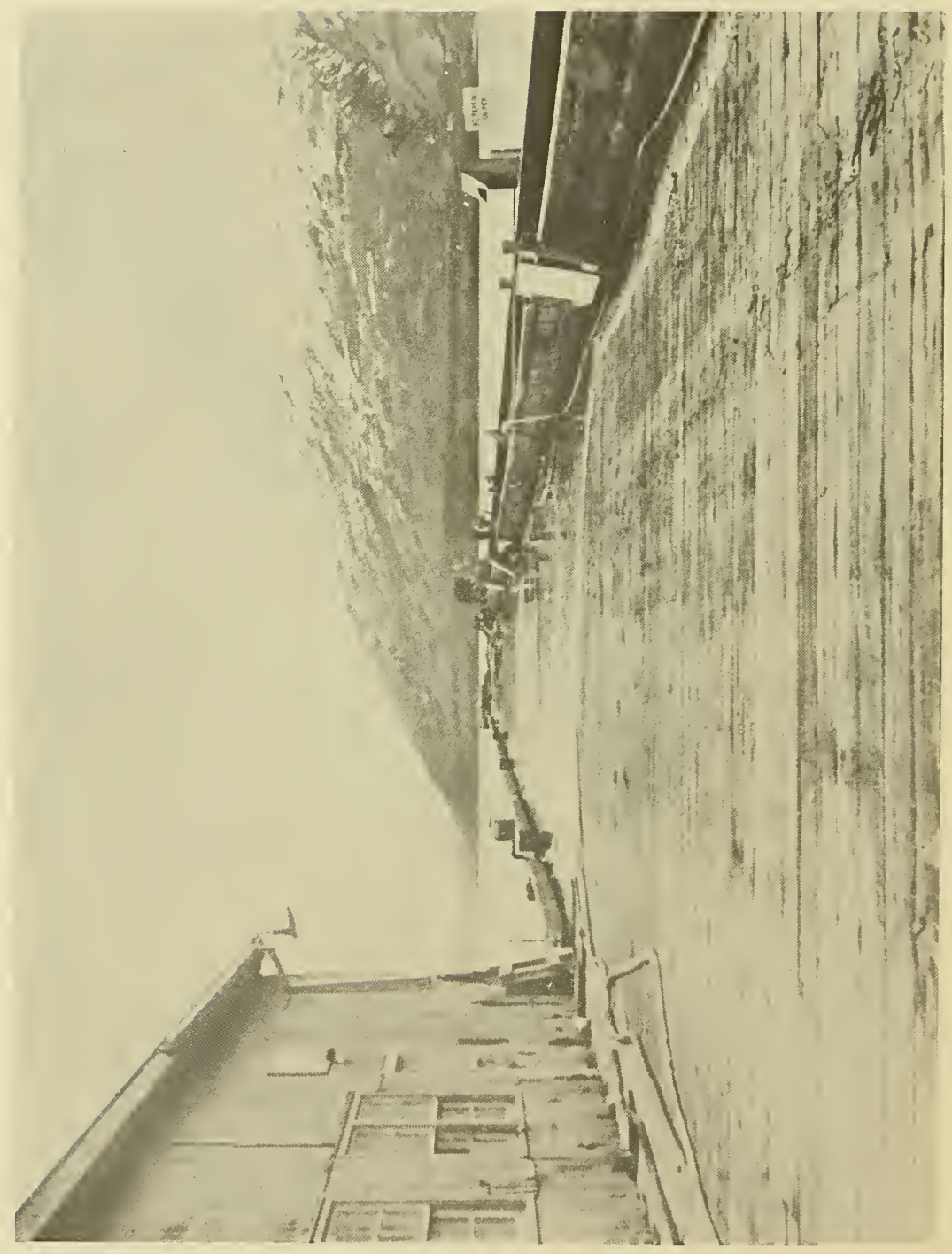

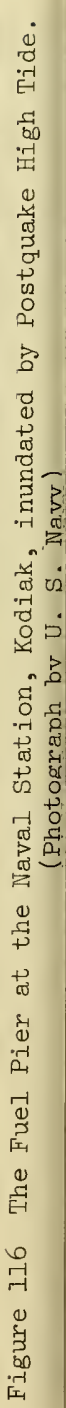


1) 1. xu whe

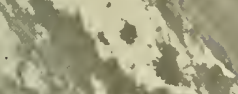

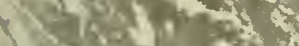

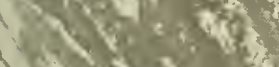

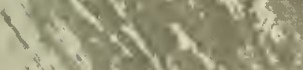
Net: U. is in int Nisu $\checkmark n$ 1

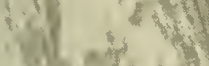
$x^{2}+x ; 1$ $(x, y)$

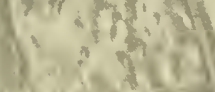

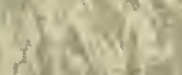

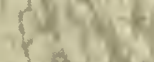

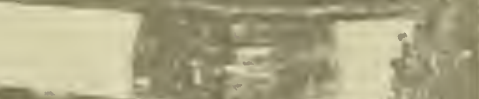
$\operatorname{lom}^{2}+1>$ t. in.

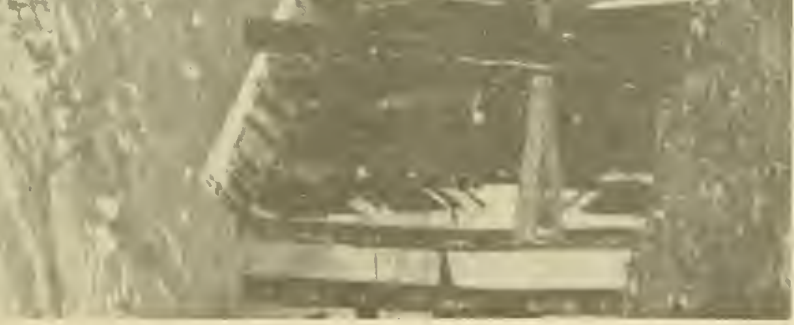

$\widehat{5}$

党

i

$\dot{p}$

$\overrightarrow{0}$

용

के

5
00
0

을

过

क्ष

.

뭉

s.

द्व

Оิ

$+$

更

吸

न

3

$\pi$

(

-

$+$

(1)

ำ

노

.

$\infty$

요

质

雚

๓

०ि

昆

응

证

न

ֻ1 


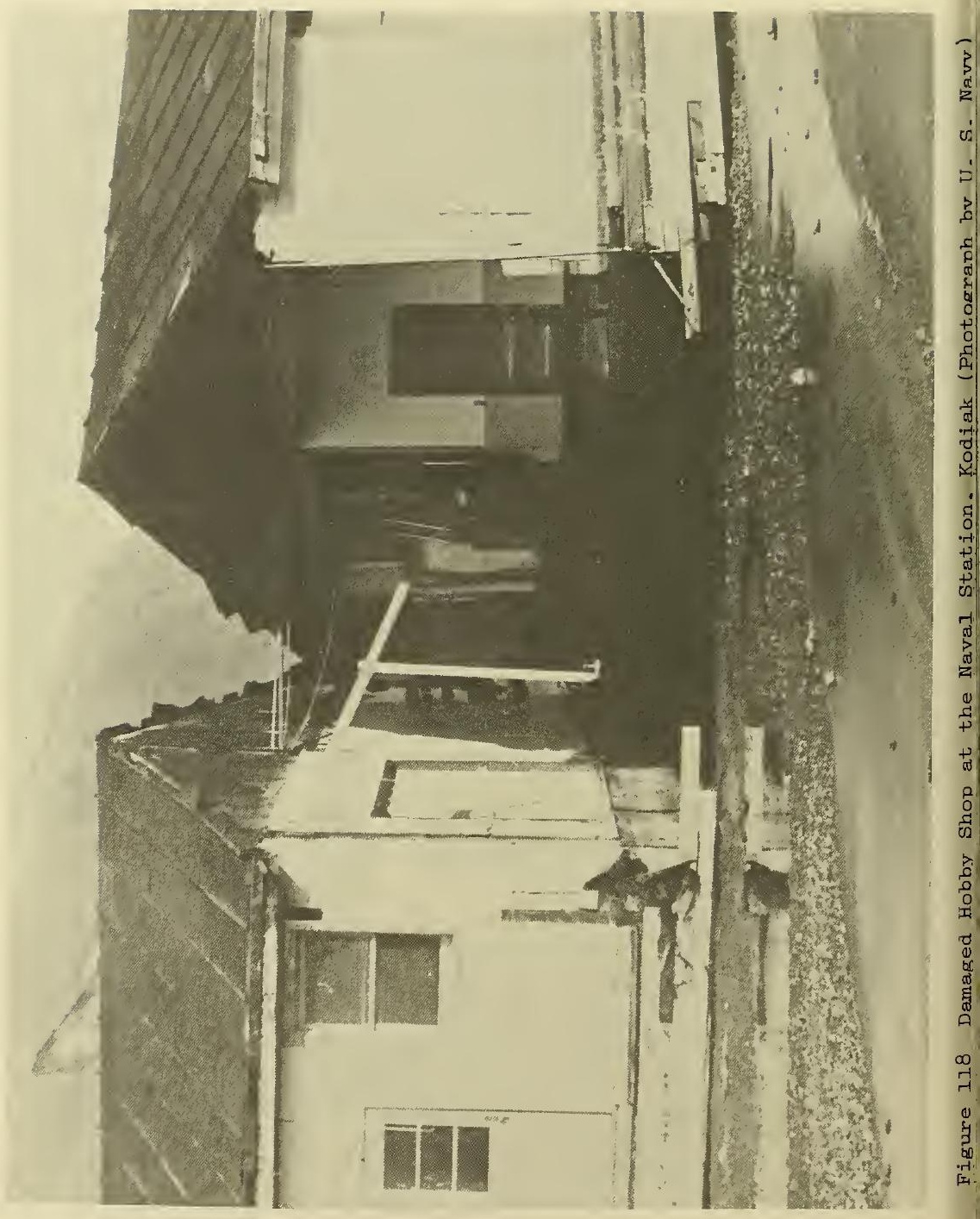




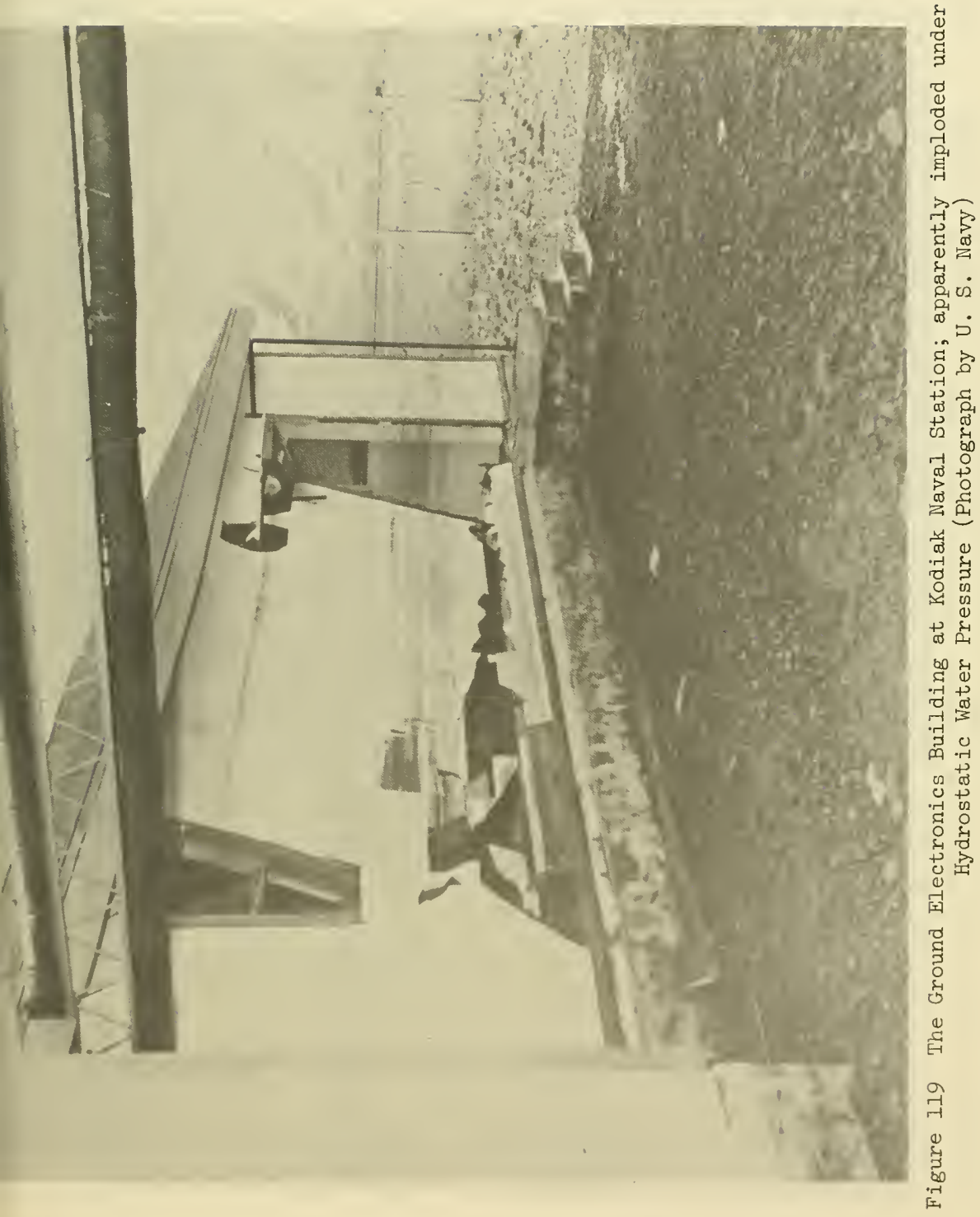


reaching to door height, probably about 6 to 9 inches above floor level. Maximum pressure at the floor would have been about 215 pounds per square foot and the total load per foot on the wall about 1,350 pounds.

A 12-foot diameter, 10-ton mooring buoy was torn loose from its anchorage in Womens Bay and deposited on the taxiway of the air terminal (Figure 120) near the supply depot at location 5 in Figure 113. It was carried to this position, about a quarter mile inland, by the fifth (and highest) tsunari wave, which crested between $11: 16$ and $11: 34$ p.m. on March 27, 18.8 feet above MLLW (Figure 38a) (Kachadoorian and Plafker, 1967). The buoy had apparently torn loose from its die-lock anchor chain. Tudor (1964) has estimated that merely the complete immersion of the buoy by the rising water would have increased tension on the mooring chain by a factor of 3.6 above the free-floating load.

The asphalt taxiways between the hangars and seaplane ramps were fragmented under the seismic action. In the hangars there were differential settlements between the fill-supported hangar deck and the pilesupported columns, and relative settlements between the hangar footings and the hangar deck occurred around the perimeter of the hangar (Tudor, 1964; Worthington, et al, 1964; Kachadoorian and Plafker, 1967). The hangars were constructed on a fill of approximately 15 to 20 feet of unconsolidated glacial till which was compacted under seismic vibrations and the additional loading of the subsequent waves (see Figure 121). According to Kachadoorian and Flafker, no significant amount of erosion accompanied this settlement.

At the edge of the seaplane parking area, the vertical sheet pile bulkhead was buckled outward along its length. It is not known whether this damage was caused by the earth tremors or by the tsunami. A slumping movement of the ground could undoubtedly have bent the steel piles. During the inundation periods, however, the fill behind the sheet piles was probably fully saturated by water filtering through a zone of cover stone between the bulkhead and the concrete parking area. This trapped water would have established a hydraulic head, which, in association with suction pressures on the retaining wall from receding flood waters, could have buckled the sheet piling outward.

At the edge of the seaplane parking area a small white house, visible in Figure 114, survived the floodings because of hold-down cables over the roof (Tudor, 1964).

According to Tudor, the ground floor of the main power plant was repeatedly flooded by water with a heavy silt load. Heavy fuel oil on the water coated the boilers, blowers, motors, and pumps on the boiler flat (deck) and rendered them inoperative. The maximum water elevation inside the plant was below the generator deck where the high voltage switching gear and control instrumentation were located.

Some low-level radioactive contamination occurred in the Ground Electronics Building when tsunami waters scattered traces or minute sources of radio-nucleides (Tudor, 1964). 


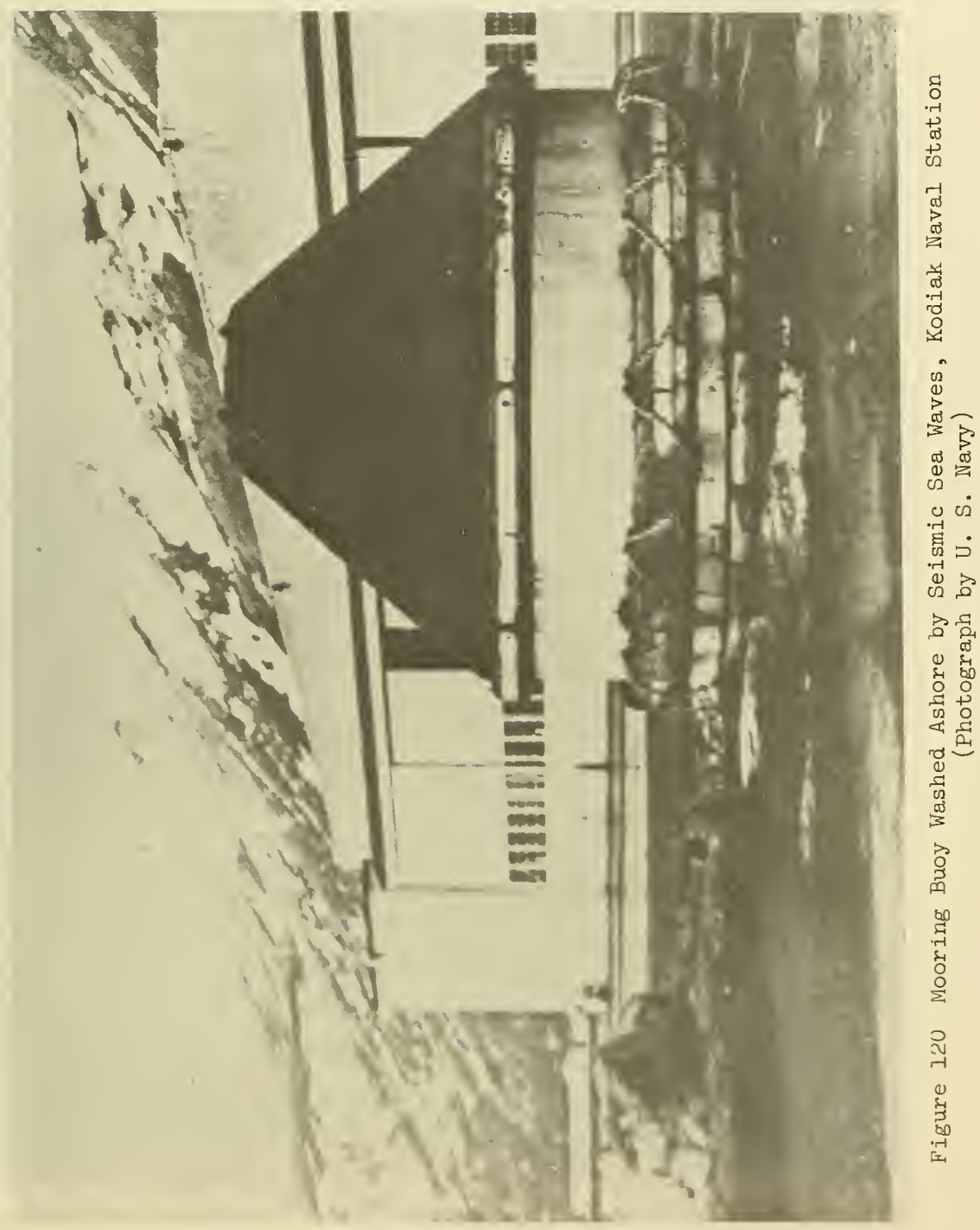




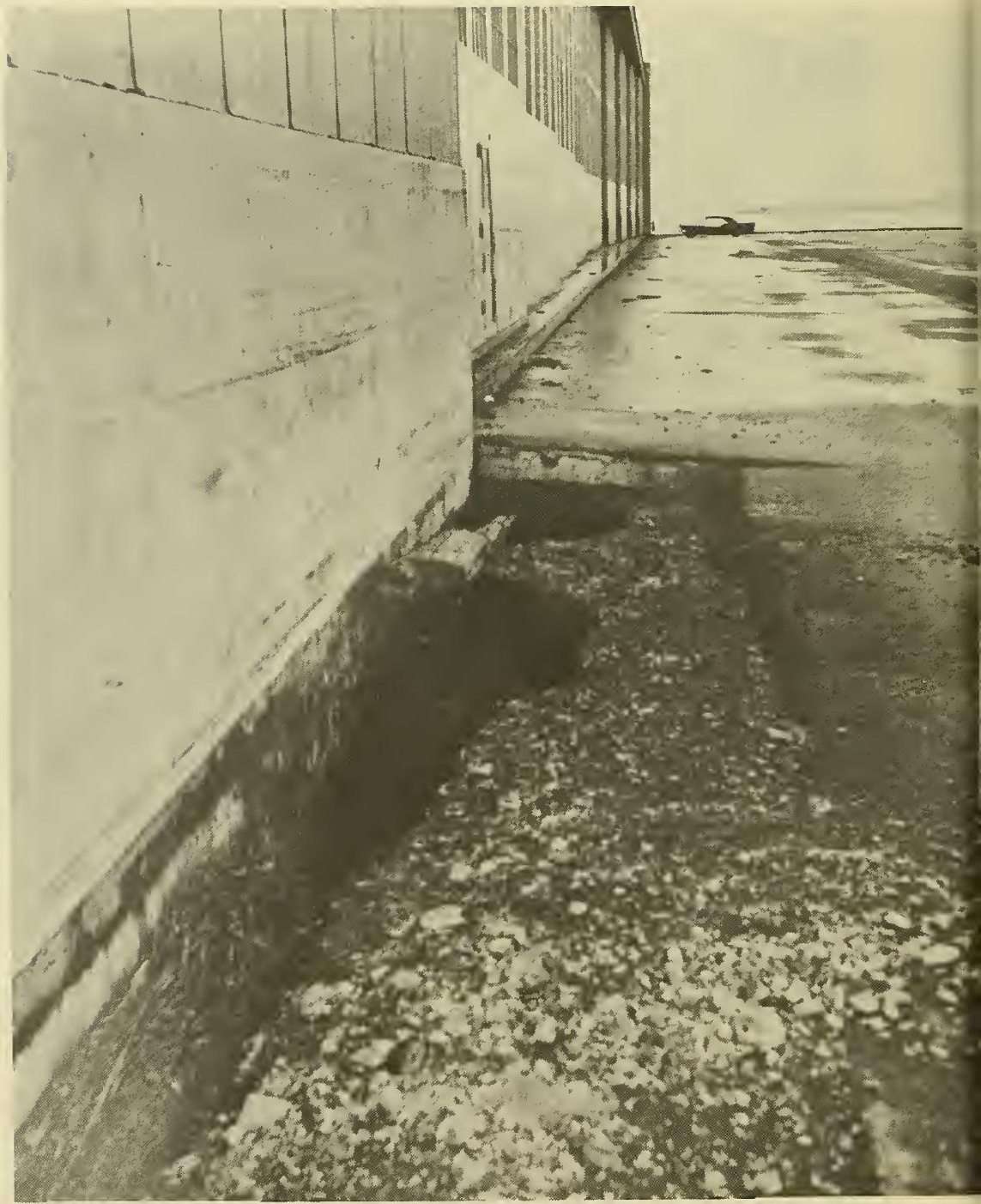

Figure 121 Evidence of Settlement of Backfill Material below Pavement Level, adjacent to the foundation of a Hangar at Kodiak Naval Station. (Photograph by U. S. Navy) 
Vehicles partially or fully submerged by the elevated waters were for the most part a total loss owing to the corrosive effect of salt water on the motors and wiring. In addition, oil slick from the water was deposited heavily on many vehicles (Tudor, 1964).

At the southwest end of the Nyman Peninsula the road bed was partly eroded from under its asphalt cover-layer (Figure 122). The road between the Naval Station and Cape Chiniak was damaged in several places. (Figures 123 to 125 present views of the scouring effects of the tsunami on roads and bridges in the low-lying deltaic region at the southwest end of Womens Bay (see Figure 88).

In adition to the damage already described, the seismic sea waves caused other miscellaneous damage. The high water (1) washed vehicles inland or into Womens Bay, (2) washed all types of debris onto the beach areas of the Naval Station, (3) destroyed the small footbridge crossing Buskin River, (4) in several localities washed ice across the highway and against buildings, and (5) destroyed several small sheds. This type of damage occurred throughout the low-lying inurdated areas of the station. The cost of the general clean-up of the station and other miscellaneous damage is not included in Table E-3 (Appendix E) (Kachadoorian and Plafker, 1967).

\section{Tsunami Damage at Other Coastal Communities on Kodiak and Neighboring Islands}

The wave sequences at places other than Kodiak City and the U. S. Naval Station, Kodiak, are not well known. It would seem likely that the seismic sea waves affecting the numerous bays and inlets of the Kodiak Island region were basically similar to those at Kodiak City and Womens Bay. The peculiarities of bays, however, would manifest themselves in giving prominence to local resonances.

Some of the runup effects along the coast of the Kodiak Island group have already been referred to briefly in Section III-2 and Figure 40, but it is impossible in a work of this kind to give detailed coverage to all the recorded effects that have been documented by such investigators as Berg, et al,(1964); Brown (1964); Denner (1964); Grantz, et al (1964); Plafker and Mayo (1965); Plafker and Kachadoorian (1966); Kachadoorian and Plafker (1967). We shall merely discuss some of the more important situations that have come to our notice particularly where damage was involved.

At Port William on Shyak Island (Figure 1) the tide receded 45 minutes after the earthquake and was followed by a wave. The highest runup was estimated by Berg, et al (1964) to be 16 feet above MLLW or about 6 feet above the high tide at midnight; slight damage occurred.

At Afognak (village) in Marmot Bay, Afognak Island (Figure 126) there was an immediate recession of water after the earthquake followed by a wave crest within 15 minutes. Four additional waves followed; the fourth and highest destroyed part of the village (Berg, et al (1964). 


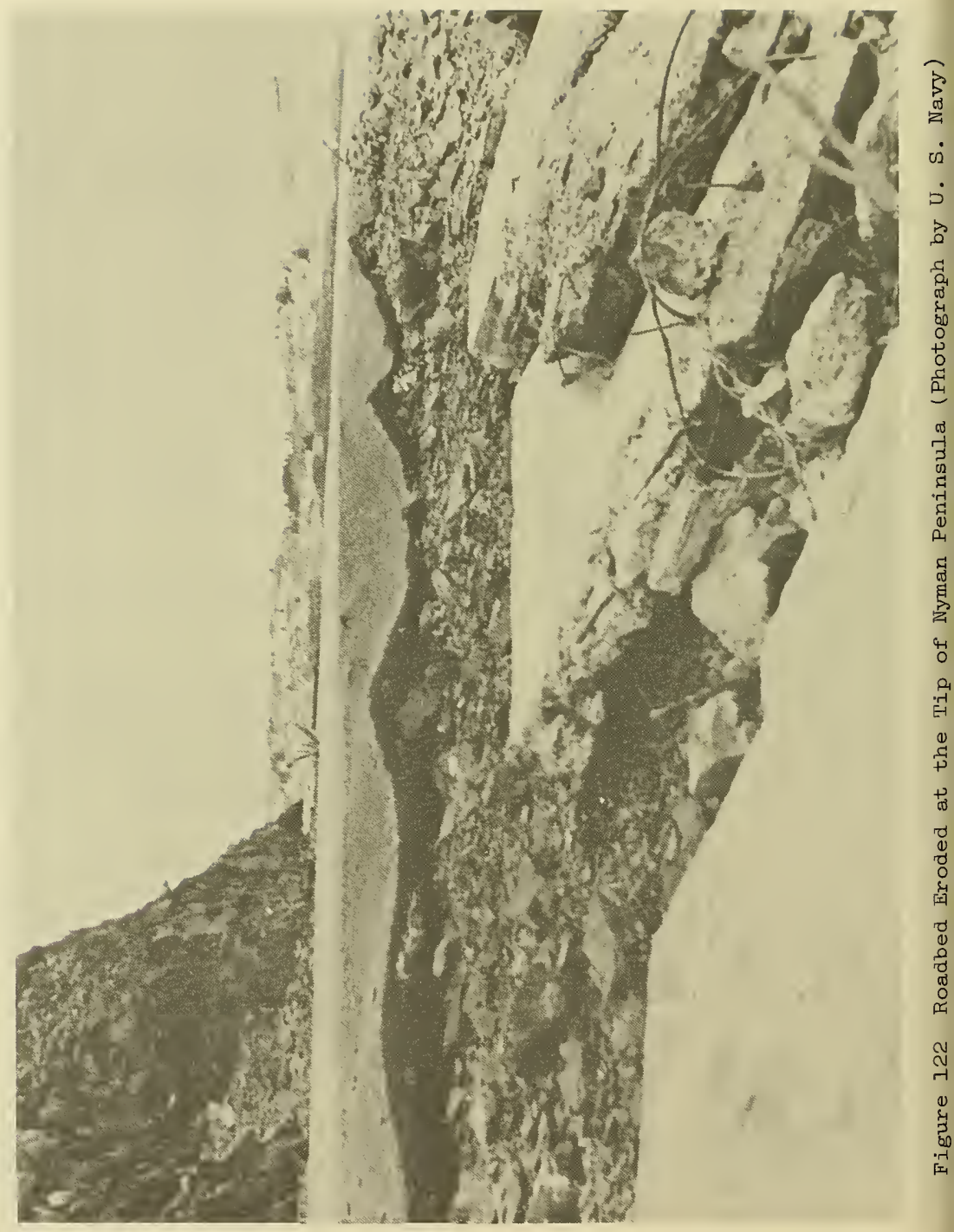




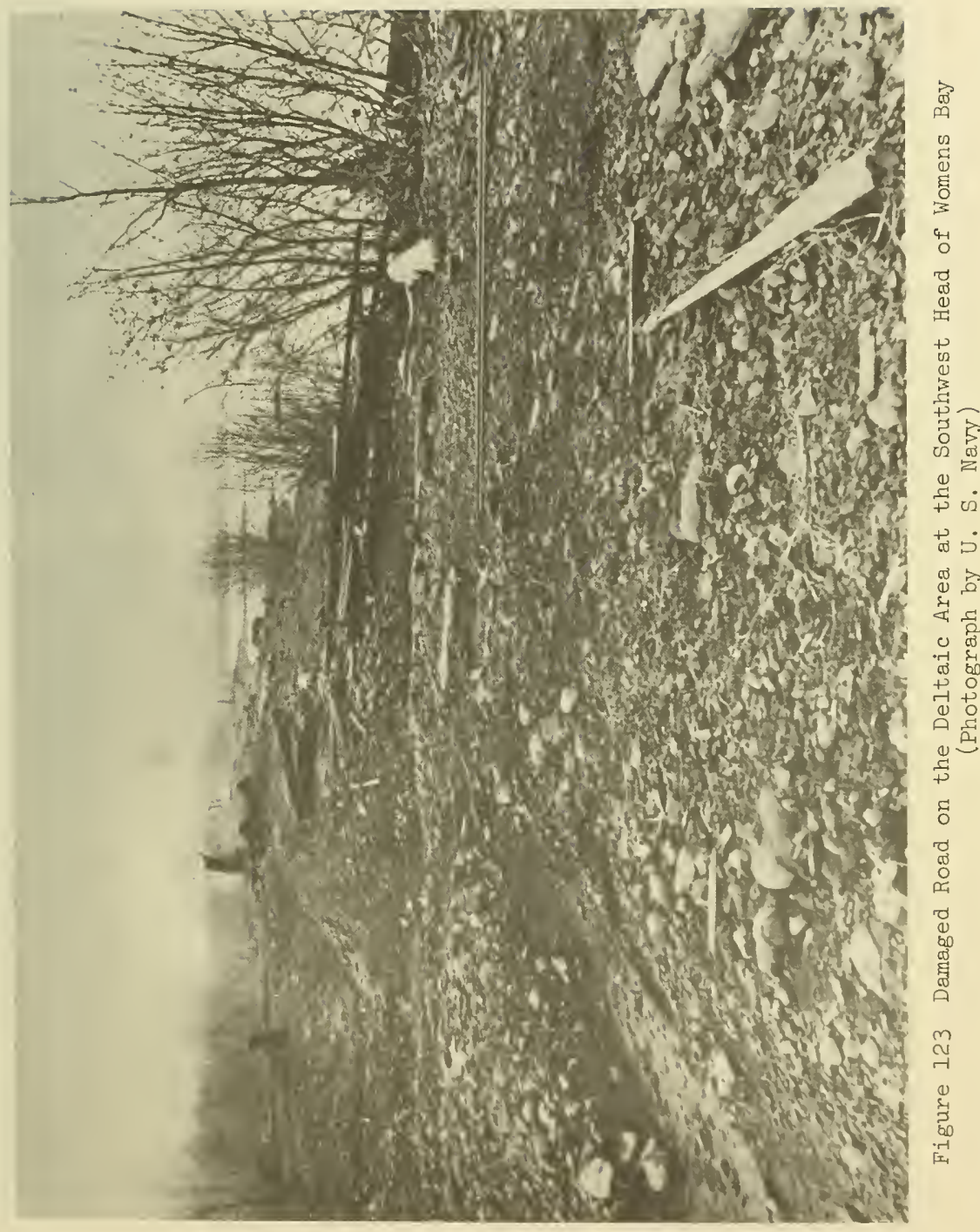




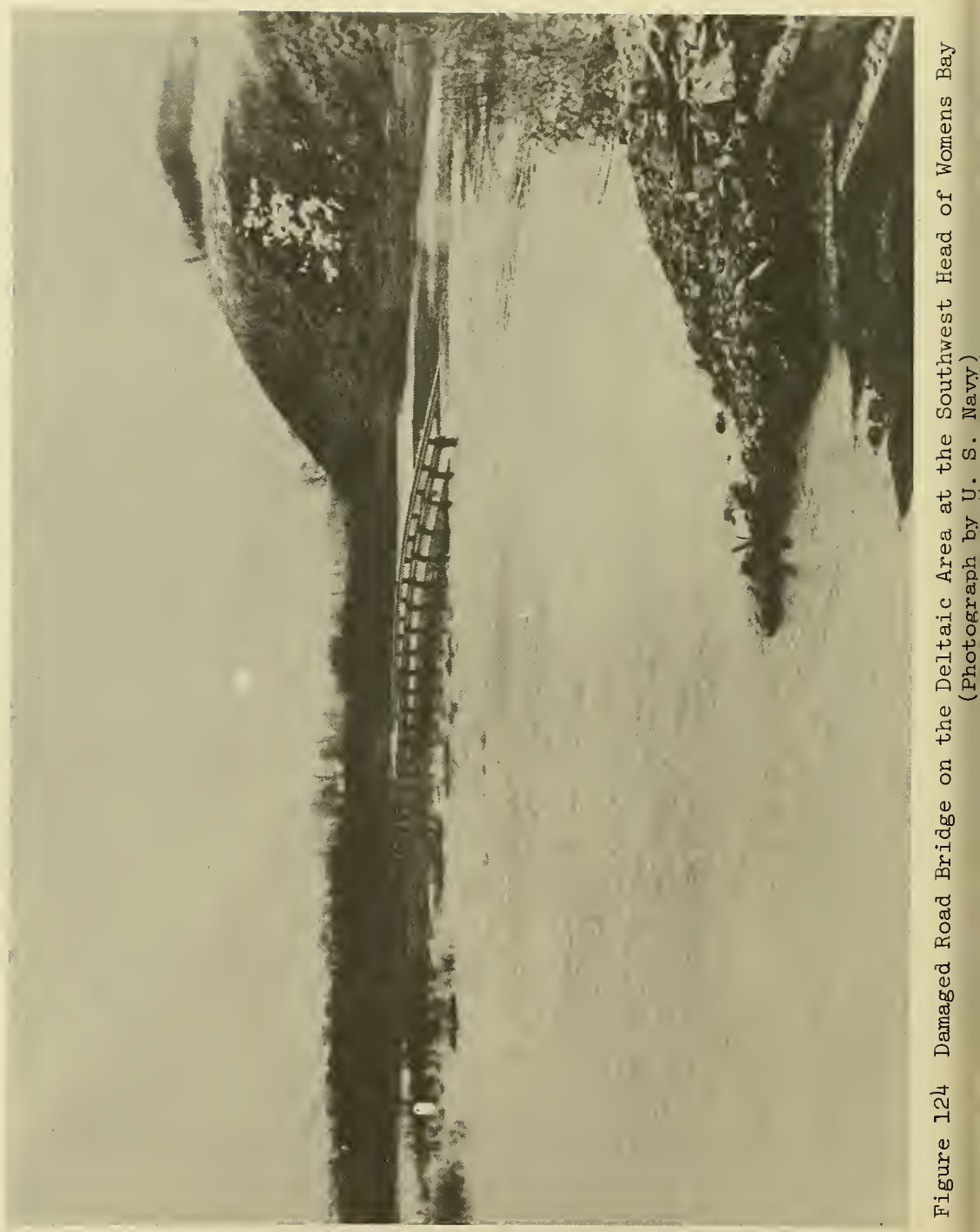




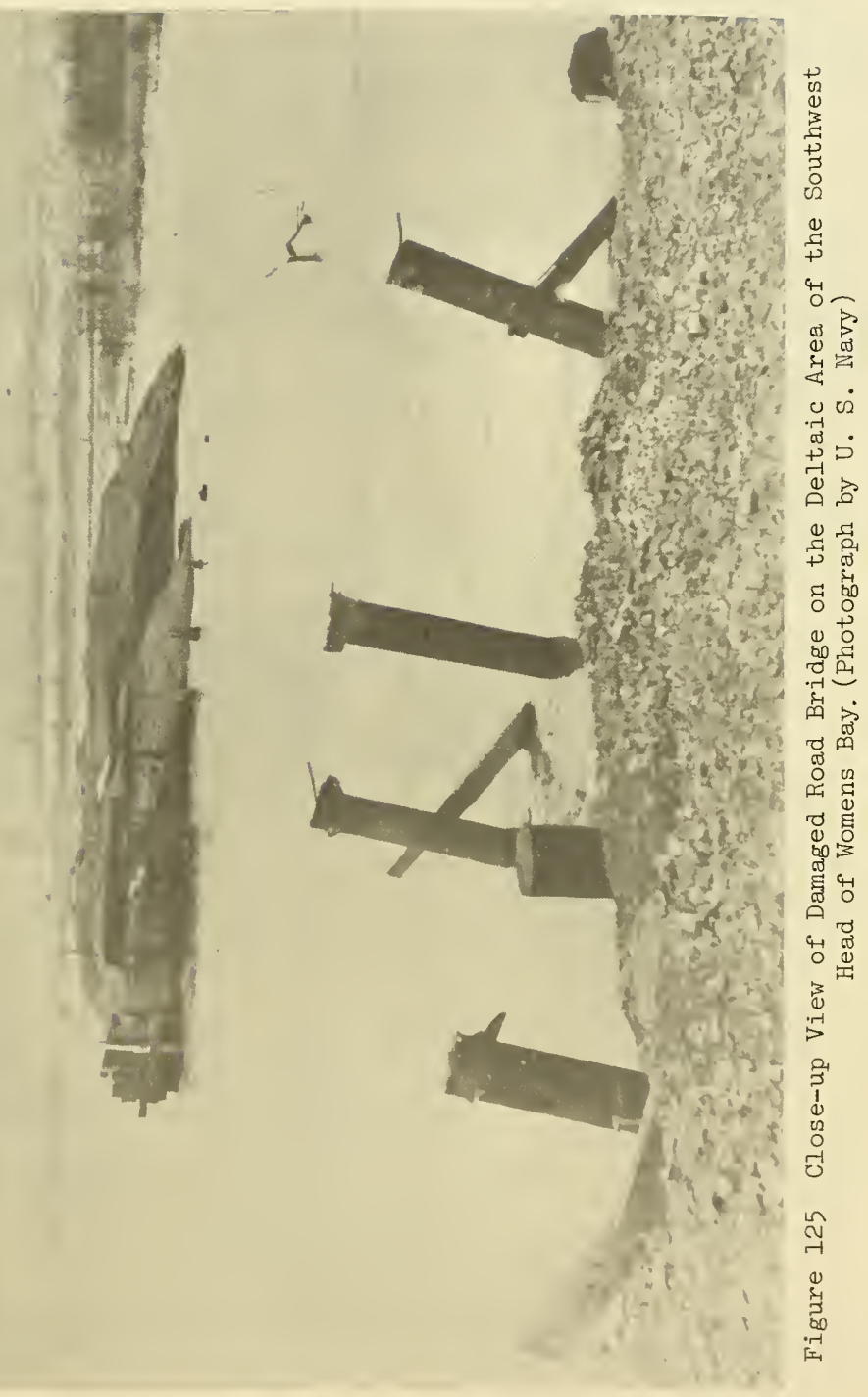




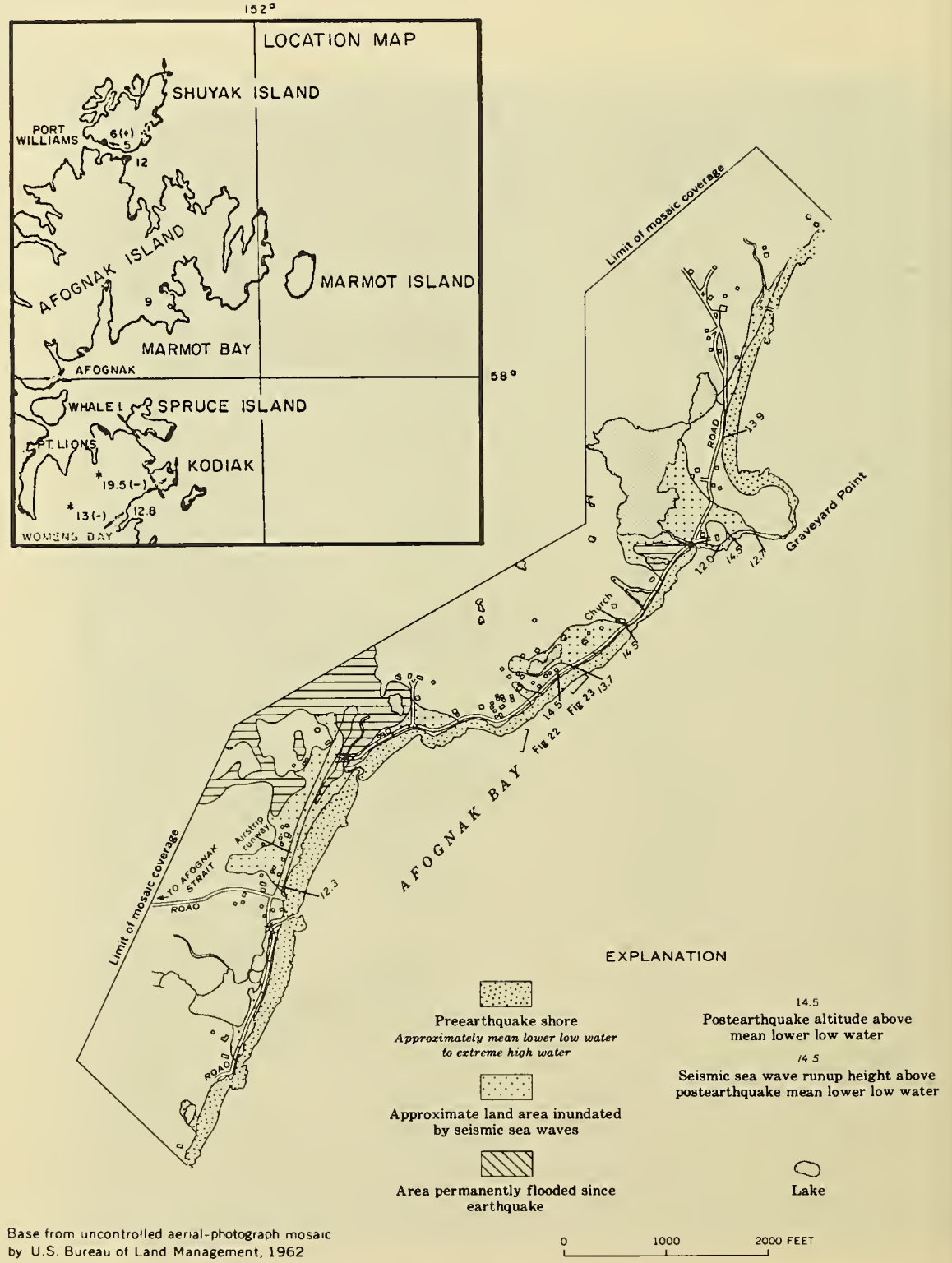

Figure 126 Planimetric Sketch-map of Afognak showing Approximate Limits of Inundation by Seismic Sea Waves. (adapted from Kachadoorian \& Plafker, 1967) 
Each wave came in with a roar, like a fast-rising tide; recession ollowed each wave leaving the bay dry in Afognak Strait between Afognak village) and Whale Island (Kachadoorian and Plafker, 1967). Several omes and the community hall were washed out to sea; other buildings were wept off their foundations and moved inland; automobiles and trucks were ashed into the small lake behind the village; and the ice in the lake as floated out to sea. Two bridges were washed out along the coastal oad.

Figure 126, prepared from aerial photographs, gives an idea of the xtent of devastation. Kachadoorian and Plafker (1967) give the maximum unup height as 14.5 feet above MLLW (Figure 126), a value somewhat at ariance from the higher estimate of 19 feet made by Berg, et al, (1964) oon after the earthquake. Plafker and Kachadoorian (1966) estimated the unup as 10.8 feet above the existing tide (Figure 40) at about 9:27 p.m. arch 27, which would suggest a wave height of about 21.6 feet at that ime.

The extent of inundation outlined in Figure 126 was mapped from the istribution of driftwood, debris, abraded bark and broken branches of rees and brush. Greatest inundation occurred in the vicinity of the irstrip and adjacent low-lying area. Because of the regional subsidence f 4.5 feet, the village is being entirely relocated to Settler Cove in izhuyak Bay, Kodiak Island, where it will be named Port Lions (Figure 26 inset). The estimated cost of this operation is $\$ 816,000$.

Port Wakefield in Raspberry Strait, between Afognak Island and aspberry Island (Figure 40), experienced waves with periods of 8 to 10 inutes for $11 / 2$ hours after the earthquake (Berg, et al, 1964). Then, t about 11:00 p.m. a series of "erratic" tides began, reversing three imes in the hour. The latter would appear to be tsunami waves arriving rom Marmot Bay. The earlier and shorter waves suggest possible transerse oscillations in a northeast-southwest direction of the water body n the straits, resulting from the earth motion.

Maximum runup of 12 feet above MLLW occurred apparently at 1:00 p.m. arch 28. The King Crab processing plant was abandoned because of subidence, and protective measures have had to be taken to buttress the ackfill at the cannery dock.

About 30 minutes after the earthquake, the water receded at Uzinki n Spruce Island (Figure 127) and then returned steadily to initiate a rain of waves. The third wave at $7: 30$ to $8: 00 \mathrm{p} . \mathrm{m}$. was apparently the ighest, causing a runup of 22 feet above MLLW (Berg, et al, 1964). igure 127, based on aerial photography (Kachadoorian and Plafker, 1967), hows the extent of runup. Homes and boats, valued at $\$ 49,800$, were estroyed, and the Ouzinkie Packing Company's salmon cannery suffered 300,000 damage.

The highest runup on the Kodiak Island coast was measured along the lmost uninhabited stretch between Cape Chiniak and Narrow Cape, and near 


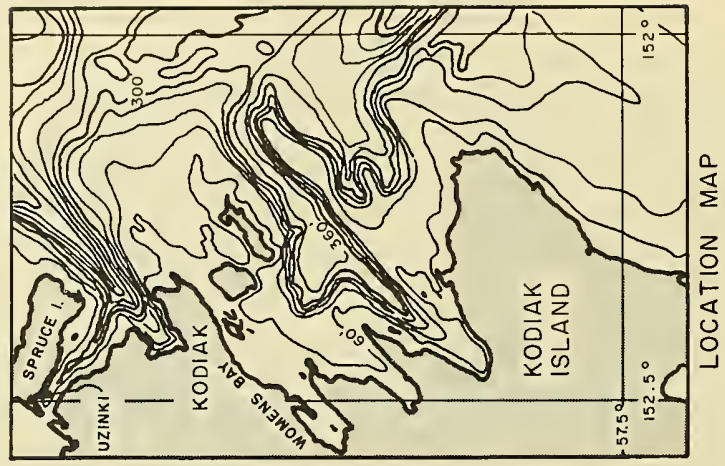

$D$

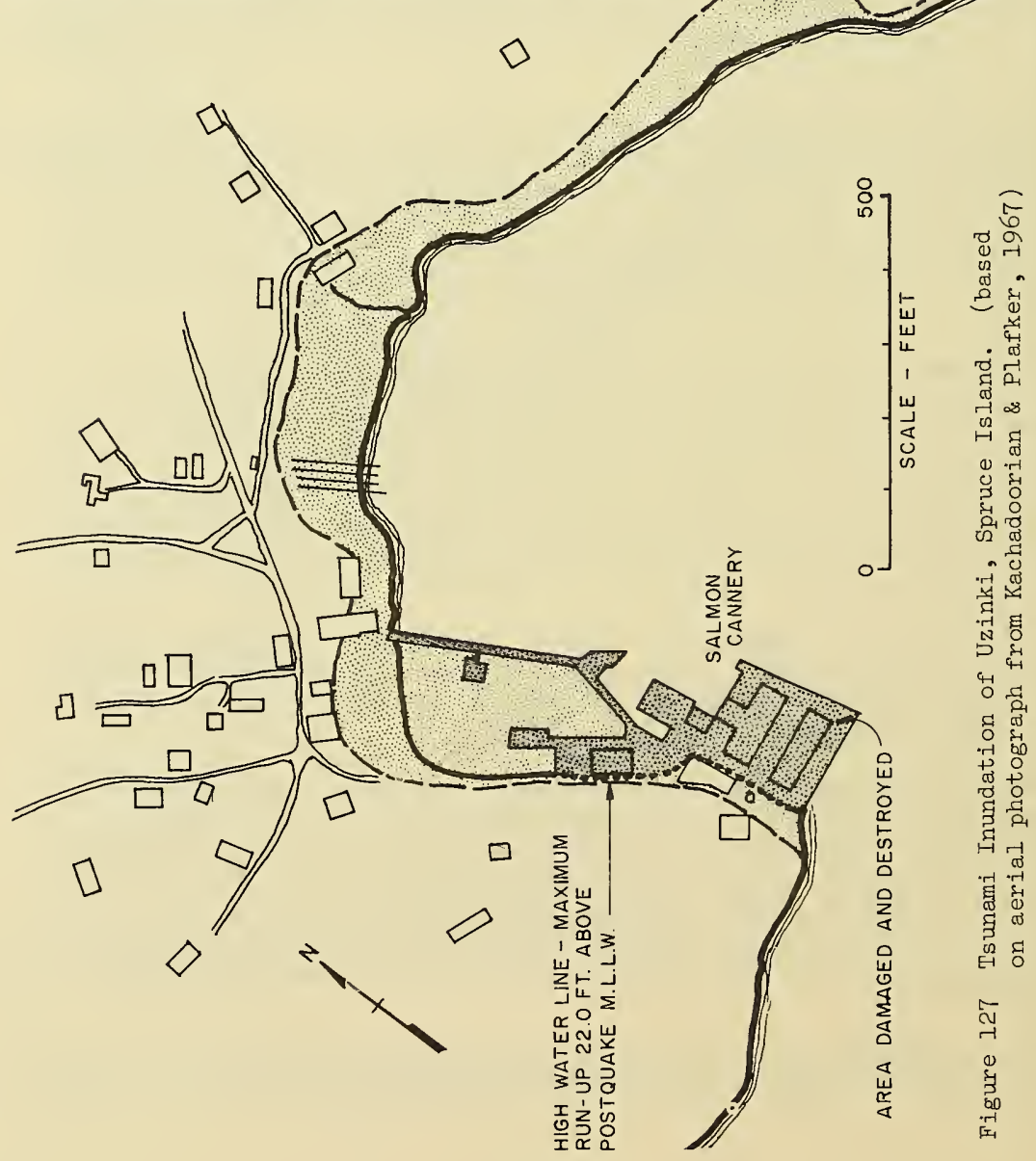


the entrance of Ugak Bay (Figures 128 and 40). Here the coast coincides approximately with the hinge line of zero vertical earth movement (see, for example, Figures 33 and 87a). Plafker and Kachadoorian (1966) cecord a runup height in this area of 31.5 feet above high spring tide on the night of the earthquake, or about 42 feet above MLLW. Berg, et al (1964) also made measurements in this area and found a runup of 36.7 feet above MLLW at Beatty Ranch north of Narrow Cape, and debris marks to an elevation of 66.6 feet above MLLW at a distance of about 2.5 nautical niles west of Narrow Cape. Here the wave had cut a scarp in the muddy sediments and considerable slumping of the scarp appeared to have taken olace subsequently. It is probable that the high wave effects around Jarrow Cape were the direct result of the concentration of wave energy oy the refractive effects of Ugak Island (Figure 40).

In Shearwater Bay, a tributary bay of Kiliuda Bay, Kodiak Island (Figures 128 and 40), the Kodiak Fisheries cannery was almost completely vrecked by the earthquake and tsunami. The cannery was located on a oroad, roughly triangular cusp of land that jutted into Shearwater Bay (Plafker and Kachadoorian, 1967). Piling supports for the cannery had seen driven to refusal, 10 to 15 feet into unconsolidated, deltaic, seach deposits. These deposits subsided from 2 to 10 feet more than the regional bedrock subsidence of 4 feet during the earthquake. Part of the cannery was buoyed off the piles and destroyed by the seismic sea vaves which ran up to an elevation of 23.5 feet above MLLW (Berg, et al, 1964). Unbroken piles were severely tilted by the ground motion and subsequent wave action. Driftpins in the piling tops were bent southward, suggesting that the superstructure was probably carried away during a Nave recession.

Old Harbor (Figures 129 and 40), at an almost central position on Sitkalidak Strait between Kodiak Island and Sitkalidak Island, was almost entirely destroyed by the tsunami, although apparently only one person among its population of 194 was drowned. With an audible roar, the seismic sea waves entered the Strait along both the north and south sides of Sitkalidak Island and had their confluence near old Harbor, thus zausing an exceptionally high runup for such a seemingly protected area.

According to Berg, et al (1964), a wave 2 to 3 feet high arrived within 15 minutes of the earthquake, followed by a second wave within 10 to 15 minutes. This second wave was followed by a recession of 6 to 10 feet. Some 30 minutes later a larger bifurcated wave arrived from north and south and inundated the village without causing damage. However, after a partial recession, and only about 5 minutes later, another crest swept into the village and floated off most of the houses. As indicated by a stopped battery-powered clock, located just below the highest watermark in the only remaining house of those inundated, this third and highest wave crested at 9:57 p.m. Kachadoorian and Plafker (1967) give the time of the damaging wave as 9:28 p.m. but make no reference to the clock. A wave almost as high came in on the high tide about midnight.

The maximum runup at 0ld Harbor varies from 22.5 to 30.5 feet above MLLW (Berg, et al 1964). These measurements disagree with the estimate 
of Kachadoorian and Plafker (1967), who considered the runup to be only 15.7 feet above MLLW.

The latter authors report that the house which survived the tsunami, although flooded, was securely tied down to a concrete foundation. Its location in Figure 129 is unknown. The cost of replacing the homes and auxiliary buildings has been estimated at $\$ 707,000$.

Kaguyak, a small fishing village at the head of Kaguyak Bay (Figures 1 and 40), although undamaged by the earthquake, was completely destroyed by the tsunami. The first wave came approximately 20 minutes after the quake and the largest (probably the third) struck at about 9:00 p.m. The houses of the village were carried across the spit on which they stood and were dumped into or washed up the far shore of the intermediate lagoon. The maximum runup was about 32 feet above postquake MLLW according to Berg, et al (1964), but is given as 25 feet above MLLW by Kachadoorian and Plafker (1967). The high runup was probably due to a resonance effect of Kaguyak Bay on the seismic sea waves. Three of the 37 inhabitants of the village drowned. Loss of property has been estimated at $\$ 321,000$. The survivors have moved to Akhiok and old Harbor.

Total losses of property and income in communities on Kodiak Island and neighboring islands have been estimated at $\$ 45,509,300$ (Kachadoorian and Plafker, 1967). The distribution of this amount is detailed in Table E-4 of Appendix E.

\section{Seismic Sea Waves in Cook Inlet}

On the Continental Shelf opposite the entrance to Cook Inlet, a vast negative wave, extending from beyond the Barren Islands into the Inlet, would have been created almost instantly with the subsidence of the land at the mouth of the Inlet. The ensuing wave system that would advance from the hinge line of zero vertical earth movement could be expected to be similar in general to the waves that reached Kodiak, but different in detail according to the special oscillating characteristics of the Continental Shelf in this region. We envision an interplay of the gravity waves of separation (Figure 42) with parallel free oscillations of the shelf, advancing on a front parallel to the hinge line (Figures 33 and 130). The first crest would have to travel a distance of about 70 nautical miles at a mean speed for a mean depth of 400 feet, according to Equation (4), of approximately 115 feet per second, and thus should have reached the neighborhood of Perl Island (Figure 130) about one hour after the earthquake, or at about $6: 40 \mathrm{p} . \mathrm{m}$. The second wave would probably have followed at about 8:40 p.m.

Perl Island was actually struck by a 28-foot wave at $8: 40$ p.m. (Waller, 1966). This was followed by a second wave of 30 feet at 11:40 p.m. and a third wave, also about 30 feet high, at $2: 30 \mathrm{a} . \mathrm{m}$. on March 28. The time interval between these waves is three hours. In the absence of a detailed calculation of the oscillating characteristics of the openended basin system illustrated in Figure $36 \mathrm{~b}$, we feel unqualified to elaborate further on this phenomenon. 
Undoubtedly the constriction effect of Cook Inlet and the shoaling effect of the Barren Islands would cause some reflection and scattering of the tsunami energy so that waves penetrating into Cook Inlet might well evolve at shorter periods. Their heights too would undergo considerable reduction from energy loss at the entrance and energy dissipation through refraction and diffraction into the wide basin of the lower Cook Inlet.

Nevertheless, there are numerous accounts of a tsunami having reached Seldovia and Homer (Figure 130), near the end of the Kenai Peninsula, within Cook Inlet. Many of these accounts (Wallex, 1966; Chance, 1968; Berg, et al, 1964) make it clear that large waves of short period (but in the category of long waves) were generated during the earthquake. The ground shaking and earth motions seem to have been predominantly in a north-south or east-west direction (Chance, 1968). Figure 16 suggests that the landmass in the Seldovia-Homer region was displaced horizontally to north-northwest by amounts varying from about 1 foot at Seldovia to 5 feet at Homer, so that ground motion would have been favorable toward inducing seismic seiches transversely across Kachemak Bay.

Waller (1966) records that three different waves or large swells were observed shortly after the quake on the Cook Inlet side of the spit at Homer. The height of the waves was estimated to be approximately nine feet. These waves apparently broke like a swell on the beach but caused no damage. In Kachemak Bay there were also some peculiar wave formations occurring during and after the quake. Several waves with heights of about 4 feet rolled onto the north shore. All except one were observed to be parallel to the north shore near Homer (Waller, 1966). Since ground waves were observed in motion in a north-south direction at Homer (Chance, 1968), some of these water waves evidently could have been excited by wave motion of the bed of Kachemak Bay. There is little information about the period of the water waves, but one report indicates waves of two minutes period and 10 feet height were observed at the time of the earthquake (Coast \& Geodetic Survey, 1964); another that waves of five minutes period and 4 to 6 feet height occurred (Berg, et al, 1964). We may note that the first three modes of free oscillation of the water body across Kachemak Bay (near Homer) would be of the order of 30,21 , and 15 minutes, but no information appears to exist suggesting that waves of this period were observed.

At about 9:30 p.m. a 20-foot wave arrived at Homer. The water rose to 4 feet above the floor level in some buildings at the outer end of the Homer spit (Waller, 1966). This could possibly be the same wave that was reported from Perl Island at $8: 40 \mathrm{p} . \mathrm{m}$. and the first major seismic sea wave. Berg, et al (1964) have drawn attention to the observation of the wharfinger at Homer Spit that the first major effect of the earthquake on the sea, other than the waves mentioned, was a withdrawal of water level to 4 to 5 feet below normal beginning at about $6: 10 \mathrm{p} . \mathrm{m}$. Undoubtedly this represented the advance of the negative tsunami wave producing a drawdown as envisioned in Figure $36 \mathrm{~b}$. 


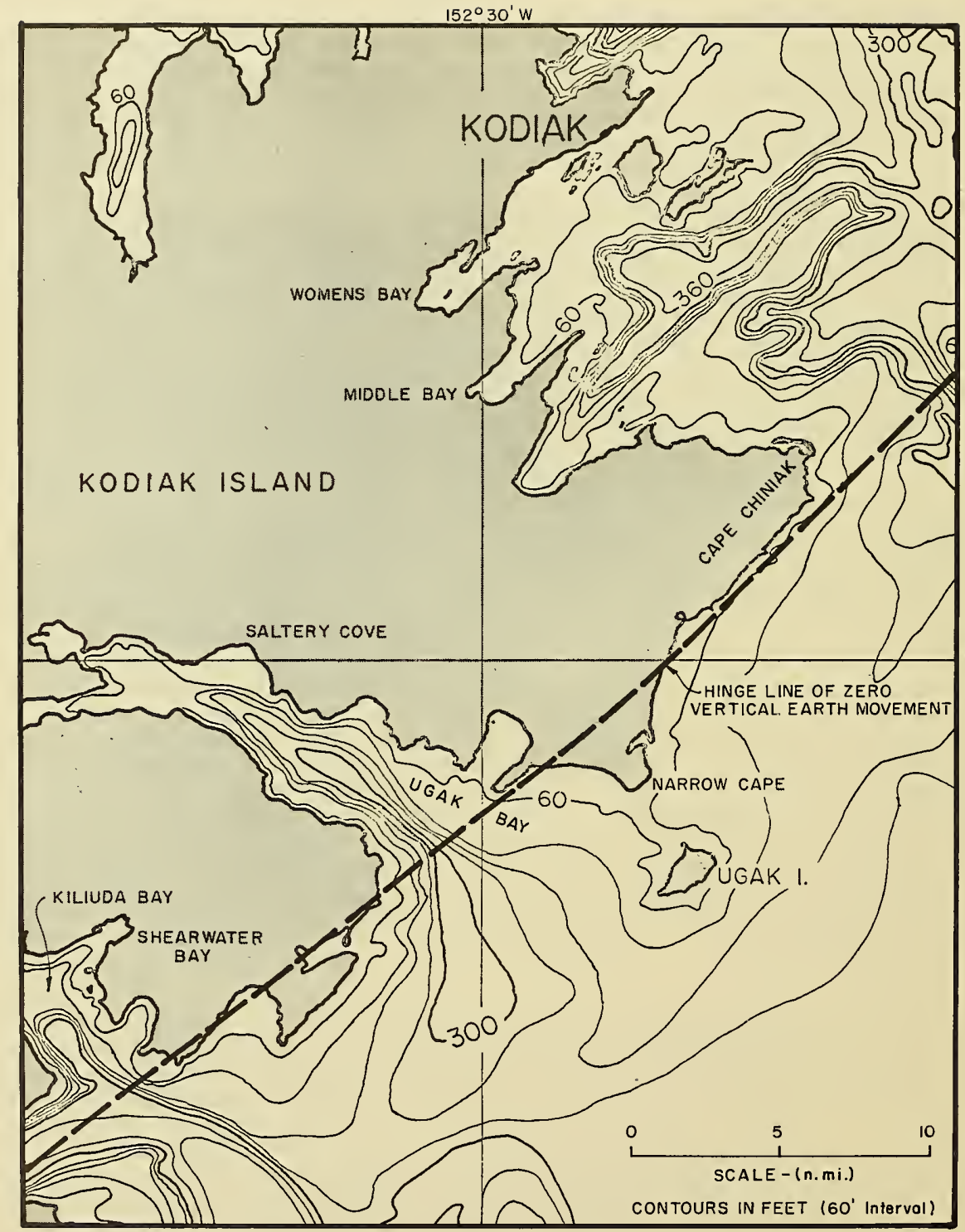

Figure 128 Bathymetry of Part of Southeast Coast of Kodiak Island 


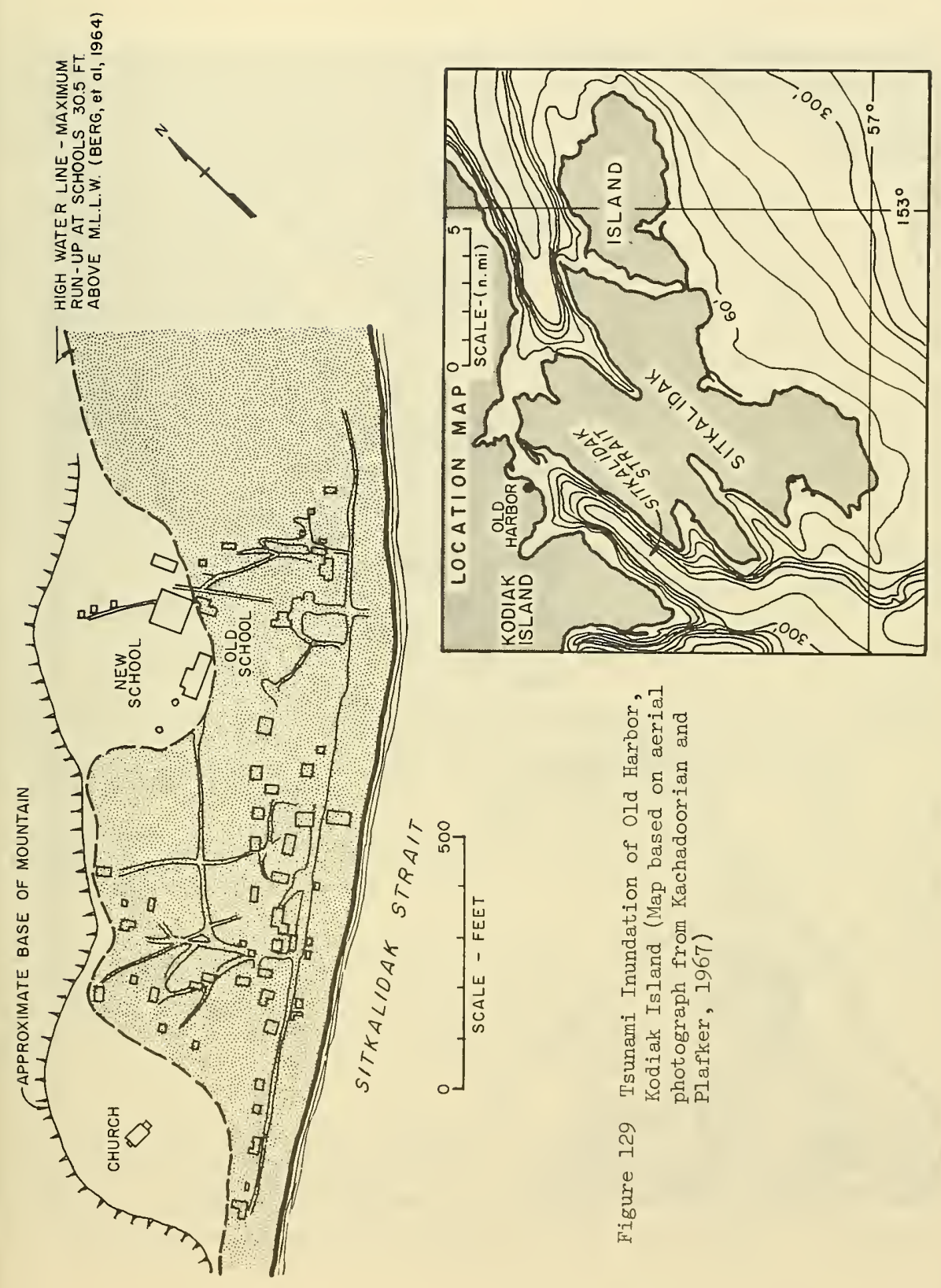




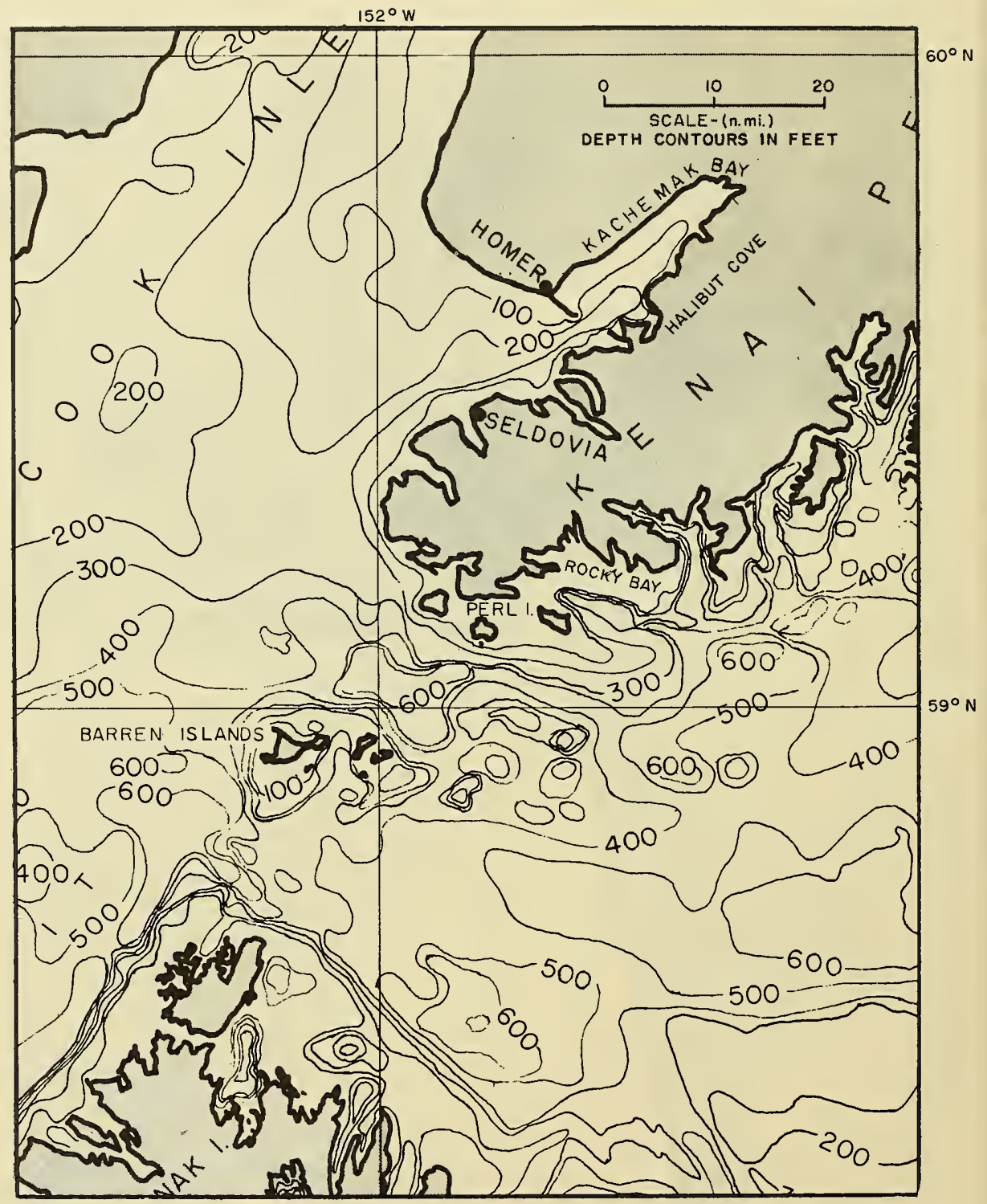

Figure 130 Bathymetry of the Continental Shelf at Mouth of Cook Inlet 
Homer suffered mainly from the regional subsidence (2 to 3 feet), ifferential compaction, and lateral spreading ( 1 to 4 feet) (Waller, 966; Gronewald and Duncan, 1965). Wave damage, confined to inundation, as slight. Figure 131 shows the general effect of the subsidence on he Spit.

At Seldovia, the earth motion appears to have been predominantly ast-west (Berg, et al, 1964; Chance, 1968). Numerous waves were reorted by different eyewitnesses which suggest that waves 12 to 15 feet bove tide level, of a period of about 2 minutes, developed during the arthquake, but did no damage because their reach was below high tide evel (Chance, 1968). Other waves, after the earthquake, appear to have ccurred at intervals of 15 minutes and 45 minutes. The surges of 3 to feet high at intervals of 15 minutes could very well be related to ransverse oscillations of the water body across Seldovia Bay (Figure 32), which may be likened to a semi-quartic basin (Wilson, 1966) of 0,000 feet length and 35 feet maximum depth (at Seldovia). Such a asin would have first and second mode oscillations of about 25 and 12.5 inutes, respectively. Without extended analysis of the whole bay, the 5 minute period waves are unexplained.

Strong tides were observed to occur at 7:00 (Berg, et al, 1964), at :00 and 9:00 p.m. (Chance, 1968). The tide at 9:00 p.m. may have reached lose to normal high tide level for the area. On its recession at about $: 10$ p.m. this wave carried away some boat floats (Chance, 1968). This s presumed to be the same wave that reached Homer at $11: 30 \mathrm{p} . \mathrm{m}$.

A second major wave is presumed to have arrived at about 11:10 to 1:30 p.m. and again at about 2:00 a.m. March 28, on the high astronomical ide (Berg, et al, 1964). The tsunami elevation above normal tide level this time was estimated by Berg, et al, to be about 4 feet.

Wave damage at Seldovia, mostly by inundation, was relatively slight. ome boat floats were lost, and the breakwater suffered some damage from ompaction due to the earth tremors and from waves (see Eckel, 1967).

Halibut Cove (a wide bay almost due east of the end of Homer Spit, igure 130) also reported a wave of 24 feet at $11: 35 \mathrm{p.m}$. (Waller, 1966) hich could have been the same one that hit Seldovia at 11:10 p.m. If hese waves were tsunamis coming in from the Gulf of Alaska, Homer was robably also hit by these waves although no high waves had been reported t Homer at that time. The reason could be simply that nobody was at the aterfront to report any waves.

We have remarked that the tsunami would encounter a strong refractive nd diffractive effect on entering Cook Inlet. The exact effect of this s difficult to assess, but it seems realistic to assume a diffraction oefficient of approximately 0.4 at Seldovia and Homer, which could explain hy the tsunamis were not more seriously felt at these places. 
The tsunamis were not reported at all at Anchorage. The reason is probably that the waves were strongly attenuated by refraction effects and by friction as they travelled up Cook Inlet. They would also have encountered very strong currents from the ebbing astronomical tide which would have dissipated their advance. It is unfortunate that no data exist to shed light on the subject other than a report by Brown (1964) that at Kenai, ice shifted position three times in 45 minutes at about 11:00 p.m., March 27, along the edge of the basin. It is not known whether any oil companies working in Cook Inlet possess marigrams that show the tide state during and after the earthquake.

There was, nevertheless, evidence of wave activity in the Turnagain Arm shortly after the earthquake (Chance, 1968). The quake occurred about an hour before predicted high tide for Hope, located about midway along the Turnagain Arm (Figures 1 and 33). Shortly after the quake, the water swept in from the north as a 40-foot tide. The water ran 200 yards inland flooding homes and other property. It is believed that this water movement was due to the readjustment of the water level as a result of the tilt which the Turnagain Arm received from the land subsidence (Figure 8 ). It is also possible that the opposite horizontal thrusting of the land at each end of the Turnagain Arm (Figure 16) induced an antinodal water effect near the center where Hope is located.

\section{The Tsunami in Resurrection Bay, Kenai Peninsula}

The tsunami as it probably formed on the Continental Shelf off Resurrection Bay (Figure 33) has been indicated in Figure 36a, which is reproduced for convenience in Figure 133, with the inclusion of Resurrection Bay, as if it were continuous with the section line $\mathrm{BB}^{\prime}$ of Figure 33 . According to Figure 8, Resurrection Bay, during the earthquake, dropped through a vertical distance of about 1 1/2 feet at the mouth to 6 feet at the head. The horizontal displacement in the direction of the bay's length, according to Figure 16, varied from about 45 feet at the head to 55 feet at the mouth. The expectation from this is that the sudden movement of the earth forming the boundaries of the bay, along with the upthrust over the Continental Shelf, would have resulted in an immediate relative upwelling of water of about 3 feet at the head of the bay, as shown in Figure 133. This estimate is an intelligent guess and makes no allowance for local or special effects.

Before proceeding to a more detailed interpretation of the wave effects actually observed in Resurrection Bay, we show the bathymetry of the region in Figure 134. Seward is situated on the west side of the bay on an alluvial fan. The length of the bay to its mouth is about 23 nautical miles and the depth varies along the length between about 650 feet at the center near Caines Head to over 950 feet near its mouth and in the northern half. The width of the bay is roughly uniform along a large portion of its length, if the series of islands in the southern half are regarded as a nominal boundary on the east side. The width is about 2 1/2 nautical miles in the northern part of the bay. The constriction formed by Caines Head and the sill of the bed at this location 


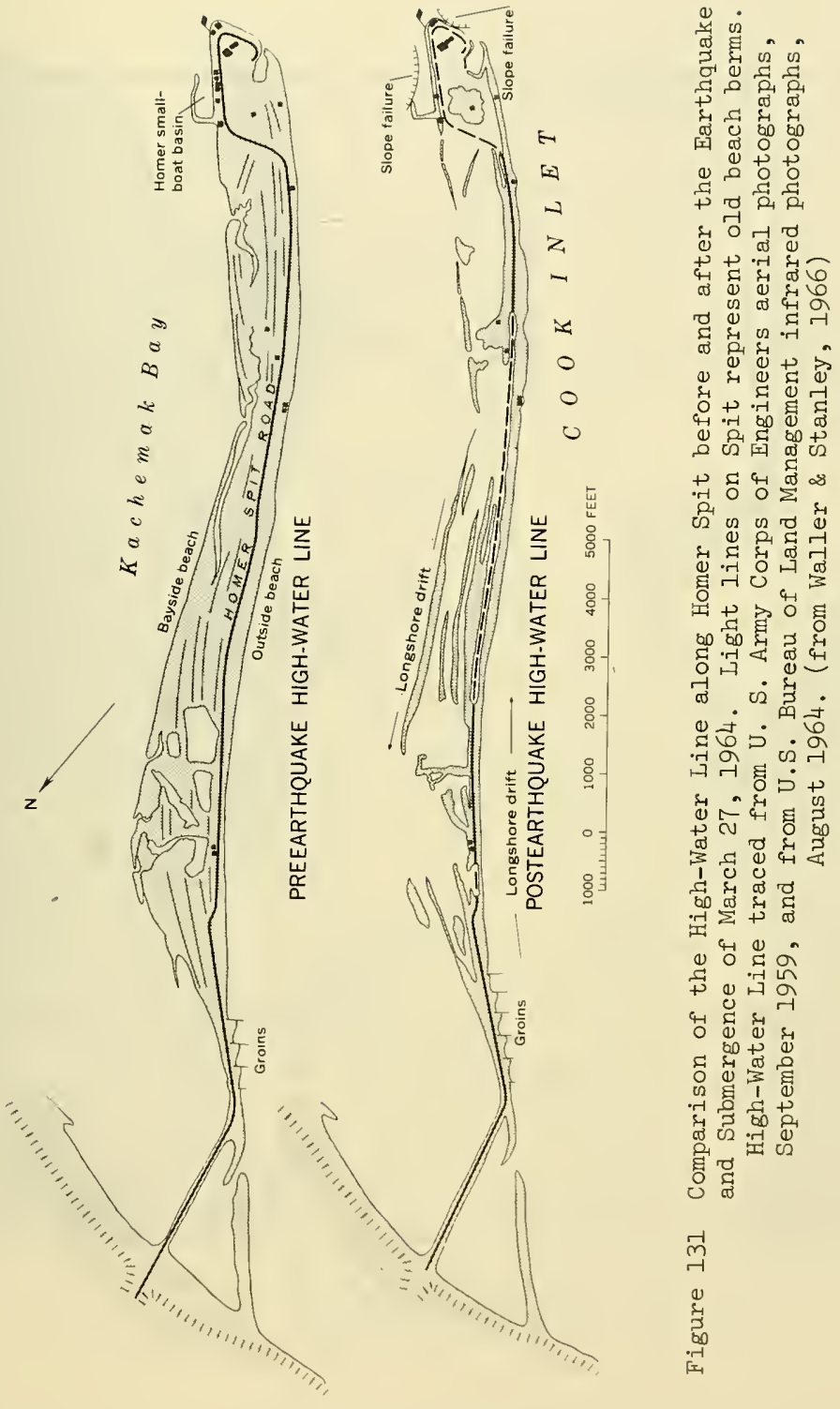




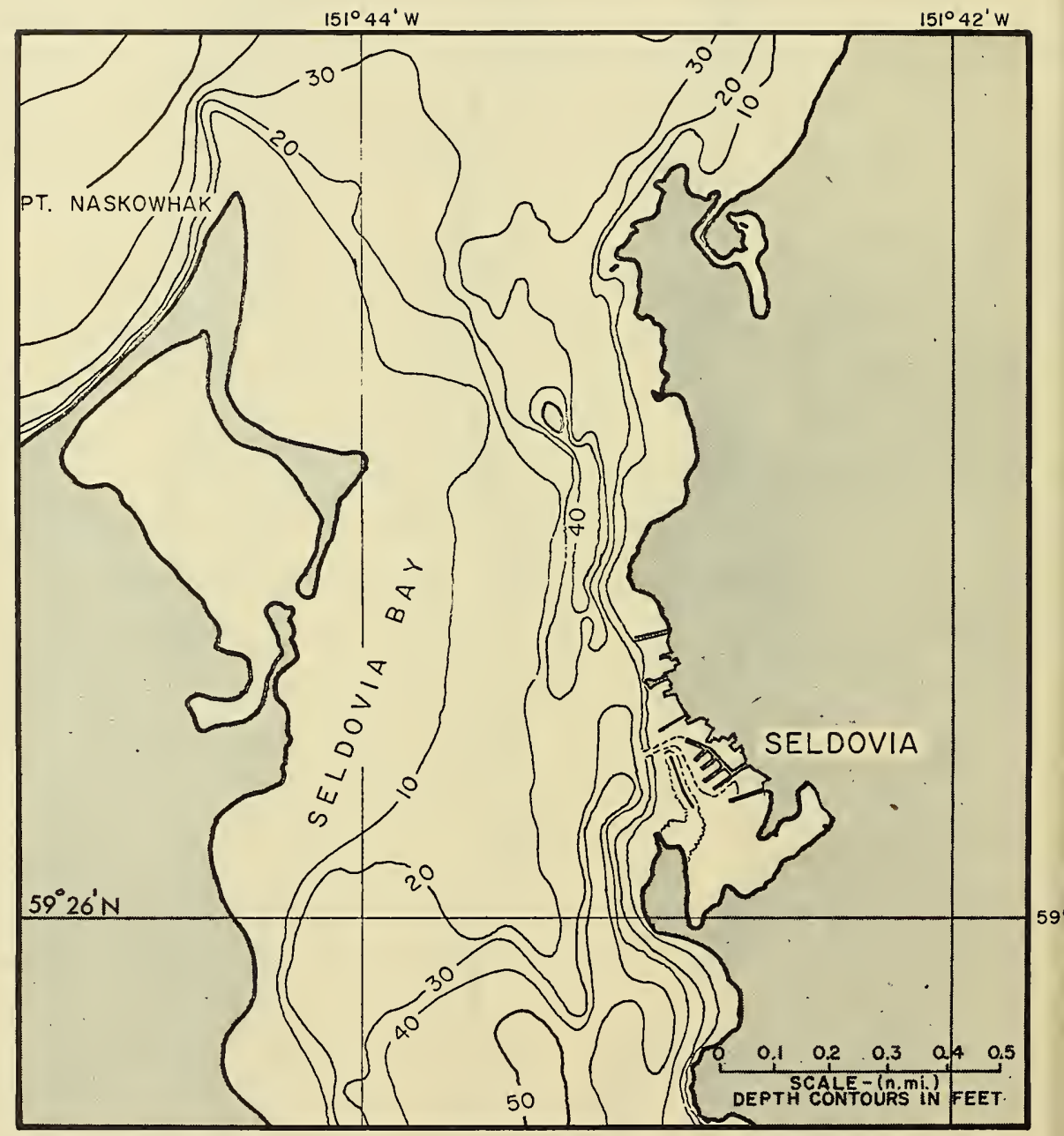

Figure 132 Bathymetry of Seldovia Bay in the Region of the Port of Seldovia 


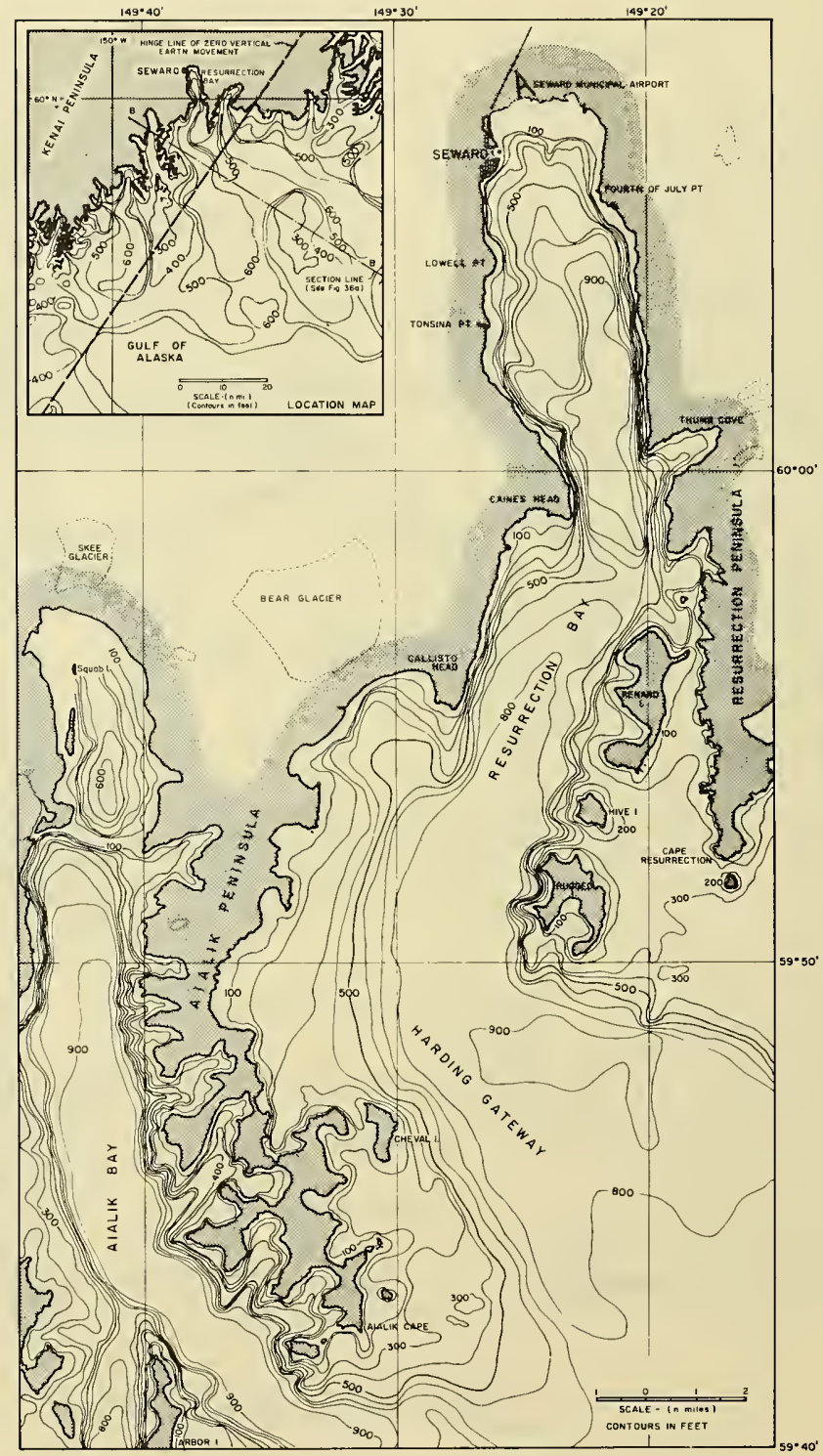

Figure 134 Bathymetry of Resurrection Bay, Kenai Peninsula and the Location of Seward 
ave the effect of separating Resurrection Bay into two deep basins conected by a narrow, shallower neck (Figures $133 a$ and 134). Thrikbay may e simulated by the geometrical analogy of two rectangular basins $I$ and II (Figure 133b) interconnected by the short, shallower channel II.

\section{TABLE VI}

Dimensions of Interconnecting Rectangular Basins

Simulating Resurrection Bay (see Figure 133b)

\begin{tabular}{|c|c|c|c|}
\hline Basin & $\begin{array}{l}\text { Length } \\
L \text { (ft) }\end{array}$ & $\begin{array}{c}\text { Breadth } \\
\text { b (ft) }\end{array}$ & $\begin{array}{l}\text { Depth } \\
d(f t)\end{array}$ \\
\hline$I$ & 47,300 & 13,500 & 875 \\
\hline II & 10,100 & 11,800 & 500 \\
\hline III & 57,500 & 15,200 & 775 \\
\hline
\end{tabular}

We investigate the oscillating properties of this chain system of asins by recourse to the impedance principle of Rayleigh (1945 Ed.) as mployed by Neumann (1948). Adopting dimensions of length L, breadth b, nd depth $d$, as found from Figure 134, in accord with Table VI, the first so modes of free oscillation of the system are found to have the periods

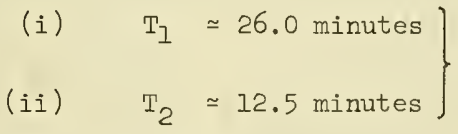

These equations show that Resurrection Bay was neither long enough or shallow enough (as Port Alberni, Canada, for example) to provide any orm of resonant response to the primary long waves of the tsunami whose eriod was about two hours. However, considering our investigation of ther situations of tsunami penetration into bays and inlets, it seems at pseudo-resonance could develop for any third harmonic or fifth armonic of the main tsunami that might exist.

Most of the available information on waves in Resurrection Bay reates to Seward, which was devastated by seismic sea waves both during and fter the earthquake. Eyewitness reports of the debacle that followed the arthquake are supported by postquake measurements of runup along the horelines (for example, see Grantz, et al, 1964; Brown, 1964; Berg, et 1, 1964; Coast \& Geodetic Survey, 1964; Denner, 1964; Plafker and Mayo, 965; Spaeth and Berkman, 1965, 1967; Lemke, 1967).

The location of Seward is shown in Figure 134 and in the prequake erial photograph, Figure 135. Upon the latter we have inserted, for ontrast, the high water line reached by the seismic sea waves and the 
postquake shoreline. A detailed prequake plan of the city and waterfront facilities is contained in Figure 136. The city, with a population of about 2,000, is a major fishing center and has strategic importance as the chief year-round port for Alaska and the rail terminal connecting the southern coast with Anchorage and Fairbanks. The port facilities were totally destroyed by the earthquake and seismic sea waves; all means of communication and transportation, other than by radio and air travel, were disrupted for some time (Eckel, 1967).

The waves which hit Seward first were caused by locally generated seismic sea waves. Later the city was assailed by the main tsunami and Continental Shelf oscillations that travelled up Resurrection Bay from the mouth. The Coast \& Geodetic Survey tide gage at Seward was located on the dock of the Standard Oil Company of California and its record was lost when the dock collapsed shortly after the onset of the earthquake. The gage, heavily damaged, was later found among the debris on board the small (1,947 gross tons) oil tanker Alaska Standard which had been moored to the dock at the beginning of the earthquake.

With the horrifying events that prevailed during and after the earthquake, it is understandable that few people took very detailed notice of the behavior of the sea. In this account of events, the sequence of waves is reconstructed as an interpretation of the observations of different eyewitnesses. This interpretation, in the form of an inferred marigram (Figure 137), is based on the data summarized in Table VII. At best this marigram can convey only a crude picture of the true state of affairs; at worst it can overcomplicate the situation by suggesting more large waves than actually arrived, owing to the uncertainty of the eyewitnesses' impressions of time.

At the southern end of Seward, while shaking of the earth (first north-south, then east-west) was in progress, the waterfront slumped away from the shore carrying with it the cannery at the south end of Seward, part of the Alaska Railroad docks, and the Standard Oil Company dock (see Figure 136). One of the two 200-ton wharf cranes at the Railroad dock disappeared in this slump and has never been found (Figure 138). This particular slide occurred within about 30 to 45 seconds of the onset of shaking, apparently only at the south end of Seward, which (Figure 134) has the steepest bottom slope of the entire fan delta. This initial slump involved only the waterfront part of Seward, including the Railroad docks and the Standard Oil Company dock. These statements are supported by the evidence of Pedersen, Smith, Kirkpatrick, Gilfillen, Trigg, Clark, Pickett and Mrs. Pickett, John and Robert Eads, and Christiansen (Chance, 1968); and of Werner, King, Lambert, and the Eads Brothers (Berg, et al, 1964).

The immediate consequence of this submarine slide as it most likely occurred, is portrayed in Figure 139. The slump caused a drawdown of the water at the southern end of Seward causing the Alaska Standard at the Oil Company dock, virtually to disappear from sight as described by witnesses (Chance, 1968). The underwater cascade would have formed a 


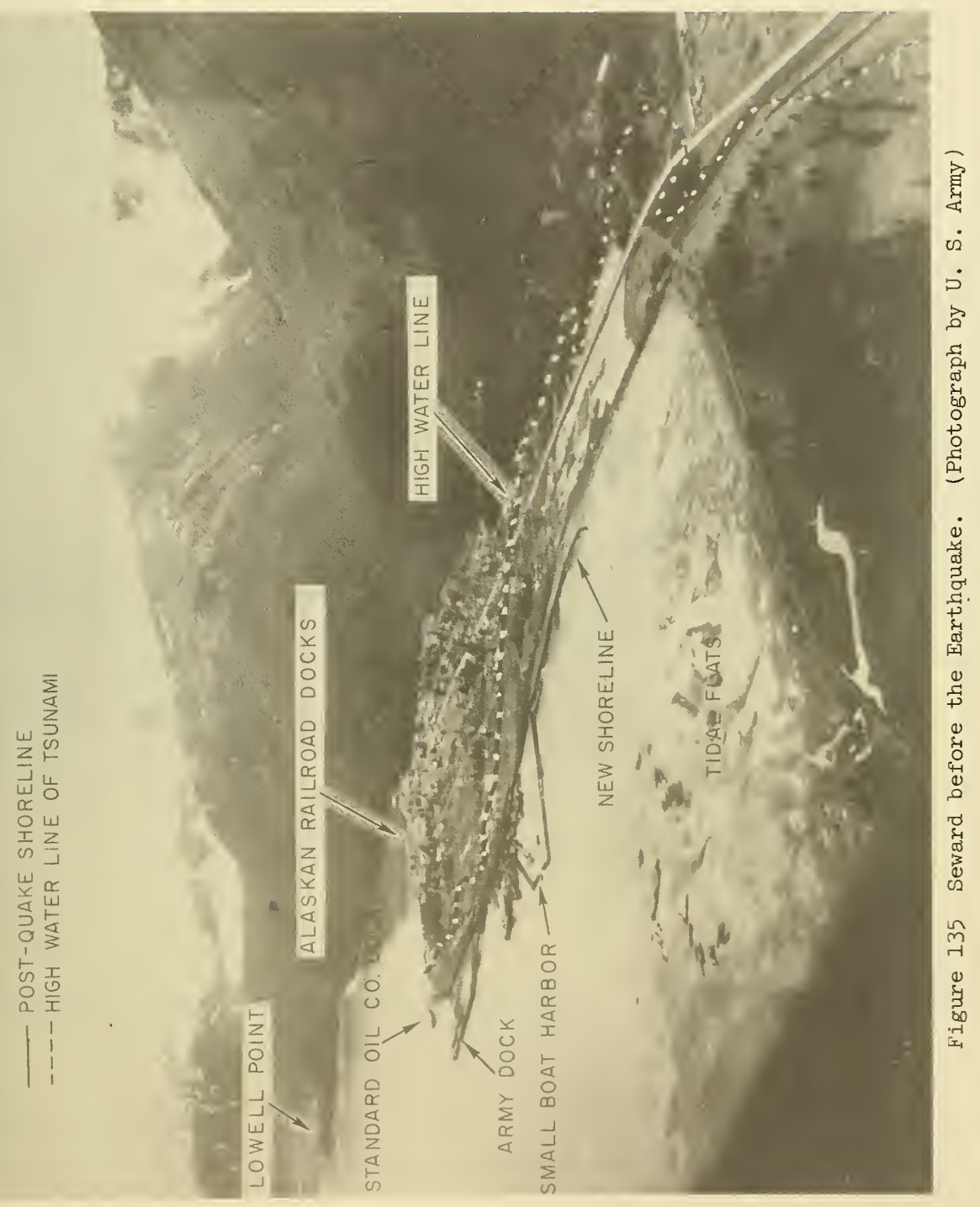




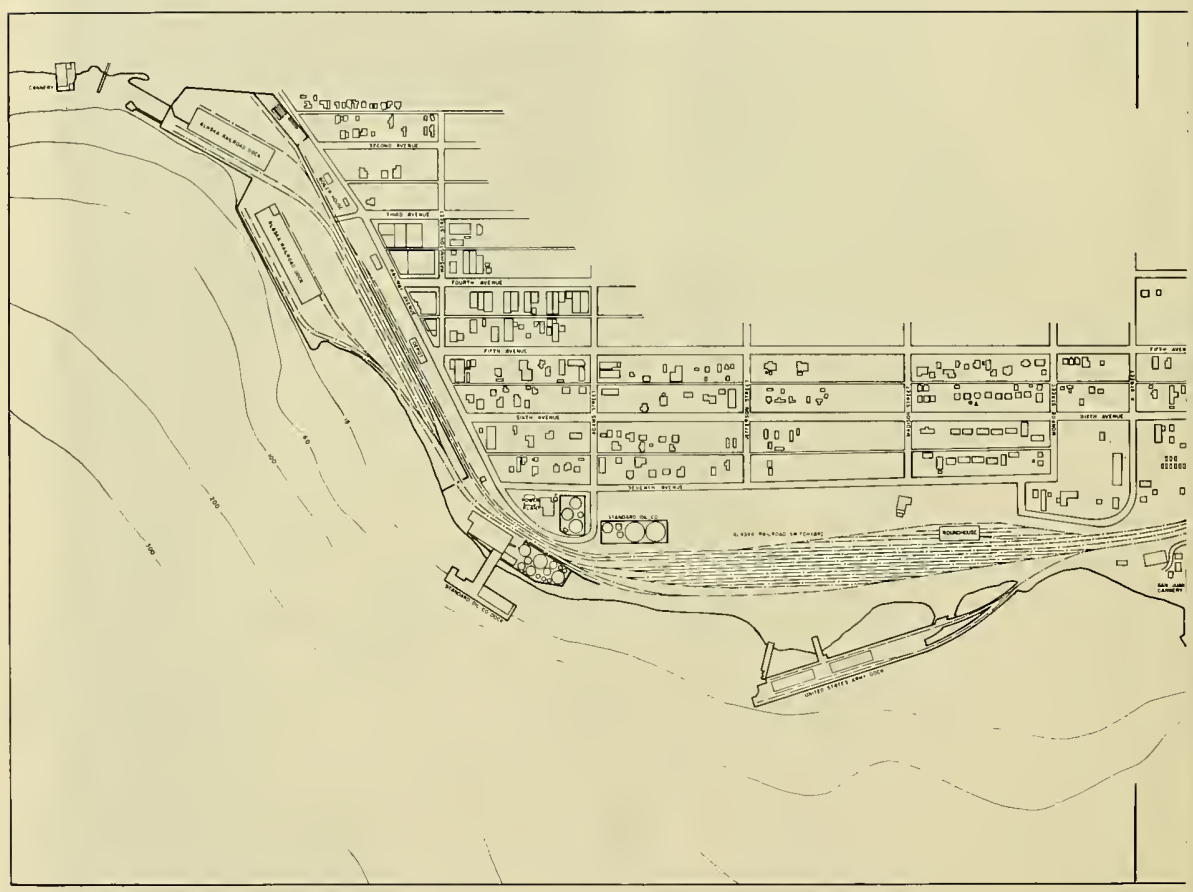




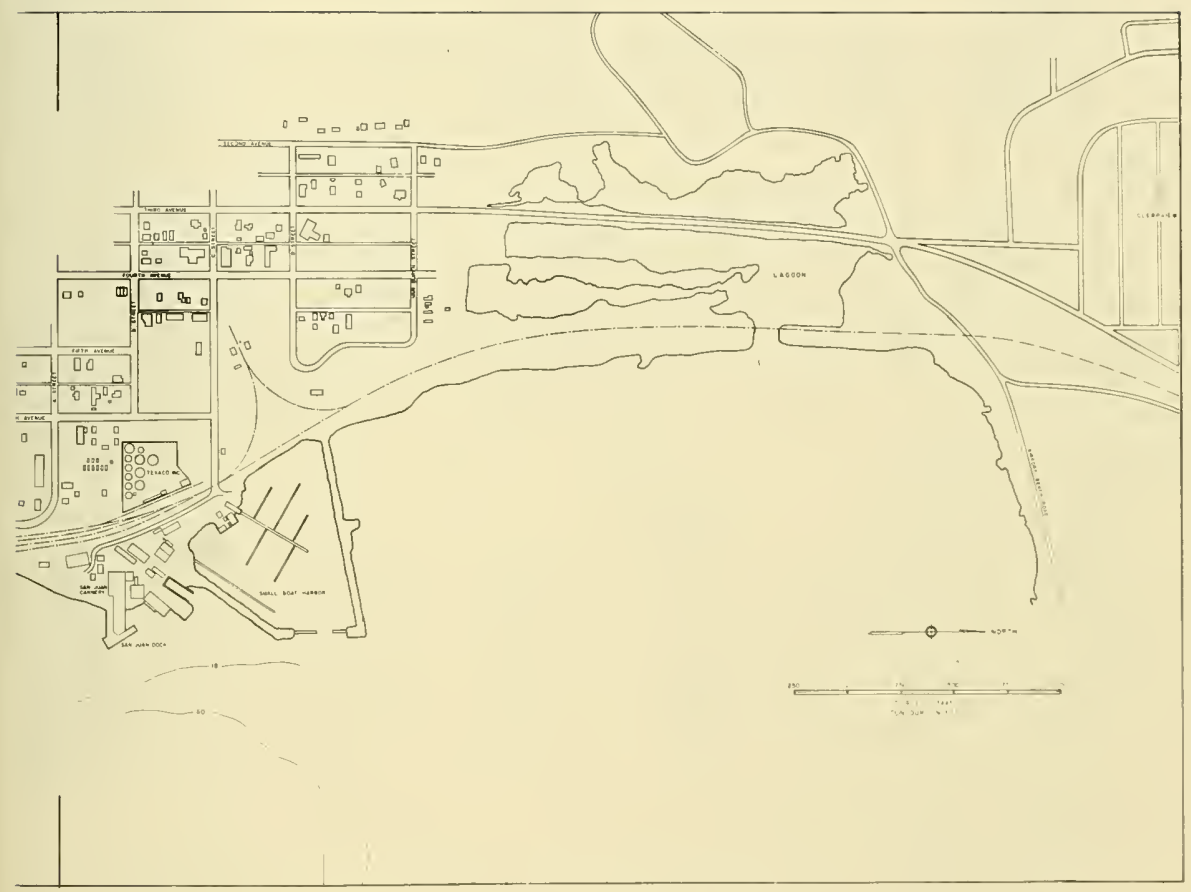

Figure 136 Plan of Seward, Alaska, as existing prior to the Earthquake of March 27, 1964 


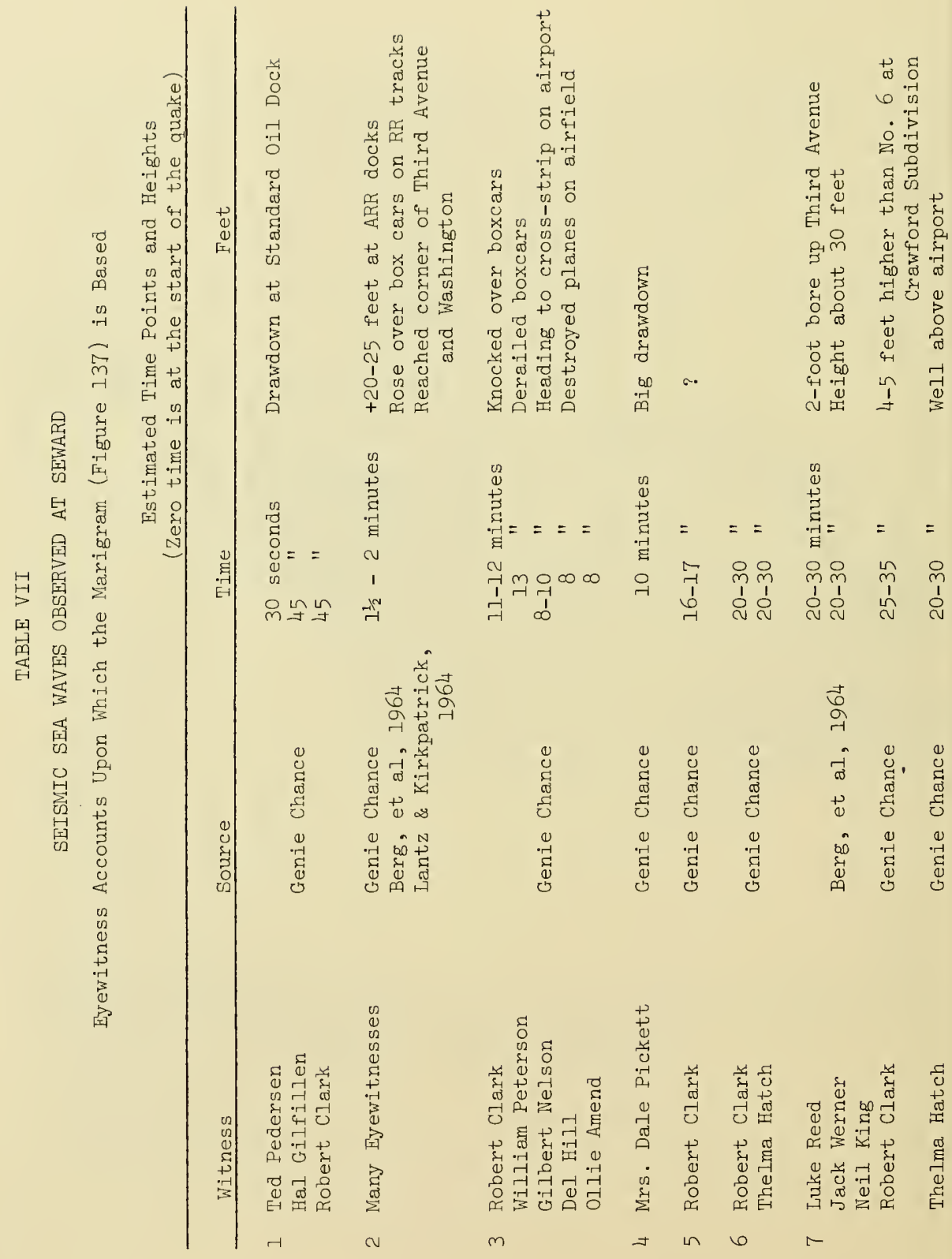




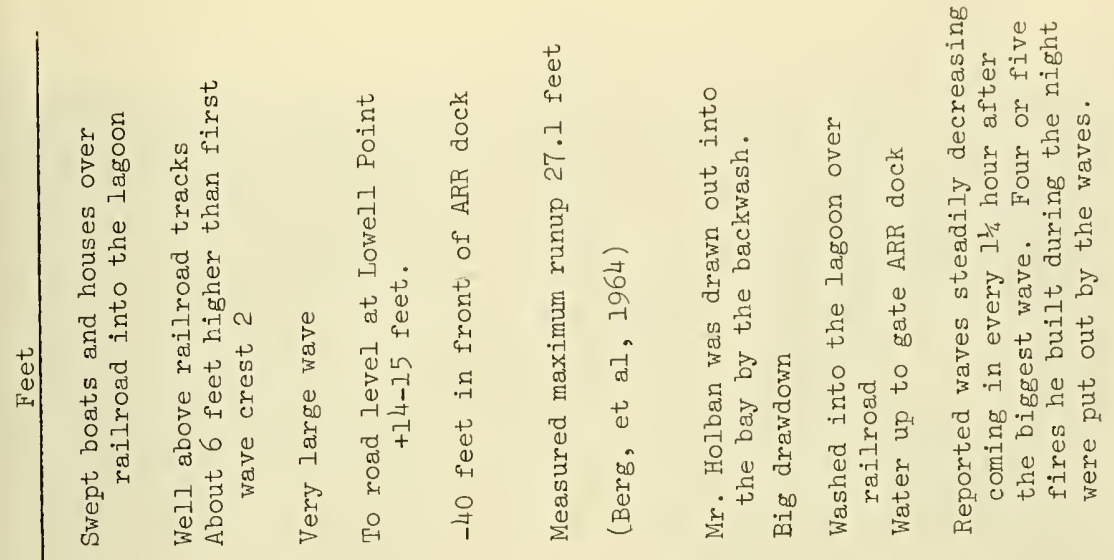

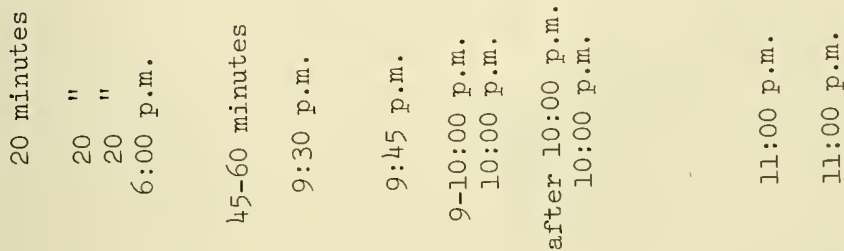

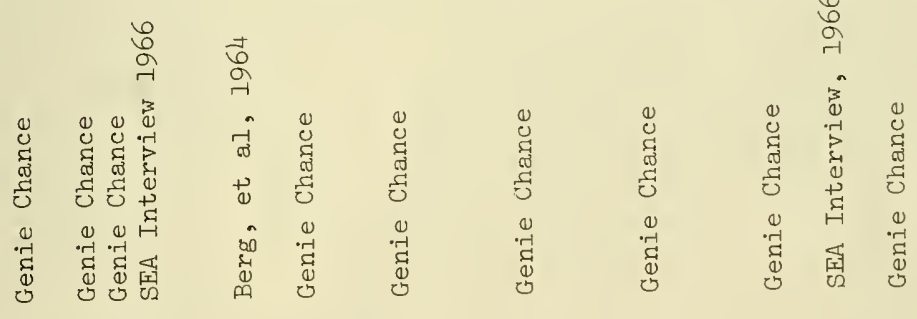

离

\&

.

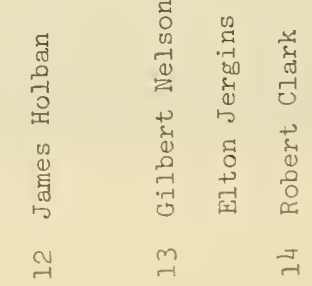




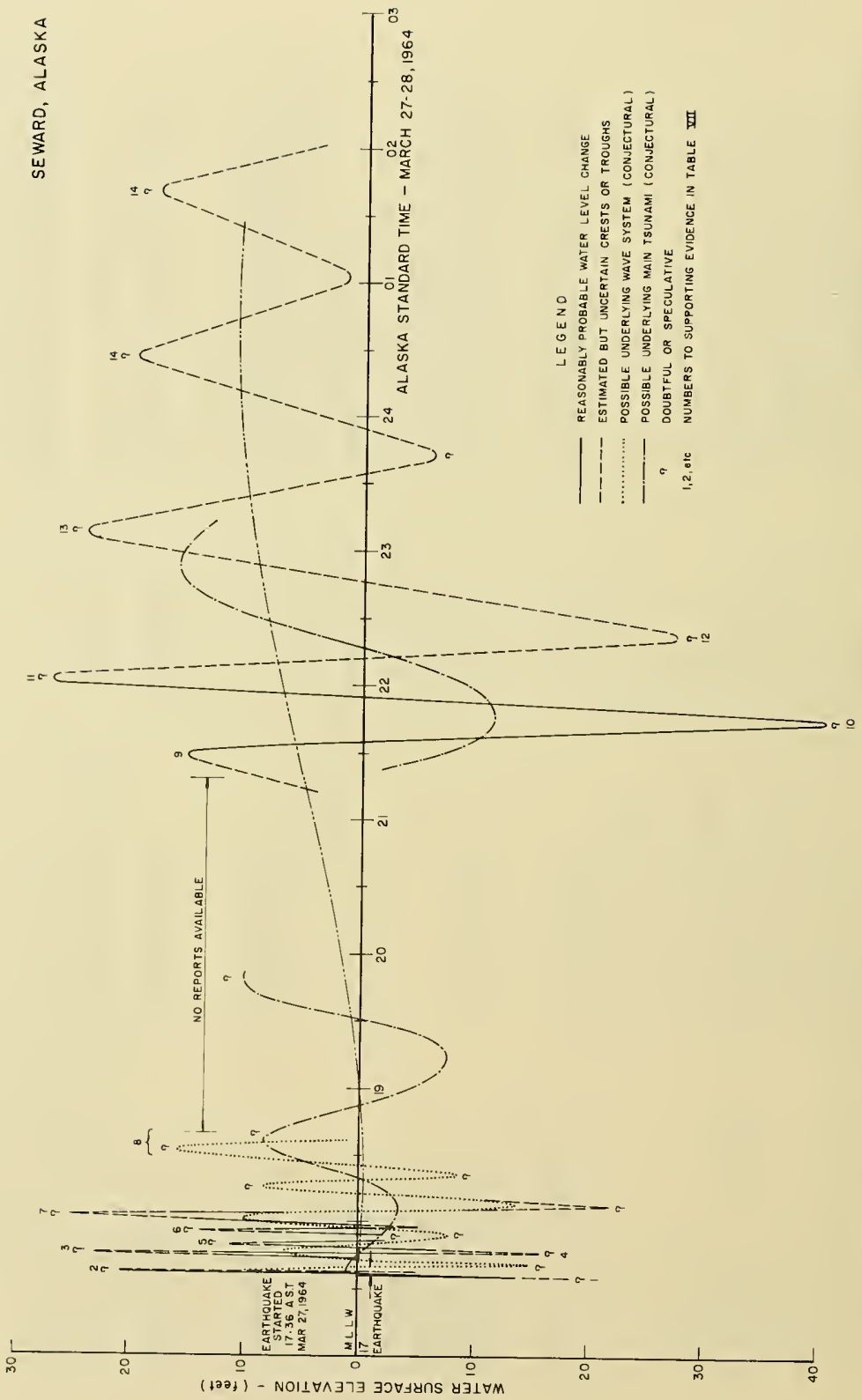




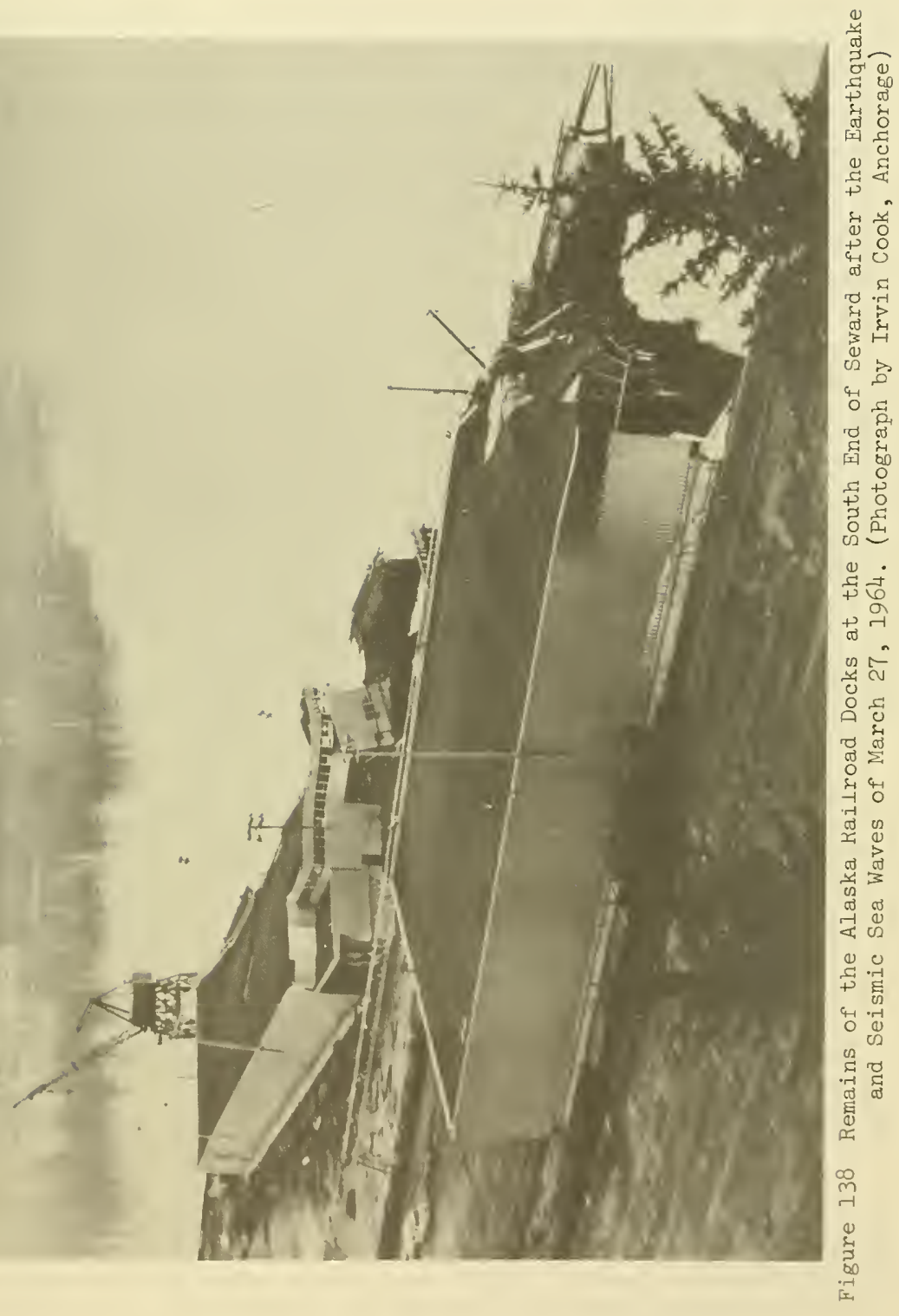


density current of roiling water, which would increasingly mound as it reached flatter slopes, presumably near the 500-foot depth contour (Figure 134). At about $1 / 2 \mathrm{mile}$ from the shore the sliding mass elevated the water to a humped surface from which waves, 15-20 feet high, radiated (Chance, 1968; Grantz, et al, 1964). These waves hit the Seward waterfront approximately $11 / 2$ to 2 minutes after the earthquake started and produced an inundation which rose over the waterfront and caused initial heavy damage. As shown schematically in Figures 139a to 139e, the Alaska Standard tore loose from her moorings and hoses and on the rising wave received a shower of dock wreckage on her foredeck which included the unconscious seaman Pedersen, who had been standing hosewatch on the dock (Figure 140).

The first wave was probably in the nature of being close to a resonant transverse oscillation for the north end of Resurrection Bay. The transverse cross section of the bay off south Seward is approximately parabolic in profile, and the calculated first mode oscillation for a width of about 45 nautical miles and a central depth of 600 feet has a period of 3.6 minutes. After the drawdown (Figure 139b) it would thus have taken about 1.8 minutes for the flood to crest at the Seward waterfront (in fair agreement with the observations, Figure 137 and Table VII). At least one witness (Jack Werner, cf. Berg, et al, 1964) records that he could see the wave that swept east from the boil and struck Fourth of July Point, where according to Lear (Berg, et al, 1964), it ran inland a quarter of a mile. Many other witnesses, however, gained the impression that two separate waves formed from the initial boil of water, the first of which was the one to strike the south part of Seward and then spread north and south (Chance, 1968).

This wave, having devastated the remains of the Standard Oil Company dock, flooded over the Army dock (Figure 136) which had been slowly sinking from the continued earth shaking. The flooding wave now lifted part of the dock in the air and slammed it down in ruins (Tom Hyde, cf. Chance, 1968). As the wave peeled along the shore it spread burning oil from the Standard Oil Company tanks toward loaded tank cars on the railroad sidings and toward the Texaco tank farm (Figure 136). The resulting explosions engulfed the waterfront in flame (Figure 141).

The wave rose over the small-boat harbor in an area where witnesses (notably Logan, Watson, Mrs. Hatch, Endreson, cf. Chance, 1968) had all failed to report any initial drawdown of water as had occurred at the south end of Seward. Many of the boats were swept over the seawalls of the boat harbor and toward the lagoon.

Two people photographed the north and south parts of this wave. One was Terrel Schenk, Manager of the Halibut Producers Co-op San Juan Cannery (located near the boat harbor, Figure 136), who took the photographs shown in Figures $142 \mathrm{a}, \mathrm{b}$ and $\mathrm{c}$ from the approximate direction and at the locations shown in Figure 145 (SEA interview, 1966). 


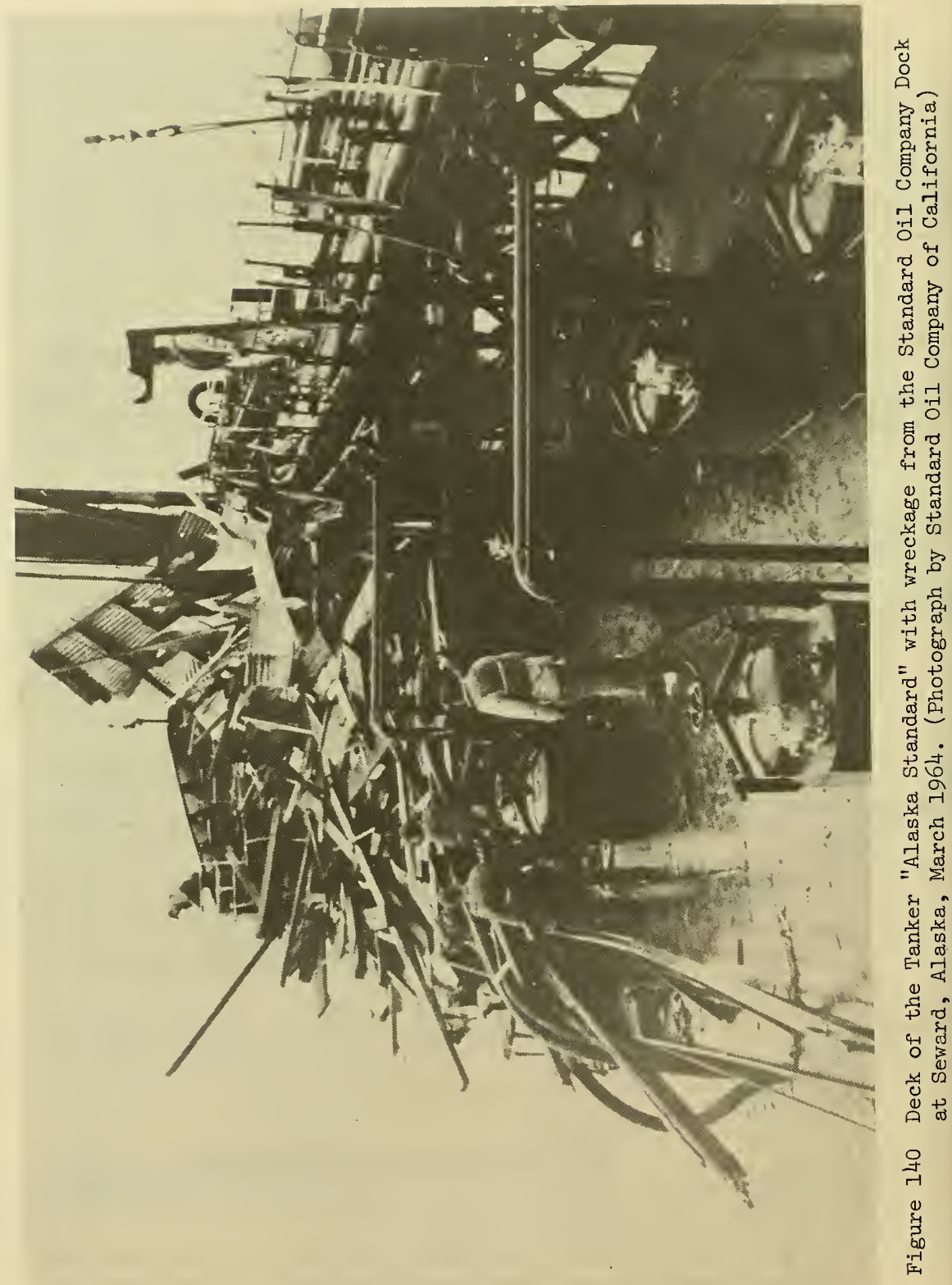


त्व

ช్తె प्d

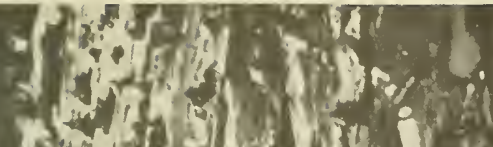

(1)

\&

मध

द O ن

○

+沓

의

६대

क्ष 의

+ ชื

बi

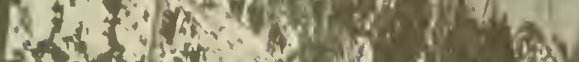

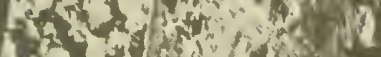

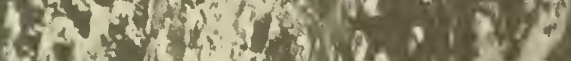

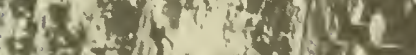

4 - Es

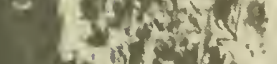

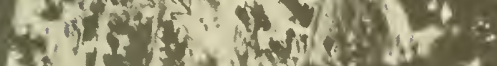

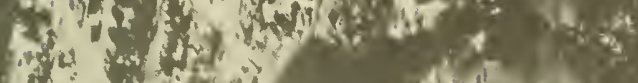

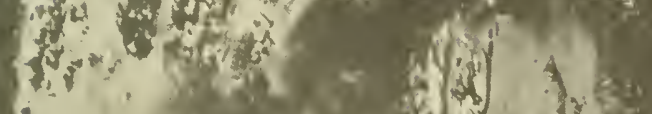

1

is

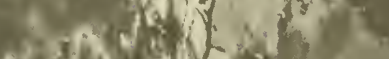

, 3 i.

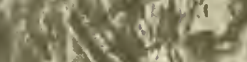

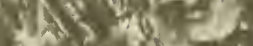

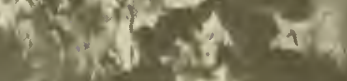

4
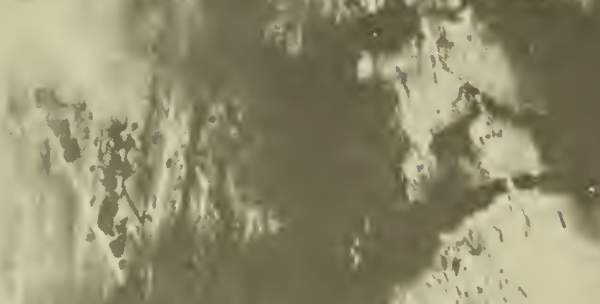

$+\infty$

†ิ

on

द्व

त

to $>$ i

है

点

व

है

으

-

तथ

苟.

is $d$

\& +

. 33

है

(1)

ते

तु

कृष

동

ह्र ज०

बाँ \&ै

स्1

本 क्ष

ฮा

E ठण

0 崩

एळ

শ

(1) 0

Eथ

ब्व क्य

$\uparrow$ b $\Omega$

क- . न्न

0300

उ 저

औथ त्र

$\rightarrow 4$

武

है

[x 


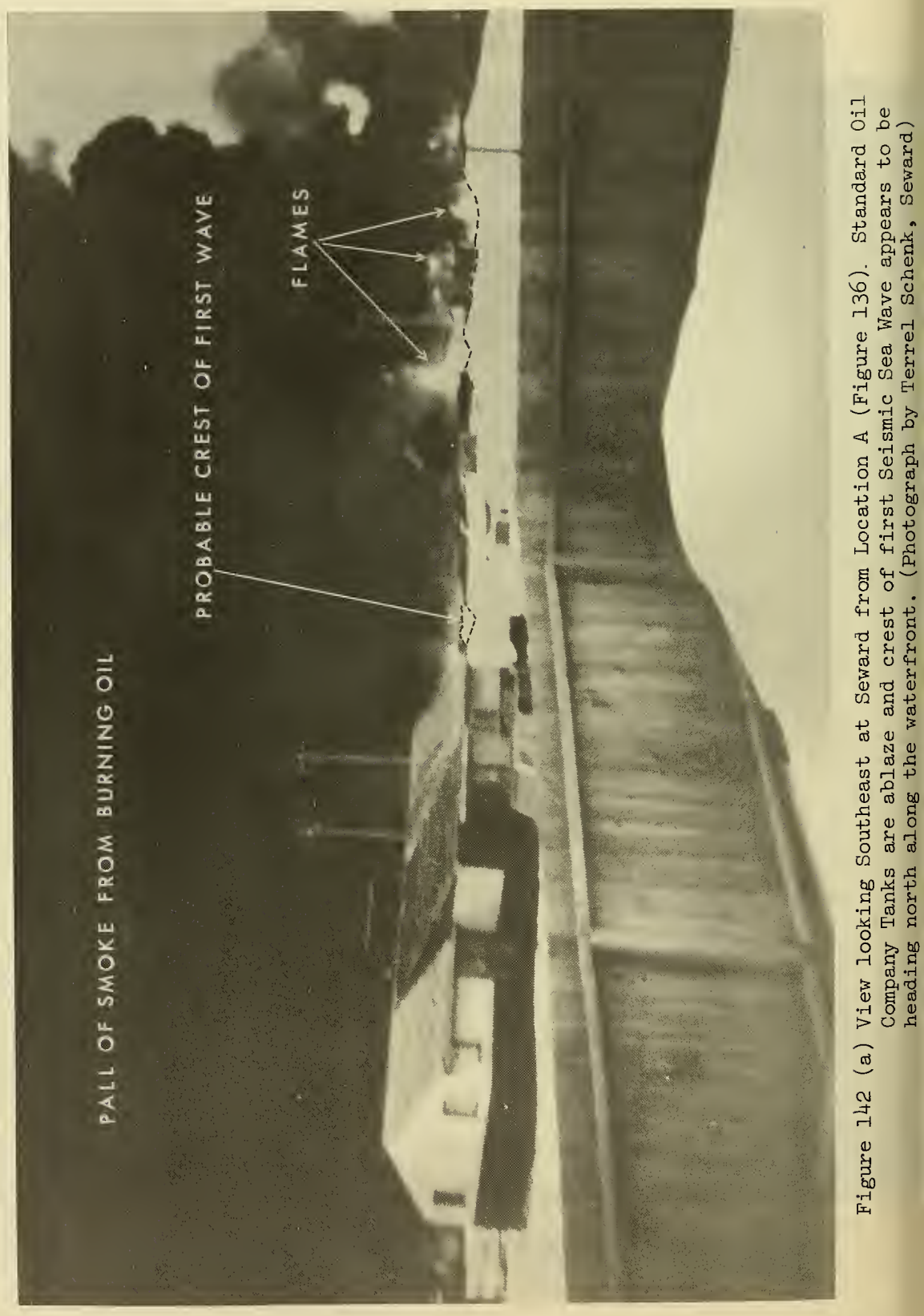




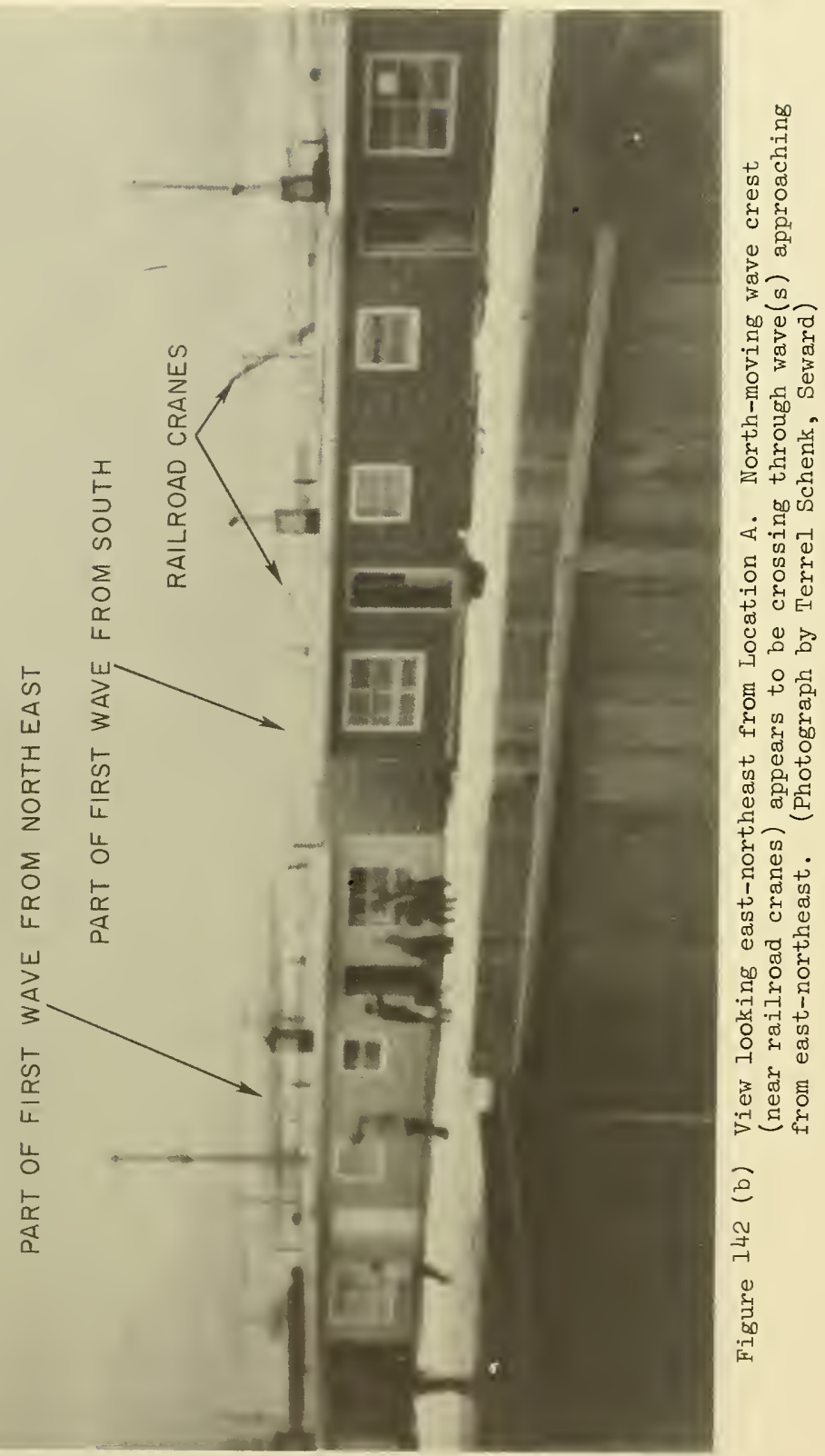




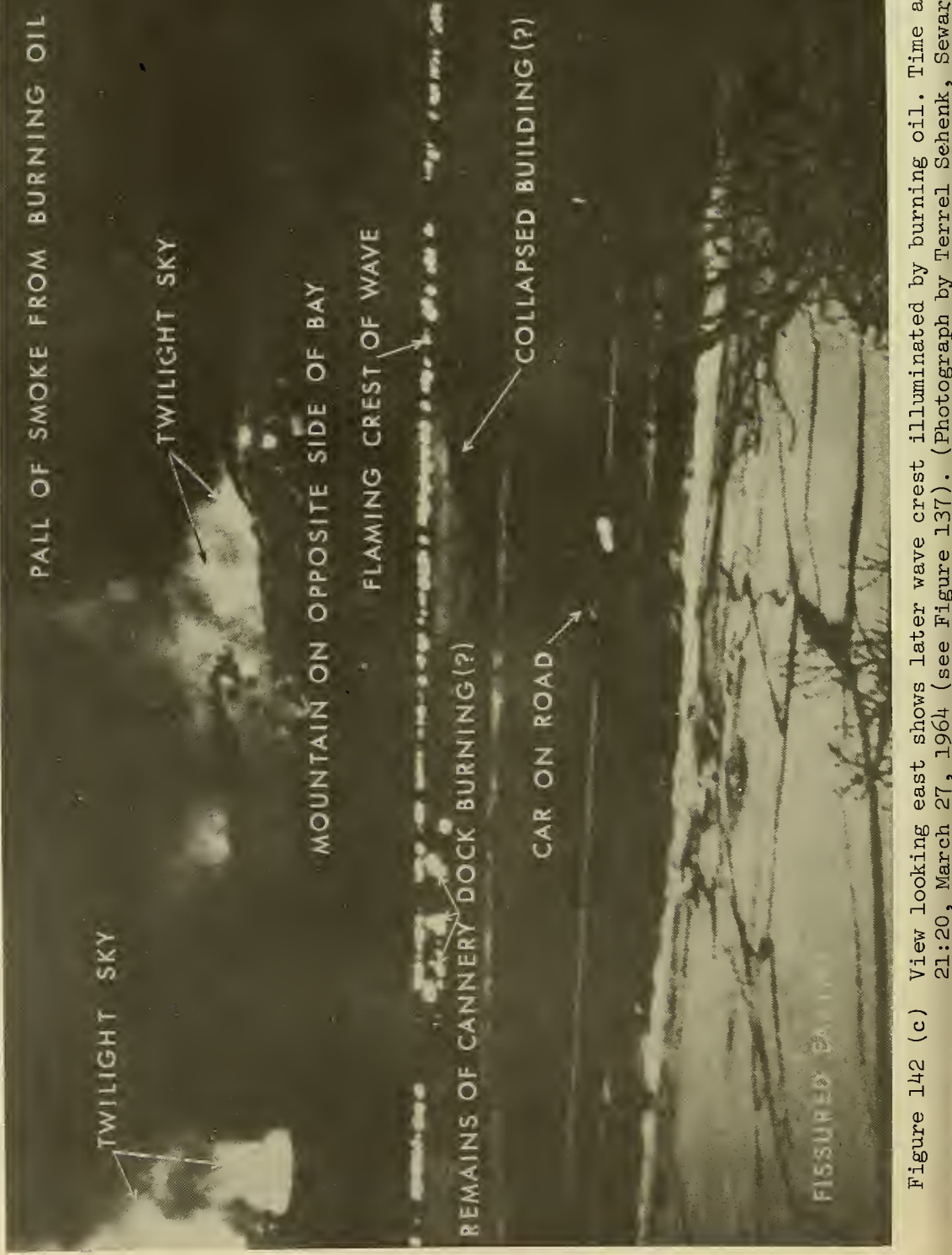


The wave appears as a smooth-line elevation of water moving toward the coast from deep water. This appearance fits the description of Tom Hyde who reported "a series of gigantic waves with glassy smooth but curling fronts hurling toward the shore at breakneck speed" (Chance, 1968). The first wave, according to Hyde, hit with terrific force and soon a wave of black oil was moving down the railroad tracks toward the boat harbor. At about this time the violent ground shaking had opened up innumerable fissures in the area surrounding the boat harbor and cannery and these structures were probably severely, but not entirely, damaged from the earthquake before the wave struck. It seems apparent that a complete slide had not yet occurred since there is clear evidence from several witnesses (Lantz and Kirkpatrick, 1964; Chance, 1968) that the waves tossed the boats around in the boat harbor and over the breakwaters. It is not known at what stage the boat harbor and cannery dock disappeared completely, but it may be surmised that whatever survived the wave probably succumbed to subsidence on the recession of the wave.

The second photograph was an $8 \mathrm{~mm}$ motion picture film taken by Robert Eads from Lowell Point (see Figure 135 for location). John and Robert Eads were closing shop at their Marine Railway and Repair Plant when the earthquake started. Looking toward Seward they saw a wave coming toward them from the direction of the Army docks and Standard Oil Company docks and about the same time another wave moving eastward on Fourth of July Point, which swept counterclockwise around the head of the bay (Berg, et al, 1964). This would fit the description of an annular ring wave expanding outward from a central source.

Robert Eads started photographing the oncoming wave with his motion picture camera, but on realization of its great speed of advance, he and Christiansen ran to their pickup truck to escape. The wave overtook them, as it did John Eads in another panel truck, and surf-rode them up into the woods at the northern end of the fan delta forming Lowell Point. The color film was damaged by seawater and is exasperatingly short and indistinct. Nevertheless, it has been found possible to reproduce the photographs of Figure 143, which show the wave as a dark band of water, elevating slightly and obviously cresting with white water at the shore. In the background, the plume of black smoke from the fire, just started at the Standard Oil Company dock, is obviously visible. The writers have examined Eads' film with care, and though little can be defined with certainty, they gain the impression that the wave could have been about 20 feet above general water level. The Eads considered the wave was travelling at a speed of over 60 miles per hour (Berg, et al, 1964); 100 miles per hour was mentioned to the writers (SEA interview, 1966). Such a speed is possible for a wave travelling as an edge wave (Lamb, 1932 Ed.) at the velocity

$$
c=(g \sin \theta) / \sigma
$$

where $\theta$ is the angle of the seabed to the horizontal and $\sigma(=2 \pi / T)$ the angular frequency of the wave, T its period. For a beach slope of about $12^{\circ}$ and an effective wave period of 3 minutes (say), this edge-wave speed would be about 180 feet per second or about 120 miles per hour. 
At Lowell Point, this wave rushed up to a height of about 33 feet above water level. A second wave, according to John Eads, rolled in at about $6: 00 \mathrm{p} . \mathrm{m}$. and was some 6 feet higher than the first (SEA interview, 1966). This would accord with the large wave of that time shown in Figure 137. This second wave apparently did most of the extensive damage at Lowell Point. For this or a subsequent wave, a runup height of about 45 feet at the north corner of the Lowell Point fan was established by the writers in 1966. On the southern side of the fan, waves reached to 100 feet (Figure 144).

It was reported by the Eadses (Chance, 1968) that, within 30 seconds of the onset of the earthquake, a wave formed about 1 mile southwest of Fourth of July Point. This wave traveled to Fourth of July Point where it was reflected toward the head of the bay. A boil reportedly formed in this area, and the Alaska Standard changed her course to avoid it approximately 10 to 20 minutes after the quake (Figure 144).

It is not obvious what caused this wave. The first slides along the waterfront area took place about 30 seconds after the earthquake started, but it is unlikely that these sliding earth masses could generate a wave in the middle of the bay within the first 30 seconds of the quake. Possibly, some other unknown slide caused this formation. On the other hand, the Eadses were probably not high enough above water level to accurately define the source point of the waves. It might simply have been closer to Seward and west of Fourth of July Point, as reported by other witnesses.

It must be mentioned, however, that the two sides of Resurrection Bay moved longitudinally through a distance of 50 feet with a differential horizontal displacement between the two sides of approximately 10 feet (Figure 16). It has also been interpreted from geologic sampling and subbottom profiling that large-scale rock movements of the order of 50 feet may have taken place along preexisting faults and folds within the northern part of Resurrection Bay (Captain Watkins, 1966; Rusnak, 1966, personal communication). Lacking details of this faulting, the writers can only acknowledge that any impulsive dislocation of the seabed horizontally along a fault at approximately $45^{\circ}$ to the axis of Resurrection Bay may have caused a pair of vortical boils of water. The boil closest to the south end of Seward could have been responsible for precipitating the submarine slide in that area, and for generating the waves.

After the first waterfront slide and the consequent waves, it is difficult to get a clear picture of wave sequence from eyewitness accounts. The waves had apparently sloshed back and forth in an irregular manner for a while. However, it seems to be definite that a high wave rushed up the landing strip of the airport approximately 8 to 10 minutes after onset of the earthquake (Chance, 1968). Two high waves with 5minute intervals occurred about $1 / 2$ hour after the earthquake. As shown in Figure 137, one of these was dominant, and conforms to the second wave to which most witnesses have referred (see also Berg, et al, 1964). 


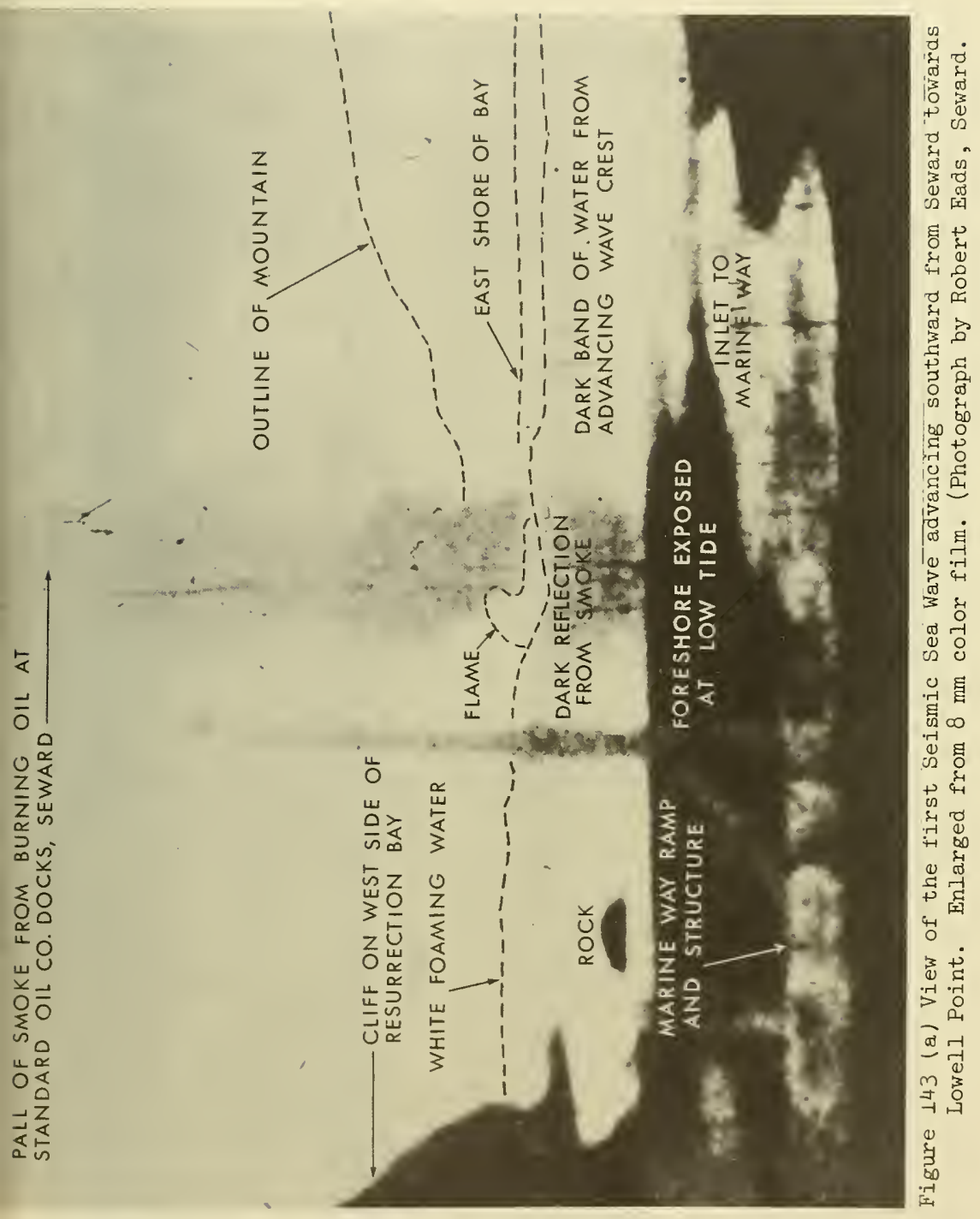




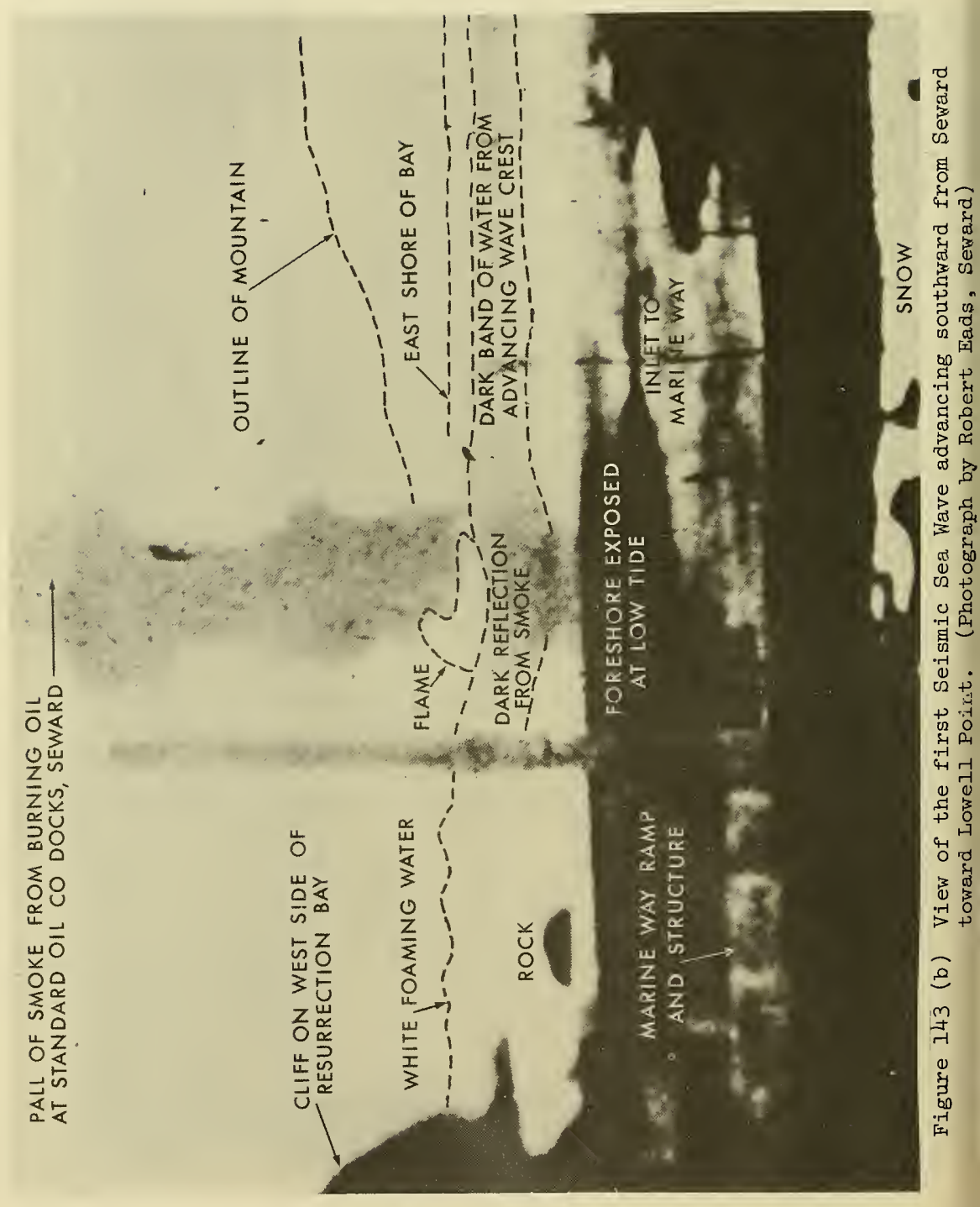




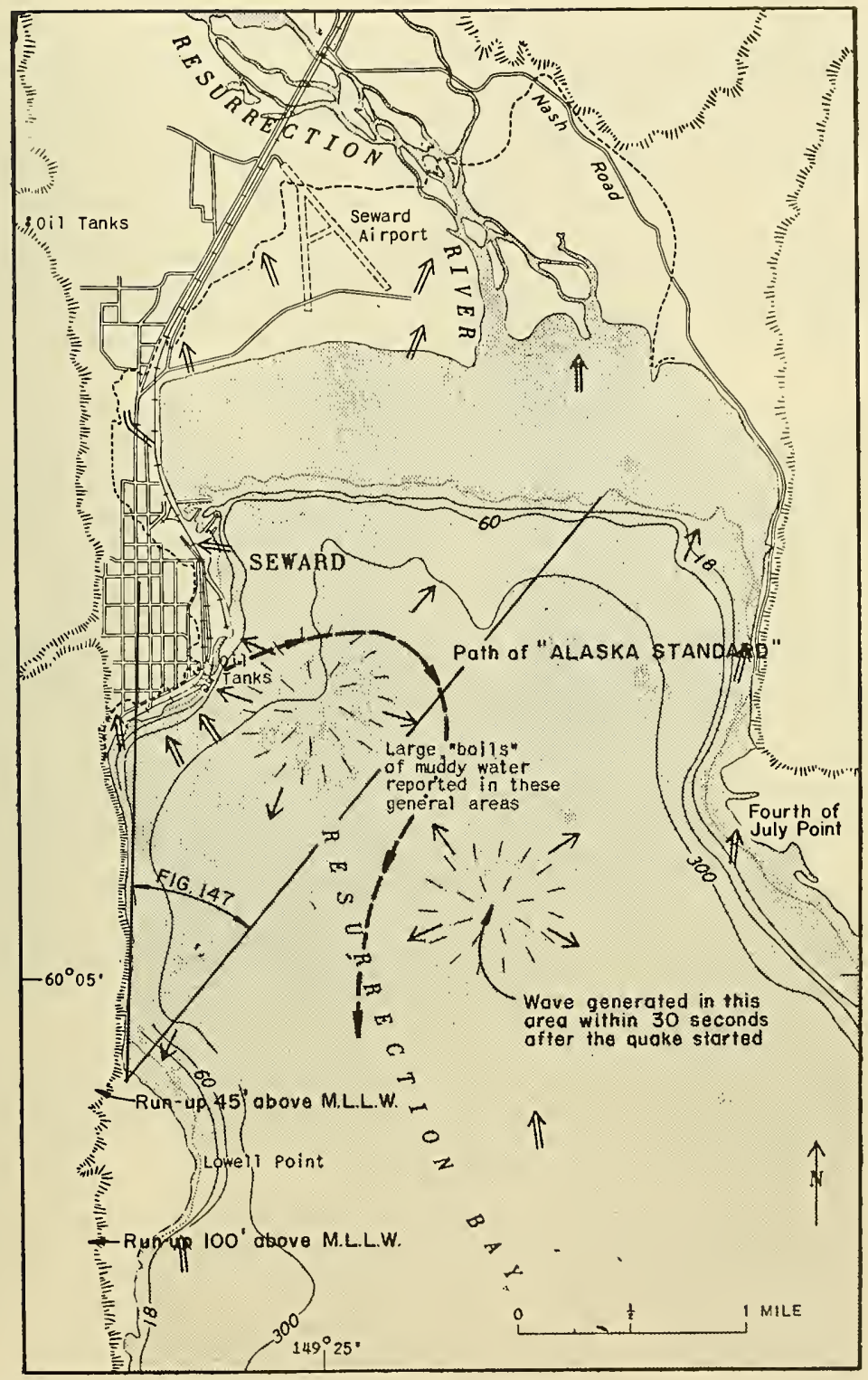

Figure 144 Map of the northern part of Resurrection Bay including Seward, Alaska (adapted from Grantz, et al, 1964). 
This wave is believed to have been higher and more damaging than the first and to have reached close to the highest runup levels recorded. However, as Figure 137 suggests, the main tsunami from the Continental Shelf was still to arrive, although it was already making its presence felt as a negative wave. We have hypothesized in Figure 137 that oscillations of period close to 12 to 15 minutes became prevalent within the first $11 / 2$ hours after the earthquake. This periodicity is close to the second-mode oscillation for the whole of Resurrection Bay, as also the first-mode oscillation of the northern part of the bay, acting as a pseudoclosed-end basin. It is believed that the first seismic sea wave arrived at about $6: 30 \mathrm{p} . \mathrm{m}$., but because of mismatched phasing, failed to reach remarkable proportions.

With the rising tide, the later tsunami waves, which were probably higher because of the same kind of modulation effect as influenced the Kodiak tsunami, became more dangerous. At about 10:00 p.m. a very large wave surged to the head of the bay, and reached maximum uprush at about 30 feet above MLLW. This wave was preceded by a phenomenal drawdown to 40 feet below MLLW according to an observation of the Eads brothers (Chance, 1968; SEA Interview, 1966). It was also followed by a very large recession which carried James Holban $1 / 4$ mile out on the tidal flats (Lantz and Kirkpatrick, 1964; Chance, 1968). How this large wave could have arisen is not clear except as some peculiar combination of superposed waves. Afterward, and throughout the night, other big waves of decreasing height surged in and out at about $11 / 4$ hour intervals (Chance, 1968).

The waves that hit the Seward waterfront during the earthquake were obviously generated by waterfront landslides or by local faulting. Not so obvious is what generated the waves that hit the airport and other places 8 to 10 minutes after the earthquake started. A slide at the head of Thumbs Cove, shortly after the earthquake started, generated a wave with a runup of 40-50 feet at the head of the cove (Lantz and Kirkpatrick, 1964; Chance, 1968). It is reasonable to suppose that a relatively big wave also emerged from Thumbs Cove at the same time. If a part of this emergent wave approached the head of Resurrection Bay, it would have reached the head of the Bay within about 9 minutes. This matches well with the reported time (Table VII) that a wave rushed up the airport landing strip. The Thumbs Cove disturbance also could have triggered longitudinal oscillations in Resurrection Bay, as envisioned in Figure 137, contributing to the violence of the second wave at $6: 00 \mathrm{p} . \mathrm{m}$.

The exact runup along the waterfront of individual waves is unknown. Maximum runup, probably caused by the wave at about 10:00 p.m., is well established from eyewitness accounts and from aerial photographs taken three days after the earthquake by Air Photo Tech Inc. of Anchorage. This runup line has been drawn in Figure 145 from inspection of vertical and oblique aerial photographs and ground photographs. Postquake contours of ground level and water depth are included in Figure 145 and prove the general consistency of the runup line, which averages about 27 feet above MLLW. In places the runup exceeds 30 feet, notably on either side of the 
two points on the shoreline at the foot and head of where the Army dock used to be. In Figure 134, offshore contours indicate the existence here of a submarine spur which by refraction would concentrate wave energy toward its center and the locations mentioned. The two points of land also had the same effect on the wave uprush and this is markedly seen in the manner in which the train of railroad cars was festooned about these shoreline cusps in Figure 146, (see also Figure 145).

Generally speaking, the description we have given of wave effects at Seward is in accord with that given by Lemke (1967), though there are differences in detail. The reader is referred to Lemke for an excellent general description of the calamity that beset seward.

\section{Tsunami Damage at Seward, Alaska}

Seward suffered its greatest damage from the subsidence and disappearance of its entire waterfront facilities (Figures 145 and 146). This appears to have been a progressive action of the earthquake which could have been assisted by the drawdown of the water table resulting from the initial slide and the subsequent alternate wave loading and suction effect. Shannon and Wilson (1964) point out that in the fan delta prior to the quake, considerable artesian pressures existed and fluctuated with the tide. These pressures would have been generally increased by the regional subsidence of about 5 to 6 feet that affected the entire area during the earthquake. Stability analyses of the soils by Shannon and Wilson (1964) confirmed that reasonable safety against failure for the slopes of the fan delta existed under static conditions but disappeared under accelerations of the order of $0.15 \mathrm{~g}$. Also, the vibration of the earthquake, with a large number of stress reversals, could have reduced cohesion of the soils and promoted liquefaction. The possibility cannot be overlooked that an impulsive shear along a fault plane in the northern part of Resurrection Bay set up a roil of water violent enough to have scoured the toe of the slopes of the fan delta, thus promoting slide failure. We shall not further discuss waterfront damage other than obvious damage that resulted from the seismic sea waves.

In the switchyard of the Alaska Railroad, yard crews had just finished coupling a freight train when the earthquake started. This train, comprising boxcars, flat cars, gondolas, refrigerator cars, and tank cars, was due to leave for Anchorage early in the evening. As shown in Figures 145 and 146 , the train was swept almost like a continuous string, and festooned around the engine house by the seismic sea wayes. It is not certain whether this was a progressive action of the entire sequence of waves or whether it was accomplished by one most powerful wave, probably at 10:00 p.m. (Figure 137). The big-wave concept seems likely, because the earlier waves probably lacked enough sustained force to accomplish such total wreckage (see Figures 147 to 151). Evidence exists, nevertheless, that the first and second wave accomplished at least some of this destruction (Lantz and Kirkpatrick, 1964; Chance, 1968). 


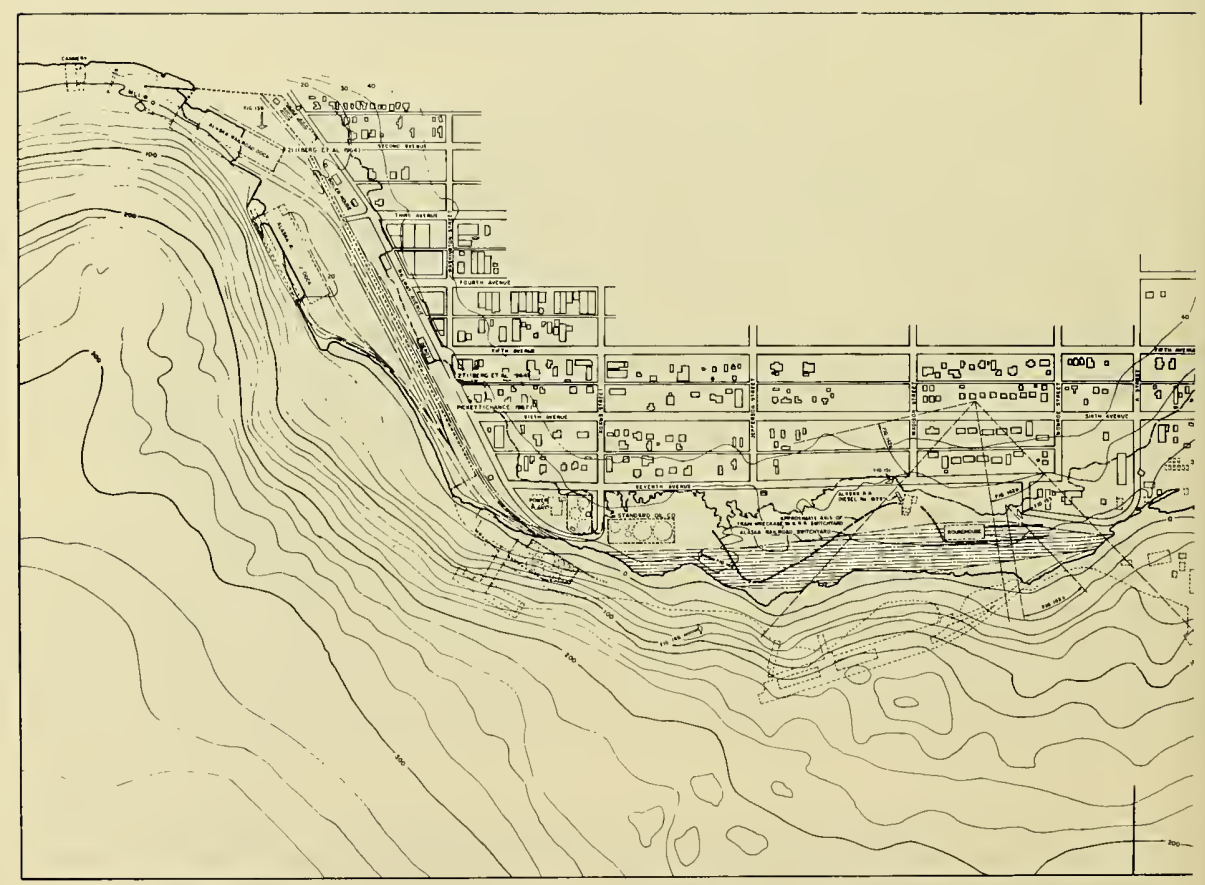

NOTE: Correct camera position for Figure 142c is at the east side of the I-shaped building, 375 feet east of position shown. 


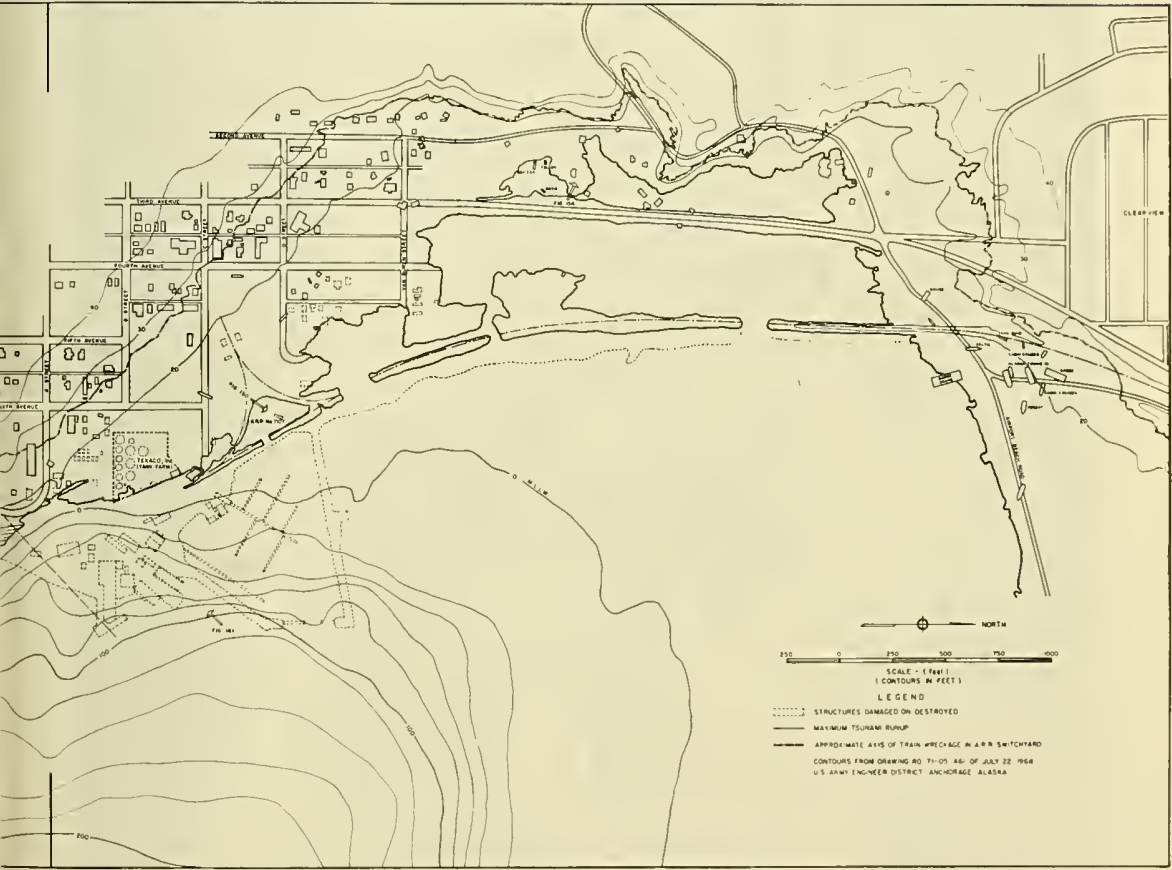

Figure 145 Plan of Seward, Alaska, after the Earthquake of March 27, 1964, showing the eroded shoreline and the limit of inundation from Seismic Sea Waves, as derived from aerial and ground photographs. 


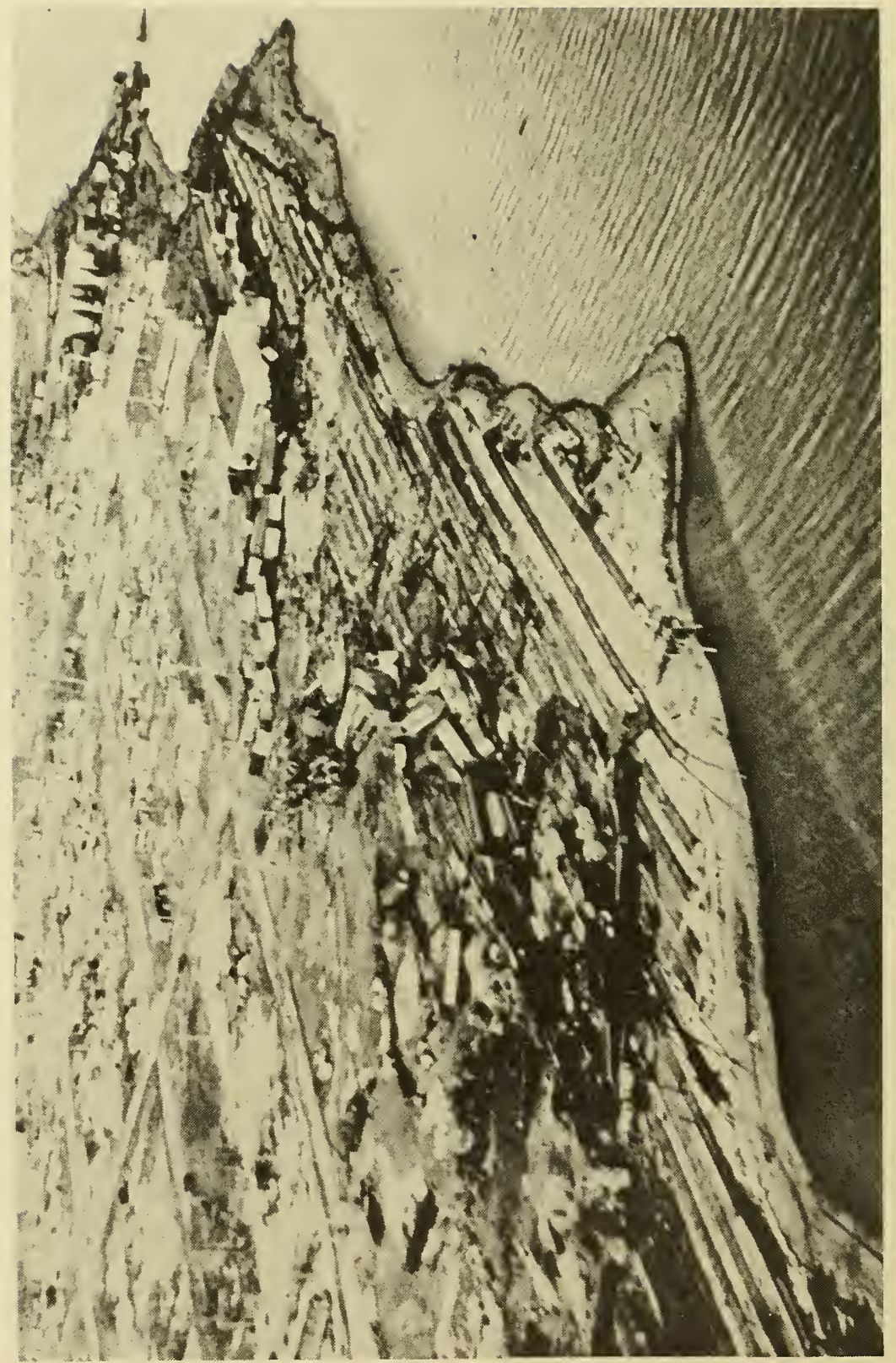

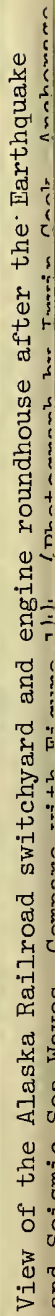

$\stackrel{7}{7}$

ปี

2
5
00
-1
5 
The apparent mystery of why the railroad tracks were stripped clean their rails (see Figure 148) is explained by an observation of Hal fillen, who reported that the quenching effect of the first wave on rails, made "cherry red" from the heat of the burning oil, "curled raised (them) like snakes stepped on" (Chance, 1968).

The Alaska Railroad conducted a survey of damaged equipment and icles after the earthquake and information is available in regard to positions occupied by each car. In the time available it has not an found possible to include these data in Figure 144. Although the jal weights of the different vehicles (tare plus the approximate load) known, it is difficult to evaluate the forces involved in moving m. Many, especially the gondolas and boxcars, undoubedly buoyed and sated for some time before filling with water. Of course, locomotives loaded tank cars would have been unable to float.

Two of the switching locomotives were rolled over and transported; e of them (No. 1828) moved about 300 feet. Since locomotive No. 7107 igure 149) was lying by itself with no other cars close by, it is asonable to assume that this engine was moved only by water. Locomove No. 1828, however, may have been pushed by impacts from other cars. esumably locomotive No. 7107 stood on the center track of the Y (turns sur) just west of where the track was ruptured by wave erosion (see yure 145). The rail elevation at this place was approximately 19 feet ove MLLW. If the wave of highest runup overturned this engine, water vel would have reached to 25 feet, and the locomotive would have been nersed in 6 feet of water. According to the approximate calculation Figure 152, it would require a water velocity of about 24.5 feet per cond to capsize the lccomotive and a force of about 700 pounds per uare foot to achieve this. However, the engine might also have been erturned and transported by a wave of lesser runup advancing with a zher, more smashing front.

The engine house of the Alaska Railroad, a steel-frame building with ncrete blocks, stood the wave attack rather well (Figure 153). It was rtly damaged by impact from cars but seemingly did not suffer much mage from the impact of running water. The waves that most severely maged the railroad cars apparently had a northwest airection since a comotive and several cars in the geometric shadow zone north of the gine house (Figures 145 and 146) were not moved. The engine house has nce been torn down because the railroad facilities have been rebuilt the head of the bay.

The waves left a shambles of houses and boats in the lagoon areas, me still looking relatively undamaged and some almost competely batred as shown in Figure 154. The type of house moved and damaged was light, wooden structure. It has not been possible, without a probitive amount of work, to re-establish where the houses stood before e earthquake. Figure 145, however, shows a few houses and boats whose entity has been traced from an interpretation of aerial photographs. 


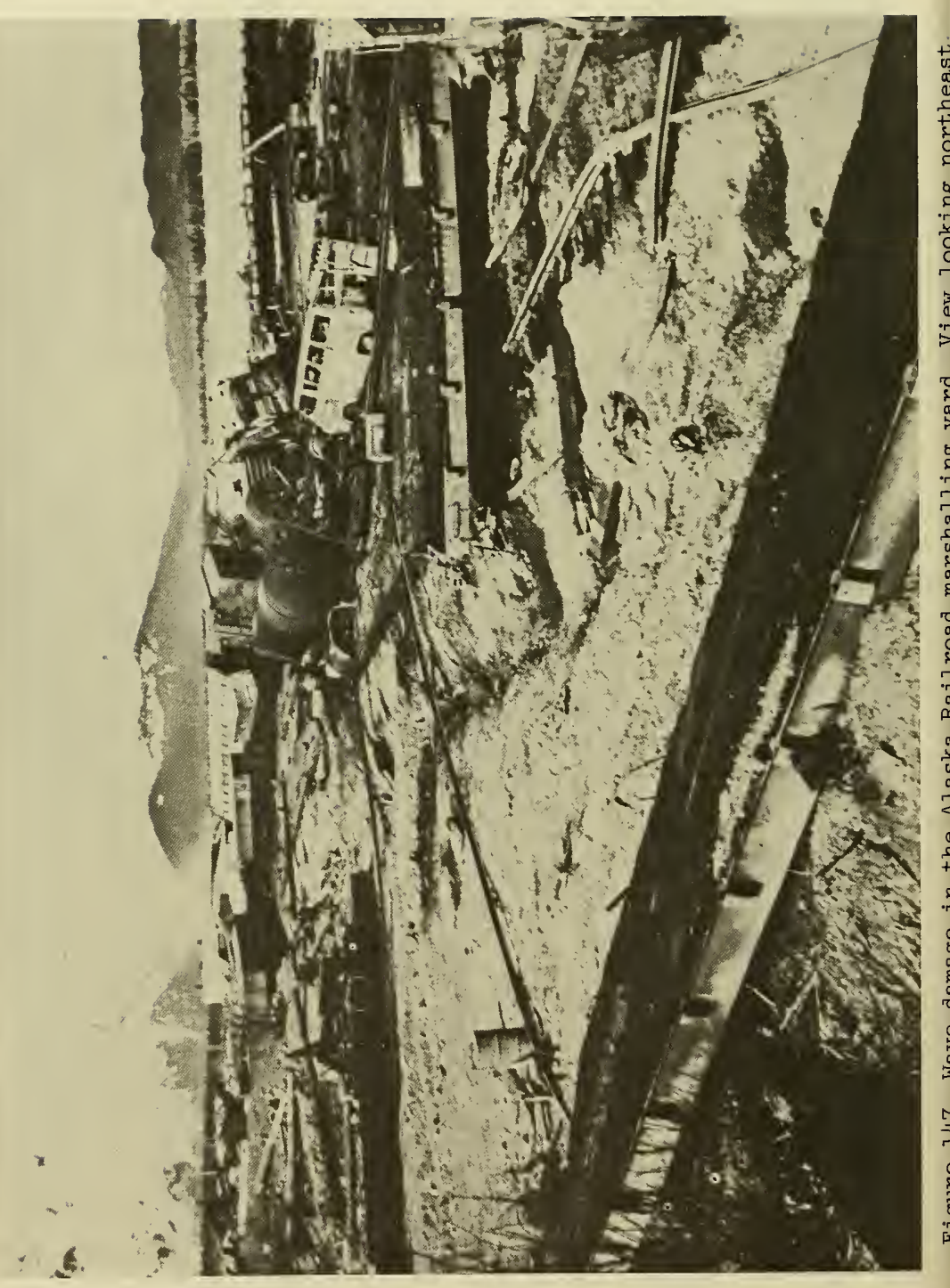




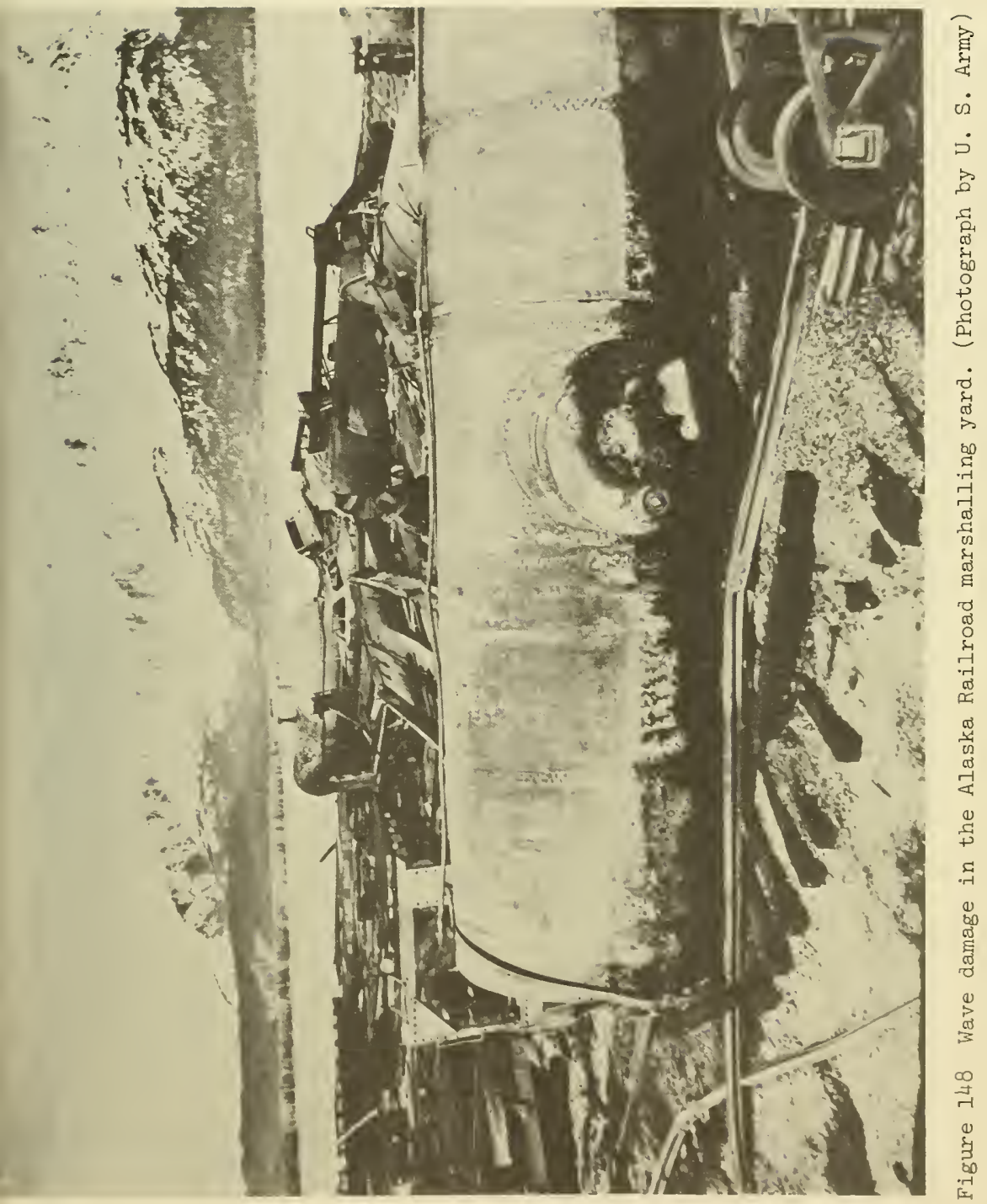




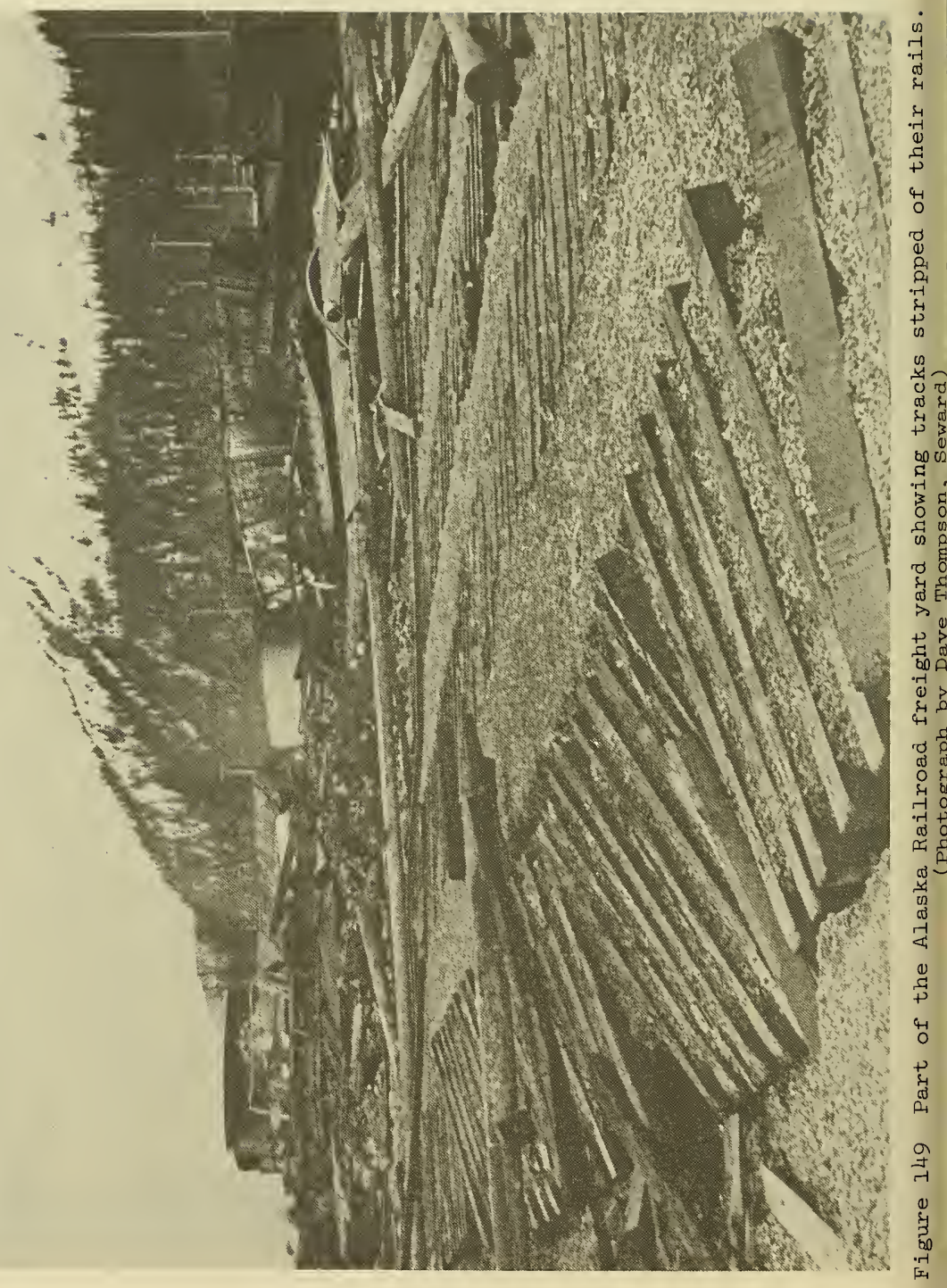




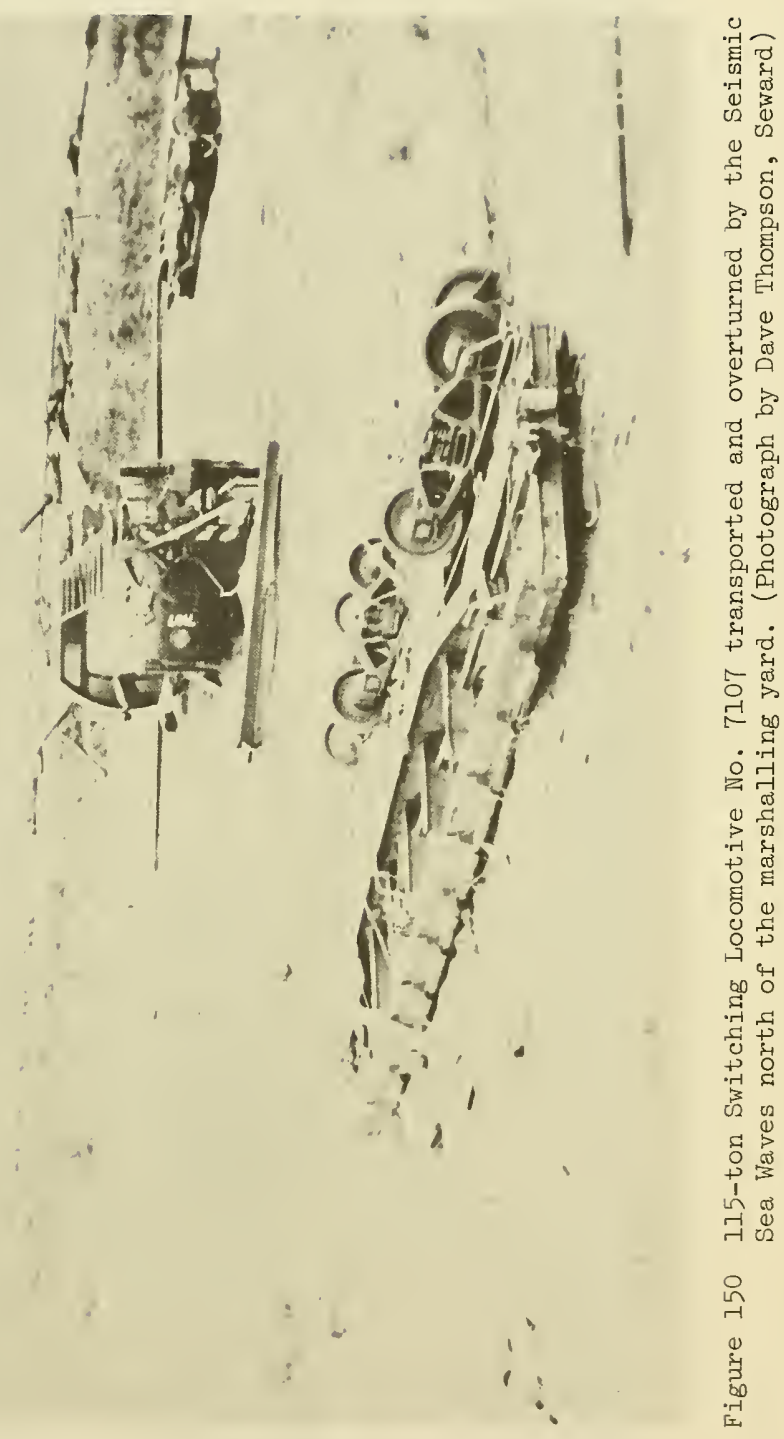




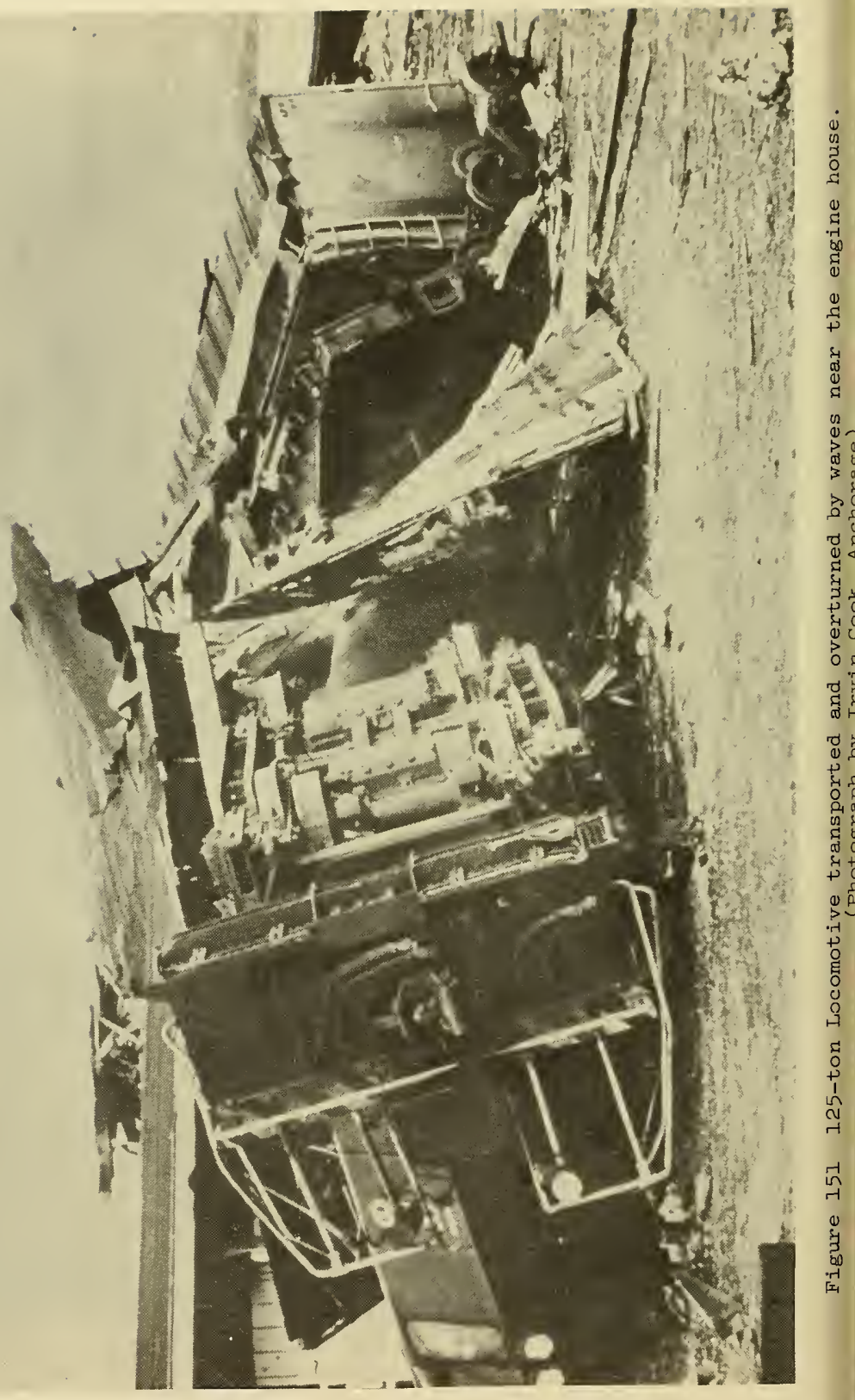



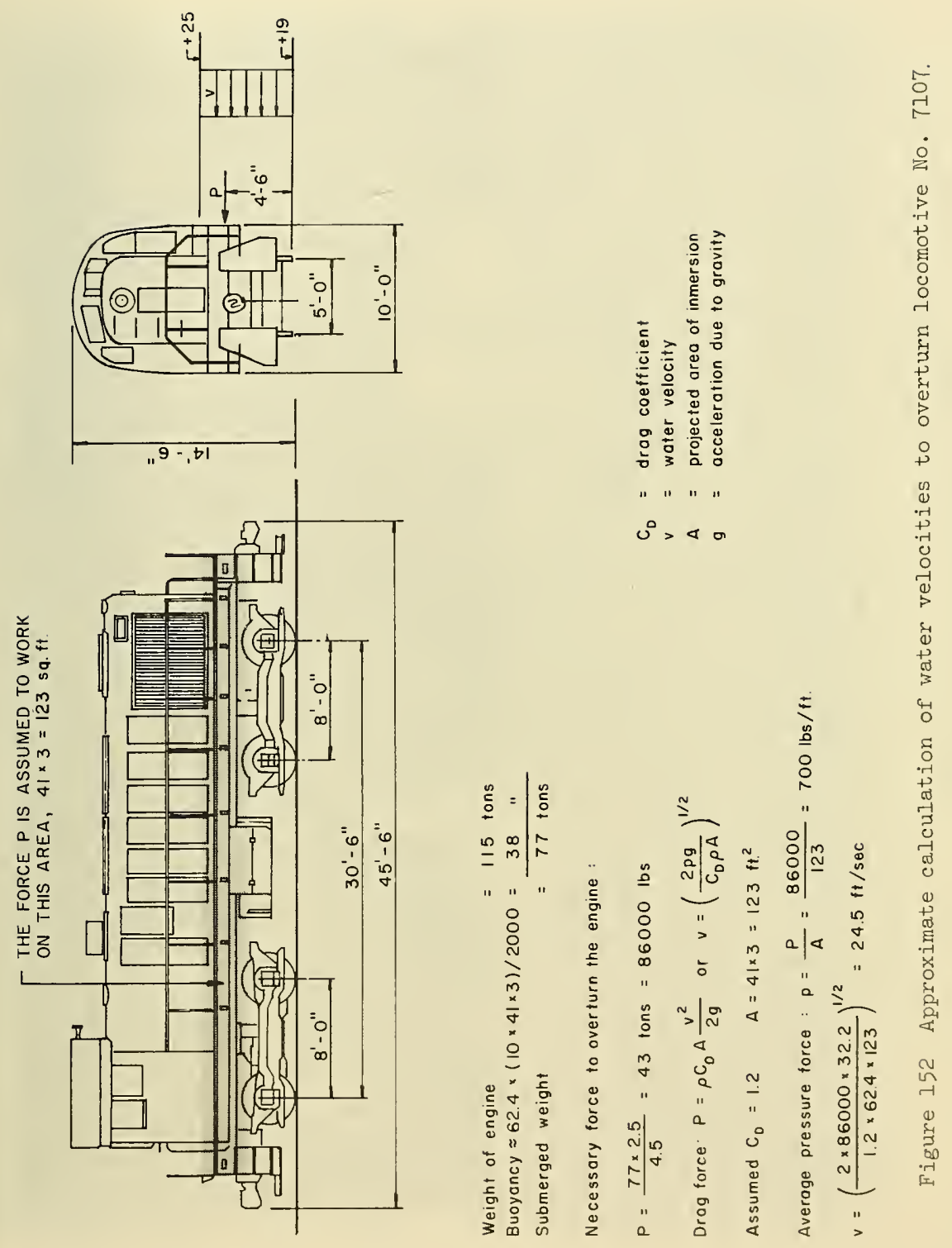


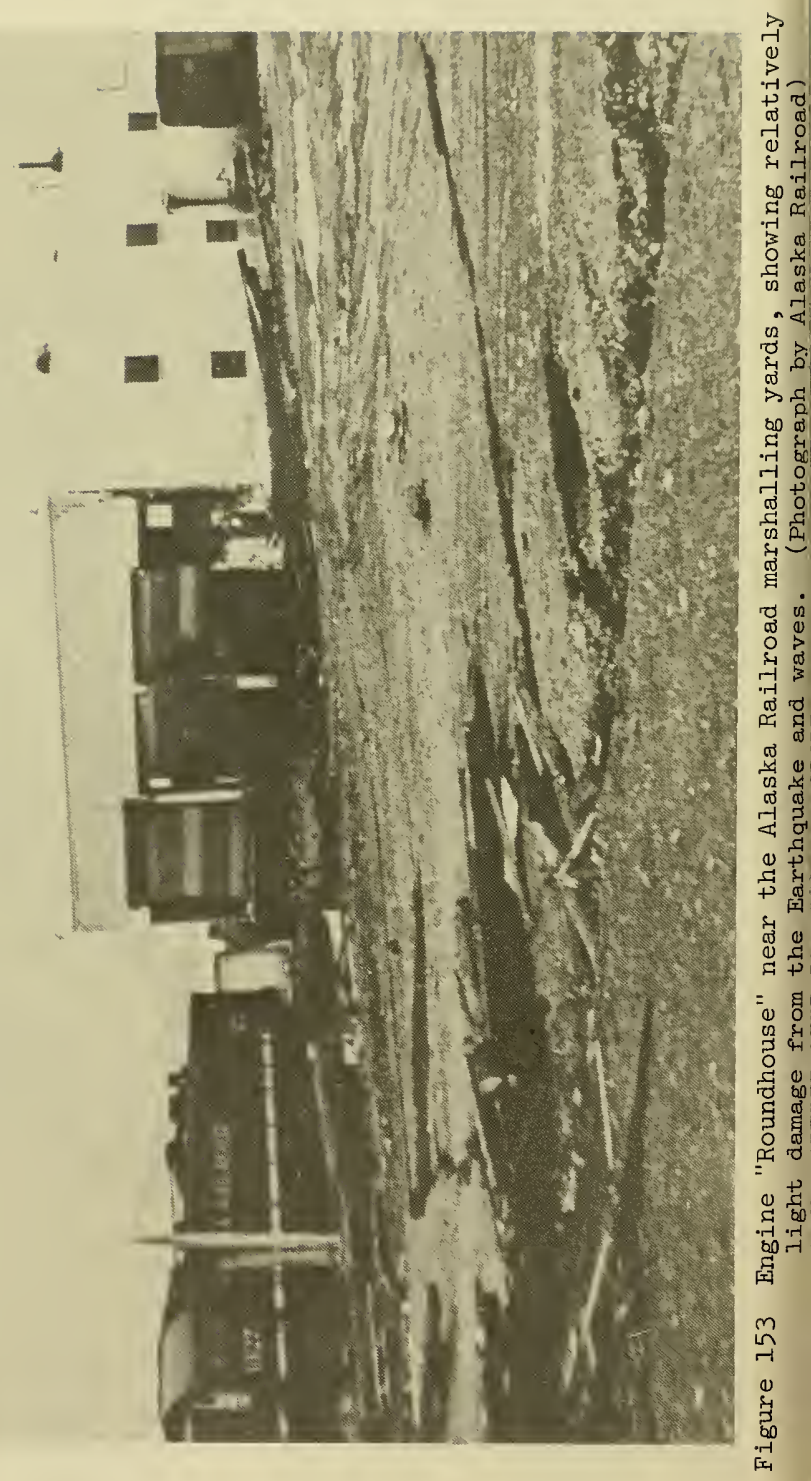


There were approximately 125 boats in the small boat-harbor at the time the earthquake started. Most of the boats were lost; some were tumbled by the first wave that hit the waterfront before the harbor disappeared; others were washed over the breakwater. The death toll in Seward was mainly from among people on board their boats in the small-boat harbor. Some of the boats were carried inland and beached far above normal high water (Figure 145); some beached among debris at the northwest head of the bay (Figure 155).

As already noted, the Alaska Standard, of 1,947 gross tons, survived the tsunami, with little damage other than a battered foredeck (Solibakke, 1964 ).

At the airport, all small planes and the Civil Air Patrol house were damaged by the wave that came in approximately 8 to 10 minutes after the earthquake started (Chance, 1968).

At Lowell Point, a newly built marina was completely demolished by the waves. The workshop, a wooden building, stood only 1 foot above the highest high water level. Different types of machinery for contracting work were parked at the marina. They were all tumbled and damaged beyond repair. The damage was massive. A 25-ton caterpillar tractor had its manganese steel frame broken by a rock; a 26-ton crane was carried 500 feet from the beach line; a 16-ton earth grader, parked in the area back of the shop, was moved about 100 feet and smashed; a 2-ton air compressor was displaced about 500 feet. The marine-way cradle was whipped along its tracks, smashing a winding drum and leveling everything in its path. The cradle tore loose from its cables, and landed in the rear parking area. The waves dislodged the winch which was not only bolted down but welded to railroad irons set in 6 feet of concrete. Wave forces sheared four pieces of railroad steel and moved the winch 6 feet inside what had been the shop. The shed completely disappeared and was never found.

Figure 156 shows the remains of the 6-ton panel truck in which Robert Eads and Christiansen survived the first wave. It was wrapped around a tree some 32 feet above water level, presumably by the second wave at $6: 00 \mathrm{p} . \mathrm{m}$.

The total damage at Seward in respect of the port and harbor facilities has been estimated at $\$ 15,375,000$ (Hansen, et al, 1966). It is difficult to say how much of this is directly due to the tsunami, but an amount of $\$ 14,614,000$ was assessed by the Anchorage Daily News of April 16, 1964 (Spaeth and Berkman, 1967). Twelve persons lost their lives to the sea waves at Seward. 


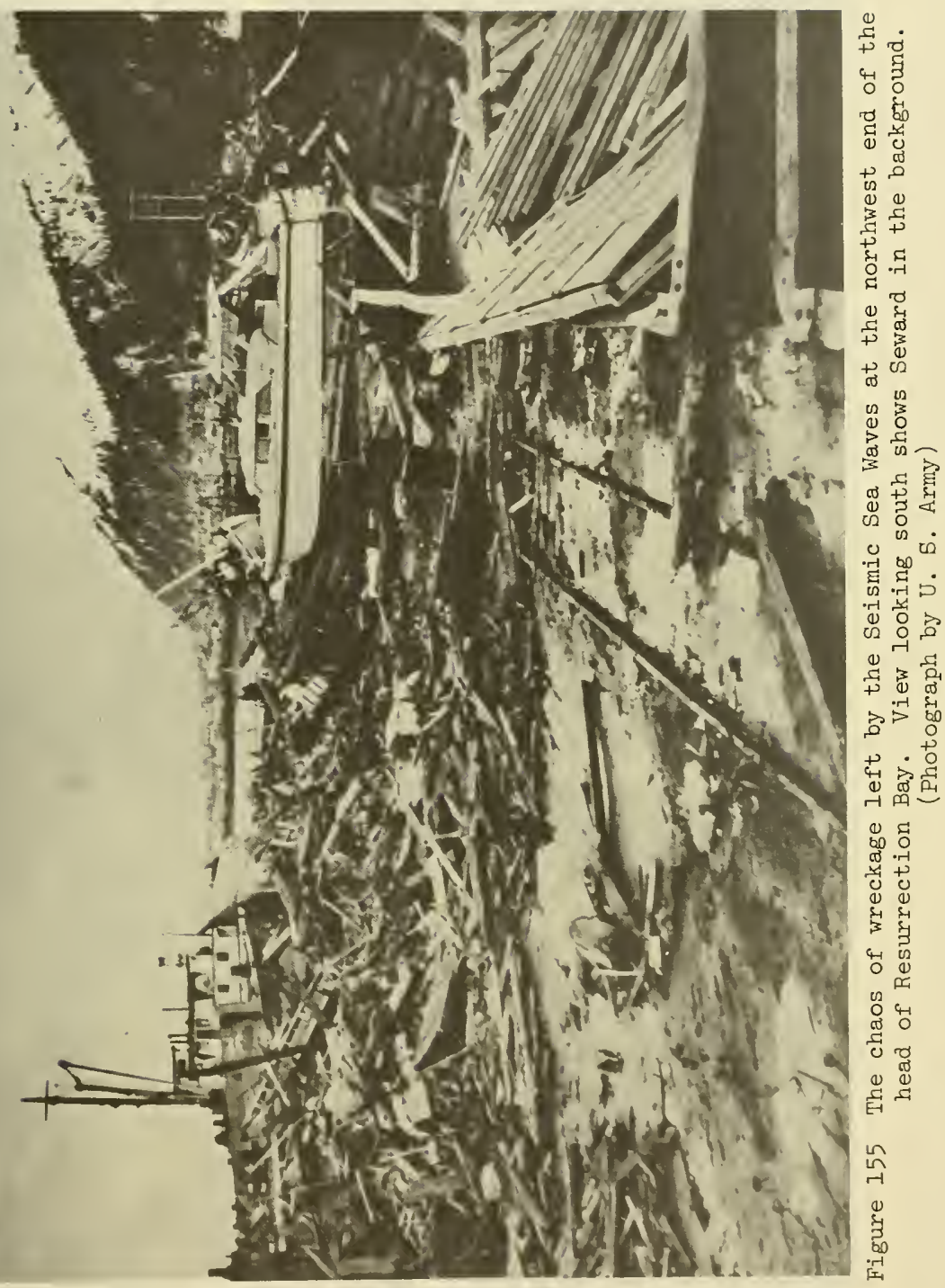




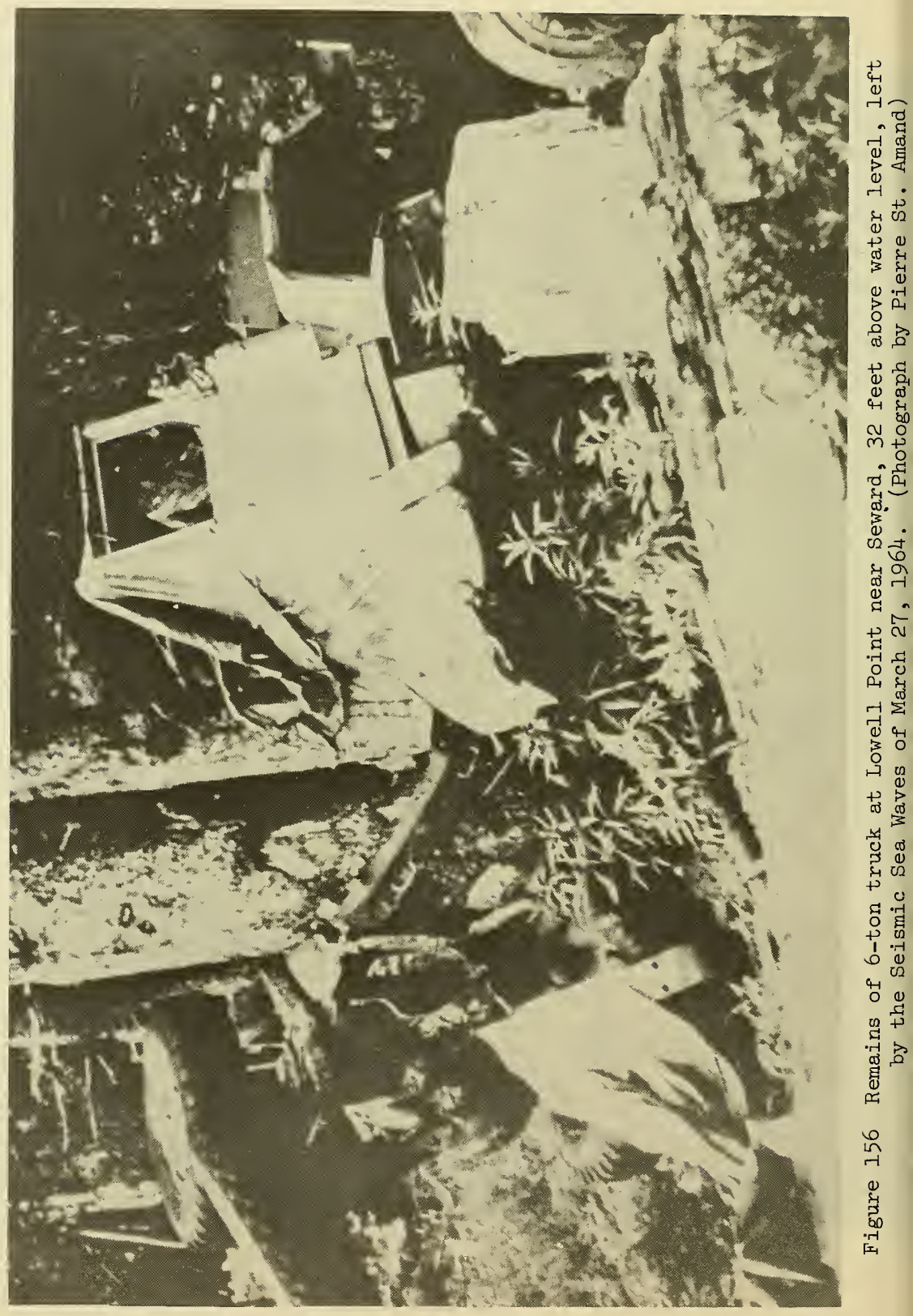


Section $V$. EFFECTS OF THE MAIN TSUNAMI AND OF LOCAL SEISMIC SEA WAVES IN PRINCE WILLIAM SOUND

\section{The Gross Picture of Behavior of Prince William Sound}

The tectonic movement which occurred during the earthquake has en defined in the Prince William Sound area with greater accuracy than iywhere else. The extent of vertical uplift or subsidence and the magnide of horizontal displacement are illustrated in Figures 9, 10, and 16. gure 10 shows that the major portion of the Sound was uplifted in the rm of a massive tilting of the seabed toward the northwest.

Figure 157 shows the main bathymetry of the region. The coastline labyrinthine in complexity and resembles a jigsaw puzzle, but in the oss the Sound can be approximated as a triangular basin ABC (Figure 157) th average depth of about 800 feet. This basin was effectively tilted the earthquake about a hinge line roughly parallel to the base line $\mathrm{BC}$ Figure 157 and about $2 / 3$ the perpendicular distance of the base $\mathrm{BC}$ from le vertex $A$.

In spite of the roughness of the approximation, it is of interest , examine the oscillating characteristics of this triangular basin, rerding it as having an open mouth along the line BC. This base line is - course, virtually a closed boundary, but in the presence of very long riod excitation such as the astronomical tides or the tsunami generated 1 the Continental Shelf, it may be approximated as an open basin.

The fundamental period $T_{1}$ is obtainable from Lamb (1932 Ed.) (cf. Lso Wilson, 1966), namely

$$
\mathrm{T}_{1}=2.616 \mathrm{~L} / \sqrt{\mathrm{gd}}
$$

here $L$ is the perpendicular length of the embayment. Irom A to BC (Figure 57) and $d$ is the mean depth. Adopting $L=4 \times 10^{5}$ feet and $d=800$ feet, find

$$
\mathrm{T}_{1} \simeq 110 \text { minutes }
$$

the $n$th mode of oscillation $(n=1,2,3, \ldots)$ the periods $T_{n}$ may be nown to be

$$
\mathrm{T}_{\mathrm{n}} \simeq 110 ; 48 ; 30 ; 22 ; . . \text {. minutes }
$$

he dominant period of the shelf-generated tsunami has already been shown $\circ$ be about the same as Equation $(46)$. This would imply that Prince illiam Sound would have been a responsive sounding box for the external timulation penetrating the straits around Montague Island, as well as or its own upheaval, which according to Figure 34, would initially have ome of the same character as the externally generated tsunami.

The tortuous coastline would no doubt have a rather profound effect $\mathrm{n}$ modifying and attenuating the main tsunami oscillations, but the 
tuning appears to be such that they could develop appreciable amplitude and persistence, nevertheless.

Because of its nearness to the epicenter of the earthquake (near Unakwik Inlet), Prince William Sound experienced more violent shaking than most other places. Slides were numerous, and locally generated effects were complex. From eyewitnesses' accounts about tsunamis in the Prince William Sound area, it is difficult to obtain an integrated concept of the wave sequences.

Many places like Chenega, Sawmill Bay, and Thumb Bay (Figure 157) were struck by high waves during the earthquake. These first waves were seemingly of short period with the character of being locally generated like the first slide-generated waves that struck Seward, Valdez, and Whittier. However, there is no evidence of visible slides that could have generated these waves. Glacial deposits such as those in which the wave-generating slides took place at Seward, Valdez and Whittier are apparently almost absent in the western and northern part of Prince William Sound. However, such deposits probably occur locally under water because depressed cirque levels in these areas indicate that shore lines have been drowned since the last major glaciation (Plafker, 1965; von Huene, et al, 1967), and indeed a substantial invisible submarine slide north of Latouche Island (Figure 157) has been reported by the U. S. Coast \& Geodetic Survey ship Surveyor (Coast \& Geodetic Survey, 1965). This slide probably generated the first waves that hit Port Ashton and Thumb Bay. Other causes of local waves of uncertain origin may have been local submarine faulting, and seiches generated by ground vibration.

Figure 158 shows a generalized distribution in the Sound of larger destructive local waves and known subaqueous slides as found by $U$. S. Geological Survey (Plafker and Mayo, 1965). Because available information about possible wave origins at present is too scanty to justify further speculation, only a description of the waves and the known damage at the larger villages and inhabited places, as reported by eyewitnesses, will be included here. Reference to the location of these places may be found in Figures $I$ and 157. Valdez and Whittier will be discussed more fully in later sections. An attempt has been made to infer marigrams for some of the places; these are shown collectively in Figure 159.

Chenega, on Chenega Island in Knight Island Passage, was one of the places hit hardest. All houses were floated away and totally lost. Twenty-five people were drowned.

About 60 to 90 seconds after the earthquake started the first wave came in like a fast-rising tide and reached half way up the beach. Some people were drowned by this wave. As the water receded one minute later to about 500 feet from the shore, it swept away some of the houses. A second wave, arriving with a roar, struck the village about four minutes after the quake started. This wave swept away all the remaining houses. 


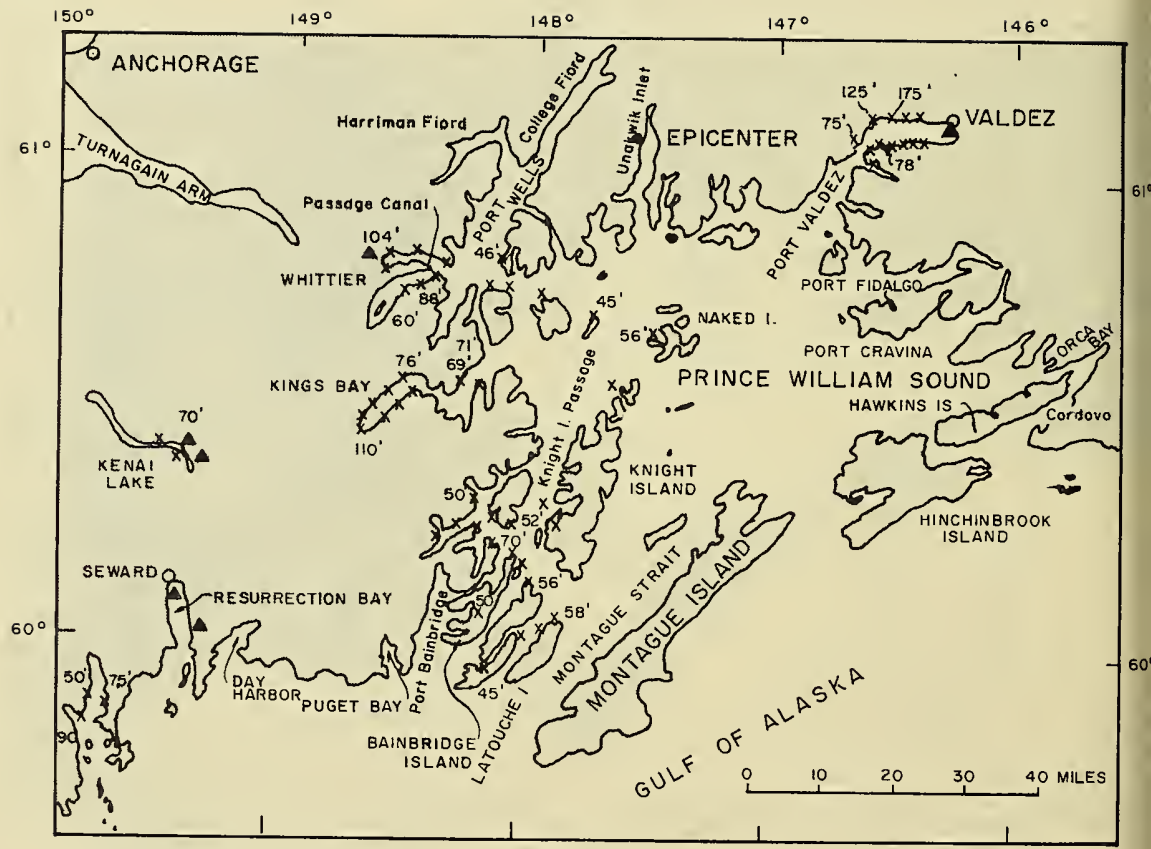

Figure 158 Generalized distribution of larger destructive local waves and known subaqueous slides in Prince William Sound and part of the Kenai Peninsula. Shorelines damaged by waves with runup heights in excess of 40 feet above lower low water are indicated by an "X"; numerals are the measured maximum runup heights. Solid triangle indicates known subaqueous slide. (from Plafker \& Mayo, 1965) 

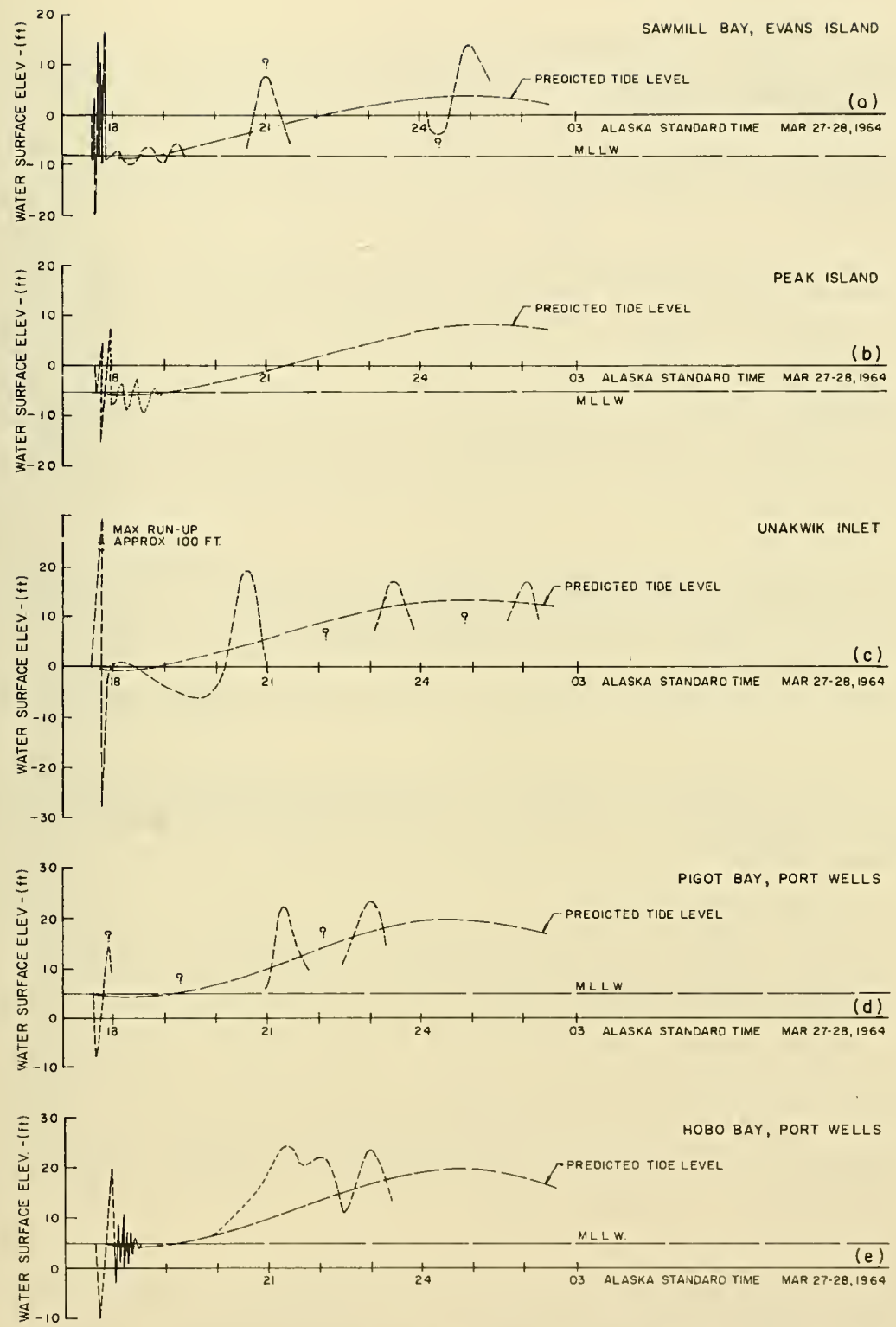

Figure 159 Inferred Marigrams at five locations in Prince William Sound, based on observations reported by Chance (1968); Berg, et al (1964) 
The school building, on a hill at an elevation of 90 feet, was reached only by water spray. Three oil tanks withstood the wave attack (Chance, 1968). The general runup height was about 54 feet above MLLW.

At Port Oceanic, Knight Island, a wave that rushed 18 to 20 feet above high tide level struck the shore 1 to 2 minutes after the onset of the earthquake (Chance, 1968).

The wave that smashed at Thumb Bay, Knight Island, 2 to 3 minutes after the earthquake, washed away trees standing 20 feet above zero tide, and piled debris at least 22 feet above the highest tide line at the head of the bay (Chance, 1968).

At Sawmill Bay, Evans Island, about 2 minutes after the earthquake began, the water started to rise smoothly and slowly, and then receded in a roaring current. Shortly afterward a second, fast wave reached to about the highest tidewater line and swept away pilings, docks, and boats (Chance, 1968).

At Port Ashton in Sawmill Bay, the first wave struck about 2 minutes after the earthquake, beaching some vessels. The water reportedly continued oscillating at 3 to 4 minute intervals until dusk. A high wave at about 9:00 p.m. swept some skiffs away (Figure 159a).

At Port Nellie Juan, a wave, about 5 feet higher than the dock, swept away pilings and toppled two buildings.

In Culross Passage, a violent current surged south and then north soon after the earthquake started. The current changed three or four times during a half hour. The surge had the form of a bore 8 to 10 feet high (Chance, 1968).

As reported by two brothers living on Perry Island, in an isolated bay, the water "ruffled" and went down to about 8 feet below low tide. Approximately 8 minutes after the earthquake started, a wave came in and rushed 26 feet above MLLW (Berg, et al, 1964; Chance, 1968).

Mrs. Clock, who lives with her family on Peak Island, reported that the water rose and "boiled furiously" along the shore, and spray went high into the trees. Then the water dropped almost 15 feet from low tide level and it was "eerie calm." About 4 to 5 minutes after the earthquake, a wave of water "five feet higher than normal moved in from the lagoon" and struck the shore. Mrs. Clock said the water "came back and forth for at least an hour." (see Figure 159b).

The fishing boat Roald was anchored in Port Wells at the time of the earthquake. The captain reported that the water withdrew about 20 minutes later. Then after another 10-15 minutes it returned like a tidal bore from the south and carried the anchored boat along with rocks and debris into its mainstream of deeper water. 
At the head of Pigot Bay, Port Wells, after the earthquake ended le sea whipped violently back and forth as it receded about $1 / 4$ to $1 / 2$ ile from the shore. The water then returned to shore as a fast-rising ide without any violent surge. About 10 minutes after the earthquake ased, the surface became calm at normal tide level. Between 9:00 and $30 \mathrm{p} . \mathrm{m}$., the sea rose 8 feet above extreme high tide, and then receded out 2 feet. At about 11:00 p.m. it again reached about 8 feet above streme high tide (Chance, 1968) (see Figure 159d).

In Hobo Bay, north of Pigot Bay, the water receded during the arthquake and exposed bottom normally below lowest tide. When the ter returned, it rose about 4 feet above high tide. After the earthlake ceased, small waves came in rapid succession every 2 to 3 minutes. ; darkness fell, the sea became calm. Shortly after dark, however, the ter began to rise and within 1 1/2 hours reached 9 feet above high tide ivel. The water then receded about 4 feet before another wave came in. or a period of 2 hours at this time the water advanced and withdrew iree times (Chance, 1968) (see Figure 159e).

The fishing vessel Quest was in Unakwik Inlet at the time of the irthquake. One of the crew members has reported that a big swell moved while the earth was shaking. The water sloshed back and forth in an ist-west direction, and ran up approximately 100 feet at some places. hen it withdrew it exposed the sea bottom about 4 or 5 fathoms deep. urge waves swept into the inlet at 1l:00 p.m. and then again at about 00 a.m. (Chance, 1968).

Another fishing vessel was about one mile inside the mouth of lakwik Inlet at the time of the quake. A crew member reported that le water started to oscillate during the earthquake, washing high on le north shore and then withdrawing an unusually great distance off1ore. The oscillations continued throughout the quake with a period approximately one minute. Immediately after the earthquake ended, ie water started to recede; the regression continued for about $21 / 2$ urs. Within 3 hours after the earthquake the water started to rise a water level higher than high water. By 9:00 p.m. the water was ain receding. At about midnight another wave brought the water level out 3 feet higher than the normal tide for that time (Chance, 1968) see Figure 159c).

At Tatitlek the water receded 15 feet, and then returned 17 to 18 et above MLLW. At 9:00 p.m. a high wave rose to within 7 inches of a requake 15-foot datum level. Forty-five minutes later there was a wave lat had a height of 5.3 feet above the normal tide of that time (Chance, 68)

At Boswell Bay, Hinchinbrook Island, it was reported that the water ceded initially. The regression was followed by 2 waves within 3 hours eter the quake. Between midnight and l:00 a.m. the water rose 8 to 12 et above the high tide level (Chance, 1968). 
The maximum tsunami runup at Zaikof Bay, Montague Island, was about 33 feet above postquake MLLW.

At a place, for the time being unknown, on Montague Island, 5 waves at about 5 minute intervals were observed travelling parallel to the shore; the first one, with a height of 12 feet, arrived at about 6:05 p.m. (Van Dorn, 1966).

\section{Tsunami Waves in Port Valdez, Prince William Sound}

The disaster that befell Seward had something of a parallel at Valdez, situated in Prince William Sound, at the head of a long fjord comprising the Valdez Arm and the Port of Valdez (Figure 160). The similarity of earthquake and tsunami effects is rendered the more interesting because of a similarity of location of the towns with respect to bays of very similar shape and size. In fact, the schematic representation of a coupled system of basins shown in Figure 133b, applies in the same sense to the Valdez fjord, which is seen to comprise two basins connected by a constricted channel of shallower water (Figure 160). Even the dimensions are quite similar. What is different in the relative situations of Valdez and Seward, is that Valdez Bay opens on Prince William Sound, a virtually closed basin, whereas, Resurrection Bay opens on the sea. Valdez, much closer to the epicenter of the earthquake than Seward, is located close to the hinge line of zero vertical earth motion (Figure 160, inset).

We investigate the oscillating properties of Valdez Arm and Port Valdez as the chain-basin system represented schematically by Figure 133b. In this case basins I, II, and III have the approximate dimensions given in Table VIII. By the impedance principle of Rayleigh as employed by Neumann (1948), we find the eigenperiods $\operatorname{T}_{n}(n=1,2,3,4 \ldots)$ for the first four modes of free oscillation of the system to be

$$
\mathrm{T}_{\mathrm{n}} \simeq 39 ; 18 ; 11 ; 7 ; \ldots \text { minutes }
$$

TABLE VIII

Dimensions of Interconnecting Rectangular Basins Simulating Valdez Arm and Port Valdez

\begin{tabular}{rrrr} 
Basin & $\begin{array}{c}\text { Length } \\
\text { I(n.mi.) }\end{array}$ & $\begin{array}{l}\text { Breadth } \\
\text { b(n.mi.) }\end{array}$ & $\begin{array}{r}\text { Depth } \\
\left.\text { ( } \mathrm{ft}^{\prime}\right)\end{array}$ \\
\hline I & 11.35 & 2.01 & 700 \\
II & 2.00 & 0.76 & 600 \\
III & 10.52 & 2.66 & 1100
\end{tabular}


Comparison of the period sequence in Equation (48) with that of quation (47) suggests that the Valdez embayment would not provide resoance for the expected fundamental period of the tsunami waves generated t the mouth of Prince William Sound. However, in view of the impliation that the Sound might well develop oscillations corresponding to he higher modes of its triangular shape, some degree of resonance or seudoresonance could amplify the effects of oscillations of period less an 50 minutes.

Figure 161 gives the results of seismic reflection profiles of the aldez embayment obtained in field surveys since the earthquake (Von dene, et al, 1967). The basement rock profile has an average depth a Valdez Arm of about 1,200 feet. It is deeper (about 1,800 feet) in ort Valdez. In Valdez Narrows, the rock forms a sill which is virtully free of sediments. Owing to the elbow bend formed between Valdez $\mathrm{cm}$ and Port Valdez, the latter is capable of functioning as an effecively closed basin for any water oscillations generated within it. he profile $A B$ in Figure 161 is not quite complete in showing the rise f sediments beyond $B$. The water depth profile, however, may reasonably ill be taken as being semiparabolic over the basin length of 11.35 autical miles, with its maximum depth of 850 feet at the west end.

The manner in which this basin would oscillate by itself longidinally may be found by considering it just half of its mirror-image asin. Applicable modes from the solution of the double basin are ily those that yield an antinode at the center. From Wilson (1966), ien, we find the fundamental and second mode periods of oscillation longitudinally) for Port Valdez to be

$$
\left.\begin{array}{l}
\text { (i) } \mathrm{T}_{1} \simeq 17.8 \text { minutes } \\
\text { (ii) } \mathrm{T}_{2} \simeq 9.8 \text { minutes }
\end{array}\right\}
$$

There is no tide record for Valdez Harbor. As at Seward, we are pendent on accounts of eyewitnesses and the studies of other investiitors for an interpretation of what happened. We shall refer to many urces of information, notably, Grantz, et al (1964); Brown (1964); rg, et al (1964); Coast \& Geodetic Survey (1964); Denner (1964); -afker and Mayo (1965); Spaeth and Berkman (1965, 1967); Coulter and gliaccio (1966); and also unpublished materials to be cited.

Valdez is situated at the eastern end of Port Valdez on the seaward ige of a large outwash delta composed of a thick section of saturated lty sand and gravel. Its general location is shown in Figure 160 and tails of the layout of the city and harbor are given in the prequake lan, Figure 162. The town was entirely contained within a V-shaped vee which prevented inundation from the frequent rampages of the Valdez ver draining from the Valdez Glacier. Figure 163 shows the appearance ( the waterfront before the development of the small boat harbor in the dal zone area between the north and south arms of the docks. 


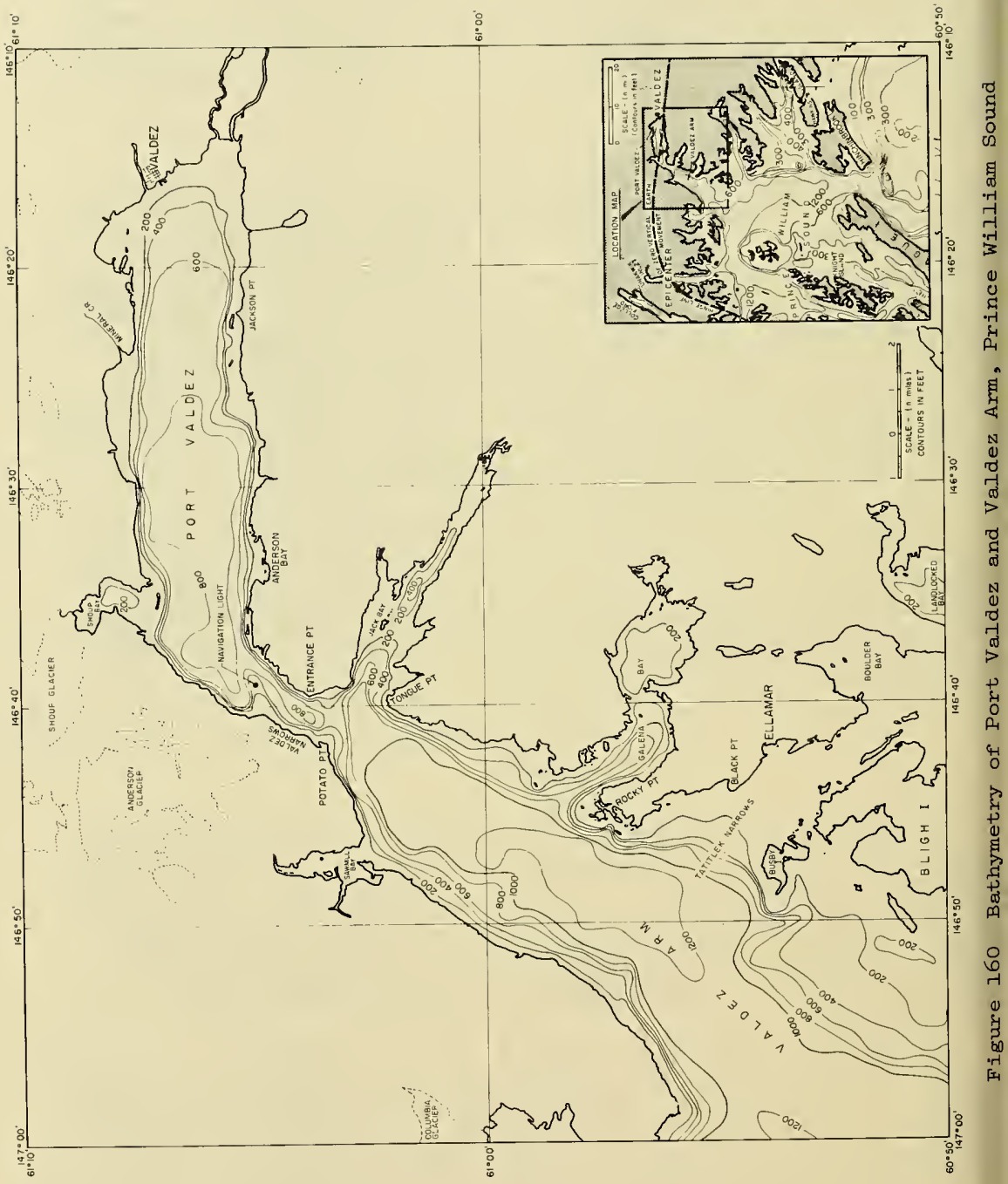



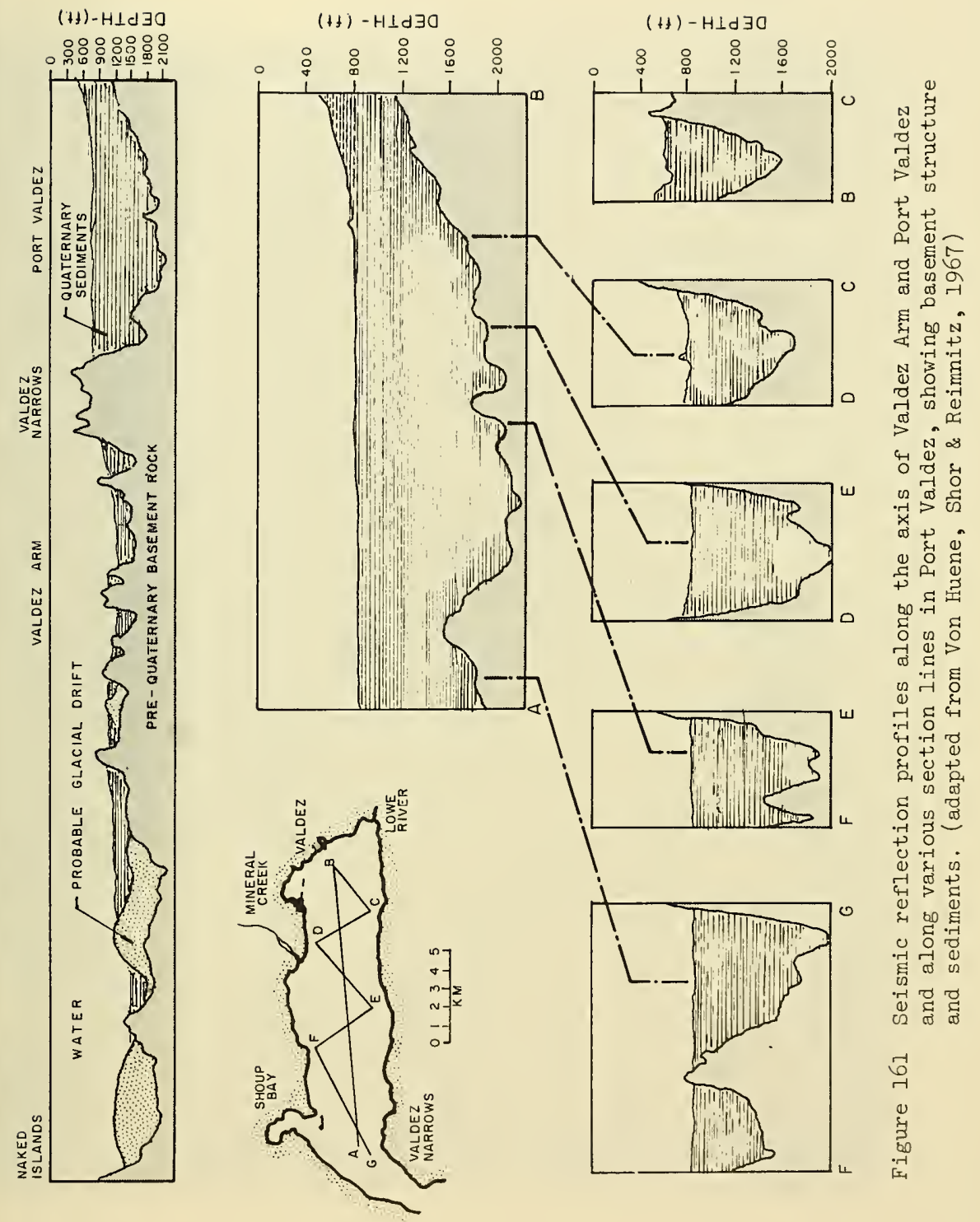


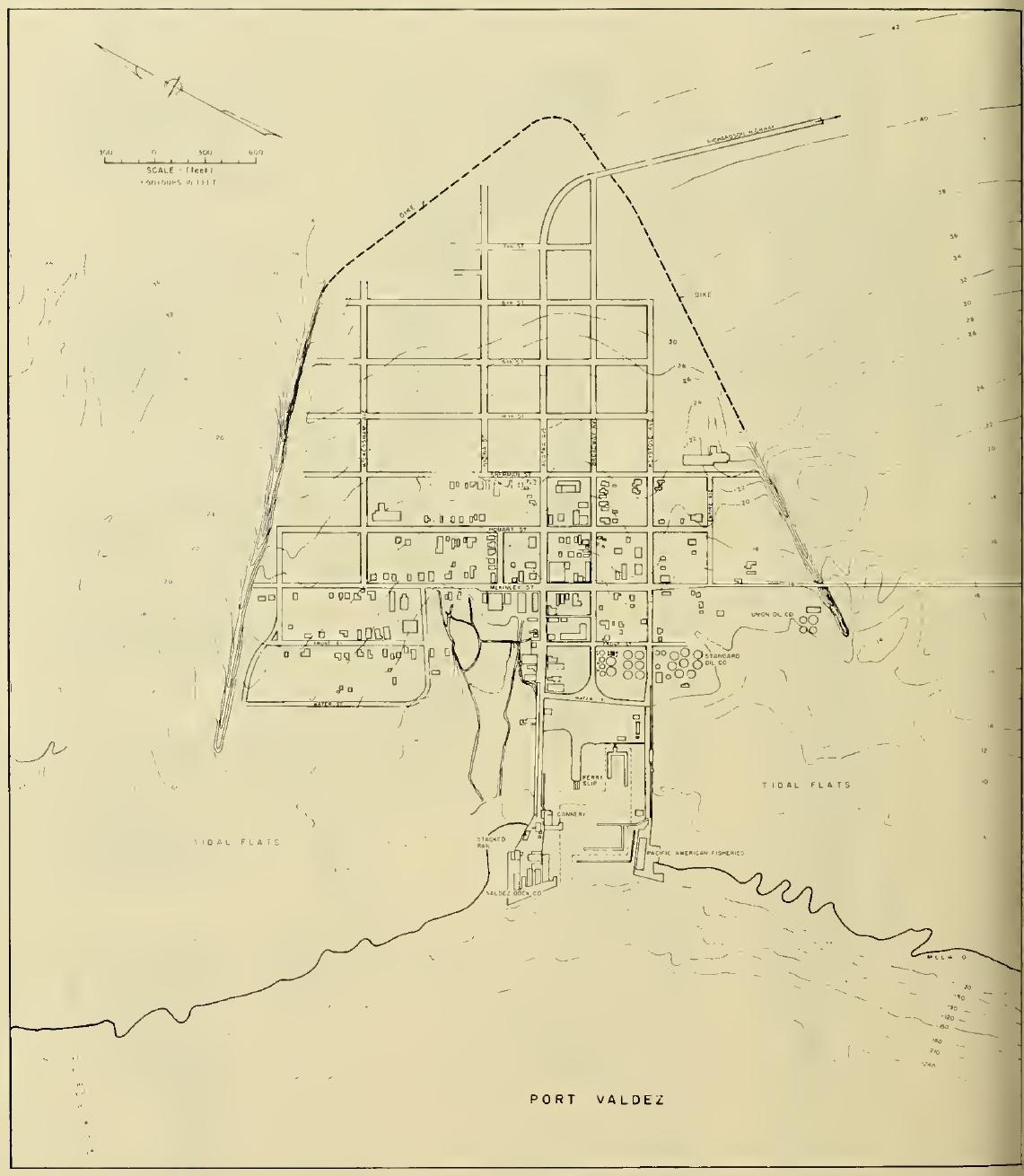

Figure 162 Plan of Valdez, Alaska, as existing prior to the Earthquake of March 27, 1964 
Valdez is the northernmost all-weather port in Alaska, but unlike Seward and Whittier, it is connected with the interior only by road links. Its people, 600, were mainly active in the shipping and fishing industries; its position as the "Switzerland of Alaska" favored a developing tourist trade. The earthquake brought overwhelming disaster to Valdez. The entire waterfront was totally destroyed, and seismic sea waves penetrated deep into the heart of town. Figure 164 is an aerial view of the city after the earthquake with the limit of tsunami runup indicated approximately. Because of the unstable sediments upon which the town was founded, it has since been condemned as a hazard (Coulter and Migliaccio, 1966; Eckel, 1967) and is slowly being vacated in favor of a new townsite at Mineral Creek, founded on stable rock (see sections DE, DC of Figure 16I).

Most authorities who have reported on the wave phenomena that destroyed valdez have mentioned four waves as having been primarily responsible for the destruction, two of which occurred during and shortly after the earthquake and two many hours later. However, although the first waves are attributed to massive submarine slumping of the sediments at the waterfront, agreement is not unanimous on just how the waves were generated. Eyewitnesses make no specific mention of a major boil of water developing in the bay (as at seward), yet this perhaps is understandable because the relative flatness of Valdez does not afford a very commanding view of the bay and the remarkable gyrations of the ship Chena distracted attention of observers from other events. Grantz, et al (1964) and Plafker and Mayo (1965) are the only sources we can find that specifically mention mounds or boils of muddy water, yet eyewitness accounts reported by Berg, et al (1964); Brown (1964); Bryant (1964); Chance (1968); Chapman (1964); Migliaccio (1964) and Coulter and Migliaccio (1966), make no direct reference to these except in the sense of purely localized mounds hitting the Chena (reported by the ship's captain); and the development of a "wall of water" out in the bay, sometime after the occurrence of the first waves (reported by Forest Sturgis, Alaska State Highway engineer). We raise this matter not because there is any question of the occurrence (which is indisputable) of a submarine slide to which the mounds and boils are attributable, but because there is the possibility that the first wave or waves may have had other associations, as we shall discuss.

We may attempt to explain what happened at the waterfront at Valdez by considering the available facts. Allowing some degree of conjecture to fit the facts, we infer that water level fluctuated in approximate accord with the marigram presented in Figure 165.

The first wave to strike Valdez occurred during the earthquake and was remarkably sudden. The time sequence of following waves is confused owing to the disastrous conditions that prevailed. People who watched the water had their attention drawn to the erratic behavior and violent movement of the Alaska Steamship Company vessel Chena, a 10,815-ton cargo ship, that was moored to the north dock when the earthquake started. Captain Merrill Stewart of this ship has given the following account of his experience (Coulter and Migliaccio, 1966): 


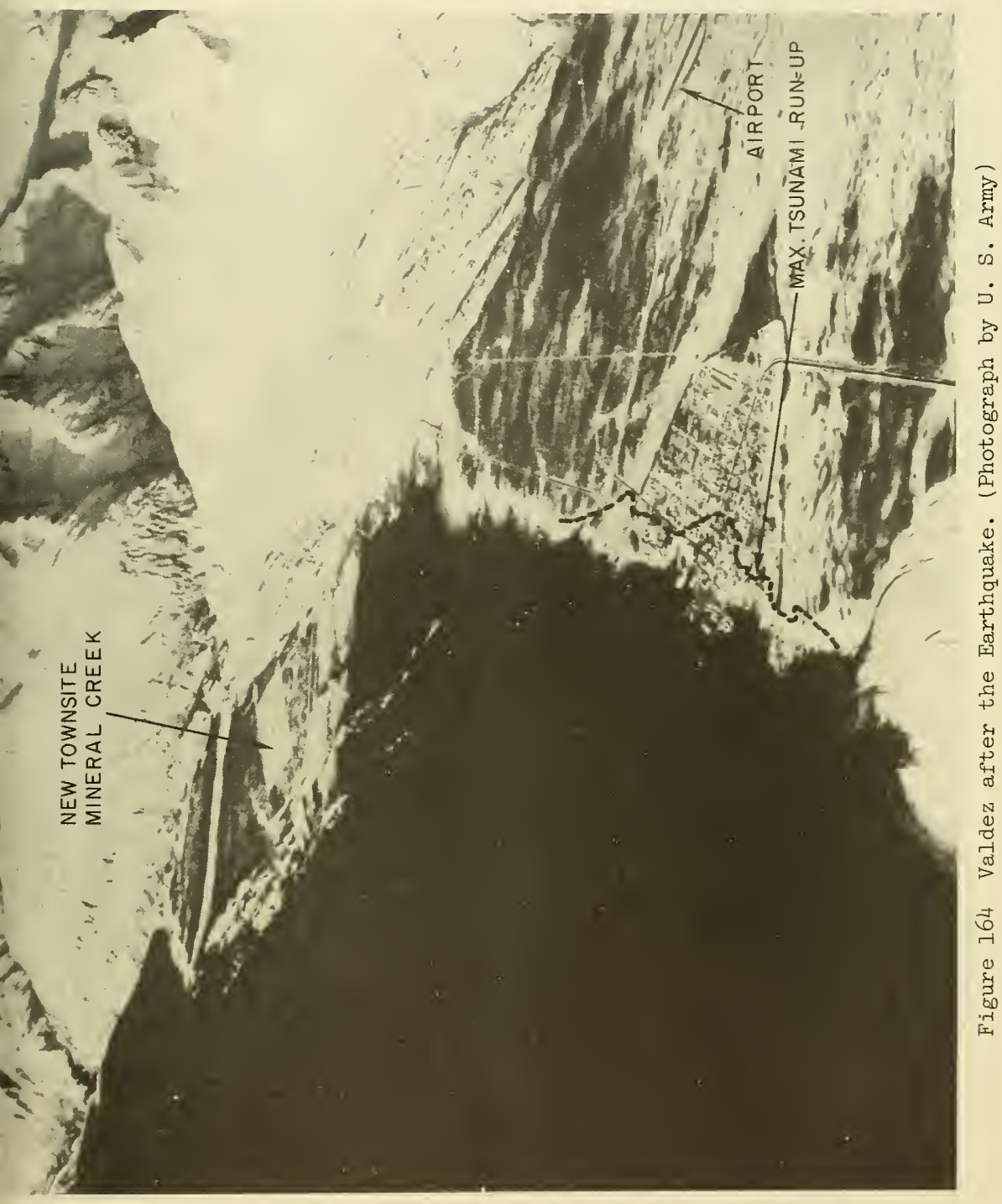




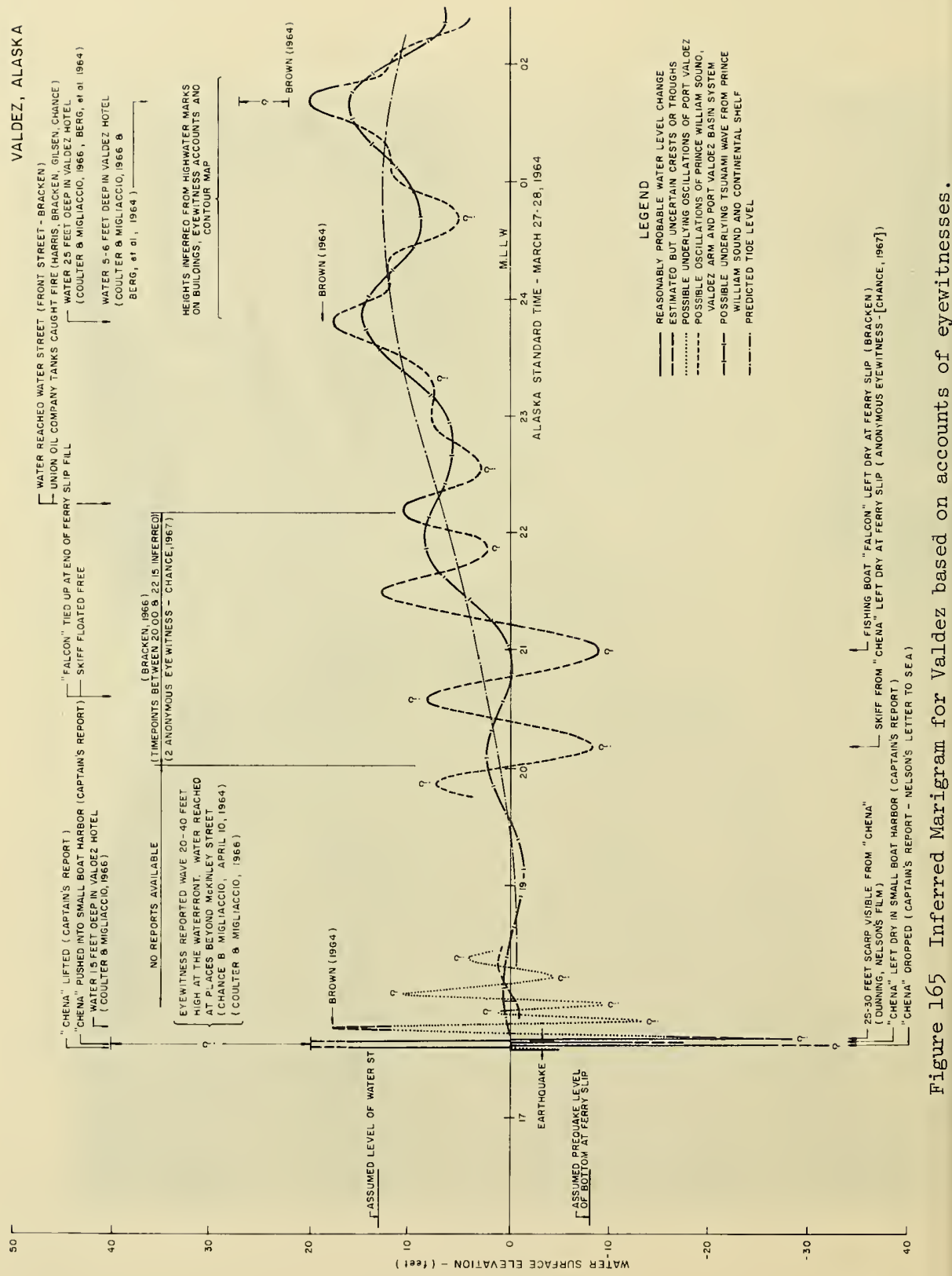


"The Chena arrived at VaIdez at 16:12 hours, March 27. About 7:31, while discharging cargo, we felt a severe earthquake followed lmost immediately by tidal waves. There were very heavy shocks bout every half a minute. Mounds of water were hitting at us from 11 directions. I was in the dining room. I made it to the bridge three decks up) by climbing a vertical ladder. God knows how I ot there.

"The Valdez piers started to collapse right away. There was a remendous noise. The ship was laying over to port. I had been in arthquakes before, but I knew right away that this was the worst ne yet. The Chena rose about 30 feet on an oncoming wave. The hole ship lifted and heeled to port about $50^{\circ}$. Then it slammed own heavily on the spot where the docks had disintegrated moments efore. I saw people running - with no place to run to. It was ust ghastly. They were just engulfed by buildings, water, mud, nd everything. The Chena dropped where the people had been. That s what has kept me awake for days. There was no sight of them. he ship stayed there momentarily. Then there was an ungodly ackroll to starboard. Then she came upright. Then we took nother heavy roll to port.

"I could see the land (at Valdez) jumping and leaping in a errible turmoil. We were inside of where the dock had been. We ad been washed into where the small boat harbor used to be. There as no water under the Chena for a brief interval. I realized we ad to get out quickly if we were ever going to get out at all. here was water under us again. The stern was sitting in broken ilings, rocks, and mud.

"I signaled to the engine room for power and got it very apidly. I called for 'slow ahead', then 'half ahead' and finally or 'full'. In about four minutes, I would guess, we were moving ppreciably, scraping on and off the mud (bottom) as the waves ent up and down. People ashore said they saw us slide sideways ff a mat of willow trees (placed as part of the fill material $n$ the harbor) and that helped put our bow out. We couldn't urn. We were moving along the shore, with the stern in the mud. ig mounds of water came up and flattened out. Water inshore as rushing out. A big gush of water came off the beach, hit he bow, and swung her out about ten degrees. If that hadn't appened, we would have stayed there with the bow jammed in a ud bank and provided a new dock for the town of Valdez!! We roke free. The bow pushed through the wreckage of a cannery. $e$ went out into the bay and had to stop. The condensers were lugged with mud and pieces of the dock. The chief mate, Neal I. arsen, checked to see then if we were taking water. We were aking none. It was unbelievable after what the ship had been hrough. We had the lifeboats all manned and ready. I didn't hink she would float in deep water. Maybe the soft mud bottom lade the difference." 
Captain Stewart's impressions of the above events were also reported by Berg, et al (1964); Denner (1964); Chance (1968); and the magazine, "Alaska Construction" (1964); collectively these sources add further important information as have interviews which the writers had in 1966 with former crew members Dunning, Harding, Nelson, and Numair.

It appears evident that immediately after the start of the earthquake, the Chena went astern in a northwest direction and either slipped or fractured her mooring lines. Sturgis, on the third floor of the Valdez Hotel, with a view seaward down Alaska Avenue (Figure 162), was in an exceptionally good position to observe this initial movement (cf. Berg, et al, 1964; Bryant, 1964; Chance, 1968). It is also confirmed by Dunning and Numair. The implied movement of the Chena is shown in Figure 166b.

This first movement of the Chena appears to have been due to water withdrawal which accompanied the initial subsidence of the docks during the first minute of the earthquake. Sturgis had also noted that the initial earth movement during the earthquake was north-south (Bryant, 1964; Chance, 1968), which seems amply proved by the numerous earth crevices and cracks in an east-west direction, measured by Bracken (1964) (see also Coulter and Migliaccio, 1966). Earth waves some 400 feet between crests and 3 to 4 feet high (Chapman, 1964) apparently rolled from north to south, producing these fissures and causing the land to start slumping toward the sea with numerous fissures forming parallel to the coast in a northwest-southeast direction. The violent earth shaking caused considerable compaction of the soil and squeezed a great volume of water to the surface which spouted in walls of spray when fissures closed with the earthwave movement (Chance, 1968; Bryant, 1964). We note too (from Figure 16) that the entire Valdez area was being pushed horizontally from northwest to southeast through a distance of about 25 feet.

The earth slump at the harbor was at first more in the nature of compaction and partial sliding on the fairly flat slope of the sediments at the east end of Port Valdez (Figure 167a). It could not have been a complete and sudden failure because the Chena returned on the crest of the first wave (Figures $166 \mathrm{c}$ and $167 \mathrm{c}$ ) and was deposited on the wreckage of the docks. Further, although the docks had by this time disappeared, the portion of the North Arm at the approach to the docks, along with the cannery, was still intact, as proved by Figure 168.* This is enlarged from a single frame (No. 110) of the $8 \mathrm{~mm}$ motion-picture film, photographed by Fred Numair, crew member of the Chena, from the approximate location, Figure $166 \mathrm{c}$ and $d$ or Figure $167 \mathrm{c}$ and $\mathrm{d}$. Figure 168

* Figures 168 through 173 are enlargements from $35 \mathrm{~mm}$ color film, reproduced from original $8 \mathrm{~mm}$ color motion-picture film. Because the original films were not of good quality, definition in the photographs is unavoidably poor. Dashlines in black or white and suitable annotation have been added, where necessary, to indicate features of interest or importance. 


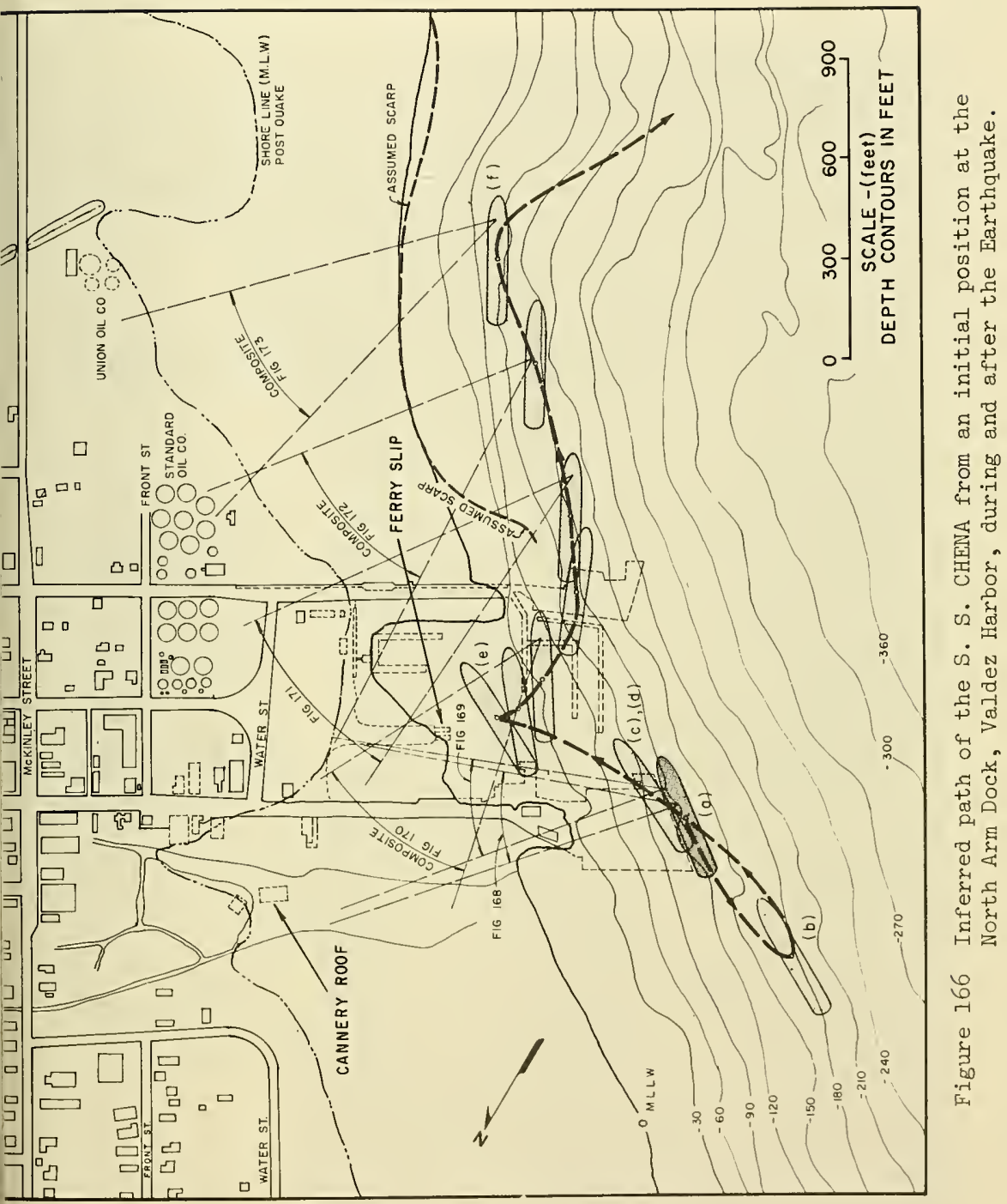




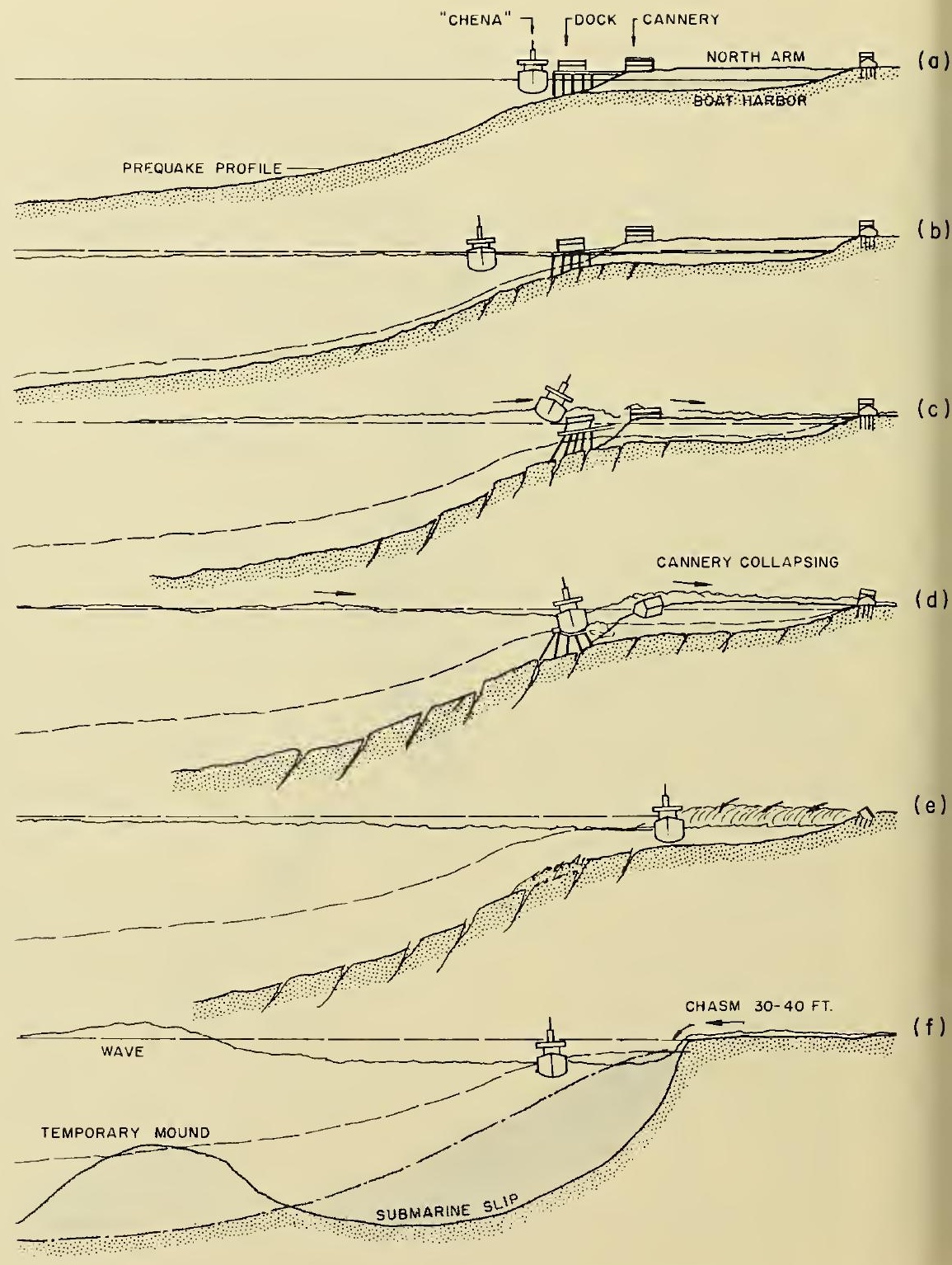

Figure 167 Sequence of schematic diagrams illustrating the movements of the S. S. CHENA and the destruction of the Harbor at Valdez. Compare with Figure 166. 


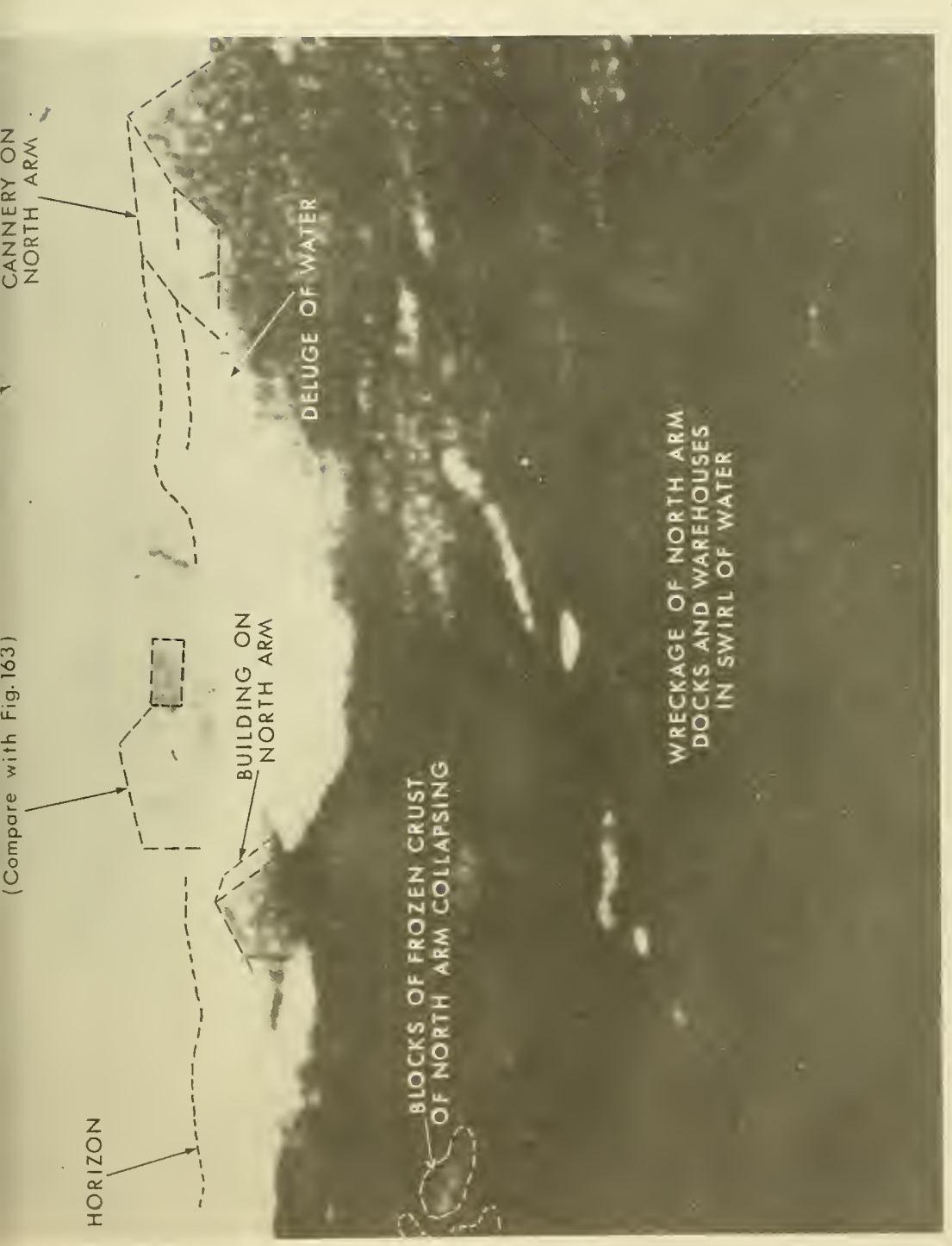

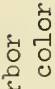

है

䚾

d)

त्

(1)

$>0$

40

토

崫

† $\infty$

어대

(2) 음

울

द्व 0

(4)

है

ฮै क

$\circlearrowright$

(1) छㅇ

मे क्ष

की त्व

.

फ

거

हु द्व

过四

5

a

56

क

() ఫ्व

व

- $\triangle$ त

है

न 1 (

(1) 0

(2) \&

+ รु क

is $30 \mathrm{~B}$

मे त्त

दा का

(1) 댕

गे है

फै क्ष

3 党 E

$\rightarrow-100$

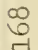

ปั 
shows the cannery being engulfed by the passing wave; it should be compared with Figure 163. Moments later (frame No. 184, Figure 169), Numair's film shows the disintegration of the cannery as the wave rushes over the North Arm from the northwest.

According to his account published in "Alaska Construction", Captain Stewart said of this happening that "the Chena heeled over $70^{\circ}$ to port and crunched down hard on the spot where the pier had disintegrated moments before. I felt the hull shudder as the ship ground into the rocks and mud and broken pilings on the harbor bottom and I thought she was done for. No ship can stand that kind of battering."

The Chena at this stage took a violent roll to starboard, presumably as a result of a trough following the wave and her entanglement in the wreckage, but with additional smaller waves which apparently followed in the wake of the first crest she was prized free and carried into the boat harbor (Figures $166 \mathrm{e}$ and $167 \mathrm{e}$ ). Here she was momentarily aground with her stern in the wreckage of the piling of the North Arm cannery. According to Sturgis (Chance, 1968); Bryant, 1964), her bow was up (presumably on the mud flats) $20^{\circ}$ to $30^{\circ}$ above the stern. The Chena now took a violent roll to starboard before the boat harbor began to fill with the great volume of water pouring over the North Arm (still from the first wave). All of this took place apparently during the period of the earthquake, whose duration has been variously given as $31 / 2$ to 5 minutes (prior to the final 30 seconds of the quake, according to Sturgis).

A flux of water from the south now filled the boat harbor and carried boats and buildings, dislodged by the first wave, toward the Valdez Hotel. It lifted the Chena which by now had power, and enabled her to float free. This moment is believed to be shown in Figure 170, which is a panoramic composite photograph prepared from the motion-picture color film of Ernest Nelson, another crew member of the Chena. Figure 170 shows the wreckage in the boat harbor. The dark spur is believed to be the remains of the ferry slip, and the parallel "wave" beyond to be the remnant of the North Arm. The Gypsy, the largest yacht in the boat harbor, is just visible off the ferry slip. In the course of the whirlpool-like movements of water between the north and south arms of the harbor, the Gypsy had apparently caromed off the side of the Chena while the latter was still stuck in the mud. The cannery roof is believed to be floating alongside of the ferry slip in Figure 170. Subsequently, it was found entrenched in the mud flats north of the harbor (see Figure 166).

The water now began to drain from the boat harbor, and a strong movement of water from northwest to southeast along the shore began. This at first helped the Chena clear the stub of the south arm and float out where the south pier and cannery had been (see Figure 166). According to Dunning (SEA interview), the deck of this pier had been swept southeast by the first wave that carried the Chena into the boat harbor, and surrounding piles showed bolts bent in that direction. Bracken (1964), moreover, records that a trailer frame was swept south from this pier. 
The Chena, now under her own power, came also under the influence a strong southerly current, which, despite her bid for deep water, ried her close along shore, as in a jet stream. Of this period Captain ewart records (Alaska Construction, 1965), "The Chena was moving but she lldn't steer away from the beach as mounds of water continuously swept inst the ship forcing her to a course next to the shore." Two obcvers who saw her at this time remarked on the jet-like speed of the vement (cf. for example, Bracken, 1964). This flow is confirmed by e motion pictures of Numair and Nelson. Figure 171 is an enlargement Jm frame No. 246 of Numair's $8 \mathrm{~mm}$ motion-picture film and is believed have been taken from the approximate location shown in Figure 166 . At is time an unidentified building floats southward as it descends a casde formed apparently by the final failure of the sediments in a major ump south of the harbor. The approximate location of the developing asm wall formed by the slump is shown in Figure 166.

Moments later Nelson, looking back toward Valdez, photographed this ntastic withdrawal of water and recorded the scene reproduced from his $\mathrm{Im}$ as a panoramic composite view shown in Figure 172. The direction d location of the picture are inferred in Figure 166. Mud flats were rming behind the ship as it hurtled south. The awesome nature of the asm formed by the submarine slide (see Figure 167f) is shown in Figure 3 which is another panoramic view from Nelson's film, photographed from e approximate position ( $f$ ) in Figure 166, using the zoom lens for greater tail. It is believed that the location of the scarp formed by the slump revealed in the lower right-hand portion of the aerial photograph, gure 174 , taken within a few days of the earthquake.

Figure 167f, which envisions the submarine slide, also suggests the rmation of a wall of water on the seaward side of the Chena. This "wall" s reported by Sturgis (Bryant, 1964; Chance, 1968) and was observed by nning, a longshoreman who survived disaster in the Chena's hold and ached the deck. This slide and the attendant wave effect certainly curred after the earthquake and was probably promoted by the major awdown of water, shown to occur in Figure 165 at about 5 to 6 minutes ter the start of the earthquake.

The submarine slide was massive; approximately 98 million cubic irds of material slumped away according to an estimate of Coulter and gliaccio (1966). Comparative contours of water depth in the vicinity Valdez are shown in Figure 175 and typical profiles along cross secions $O A, O B$, and $O C$ are shown in Figure 176. Off the delta to the south - Valdez, depth changes exceeding 300 feet took place; off Valdez itself le change is less but still about 100 feet. The major part of the slide us took place off the Lowe River delta, but a substantial part consoliated and slid away at the Valdez waterfront and along the shore to the orth.

The Chena escaped to deep water before the next large wave rolled $n$ over the demolished waterfront. This wave reached a level of 18 nches in the Valdez Hotel (Coulter and Migliaccio, 1966; Brown, 1964).

Text resumes on page 278 


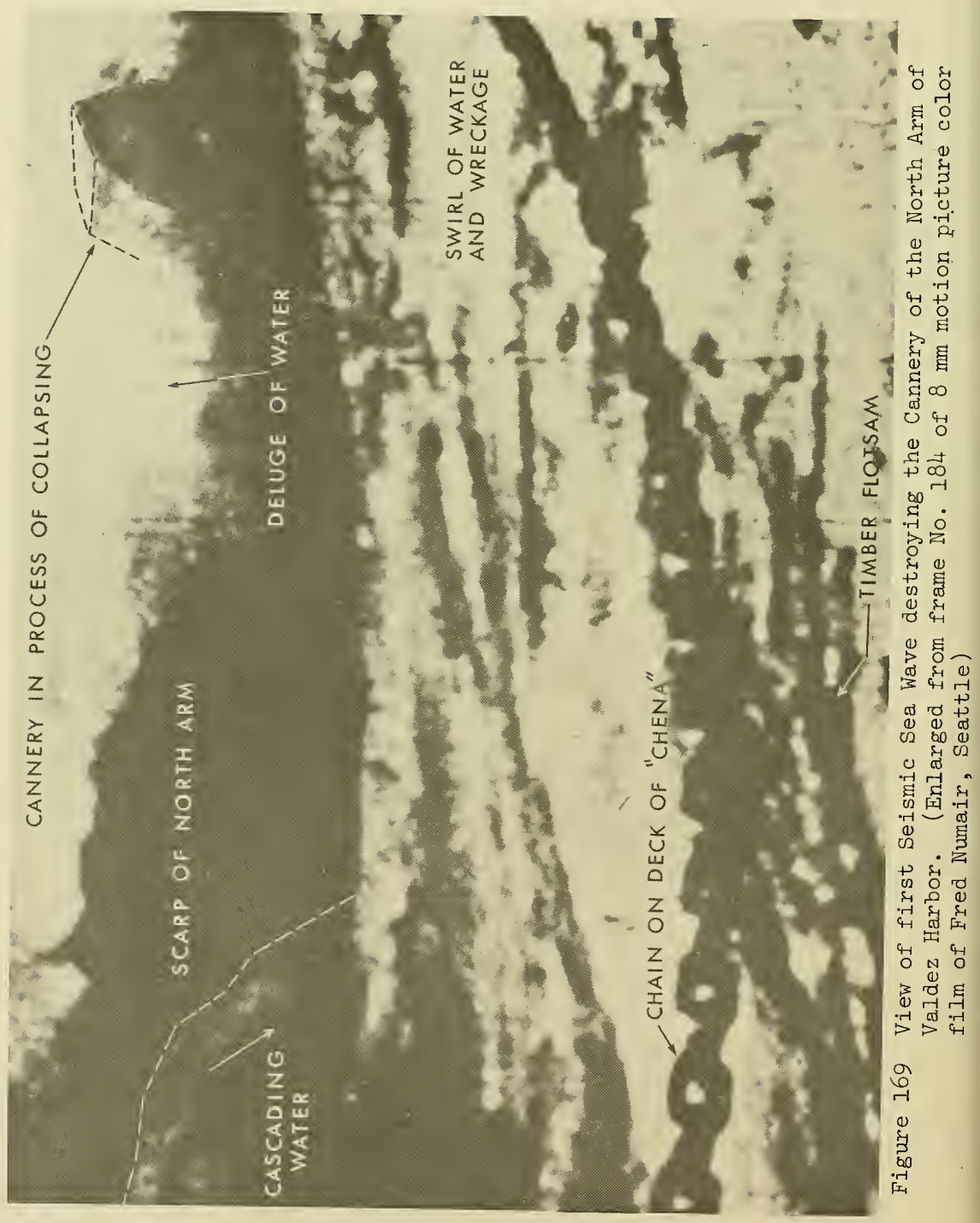




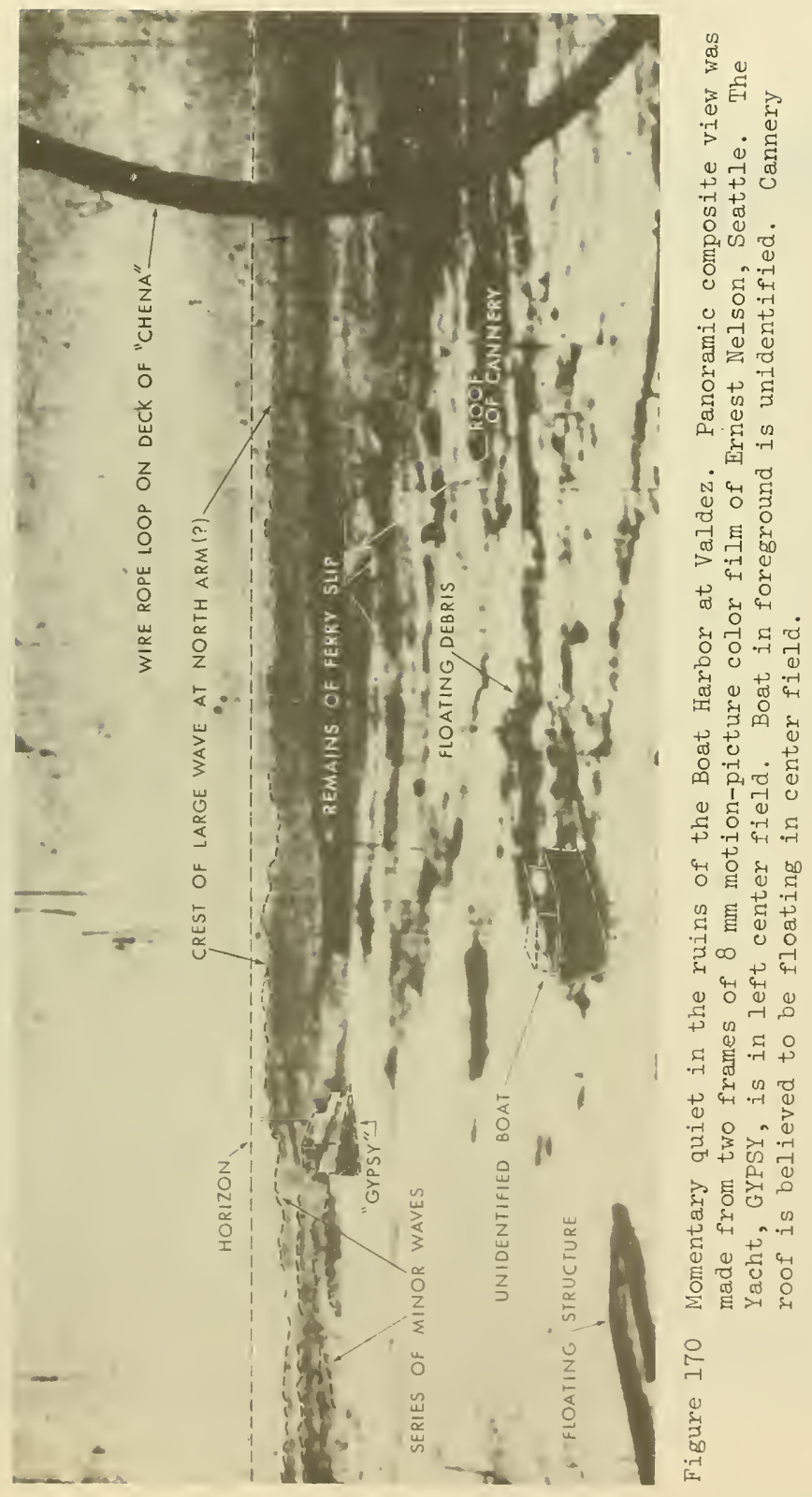




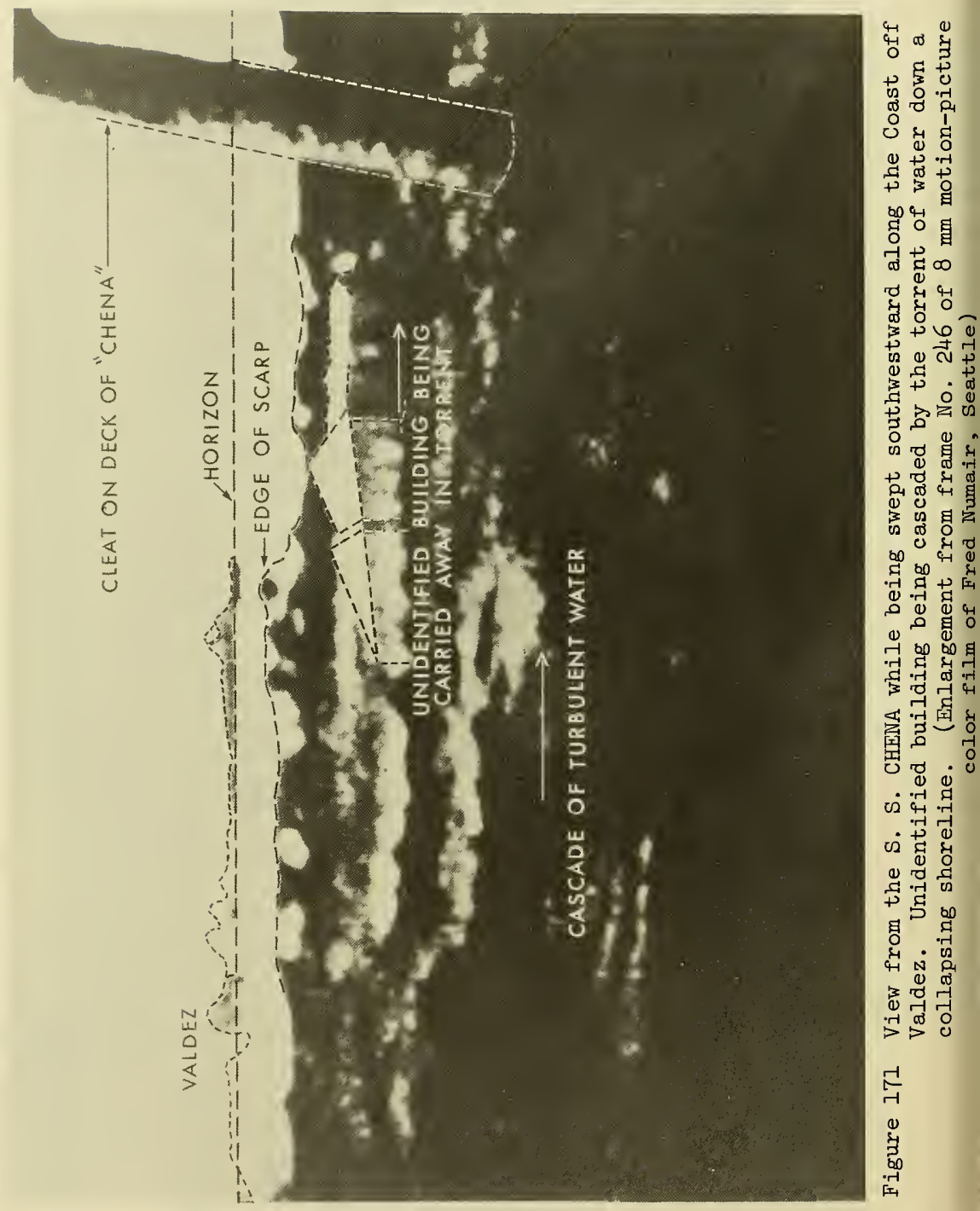




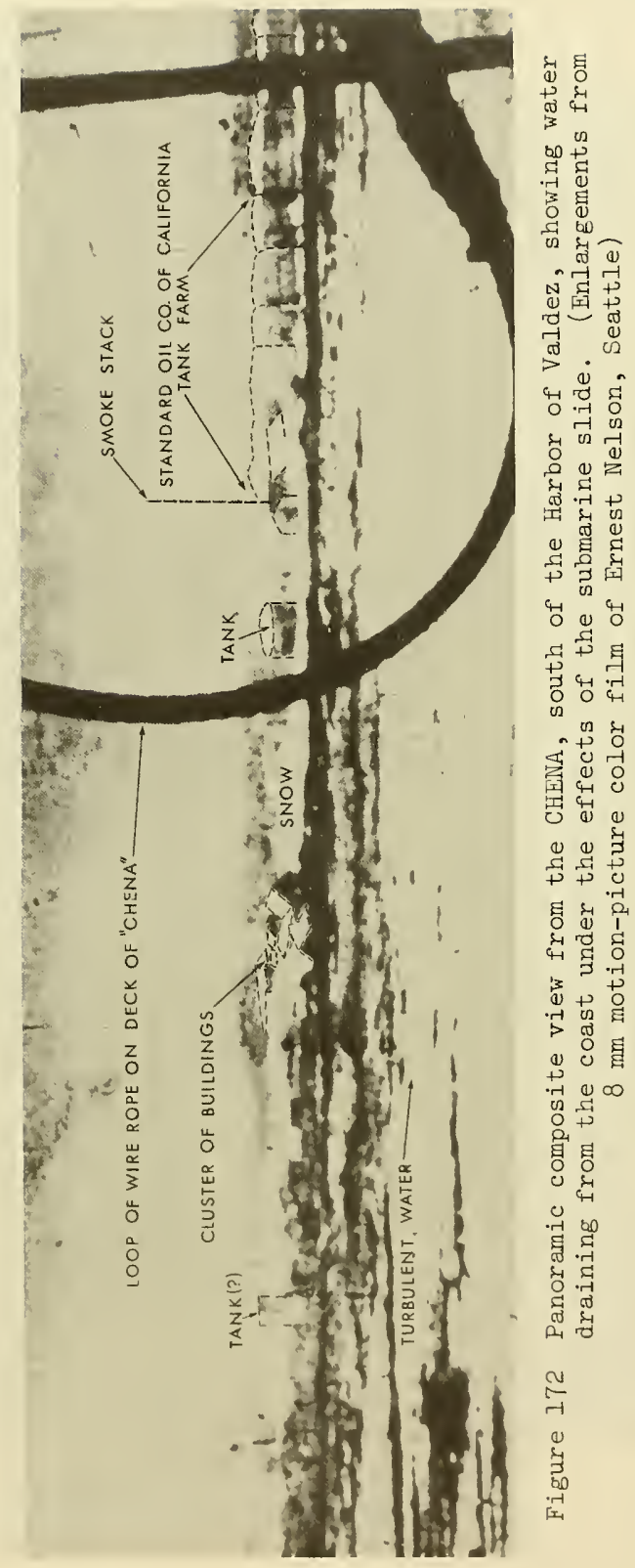




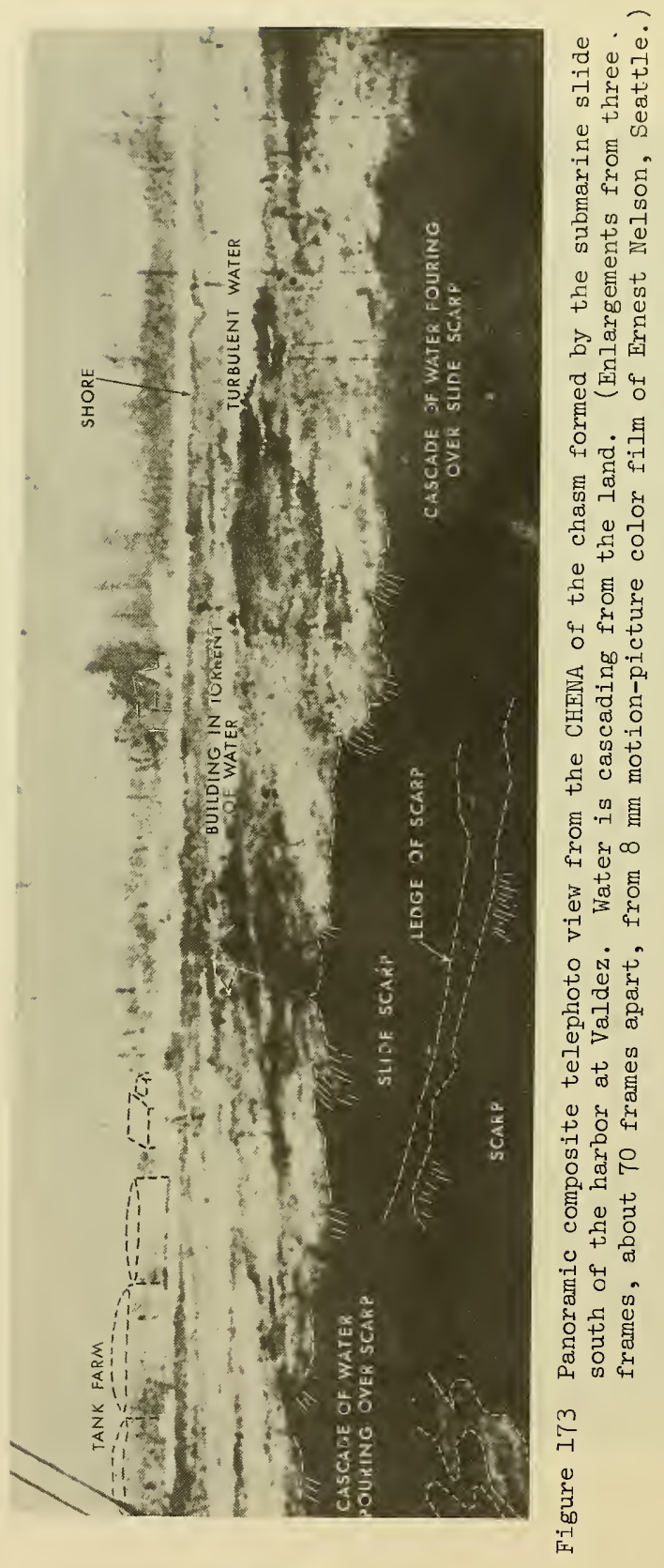




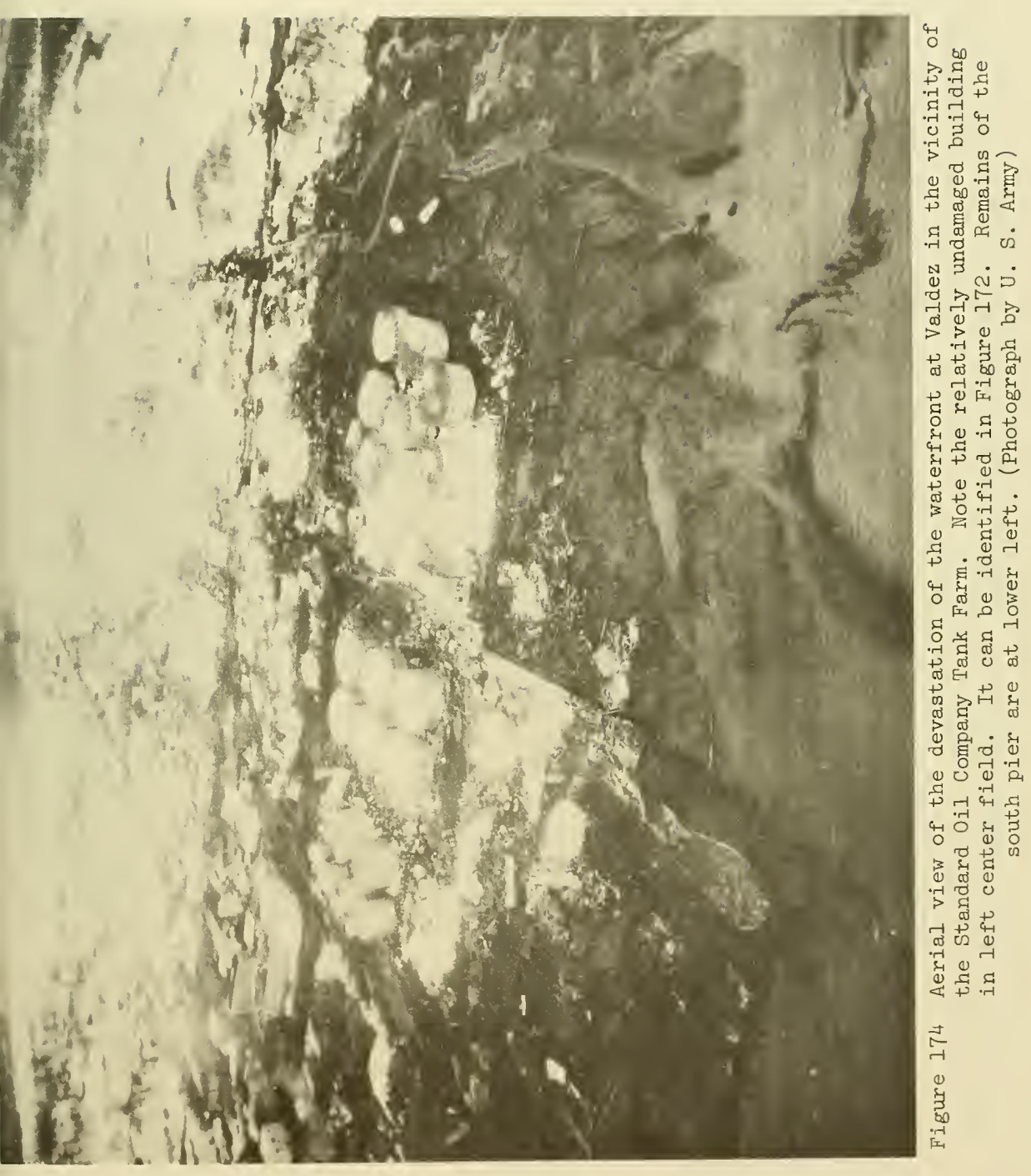




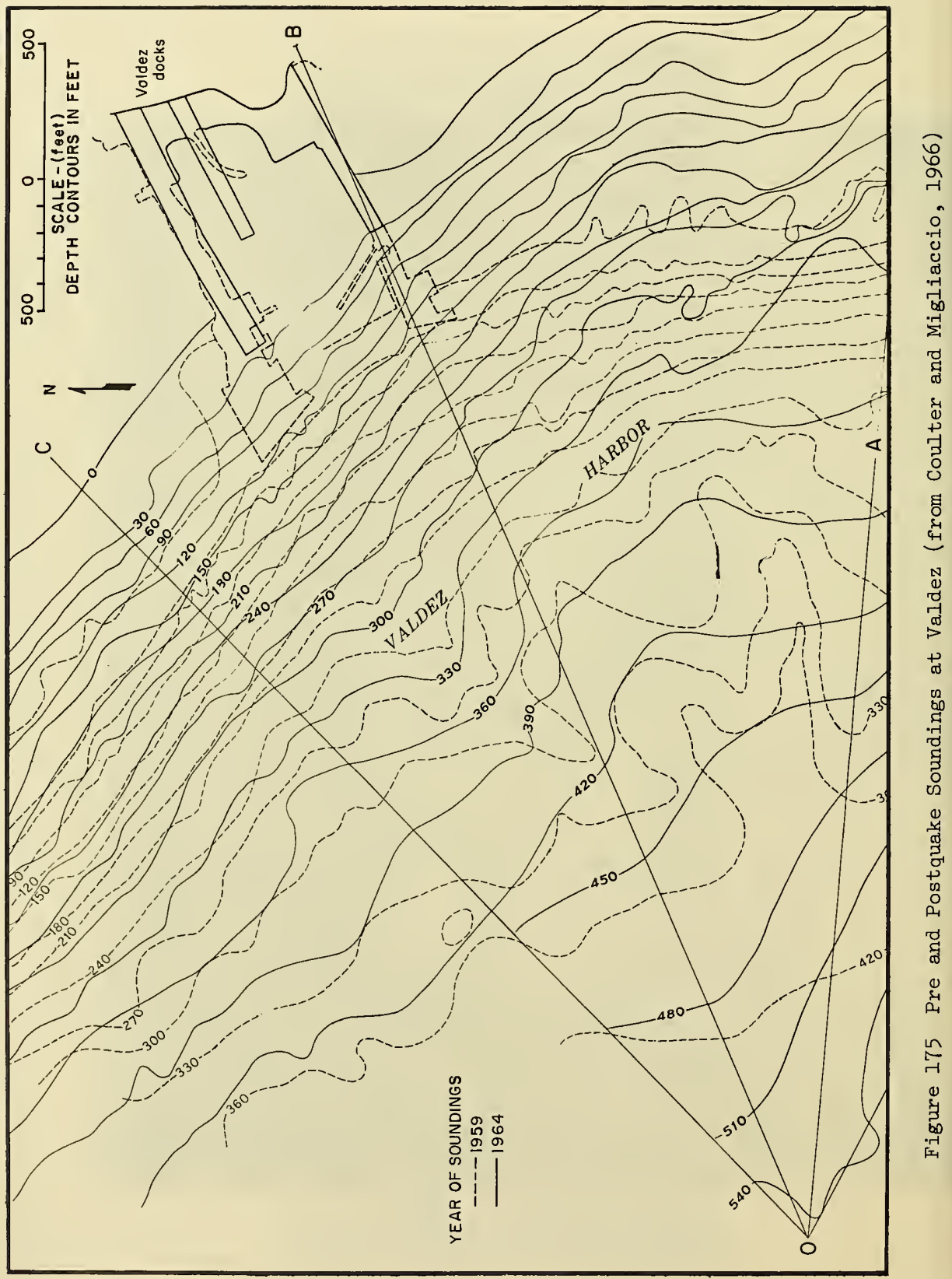




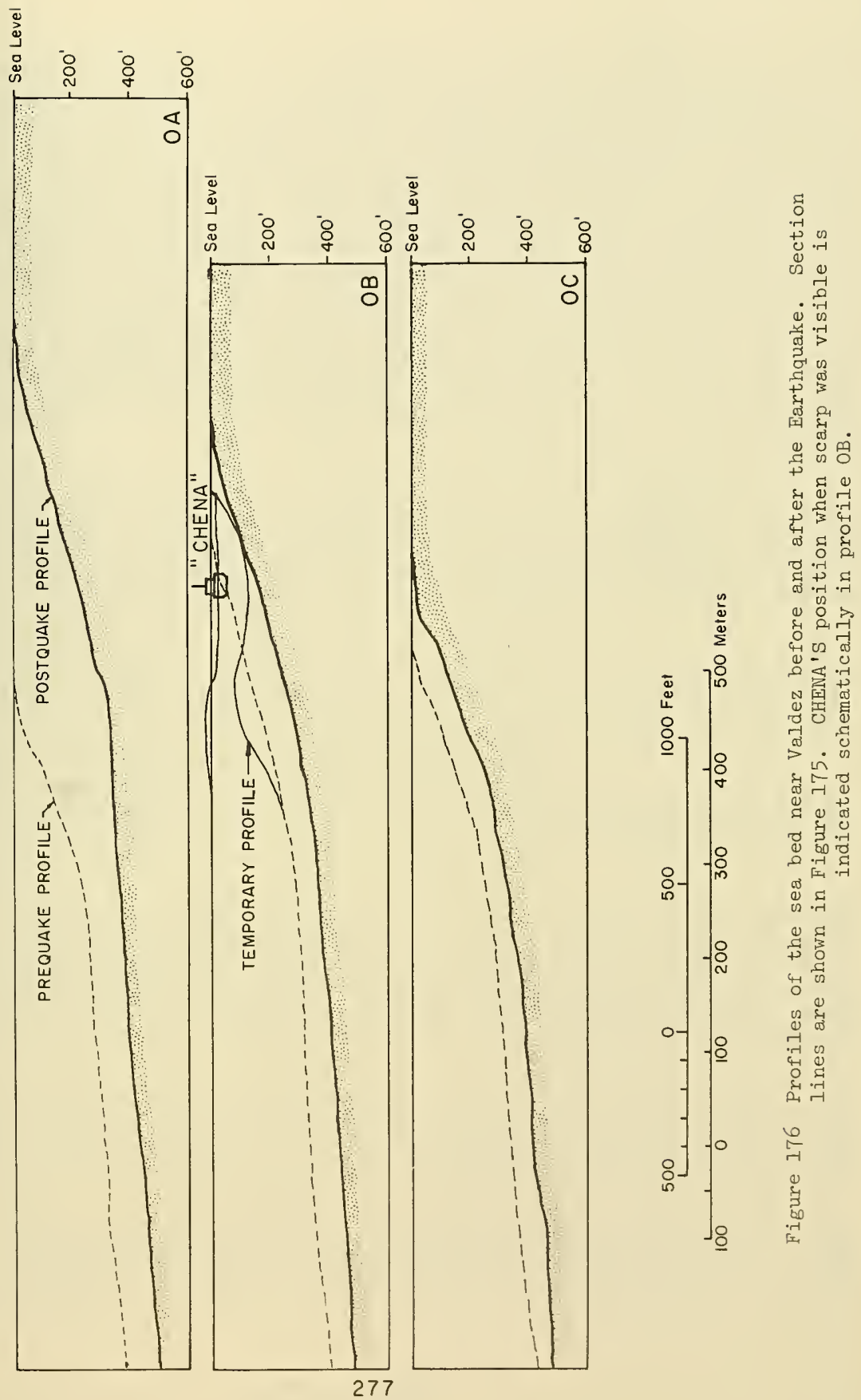


The nature of these early waves now demands some explanation, particularly in regard to the direction of the flow effects. A plausible explanation for the effects might be as follows. It is supposed that the sediments off the Lowe River delta and Valdez glacier outwash were much finer than those found off Valdez, and that these fine sediments liquefied at an early stage of the earth vibration and caused a slide in the southeast corner of Port Valdez. Simultaneously the entire basin of Port Valdez was being jerked horizontally to the southeast parallel to the coastline of Valdez (Figure 16). The net effect of this would be to pile water to the north shore near Mineral Creek (Figure 160), and draw it from the south shore. Off Valdez itself, a pseudonodal situation would arise in which a flow of water would take place to the northwest without a great deal of recession. This flow would have pulled the Chena to the northwest; alternately, if the horizontal land thrust were sudden enough, the harbor would have been pushed southeast of the Chena, which momentarily remained fixed in space, with the same relative effect.

If this supposition is anywhere near correct, a transverse seiche would have developed, and thrown an edgewave southward along the Valdez shoreline. Taking the velocity $\mathrm{c}$ of the edgewave as that in Equation (44) and assuming the period $T$ of the seiche for a rectangular transverse profile of width $L$ at the head of the bay (Figure 16) to be

$$
T=\frac{2 L}{c}
$$

we find the period of the edgewave to be (on elimination of $c$ between Equations (4L) and (50) )

$$
T=(4 \pi \mathrm{L} / \mathrm{g} \sin \theta)^{1 / 2}
$$

For a bottom slope of about 1 in 11 and a width $I \simeq 2.94$ nautical miles, the wave period is calculated to be

$$
\mathrm{T} \simeq 4.4 \text { minutes }
$$

which could mean that the edgewave struck Valdez (midway between the north and south shores of Port Valdez) within 1.1 minutes of the start of the earthquake. As an edgewave it would have had the directional effect to sweep the Chena southeast onto the collapsing docks, and cause the extraordinary flow of water which carried away the south pier and the cannery from the North Arm.

The backlash from the edgewave would have come about 4.4 minutes later, and presumably filled the boat harbor, freed the Chena, and caused the northward flow, which may have carried small boats and debris in that direction, as observed by Sturgis.

There would then have followed the returning nodal flow in a southeast direction which could account for the jetlike evacuation of the Chena. The resulting suctionlike withdrawal of the water table could account for the sudden failure of the seabed as envisioned in Figure $167 f$. 
re is no report that the wall of water observed by Sturgis and Dunning $r$ hit the Valdez Waterfront as a big destroying wave.

The third big wave hit the town approximately 10 minutes after the thquake ceased, and left 18 inches of water in the Valdez Hotel on inley street. The origin of this wave is not certain. The earliest erpretation was that it was one of the waves generated by slides at Valdez waterfront that returned as a reflection from the western of Port Valdez. The travel time for a long wave to propagate to the dez Narrows and return, however, would be 17.8 minutes according to ation (49), and so could not support such an explanation. Later intigations have emphasized more the idea that the wave was generated a major slide along the steep shore of the west end of Port Valdez afker and Mayo, 1965). The travel time would then accord with ation (49ii), namely, 9.8 minutes, and meet the situation shown Figure 165.

The waves generated at the west end must have been singularly powerto produce the tremendous runup recorded at different places (Figure ) (Plafker and Mayo, 1965). It is assumed that there were two subine slides at the mouth of Shoup Bay, one near the abandoned Cliff le and one of the west side of the entrance of Shoup Bay. Shoup Bay upies a hanging valley whose floor is more than 500 feet above the tom of Port Valdez. The Shoup Glacier has left a high deposit of cial debris that blocks the entrance to Shoup Bay. This material presumed to have slumped. The first wave obliterated all sizeable ldings at the Cliff Mine site, left driftwood 170 feet above lower water, and splashed silt and sand to elevations of 220 feet. From vicinity of Cliff Mine it moved east and probably south with dually diminishing height.

The wave that was generated on the west side of Shoup Bay apparently hed up to an elevation of 125 feet near its inferred source (Plafker Mayo, 1965).

These two slide-generated waves caused considerable runup on both west and south sides of Port Valdez as evident in Figure 177 . It believed that the large wave that hit Valdez about 10 minutes after e earthquake (Figure 165) was one of these waves. Probably the major :tion of the wave energy propagated throughout the Valdez Narrows, stroying the navigation light on top of the lighthouse 35 feet above ver low water (Figure 178).

The fishing boat, Falcon, at Potato Point (see Figure 160), near a mouth of the Narrows, was lucky to survive this wave. As recorded by ance (1968), two crew members were on shore when the earthquake started. en they headed for the anchored 30-foot boat in their skiff, a drawdown the water suddenly left the skiff beached, while the fishing boat dispeared out of sight behind a break in the bottom of the Narrows. Within ments turbulent water rose again, and flushed the skiff out of control. 


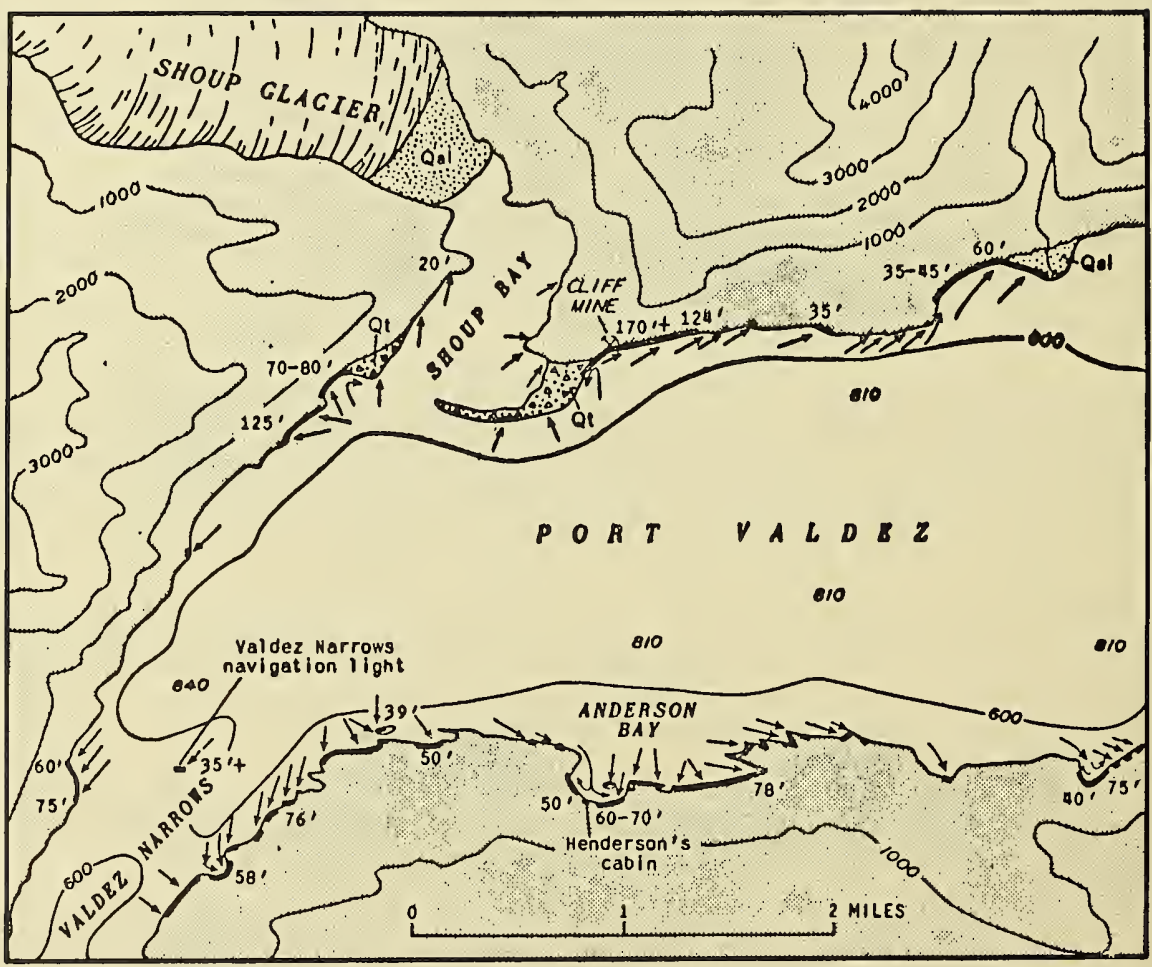

Figure 177 Heights and inferred directions of local waves in the Western Part of Port Valdez, Prince William Sound. Heavy line along shore indicates distribution of damage; numeral is measured maximum runup. Shaded pattern, bedrock; dotted pattern, alluvium and intertidal mud; triangular pattern, terminal moraine of the Shoup Glacier. Contour interval on land is 1,000 feet; submarine contour interval is 600 feet. (from Plafker and Mayo, 1965) 
It appears to have been extraordinary luck for the boatmen that their skiff came sufficiently close to the Falcon that they could dive across and pull themselves out of the water onto the larger boat. After starting the engine, approximately 5 minutes after the earthquake, they saw a huge wave, building up behind the lighthouse and heading out of the Narrows. It overtopped the lighthouse about 2 minutes later. They estimated the wave as 35 to 50 feet high in the Narrows and laden with mud, timber, and other debris. The Falcon was overtaken by the wave just outside the Narrows, but by then, fortunately, the wave had spread laterally into Jack Bay and Valdez Arm (Figure 160) and attenuated in height, thus enabling the boat to ride over the top. Later they saw many large waves, one right after the other, in the vicinity of the mouth of the Narrows and Jack Bay (Chance, 1968).

As envisioned in Figure 165, it is believed that Valdez was subject at about this time to a combination of successive waves which were probably the fundamental and binodal seiches for Port Valdez embodying the periods of 17.8 and 9.8 minutes (Equation (49)). Since the fundamental period for Port Valdez is about the same as the second mode period (18 minutes) for the entire Valdez Arm, Narrows, and Port basin system (Equation (48)), we should expect that these waves gradually set the system rocking in its fundamental mode of about 39 minutes (Equation (48)). Figure 165 also expresses our belief that the first crest of the main tsunami, generated at the mouth of Prince William Sound, would have reached Valdez within about 30 minutes with rather insignificant amplitude. However, the development of oscillations from within the embayment and from without may be assumed to have developed a strong system of beat oscillations, which is suggested in the later part of the inferred marigram of Figure 165. The fundamental tsunami wave on the shelf, meanwhile, in tune with the fundamental period ( $T \simeq 110$ minutes) of Prince William Sound, may be expected to have built up the amplitude of oscillation of about this period which penetrated into the Valdez embayment. These conditions are shown in the marigram, which has been constructed basically from eyewitness observations of the later waves, but with a foreknowledge of the probable oscillating characteristics of the regime.

After the first 25 minutes of horror, the waves reaching Valdez on the low tide were not high enough to draw special attention, and presumably failed to reach even normal high tide level. As the tide rose, however, the oscillations in the Sound increased in amplitude, and Valäez faced further destruction (Figure 165).

Two large waves reached Valdez on the high tide during the night. There is some discrepancy between reports as to their arrival times (Berg, et al, 1964; Chance, 1968); Coulter and Migliaccio, 1966; Migliaccio, 1964; Dunning and Gilson, SEA interview (1966). The reported crest times for the first of these two waves vary from 10:30 to midnight and for the second from 12:30 to 1:45. However, the most likely times of occurrence of the wave crests are 11:45 and 1:35, as suggested in F'igure 165 . 
The damaging wave that came in about 11; 45 reached as far as Hobart Street (see Figure 162) and was reported to have been $21 / 2$ feet deep in Valdez Hotel. This wave came in like a fast-moving tide.

Water from the wave which came in at about 1:35 was 5 to 6 feet deep in buildings along McKinley Street and 2 feet on Hobart Street. Although it was not a smashing wave, it evidently advanced and receded with considerable speed, because the high water marks were in most cases higher outside than inside the buildings. The reason for this is suggested in Figure 165, which supposes that peak level represented the combination of two waves, one of approximately 2 hours period and the second of about 40 minutes period, representing the primary oscillations for Prince William Sound and the Valdez embayment, respectively. In terms of height, each constituent would appear to have had an amplitude of about 5 feet.

It is not possible to differentiate in detail the runup for each particular wave. The last wave caused the highest runup and from watermarks it has been possible to trace approximately the runup within the town. The runup distribution was sporadic and many apparently anomalous effects were reported to have occurred. These can generally be explained in large part by the existence of high snow berms and a deep snow cover which channeled the water and restricted its distribution (Coulter and Migliaccio, 1966).

In Figure 179 we give an interpretation of the inundation from the highest waves based on aerial photographs, examination of ground phouographs, and consideration of eyewitness accounts. Contours on land, referenced to MLLW, are based on a prequake survey of 1953 made by Thomas Bourne Associates of Alaska, Inc., Anchorage, for the Alaska Public Works Division. They have been adjusted for a regional subsidence of 1 foot at Fifth Street in Valdez and for proportionally larger subsidences approaching the waterfront, based on postquake observations made on buildings at the waterfront by Kajiura and Kawasumi (Berg, et al, 1964; Berg, personal communication, 1966). Contours check well for consistency with water level measurements made on numerous buildings throughout the town and with observations made by the writers in 1966. In general, it may be said that the highest runup was to 20 feet above MLLW.

Prior to the highest waves, there was other wave activity throughout the evening. At about 8:00 p.m. a lifeboat from the chena came in and tied up at the ferry slip (Figures 162 and 179). Later (about 8:15) this boat was found beached where the water had receded. While efforts were being made to launch it, the boat was floated free again by an incoming wave, and was able to return to the Chena (Bracken, 1964). It appears that about 8:30, the Falcon returned from its sensational experience in the Valdez Narrows and tied up at the ferry slip. By 9:00, withdrawal of water left the Falcon beached at this point. Then, at about 9:30 (Chance, 1968), another, higher wave reached as far as Water Street on Alaska Avenue (Figure 179). This wave, according to Bracken (1964), was like a fast-rising tide which he could evade only by walking 
rapidly ahead of it. Still another, but lesser, wave rolled in about 10:15 and apparently started a fire at the Union Oil Company tanks (Bracken, 1964; Chance, 1968; Gilson, SEA interview, 1966). The large yacht, Gypsy, at this time was lodged alongside the ferry slip, and had an open seam near her keel. In the later waves of that night, she was carried out to sea and was sighted from the Chena far out in Port Valdez, in a waterlogged condition. By dawn only the cabin was floating (Bracken, 1964).

\section{Tsunami Damage at Valdez, Alaska}

Most of the damage at Valdez waterfront was caused by the submarine landslides, while the principal cause of damage away from the waterfront was ground breakage. Approximately 40 percent of the homes and most of the larger commercial buildings were seriously damaged by ground heaving and fissures extending under or near them.

The slides caused both docks with their warehouses and canneries to disappear; also, the breakwater protecting the small-boat harbor disappeared. Figure 180 is a panoramic view of the small-boat harbor just a day or two before the calamity. Figure 181 in contrast is an aerial view of the waterfront the day after the earthquake.

The whole town subsided owing to the compaction of the deltaic materials during the tremors. The subsidence, greatest at the waterfront, gradually decreased away from the shore. Figures 162 and 179 may be compared for post- and prequake contours in the waterfront area. Water Street subsided as much as 9 feet near Alaska Avenue. This drop has a bearing on the wave damage in the waterfront area and is symptomatic of the disappearance of the docks. In addition to the subsidence, the waterfront area moved laterally (Figure 16). The concrete bulkhead at the head of the small-boat harbor apparently moved 25 feet seaward (Coulter and Migliaccio, 1966).

The initial waves caused damage to the whole waterfront and the downtown area as far as the runup line shown in Figure 179. A wave, presumably the one that came in about $21 / 2$ minutes after the earthquake started, damaged almost all the boats and boat floats in the small-boat harbor. Many of the boats were beached temporarily, and were washed into the bay by the higher waves later in the evening.

This wave also destroyed three of four buildings at the head of the small-boat harbor and another building along Alaska Avenue (see Figures 166 and 182). The buildings, like the majority of buildings in Valdez, were of light wooden frame construction. Particulars of a few buildings damaged or destroyed are given in Table IX. Their location is identified by number in Figure 179.

Some heavy trucks from the docks were also washed inland (see Figures 179 and 184). The roof of the cannery from the inner end of the north dock may be seen partly sunk in mud flats northeastward of the North Arm in Figures 1€6, 179, 181, 183, and 184. 


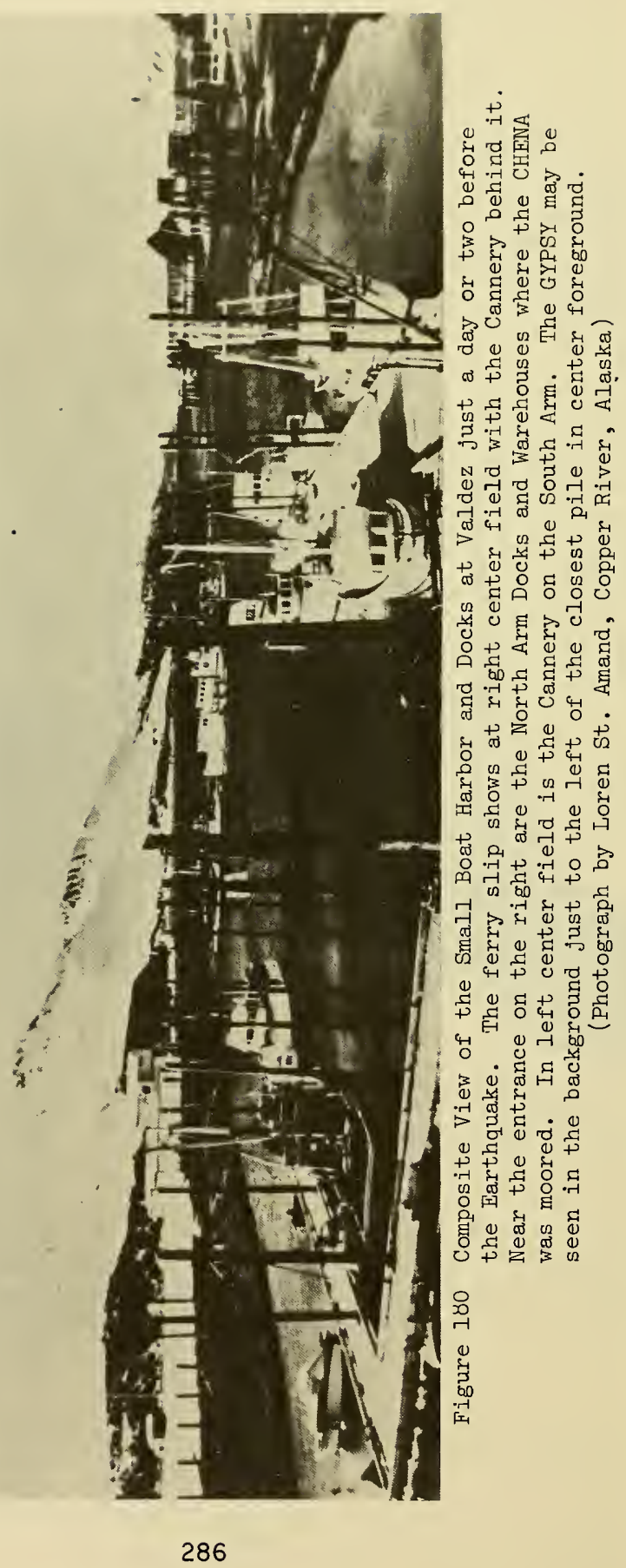




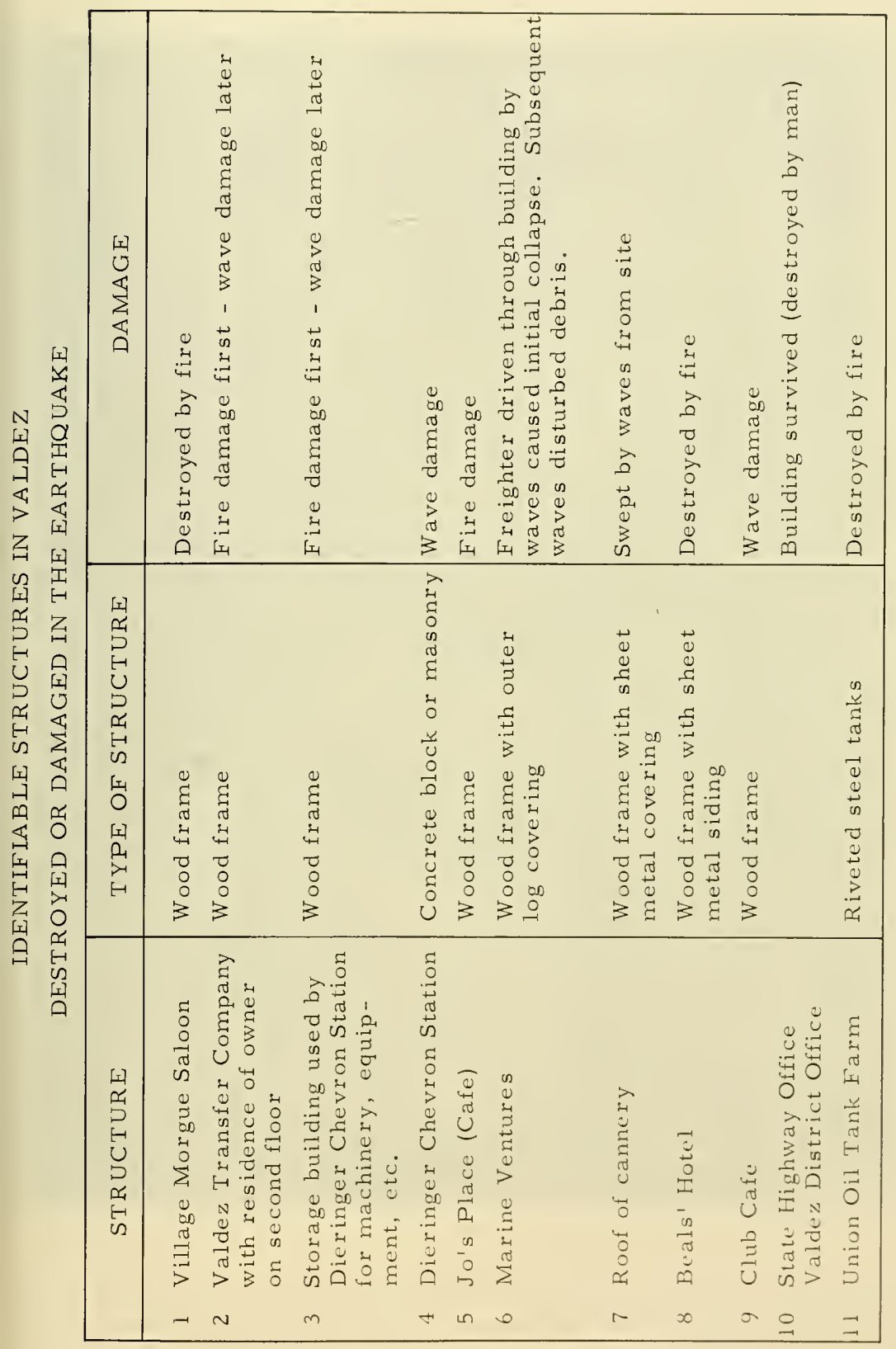




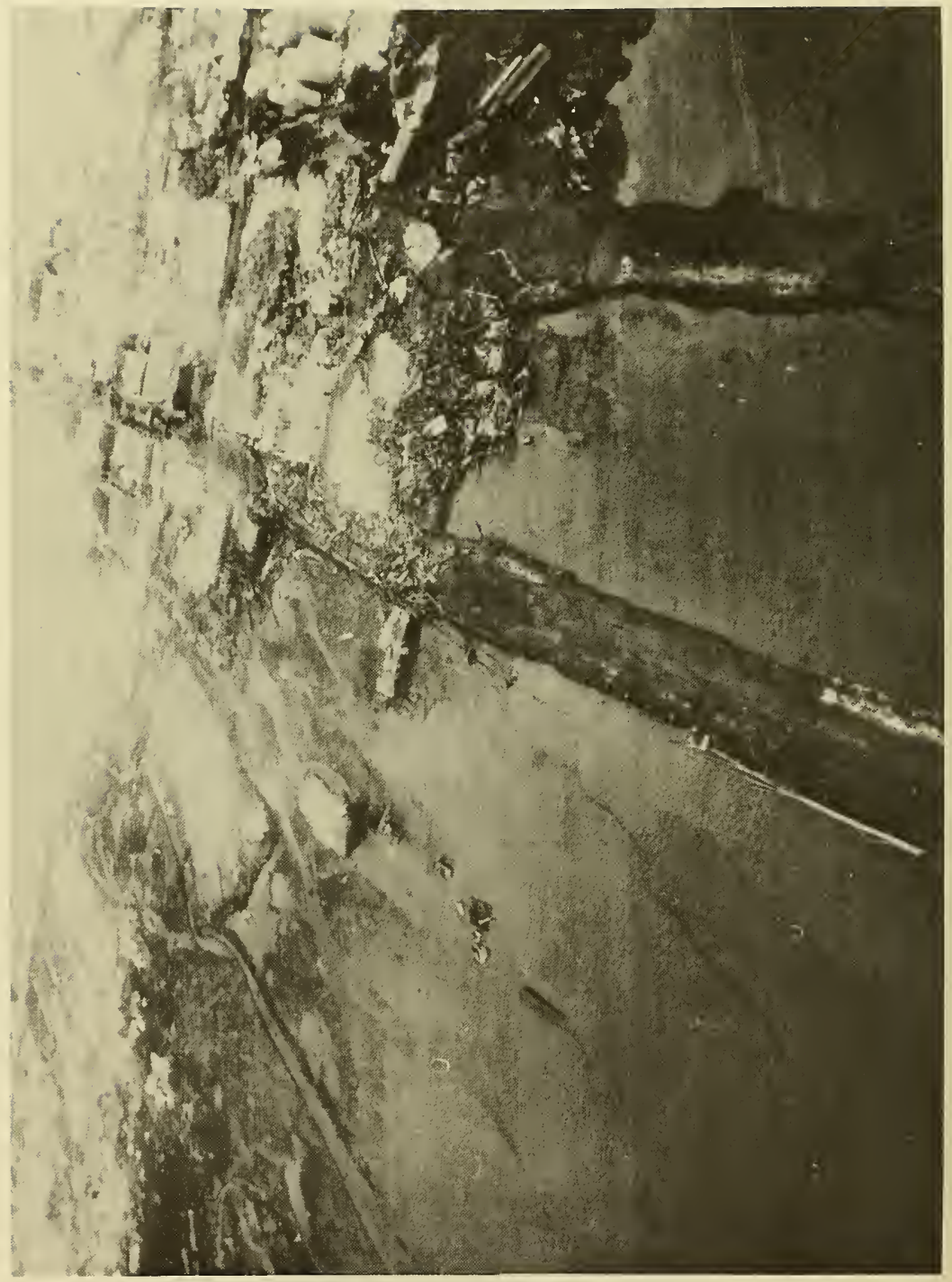

•.

ฮี

0

का

o

प्ञ

a

(1)

$+$

崩

$+$

क

N

$\stackrel{d}{d}$

$\stackrel{0}{\stackrel{c}{p}}$

H.

.

5

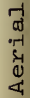

$\infty$

a)

4
3
001
+1
rey 


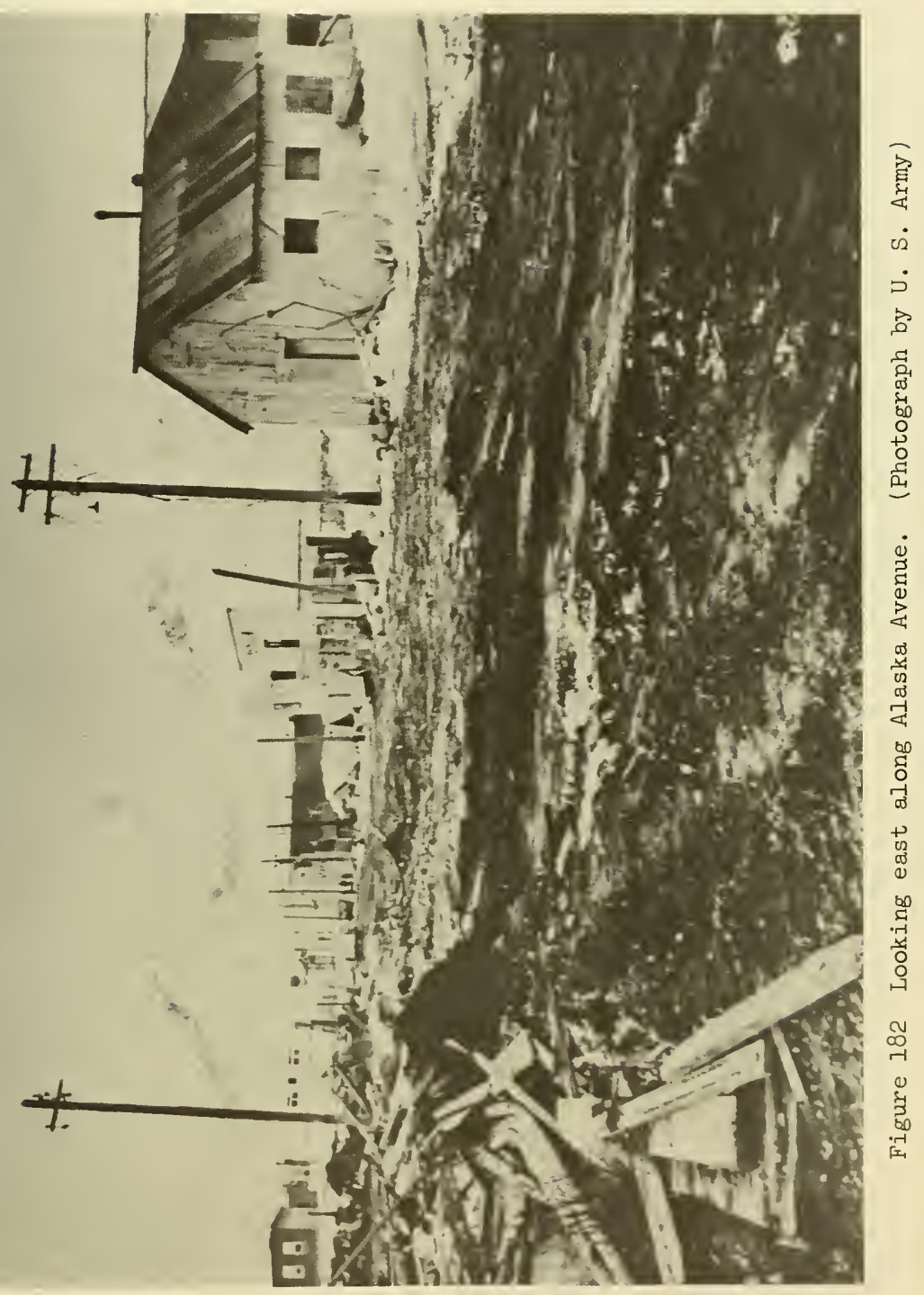




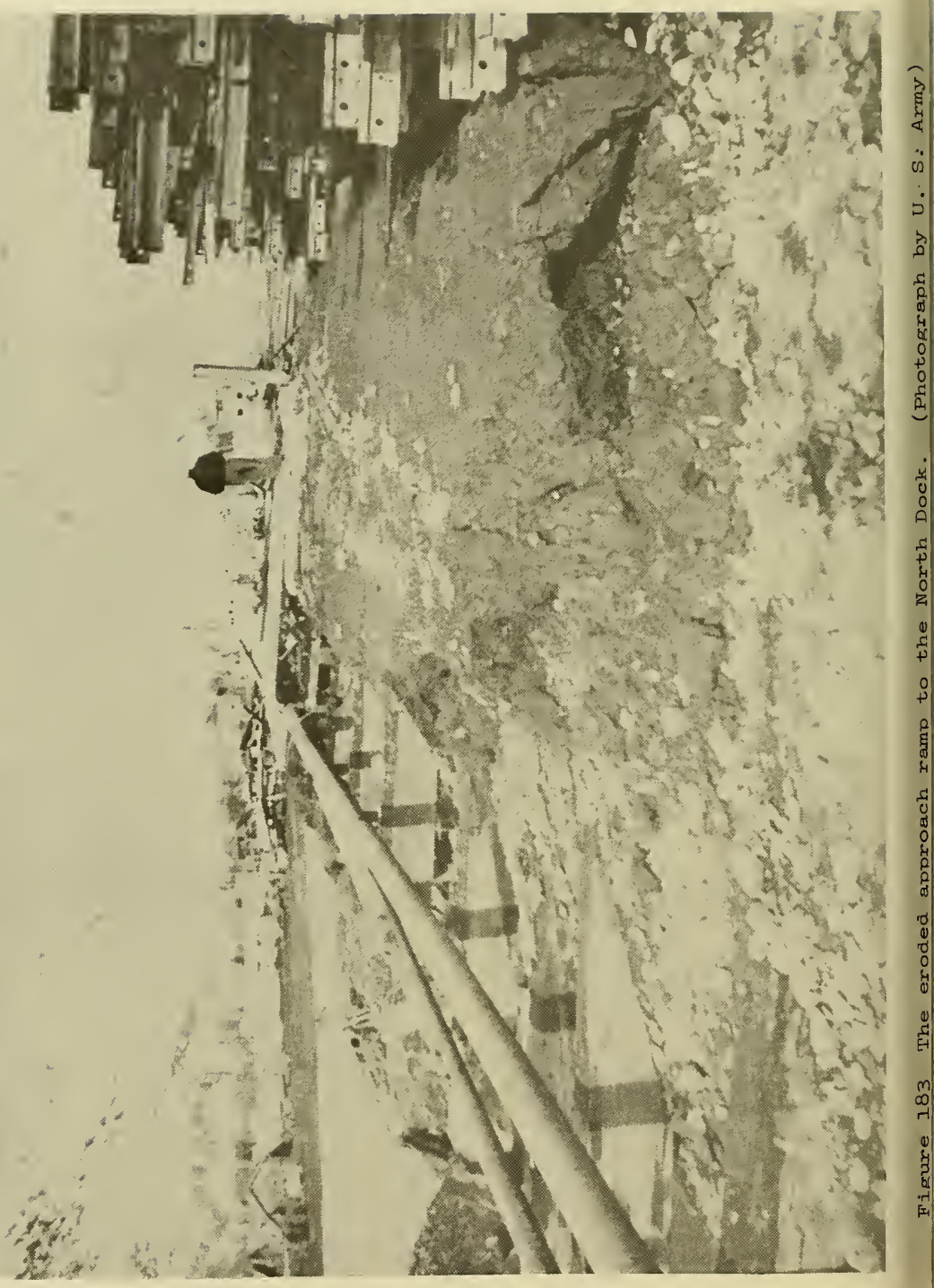




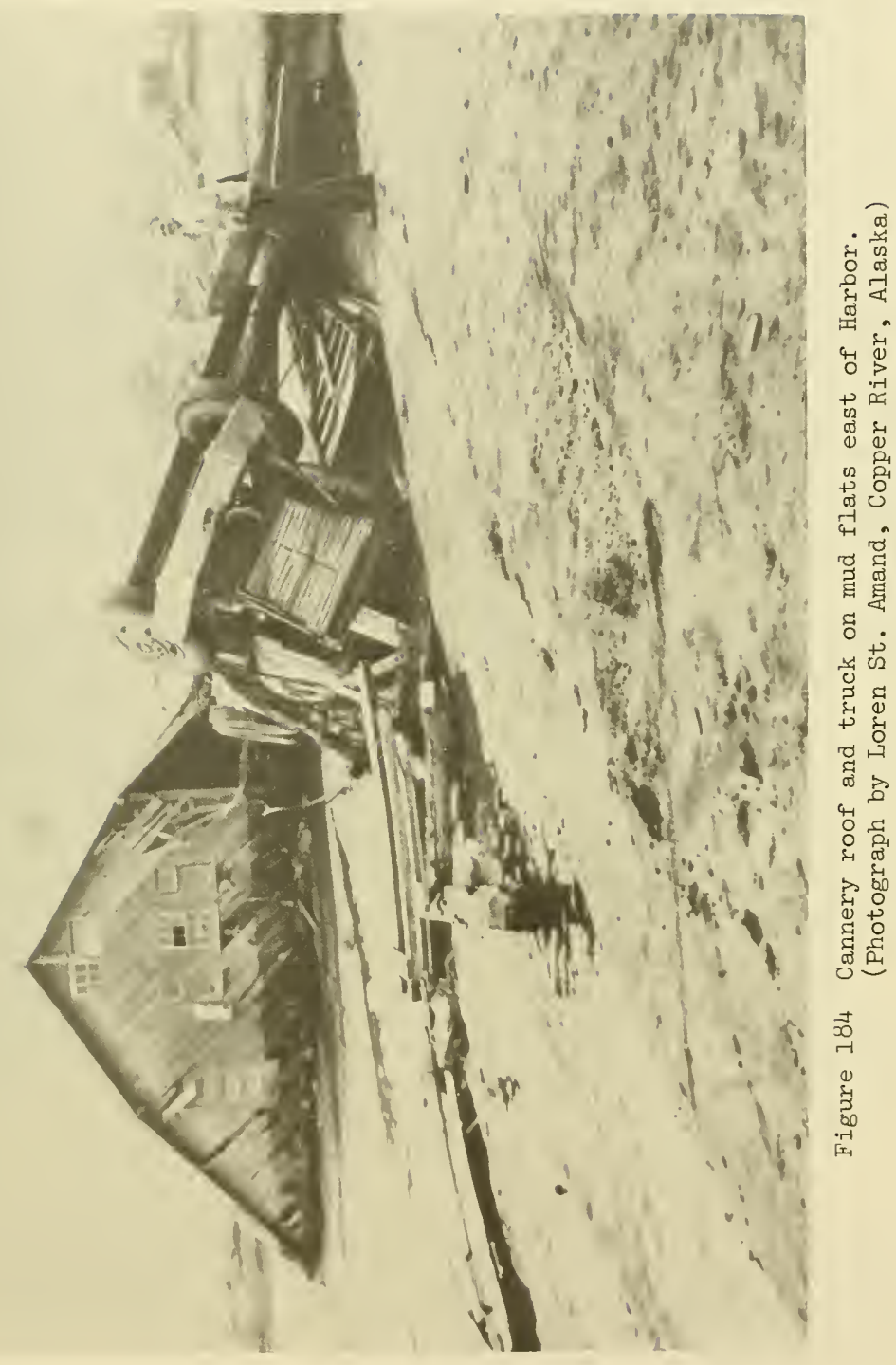


One of the asphalt storage tanks at the Standard Oil Company of California tank farm was punctured during the earthquake, probably by floating debris. The escaping asphalt contaminated a large area of Port Valdez as shown in Figure 185 (Maclvamara, 1964).

Gasoline also leaked from the tanks, and about 10:15 p.m. on the day of the earthquake, the Standard Oil tanks caught fire, probably by wire short-circuiting caused by water. Shortly afterwards, the Union Oil tank farm also caught fire (Bracken, 1964).

The high waves that came in about $11: 45$ and $1: 35$ during the night had apparently no smashing effects. However, they refloated boats and debris; and also some of the wooden structures were floated free, but were apparently not moved very much. These two waves were responsible for most of the wetting damage to buildings, homes, merchandise and supplies in the commercial establishments along McKinley street and west of it. The water was heavily laden with silt and large volumes of silt were deposited in and around buildings. The backwash of the last wave had a strong current, and debris and beached boats were washed out into the bay. Some of the general melee on the waterfront is illustrated in Figures 186 and 187.

At Jackson Point, a cannery was swept off its foundation by a wave that rushed up 32 feet. Later, parts of the cannery were found floating about 2 miles west of Jackson Point (see Figure 185).

An inhabited cabin in Anderson Bay was completely swept away by the waves generated in the Cliff Mine area.

According to Spaeth and Berkman (1967), 31 persons died at Valdez as a result of the earthquake and tsunami, the highest number of deaths of any community in Alaska. It has been stated that if the earthquake had occurred just one-half hour earlier, while the dock was still crowded with townspeople, the death toll would have been many times greater.

The estimate of property damage caused by the waves is $\$ 12,568,000$ of which $\$ 8,453,000$ was privately owned and $\$ 4,115,000$ publicly owned. Relative to its population size, Valdez suffered more acutely than Seward, although total damage losses at Seward were higher.

\section{Tsunami Waves at Whittier, Prince William Sound}

Whittier was built in $1942-43$ to provide a second all-weather terminal (besides Seward) for the Alaska Railroad. Figure 188 shows its location near the head of Passage Canal in Prince William Sound, one of a series of fingerlike fjords that connect with Port Wells and Wells Passage. The town is owned and operated by the Alaska Railroad of the U. S. Department of the Interior. However, some of the land has been leased to private enterprises. As a result of the earthquake, 13 of the 70 people living in Whittier died. 


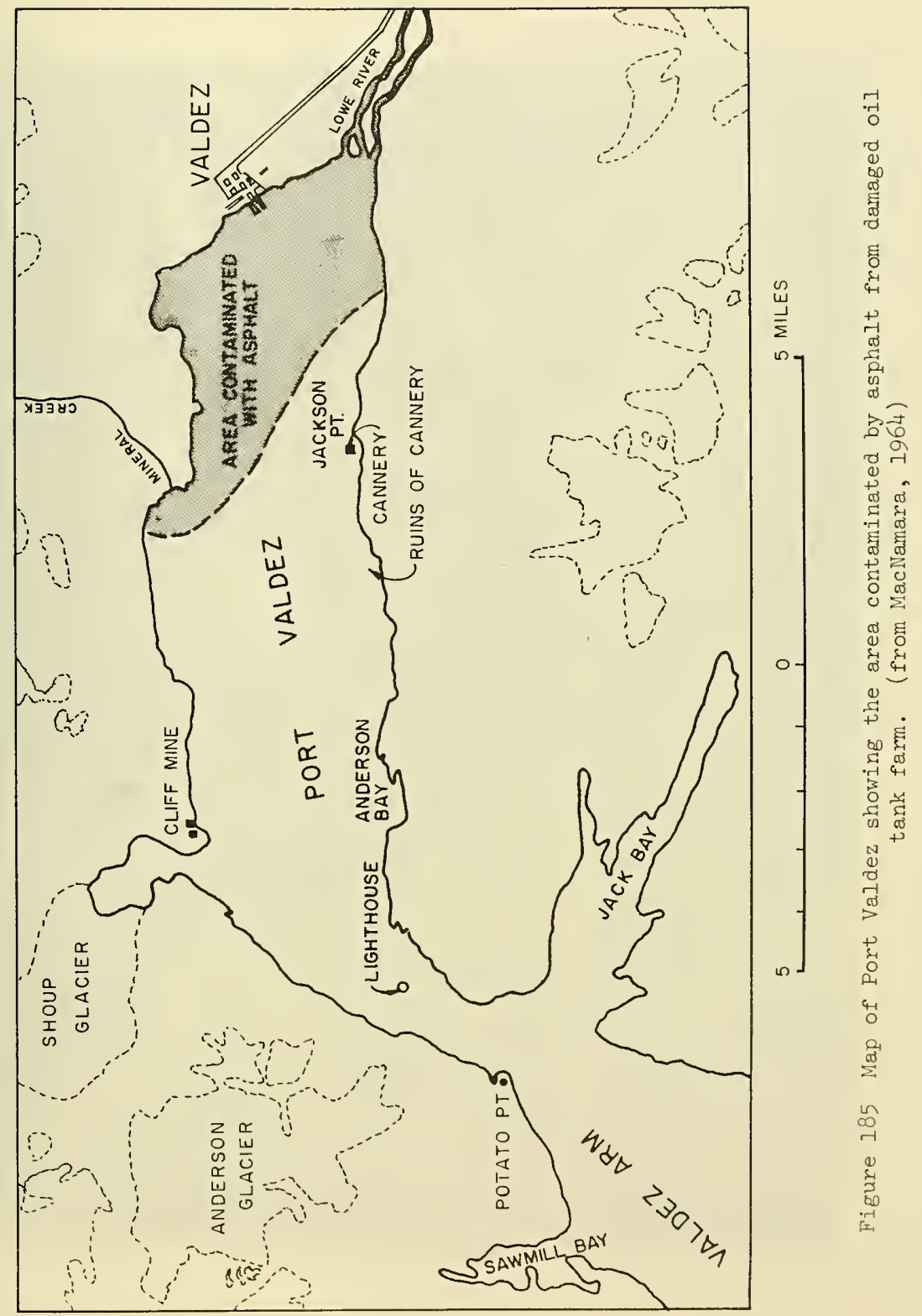




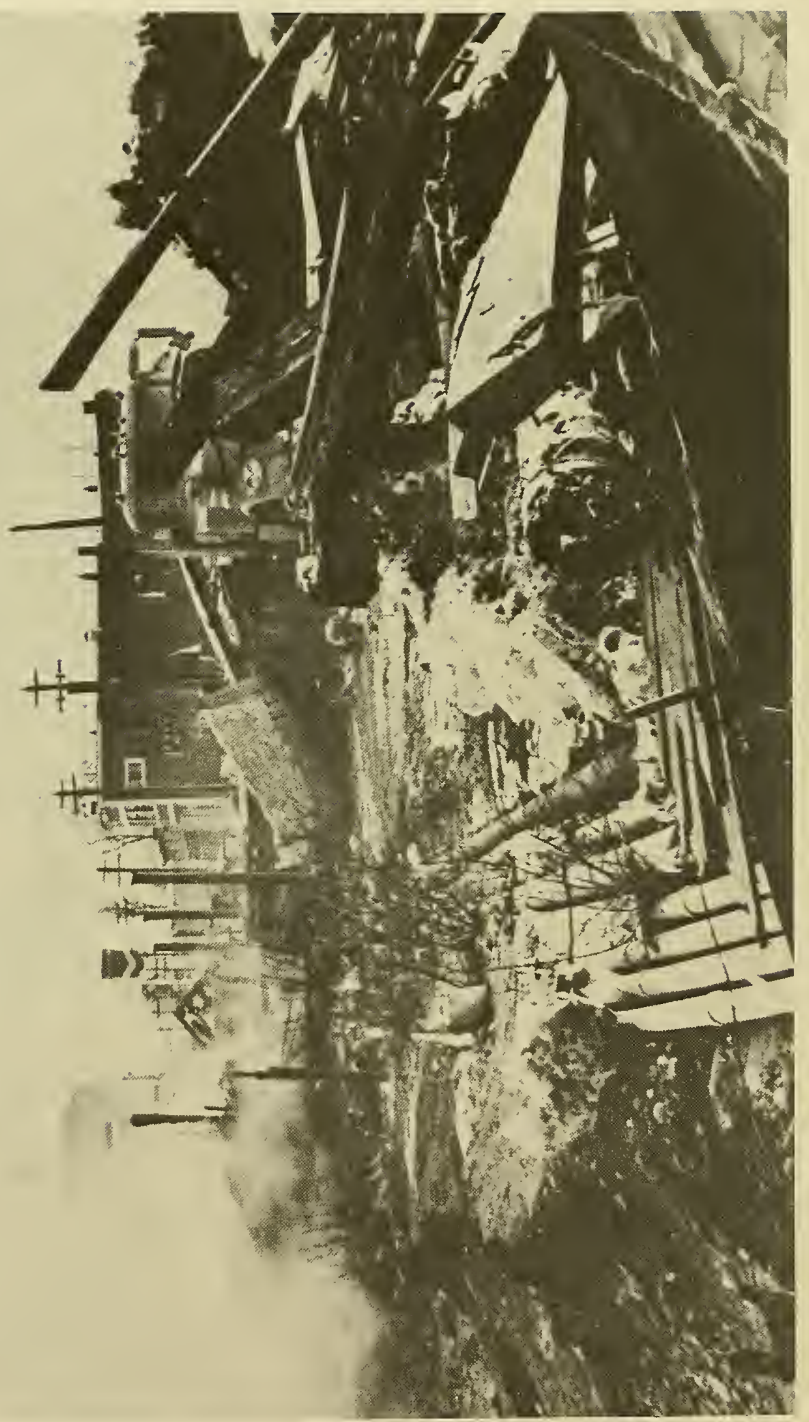

告

@ 


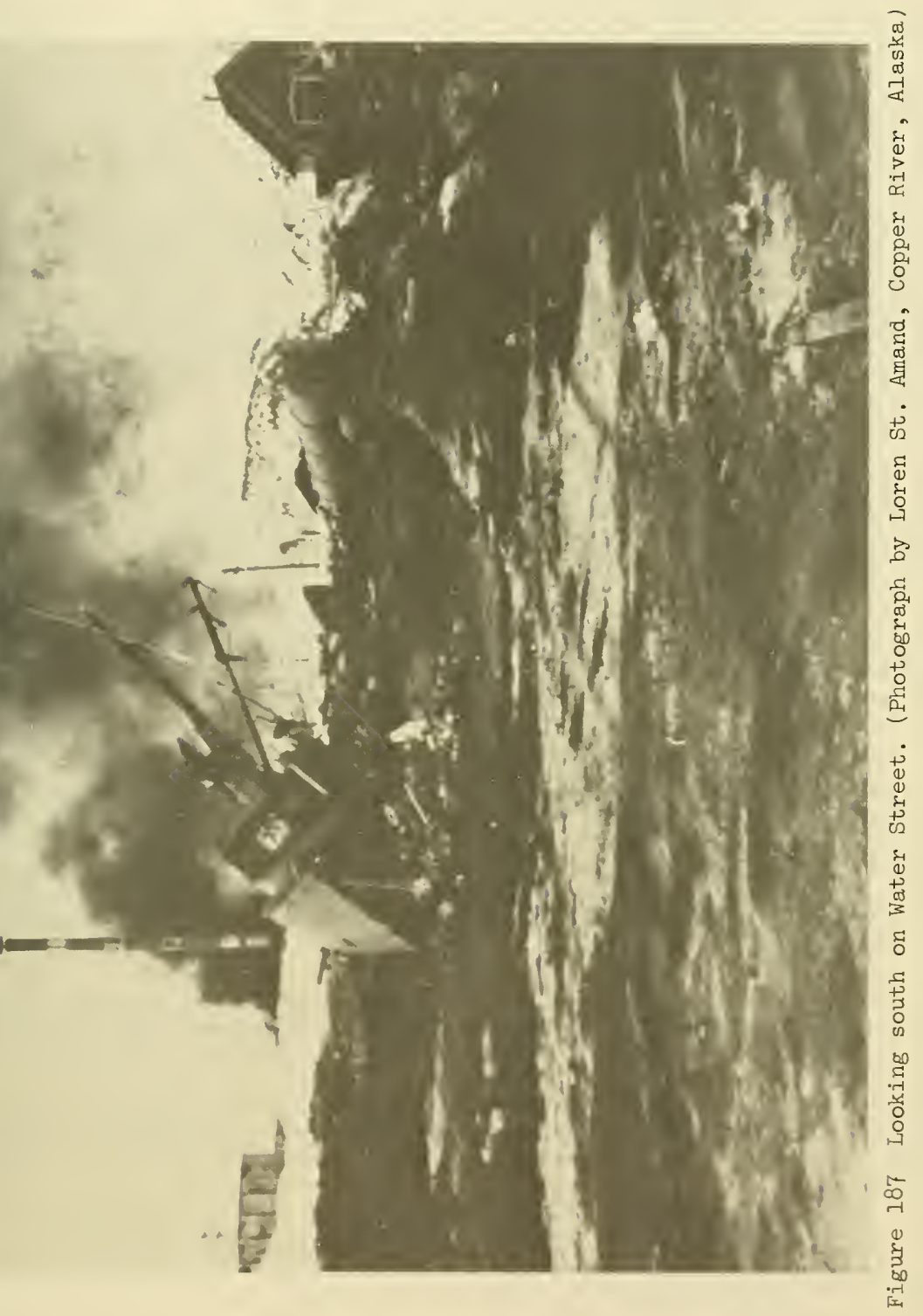


Figure 188 shows that Port Wells and its tributary fjords are a relatively deep and intricate system of connecting basins whose oscillating characteristics are apt to be complex. No attempt has been made to determine this oscillating regime. It may be noted from Figure 188 (inset) that Whittier lies on the northwest side of the hinge line of zero vertical earth movement running through Prince William Sound.

The delta upon which Whittier rests and also the southern part of the delta at the head of Passage Canal are formed of unconsolidated deposits. These consist of outwash and stream gravels composed predominantly of subangular to subrounded gravel in a matrix of coarse sand (Kachadoorian, 1965). Figure 189 is a prequake map of Whittier and its immediate vicinity; its rather limited area on the fan delta is illustrated by the aerial view of the town and port facilities prior to the earthquake (Figure 190).

The extensive damage suffered by Whittier was caused by (I) seismic shock, (2) submarine landslides, (3) waves, (4) fracturing and compaction of fill and unconsolidated sediments, (5) fire, and (6) a 5.3-foot subsidence of the landmasses. The port was rendered totally inoperative, and for a time was without rail communication (Eckel, 1967).

The destructive waves that lashed Whittier were undoubtedly generated by submarine landslides. Figure 191 shows the areas affected by slides and some pre- and postquake profiles indicating the amount of landmasses involved in the slides (Kachadoorian, 1965).

An inferred marigram for Whittier has been constructed in Figure 192, but data are extremely limited. Not many people witnessed the waves. Some of those who watched the water (cf. Bryant, 1964; Kachadoorian, 1965; Chance, 1968) have reported that, approximately one minute after the earthquake started, the water in Passage Canal in the vicinity of the town rose rapidly to about 30 feet above tide level for that time, which was about 1 foot above MLLW. The water was glassy and did not contain any debris.

The water immediately receded, and the "glassy hump" apparently did not encroach on the shore as a wave above normal maximum tide level. The first damaging wave struck Whittier at 1 to 1.5 minutes after the glassy hump occurred. This wave was muddy and contained much debris which radiated from a boil halfway across Passage Canal. The crest of the wave was 34 feet above water level when it reached the Alaska Railroad depot (see Figures 191 and 193). It struck the depot 8 to 10 feet above ground level.

About $1 / 2$ to 1 minute after the first damaging wave (second rise of water) another damaging wave rolled in on whittier. Its crest reached about 30 feet above tide level at the Alaska Railroad Depot (Bryant, 1964).

No waves other than the two that struck during the earthquake have been reported. The high waves which reached Cordova and Valdez late in 
he evening, (also reported in Pigot Bay, close to Whittier (see Figure 59d)), apparently were not felt or noticed at Whittier. The reason is ot known, and will probably remain unexplained as one of many apparently nomalous wave patterns within Prince William Sound during and after the arthquake.

There were apparently no eyewitnesses to the waves in parts of the own other than at the Alaska Railroad Depot, but high watermarks on now, trees, and deposits of debris have made it possible to trace the igh water line shown in Figure 191. The main wave directions, inferred rom debris, are shown in Figure 191 (Kachadoorian, 1965).

The highest runup occurred on the north side of the Passage Canal here high watermarks have been measured 104 feet above MSL. Highest unup levels in the downtown area were 35 feet at the railroad depot nd 43 feet somewhat east of the depot.

It is difficult to give a plausible explanation for the behavior of he water in Passage Canal during the earthquake. In many ways the wave equence resembled that occurring at Seward. There are, however, differnces also, which obviously must be accounted for by the different time equences of the slides. There was no glassy elevation of water at eward as reported at whittier. How this hump was generated, and why a ig wave apparently did not radiate from it, is intriguing. Possibly he hump was generated by some early configuration of slides and a wave, adiating from it, hit the shore when the water level was at its lowest uring the reported drawdown. The drawdown was apparently caused by the asses sliding away.

The two destructive waves at Whittier apparently originated from ifferent locations, and probably at different times, but the generation echanisms were probably similar to that inferred for seward and sketched chematically in Figure 139.

\section{Tsunami Damage at Whittier, Alaska}

The U. S. Geological Survey has comprehensively surveyed the amage at Whittier (Kachadoorian, 1965). The map of Figure 193, reprouced from their report, shows the extent and causes of the damage. The amage is also shown in Figure 194 which should be compared to Figure 190.

When their foundations slid away, the outer ends of the Union Oil ock and the Army Dock collapsed. The approach trestles were totally estroyed by the subsequent waves.

The tank farms and buildings nearby were destroyed by waves and fire. ne Union Oil tank containing ballast was moved at least 40 feet south by aves and another tank containing one million gallons of fuel was moved 5 feet. Particulars of the damage and direction of movement of dislaced tanks in the Union Oil Company's tank farm are given in Figure 95. 


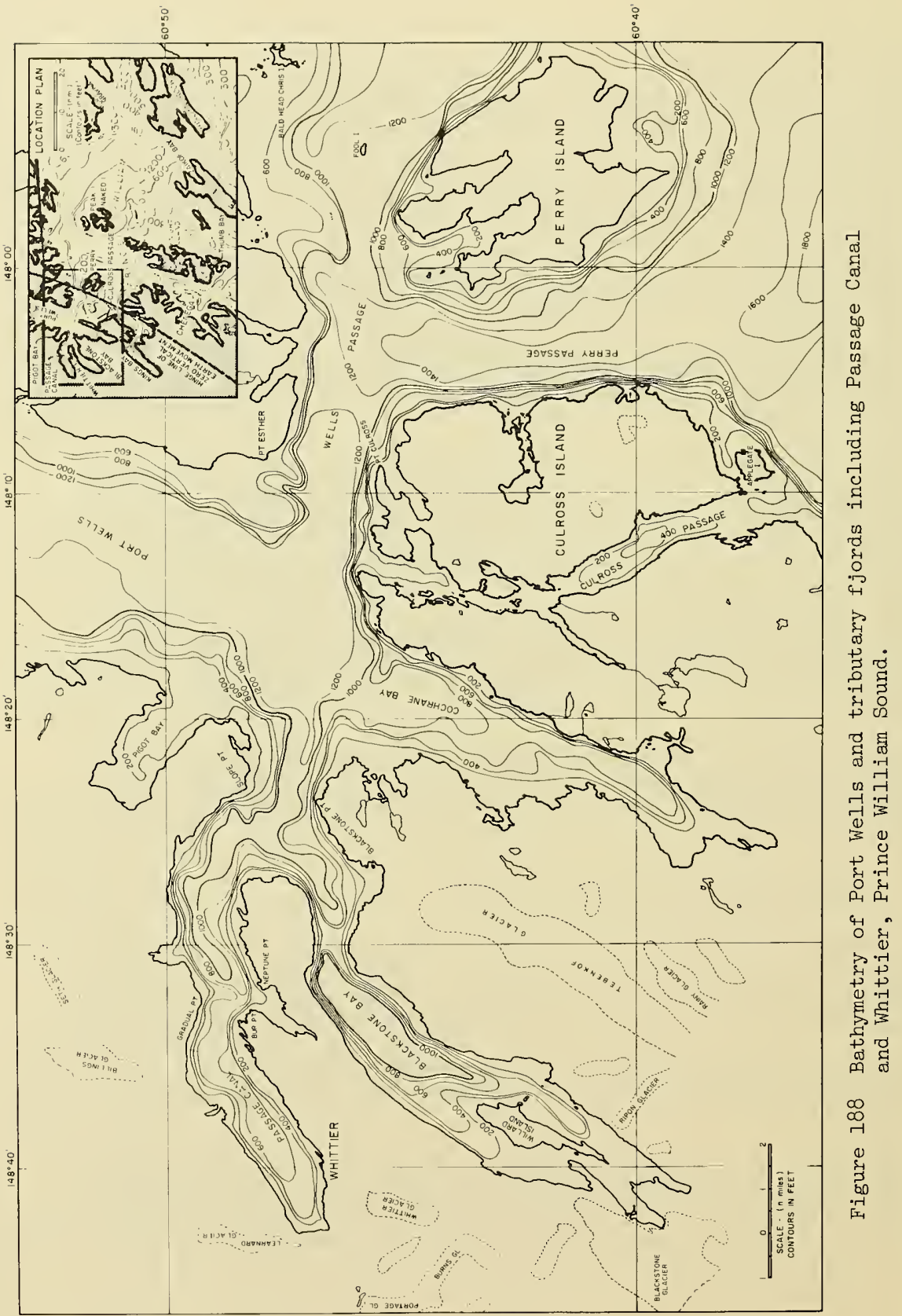




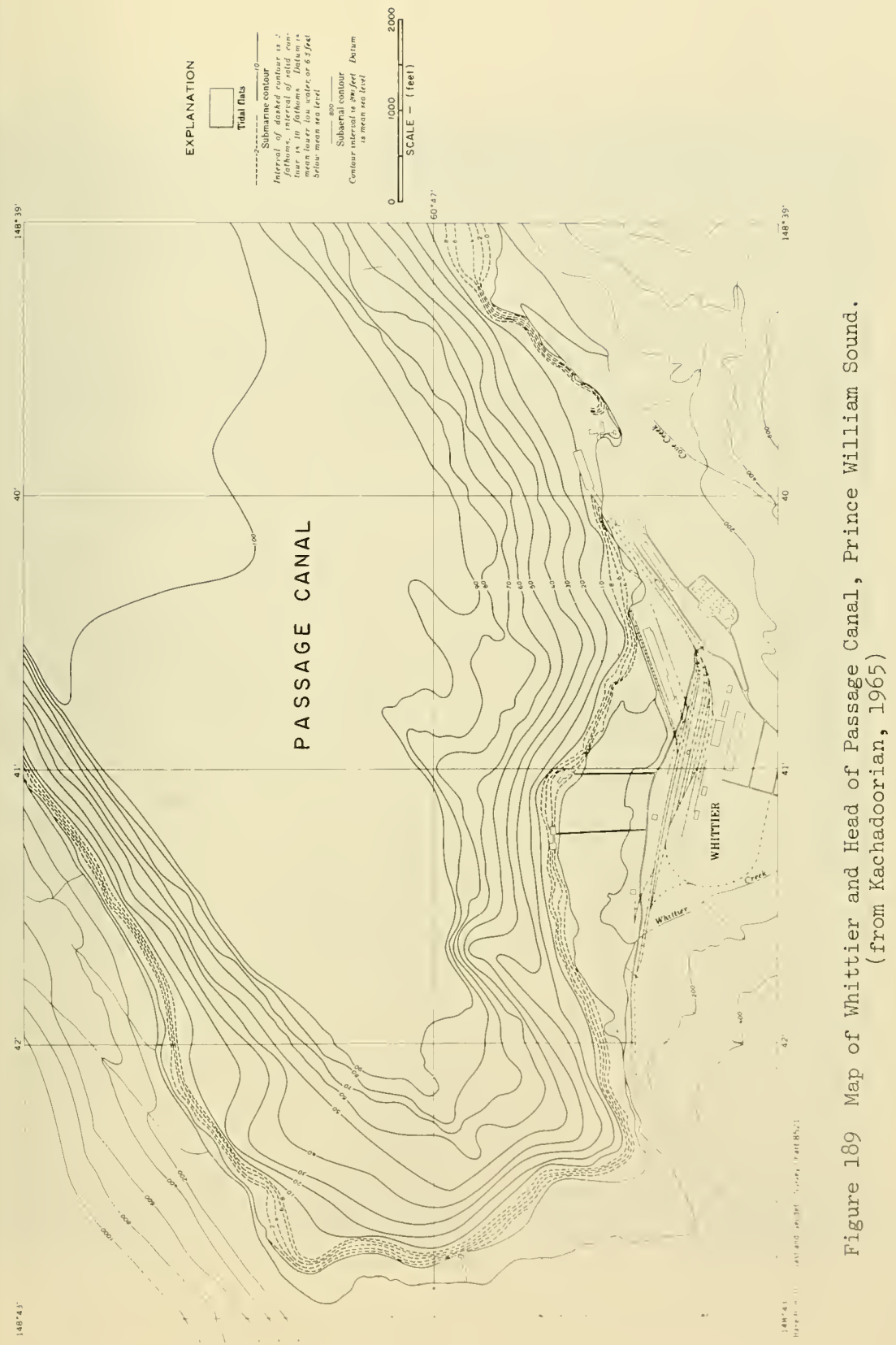


The Columbian Lumber Company plant and camp were completely wiped out by the waves. Almost nothing remains of the facilities which occupied the west end of the waterfront at Whittier (see Figure 196). Of the 13 people who died, 12 were in a camp building of the lumber company.

One slip tower of the car-barge, slip dock collapsed when its foundation slid away; the other was destroyed by the waves. Bending of the slip, steel beams (shown in Figure 197 and 198) gives an indication of the power of the forces involved.

A 4-cubic-yard, barnacle-covered boulder was carried from the tidal zone, presumably, about 125 feet inland and deposited on the Alaska Railroad tracks near the depot at an altitude of about 26 feet. Boulders as much as 6 feet across were strewn on the road between the small-boat harbor and the Union Oil Company (Chance, 1968).

The depot of the Alaska Railroad was heavily damaged by waves (Figure 199).

Waves that struck the shoreline at the head of Passage Canal detroyed practically all the structures near the shore. The waves washed away 3 unoccupied homes on the shore, 200 to 400 feet south of the FAA stations, and completely destroyed the buildings of the Two Brothers Lumber Company. The buildings of the Two Brothers Lumber Company were carried inland in a southwest direction; the company's trimmer and conveyor chain were moved 200 feet, the bucking machine 40 to 50 feet, and the 2,300-pound mill about 100 feet to the southwest. The nearby FAA station, although partially inundated by waves, was not significantly damaged.

It is inferred from debris and watermarks that the waves (or wave) that damaged the west coastline of Passage Canal (Figure 191) originated along the north coastline of the canal and traveled southwest. The waves were apparently diverted near the eastern end of the airstrip, because a structure about 300 feet south of the airstrip was only moderately damaged (Kachadoorian, 1965).

The waves traveling southwest and south struck the point along the south shore, about 4,000 feet west of Whittier Creek, with tremendous force. Here one wave reached more than 50 feet above MSL. It carried a l-ton winch and a boulder weighing 2-3 tons 120 feet south and deposited them on the Alaska Railroad tracks (Chance, 1968).

According to Spaeth and Berkman (1967), the seismic sea waves at Whittier were responsible for about $\$ 10$ million worth of damage (see Table E-5, Appendix E). Relative to its population of 70, Whittier must be considered to have suffered most acutely of all the coastal communities of Alaska. For more details, the reader is referred to the excellent monograph of Kachadoorian (1965). For greater understanding of the wave effects, however, there is need for a more extensive study of the oscillating characteristics of the Port Wells complex of fjords. 


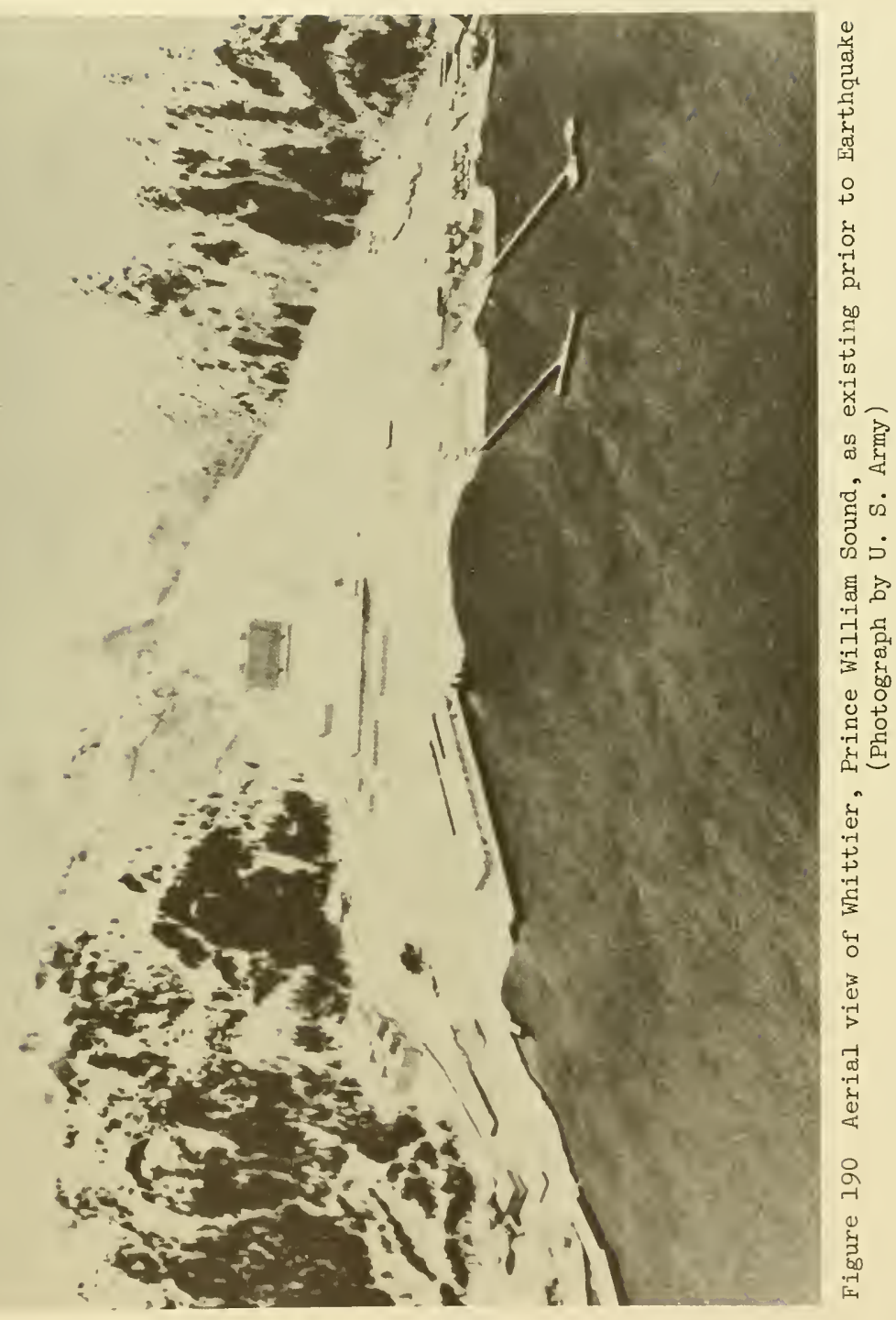



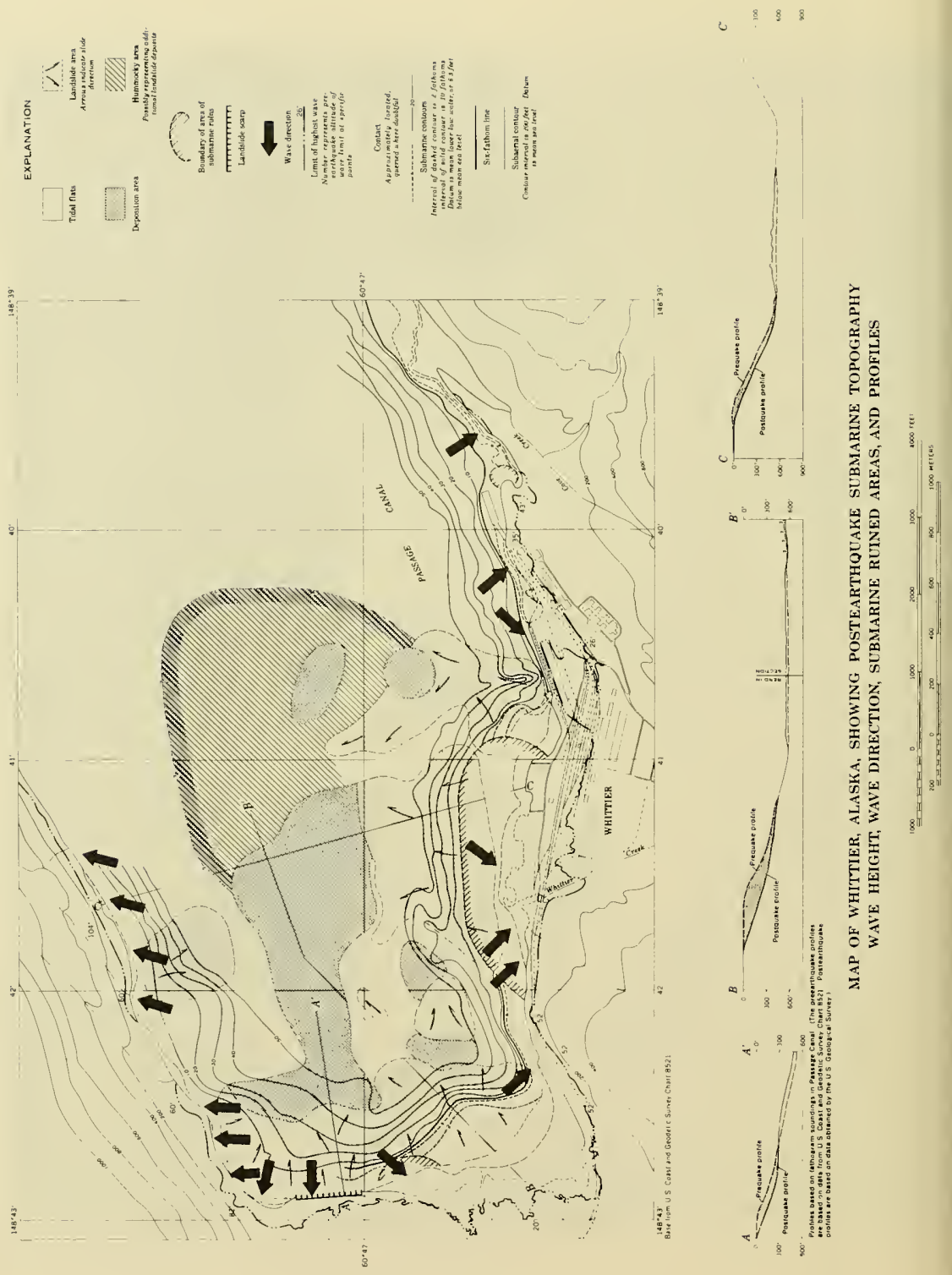


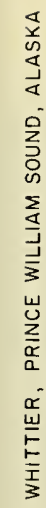
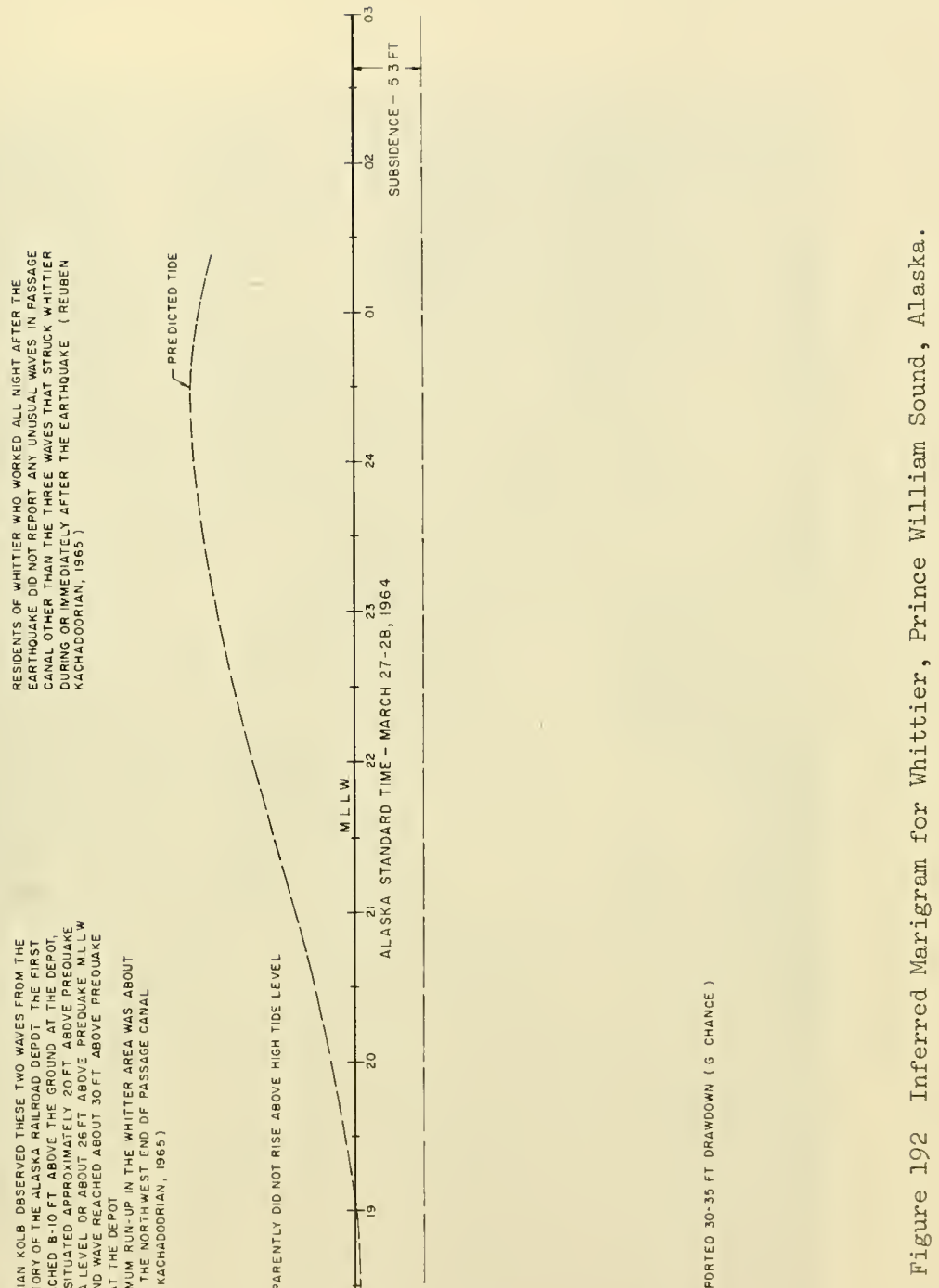

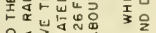

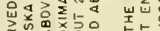

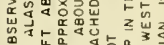

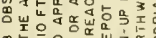

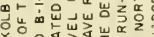

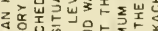

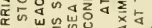

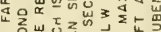

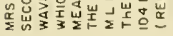

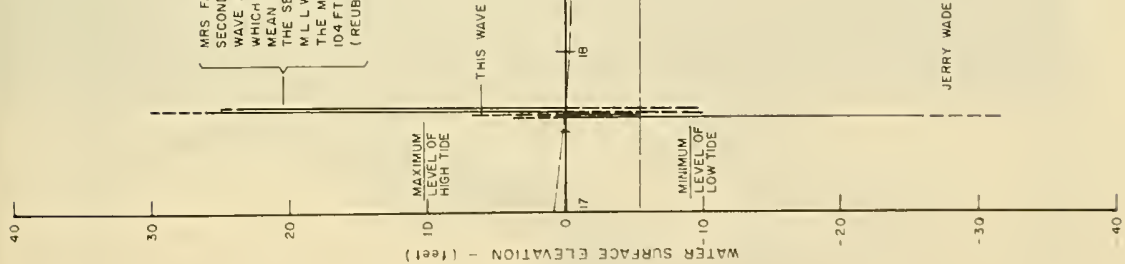




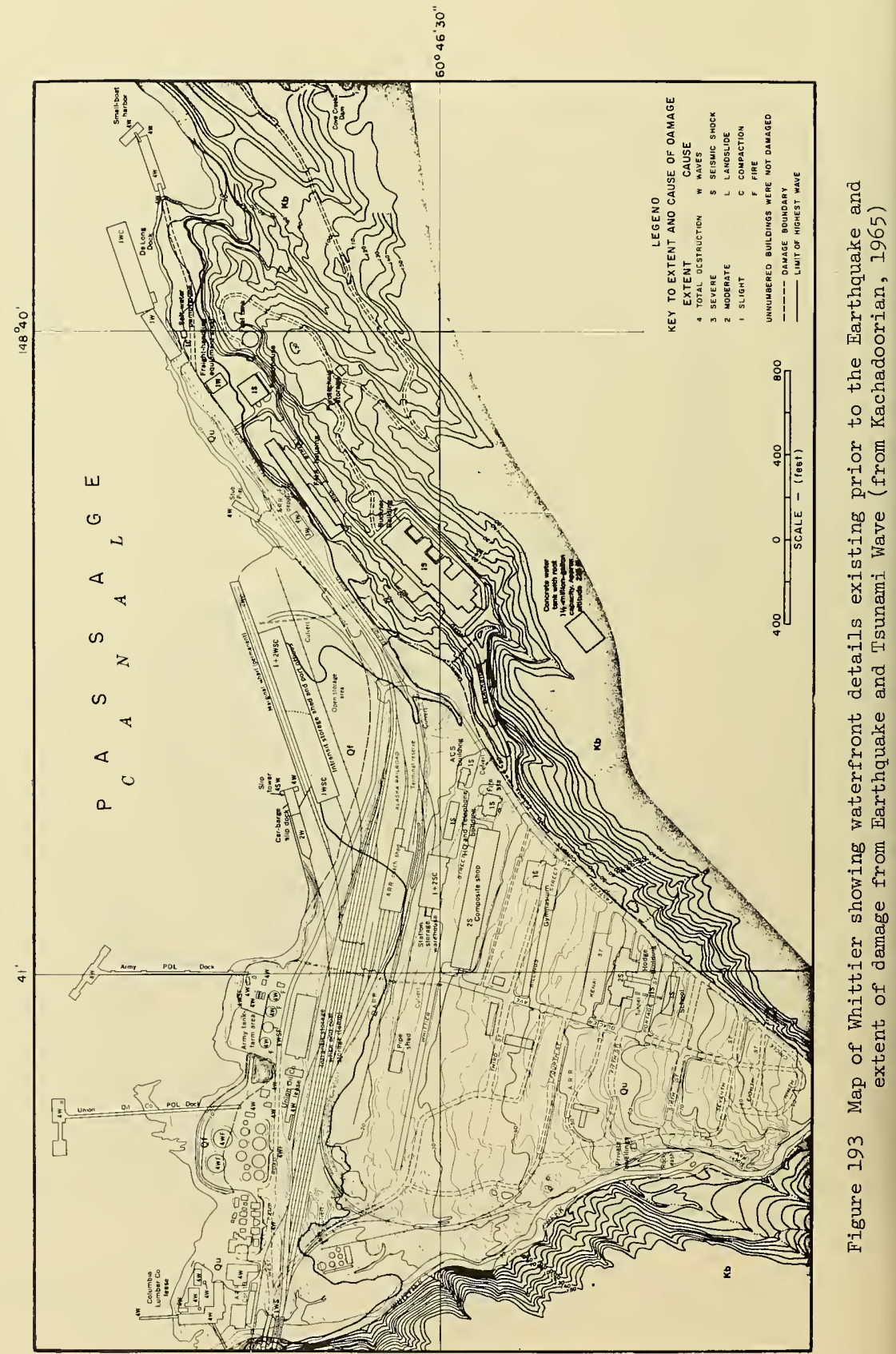




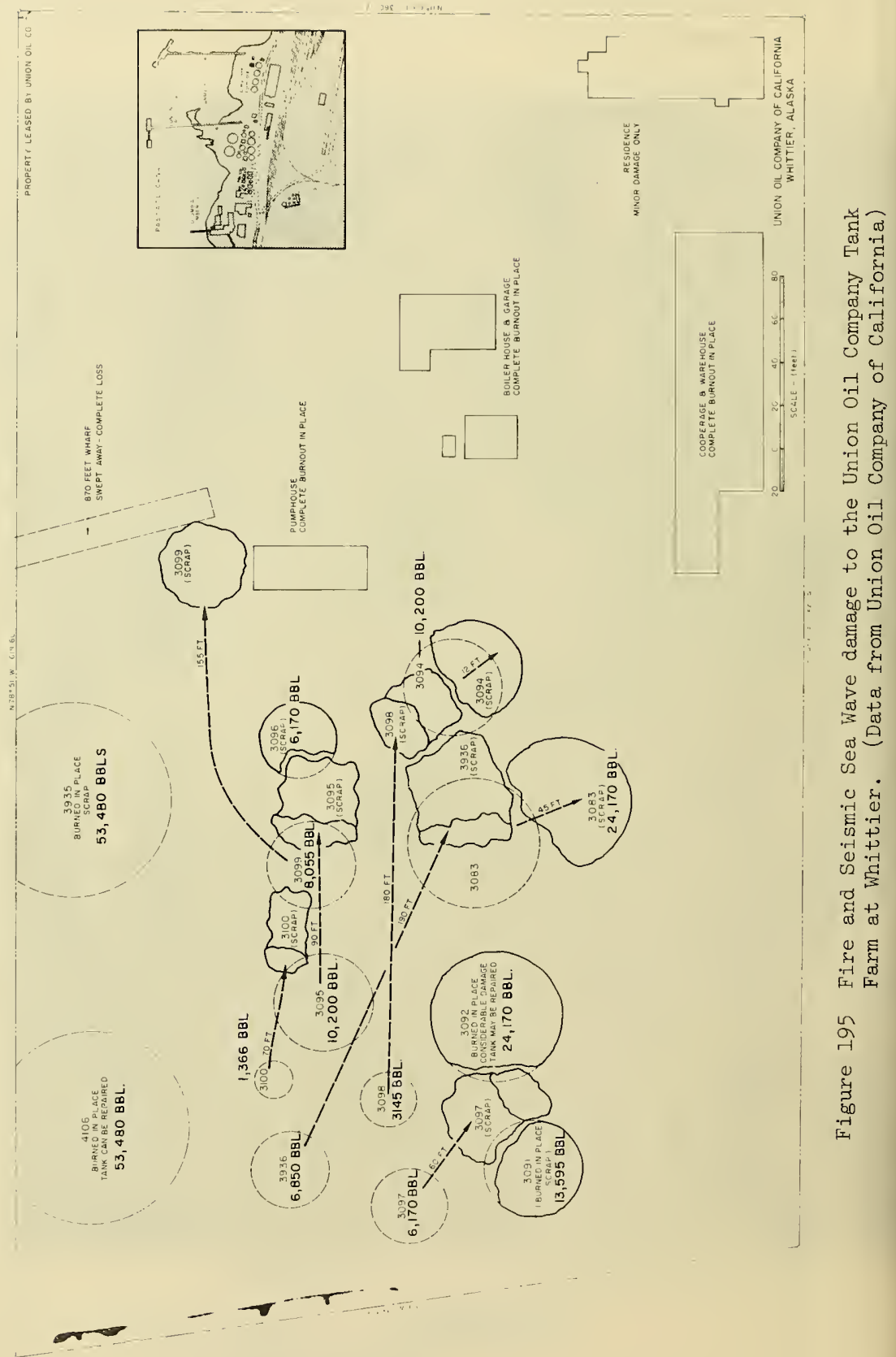




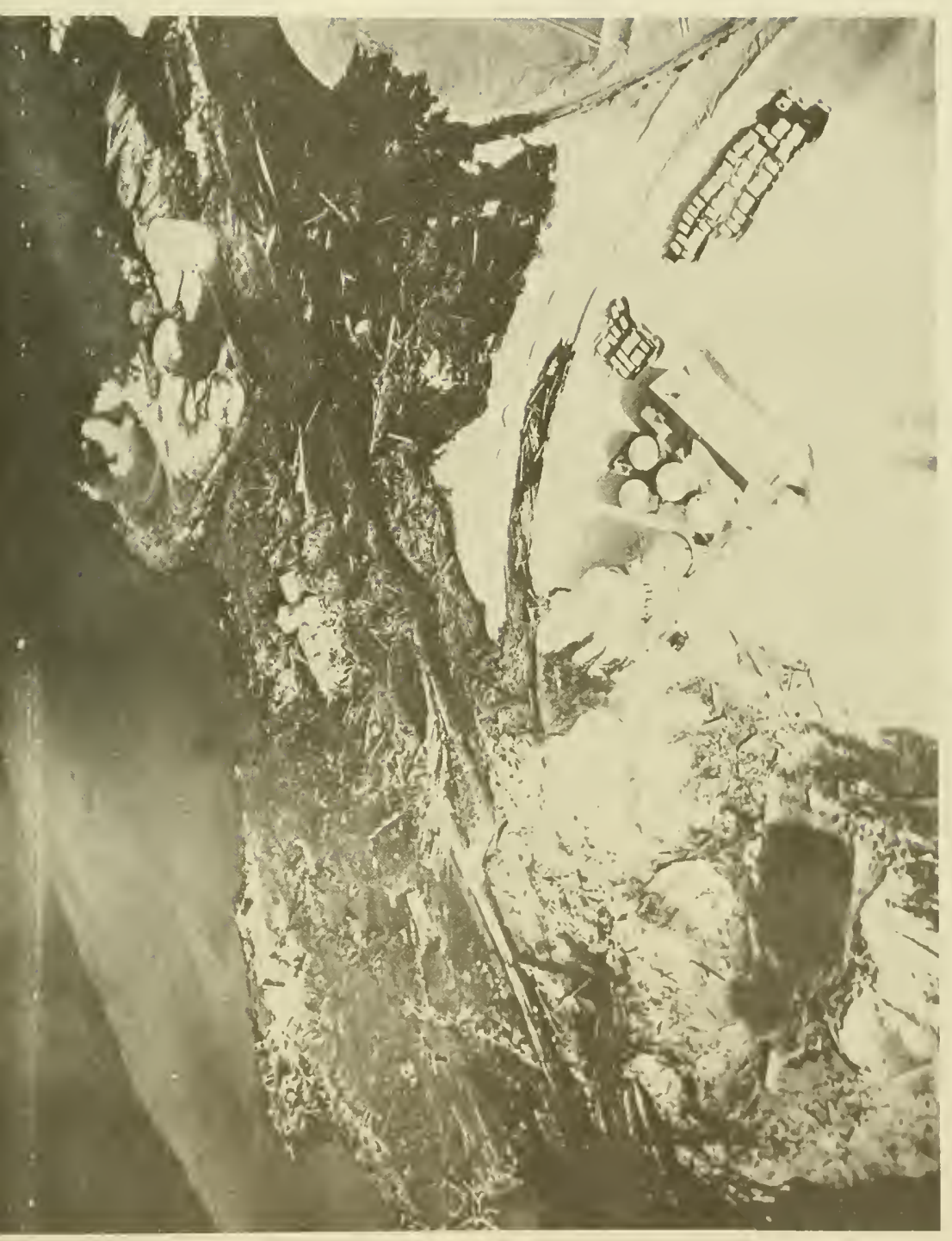

थ 02 है

है

का (1)

出

สె口

다 द्रे

㲾

豆获

0 O 0

न्-

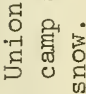

-

今 द्व

मे त्र

क द्वि

\& 0

त्से है

이 0

\& \&ै 0

1)

†

$+r \mapsto ?$

远结?

- 10

फ 官

त) द્10 0

$+\stackrel{+}{+}$

(1) +

(1) $\cdot-1$

究 मे

फ्य है

ह

35

(1)

त)

त) $N$ त

\% 100

(1) 긍

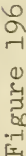




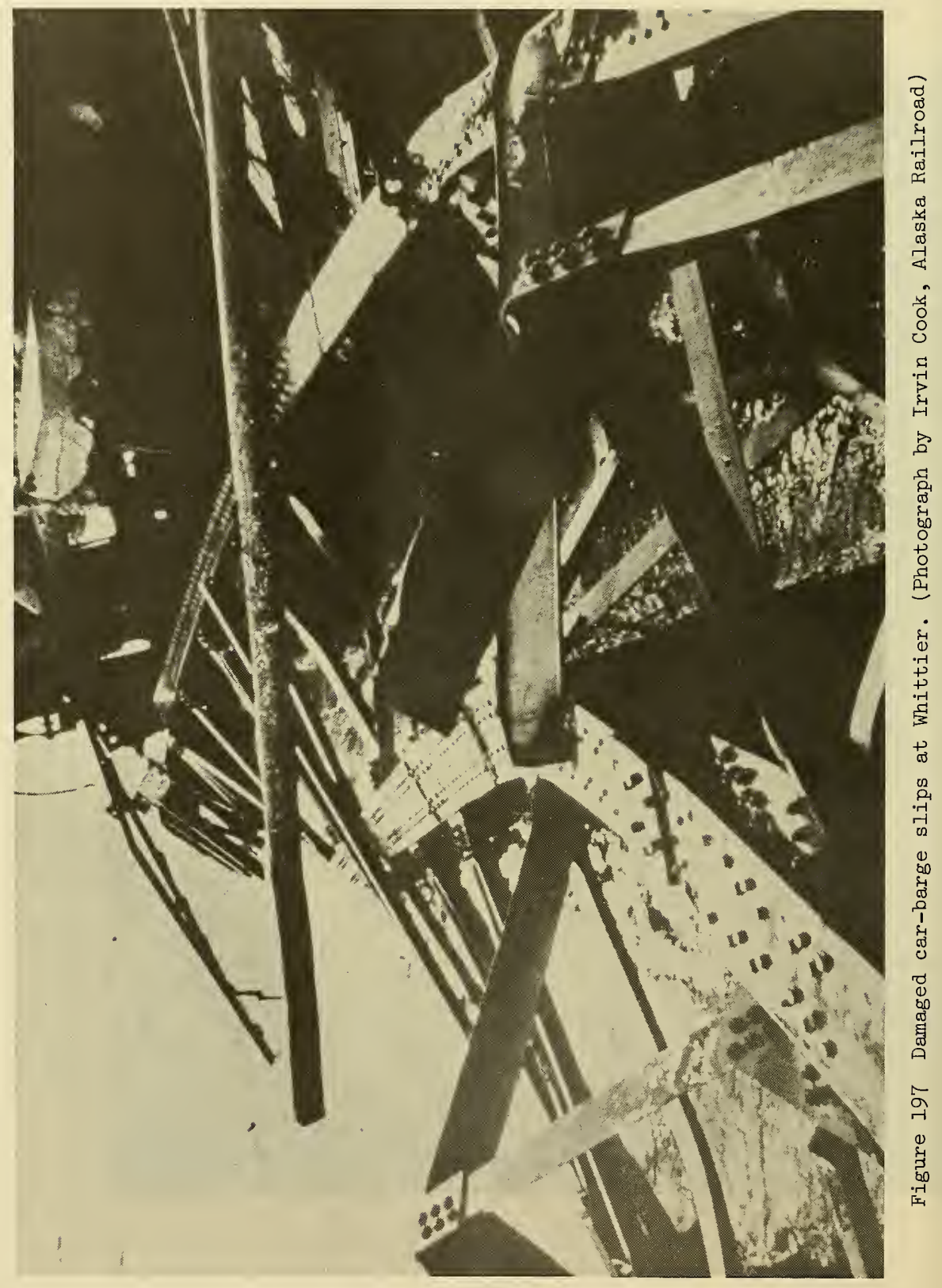




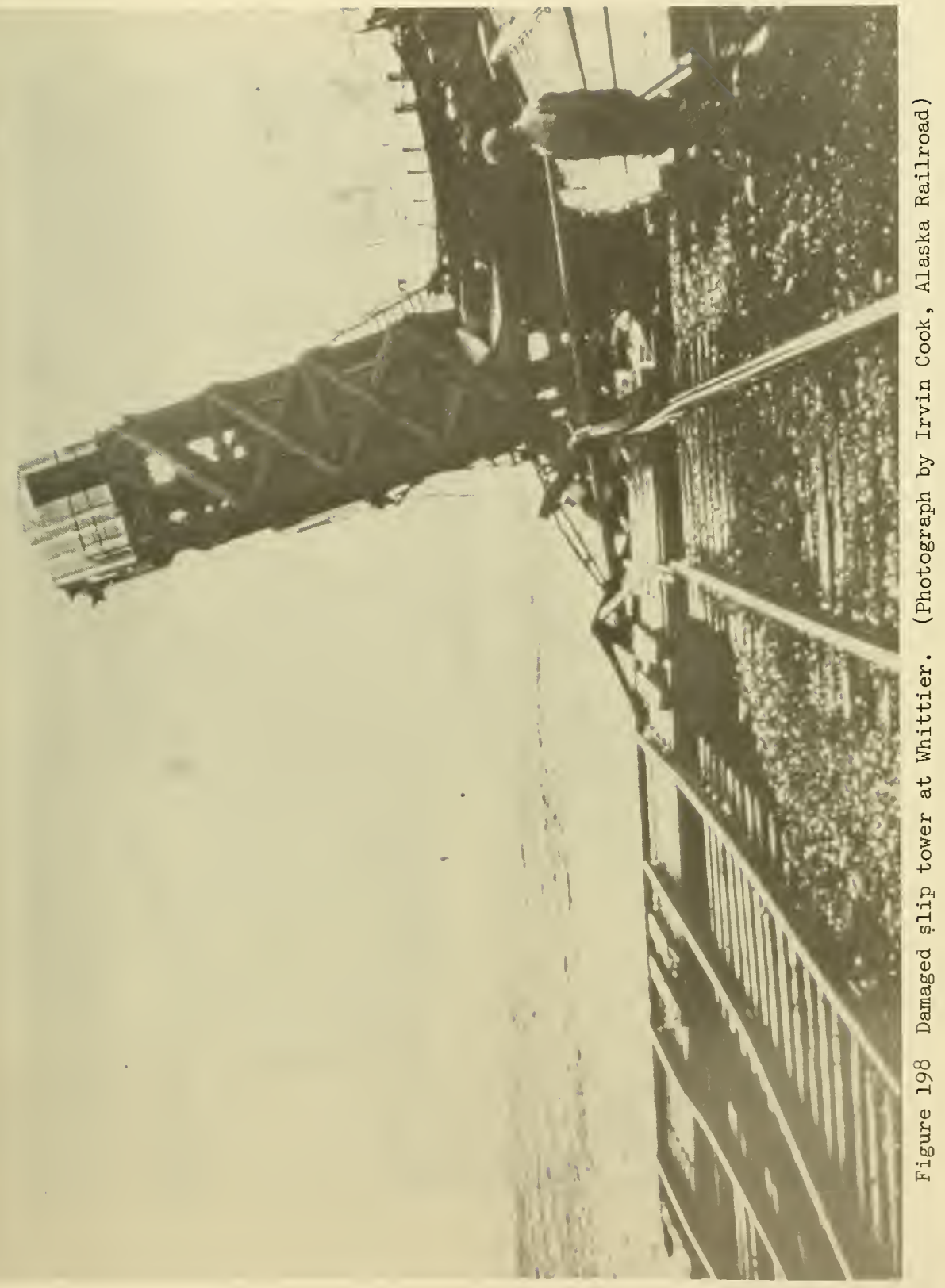




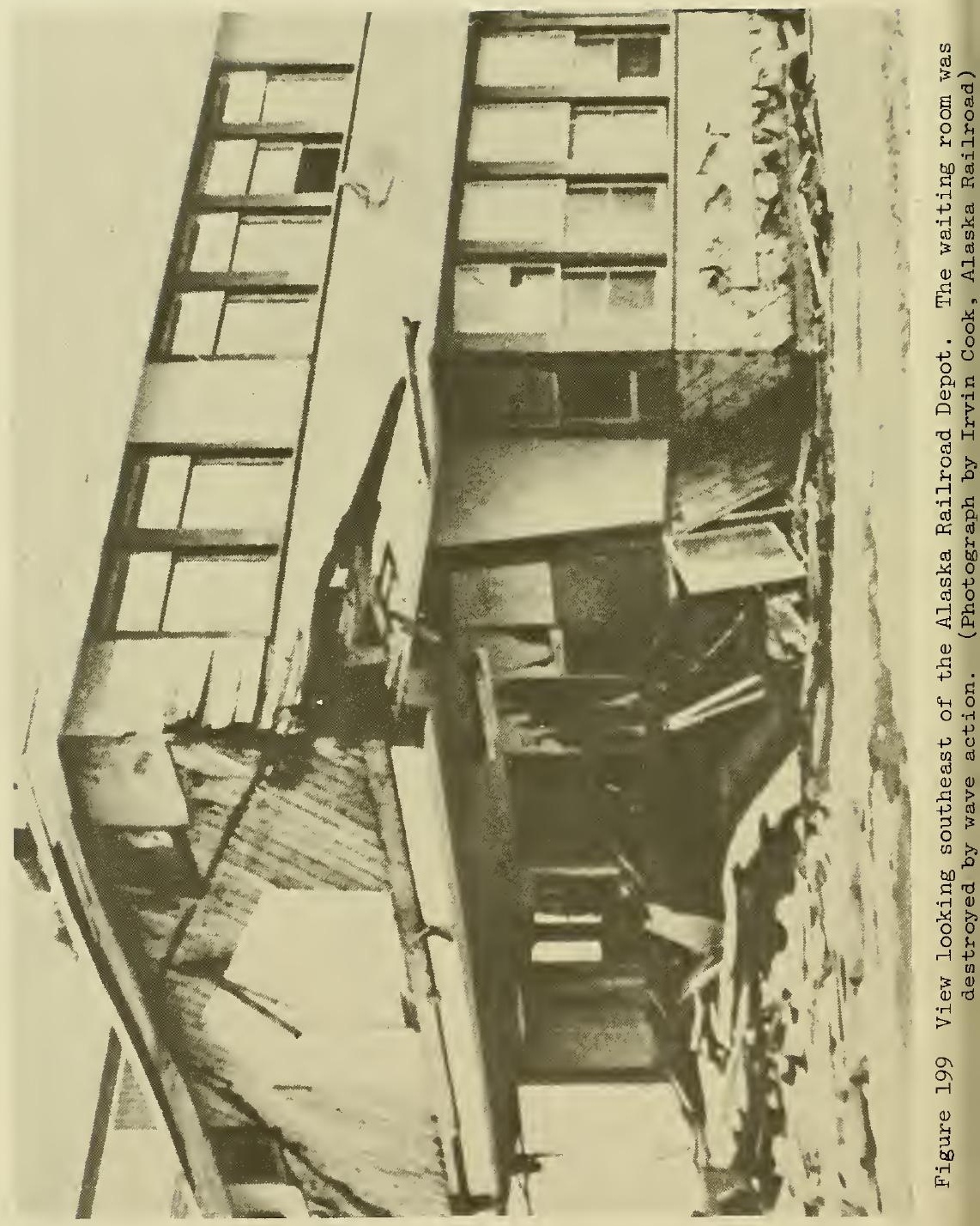




\section{Tsunami Waves and Damage at Cordova, Prince William Sound}

Cordova, on the south side of the Orca Inlet, at the mouth of ince William Sound, is an important fishing community. The bathymetry this region is shown in Figure 200. Unlike other towns of Prince lliam Sound, Cordova has shallow access routes which militate against $s$ development as an important terminal for oceangoing vessels. A tailed map of the harbor and waterfront area of Cordova is shown in sure 201.

The town, situated mostly on bedrock, suffered relatively little nage from earth tremors. One exception was the city dock, a timber ructure, that was severely shaken by the earthquake. Loosened pilings aned askew, and canneries and several other buildings adjacent to the ak were pulled 6 to 12 inches away from the dock (Chance, 1968). The Nh was elevated approximately 6 feet due to the regional tectonic upft. This upheaval caused inconvenience to many shore facilities such canneries, and posed a major problem of dredging access routes through Nly created shoal areas (Hansen, et al, 1966). The canneries had to tend their docks an average of 110 feet to reach water depths equal those prevailing prior to the earthquake (Eckel, 1967).

Most of the damage to structures at Cordova and vicinity was caused tsunamis. It is difficult from eyewitness accounts to get a clear sture of the wave sequence at Cordova. Nevertheless, an inferred rigram has been compiled in Figure 202.

Immediately after the earthquake the water started to recede from harbor leaving the boats grounded. Several subsequent long waves peatedly grounded the boats in the small-boat harbor. The periods of e waves have been estimated by different persons to have been from $1 / 2$ ar to 1 hour. Sufficient time has not been available in this study estimating the oscillating characteristics of the embayment.

A wave reported at about $7: 00 \mathrm{p} \cdot \mathrm{m}$. was apparentIy from 4 to 10 feet gh. A large recession to about 24 feet below MLLW occurred at 8:20 as corded by the Coast Guard Cutter Sedge (see below). Another big wave llowed at about 9:00. No specific height was assigned to this wave. about 10:15 the water was reported to be 10 feet below MLLW, after ich it reached a high level of about 13 feet above MLLW. The only wave at rose above the former high water line came in at about 1:00 a.m. is wave rose to a level about 3 feet over the dock, or about 20 feet ove MLLW. According to tide tables, high tide occurred at 12:34 a.m. the night of the earthquake and the predicted height was 13 feet ove MLLW.

This last wave lifted the dock, and set it off to the side of its pporting pilings. The water penetrated some 300 feet inland in the rbor area, damaged waterfront buildings, and carried away several small uses at Point Whitshed (Figure 200). These houses were floated toward rdova City; one knocked the radio tower off its pedestal. The tower, 
which stood above the high tide line, had whipped back and forth during the earthquake, but had not been damaged until that time. Another of the floating houses rammed the city dock and tore the end off the dock.

The Coast Guard Cutter Sedge was tied up at Cordova when the earthquake occurred. By 7:00 p.m. the ship was underway. However, at 8:19 it ran aground near North Rock Light, at a place with a depth of about 43 feet below MLLW, according to prequake sounding. Taking into account the 13-foot draft of the ship, the 6-foot upheaval of the land, and the tide level of one foot above MLLW, the drawdown must have been at least 25 feet. By 8:20 the ship floated free and returned to the harbor of Cordova. The Sedge left Cordova again at the time of the highest wave later in the night. In making good its escape it had to evade the same floating house that had sheared off the end of the city dock.

A fisherman who lived at Point Whitshed (Figure 200) reported that the highest wave could be heard approaching on the northwest side of Hawkins Island about 1 hour before it arrived (Chance, 1968). It approached from Hawkins Cutoff and from Cordova simultaneously, and the two waves met near the Point. The wave coming from Cordova appeared to be about 25 feet high and was breaking all across the 3-mile wide Orca Inlet. A rush of air was said to have preceded the wave (Chance, 1968).

Water particle velocities associated with this wave were apparently about 30-40 knots. It is evident that the tsunamis had both a scouring and silting effect on the sand sediments in the Orca Inlet. This is indicated in Figure 203 where soundings taken in 1963 and about 3 weeks after the quake are compared. These soundings were taken by Reimnitz and Marshall (1965) and the location of the profiles is shown in Figure 200. It is also to be noted that great change in bottom configuration occurred during the 2-week interval between soundings taken by the $U$. $S$. Coast and Geodetic Survey (a few days after the earthquake) and those by Reimnitz and Marshall. These authors have compared pre- and postquake soundings (U.S.C. \& G.S.) to indicate where deposition has taken place north of Cordova (Figure 204).

Evidence of erosion is found in the fact that dead clams in patches up to hundreds of feet in diameter littered the surface of the shoals. The most common shell in these accumulations was that of the cockle, Chinocardium nuttalzi (Conrad), which lives just below the sediment surface. Also present in large numbers were horse clam shells, Schizothaerus capax, which lives normally at a depth of about 30 inches. The accumulation of clams indicates that, in relatively large areas, the upper 30 inches or more of the seabed were planed off by strong currents. Strong currents were also evidenced by the fact that the Coast Guard channel buoys, moored with more than one ton of ballast, were moved for miles.

Figure 205 is generally illustrative of the Cordova waterfront as affected by the regional uplift from the earthquake. The damage sustained at Cordova from wave action was estimated by the Anchorage Daily News of April 18, 1964, to be $\$ 1,775,000$ (see Table E-5, Appendix E). There were no casualties in this immediate area. 


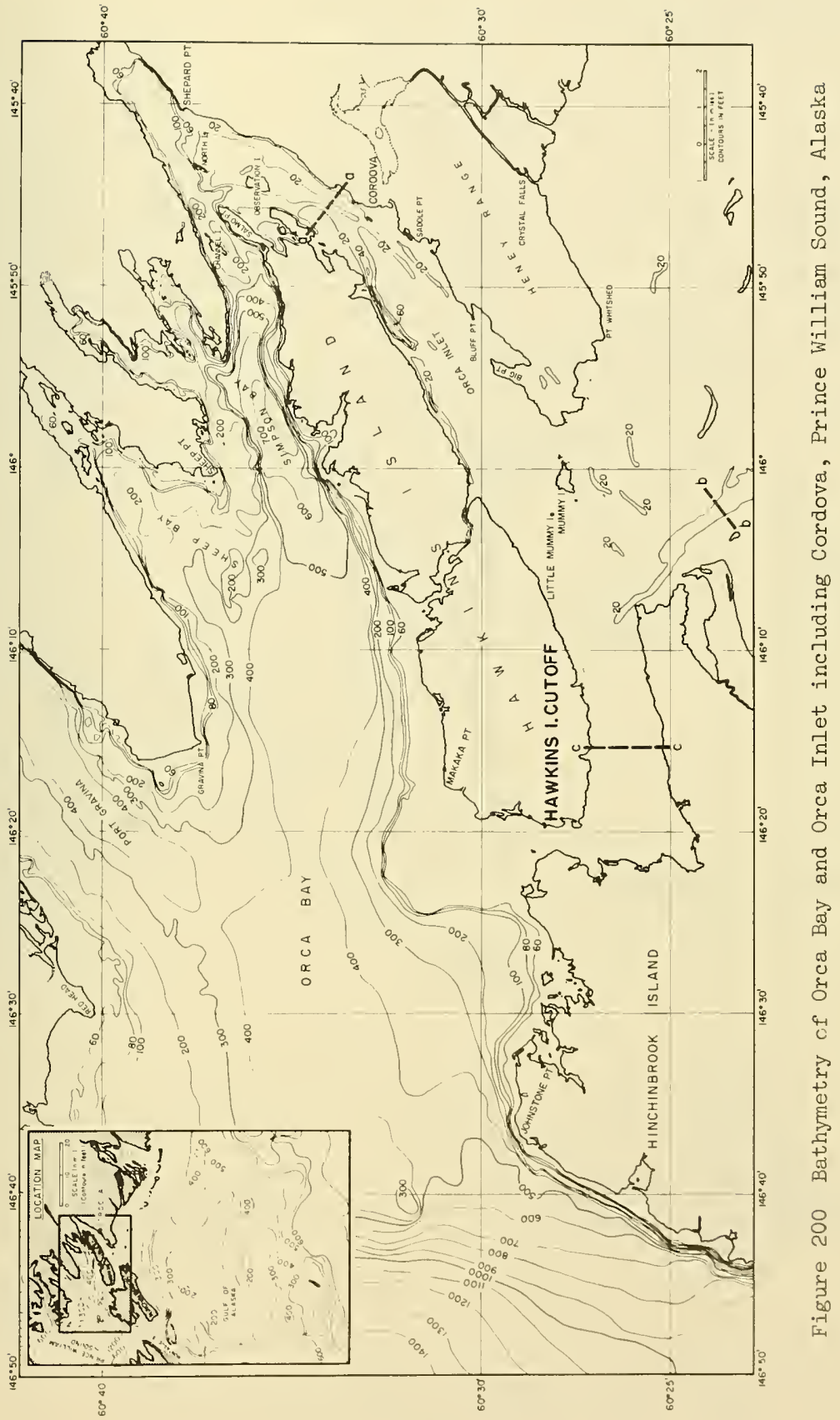




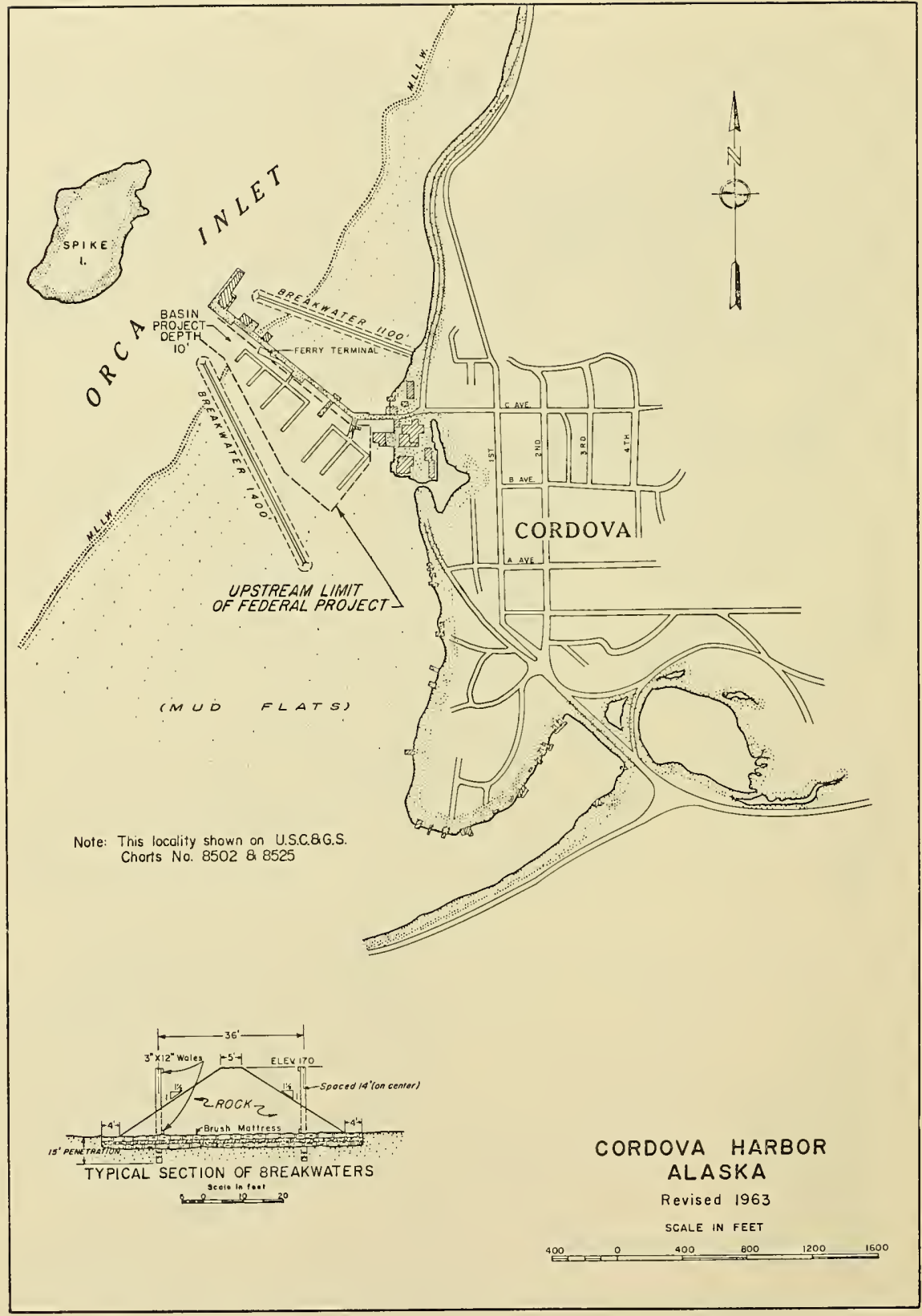

Figure 201 Cordova Harbor and Waterfront area. (U. S. Army Corps of Engineers) 


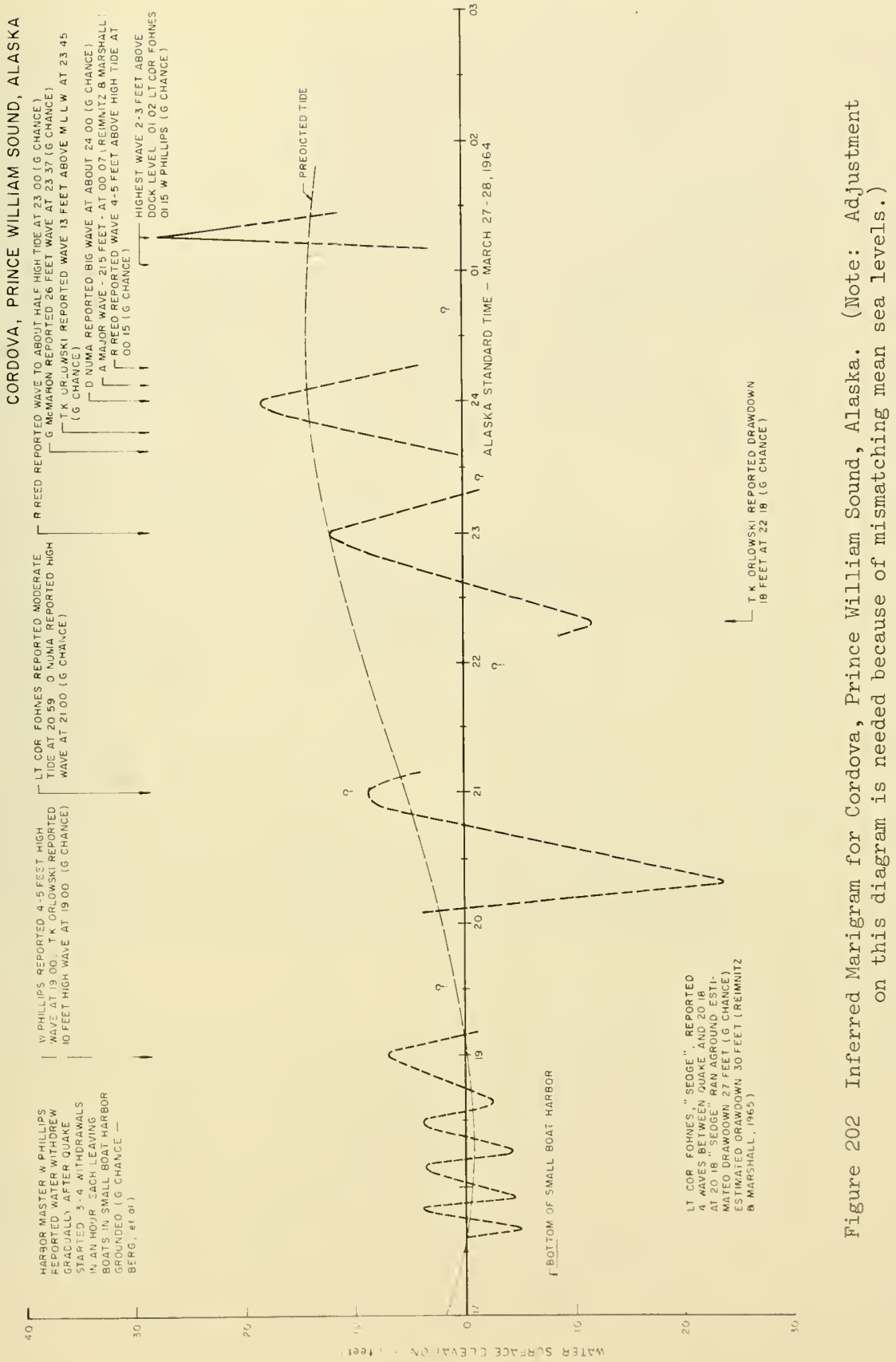



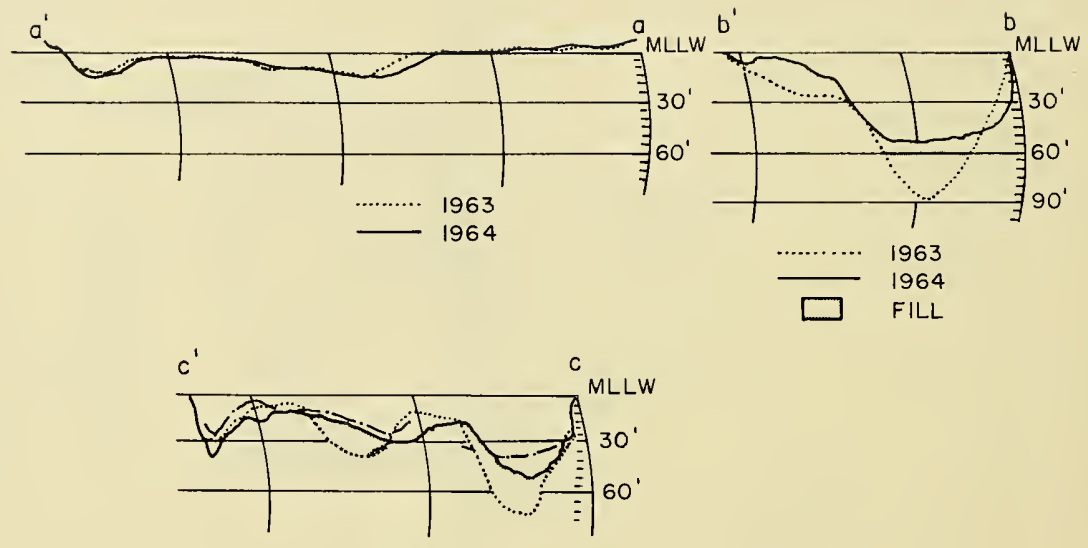

1963

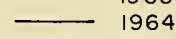

$\square$ U.S.C.QG.S
$\square$ FILL

Figure 203 Comparative Profiles, Orca Inlet, before and after Earthquake showing Erosion and Deposition. Note 10 to 15 feet erosion of channel fill in profile $c c^{\prime}$, comparing postearthquake soundings made about two weeks apart. For location of profiles refer to Figure 200. (from Reimnitz and Marshall, 1965) 


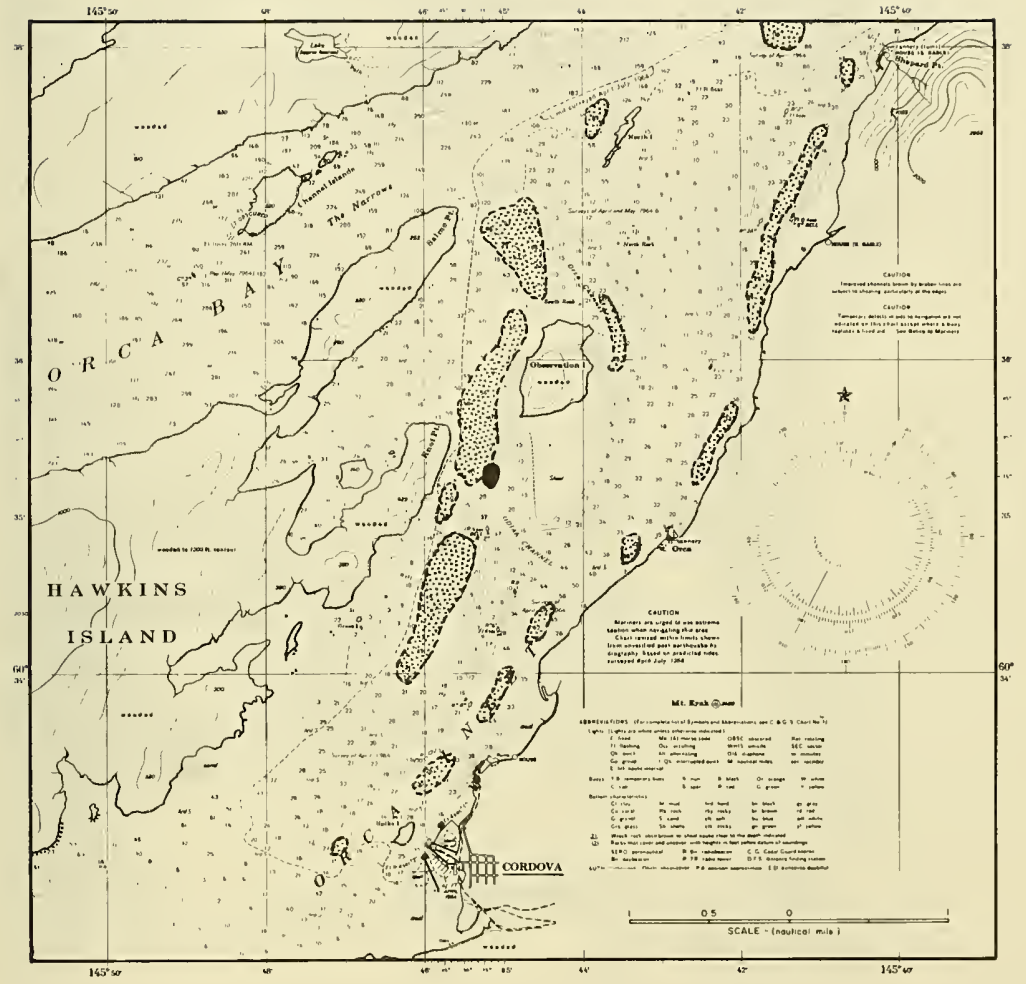

Figure 204 Postearthquake soundings of the U. S. Coast and Geodetic Survey superimposed on old chart show approximate pattern of deposition. Almost all dotted areas show at least 10 feet of deposition; some show up to 30 feet of deposition. The black spot in center indicates 26 feet of erosion. (from Reimnitz and Marshall, 1965) 


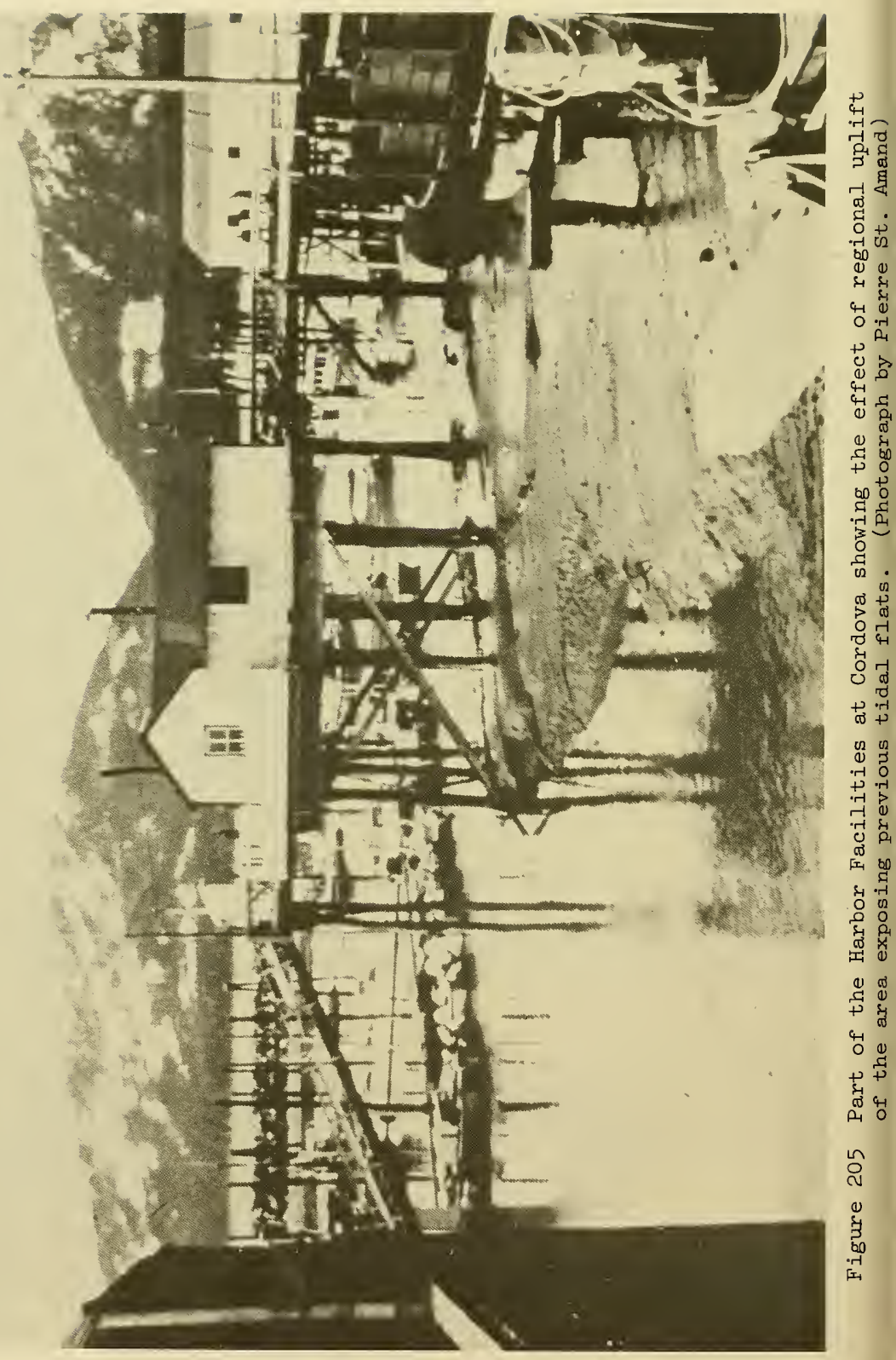




\section{Tsunami Damage Along the Canadian Pacific Coast}

We return to a consideration of the effects of the tsunami along e Pacific Coast of North America. The nature of the waves has already en discussed in Section III.

The tectonic movements in the Gulf of Alaska directed the major part the energy of the seismic sea waves in a southeast direction toward e west coast of North America. Except for the Gulf of Alaska, this astline suffered the greatest damage of any in the Pacific arena. Most avily damaged were Crescent City, California, and Port Alberni on ncouver Island, Canada.

The tsunami waves of the Alaskan earthquake were larger than any eviously recorded on the British Columbia coast according to Wigen and ite (1964). Damage was estimated by insurance adjusters at from $\$ 2.5$ $\$ 3$ million. However, according to Spaeth and Berkman (1967), the final mage estimate was more than $\$ 10$ million (see Table E-5, Appendix E).

All damage in Canada was produced entirely by the tsunami (Wigen d White, 1964). The combination of high waves with high tides caused e crests to surge above normal high water and flood low-lying areas. ildings were swept away, wharves damaged, and log booms destroyed. wever, only one case of severe bodily harm to an inhabitant was ported along the coast of British Columbia.

At the head of Hot Springs Cove near the central part of the west ast of Vancouver Island (Figure 78), an Indian village suffered severe mage. Homes were scattered into the inlet. The general store and reeling station, about a mile from the head of the inlet, suffered minor mage. The wharf was structurally damaged and fuel lines leading from e tanks on the slope behind the store were broken (White, 1966).

Nootka Sound and Esperanza Inlet, waterways to the south and north Nootka Island (Figure 78 ), provide entrances to the connecting passages d inlets surrounding the island and extending radially inland from it. e peak height reached by the largest wave of the tsunami seems to have en less in this system of inlets than for others to the north and south igure 78). No damage was reported at Tahsis or at the Nootka Mission sociation Hospital at Esperanza. At Gold River, dormitory buildings of e Elk River Company were flooded to a depth of 2 feet. Waves surged up e main street of Zeballos, moving some buildings and causing extensive ooding damage in homes and stores. The first wave reached its maximum ight there at about $11: 00 \mathrm{p} . \mathrm{m}$. Pacific standard time. A recession to proximately zero tide was reported between the first and second waves hite, 1966).

A large number of bottom fish, some dead, and others barely showing gns of life, were reported found on the surface of the water in Tahsis 
Narrows. Turbidity near the bottom, indicated by the muddy water in the Narrows, may have caused the fish to move rapidly out of their depth. Inflation of the air bladder would result from the reduced pressure and cause them to surface.

At Fair Harbor, Kyuquot Sound, the maximum wave height reached to 21 feet (Figure 78), resulting in damage to bridges across the mud flats at the head of the inlet. Only minor damage occurred at the camp of the Tahsis Company. On the Amai Inlet of this Sound, at the camp of Jorgeson Brothers, about half of the houses were shifted and some were carried up the river. The small logging camp located on floats at Cachelot was not affected by the tsunami. At Kyuquot, a small island community, a wave equivalent to a 17-foot tide was reported (White, 1966).

At Winter Harbour in an inlet near the entrance to Quatsino Sound, Vancouver Island (Figure 78), a wave equivalent to a 16-foot tide was reported by the W. D. Moore Logging Company. Log-boom ground piles were completely demolished by the first wave. A 38-foot tender was carried out of one inlet by the recession of water after the first crest, and was carried up another inlet and beached by the second crest.

Port Alice, near the head of Neroutsos Inlet, is the location of a pulp plant operated by Rayonier Canada. The maximum crest reached the height of a 19-foot tide. Log booms were disarranged. Small wharves were swept away, and some boats were lost. Little damage, however, occurred in the town or at the plant (White, 1966).

Only small surges (about 1 foot in amplitude) were reported at Coal Harbour in Holberg Inlet of Quatsino Sound. This inlet appeared to have been protected by the narrow passage connecting it to Quatsino Sound, and there was probably insufficient time for the transfer of water to the inlet in response to the relatively rapid changes in water level taking place in the outside channel.

At Klaskino Inlet (Figure 78) the maximum crest reached 19 feet above tidal datum. No damage occurred to the logging camp located on floats.

Although rough water prevented a landing in San Josef Bay, Vancouver Island, soon after the earthquake, observations were made from the air and photographs taken. In addition, reports were obtained from the Royal Canadian Air Force Station at Holberg and from the W. D. Moore Logging Company. It has been well established that large trees were swept from the north bank of the river near its entrance into San Josef Bay by the waves. Shifting of the sand bars from the north to the south bank of the river mouth was reported. A clam bed, near the small stream entering the river from the north, was denuded, and the stream was jammed with logs at the tree line (White, 1966).

In Queen Charlotte Strait, the Pioneer Timber Company at Port McNeill reported a high water crest equivalent to a 17-foot tide. Pilings and 
dolphins in the booming ground were snapped off. Log booms, loose logs, and boom boats were swept out of the bay.

In the Juan de Fuca Strait and the Strait of Georgia at the south of Vancouver Island (Figure 78) no serious damage was reported. The waves penetrated up the Fraser River and were recorded on the waterlevel gage at Pitt Lake, a fresh water tidal lake over 30 miles from the sea (Figure 78). For greater details of the above damage survey, the reader is referred to Wigen and White (1964), White (1966), and Spaeth and Berkman (1967).

\section{Tsunami Damage at Port Alberni, Vancouver Island, Canada}

The twin cities, Alberni and Port Alberni (Figure 206), are an industrial center noted for pulp, paper, and plywood. They are located at the head of Alberni Inlet about 40 miles from the west coast of Vancouver Island. As noted in section III, the inlet is a narrow channel, ranging from less than $1 / 2$ mile to about 1 mile in width, leading inland from Barkley Sound (Figure 78). Its depth varies somewhat irregularly over its length from more than 100 fathoms near its mouth to about 30 fathoms and less near its head.

The first tsunami surge began at the head of the Alberni Inlet just before midnight on the night of the earthquake, and reached its peak at 12:15 a.m., P.s.t., March 28. Fortunately, this first wave served as a warning for the second, higher wave which crested about $13 / 4$ hours later. Some residents of low-lying areas were alerted by flooding which had taken place in their homes. Others were warned by the Royal Canadian Mounted Police, by workers of the Department of Social Welfare, and by volunteer helpers. Families affected moved out of low-lying areas to find temporary shelter in the homes of friends or in public and commercial facilities made available (White, 1966).

Local civic and welfare agencies and volunteer emergency organizations quickly took rescue measures to cope with the rapidly developing disaster. On the following day in the Alberni Fire Hall, Provincial Civil Defense authorities set up headquarters for the purpose of coordinating rescue operations in cooperation with the civic authorities of the two cities.

Damage has been estimated at $\$ 5$ million in the Alberni-Port Alberni area, exclusive of damage to heavy industry and private automobiles, which probably doubles the figure (Spaeth and Berkman, 1967, Table E-5, Appendix E). Most severe loss occurred in the low-lying areas bordering the head of the Alberni Inlet and along the northeast bank of the Somass River (Figure 206). The waves surged to the head of the inlet and out across the low-lying residential area on the north side of the Somass River, carrying with them houses, logs, boats, and any other moveable objects that lay in their path. Following the crest of the waves, the recessions tended to carry the floating structures back toward their 


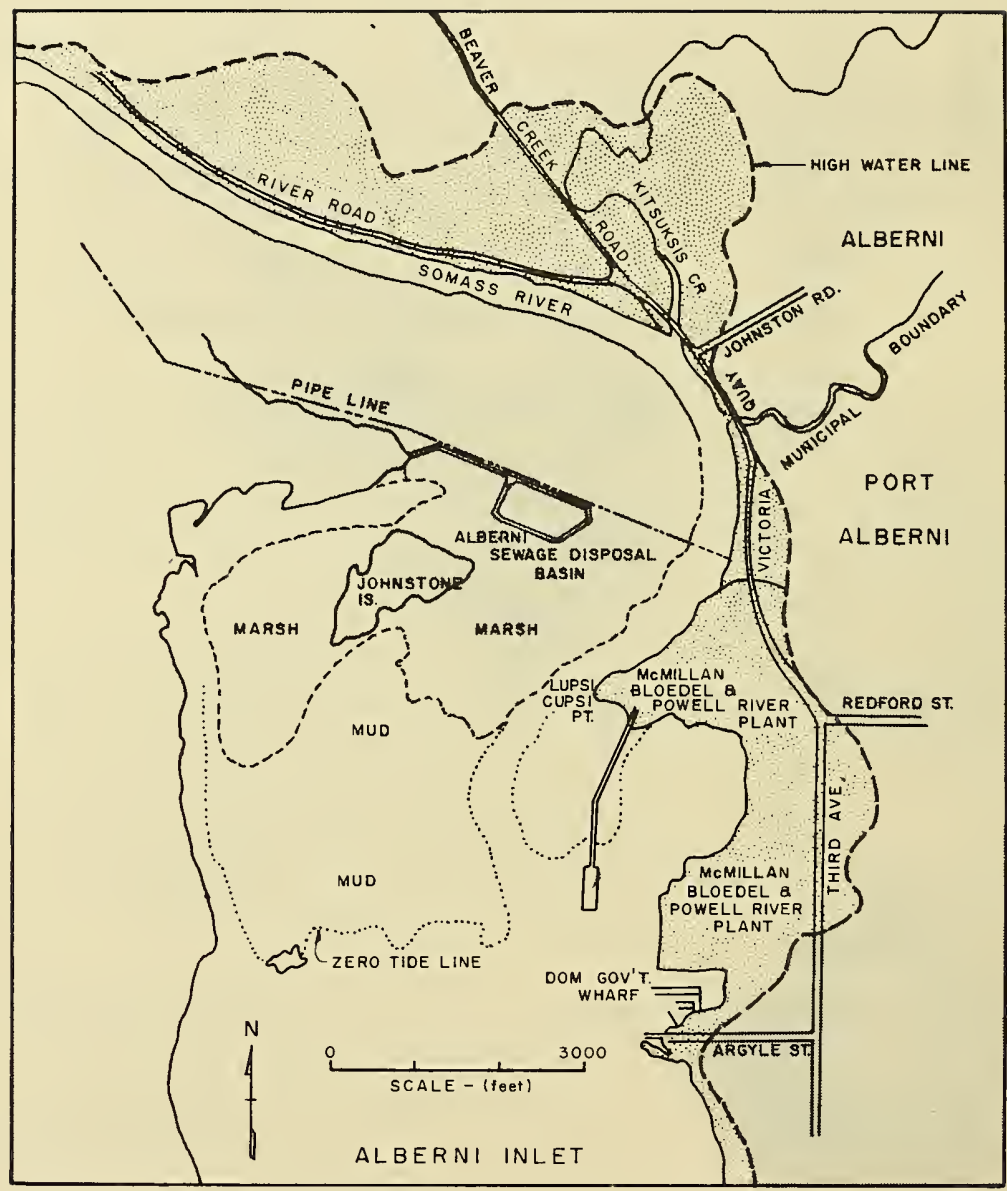

Figure 206 The Cities of Alberni and Port Alberni (from White, 1966) 
original locations. Houses and tourist cabins along River Road were shifted, and in some cases, carried back as much as 1,000 yards. Damage ranged from total destruction to minor water damage. Houses on substantial foundations with the superstructure secured to the foundation (presumably by bolts) remained in place. Observers reported floating logs and houses to have reached speeds in excess of 20 miles per hour (White, 1966).

A 54-inch water pipeline supplying the McMillan-Bloedel and Powell River Company plant was carried away by logs which collided with it as they were carried along with the wave. The pipeline was mounted on trestles, and traversed the mud flats near the head of the inlet. The sewage disposal basin in the same area was filled with logs, but no permanent damage occurred to the system (Figure 206).

Many commercial establishments along the waterfront in Port Alberni were severely water damaged. The cleanup operations were complicated by mud which accompanied the flooding. Engineering and warehouse buildings near the Canadian Pacific and Dominion Government Wharf were affected. Stocks on the lower shelves in these buildings were badly damaged by wetting. Considerable damage was done also to wharf structures as a result of the decks rising with the waves and then becoming distorted and buckled in some parts during the recession. Fisherman's Wharf was raised with enough force to fracture 6- by 10-inch, timber, cross bars on the pilings (White, 1966).

At the site of the China Creek logging operation of the McMillanBloedel and Powell River Company, a wharf was lifted off the supporting pilings, and left resting on the dowell pins. Here, log booms were not seriously disarranged by the waves. However, at the Franklin River operation, farther down the Inlet, many log booms were broken up. Large concrete anchors used to hold log markers in place were dragged out into the inlet. The deck of a wharf was carried away and some residences were flooded. Two beacons, which marked the Sproat Narrows on both sides of the inlet, were swept away together with their supporting dolphins. The transpacific submarine cable and the telephone cable, which are laid in the Alberni Inlet, were reported damaged in the vicinity of the Narrows.

Estimates of wave heights of from 2 to 8 feet above high water were reported from communities farther down the Inlet at Kildonan, Bamfield, and Turtle Islands. Logs were moved well back from the beach at Pachena Bay by waves of large amplitude. The above information is quoted almost verbatim from White (1966).

3. Tsunami Damage along the Washington-Oregon Coasts, United States

Along the Washington coast some damage was caused by the tsunami. Table B-4, Appendix B, shows highest water level at several places and lists the major damages. The total monetary loss along tre liashington coast has been estimated to be about $\$ 104,500$ (Hogan, et al, luth). 
By far the greatest damage $(\$ 75,000)$ occurred to a reinforced concrete bridge forming part of the Joe Creek State Highway north of Grays Harbor, Olympic Peninsula (see Figure 79 and Table B-4). The supporting piles sustained serious damage presumably as a result of the battering effect of $\log$ debris hurled against the structure by the waves.

Some damage was also done on Lake Union, Seattle, by seiching caused by the earthquake vibration. The disturbance caused minor damage to the gangway of the U.S.C. \& G.S. ship Patton, and snapped a mooring line on the U.S.C. \& G.S. ship Lester Jones. Minor damage was also caused to several pleasure craft along the coast, house boats, and floats which broke their moorings (Coast and Geodetic Survey, 1964).

A relatively greater amount of damage appears to have occurred along the Oregon coastline, perhaps as a result of the slight concavity favoring more direct wave attack than along the Washington coastline. This is generally borne out by the data plotted in Figure 79.

Places hardest hit were Cannon Beach City (damage $\$ 230,000$ ), Coos Bay $(\$ 20,000)$, Florence $(\$ 50,000)$, Seaside $(\$ 276,000)$, and the WaldportAlsea area $(\$ 160,000)$ (Spaeth and Berkman, 1967). A listing of the damages estimated by the Office of Civil Defense is given in Table E-6 (Appendix E). Figure 207 shows details of the inundation at Seaside, Oregon. Detailed damage information is rather scanty.

Four children, camping with their parents on the beach near Newport, Oregon, were engulfed in the waves and drowned (Spaeth and Berkman, 1967).

4. Tsunami Damage along the California Coastline

The tsunami effects along the coast of Northern California have been extensively reported by Magoon (1965). Table B-5 (Appendix B) lists the main features of the tsunamis and the damage costs along this coast. Table B-5 also gives useful information on the tsunamis of 1946 and 1960 (Magoon, 1965).

At most places the tsunamis occurred as a fast-rising tide with a maximum rate of change of level from 1 to 2 feet per minute with strong reversing ebb and flood currents. Runup levels attained are summarized in Figure 82 of Section III.

Observers at Noyo River and Albion River, however, described an almost vertical wall of water progressing upstream, apparently in the nature of a bore. At Noyo (Figure 82) this disturbance travelled upstream almost 30 miles.

Except at Crescent City, the damages from the 1964 tsunami in Northern California involved mainly commercial fishing or pleasure craft and their associated shoreside facilities. The following is quoted from Magoon (1965) with only minor changes. 


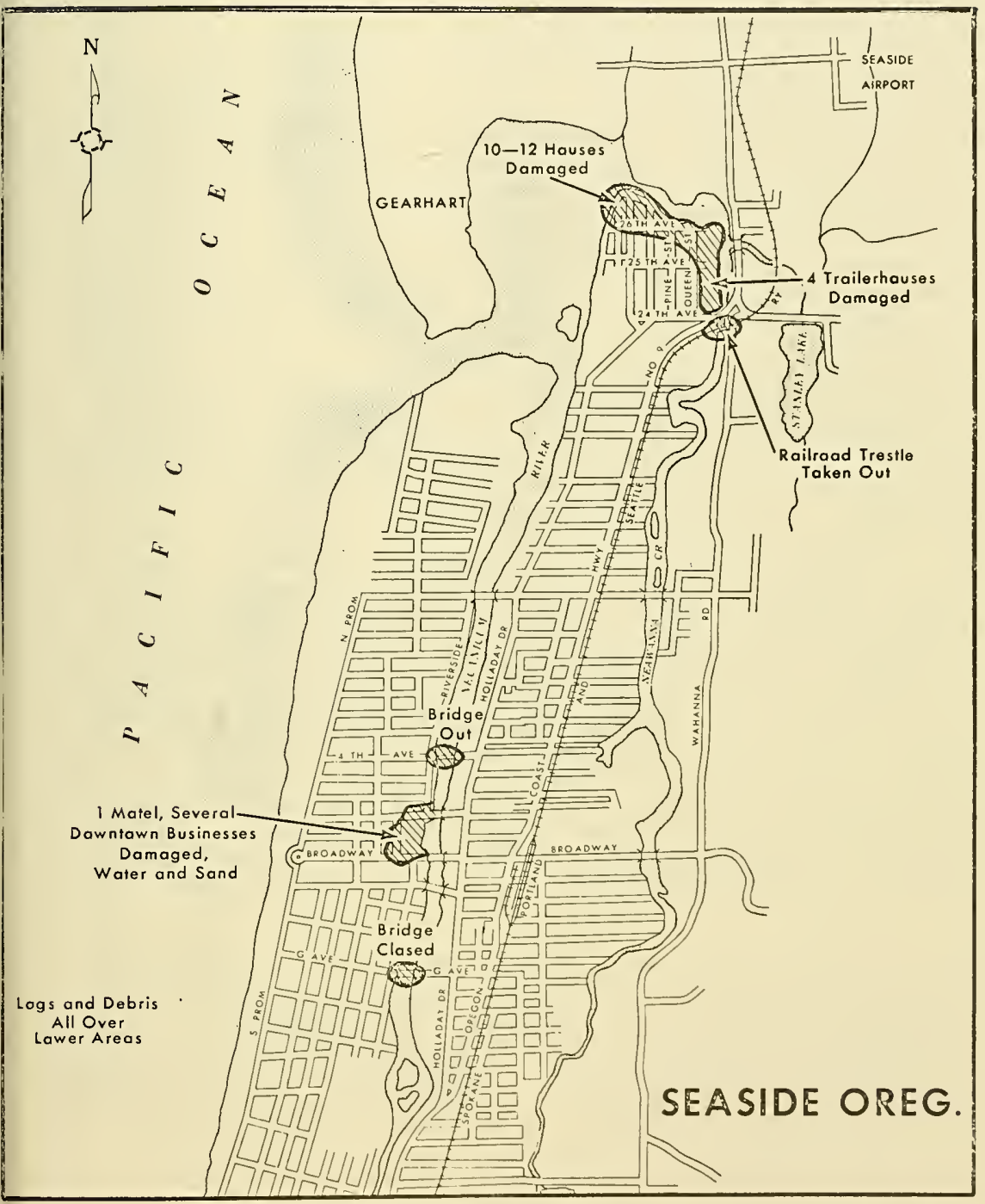

igure 207 Inundation suffered by Seaside, Oregon, from the Tsunami Waves of the Earthquake, March 28, 1964 (from Spaeth \& Berkman, 1967) 
"A typical example of a location subject to damage by horizontal currents is Santa Cruz Harbor (shown in Figure 208). During the 1964 tsunami the water level varied from a high of 11 feet to a low of about -8 feet MLLW. During the major portion of the drawdown, the water level dropped at a rate of about 1 foot per minute for about 10 to 15 minutes. Obviously, strong horizontal currents were produced by this disturbance. A floating hydraulic dredge was docked near the entrance just before the tsunami arrived. One of the early waves induced such a drag on the dredge that the mooring lines parted and the dredge was swept seaward. As it moved out the entrance, it struck the east jetty and finally sank along the entrance channel on the centerline extension of the east jetty. Shortly thereafter a 38-foot cabin cruiser struck a submerged object (presumably the sunken dredge) while attempting to leave the harbor and sank. The strong currents induced by the tsunami also caused movement of material in the entrance channel bottom. Several small floats located near the public pier were damaged from being caught against the pier and were wrecked or twisted as the water fell. With the exception of damage to the small floats mentioned above, all other floating facilities withstood the tsunami.

"Inside of San Francisco Bay both the May 1960 and March 1964 tsunamis were greatly attenuated after passing through the Golden Gate. Based on very limited data, a tsunami at Richmond on the north and Hunter's Point on the south is reduced to one-half the height at the Golden Gate. A tsunami at the easterly end of San Pablo Bay and Alviso on the south is reduced to less than one-tenth the height at the Golden Gate. Damage in San Francisco Bay was largelv to pleasure boats. The highest damage was reported from marinas in Marin County where strong currents caused boats, and in some cases, portions of floating slips to break loose. These objects attained the velocity of the moving water and cauc ad damage when they struck the other craft.

"At Noyo Harbor the entrance is restricted, but the harbor is also restricted and the full effects of the waves were felt over the entire reach of the harbor. In the March 1964 tsunami the first wave rose relatively slowly, and exhibited the characteristics observed elsewhere along the coast. The second wave, occurring about 15 minutes after the first, formed a bore-like face, about 7 feet high, consisting of a series of step-like jumps. One observer saw the bore form at the entrance and rapidly drove $h$ is automobile at about 30 miles per hour parallel to the travel of the bore, but was unable to pass it. At Noyo damage was to floats and to commercial fishing vessels that broke loose during the tsunami." 
Particulars of tsunami damage for Southern California are peculiarly scarce, considering the sizable losses listed in Table E-5 (Appendix E). From $\$ 175,000$ to $\$ 275,000$ worth of damage occurred in Los Angeles Harbor, and $\$ 100,000$ in Long Beach Harbor, but the writers have been unable to secure any documentary details on these losses. From personal communieation with Mr. William Herron of the U. S. Army Corps of Engineers, Los Angeles District, it is understood that most of the damage was sustained as a result of swift currents in the inner harbors and small-boat harbors. Details, particularly as regards effects on large vessels, are unfortunately lacking.

Tsunami damage at Crescent City amounted to $\$ 7,414,000$ (Spaeth and Berkman, 1967), and is being re-evaluated at present time. Estimated losses elsewhere along the California coast total between about $\$ 11 / 2$ and $\$ 23 / 8$ million (see Table E-5, Appendix E).

\section{Tsunami Damage at Crescent City, California}

The wave sequence at Crescent City has already been discussed in Figure 49 and Section III and some inferences were drawn in regard to the character of the waves. We quote again from Magoon (1965):

"Due to the relatively severe tsunami damage produced at Crescent City in 1964, an investigation was made of the coast on both sides of Crescent City to determine the water levels reached by the tsunami. Based on elevations determined at locations positively identified as those caused by the tsunami it is concluded that runup elevation reached by the third wave of this tsunami was essentially constant at the shore for a distance of almost 2 miles southwest of Crescent City. This high water elevation along the shore reached 20 to 21 feet above MLLW. The line of maximum tsunami inundation generally followed the $+20 \mathrm{MLLW}$ contour where the ground elevations increased to landward from the shore. This would include most of downtown Crescent City and the pasture land in the vicinity of HWM No. 5 (see Figure 209).

"A definite departure from this characteristic runup pattern was found where the ground elevation decreases to seaward from the coast and either decreases or remains essentially level landward from the coast. Under this condition, water flowed over the narrow coastal dunes or raised areas near State Highway 101 in a similar manner as water flowing over a broad weir. Apparently the quantity of water transported landward in the individual waves was insufficient in some instances to fill the low area to landward, thus reducing runup."

The runup limits found by Magoon and shown in Figure 209 could be consistent with the explanation for the high-wave effects offered in Section III(6) and Figure 73. However, either the limited extent of the survey or the nature of the coast fails to show whether the high 


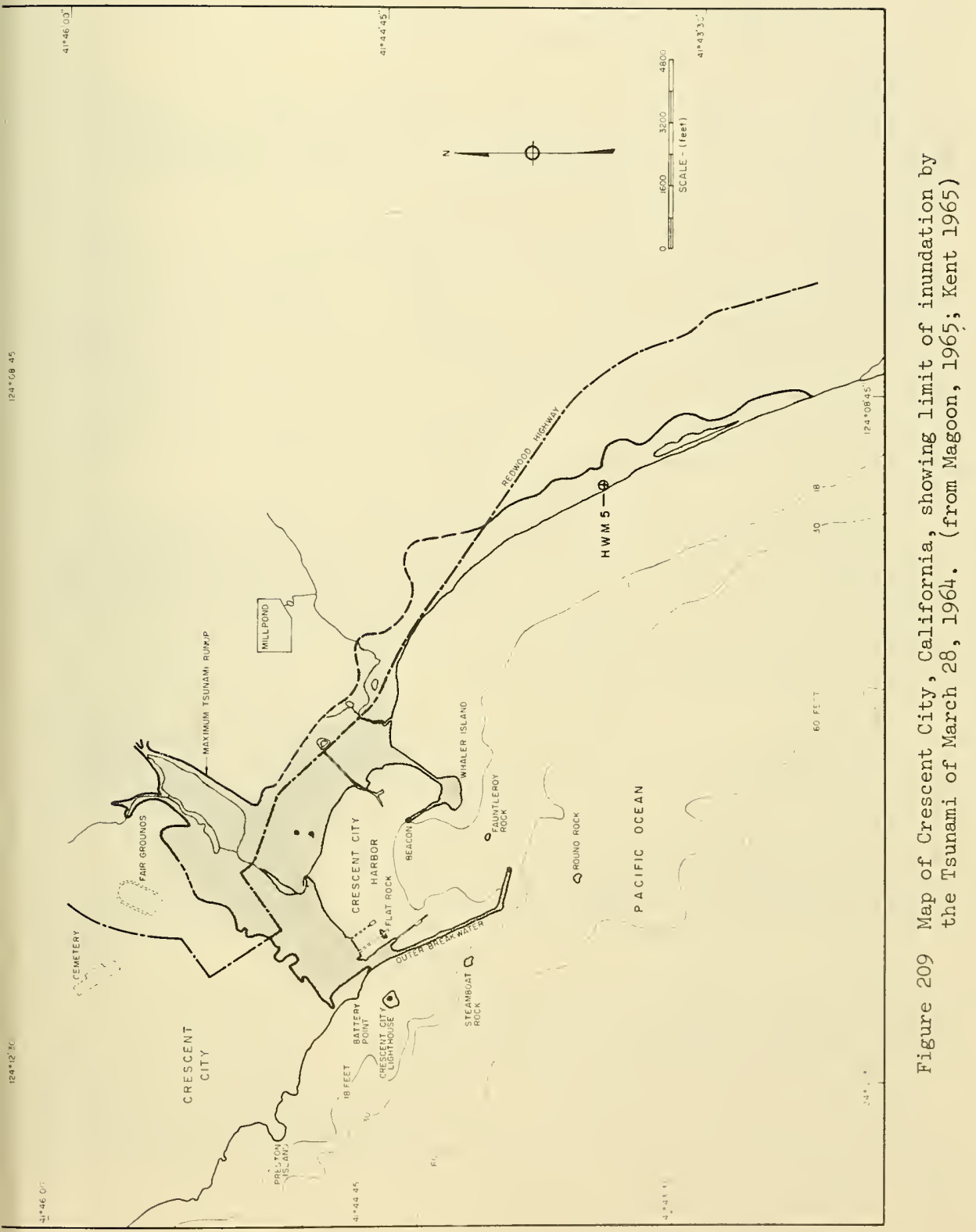


runup line continues to the south toward Patrick's Point as envisioned in Figure $73 \mathrm{~d}$.

Crescent City Harbor is one of the oldest on the Pacific Coast of the United States. Over 100 commercial fishing vessels are based here, as well as many pleasure craft and sport-fishing boats. Lumbering and timber products are the principal industries of the city's population of about 3,000 .

The first of the four damaging waves shown in the inferred marigram of Figure $49 \mathrm{e}$ caused no damage other than inundation damage. The second wave was smaller than the first. The third and largest wave was preceded by a considerable drawdown which left the inner harbor almost dry. This wave then entered the harbor more as a fast-rising tide than a bore (Magoon, 1965). Evidence for this is found in the fact that the breakwaters suffered no damage (Tudor, 1964). Locations and characteristic cross-sections of these breakwaters are shown in Figure 210a. The runup line of this third wave is shown in Figure 209. Detail runup within the city is shown in Figure $210 \mathrm{~b}$.

In the harbor 15 fishing boats capsized and 3 disappeared. In the fishing boat mooring area 8 were sunk. Several boats were washed onto the beach at the beachfront development site, and the rest were beached and capsized in scattered areas (Tudor, 1964). Figure 211 shows the litter of flotsam at the northwest end of the harbor the next day. Downcoast, the scatter of wreckage shown in Figure 212 is typical of hundreds of miles of the coastline northward in Oregon and Washington as it looked af'ter the giant waves.

In the harbor, Citizens Dock suffered severely. It was constructed in 1949, and since then, additional construction and repair had expanded and kept the dock in good shape. Figure 213 shows a typical section of the dock. The largest wave caused a moored lumber barge of immense inertia to smash into the dock (Figures 214 to 217). Adjacent to the area where the barge was moored, the dock planking of the cargo pier was pushed into piles resembling giant jackstraws. The corbels, decking, fender systems, and bollards were so badly damaged that they all needed to be replaced (Tudor, 1964).

The dock area, forward of the moored barge location, received damage to its blocking compound, ribbon fenders, and wheel guards, all of which required rebuilding. The area to the stern of the barge was slightly damaged and required some rebuilding.

The only damage to the fish pier on Citizens Dock (Figure 214) was along the centerline. Here the deck was raised about 6 inches.because of a lack of steel straps between pile caps and stringers. The commercial fish shacks on the pier were displaced as shown in Figure 218 (Tudor, 1964).

The approach to Citizens Dock was also damaged and badly twisted when, under the force of the tsunami, the deck was buoyed and the 


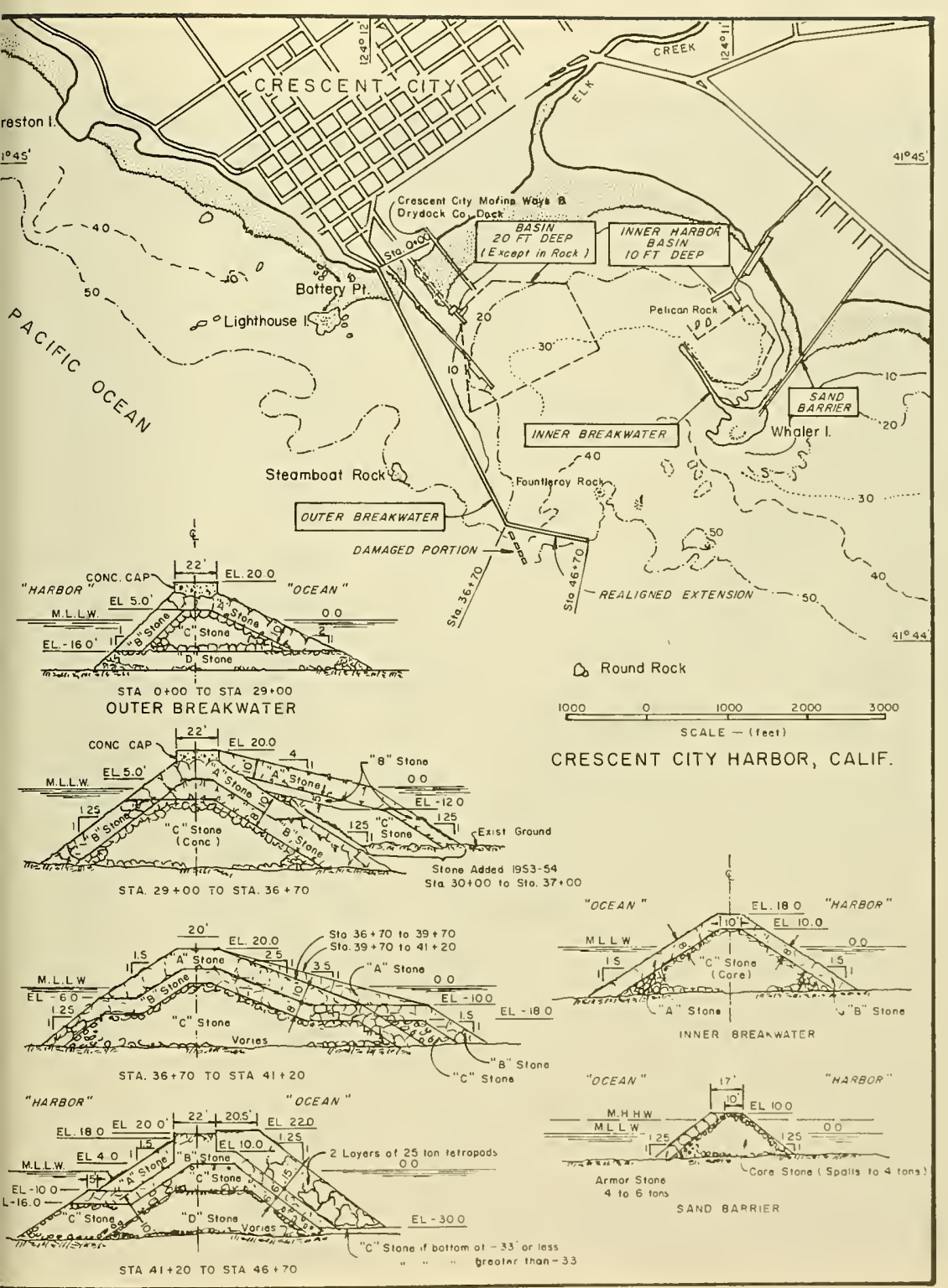

Figure 210 (a) Map of Crescent City Harbor, California, with details of breakwater construction. (from Magoon, 1965) 


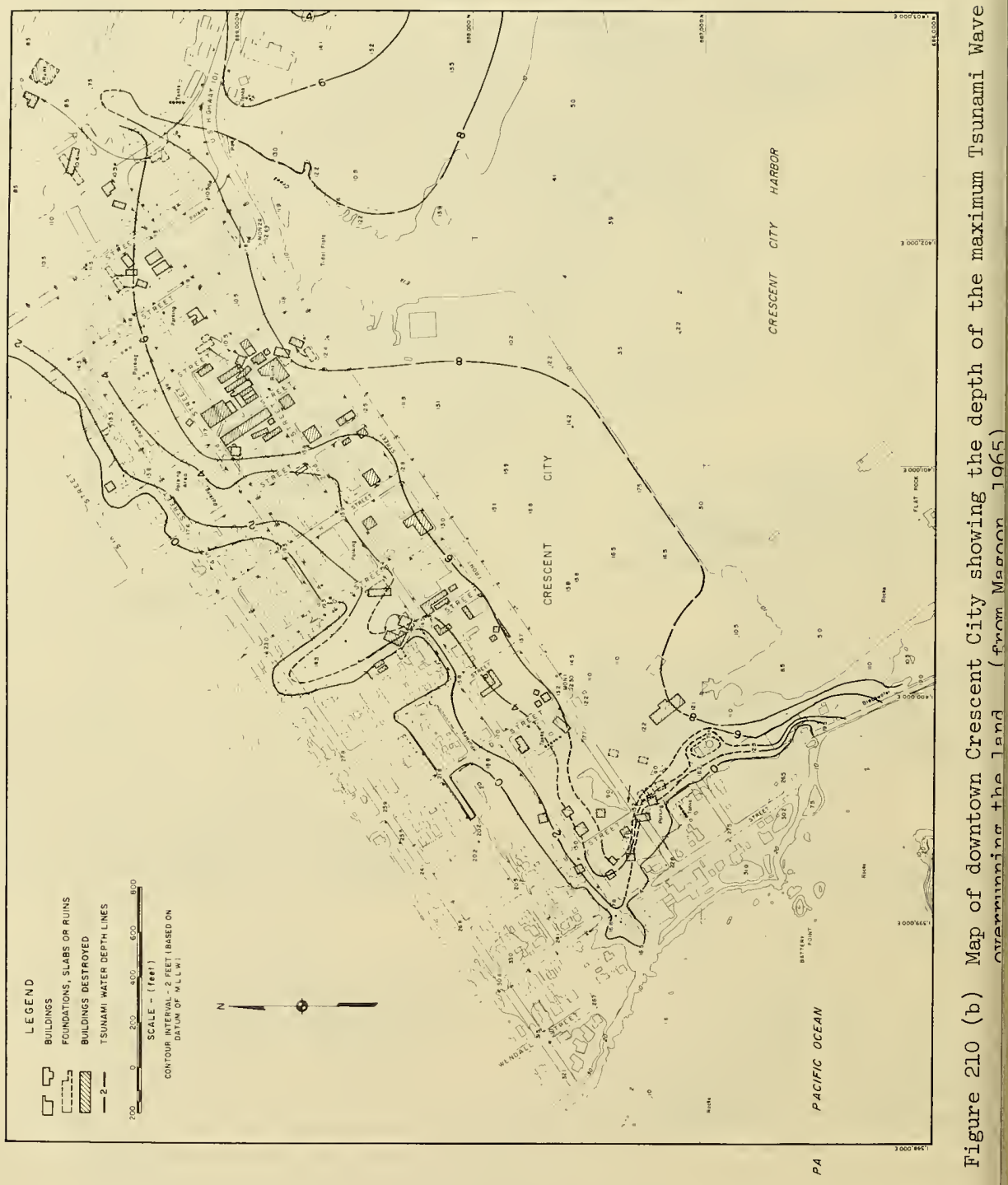




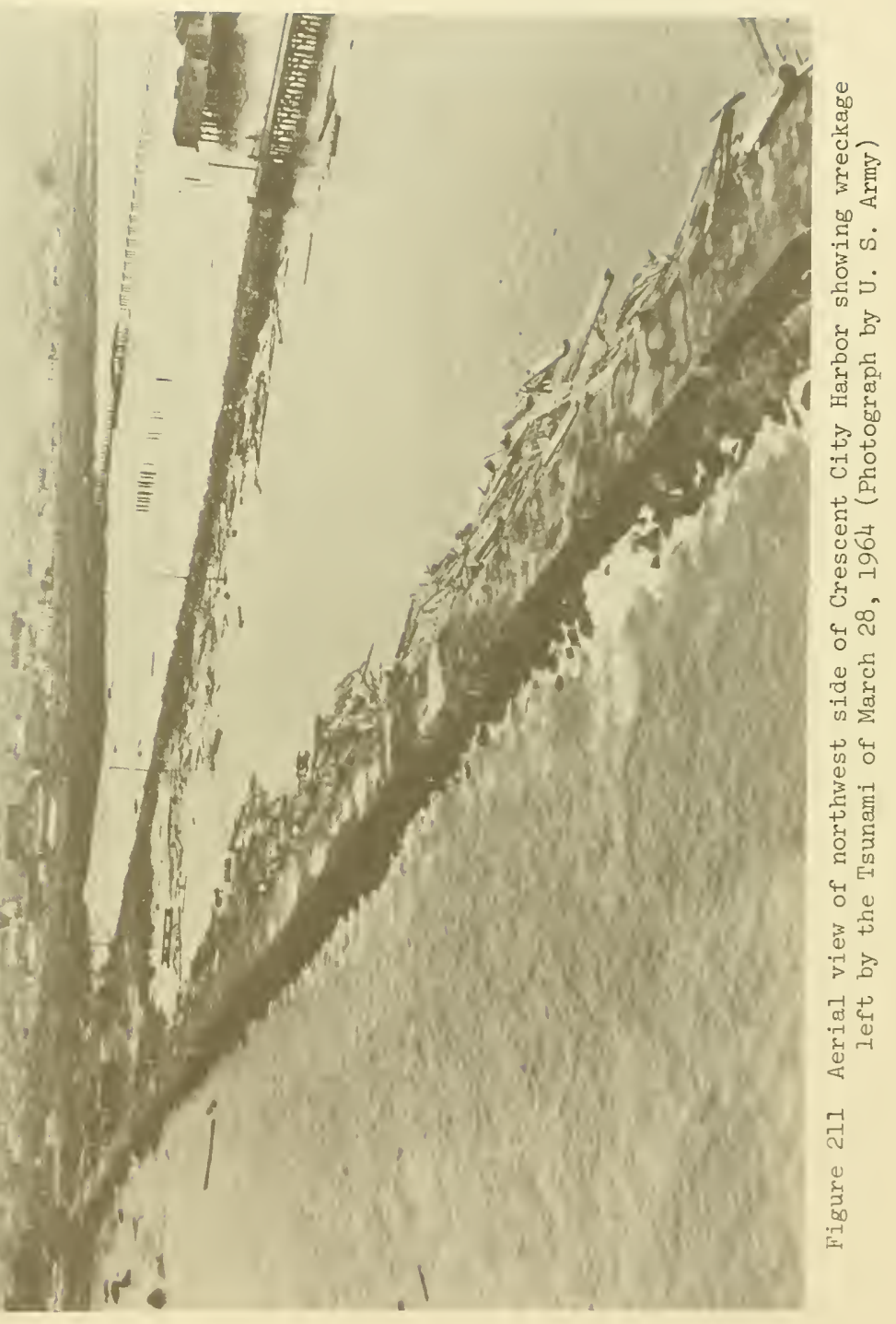




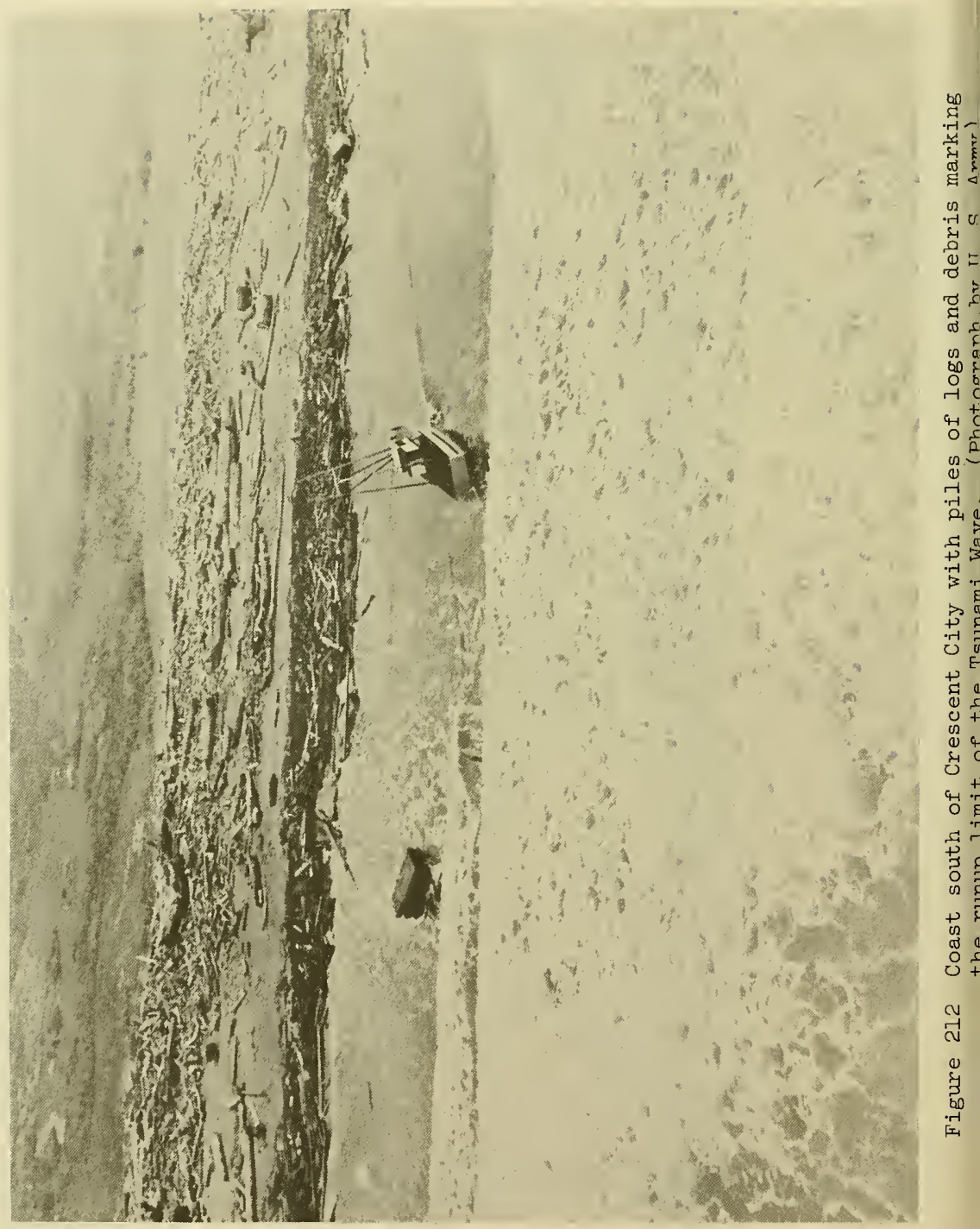




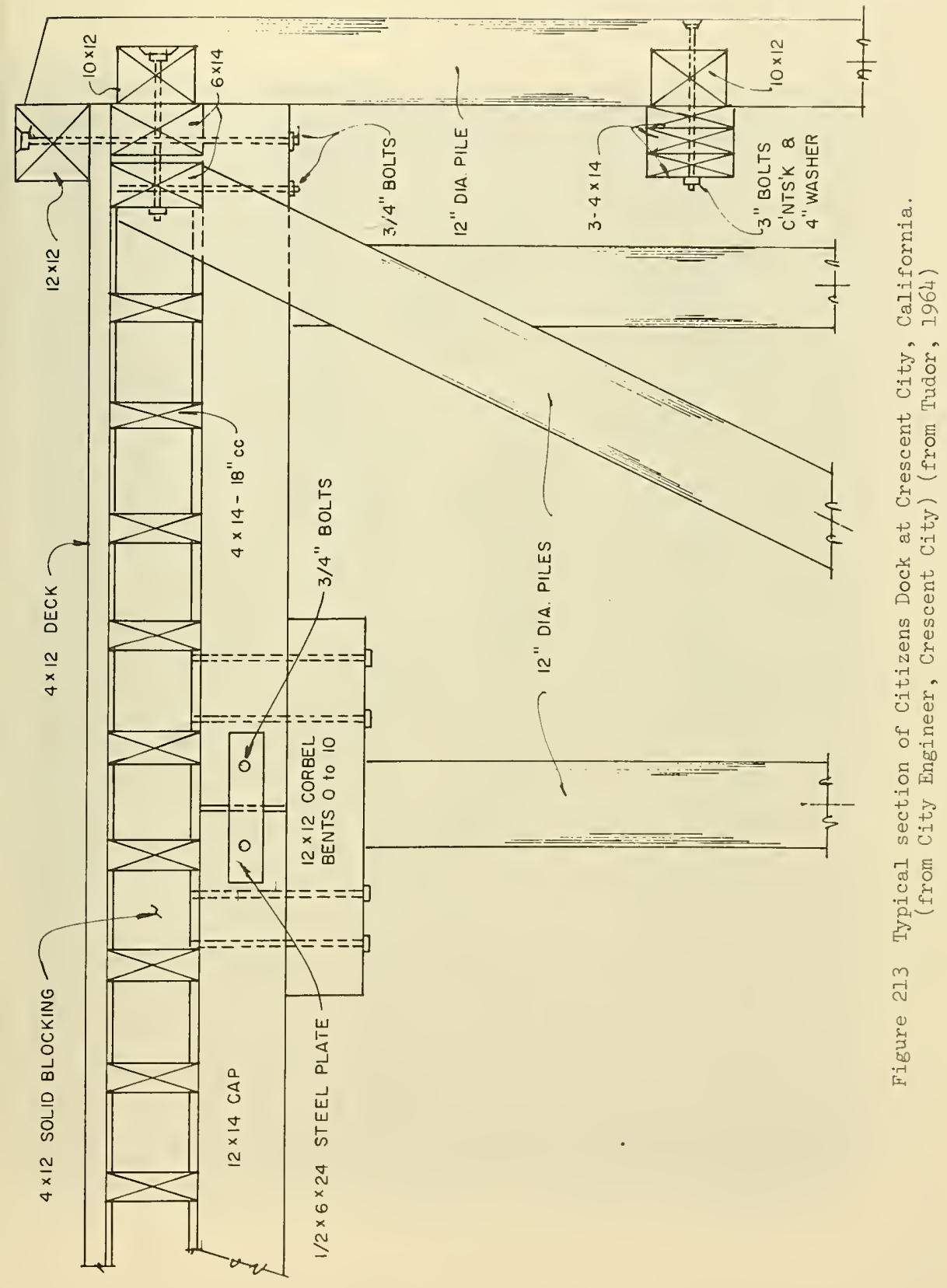




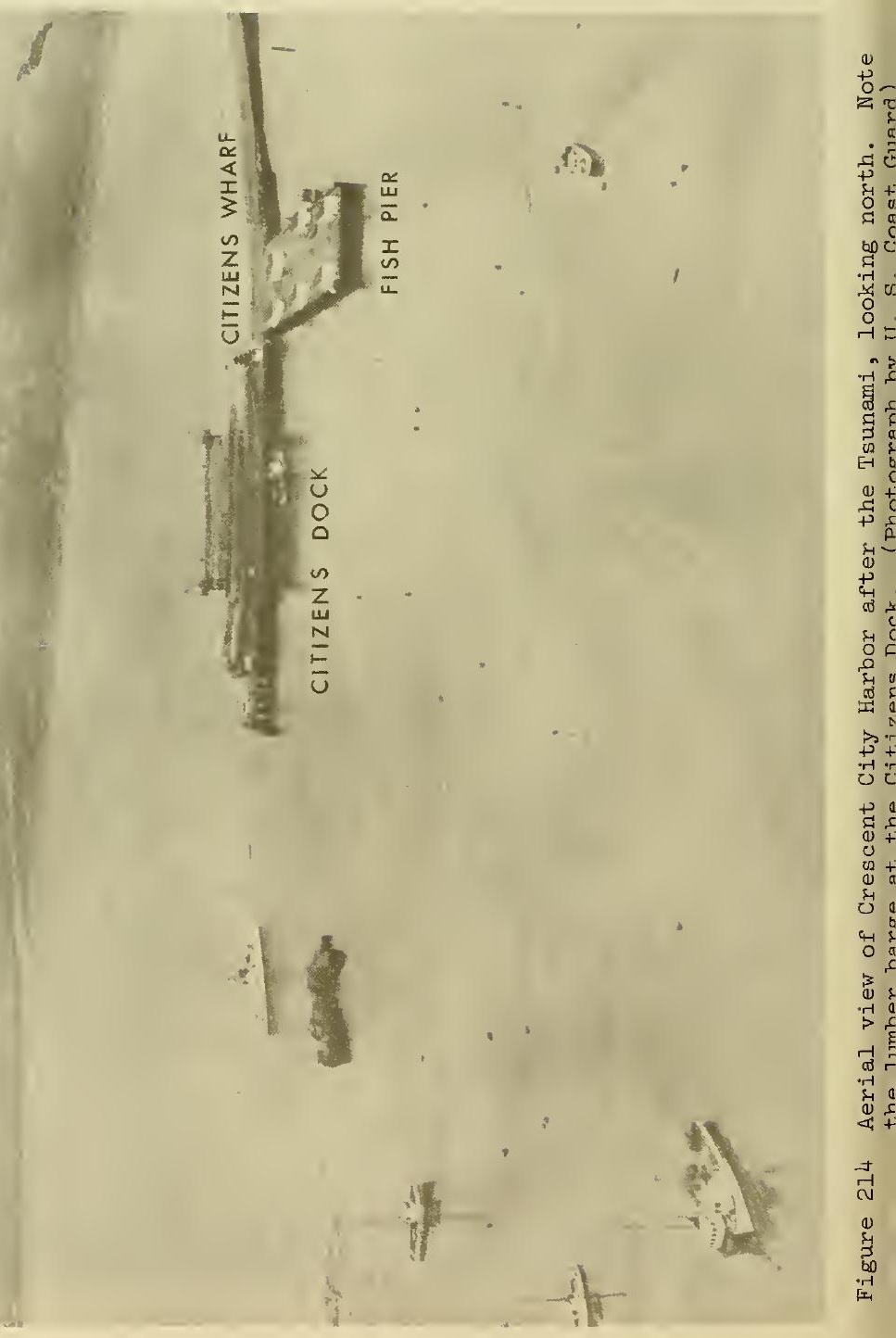




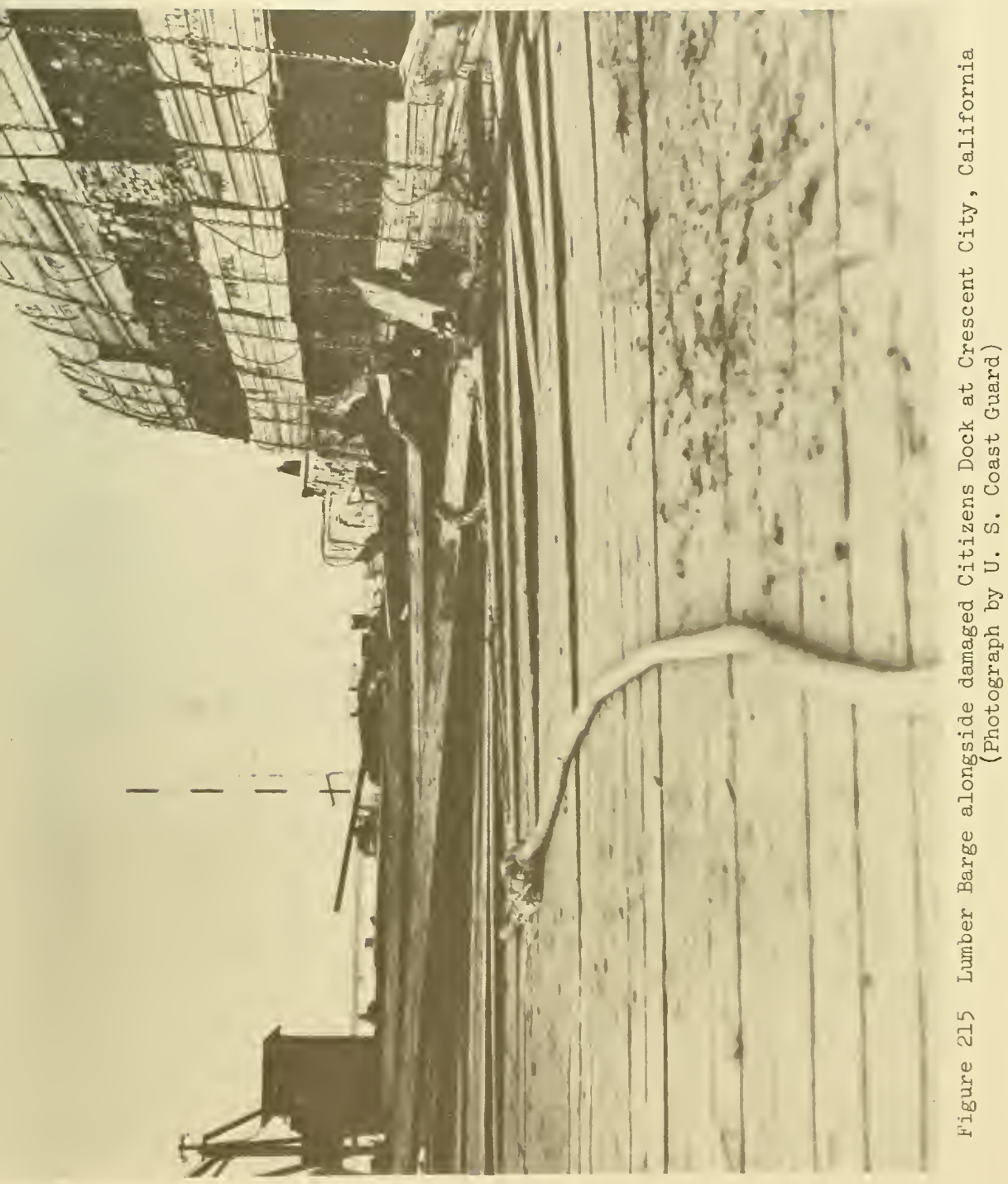




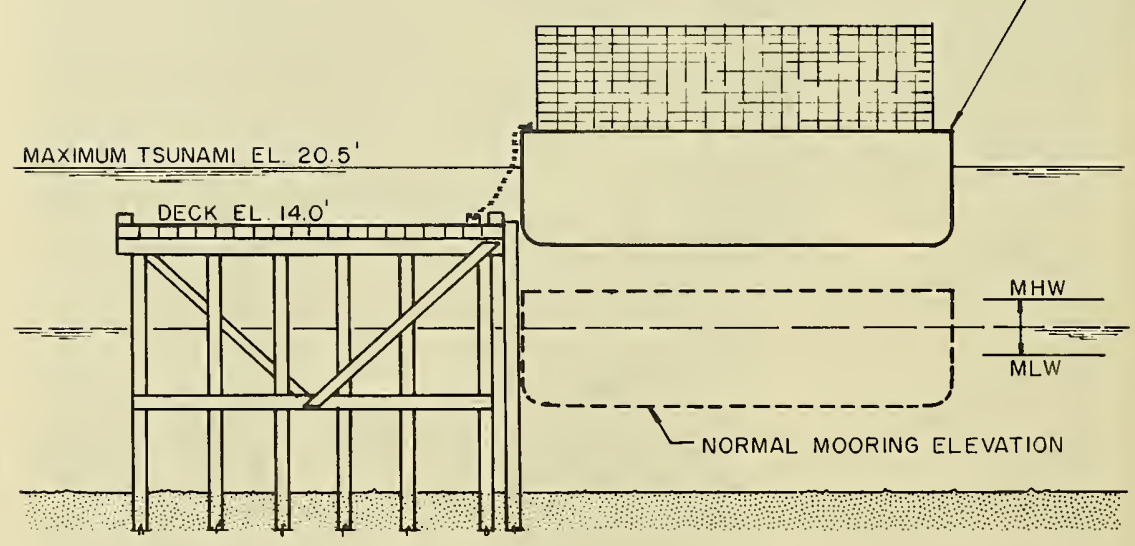

Figure 216 Cross-section of Citizens Dock showing lumber barge elevated by the maximum Tsunami Wave. (from Tudor, 1964) 

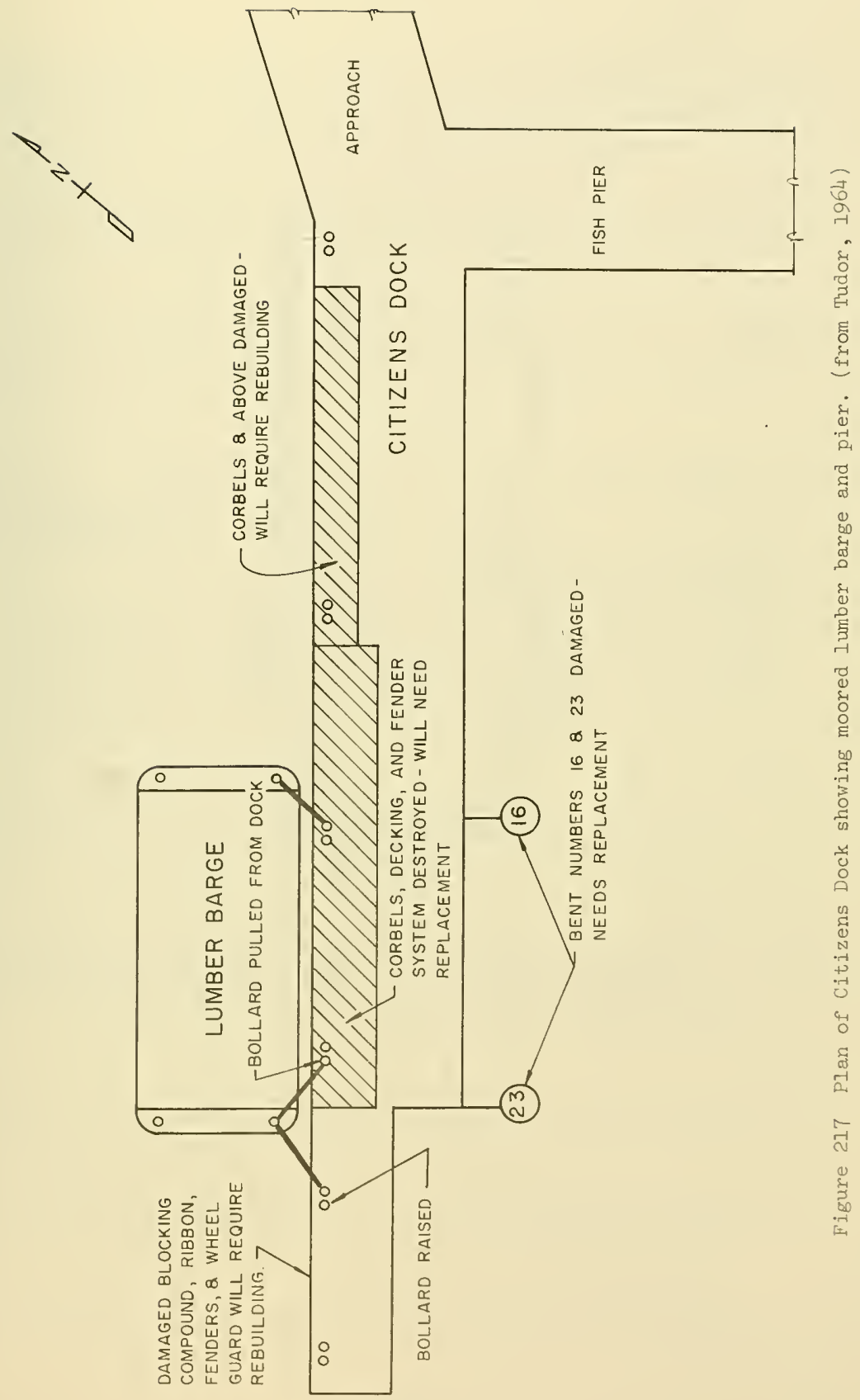


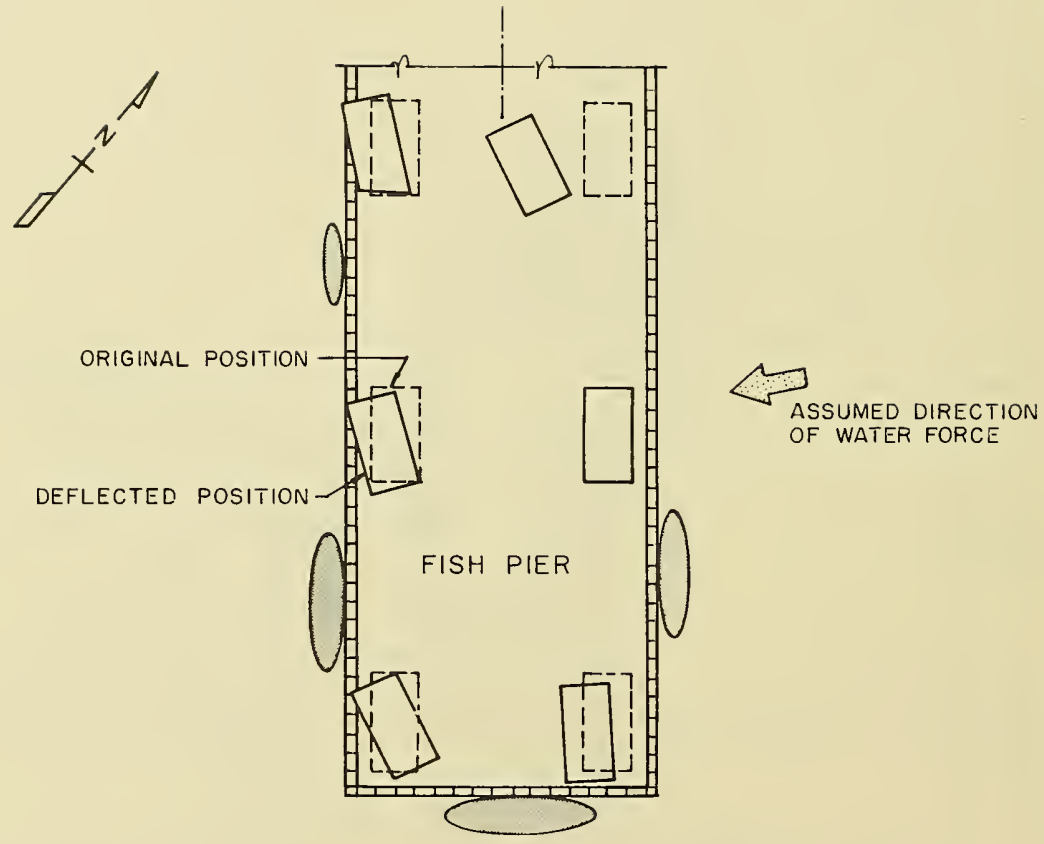

Figure 218 Fish shacks nailed to decking jolted from original positions. Shack that did not move was reinforced and had strong columns at corners. (from Tudor, 1964) 
upporting piling snapped (Figure 219). Parts of the concrete wave arrier under Citizens Dock were broken by $10 \mathrm{~g}$ impacts and water forces $s$ the harbor filled and emptied. The piles under the approach trestle, hich were encased in this barrier were carried away with the wall igure 220).

The Dutton Dock survived with hardly any damage owing to the steel traps and bolted connections between the decking and the pile caps and he abundant cross-bracing. The absence of moored ships at this dock lso helped.

The Sause Dock, abandoned for several years, was in a state of decay. he decking, secured to the pile caps only with drift pins, was lifted ad displaced. The piling and pile caps received most of the damage Tudor, 1964).

Regarding structural damage in the downtown area of Crescent City, . following is quoted from Magoon (1965).

"In searching for the reasons for the severity of structural damage at Crescent City, it should be remembered that the primary industry of the northwestern portion of the State is the production of commercial lumber. Thus the majority of buildings are of wood frame construction, many of which appeared to have been built a number of years ago. Prior to the tsunami, the coastal area to the southeast of Crescent City and also the harbor shoreline were covered with vast quantities of timber debris, including large logs and tree stumps.

"Severe damage was observed in areas where the tsunami exceeded 4 to 6 feet above the ground surface (see Figure 210). The water depth reached or exceeded 6 feet along the entire length of Front Street, and about nine blocks of the main portion of Crescent City. The majority of the one story wood frame structures in this area were either totally destroyed or damaged to such an extent that they were a menace to public health and had to be torn down. It is the opinion of the writer that the majority of the structural damage at Crescent City was probably the result of one or a combination of three conditions listed below.

"The first, and probably the most damaging, was the impact of logs, and other objects such as automobiles or baled lumber, directly on structures.

"This debris caused damage by either destroying the load carrying capacity of walls or by bending or breaking relatively light unprotected columns and allowing subsequent failure. The effect of debris is highly indeterminate. For example, the debris may build up in front of a structure to such an extent that the debris actually forms a shield against further damage, 


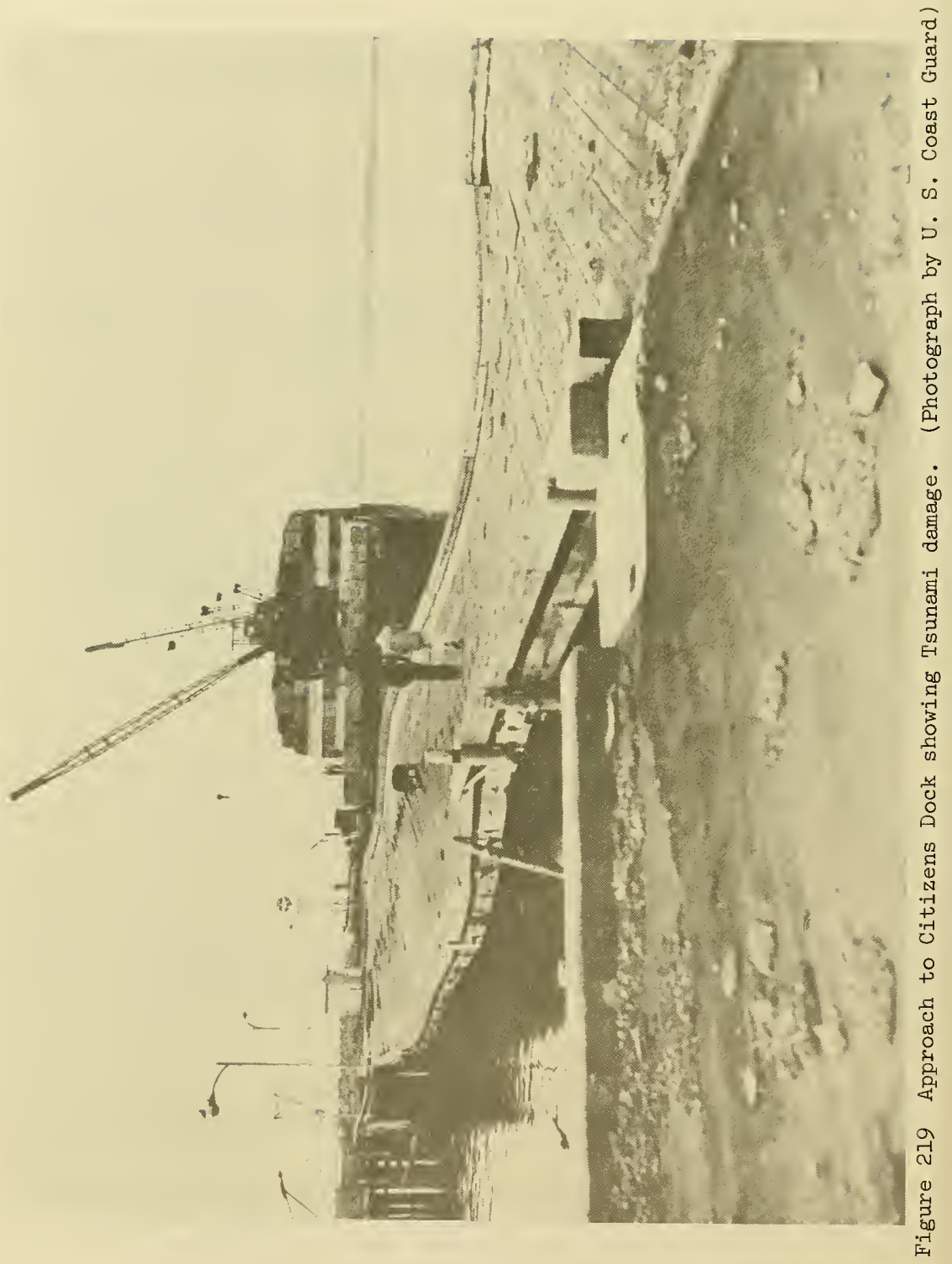




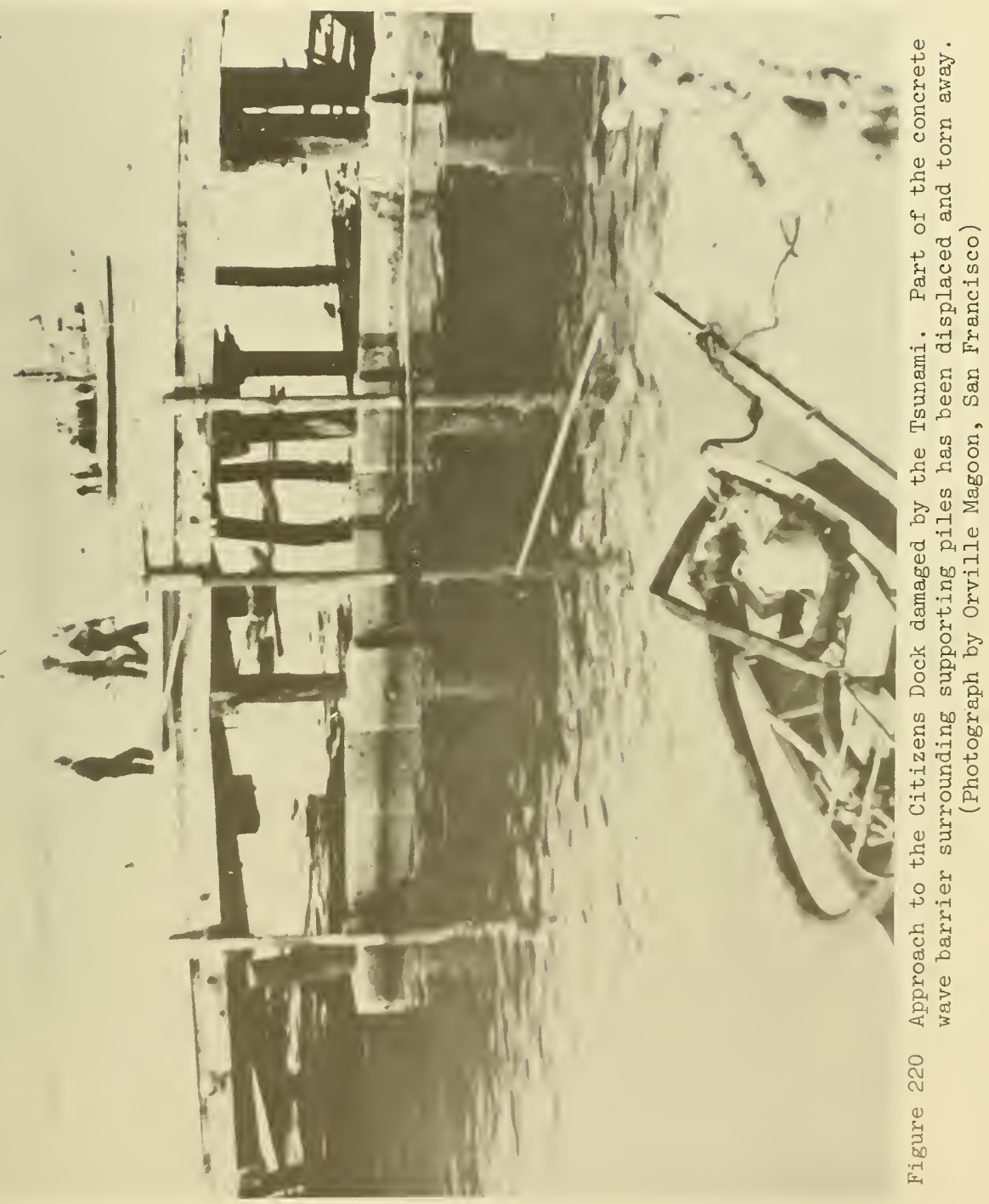


or the increased area resulting from this debris may result in sufficient force from the tsunami to cause the entire structure to be swept away.

"Structures that were sufficiently anchored (generally on noncontinuous footings) floated off their foundations and were seriously wrecked or rendered useless when they finally settled on the ground.

"The third major cause of loss was the general lack of resistance to horizontal forces in many structures, normally provided by shear walls in buildings and cross bracing in open-pile structures.

"Generally, the more substantially constructed structures, particularly multistory wood, hollow block, and reinforced concrete, withstood the tsunami. These structures required considerable internal refurbishing due to water damage, but are in use today".

Figure 221 shows, fairly typically, how buildings were moved from their original locations by the force of moving water downtown. A 25ton concrete tetrapod mounted loosely on a pedestal as a monument to the harbor development at Front Street (Figure 210) was moved bodily through a distance of about 10 feet by wave forces. Tudor (1964) calculated the velocity of flow required, and arrived at a water speed of 20 feet per second. However, the calculation is not likely to be very meaningful because it is known that the tetrapod had been pushed by a large diameter, long log which lay astraddle of it when it was found out of place.

Tudor (1964) also calculated probable water flow velocities based on the evidence of the bending of the supports of a detached light box. His calculation is given in Figure 222, in which the direction of bend would be normal to the paper. Here he tends to find a velocity of flow of about 11 feet per second and a pressure force of about 43 pounds per square foot.

The total estimated cost of tsunami damage at Crescent City was $\$ 7,414,000 .^{*}$ Details are given in Table E-7 of Appendix E. Approximately 30 blocks of the city were devastated, and the area was strewn with rubble and logs swept in by the waves. Automobiles were heaped in scattered piles, and stock from damaged stores scattered widely. Quoting Spaeth and Berkman (1967):

"The third wave picked up a gasoline tank truck parked at the Texaco station and slammed it through the garage door of the Nickols Pontiac building. The impact knocked loose an electrical junction box just inside the door and a fire started which destroyed the building, and spread back to the Texaco tank farm, which burned for three days".

* This figure is now revised upward to \$1l million (see Table B-5) 


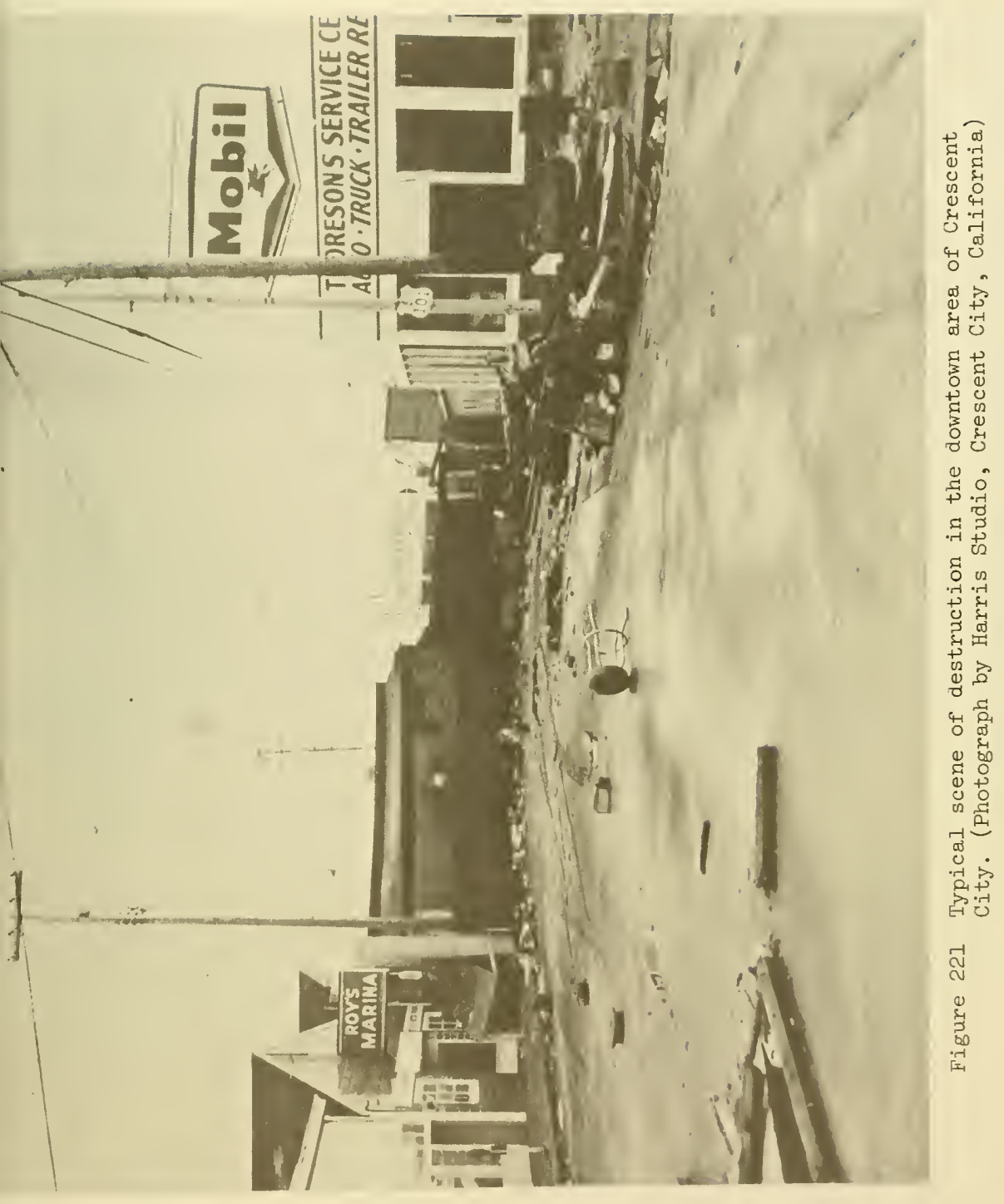




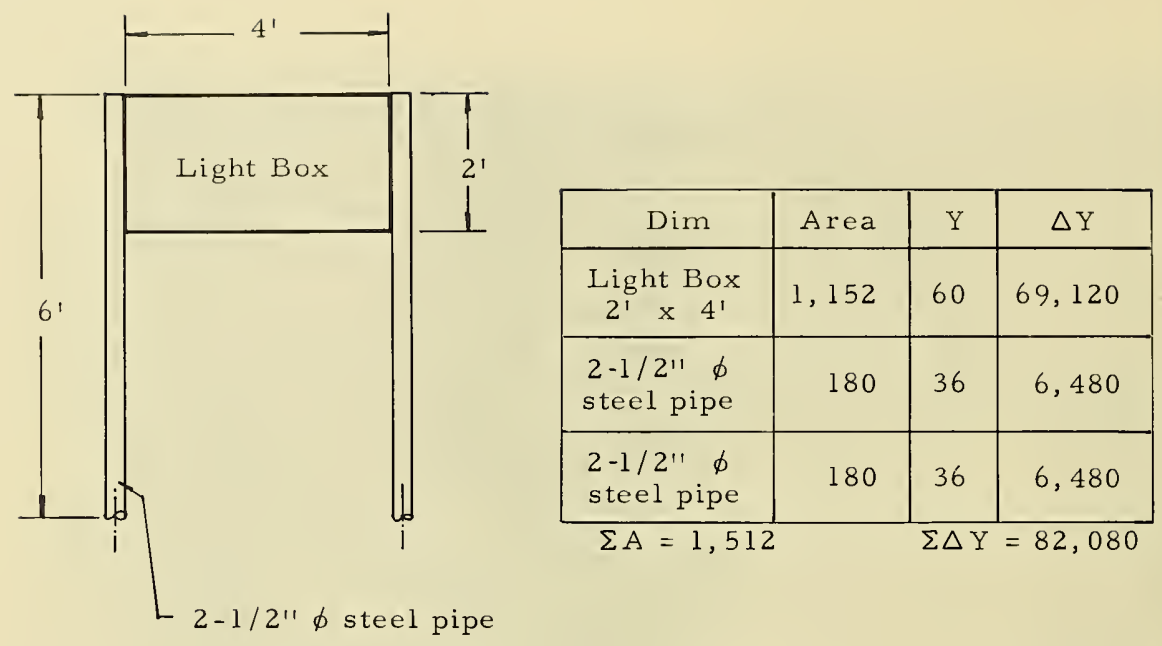

Prob: Find load per in ${ }^{2}$ which will produce yielding of post at base.

Assume: $\mathrm{S}=30 \mathrm{KSI}$

$$
\begin{array}{ll}
\text { I post } & =1.18 \mathrm{in} 4 \\
\mathrm{ID} & =2.468 \\
\mathrm{OD} & =2.875 \\
\mathrm{C} & =1.437 \\
\mathrm{C}_{\mathrm{D}} & =0.35 \\
\overline{\mathrm{y}} & =\frac{\sum \Delta \mathrm{y}}{\sum \mathrm{A}}=\frac{82,080}{1,512}=54.2^{\prime \prime} \\
\bar{y} & =54.2^{\prime \prime} \\
\mathrm{M} & =\frac{\mathrm{SI}}{\mathrm{C}} \frac{(30,000)(1.18)}{1.437} \\
\mathrm{M} & =24,600 \mathrm{in}-\mathrm{lb} \\
\mathrm{P} & =\frac{\mathrm{M}}{\overline{\mathrm{y}} \mathrm{\sum \textrm {A }}} \frac{24,600}{(54.2)(1512)}=.3 \mathrm{lb} / \mathrm{in}^{2} \\
\mathrm{P} & =43.2 \mathrm{lb} / \mathrm{ft}^{2} \\
\mathrm{~V} & =\frac{(2)(43.2)(32.4)}{(.35)(64)}=11.2 \mathrm{ft} / \mathrm{sec}^{2} \\
\mathrm{~V} & =11.2 \mathrm{ft} / \mathrm{sec}
\end{array}
$$

Figure 222 Calculation of wave force required to bend a light box normal to the plane of the diagram. (from Tudor, 1964) 


\section{Introduction}

The Alaskan earthquake of Good Friday, March 27, 1964, occurred at $5: 36 \mathrm{p.m}$. (local time) with an estimated magnitude of 8.5 on the Richter Scale. Its epicenter was probably located west of Unakwik Inlet in the Chugach Mountains of Prince William Sound at latitude $61.1^{\circ} \mathrm{N}$. , longitude $147.7^{\circ} \mathrm{W}$. Its focal depth has been given as between 20 and 50 kilometers.

This earthquake caused violent ground shaking for about 5 minutes during which time massive earth movements took place, horizontally and vertically, over a large extent of south central Alaska and its Continental Shelf. The total movement generated a train of tsunami waves which surged throughout the intricate Alaskan coastline and crossed the Pacific Ocean to the farthest reaches. Numerous seismic sea waves were triggered by submarinc slumping of unstable glacial deltas or by landslides in the fjords along the Alaskan coastline.

More remotely, the earthquake was responsible for a great number of seismic seiches developing in lakes and reservoirs throughout North America. Seismic sea waves were generated even in the Gulf of Mexico as a result of ground vibration.

The earthquake occurred at a period of low tide along the open coast of Alaska and in Prince William Sound, but at high tide at the head of Cook Inlet. The full damage potential of the tsunami in Alaska was greatly mitigated by the coincidence of the tremors and low tide.

\section{The Nature of Earth Dislocation and Movement}

The Alaskan Pacific seaboard is one of the most active seismic regions in the world, and forms part of the circum-Pacific belt of seismicity which has been responsible for a major portion of the earthquake and volcanic activity throughout the world. Statistics covering some 60 years provide the empirical relationship for Equation (1), page 5, that allows a reasonable estimate for the frequency of occurrence of an earthquake of given magnitude in the Alaskan-Aleutian are region. According to this, an earthquake of magnitude $M=8.5$, such as that of March 1964 , has about a l-in-30-year chance of occurrence within this region. This is a somewhat higher frequency rate than applies to Japan, which is also one of the most seismically active zones in the Pacific.

The region in which the earthquake occurred is typified by a serration of geanticlines and geosynclines which tend to parallel the coast of the Gulf of Alaska. The substructure of the coastal area mainly affected comprises cretaceous sediments of graywacke, folded and warped into this system, within which lie also a series of arcuate faults, roughly farallel with the coast. 
The earthquake caused a vast deformation of the land in a vertical sense about a hinge line in parallel with the structural system mentioned. Northwest of the hinge, subsidence of the land occurred; southeast, the land was uplifted. The hinge line (see Figure 33) flanks the southeast coast of Kodiak Island, skirts the southeast coast of the Kenai Peninsula, across which it also penetrates into the northwest corner of Prince William sound.

The major part of Prince William Sound was thus uplifted and was raised to its maximum extent of 33 feet along the axis of Montague Island at its southern end. Southwest of Montague Island to a distance of about 10 nautical miles intensive surveying has indicated an uplift of the seabed in excess of 50 feet. Deductive reasoning suggests that this crest of maximum uplift extends in line with Montague Island parallel to the hinge line along the entire Continental Shelf, perhaps as far as the south of Kodiak Island. The trough of the subsidence area is also roughly parallel with the hinge line and has its maximum depression of about 8 feet on the Kenai Peninsula (see Figure 8).

In adition to the vertical earth movements, the entire southcentral area of Alaska, out to the shelf edge appears to have suffered a differential horizontal displacement in directions varying from southeast in the Prince William Sound area to south and southwest in the Kodiak Island region. The zero line of this movement parallels the Knik Arm of Cook Inlet and runs south-southwest across the Kenai Peninsula. Extrapolation might suggest that it would coincide with the northeastsouthwest axis of Kodiak Island and the Barren Islands at the Cook Inlet entrance. North of this zero line, horizontal land displacement was apparently directed to the northwest ( 5 to 10 feet along the Kenai coast of Cook Inlet). Southeast of the zero line, the amount of the horizontal aisplacement appears to have reached a peak of over 80 feet on the Continental Shelf southwest of Montague Island (see Figure 16) approximately along the ridge of highest vertical uplift. The approximate extent of maximum resultant earth movement appears to be predictable in terms of earthquake magnitude (see Figure 17).

The shot-scatter of aftershock epicenters, following the earthquake, covered an area about 800 kilometers long in the northeast-southwest direction and 250 kilometers wide over the Continental Shelf and coast of Alaska. Determinations of the fault plane mechanism of the earthquake and aftershocks by various seismologists suggest the possibility that two fault planes, mutually at right angles, may have been involved. One of these planes is alomost vertical, and would, in effect, underlie the hinge line of zero vertical earth movement without physically breaking surface there. The second plane would underlie the hinge line at the surface by about 50 kilometers, dipping northwest at a small angle, and would probably intersect the seabed along the northwest wall or bottom of the Aleutian Trench.

Computations of ground deformation based on dislocation theory, in comparison with the deformations observed, tend to favor the view that 
1e main earthquake occurred as a differential thrust dislocation of pout 20 meters along the second of these fault planes. However, the ossibility that some dislocation occurred also along the near-vertical ault plane cannot be discounted. The overall length of the fault (or aults) appears to be about 800 kilometers and accords well with an npirical statistical result for world data relating fault length to arthquake magnitude, Equation (2) (p. 28).

The above inferences on earthquake mechanism and ground deformation ver the length of the fault, are supported by evidence from tsunami ecordings. By following the tsunami wave fronts backward in distance rom tide gage stations throughout the Pacific, over the time intervals etween the occurrence of the earthquake and the arrival of the first ave at the stations, it is found that the generation front of the sunami tends to lie along the Aleutian Trench axis off Prince William ound and Kodiak Island, terminating opposite the Trinity Islands, at ne southwest extremity of Kodiak Island (Figure 27). The evidence apports the view that the crest trough (dipole) type of earth deformaion was largely sustained at the magnitudes measured in the region of ontague Island, along the entire length of the fault.

The areal extent of the tsunami generation region conforms well to empirical statistical result based on Japanese data (Equation (3), 39) relating equivalent diameters to earthquake magnitude $M$.

Some speculation is made regarding the fact that the Alaskan earthuake occurred on Good Friday, near sunset and shortly after the vernal quinox. At this time the earth, moon, and sun were in opposition at yzygy and ocean tides were at maximum range (springs). A sampling of ix other great earthquakes, whose magnitudes exceeded 8.2 , shows that 11 occurred when the relative sun-earth-moon positions were at or near yzygy, either in opposition or conjunction. From these data it is nferred that earth-tides, which are maximum under these conditions, as lso oceanic tides, are perhaps important triggering loads for releasing ent-up seismic strain in the earth's crust.

The actual time of occurrence of the Alaskan earthquake conforms o the time at which earth-tide would have produced maximum tangential ompressive stress in the earth's crust in an almost due north-south irection at the epicenter, in keeping with the observed directionality f the inferred thrust faulting on the low angle fault plane. The fact hat the oceanic tides were at their lowest in Prince William Sound and long the Gulf of Alaska coastline, and at their highest at the head of look Inlet, could have provided an important additional triggering load und moment for unleashing the earthquake.

Attention is drawn to a peculiarity of a water level record for 'ensacola, Florida, which, besides showing impulsive type decaying sscillations at a time that seismic Love and Rayleigh waves could be expected to reach Pensacola from the hypocenter of the earthquake, also hows similar water oscillations occurring prior to the earthquake. 
It is speculated that these prequake water oscillations may have been evidence of a forced vibration of the earth in its second (football) spheroidal mode, induced by the lunisolar earth tides. Seismic seiches induced by the earthquake in lakes, canals, and ponds reached their greatest amplitudes in the Gulf of Mexico region, suggesting that the epicenter of the earthquake formed the antinode of a binodal (football) mode of free oscillations of the earth which followed the earthquake. The epicenter would also have been on the antinode of the forced binodal (football) mode of earth vibration caused by the lunisolar earth tides at the time of the earthquake.

\section{Generation, Propagation and Dispersion of the Main Tsunami Waves}

The emergent picture of the earth deformation along the length of the fault is that of a skew thrust and dipole heave which would have had the general effect upon the sea of a gigantic wave paddle.

Attempts are made to envision the magnitude and nature of the ground movement in profile along typical cross sections transverse to the Continental Shelf between Prince William Sound and Kodiak Island. From these the heights of the initial tsunami wave are inferred to lie between 10 and 20 meters with greatest heights occurring southwest of Montague Island and perhaps at the extremity of the fault length, south of the Trinity Islands and Kodiak Island, where a high center of strain release has been detected. These heights are generally consonant with the runup heights of waves observed along the coasts of Kodiak Island and the Kenai Peninsula (allowing for some amplification). This range of wave heights accords well with statistical trends of relationship between tsunami wave height near the source and earthquake magnitude as established from Japanese data (see Figure 41). An approximate prediction formula relating initial tsunami height $\mathrm{H}$ to earthquake magnitude $M$ is thus available in Equation (6) ( $p .62)$.

All tide gages operating in the Alaskan coastal region (at Kodiak and Seward) were rendered inoperative by the earthquake and sea waves. Definitive knowledge of the types of waves encountered in the earthquake region would be almost entirely lacking were it not for the log of wave heights and times kept by Lt. C. R. Barney of the U. S. Fleet Weather Central at the Naval Station, Womens Bay, Kodiak, and for the observations of C. R. Bilderback of wave runup heights at Yakataga. These data, plotted against recorded time, make it possible to infer equivalent marigrams.

Subjective analysis of these marigrams (Figure 38) leads to the conclusion that the dominant wave system to strike the coastline of Kodiak and Alaska and penetrate Cook Inlet was a modulated beat of very long period waves ( $T \simeq 1.8$ to 2.5 hours) whose first wave was a negative trough created by the subsidence of land northwest of the hinge line of zero vertical earth movement. These waves, however, were overridden by large amplitude modulated waves of somewhat shorter period $(T \simeq 80$ to 110 minutes) representing apparently the second mode free oscillations 
$f$ the Continental Shelf. They appear to have been underlain also by he fundamental free oscillation of the shelf $(T \simeq 5$ hours). The echanism of generation envisioned is that the initial forced dipole sunami immediately divided into two gravity wave systems along its approximate) 650 kilometers front, one of which propagated seaward in southeasterly direction as an initially positive wave, and the other orthwestward as an initially negative wave. The pseudoperiod of the orced dipole-wave was apparently so close to the second mode free scillation of the shelf that pseudoresonance from repeated reflections ff the coast and the Continental Shelf oscillation rapidly developed.

The tsunami, propagating off the Continental Shelf, spread across he entire Pacific Ocean. It probably expanded across the deep ocean $\mathrm{n}$ fairly pure form as a modulated system of waves approximating 1.8 ours in period. This system can be discovered in all the tide gage races from recording stations around the Pacific Ocean, and the pattern $f$ beats is reasonably consistent (Figures 43 to 66). At many places hese long waves are unaccompanied by waves of higher frequency, thus eading to the above inference. At other places the influence of coninental and insular shelves or of island barriers on the long period aves is evident through the development of local oscillations as a esult of some transference of the tsunami energy to higher frequencies. 'he exact mechanism for this phenomenon is not yet properly understood, ut both observational and experimental evidence support the fact that $\mathrm{n}$ the presence of discontinuities of depth, waves have a tendency to evelop their odd harmonic frequencies of which the third and fifth armonics usually carry most strength next to the fundamental, but in hich still higher frequencies may well arise if favored by local esonances.

A specific example of shelf and local resonance effect appears to e evident at Hilo Bay, Hawaii, whose fundamental free oscillation period $s$ about the same as the fifth harmonic of the tsunami ( $T_{5} \simeq 21.5$ minutes). lthough unproved at this time, it is believed that the coupled Hilo Baynsular shelf system has a fundamental free oscillation approaching 33 inutes in period, appropriate for stimulation by the third harmonic of ihe tsunami waves ( $\mathrm{T}_{3} \simeq 36$ minutes). Wave energy spectra of the tide ;age record for $\mathrm{Hilo}$ at the time of the tsunami tend to show prominences t or near these periods, along with peaks which are higher mode frequencies of these bay or quasi-basin oscillations (Figure 67). The ipectra fail to register the residual energy of the fundamental tsunami the wave period ( $T \simeq 1.8$ hours), ( see Figure 59), because of an nadequate resolution of the analysis at low frequencies.

At San Francisco, California, the reaction of the bay to the tsunami ras clearly one of near-resonant response to both the fundamental tsunemi seriod and its third harmonic. The development of the latter as an exitation may have been brought about by the entrance constriction to San rrancisco Bay or by the Continental Shelf.

The case of Crescent City, California, has been considered. It has Jeen largely a mystery why Crescent City was inundated by such large waves. 
The inference of this report is that the explanation could be twofold; first, that a "caustic" concentration of high energy bearing on Crescent City may have originated from as far back as the tsunami source region, and second, that resonance of a binodal form of shelf oscillation may have been promoted by the third harmonic of the tsunami waves $\left(\mathrm{T}_{3} \simeq 36\right.$ minutes). In this case a mode of oscillation of the Continental Shelf which could have responded to the second harmonic of the tsunami waves $\left(\mathrm{T}_{2} \simeq 54\right.$ minutes $)$ was not excited, presumably because of the absence of this stimulation.

The response of Monterey Bay, California, to the tsunami is perhaps typical of many another indented coastline of concave shape. It appears that the bay is capable of functioning to some extent as the quadrant of a circular basin with a paraboloidal bed. Many of the dominant periods of oscillation recorded in the area appear to agree with the numerous modes in which such a circular basin can oscillate within the limitation that a node must lie at the edge of the Continental Shelf or at the mouth of the bay. At Crescent City the Continental Shelf and coast approximate a semi-ellipsoidal bowl, and the permissible modes of oscillation of the bowl that describe modes for the shelf require a node along the major axis (or Continental Shelf edge).

Along the narrow Continental Shelf and in the deep fjords off the Canadian coast, the tsunami waves were enabled to reach into the inlets before feeling the effects of rapid changes of depth. The effects at Port Alberni, Canada, were phenomenal. Alberni Inlet is a long canal-like fjord with a shelving bed from deep water at its mouth in Barkley Sound. It is found to have a funamental period of free oscillation of about 1.85 hours, and therefore acted as a natural resonator for the reception of the tsunami waves. It is estimated that amplification of the waves from the mouth to the head of the Inlet may have involved a factor of about 10 .

At Lyttelton, New Zealand, where the long waves were of remarkably pure form, it would seem that the influence of local resonance is the cause also of a change in shape of the beat of the tsunami wave system. This appears to have been brought about by a greater degree of pseudoresonant amplification of later waves than leading waves, ascribed to the effect of the Port Lyttelton Inlet.

The heights and periods of what appear to be the main constituents of the tsunami waves registered by tide gages at a selected number of stations around the Pacific Ocean are summarized in Table III (p. 100).

In a rather qualitative way it is shown that the heights $H$ of the fundamental tsunami waves $(T \simeq 1.8$ hours) appear to decay with distance $r$ from their origin according to the laws $\mathrm{H} \propto \mathrm{r}^{-1 / 3}$ or $\mathrm{H} \propto \mathrm{r}^{-1 / 2}$, at all receiving stations along the seaboard of the Americas, toward which the waves would have had essentially a one-dimensional (nonradial) type of propagation. The law $\mathrm{H} \propto \mathrm{r}^{1 / 3}$ applies best to data for stations along the North American coast and $\mathrm{H} \propto \mathrm{r}^{-1 / 2}$ for South American stations that 
are more remote. These results tend to agree with theoretical indications :or one-dimensional propagation.

Data for the remaining stations of the west and central Pacific Ocean ippear to accord best with a height decay law, $H \simeq r^{-2 / 3}$, which theoreti:ally is appropriate to the leading waves of a tsunemi in two-dimensional radial) expansion.

The uniformity of the beat structure of the fundamental tsunami as egistered along the seaboard of the Americas suggests that the earth lovement along the fault length must have been fairly uniform. The number of waves in the leading envelope tends to be five, and the shape of the nvelope is probably related to the shape of the initial vertical earth lovement. With distance from the origin the number of waves in the beat ncreases to 8, 9, or 10, but this is ascribed to an interference or verlapping effect of competing wave trains.

The period of the dominant tsunami waves ( $T \simeq 1.8$ hours) is found to ccord well with statistical trends relating tsunami period with earthjuake magnitude $M$ (Figure 71 ). Thus, an empirical relationship between ? and $M$ can be specified (Equation (19), p. 104) which suggests that arge magnitude earthquakes will always yield long-period tsunamis.

Empirical relationships connecting tsunami period $T$ and tsunami ource diameter $S$ with earthquake magnitude $M$ are found to yield closely direct proportionality between T and S (Equation (20), p. 104). Such proportionality, it turns out, can be established theoretically (Equaion (25), p. 106). When wave period $\mathrm{T}$ is calculated in terms of tsunami ource size $\mathrm{S}$, the result ( $\mathrm{T}=1.99$ hours) confirms quite well the wave eriod identified in the tide gage records.

The subjective analyses made of selected marigrams (Figures 43 to 6) appear to show low waves that are still longer in period than 2 hours. these may have derived from the horizontal thrust of the Alaskan landmass or may be nonlinear subharmonics of the main tsunami waves developed at he confining boundary.

When tsunami waves traverse a Continental Shelf, a degree of resoance is possible even if the coastline is straight, and the shelf forms uniformly inclined plane out to a straight shelf edge parallel with he coastline. The criterion for the development of this resonance is ihe ratio of the effective relative depth $\left(\mathrm{d}^{\prime} \mathrm{T}^{2}\right)$ at the shelf edge to the quare of the shelf slope $\left(s^{2}\right)$ (see Figure 76$)$. The theoretical indicaions here require confirmation from experiments. In the presence of leavy damping, as is likely to exist, the implication is that runup leights of tsunami waves as a ratio of wave height $H$ at the shelf edge ire seldom likely to exceed a value of about 4 from this phenomenon alone. t has been concluded in general that the wave height $\mathrm{H}_{\Upsilon}$ at the coastal oundary (not necessarily the runup height) for the Alaskan tsunami was ibout $1.5 \mathrm{H}$. 
The heights of runup of the tsunami are traced along the coastline of Kodiak (Figure 40), along the seaboard of North America (Figures 77 , 78,79 and 82) and around the islands of Hawaii (Figure 86). It is shown that over a large stretch of coastline from Canada to Northern California the highest tsunami waves arrived simultaneously with the crest of the high spring tide. The combination produced widespread flooding and inundation beyond the highest high tide mark.

The tsunami waves arriving from the north and the astronomical tide wave from the south penetrated the Columbia River with the tsunami front preceding the tide crest by about 1.5 hours. This meant that the highest waves of the leading envelope of tsunami waves rode the crown of the tide wave. There are several interesting features of this forced companionship of big waves. It is shown, for instance, that the speed of advance of the parasitic tsunami waves was at first less than, then later greater than, that of the tide wave. Because of this and the progression of the tsunami waves through the tide wave, the effective period of the tsunami waves changes upriver from its value at the mouth. The tide wave itself enhances in amplitude before it decays inland from the mouth, presumably as a result of pseudoresonance within the tidal region of the river. Further, the heights of the first and second tsunami waves riding the tide crest reverse their order of relative magnitude apparently because of a third mode tidal oscillation in the estuary of 3.6 hours period, which has its due effect in steepening the front of the astronomical tide itself during its upriver run.

\section{Effects of the Main Tsunami and of Local Seismic Sea Waves in Alaska}

The topography of the seabed off Kodiak City and the Naval Station, Womens Bay, Kodiak, would have favored tsunami waves reaching Kodiak City first from the northeast via the narrow channel between Near Island and Kodiak. In the immediate neighborhood of Kodiak City the land subsided 5.8 feet during the earthquake, and the sea apparently dropped with it. Some inertial effects of the sea relative to land would have registered at once as an initial wave in this region, but conflicting opinion was expressed by eyewitnësses regarding the occurrence of such a first wave, closely following the earthquake.

The evidence of eyewitnesses has been carefully weighed in relation to an inferred marigram for Kodiak City (Figure 90), from which it is concluded that the first wave was probably real and related to an initial and purely local oscillation of water between Womens Bay and St. Pauls Harbor. This oscillation could have been a seismic seiche created by the southwestward thrust of the land during the earthquake. Owing to the topography of the quasi-basin it was probably not very noticeable at Kodiak City nor in Womens Bay, though prominent at the City Dock (Figure 89).

Certain paradoxical features of eyewitness accounts of succeeding waves are believed to have been resolved in this report. The first large 
wave of consequence, actually the second wave, rose like a fast tide at both Kodiak City and in Womens Bay and inundated the waterfronts at both places. This flooding was photographed at the two places in the twilight overcast of the setting sun at about $6: 20 \mathrm{p} . \mathrm{m}$.

Only wetting damage resulted from this inundation, but it was followed by an awesome withdrawal of water from St. Pauls Harbor. Velocities were estimated to have been as high as 25 miles per hour as the sea obeyed the trough motion of what is considered to have been a combination of the astronomical tide, the main tsunami, the large Continental shelf oscillation, and the local St. Pauls Harbor oscillation (Figure 97). The first damage resulted during this withdrawal of water which apparently sucked out part of the southwest breakwater of the boat harbor, and a store and hangar alongside the Near Island Channel. It carried away many of the boats in the boat harbor and left others on the exposed bed of the harbor and in the channel.

The next, "third" wave (35 to 40 feet high) was a combination of the first progressive wave crest of the coastward moving tsunami, the second wave of the shelf oscillation and additional local oscillations, which now moved into the denuded area via the Near Island Channel as a foaming bore (Figure 99). Its velocity of advance up this channel appears to have been close to 50 miles per hour. Although a crab boat surf-rode the slope of this monstrous wave and survived, the wave tore out docks and canneries in the channel and invaded the boat harbor where, with its counterpart from the Gull Island passage, it swirled and swept the fishing fleet and docks into the lower part of town. Whatever survived was weakened by this huge wave, and fell prey to a similar but higher wave that moved in later during the night on the rising tide in much the same way.

The destruction caused by the tsunami in Kodiak City is shown in Figure 103. Nearly all wooden frame buildings in the path of the waves were either buoyed off their foundations and swept away, or were pounded to destruction by the momentum of water and accumulated debris. Reinforced concrete structures fared much better, however; one (Krafts Grocery) near the waterfront and in the full sweep of the waves, was rated salvable though damaged.

Eight people died at Kodiak City, and nearly 100 vessels were lost or damaged. Total estimated property damage according to the Office of Civil Defense exceeded \$3l million.

At the Naval Station on Nyman Peninsula, Kodiak (Figure 113), the sequence of waves was similar but differed in detail according to the nature of the local oscillations (Figure 38). The damage here was in excess of $\$ 10$ million, most of which was caused by the tsunami. The force of moving water was much less here than at Kodiak City, and most of the damage occurred through dock structures being buoved off their piles or out of their pile holes, through inundation and through foundation settlement. It is noteworthy that neither at Kodiak City nor at the Naval Station were the oil tank installations set on fire, largely because they were out of reach of the waves and no oil spillage occurred. 
Other inhabited places in the Kodiak Island region which suffered damage from the tsunami included Port William, Shyak Island; Afognak (village), Afognak Island; Port Wakefield, Raspberry Island; Uzinki Spruce Island; Shearwater Bay, Kodiak Island; Old Harbor, Kodiak Island; and Kaguyak, Kodiak Island. Afognak (village), Old Harbor, and Kaguyak were almost totally destroyed, and the Indian communities of Afognak and Kaguyak have now been relocated to other areas. Damage in all these areas totaled about $\$ 10$ million.

In Cook Inlet, tsunami activity was relatively minor and almost entirely absent in the upper reaches near Anchorage. This is ascribed to the fact that the main tsunami probably lost a great deal of energy by reflection, refraction, and diffraction on entry at the mouth of Cook Inlet where a natural sill exists. The tsunami, as it progressed up the Inlet, would also have encountered strong attenuation from friction and from powerful ebb currents of the outgoing spring tide. Its main effects were felt, as expected, at Homer and Seldovia in the wide basin of the lower Cook Inlet. Wave damage at Homer was slight, and damage was mainly from inundation and subsidence. Seldovia suffered somewhat more from wave action than Homer. Damage here was estimated at about one-half of a million dollars.

Off the Kenai Peninsula the tsunami had a direct approach to Resurrection Bay at the head of which lies the town of Seward with a population of about 2,000. This bay effectively forms a chain system of three basins which jointly have first and second modes of free oscillation with periods (Equation (43)) that are short in comparison with the effective period of the tsunami. This circumstance prevented any resonant response to the fundamental tsunami and spared Seward a far worse fate than it might have had if the bay had been shallow.

An inferred marigram for Seward (Figure 137) has been prepared from eyewitness accounts of what happened. It seems apparent that the immediate effect of the earthquake at Seward was to jolt loose a large slice of the steepest part of the glacial delta near the Standard Oil Company docks, at the southern convexity of the Seward waterfront. This presumably slid away as a fast density current and carried with it much of the oil docks and part of the Alaska Railroad docks farther south.

The consequence of this was both a drawdown of water and a backlash of seismic sea waves. The first wave is thought to have been of annular type perhaps 40 feet high originating from a mound of water displaced by the submarine slide. This wave appears to have returned and hit first the very point of origin of the slide. The Standard Oil tanks caught fire at about this time which was within the duration period of the earthquake.

The annular type wave front, striking this promontory of coast, separated into two components which swept north and south along the waterfront. Both components of the wave were photographed (Figures 142 and 143).

At the oil docks, the Alaska Standard, a small tanker of 1,947 gross tons, was first drawn seaward with the collapse of the docks and then 
landward by the wave, but was in sufficiently deep water, as a result of the slide, to escape entrapment at the shore. She sailed, under power, through oil burning on the surface, to the safety of deep water.

The northmoving wave inundated the water front and carried burning oil to the Alaska Railroad switchyard where a train was in readiness to depart for Anchorage. Loaded tank cars caught fire and exploded as they became enveloped in flame. The wave helped destroy the U. S. Army docks and the cannery dock and boat harbor, already in the process of collapse and disintegration from the earthquake. Boats were carried over the breakwater of the small-boat harbor, and swept into the lagoon on the north side of Seward. The Texaco tank farm near the boat harbor also caught fire.

It is presumed that the effective period of the initial and immediately subsequent waves was between 3 and 4 minutes, and that this may well have been resonant for the head of Resurrection Bay in the transverse sense. Scme evidence supports the view that the initial waves originated from two boils of water in the northern part of Resurrection Bay, and that these may have been associated with a horizontal skew faulting of the seabed in this area. The details of this bottom movement are not presently available. It is known, however, that the Bay, as a whole, moved southward through a distance of about 50 feet and that a differential displacement of about 10 feet occurred between the two sides.

It is believed that longitudinal oscillations of the northern part of Resurrection Bay or of the whole Bay in its second mode became prominent during the first hour following the earthquake and contributed toward two further damaging waves which struck the waterfront. The main tsunami waves are presumed to have reached the head of the Bay at about $6: 30 \mathrm{p} . \mathrm{m}$. but lacked punch at that time because of low tide. Their amplitude probably increased with time (as at Kodiak) and later waves on the high tide during the night reached an average flood level of 27 feet above MLLW in Seward. At certain places, however, runup exceeded 30 feet within Seward (Figure 145). At Lowell Point, to the south, the runup was much higher (Figure 144).

Seward suffered greatest damage from the foundation collapse of the entire waterfront. This was a progressive action of the earthquake, undoubtedly assisted by the seismic sea waves which with every drawdown would have favored subsidence of the delta under artesian pressure and vibration.

The train in the switching yard was a total loss and was festooned in a string around the resistant, steel-frame, concrete-block wall engine house. Sudden quenching by water of the rails, made red hot by burning oil, caused them to snake off their tracks. Switching locomotives weighing 115 tons were overturned and transported by the momentum of the sea waves. Boats and houses in the path of the waves were carried away or totally destroyed. The power of the waves was dramatically attested by the destruction of heavy machinery at a marine-way workshop on Lowell 
Point where maximum runup was 44 feet above MLLW. It has been estimated that tsunami damage at Seward exceeded $\$ 14$ million; the death toll was 12 persons, most of whom were in small boats in the boat harbor at the time of the earthquake.

\section{Effects of the Main Tsunami and of Local Seismic Sea Waves in Prince William Sound}

Prince William Sound is an almost land-locked embayment with a grotesquely contorted coastline comprising deep fjords and bays and innumerable islands. Its gross shape is triangular (Figure 157), and its natural periods of oscillation probably approximate the values of Equation (47) (p. 247). Its fundamental mode period of 1.8 hours would make it responsive to the main tsunami despite an expected high damping effect from its greatly indented coastline.

General uplift of the Sound during the earthquake occurred in the form of a tilt in a northwest direction on a hinge at about $2 / 3$ of the distance from the mouth to the apex. The water surface may be assumed to have followed this sudden tilt fairly closely, and set in motion a complicated system of seiches. On this would have been impressed the tsunami from the Continental Shelf with rather limited access through the island straits. Experience of harbor surging phenomena suggests that the Continental Shelf oscillation could have successfully pumped and sustained the seiches in the Sound.

Because of its deep fjords and its proximity to the earthquake epicenter, Prince William Sound experienced numerous slides whose wave effects added to the general complexity of water movements. At many places it would seem that the pattern of waves was similar to the pattern at Seward (see Figure 159).

The Indian village of Chenega, on Chenega Island in Knight Island Passage, was almost totally destroyed. Sea waves, striking during the earthquake, killed 25 persons. Powerful initial damage from slidegenerated waves of relatively short period (3 to 5 minutes) occurred at Whittier and Valdez.

The case of Valdez is the best documented in the Prince William Sound area. Valdez, with a population of about 600 , has a location at the head of Port Valdez and Valdez Arm, a long embayment within the Sound which, like Resurrection Bay, forms effectively a chain of three basins, whose periods of free oscillation, as a group, approximate the values given in Equation ( 48$)(p .254 \%$. However, the last link in the chain, Port Valdez, is virtually a closed basin and because of the narrow throat and elbow bend of the adjoining link (Valdez Narrows) is considered to be fully capable of responding to its own modes of free oscillation in the longitudinal direction. These periods, to the second mode, are given by Equation (49) (p.255). It is noteworthy that the first mode period of 18 minutes for the latter agrees closely with the 
second mode period ( 17.8 minutes) for the entire Valdez embayment; also that the fundamental period ( 39 minutes) for the embayment is within response range of the second and third mode periods (respectively 48 and 30 minutes) of oscillation of the Sound. These circumstances are considered to have a bearing on the development of waves at Valdez after the earthquake, as portrayed in the inferred marigram for Valdez (Figure 165).

Our interpretation of what happended at Valdez is based on eyewitness accounts, published literature, and photographic evidence drawn from motion picture films taken by two crew members aboard the S. S. Chena, a cargo vessel of about 11,000 gross tons, which was moored at the north pier of the harbor when the earthquake occurred.

The suggested explanation for what happened is that during the intense shaking of the earthquake in a north-south direction (in which direction there was also a 25-foot displacement of the land southward), a seismic seiche was generated transverse to Port Valdez along the Valdez waterfront. The mechanism for generation of this seiche could have been a submarine slump of the fine sediments off the glacial delta and outwash at the mouth of the Lowe River in the extreme southeast corner of Port Valdez, or it could have been the movement of the land, or both, acting together.

The Chena responded to the initial northwest nodal surge of water by pulling away from the dock. The docks at the same time began to settle as violent ground shaking produced consolidation of the sediments and incipient slippage of the delta slope. The returning "backlash" wave slammed the Chena on the wreckage of the collapsing docks of the North Arm where she was momentarily caught before being swept into the smallboat harbor (see Figures 166 and 167). This initial wave is believed to have been, possibly, 40 to 50 feet high and of 4 to 5 minutes periodicity. It carried away canneries and facilities on both the North and South Arms of the harbor in the same southeasterly direction as the Chena.

The Chena was temporarily aground in the wreckage of the boat harbor before the return flow (in the northwest direction) lifted and freed her, and enabled her to escape under power. The next reversal of the flow to the southeast, however, after the earthquake had ceased, frustrated the Chena's bid for deep water and carried her, virtually out of control, at jetlike speed in a southeasterly direction alongshore (Figure 166). It is at this stage, according to the photographic evidence (see Figure 173) that the major submarine slide took place south of Valdez, creating a 30- to 50-foot high scarp along the shore over which water cascaded into the depression. It was toward this that the Chena herself was being pulled by the drawdown. The temporary mounding of sediments from the submarine slip is presumed to have caused the wall of water, observed to starboard (seaward) of the Chena at this time. As the depression of water level filled, the Chena finally escaped, miraculously unscathed, to the safety of deep water. Presumably also the rapid dispersal of the submarine mound of sediment acted to dissipate any serious wave formation. All this occurred within about 6 or 7 minutes of the onset of the earthquake. 
These first waves, assisted by the subsidence, virtually annihilated the Valdez waterfront. They damaged or destroyed almost all the boats and facilities in the small-boat harbor and left the North and South arms looking like amputated stubs. The waves reached to a level about 16 feet above MLLW at McKinley Street, in the lower part of town (Figure 179), and did considerable damage to light wooden-frame buildings.

Higher and much longer period waves were to inundate Valdez later during the night. Shortly after the Chena's escape, another large wave of longer period assumed to be about 18 minutes, rolled in on Valdez and filled the Valdez Hotel to a level of 18 inches (Figure 165). This is held to be an antinodal surge from the longitudinal uninodal seiche for Port Valdez ( $T=18.0$ minutes), generated by a large submarine slide at the opposite end of Port Valdez near the Narrows. Large waves, apparently deriving from submarine collapse of the submerged glacial deposits at the mouth of Shoup Bay, rushed southward out of the Narrows destroying the Valdez light at an elevation of 37 feet above MLLW. Runup and splash marks were identified to elevations of 125 to 220 feet near Shoup Bay. These waves are presumed to have set in motion longitudinal seiches in the Valdez embayment which began to build up in the lowest frequencies, as stimulation from Prince William Sound also made itself felt.

The most likely system of waves to fit all the facts of eyewitness reports, including the periods of local seiches and oscillations of Prince William Sound, is shown in Figure 165. On the high tide during the night the combination of waves produced the highest runup in Valdez to a level about 20 feet above MLLW. These later waves were like fast-rising tides, and being more sustained than earlier waves, produced more wetting damage, but not much violent motion. Oil tanks, however, were set on fire by these waves.

The heaviest loss of life at one place (31 persons) occurred at Valdez. The waves are estimated to have caused damage between $\$ 12$ and $\$ 13$ million.

The destruction that occurred at Whittier near the head of Passage Canal on the west side of Prince William Sound is less well understood than at Seward or Valdez, mainly because of fewer eyewitnesses. It is evident, however, that the waves which assailed and destroyed the waterfront of Whittier were waves of displacement created by submarine slumping of the slope and toe of the unconsolidated glacial deposits on which the town is founded and of neighboring deposits at the head of the bay.

The waves are said to have been exceptionally high and their penetration reached an elevation about 30 feet above MLLW along a wide front, and 40 feet in localized places. At the head of the bay the waves washed more than 50 feet above MSL. Only two waves are recorded as having struck during the earthquake. The existence of later, longer-period waves, occurring on the high tide, is completely unrecorded. The reason for this is unknown, but probably resides in the complicated oscillating behavior of the Port Wells complex of fjords, and possibly the absence of witnesses during the night. 
As at Seward and Valdez, the waterfront was destroyed mostly by the collapse of the foundations resulting from the submarine slides and the regional subsidence of 5.3 feet. However, the wave damage was extensive and involved the Union Oil tank farm, which was set on fire, and two lumber company plants which were virtually demolished, as also the Alaska Railroad docks, and numerous homes and small buildings.

The sea waves are credited with having caused $\$ 10$ million worth of damage at Whittier, and took 13 lives out of a population of 70 . Undoubtedly the waves were relatively more severe than at Valdez and Seward.

At Cordova, in the Orca Inlet near the mouth of Prince William Sound, the regional tectonic movement was 6 feet of uplift and about 40 feet of horizontal thrust to the southeast.

Sea approaches to Cordova are relatively shallow, and there is no evidence of submarine slides having occurred in the region. The wave pattern of the inferred marigram (Figure 202) thus has no large amplitude waves of 3 to 5 minutes period such as characterized the situations at Seward, Valdez, and Whittier. Initial waves following the earthquake proved to be of little consequence, but shortly after midnight an exceptional wave rose above the preexisting highest tide level. This wave buoyed the dock off its pilings, carried away several small houses and buildings, and generally flooded the waterfront.

Wave damage at Cordova was estimated at $\$ 2$ million. General upheaval of the harbor created problems of dredging new access routes through shoals or of extending piers about 100 feet to reach water of suitable depth, equivalent to prequake conditions. The tsunami had the notable effect of producing both scouring and silting in different places of the Orca Inlet.

\section{Effects of the Main Tsunami along the North American Seaboard}

The tectonic movement in the Gulf of Alaska was such as to prescribe direction of the main part of the energy of the tsunami toward the North American coastline. Damage in excess of $\$ 10$ million occurred along the greatly indented coastline of Canada, mainly in the form of flooding, buildings swept away, wharves damaged, and log booms and lumber mills destroyed. No loss of life was reported in this area.

The most serious damage in Canada occurred at Port Alberni. Here the greatly amplified tsunami waves arrived on the high spring tide (range about 17 feet), but, by good fortune, the first wave (of lower amplitude than the second) arrived slightly ahead of the tidal peak and alerted the population to the danger. Houses, boats, logs, and other moveable objects were swept away and destroyed; wharf structures were buoyed and buckled. The damage at Port Alberni alone was estimated to be $\$ 10$ million. 
Along the Washington coast of the United States, the damage probably exceeded $\$ 100,000$, but this was much less than the estimated $\$ 750,000$ for the Oregon coast, which probably suffered more because of its slight concavity favoring more direct attack. Four deaths were reported from Oregon.

The California coastline suffered damage in excess of $\$ 9$ million, a large part of which reflects losses to commercial fishing interests and small boat marinas. Most heavily hit was Crescent City where the total damage was close to $\$ 7.5$ million. (A more recent estimate has raised this figure to $\$ 11$ million.)

The peculiarity of Crescent City's situation has already been discussed. The tsunami waves occurred as fast-rising tides which flooded over the coastline and into the lower parts of the city (see Figure 209) to a height about 20 feet above MLLW. A giant lumber barge, heavily loaded and of immense inertia, moored at the Citizens Dock, severely mauled and buckled this structure, but was not itself a casualty. The waves wrought great damage to buildings and automobiles as a result of the great momentum of the water with its entrained mass of logs and debris. The Texaco tank farm was set ablaze as a direct consequence of the waves. 


\section{Introduction}

From the details in this study on the origin and effects of the Alaskan tsunami, we now draw conclusions to add to existing knowledge, and provide criteria for the planning and design of protective measures against potential damage.

In the area affected by the Alaskan earthquake there was usually a complex interaction between different categories of damage, involving cegional earth movement, seismic shock, compaction settlement, slides and fissuring, fire, and tsunami wave damage with associated impact from floating debris. In most cases where major wave damage was involved, it zould be fairly well identified.

Because this study was started almost two years after the earthquake occurred, there were few damage cases remaining that could possibly je analyzed for evaluating the wave forces. However, it is possible to arrive at some general conclusions regarding the ability of different structures withstand tsunami forces.

\section{Water Particle Velocities and Pressure Forces from Tsunamis}

It would appear that the damaging effect of tsunamis depends very sreatly upon the amplitude and the period of the waves, the nature of the terrain they invade, and the development of breaking or bore formation in the coastal inundation. The availability of easily floatable debris, logs, boats, automobiles, and timber-frame structures) which acquire the nomentum of the water, provides a ready means of increasing the damaging ounch of the waves when striking obstacles.

To calculate the force of the water on any obstacle it is necessary to know the velocity and direction of flow, as well as the water level as a function of time. The nature and shape of the obstacle are, of course, of basic importance.

In tsunami-damaged areas, we have found few cases from which some idea of water particle velocities may be obtained. One case is the overturning of a locomotive at Sewara. Calculations related to the overturned engine (see Figure 152) give a water velocity of 24.5 feet / second with an average pressure force of 700 pounds per square foot. The approximations made for this calculation are, admittedly rather rough. Using a formula based upon pure frontal drag is open to question, since the direction of water flow around the locomotive may have been oblique rather than normal. The use of the alternative formula (Equation (D-24) of Appendix D) might also be questionable. It is nevertheless of interest to determine the applicable value of the coefficient $K$ in Equation (D-17) of Appendix I, that would have yielded the overturning conditions of the locomotive. 


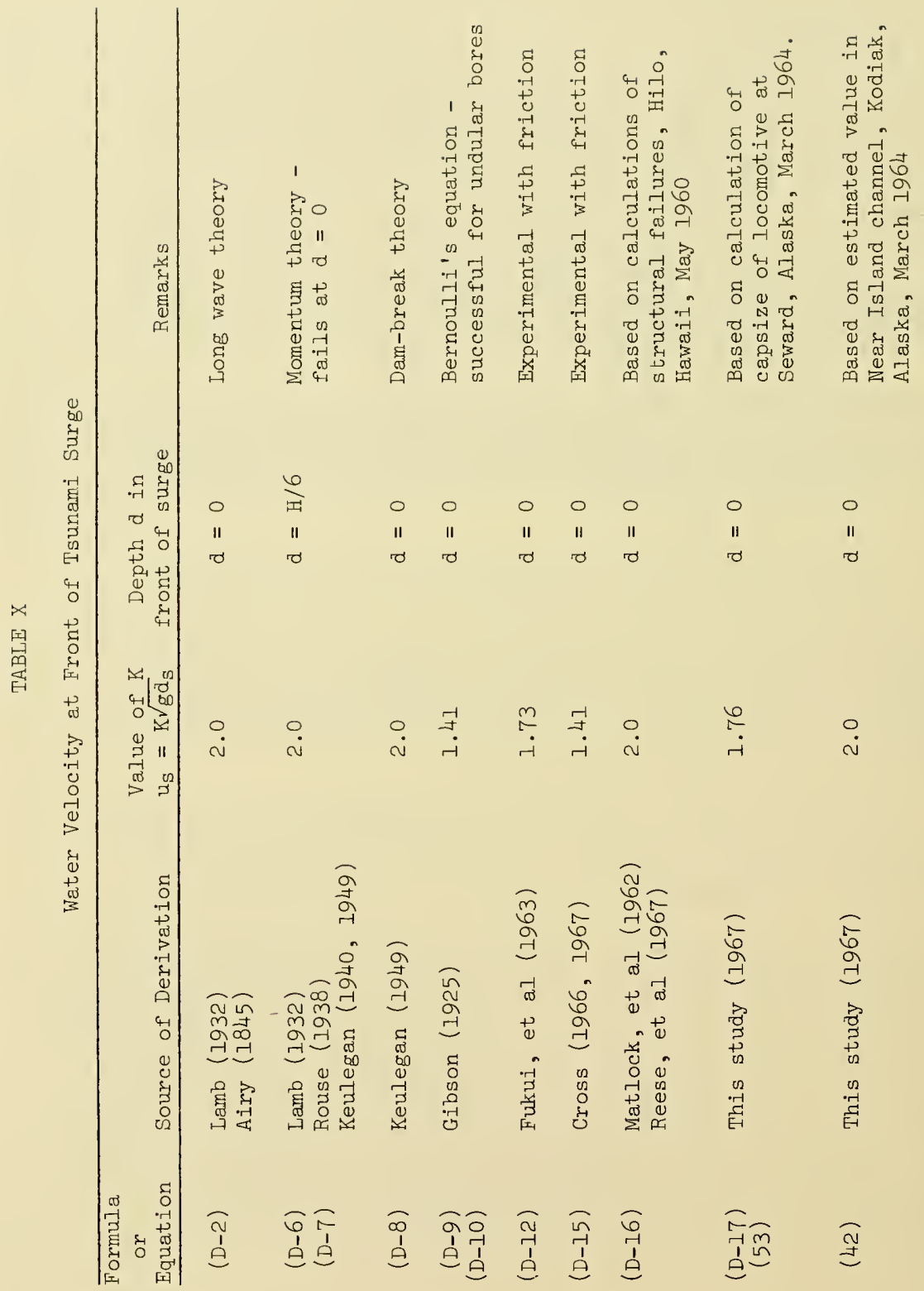


hus for $a_{S}=6$ feet, $u_{S}=24.5$ feet per second, we find

$$
K=\frac{u_{s}}{\sqrt{g_{s}}}=1.76
$$

In Appendix D, it has been shown from a discussion of theoretical nd experimental information bearing on tsunami surge velocities and orces, that a tsunami surge, with the characteristics of the experiental waves illustrated in Figure 99, tends to have a frontal velocity $n$ accord with Equation (53) for K-values between 1.5 and 2.0. The -value 1.76 of Equation (53) supports the conclusions, despite the oughness of the analysis of Figure 152 .

Further support for the conclusion is discussed in Section IV-2, in onnection with the tsunami surge in the Near Island channel at Kodiak, 'here an eyewitness' estimate of water speed is found to be in approxiate accord with Equation (42) or Equation (53) for a K-value of 2.0 .

The case of the light box at Crescent City (Figure 222) suggests that water velocity of 11.2 feet per second over a minimum depth of 6 feet ould have caused failure of this light structure. We should here find a -value less than half that of Equation (53), but the probability is that he nature of the flow was not like a surge but more like a fast-rising ide, in which case Equation $(D-20)$ of Appendix D would apply.

It is convenient to summarize the findings of this study regarding he water velocity of the front of a surge moving over dry or wetted round. Thus the main conclusions of Appendix D and such other cases s apply from the body of this report are drawn together in Table X, hich suggests that a suitable design value of $K$ in Equation (53) or D-17) would lie between 1.5 and 2.0 .

It is pointed out in Appendix D that, although calculations of force iased on the drag formula, Equation (D-16), are probably valid for relaively small objects or structures which become enveloped in the flow of tsunami surge, calculations for larger objects with broad or continuous rontage are better performed with a momentum formula such as Equation D-24).

The behavior of a tsunami surge striking a wall or breakwater is haracteristic. The action is jetlike, and the momentum is deflected pwards and possibly sideways if the approach is oblique to the structure. gainst a vertical wall of sufficient height the surge rises vertically is a wall of water to a height roughly equivalent to the velocity head of the stream. The collapse of this wall of water provides the physical ody for a reflected bore which moves out on the still incoming surge. eak pressure on the structure occurs when this mass of water descends on the incident surge. When the structure walls are sloping inland, as rith a seawall or breakwater, the pressure force on the structure is relieved to the extent that momentum is carried forward in the overcopping volume of fluid. 
A possible design formula for estimating tsunami pressure forces per unit length on vertical walls is given by Equation (D-26) in Appendix D, which is restated here in the form

$$
\begin{aligned}
& \text { (i) } F=C_{p}\left(\frac{1}{2} p g d_{s}^{2}\right) \\
& \text { (ii) } C_{p} \simeq 14
\end{aligned}
$$

Equation (54i) expresses the force in terms of the hydrostatic pressure force for the surge depth $\mathrm{d}_{\mathrm{S}}$ above the toe of the structure (see Figure $\mathrm{D}-1$, Appendix D). The factor $\mathrm{C}_{\mathrm{p}}$, a pressure coefficient, represents the number of times the dynamic force exceeds the static. Based upon an average value of $\mathrm{K}$ from the total results of Table $\mathrm{X}$ and upon experimental indications that the vertical jet height at the wall is from 1.5 to 2 times the velocity head of the surge, $C_{p}$ appears to average about 14.

\section{The Ability of Structures to Withstand Tsunamis}

In the coastal cities and villages that suffered tsunami damage, the houses were generally old, one-story, wooden-frame buildings. Such houses had a poor capacity for withstanding the tsunami forces. One design detail, usually lacking, which should be emphasized in future design, was adequate connection between the wooden-frame structure and the footings. This weakness caused many houses to be floated off their foundations, and was probably the main cause of tsunami damage to wooden buildings close to the maximum runup. This is true not only for smaller buildings but also for larger ones like the two-story odd Fellows building in Crescent City.

Houses and buildings that were floated off their foundations and survived the attrition of tsunamis and impacts from other floating debris or the impacts of stranding, were razed during cleaning-up operations. It is therefore impossible to tell to what extent these structures would have been able to withstand the tsunamis had they been adequately connected to their foundations. Many of the older and smaller wooden structures like the houses in many small villages, were completely demolished by the tsunami.

The few concrete-block and reinforced-concrete structures in tsunamiinundated areas withstood the waves rather well. Such buildings include the concrete-block, steel-frame engine house in Seward, some concreteblock buildings in downtown Kodiak and on the Kodiak Naval Station, and the reinforced-concrete, five-story hotel on Front Street in Crescent City. Some of these buildings, however, were damaged from the impacts of floating boats and debris.

Floating timber caused much of the damage at Crescent City. Huge logs acted as battering rams in punching through walls, and functioned as dragnets in concentrating pressure. During a tsunami the floating timber has 
jeen dangerous on many occasions at sawmill or paper factories. Horikawa (1961) has stressed consideration of appropriate measures for anchoring tacked timber at such tsunami-endangered places; the writers strongly support this view.

In general, the type of land structure that can best survive tsunami nundation is one of sound reinforced-concrete construction with deeply mbedded foundations or solid raft foundation (foundation mats) capable f resisting scour. Shear walls are desirable. Orientation of structures is important in that long axes are directed toward the sea and parallel he path of attack so that minimum areas of resistance are exposed to raves. Well-constructed, timber-frame buildings, firmly secured to adeluate deep-set foundations, may be considered for areas on the lee side ff a belt of more solid buildings which could break the impact of debris. jood-frame structures, however, should be strongly braced both vertically and horizontally at floor and ceiling levels. It may be desirable in zertain circumstances to design structures with substantial framing but vith expendable ground-floor walling. Upper floors in such buildings rould generally be immune to wave and water damage; ground-floor damage rould be considered tolerable (cf. Matlock, et al, 1962; Wiegel, 1965; lagoon, 1965; Reese and Matlock, 1967).

\section{Harbor Structures: Their Damage and Protection}

The docks in the areas that suffered substantial tsunami damage vere all of timber construction with the exception of the sheet-pile ailroad docks in Seward, which were damaged by slides.

The old Cargo Dock at the Kodiak Naval Station was completely lestroyed, basically because of inadequate connections between piles and the deck, but also because extracted piles failed to return to the augered pile-holes in the rocky bottom. A moored ship raised the bollards during isunami-induced motions, and probably also caused damage while slamming against the dock.

The Marginal Pier of the Naval Station suffered minor damage, mainly from a moored barge which loosened a bollard and some decking. This dock, paradoxically, had to be loaded down with heavy chains after the earthquake so it would not float away during later high tides, which subsequently reached a higher level because of land subsidence. The Tanker and Tender Pier of the Naval Station was not critically damaged.

At Crescent City, California, the Citizens Dock was damaged mainly by a moored timber barge that slammed against the dock. Much repair work was needed on corbels, decking and fenders on this dock. The approach pier to Citizens Dock was heavily damaged when the deck was buoyed by the tsunami waves. The majority of the supporting pilings which were encased in a concrete wave barrier under the dock snapped when this barrier was exposed to high lateral forces resulting from different water levels on the two sides of the barrier. 
The Dutton Dock in Crescent City survived mainly because of the steel straps and the bolted connections between the decking and pile caps and the abundant cross-bracing. The absence of moored ships at the dock also helped.

These findings show the importance of adequate connections between pilings and decking on a timber dock in tsunami-endangered regions. It is equally important that the piles be capable of resisting vertical uplift forces without being drawn out of the ground.

All the boatfloats in Kodiak Harbor were completely demolished when the piles to which they were attached broke as result of the heavy lateral forces caused by the tsunami.

The breakwaters at Kodiak City were badly damaged, by settlement during the earth tremors, and by erosion from the tsunami. These breakwaters were built mainly to protect the harbor from local wind waves, and the armor stones were not large enough to resist scour from highvelocity water. At Seldovia, Kenai Peninsula, the breakwaters, which were built to protect the harbor against local wind waves, suffered damage from both the earth tremors and the tsunami overtopping. The breakwater at Cordova, Prince William Sound, was apparently undamaged. At Crescent City, California, the breakwaters, built partly with 25-ton tetrapods in the cover layer for protection against large storm waves, also sustained no noticeable damage during the tsunami attack.

The pattern of structure damage resulting from tsunamis has almost always been the same. Land structures, weakly secured to their foundations, have been swept away either by sheer force of moving water or by battery from accumulated debris cascaded in front of an advancing wave. In some cases displacement has occurred merely by lifting of a structure through floatation. In harbor areas, breakwaters have been denuded by weir-action flow across their tops. In dock areas, pile structures have been eroded by scour at the base, battered by ships, or stripped of their decks by buoyant forces. Solid dock walls have been overturned by suction action during wave withdrawals; dock slabs, collapsed by erosion of supporting sand fill; retaining walls, undermined and destroyed.

If the economics justify it, special seawalls, dikes, breakwaters, or barriers may be designed to shield low-lying areas. Such protection may be built on land (in the dry) or in water at advantageous points. Examples are the proposed Hilo Harbor tsunami barrier, the Narragansett Bay storm-surge barriers, and the tsunami-barrier walls built in Japan at Yoshihama and Yamada (cf. Horikawa, 1961). Design criteria demand deep and firm foundations, interlocked construction for mass walling, non-erodable revetments and breakwater capping in front and rear, even possible closure gates of unique and dependable design.

The problem of immunizing dock and harbor facilities is much more difficult. Again economy is a factor which will predicate just how substantial a breakwater or harbor enclosure should be built, or how 
sophisticated a dock wall, pier or jetty design should become. Any given case would have to be considered on its merits.

The need for proper provision and planning of oil storage tanks is extremely important. These usually are located near the waterfront of ports, whose oil supplies must come from overseas. Invariably oil spillage caused by an earthquake or its tsunami results in fire, which can spread rapidly and make a holocaust of any coastal town or city. Oil tanks caught fire at Seward, Valdez, Whittier and Crescent City as a. consequence of the earthquake and tsunami of March 1964. All of these fires were spread by waves. Proper placing and adequate containment of all storage tanks in harbor areas is therefore important. If the tanks cannot be sealed off and recessed below normal ground level or placed on high ground out of reach of tsunami runup, they should be contained by a perimeter wall or dike capable of repelling water and retaining oil.

\section{Damage from Scour}

Scouring damage from the Alaskan tsunami, on the whole, was not as extensive as expected. The scouring effect was probably most noticeable in the Orca Inlet at Cordova where considerable deepening and shoaling occurred in many areas and destroyed many clam beds, and also in the Near Island channel at Kodiak where the channel was denuded almost to bedrock.

In downtown Kodiak and at the Kodiak Naval Station there was some minor scouring damage. Roads on Kodiak Island were also heavily eroded. Cases of eroded roads and bridge pile bents have been reported from several places along the Pacific Coast of North America.

In Seward, railroad fill along the shoreline was partly eroded, and at Valdez the harbor moles undoubtedly sustained erosive damage from the sea waves. Some harbors and entrance channels were affected by scouring, but none too seriously.

At Kodiak Naval Station a steel sheetpile retaining wall was bowed seawards by hydrostatic pressure and suction from withdrawals of the tsunami waves. Collapse seaward of seawalls from this cause has been frequently noted (cf. Horikawa, 1961).

\section{Protective Measures for Ships and Boats in Harbors}

In those harbors hit hardest by the Alaskan tsunami, small boats suffered severely. They were either sunk or carried ashore. Sinking was in many cases caused by direct damage from impact. Other boats capsized when their moorings withheld them from rising with the water level. In Crescent City, it has been reported that strong currents normal to the long axis of boats, moored to anchor-buoys fore and aft, forced the boats to keel so much that they would take in water and sink. There is 
also evidence from Kodiak that boats, left dry by a drawdown, were toppled when the water started to rise again, especially when the wave came in with a steep, breaking front.

Large vessels survived the tsunami. Most remarkable is probably the survival of the 1l,000-ton ship Chena during the slide-generated waves at Valdez. All the smaller boats in that harbor were completely destroyed. Also the 2,000-ton tanker Alaska Standard weathered the slide-generated waves at Seward, whereas the small boats there were either badly damaged or destroyed.

The large vessels that were moored to the Marginal Pier and the Cargo Dock of the Kodiak Naval Station, as well as the large timber barge that was moored to Citizens Dock at Crescent City, all withstood the tsunami well. However, these vessels severely damaged the dock structures, particularly at Crescent City.

It should be noted here that in other great tsunamis, particularly that of the Chilean earthquake of May 1960, large ships have not fared so well, especially when caught in narrow waterways where the whip-action of violent surge currents carried them out of control (cf. Sievers, et al, 1963; Takahasi, et al, 1961).

Many times it has been proven that the safest place for ships and boats of all types during the rampage of a tsunami is the open sea. In fact, a standard procedure of the seismic-sea-wave, warning system of the U. S. Coast \& Geodetic Survey is now to advise that ships vacate any threatened port and make for open water, as far from shallow water and enveloping coastline as possible (Coast \& Geodetic Survey, 1964).

A problem remains, however, in respect to ships or boats which cannot generate power, or muster a crew, in time to escape the inrush of a tsunami. It may even happen that the extent of advance warning of the approach of a tsunami might be insufficient to warrant risking the lives of crews in attempts to undock ships and head for open sea. There may not be a great deal that can be done for ships and boats in such circumstances.

Primary protection for shipping, however, must come from outer breakwaters or tsunami barriers when the economic issues justify barriers capable of blunting tsunami attack. It is almost certain, however, even with barrier protection, that very long-period, high-amplitude seismic sea waves will cause overtopping and violent flushing of harbor and marina basins, and that the induced currents may be powerful enough to tear ships from their moorings and small-boat, landing floats from their pylons. Conventional mooring facilities would probably be unable to resist chaotic disorder of this kind, so that important secondary protection for shipping must be devised within the dock areas themselves.

For protection of large ships, a primary requirement would be the provision of elastic shock-absorbing fenders as permanent fixtures of 
the quay walls and piers, coupled with the use of well-secured, shockabsorbing, floating fenders. A second stipulation might be that ships of large size, permitted to berth, be equipped with automatic constant tensioning, high-capacity, deak winches capable of ensuring taut moorings at all stages of the tide or water level. Ships above a certain tonnage, not meeting port requirements in this regard, could be compelled by regulation to anchor in the roadstead outside the harbor, to specially designed clump and groundline anchorages marked by permanent surface buoys. Under normal sea conditions the dead weight of the clump resting on the seabed would be a sufficient anchor for holding a ship in the exposed roadstead. Under high sea or tsunami conditions, however, the additional force impased on the anchor line would lift the clump and bring into action the ground line and true anchor, and thus cushion the strain of severe drag while maintaining a small angle of inclination of the ground line at the anchor and so preserving its holding power (see also Wiegel, 1965). Such berthings would obviously require barge ana lighterage operations with attendant higher port charges for ship owners, who would thereby be induced to equip their vessels with regulation winch machinery to gain the facility of protected harbor berthings.

In small-boat basins, landing floats and platforms should be required to meet particularly stringent specifications ensuring more robust equipment than is normally required of marinas, not subject to tsunami attack. In particular, vertical guide piles could be interconnected at an appropriate overhead level by longitudinal, cross and diagonal bracings, so that loads are transmitted to the equivalent of a large framed structure rather than to single flexible piles. Small-boat lashings to the floating docks should also be required to meet stringent specifications for size and type, in keeping with the nature and size of the craft moored.

\section{Economic Aspects of Protective Measures}

Standards of safety and economy that would apply in any given coastal region having a potential for tsunami attack, will obviously depend on a number of factors, such as:

a. The degree to which the region is seismically active.

b. The historically prevalent nature of earthquake faulting.

c. The extent to which earthquakes occur seaward or landward of the coastline.

d. The statistical trend of focal depth of local earthquakes in relation to distance from the coastline.

e. The exposure of the coast to transocean tsunamis.

f. The protection afforded by offshore islands. 
g. The peculiarities of the coastline to concentrate tsunami energy in specific places.

h. The resonating capacity of particular bays and inlets to amplify tsunami runup.

i. The geological nature of the coastal area, particularly its susceptibility to submarine landsliding, to compaction with vibration, and to earth avalanches.

j. The extent to which a large area may be prone to subsidence during a local earthquake.

When all these factors are taken into account, it is clear that completely different standards of safety are likely to prevail in different regions. As compared with Alaska, for example, California would appear to be rather favored, particularly Southern California, which, for the most part, is protected by offshore islands, and historically is not particularly prone to local tsunami generation.

There is as yet no hard and fast rule for determining a safety standard. The lessons of the Alaskan earthquake of 1964 emphasize the need for secure foundations for waterfront structures, but in the presence of total land subsidence, even the best of foundations cannot necessarily ensure safety either for the structure it bears or for the people that occupy the structure.

Generally, if subsidence is not a problem, then real safety begins with the placing of all structures on good foundations at a level above the design runup. Such a measure may be impossible in a practical sense, particularly when waterfront facilities are involved and land levels are low. It may then be necessary to resort to some sort of protective works as are currently being considered for Hilo in Hawaii. The question of economy is then directly involved. Assuming that tsunami warning services can ensure safety of human life, at what stage does it become economic to resort to total or partial protection of the assets of a seaside comunity by such measures as special breakwaters, barriers, seawalls, dikes, plantations of trees, or shelter buildings? There are at present no general answers, except to say that each area seeking immunity from tsunami attack must be separately and carefully investigated. 
It seems desirable to set out in succinct form the broad conclusions and immediately useful information which appear to emerge from this study. For convenience these are listed by categories.

\section{Earthquake and Tsunami Generation Characteristics}

a. The tectonic earth movement of the Alaskan earthquake giving rise to the main tsunami, was a dipole (crest-trough) vertical deformation over the Continental Shelf of the Gulf of Alaska, accompanied by a differential horizontal thrust of the land seaward.

b. The earth deformation apparently occurred as result of a differential dislocation along a low-angle fault-plane and possibly also, a near-vertical buried fault-plane, extending over a distance of 800 kilometers.

c. This fault length confirms an empirical-statistical result (Equation (2), p. 28), based on world data, which permits approximate prediction of fault length from earthquake magnitude.

d. The frequency of occurrence of earthquakes in Alaska, as a function of magnitude, follows the trend of world data and of independent Japanese data. The probability of occurrence of an earthquake of the magnitude (8.5) of the Alaskan earthquake in the Alaska-Aleutian Island region is about 1 in 30 years.

e. The maximum resultant earth deformation confirms an empirical statistical trend of world data (Figure 17) which permits approximate prediction of expected maximum tectonic deformation in terms of earthquake magnitude.

f. Defined by backward refraction of the waves from recording stations around the Pacific Ocean, the tsunami source region occupies the Continental Shelf of the Gulf of Alaska, out to the Aleutian Trench over a distance of 800 kilometers.

g. The equivalent diameter of this source region ( $\mathrm{S}=425$ kilometers) confirms an empirical-statistical result (Equation (3), p. 38) based on Japanese data, which permits approximate prediction of tsunami source size in terms of earthquake magnitude.

h. The initial deformation of the sea surface over the icntinental Shelf during the earthquake was frobablv a sroothed replica of the vertical earth leformation, and comrised a dipole wave with a probable crest height varying rernars from 30 to 60 feet. 
i. This wave ostensibly had a continuous front over a distance of approximately 650 kilometers and propagated mainly northwest and southeast.

$j$. The inferred heights of the tsunami at or near the source confirm an empirical-statistical result (Equation (6), p. 62), based on Japanese data, which permits approximate prediction of tsunami height near an earthquake source in terms of earthquake magnitude.

k. The tsunami propagated outward across the Pacific Ocean as a fairly pure system of virtually non-dispersive, long waves with a period averaging 1.8 hours.

1. This period of the tsunami waves confirms an empiricalstatistical result (Equation (19), p. 104) based on Pacific Ocean data, which permits approximate prediction of primary tsunami wave period for any given earthquake magnitude.

$m$. The empirical results mentioned under items ( $g$ ) and ( 1 ) indicate that tsunami period $T$ is directly proportional to source region size (equivalent diameter $\mathrm{S}$ ), a result which is verified theoretically.

n. The proportionality relationship betveen $\mathrm{T}$ and $\mathrm{S}$ yields a value of $\mathrm{T}(=1.99$ hours $)$ for the value of $\mathrm{S}(=425$ kilometers $)$ in fair agreement with the average tsunami period $(\mathrm{T}=1.8$ hours) found in tide records.

\section{Tsunami Propagation Characteristics}

a. The tsunami appears to have propagated across the Pacific as a system of modulated waves with five waves in the first beat. The modulation shape was probably related to the transverse profile shape of the vertical tectonic earth movement.

b. Changes in beat-modulation shape of the primary tsunami waves result from interference of tsunami wave trains, probably through "caustic" effects of wave refraction.

c. On propagation of the tsunami waves over a continental or insular shelf there appears to be immediate transfer of energy to higher harmonics which seem restricted to the odd harmonics.

d. Particular coastlines, inlets, and bays of the Pacific Ocean boundary are resonators for the primary and/or odd harmonics of the tsunami waves and amplify the effects to large proportions. 
e. It follows from (d) that certain coastal areas will always be peculiarly susceptible to large damaging waves from great tsunamis whose energy content is high in keeping with large earthquake magnitudes; (Port Alberni, Canada; Crescent City, San Francisco, and Santa Monica, California; Hilo and Kahului, Hawaii; and Lyttelton, New Zealand, are cases in point).

f. Generally, tsunami wave height decays with distance from the source; in one-dimensional propagation, as the inverse $1 / 3$ or $1 / 2$ power of the distance, and in two-dimensional (radial) propagation as the inverse $2 / 3$ or $5 / 6$ power of distance, respectively, near the front of the waves and in the body of the waves.

g. There would appear to be a natural tendency for dynamic amplification of the height of tsunami waves reaching a straight coastline over a uniformly sloping Continental Shelf. This is indicated by theory, but is as yet unconfirmed by experiment.

h. Some evidence exists to show that the Alaskan earthquake produced waves of from 3 to 5 hours period, possibly resulting from the seaward thrust of the coastal landmass, or developing as nonlinear subharmonic responses to the ocean boundaries.

\section{Features of Tsunami Damage}

a. Tsunami waves from the Alaskan earthquake had their most damaging effects when they occurred on the high spring tide.

b. The possibility of relationship of earthquakes of large magnitude with times of high spring tides predicates a design criterion that concurrence of high spring tide with maximum tsunami wave height should always be considered.

c. At Seward, Valdez and Whittier, heavy tsunami damage was caused by submarine slide-generated waves of about 3 to 5 minutes period and 30- to 40-foot height. These waves broke with bore effect on the coastlines and displaced or smashed objects in their path.

d. At Kodiak, Alberni, and Crescent City, as also at Seward and Valdez, the main tsunami waves, with or without overriding harmonics or local seiche waves, acted as fastrising and ebbing tides, without bore formation (except in the narrow Near Island channel at Kodiak). They buoyed objects and moved them with massive and sustained stream effect against nonmoving objects. 
e. The worst effects of (c) occurred during and immediately following the earthquake. The worst effects of (d) were contingent upon the concurrence of highest tsunami waves with highest tide, several hours after the earthquake.

f. Tectonic regional subsidence of the land increased the damage potential of the tsunami, as at Kodiak, Seward, and Whittier, and mildly at Valdez; uplift of the land decreased the damage potential, as at Cordova.

g. Submarine sliding and collapse of waterfront areas at Seward, Valdez, and Whittier, were probably promoted by drawdown of the water table as a result of seismic seiches generated by the earthquake or initial seismic sea waves of displacement. Primary cause of collapse was the unstable nature under vibration of the glacial deposits on which these towns are founded.

h. Small boats and marina docks suffered severely from the waves. If beached and caught by turbulent water they were frequently rolled and waterlogged or otherwise smashed. If anchored fore and aft, they were often keeled by broadside currents, and sunk at their moorings.

i. Larger boats usually floated and had a better chance of survival, but were usually damaged by battery. Vessels of ship size showed best survival abilities.

j. Pile-supported dock structures and decking were frequently buoyed off their piles as a consequence of inadequate connections (usually driftpins) and were carried away and destroyed. Inadequately braced pilings were ready victims for destruction. Some piles were pulled from their sockets because of inadequate adhesion in the foundation. Usually these piles had insufficient penetration in the foundation.

k. At Kodiak, the breakwaters were severely damaged by compaction-settling of the foundation, regional subsidence, resultant wave overtopping and severe scour from high velocity flows probably exceeding 40 feet per second.

1. Land-based structures of timber construction, insecurely fastened to their foundations, suffered severely. They were usually floated off and beached near the high water limit, or were splintered and smashed by impacts against obstacles or by momentum from behind.

m. A.t Kodiak Naval Station, the value of hold-down cables was demonstrated when a small building, so provided, withstood the waves in an area where others of its kind were swept away. 
n. At Crescent City, stacks of floatable building timber and logs at the lumber dock proved a great hazard by furnishing flotsam to the waves.

o. Reinforced concrete, concrete block, and stone-wall structures were much less susceptible to tsunami damage, in terms of collapse or displacement, than wooden structures. Generally they survived the tsunami well, but suffered from impact damage, wetting, and cracking under uneven foundation settlement.

p. Oil storage tanks at the waterfronts were devastated by the tsunami waves at Seward, Valdez, Whittier, and Crescent City. At all of these places, oil fires were started and spread by water, and burned uncontrolled. Oil contamination from spillage and spreading by the waves was serious. At Kodiak City and Kodiak Naval Station, oil tanks were at levels above the reach of the waves, and oil fires did not occur.

q. The power plant at the Naval Station, Kodiak, was vulnerable to flooding, and contamination from heavy fuel oil rendered all machinery inoperable and unsalvable.

4. General Design Criteria for Tsunami Protection

a. Safety, Economy and Design

(1) For any given location subject to attack from tsunamis, a standard of safety and economy needs to be established that takes into account the following factors:

(a) The degree (magnitude-frequencies) to which the region is seismically active (eg. Figures 3, 4, \& 5).

(b) The geological and historical nature of earthquake faulting (eg. Figures 2, 3, \& 4).

(c) The statistical trend of focal depth of local earthquakes in relation to distance from the shore (eg. Figure 6).

(d) The exposure of the coast to transocean tsunamis (eg. Figure 27).

(e) The protection afforded by offshore islands.

(f) The peculiarities of the coastline to concentrat: energy in specific places (eg. Figures 72 and 73 ).

(g) The resonating capacity of particular bays and 
inlets toward amplifying tsunami runup (eg. Figures 72, 133).

(h) The historical evidence for tectonic earth movement, whether horizontal, vertical, or both.

(i) The geological nature and stability of the coastal area, particularly the susceptibility to submarine landsliding, earth avalanches, and to consolidation under vibration.

(j) The history of tsunami inundation for the region.

All these considerations amount to a risk analysis for defining a design earthquake or a design tsunami. In this, statistical guidelines such as Figures 17, 23, 28, 41, and 71 or Equations (2), (3), (6), and (19) may be useful. Distribution functions of frequency of occurrence of tsunami runup height (cf. Wiegel, 1965) are also helpful. The economic aspects of the problem should determine whether tsunami barriers are both feasible and justifiable.

(2) Estimates of water velocity likely to be encountered at different places from the design tsunami should properly take account of the wave propagation in the area. If bore formation is expected, velocities at the front are calculable from Equation (D-17) (Appendix D) with $K=2.0$, say. If bore formation or breaking does not occur, velocities may be calculated from Equation $(D-2)$ or $(D-20)$.

(3) Water forces on objects, which are not unreasonably large, may be calculated by use of Equation ( $D-16)$, Appendix D. The Reynolds number appropriate to the flow and the shape of the object should be determined in order to arrive at a suitable value of drag coefficient $C_{D}$. More careful analysis may be needed to allow also for lift-forces developing from the flow between the object and its support.

(4) Water forces on objects which present large continuous surfaces such as breakwaters, seawalls, large buildings, highway embankments, etc., may be calculated by use of Equation (D-24), Appendix D, or its simplification Equation (54i). If the latter, an appropriate value of the pressure coefficient $C_{p}$ needs to be chosen between the range 1 to 14.

b. Harbor Structures

(1) Breakwaters should have stone or blocks of sufficient weight to resist the flow of water at expected scourvelocities from overtopping. 
(2) Timber-pile structures should have piles of adequate strength capable of developing sufficient soil adhesion to resist pullout from buoyant forces.

(3) Timber decking for harbor structures should be adequately fastened to the supporting piles to resist uplift pressures.

(4) Adequate structural strength and adequate bracing in piled structures are important.

(5) Guide-piles for floating small-craft landing decks should desirably be crossbraced above and below water to develop adequate truss strength against water loading.

c. Land and Waterfront Structures

(1) Buildings on exposed land areas should have deep foundations of reinforced concrete of the beam and raft type, to resist scour and undermining.

(2) Buildings should be oriented, if possible, to expose their shorter sides to potential wave inundation.

(3) Reinforced concrete or steel frame buildings with shear walls are desirable.

(4) Wooden-frame buildings should preferably be located in the lee of more substantial buildings.

(5) Wooden-frame buildings should be well secured to their foundations, and have corner-bracing at ceiling level.

(6) Frame buildings in very exposed, low-lying areas should be designed so that the ground floor area may be considered expendable, since wetting damage would be inevitable. Elevated "stilt" design of aesthetic quality should be considered.

(7) Tree screening should be considered as a buffer zone against the sea and for its aesthetic value.

a. Power Plants and Oil Storage

(1) Power plants should be located out of reach of water.

(2) Oil tanks should be located on high ground or surrounded by dikes or walls to prevent oil spillage and fire hazard. 
e. Mooring Practice and Protection of Shipping

(1) All ships and boats should leave harbor for deep water following a tsunami warning, if time is available, and if adequate protection is not assured.

(2) Docks for seagoing vessels should be provided with specially designed shock-absorbing fenders.

(3) Large ships should be required to carry constanttensioning winches as standard equipment.

(4) Special moorings and mooring techniques should be evolved. 
A

b

C

$\mathrm{C}_{\mathrm{d}}$

$\mathrm{C}_{\mathrm{F}}$

$\mathrm{C}_{\mathrm{p}}$

d

$\mathrm{d}_{1}$

$\mathrm{d}_{\mathrm{s}}$

$d_{t}$

$\mathrm{d}$

f

g

$\mathrm{H}$

$\mathrm{H}$

$\mathrm{H}_{r}, \mathrm{H}_{1}$

$\mathrm{H}_{2}, \mathrm{H}_{3}$

$H(k)$

$J^{0}$

k

Half-length of rectangular tsunami source region

(1) Projected area of an obstacle in the vertical plane;

(2) also amplitude of sinusoidal water wave.

Half-breadth of rectangular tsunami source region

Phase velocity of water waves

Dimensionless drag coefficient in horizontal fluid flow

Dimensionless momentum force coefficient (Eq. D24)

Dimensionless pressure coefficient

Variable water depth

Value of $d$ at mouth of open bay or estuary

Total depth of tsunami surge above ground level at the front or tip

Depth of tsunami surge at the toe of a wall at the moment of maximum impact

Greatest depth of vertical column of water ejected up a wall on impact of a surge

Function of variable

Acceleration due to gravity

(1)Wave height; (2) wave height at edge of continental shelf;

(3) also height of bore (Appendix D)

Tsunami wave height at the generating source

Height of tsunami wave at coastal boundary (not necessarily run-up height)

Hankel transform (function of $k$ )

Zero-order Bessel function

Dimensionless wave number $(=2 \pi ! \lambda)$ 
(1) Dimensionless wave number (Eq. 9); (2) also numerical surge velocity coefficient (Eq. D-17)

L

m

M

n

$\mathrm{Na}$

$Q(r)$

Q

$r$

$\mathrm{R}$

S

S

t

$\mathrm{T}$

$\mathrm{T}_{\mathrm{n}}$

$\mathrm{T}_{\mathrm{m}}$

u

$u_{\mathrm{s}}$

$\mathrm{x}$

a

$\beta$

(1) Length of earthquake fault; (2) also length of channel or embayment

Numerical integer

Earthquake magnitude (Richter scale)

Numerical integer

Mean annual number of earthquakes (felt beyond a radius of $200 \mathrm{~km}$. from their epicenters)

Magnitude of initial water surface elevation (function of $r$ )

Constant value of $Q(r)$

Variable (radial) distance

Limiting radius of initial water surface elevation

Slope of sea bed or of land near the coast

Equivalent diameter of tsunami source region

Variable time

Wave period

Value of $\mathrm{T}$ for $\mathrm{n}^{\text {th }}$ mode of oscillation of a basin or embayment $(n=1,2,3 \ldots)$

Value of $\mathrm{T}$ for $\mathrm{m}^{\text {th }}$ mode of oscillation of a continental shelf

Horizontal water particle velocity in a wave or surge

Water velocity at and near the front of a tsunami surge

Variable distance

Amplification factor for wave amplitude

Numerical coefficient (Eq. 23)

Ratio of crest height above still water level to wave height

Dimensionless disturbance coefficient representing energy loss at the front of a bore 
Resultant surface ground displacement caused by earthquake Vertical uplift component of tectonic surface ground movement Variable water surface elevation above still water level Crest height of wave above still water at coastal boundary (not necessarily the run-up height)

Angle of the sea bed to the horizontal at the coastal boundary Wave length

Horizontal thrust component of tectonic surface ground movement

Universal constant (3.14159...)

Mass density of sea water

Angular frequency of wave $(=2 \pi / T)$

Angle of inclination to the horizontal of the surface slope of a tsunami surge (Fig. D-1) 

Abernethy, D., Lommen, H. and Luecke, F. (1964) "Tidal Disaster in Alberni and Port Alberni, Picture Report," Lucky Printers and Lithographers, Alberni, B. C., Canada. 1964.

Airy, C. B., "Tides and Waves," (1945) Sect. VI, Encyclopedia Metropolitana, London, 1845.

Alaska Railroad (1964), "A Summary of Damage and Repairs to Roadbed and Track Following Earthquake of March 27, 1964," File Report, Alaska R. R., U. S. Dept. of Interior, 1964 (unpublished).

Alaska Command (1965) "Operation Helping Hand," Office of Commander-inChief, Alaska Command Headquarters, Seattle, Washington, 1965, 88 pp.

Alaska Construction (1965) "The Bouncing Chena," Alaska Construction (Magazine) May-June, 1965, p. 19

Algermissen, S. T. (1966) "Mechanism of the Prince William Sound Earthquake," Proceedings, ESSA Symposium on Earthquake Prediction,

Environmental Science Services Administration, U. S. Dept. of Commerce, Rockville, Maryland, Feb. 1966, pp. 20-25.

Allen, J. (1947), Scale Models in Hydraulic Engineering, Longmans, Green \& Co., London, 1947, 407 pp.

Allen, M. W. (1936), "The Lunar Triggering Effect on Earthquakes in Southern California," Bulletin, Seismological Soc. of America, April 1936.

Anchorage Printing Company (1964), Alaska Quake (Pictorial Review), Anchorage, Alaska, 1964.

Armstrong, B. B., et al (1964) "Reconstruction and Development Survey of Earthquake Damages in Alaska", Report of Alaska Construction Consultant Committee to Federal Reconstruction and Development Planning Commission, May 1964, 86 pp.

Armstrong, K. (1964) "Kodiak Tsunami - First 29 Days," Report of City of Kodiak, Alaska, 1964.

Bading, P., McCutcheon, S., Madsen, A. and Balog, J.(1964) "A Full Color Pictorial Fresentation of the Alaska Quake of Good Friday, March 27, 1964, 5:36 P.M.," Plastichrome Travel Series, Vol. 315, Series C, 1964, J\&H Siles, Spenard, Alaska.

Bailey, l. F. (1960), "The Use of Historical Tsunami Wave Height Data in Forecasting Run-up," Proceedings, ESSA Symposium Earthquake Predistion" Environmental Science Services Administration, U. S. Department of Commerce, Rockville, Ma., Feb. 1966, pp. 110-111. 
Benioff, H. (1964), "Earthquake Source Mechanisms," Science, Vol. 143 (3613), Mar. 1964, pp. 1399-1406. Copyright 1964 by the American Association for the Advancement of Science.

Benioff, H., Press, F. and Smith, S. (1961) "Excitation of Free Oscillations of the Earth by Earthquakes," Journal, Geophysical Research, Vol. 66 (2), Feb. 1961, pp. 605-619.

Ben-Menahem, A. (1961), "Radiation of Seismic Surface Waves from Finite Moving Sources," Bulletin, Seismological Society of America, Vol. 51 (3), 1961, pp. 401-435.

Berg, E. (1964), "The Alaskan Earthquake: Its Location and Seismic Setting" Proceedings, 15 th Alaskan Science Conference, AAAS, College, Alaska, Sep. 1964, pp. 218-232

Berg, E., Cox, D. C., Furumoto, A. S., Kajiura, K., Kawasumi, H., Shima, E. "Field Survey of the Tsunami of 28 March 1964 in Alaska," Report, Hawaii Institute of Geophysics, 1964 (unpublished).

Biesel, F. (1966), "Radiating Second-Order Phenomena in Gravity Waves," in French, La Houizle Blanche, Vol. 2I(4), 1966, pp. 403-420.

Bouasse, H. (1924), Houle, Rides, Seiches et Marees, Librarie Delagrave, Paris, 1924, 511 pp.

Bracken, E. O. (1964), "Observations of Results of Earthquake Action, March 27, 1964, at Valdez, Alaska," Report of Alaska State Highway Department, Valdez, Alaska, 1964 (unpublished).

Brevdy, J. (1964), "Target Vulnerability Studies: Recovery Research, Alaska Project, 1964," U. S. Naval Radiological Defense Laboratory, San Francisco, California, 1964.

Brown, D. L. (1964), "Tsunami Activity Accompanying the Alaska Earthquake, 27 March 1964," Technical Report, U. S. Army Engineer District, Alaska, Corps of Engineers, Amchorage, Alaska, April 1964.

Bruder, W. A., (1964), "Earthquake Changes Alaska Shoreline," Proceedings, 15th Alaska Science Conference, AAAS, College, Alaska, Sep. 1964, p. 284 (Abstract only).

Bryant, F. J. (1964) "Transcripts of Tape Recordings of Eyewitness Accounts, Earthquake and Wave Damage at Valdez, Alaska, C\&GS, U. S. Dept. of Commerce, Washington, D.C. May 1964 (unpublished).

Bryant, J.J. (1964), "Estimates of Local Effects of Seismic Activity of 27 March 1964," Letter Report to Commerce Office, U. S. Naval Station, Kodiak, Alaska, C\&GS, U. S. Department of Commerce, 6 April 1964 (unpublished). 
Case, J. E., Barnes, D. F., Plafker, G. and Robbins, S. L. (1966) "Gravity Survey and Regional Geology of the Prince William Sound Epicentral Region, Alaska," Professional Paper 543-C, U. S. Geological Survey, Washington, D. C., 1966, $12 \mathrm{pp}$.

Chance, G., (1966), "Chronology of Physical Events of the Alaskan Earthquake," Report, National Science Foundation, Washington, D.C., 1966.

Chance, G. (1968), "Chronology of Physical Events as a Resurt of the Alaskan Earthquake, March 27, 1964, Valdez, Prince William Sound and Gulf of Alaska Localities, Cordova, Seward, Kodiak, Homer and Kenai," Reports to Committee on Alaska Earthquake, National Academy of Science, 1968 (unpublished)

Chapman, R. M. (1964), "A Reconnaissance Geological Examination of Earthquake Features in the Valdez Area and Along the Richardson Highway," File Report, U. S. Geological Survey, Fairbanks, Alaska, 1964, (unpublished).

Coulter, H. W. (1964), "Preliminary Report on the Geologic Effects of the March 27 Earthquake at Valdez, Alaska," Report, U. S. Geological Survey, Fairbanks, Alaska, 1964 (unpublished).

Coulter, H. W. and Migliaccio, R. R. (1966), "Effects of the Earthquake of March 27, 1964, at Valdez, Alaska," Professional Paper 542-C, U. S. Geological Survey, Washington, D. C., 1966, 36 pp.

Cox, D. C., Homma, M., Suzuki, M., Takahasi, R. and Wiegel, R. L. (1965) "Physically Feasible Means of Protecting Hilo from Tsunamis," 3rd Report, Hilo Tech. Tsunami Advisory Council, Dec. 1965, 38 pp.

Cox, D. C. and Mink, J. F. (1963) "The Tsunami of 23 May 1960 in the Hawaiian Islands," Bulletin, Seismological Society of America, Vol. 53(6), Dec. 1963, pp. 1191-1209.

Cross, R. H. (1966), "Water Surge Forces on Coastal Structures," Technical Report HEL 9-10, Hydrauiic Engineering Laboratory, University of California, Berkeley, California, July 1966, 106 pp.

Cross, R. H. (1967) "Tsunami Surge Forces", Proceedings, American Society of Civiz Engineers, Vol. 93, WW4, Nov. 1967, pp. 201-231.

Cumberbatch, E. (1960), "The Impact of a Water Wedge on a Wall," Joumal, Fluid Mechanies, Vol. 7, 1960, pp. 353-373.

Davis, T. N. and Echols, C. (1962), "A Table of Alaska Earthquakes, 17881961; Geophysical Research Report No. 8 (UAG-RI3I), Alaska University Geophysics Institute, Fairbanks, Alaska, 1962, 43 Ip.

Davison, C. (1936), Great Earthquakes, J. Murby and Co., Iondon, 1936. 
Dean, R. G. (1964), "Long Wave Modification by Linear Transitions," American Society of Civil Engineers, Vol. 90, WWI, Feb. 1964, pp. 1-29.

Denner, W. W. (1964), "Notes on Measurements of Tsunami Run-up Heights at Various Places Along Coastline of Alaska," April 1964, Personal Communication (unpublished).

Dorn, W. L. (1964), "Alaska Earthquake of 27 March 1964; Remote Seiche Stimulations," Science, Vol. 145, July 1964, pp. 261-262.

Dressler, R. F. (1952) "Hydraulic Resistance Effects upon the Dam-Break Functions," Journal of Research, National Bureau Standards, Washington, D. C., Vol. 49, 1952, pp. 217-225.

Eaton, J. P., Richter, D. H. and Ault, W. V. (1964), "The Tsunami of May 23, 1960 on the Island of Hawaii," Bulletin, Seismological Society of America, Vol. 51(2), April 1964, pp. 135-157.

Eckel, E. B. (1967), "Effects of the Earthquake of March 27, 1964, on Air and Water Transport, Communications and Utilities Systems in South Central Alaska," Professional Paper 545-B, U. S. Geological Survey, Washington, D. C., 1967, 27 pp.

Engle, E. (1966), Earthquake: The Story of Alaska's Good Friday Disaster, John Day Co., New York, 1966, 217 pp.

Fisher, W. E. and Merkle, D. H. (1965), "The Great Alaska Earthquake," Technical Report No. AFWL TR-65-92, Air Force Weapons Laboratory, Research and Technical Division, Air Force Systems Command, Kirtland Air Force Base, New Mexico, Vol. I, 93 pp., Vol. II, 312 pp. L965.

Foley, R. E. (1964) "Crescent City Tidal Waves," Shore and Beach, Vol. $32(1)$, April 1964, p. 28.

Francis, J. R. D. (1958), Fluid Mechanics, Edward Arnold, Ltd., London, $1958,340 \mathrm{pp}$.

Freeman, J. C. and Lé Mehauté, B. (1964), "Wave Breakers on a Beach and Surges on a Dry Bed," Proceedings, American Society of Civil Engineers, Vol. 90, HY2, March 1964, pp. 187-216.

Fukui, Y., Nakamura, M., Shiraishi, H. and Sasaki, Y. (1963):"Hydraulic Study of Tsunami, Coastal Engineering in Japan, Vol. 6, 1963, pp. $67-82$.

Furumoto, A. S. (1965), "Source Mechanism Study of the Alaska Earthquake and Tsunami of 27 March 1964, Part II, Analysis of Rayleigh Wave," Technical Report HIG-65-17, University of Hawaii, Dec. 1965, pp. 31-42.

Gibson, A. H. (1925), Hydraulics and its Applications, Constable \& Co. Ltd., London, 1925, 801 pp. 
Goldsbrough, G. R. (1930), "The Tidal Oscillations in an Elliptic Basin of Variable Depth," Proceedings, Royal Society, London, Vol. 130(A), 1930, pp. 157-167.

Granthem, K. N. (1953), "Wave Run-up on Sloping Structures," Transactions, American Geophysical Union, Vol. 34(5), Oct. 1953, pp. 720-724.

Grantz, A., Plafker, G. and Kachadoorian, R. (1964), "Alaska's Good Friday Earthquake, March 27, 1964: A Preliminary Geologic Evaluation,"

Circular 491, U. S. Geological Survey, Washington, D.C., 1964, 35 pp.

Graves, W. D. E. (1964), "Alaska Earthquake: Horror Strikes on Good Friday" National Geographic Magazine, Vol. 126(1), July 1964, pp. 112-139.

Griffin, W., Hensinger, C., Pyke, V. et al (1964), Crescent City's Dark Disaster, Crescent City, California, 1964.

Gronewald, G. J. and Duncan, W. W. (1965), "Study of the Erosion Along Homer Spit and Vicinity, Kachemak Bay, Alaska," Proceedings, American Society of Civil Engineers, Coastal Engineering Conference, Santa Barbara, California, Oct. 1965 (publication pending).

Gutenberg, B. and Richter, C. F. (1954), Seismicity of the Earth and Associated Phenomena, Princeton University Press, Princeton, N. J. $1954,310 \mathrm{pp}$.

Hansen, W. R. (1965), "The Alaska Earthquake, March 27, 1964, Effects on Communities, Anchorage," Professional Paper 542-A, U. S. Geological Survey, Washington, D. C., 1965, 68 pp.

Hansen, W. R., Eckel, E. B., Schaem, W. E., Lyle, R. E., George, W. and Chance, G. (1966) "The Alaska Earthquake, March 27, 1964, Field Investigations and Reconstruction Effort", Professional Paper 541, U. S. Geological Survey, Washington, D.C. 1966, 111 pp.

Herringstad, G. (1964), "Earthquake Damage Survey, Valdez, Alaska," File Report, Plan and Report Branch, OREC, April 2, 1964 (unpublished).

Hicks, J. (1964), "Seward (An Eternity That Was All Over in Five Minutes)" Life Magazine, April 10, 1964, p. 32E.

Hicks, S. D. and Shofnos, W. (1965), "The Determination of Land Emergence from Sea Level; Observations in Southeast Alaska," Journal, Geophysical Research, Vol. 70(14), July 1965, pp. 3315-3320.

Hodgson, J. H. and Stevens, A. E. (1964), "Seismicity and Earthquake Mechanism" Chapter 2, Research in Geophysics, Vol. 2, Solid Earth and Interface Phenomena, MIT Press, Cambridge, Mass., 1964, fp. 27-59.

Hogan, D., Whipple, W. W. and Lundy, C. (1964), "Tsunami of 27 and 28 March 1964, State of Washington Coastline", File Report, U. S. Army Corps of Engineers, Seattle, Washington, 1964 (unpublished). 
Honda, K., Terada, T. and Isitani, D. (1908), Secondary Undulations of Ocean Tides, Philosophical Magazine, London, Vol. 15, 1908, p. 88.

Horikawa, K. (1961), "Tsunami Phenomena in the Light of Engineering View Point, Report on Chilean Tsunami of May 24, 1960, as observed along the Coast of Japan", Dec. 1961, pp. 136-150.

Houston Chronicle (1964), "Rice Experts Tell Theory on Earthquake", Houston, Texas, March 29, 1964.

Iida, K. (1958), "Magnitude and Energy of Earthquakes Accompanied by Tsunami and Tsunami Energy", Journal, Institute of Earth Science, Nagoya University, Japan, Vol. 6(2), 1958, pp. 101-112.

Iida, K. (1959) "Earthquake Energy and Earthquake Fault", Journal, Institute of Earth Science, Nagoya University, Japan, Vol. 7(2), 1959, pp. 98-107.

Iida, K. (1963), "A Relation of Earthquake Energy to Tsunami Energy and the Estimation of the Vertical Displacement in a Tsunami Source", Journal, Institute of Earth Science, Nagoya University, Japan, May 1963, pp. 49-67.

Isaacs, J. D. (1946), "Field Report on the Tsunami of April 1, 1946" Department of Engineering, University of California, Berkeley, May 1946.

Johnson, J. W., Fuchs, R. A. and Morison, J. R. (1951), "The Damping Action of Submerged Breakwaters", Trans. American Geophysical Union, Vol. 32(5) October 1951, pp. 704-718.

Kachadoorian, R. (1965), "The Alaskan Earthquake, March 27, 1964, Effects on Communities, Whittier", Professional Paper 542-B, U. S. Geological Survey, Washington, D.C., 1965, 21 pp.

Kachadoorian, R. and Plafker, G. (1967), "The Alaska Earthquake of March 27, 1964, Effects on Communities, Kodiak and Nearby Islands", Prof. Paper 542-F, U. S. Geological Survey, Washington, D.C. 1967.

Kajiura, K. (1963), "The Leading Wave of a Tsunami", Bulletin, Earthquake Research Institute, Tokyo, Japan, Vol. 41, 1963, pp. 535-571.

Karo, H. A. (1964), "The Alaskan Earthquake: Coast and Geodetic Surveys of Earthquake Effects", The Military Engineer, July-August 1964 , pp. 251-253.

Kent, R. E. (1965), "Water Level Changes Produced on the Pacific Coasts of the United States and Canada by the Alaskan Tsunami of 1964", Technical Report to Office of Naval Research, Oceanographic Services, Inc., Santa Barbara, California, 1965, $14 \mathrm{pp}$. 
Keulegan, G. H. (1949) "Wave Motion", Chapter XI, Engineering Hydraulics, H. Rouse, Editor, John Wiley, New York, 1949, pp. 711-768.

Keulegan, G. H. (1962), "Hilo Bay Tsunami Model", Appendix A to Research Report No. 2-3, "Pilot Model Study for the Design of Hilo Harbor Tsunami Model" by J. G. Housley, Waterways Experiment Station, U. S. Army Corps of Engineers, Vicksburg, Mississippi, March 1965.

Keulegan, G. H. and Patterson, G. W. (1940), "Mathematical Theory of Irrotational Translation Waves", Journal of Research, National Bureau of Standards, Vol. 24(1), 1940, pp. 47-101.

Keys, J. G. (1963), "The Tsunami of 22 May 1960 in the Samoa and Cook Islands", Bulletin, Seismological Society of America, Vol 53(6), Dec. 1963, pp. 1211-1227.

Knopoff, L. (1964), "Earth Tides as a Triggering Mechanism for Earthquakes" Bulletin, Seismological Society of America, Vol. 54(6), Dec. 1964, pp. $1865-1870$.

Kodiak Mirror (1964), "Tidal Wave Demolishes Downtown Area" April 3, 1964. Kranzer, H. and Keller, J. (1959) "Water Waves Produced by Explosions", Journal of Applied Mechanics, Vol. 30(3), 1959; pp. 398-407.

Kunreuther, H. and Fiore, E. S. (1966), "The Alaskan Earthquake; a Case Study in the Economics of Disaster", Study S-228, Inst. for Defense Analysis,Economics and Political Studies Division, U. S. Office of Civil Defense. Feb. 1966. 162 pp.

Lamb, H. (1932), Hydrodynamics, Cambridge University Press, 6th Edition, 1932 , p. 262

Lantz, B. and Kirkpatrick, M. (1964), "Seward Quake, Good Friday, 1964" Kirkpatrick Printing Co., Seward, Alaska, 1964.

LéMehauté, B. (1960), "Periodical Gravity Wave on a Discontinuity", Proc. American Society Civil Engineers, Vol. 86, HY9, Nov. 1960, pp. 11-41.

Lemke, R. W. (1967), "The Alaska Earthquake of March 27, 1964, Effects on Communities, Seward", Professional Paper 542-E, U. S. Geological Survey, Washington, D. C. 1967.

Life Magazine (1964), "Earthquake in Alaska", Life Magazine, April 10, 1964, pp. 26-38.

Loomis, H. G. (1966), "Spectral Analysis of Tsunarni Records from Stations in the Hawaiian Islands", Bulletin, Seismological Society of America, Vol. 56(3), June 1966, pp. 697-713. 
Loomis, H. G. (1967), "The Tsunami of March 28, 1964, in the Hawaiian Islands", Personal communication, Joint Tsunami Research Effort, ESSA, U. S. Department of Commerce, Honoluiu, Hawaii, 1967 (incorporated in this report with minor amendment).

MacDonald, G. A., Shepard, F. P. and Cox, D. C. (1947), "The Tsunami of April 1, 1946, in the Hawaiian Islands", Pacific Science, Vol. I(I), Jan. 1947, pp. 21-37.

MacNamara, F. (1964), Report to the U. S. Army Corps of Engineers, May 1964.

Magoon, O. T. (1962), "The Tsunami of May 1960 as it Affected Northern California", Paper presented at American Society of Civil Engineers, Hydraulics Division Conference, University of California, Davis, August 1962 (unpublished).

Magoon, O. T. (1965), "Structural Damage by Tsunamis", Proceedings, American Society Civil Engineers, Specialty Conference on Coastal Engineering, Santa Barbara (California), Oct. 1965, pp. 35-68.

Malloy, R. J. (1964), "Crustal Uplift Southwest of Montague, Alaska", Science, Vol. 146, Nov. 1964, pp. 1048-1049. Copyright 1964 by the American Association for the Advancement of Science.

Malloy, R. J. (1965), "Gulf of Alaska: Seafloor Upheaval", Geo-Marine Technology, Vol. I(6), June 1965, pp. 22-26.

Malloy, R. J. (1967) "Marine Geological Reconnaissance of Epicentral and Aftershock Regions, 1964 Alaska Earthquake", U. S. Coast and Geodetic Survey, U. S. Dept. of Commerce, Rockville, Maryland, 1967.

Malloy, R. J. and Merrill, G. F. (1967), "Vertical Crustal Movement Associated with the 1964 Alaska Earthquake", U. S. Coast and Geodetic Survey, U. S. Dept. of Commerce, Rockville, Maryland, 1967.

Marine Advisers (1964), "A Broad-Frequency Band Wave Study at Monterey Harbor, California", Report to U. S. Army Corps of Engineers, San Francisco, Marine Advisers, La Jolla, California, July 1964, 19 pp. plus figures, tables.

Maruyama, T. (1964), "Statical Elastic Dislocations in an Infinite and Semi-Infinite Medium", Bulletin. Earthquake Research Institute, Tokyo University, Japan, Vol. 42, 1964, pp. 289-368.

Marlette, J. W., Chan, H. H., Clifton, P. L., Gibson, W.M., Gordon, B. B. and Hill, D. M. (1965), "The Alaskan Earthquake", Bulletin 116-5, California Department of Water Resources, Sacramento, California, Oct. $1965,64 \mathrm{pp}$.

Matlock, H., Reese, L. C. and Matlock, R. B. (1962), "Analysis of Structural Damage from the 1960 Tsunami at Hilo, Hawaii", Technical Report Defense Atomic Support Agency 1268, Structural Mechanics Research Laboratory, University of Texas, Austin, March 1962, 95 pp. 
McCulloch, D. S. (1966), "Slide Induced Waves, Seiching and Ground Fracturing Caused by the Earthquake of March 27, 1964, at Kenai Lake, Alaska", Professional Paper 543-A, U. S. Geological Survey, Washington, D. C. $1966,41 \mathrm{pp}$.

McGarr, A. (1965), "Excitation of Seiches in Channels by Seismic Waves", Journal, Geophysical Research, Vol. 70(4), Feb. 1965, pp. 847-854.

McGarr, A. and Vorhis, R. C. (1967), "Seismic Seiches from the Alaska Earthquake", Professional Paper 544-E, U. S. Geological Survey, Washington, D.C. 1967.

Melchior, P. (1958), Earth Tides; Advances in Geophysics, Academic Press, New York, Vol. 4, 1958, pp. 391-443.

Melchior, P. (1964), Earth Tides; Research in Geophysics, Chapter 7, Solid Earth and Interface Phenomena, MIT Press, Cambridge, Mass., Vol. 2, 1964, pp. 163-193.

Miche, R. (1951), "Le Pouvoir Reflectuissant des Ouvrages Maritimes", Annales des Ponts et Chaussees, May-June 1951.

Migliaccio, R. R. (1964), "Drilling and Boring Logs on Valdez Waterfront", Letter Report to Resident Engineer, U. S. Army, Corps of Engineers, Valdez, Alaska, May 1964 (unpublished).

Migliaccio, R. R. (1964), "Earthquake of March 27, 1964, Valdez", File Report to R. G. Sherman, Chief Geologist, Alaska State Highway Department, College, Alaska, April 10, 1964 (unpublished).

Milne, J. and Lee, A. W. (1939), Earthquakes and other Earth Movements, Blekiston's Son \& Co, Inc., Philadelphia, Pa. 1939.

Milne-Thomson, I. M. (1960), Theoretical Hydrodynamics, The MacMillan Company, New York, 1960, 660 pp.

Momoi, T. (1962), "The Effects of Coastlines on the Tsunami, (1) and (2) and Some Remarks on the Chilean Earthquake", Bulletin, Earthquake Research Institute, Tokyo University, Tokyo, Japan, Vol. 40, 1962, pp. 719-746.

Munk, W. H. (1962), "Long Ocean Waves", Chapter 18, Vol. I, The Sea, Interscience Publishers, New York, 1962, pp. 647-663.

Munk, W. H. (1963), "Some Comments Regarding Diffusion and Absorption of Tsunamis", Proceedings, Tsunami Meeting, 10th Pacific Science Congress, International Union of Geodesy and Geophysies, Monograph No. 24, July 1963. 
Munk, W. H., Snodgrass, F. E. and Tucker, M. J. (1959), "Spectra of Low Frequency Ocean Waves", Bulletin, Scripps Inst. of Oceanography, Vol. $7(4), 1959$, pp. 283-362.

National Board of Fire Underwriters and Pacific Fire Rating Bureau (1964), "The Alaska Earthquake, March 27, 1964", Distributed by American Insurance Association, San Francisco, 1964, 35 pp.

National Geographic Magazine (1964), "Alaska Earthquake", National Geographic Magazine, Vol. 126(1), July 1964, pp. 112-156.

Nautical Almanac (1964), "The American Ephemeris and Nautical Almanac for the Year 1964", Nautical Almanac Office, U. S. Naval Observatory, U. S. Govt. Printing Office, Washington, D.C. 1962, $520 \mathrm{pp}$.

Neumann, G. (1948), "On Resonance Oscillations of Bights and the Mouth Correction for Seiches", Deutsche Hydrographische Zeitschrift, Vol. I, 1948, pp. 79-101.

Norton, F. E. E. and Haas, J. E. (1966), "Chronological Narrative of Human Response to Alaska Earthquake, March 27, 1964, Kodiak, Whittier, Afognak, Alitak, Ouzinkie, Anchorage, Seldovia, Kaguyak, Alaska", Reports, Disaster Research Center, Department of Sociology, Ohio State University, 1966 (unpublished).

Nowroozi, A. A. (1965), "Eigenvibrations of the Earth after the Alaskan Earthquake", Journal, Geophysical Research, Vol. 70(20), Oct. 1965, pp. 5145-5156.

Office of Emergency Planning (1964), "The Alaska Earthquake: A Progress Report; 279 Days of Federal Reconstruction Effort", U. S. Office of Fmergency Planning, Executive Office of the President, Dec. 29, 1964, $45 \mathrm{pp}$.

Pararas-Carayannis, G. (1965), "Source Mechanism Study of the Alaska Earthquake and Tsunami of 27 March 1964", Part I, Water Waves, Technical Report HIG-65-17, Hawaii Institute of Geophysics, December $1965,28 \mathrm{pp}$.

Park Letter Service, Inc. (1964), "Quake (Pictorial Record)", Park Letter Service, Inc., Alaska, 1964.

Parker, M. (1964), "Valdez (An Eternity that was All Over in Five Minutes)" Life Magazine, April 10, 1964, p. 32E.

Parkin, E. J. (1966), "Alaskan Surveys to Determine Crustal Movement", Part II, Horizontal Displacement, Proceedings, American Congress, Surveying and Mapping, Washington, D. C., March 1966. 
Plafker, G. (1964), "Tectonic Movements, Seismic Sea Waves, and Locally Generated Waves Associated with Alaska's Good Friday Earthquake", Paper presented to American Geophysics Union, Seattle, Washington, Dec. 1964, Transactions, American Geophysics Union, Vol. 45(4), 1964, pp. 633-634 (abstract only).

Pafker, G. (1965), "Tectonic Deformation Associated with the 1964 Earthquake", Science, Vol. 148(3678), June 1965, pp. 1675-1687. Copyright 1965 by the American Association for the Advancement of Science.

Plafker, G. (1967), "Surface Faults on Montague Island Associated with the 1964 Alaska Earthquake", Geological Survey Professional Paper 543-G, U. S. Geological Survey, Department of The Interior, Washington, D.C. 1967 .

Plafker, G. and Kachadoorian, R. (1966), "Geologic Effects of the March 1964 Earthquake and Associated Seismic Sea Waves on Kodiak and Nearby Islands, Alaska", Professional Paper 543-D, U. S. Geological Survey, Washington, D.C., 1966, 46 pp.

? Iafker, G. and Mayo, L. R. (1965), "Tectonic Deformation, Subaqueous Slides and Destructive Waves Associated with the Alaskan March 27 , 1964 Earthquake, an Interim Geologic Evaluation", Report, U. S. Geological Survey, Menlo Park, California, 1965, 19 pp.

Press, F. (1964), "Long Period Waves and Free Oscillations of the Earth", Chapter 1, Research in Geophysics, Solid Earth and Interface Phenomena, Vol. 2, MIT Press, Cambridge, Massachusetts, 1964, pp. 1-26.

Press, F. (1965). "Displacements, Strains and Tilts at Teleseismic Distances", Journal, Geophysies Research, Vol. 70(10), May 1965, pp. 2395-2412.

Press, F. and Brace, W. F. (1966), "Earthquake Prediction", Science, Vol. 152(3729), June 1966, pp. 1575-1584.

Press, F., Ben-Menahem, A. and Toksoz, M. N. (1961), "Experimental Determination of Earthquake Fault Lencth and Rupture Velocity", Journal, Geophysies Research, Vol. 66(10), October 1961, pp. 3471-3485.

Press, F. and Jackson, D. (1965), "Alaskan Earthquake, 27 March 1964: Vertical Extent of Faulting and Elastic Strain Energy Release", Science, Vol. 147, Feb. 1965, pp. 867-868. Copyright 1965 by the American Association for the Advancement of Science.

Raudio, V. J. (1965), "Possible Causes of Unusually High Tsunamis at Crescent City, California", B.S. Thesis, U. S. Naval Postgraduate School, Monterey, California, 1965 (unpublished).

Rayleigh, J. W. S. (1945), The Theory of Sound, Dover Publications, INew York, 1945 Edition. 
Reese, L. C. and Matlock, H. (1967), "Structural Damage from Tsunami at Hilo, Hawaii", Conference Preprint 552, ASCE National Meeting, Water Resources Engineering, New York, Oct. 1967, 45 pp.

Reimnitz, E. and Marshall, N.F. (1965), "Effects of the Alaska Earthquake and Tsunami on Recent Deltaic Sediments", Journal, Geophysics Research, Vol. 70(10), May 1965, pp. 2363-2376.

Roberts, J. A. (1964), "The Reshaping of South Beach, Crescent City, California, After the Tsunami of 27-28 March 1964", Paper presented to Beach Erosion Control Conference, California State Department Water Resources, Santa Monica, California, Dec. 1964, 18 pp. (unpublished).

Roberts, J. A. and Chien, C. W. (1965), "The Effects of Bottom Topography on the Refraction of the Tsunamis of 27-28 March 1964; The Crescent City Case", Transactions, Ocean Science and Ocean Engineering, Washington, D. C., Vol. 1 and 2, 1965, pp. 707-716.

Rouse, H. (1938), Fluid Mechanics for Hydraulic Engineers, Dover Publications, Inc., New York, 1961 Edition, 422 pp.

Rusnak, G. (1966), "Evidence for a Fault Movement in Resurrection Bay"; Personal Communication and SEA Interview, U. S. Geological Survey, Menlo Park, California, Oct. 1966, Jan. 1967.

Ryall, A., Van Wormer, J. D. and Jones, A. E. (1967), "Triggering of Micro-earthquakes by Earth Tides and Other Features of the Truckee, California Earthquake of September 1966", Bulletin, Seismological Society of America, 1967 (publication pending).

Savage, J. C. and Hastie, L. M. (1966), "Surface Deformation Associated with Dip Slip Faulting", Journal, Geophysical Research, Vol. 71(20), October 1966, pp. 4897-4904.

Schatz, C. E., Curl, H. and Burt, W. V. (1964), "Tsunamis Along the Oregon Coast; the Ore Bin", Department of Geology and Mineral Industries, State of Oregon, Vol. 26(12), Dec. 1964, pp. 231-233.

Schoklitsch, A. (1917), Uber Dambruchwellen; Sitzungsberichte der k. Akademie der Wissenschaften, Vienna, Abt. IIa, Vol. 126, 1917, p. 1489.

Shannon, W. L. (1964), "Subsurface Investigation for City of Seward, Alaska and Vicinity, Technical Report to U. S. Army Corps of Engineers, Anchorage, Alaska, August 1964.

Shannon and Wilson (1964), "Subsurface Investigation for City of Seward, Alaska and Vicinity", Report to U. S. Army Corps of Engineers, Shannon and Wilson, Inc., Seattle, Washington, August 1964.

Shepard, F. P., MacDonald, G. A. and Cox, D. C. (1950), "The Tsunami of April 1, 1946", Bull., Scripps Inst. of Oceanography, Vol. 5(6), 1950, pp. $391-528$. 
Sievers, H. A., Villegas, C. G. and Barros, G.(1963), "The Seismic Sea Wave of 22 May 1960 Along the Chilean Coast", Bulletin, Seismological Society of America, Vol. 53(6), Dec. 1963, pp. 1125-1190.

Small, J. B. (1966), "Alaskan Surveys to Determine Crustal Movement", Part I, Vertical Bench Mark Displacement, Proceedings, American Congress, Surveying and Mapping, Washington, D. C., March 1966.

Smith, S. W. (1966), "Free Oscillations Excited by the Alaskan Earthquake", Joumal, GeophysicalResearch, Vol. 71(14), Feb. 1966, pp. 1183-1193.

Snodgrass, F. E., Munk, W. H. and Miller, G. R. (1962), "Long Period Waves over California's Continental Borderland", Part I, Background Spectra, Journal Marine Research, Vol. 20(1), March 1962, pp. 3-30.

Solibakke, H. (1964), "Earthquake, Seismic Wave and Fire - Seward, Alaska", Letter report to Mr. R. B. Robertson, General Manager, California Shipping Co. San Francisco, California, April 1, 1964 (unpublished).

Spaeth, M. G. and Berkman, S. C. (1965), "The Tsunami of March 28, 1964, as Recorded at Tide Stations", U. S. Coast and Geodetic Survey, Dept. of Commerce, Rockville, Md. April 1965, 59 pp.

Spaeth, M. G. and Berkman, S. C. (1967), "The Tsunami of March 28, 1964, as Recorded at Tide Stations", Contribution from U. S. Coast and Geodetic Survey to Report of Comittee on Alaska Earthquake, National Academy of Science, National Research Council, No. 33, 1967.

Standard Oi.l Company of California (1964), "Report of Damage to Oil Tank and Pipeline Facilities from Alaskan Earthquake of 1964", Producing, Manufacturing and Marketing Departments, Standard Oil Company of California, 1964 (unpublished).

Stanley, A. A. (1964), "Crescent City Sea Wave", Shore and Beach, Vol. 32(1), April 1964, p. 29.

Stauder, W. (1962), The Focal Mechanism of Earthquakes; Advances in Geophysics, Academy Press, New York, Vol. 9, 1962, pp. 1-76,

Stauder, W. and Bollinger, G. A. (1966), "The Focal Mechanism of the Alaska Earthquake of March 28, 1964, and of its Aftershock Sequence" Joumal, GeophysicalResearch, Vol. 71(22), Nov. 1966, pp. 5283-5296.

Stoker, J.J. (1957), Water Waves, Interscience Publishers, Inc., New York, 1957, $567 \mathrm{pp}$.

Stroh, A. (1964), "The Alaska Earthquake: Navy Operations at Kodiak", The Military Engineer, July-August 1964, pp. 254-255.

Sturm, C. G. and Sturm, W. B. (1964), Good Friday Nightmare, Sturm Publishing, Portland, Oregon, 1964. 
Takahasi, R. (1963), "On the Spectra and the Mechanism of Generation of Tsunamis", Proceedings 10th Pacific Science Congress, University of Hawaii, Honolulu, 1961; Monograph No. 24, International Union Geodesy and Geophysies, July 1963, pp. 19-25.

Takahasi, R. (1961) "Report on the Chilean Tsunami of May 24, 1960, as observed Along the Coast of Japan", Committee for Field Investigation of the Chilean Tsunami of 1960, Tokyo, Japan, Dec. 1961, 397 pp.

Thornton, D. L. (1946), "Seismic Sea Waves", Engineering, London, May 1946, p. 484 .

Tobin, D. G. and Sykes, L. R. (1966), "Relationship of Hypocenters of Earthquakes to the Geology of Alaska, Journal, Geophysical Research, Vol. $71(6)$, March 1966, pp. 1659-1667.

Tocher, D. (1963), "Source Mechanism of Shallow Seismic Events", Bull. Seismological Society of America, Vol. 48, 1963, p. 147.

Toksoz, M. N., Ben-Menahem, A. and Harkrider, D. (1965), "Source Mechanism of Alaska Earthquake from Long Period Seismic Surface Waves, Transactions, American Geophysical Union, Vol. 46, 1965, p. 154 (abstract only).

Townshend, J. B. and Cloud, W. K. (1964), "Preliminary Intensity Evaluation of the Prince William Sound Earthquake of March 28, 1964; Symposium on the Alaskan Earthquake, Proceedings, 15th Alaskan Science Conference, AAAS, College, Alaska, Sep. 1964, pp. 233-238.

Tudor, W. J. (1964), "Tsunami Damage at Kodiak, Alaska and Crescent City, California, from Alaskan Earthquake of 27 March 1964", Technical Note No. N-622, U. S. Naval Civil Engrg Laboratory, Port Hueneme, Calif., Nov. $1964,128 \mathrm{pp}$.

Twenhofel, W. S. (1952), "Recent Shoreline Changes along the Pacific Coast of Alaska, Amexican Journal Science, Vol. 250(7), 1952, pp. 523-548.

U. S. Army Corps of Engineers (1965), Map of Crescent City Harbor Tsunami High Water Marks, U. S. Army Engineer District, San Francisco, Corps of Engineers, May 1965.

U. S. Coast Guard, "Radio Messages from Light Stations at Cape Hinchinbrook, St. Elias and Other Coast Guard Stations, Alaska", Coast Guard, U. S. Treasury Department, Washington, D.C., 1964 (unpublished).

U. S. Coast and Geodetic Survey (1964), "Assistance and Recovery in Alaska, 1964", Report, C\&GS, Dept. of Commerce, Washington, D.C. March 1965, $45 \mathrm{pp}$. 
U. S. Coast and Geodetic Survey (1964), "Preliminary Report, Prince William Sound, Alaskan Earthquakes, March-April 1964", C\&GS, U. S. Dept. of Commerce, Washington, D.C. April 1964, 100 pp.

U. S. Coast and Geodetic Survey (1964), "Preliminary Report, Tidal Datum Plane Changes, Prince William Sound, Alaskan Earthquakes, March-April 1964", C\&GS, U. S. Dept. of Commerce, Washington, D. C., Sep. 1964 , $4 \mathrm{pp}$.

U. S. Coast and Geodetic Survey (1964), "Tsunami: The Story of the Seismic Sea Wave Warning System", C\&GS, U. S. Dept. of Commerce, WAshington, D. C., 1964 .

Van Dorn, W. G. (1961), "Some Characteristics of Surface Gravity Waves in the Sea Produced by Nuclear Explosions, Journal, Geophysical Research, Vol. 66(11), November 1961, pp. 3845-3862.

Van Dorn, W. G. (1965), "Source Mechanism of the Tsunami of March 28, 1964, in Alaska", Proceedings, 9th Conference Coastal Engineering, Lisbon, Portugal, June 1964, Coastal Engineering Research Council, ASCE, New York, 1965.

Van Dorn, W. G. (1965), "Tsunami Waves off Montague Island", Letter to W. I. Petrie, Scripps Institution of Oceanography, 2 November 1965 , (unpublished).

Van Dorn, W. G. (1965), Tsunamis; Advances in Hydroscience, Vol. 2, Academic Press, New York, 1966, pp. 1-48.

Vitousek, M. H. (1963), "The Tsunami of 22 May 1960 in French Polynesia" Bulletin, Seismological Society of America, Vol. 53(6), Dec. 1963, pp. 1229-1236.

Von Huene, R. (1964), "Landsliding at Cape Hinchinbrook, Hinchinbrook Island, Alaska, Resulting from the Alaskan Earthquake, March 27 , 1964", Notes and Report to U. S. Coast Guard, U.S. Naval Ordnance Test Station, China Lake, California, 1964 (unpublished).

Von Huene, R., Malloy, R. J., Shor, G. G., and St. Amand, P. (1967), Geologic Structures in the Aftershock Region of the 1964 Alaskan Earthquake, Journal, Geophysical Research, Vol. $72(14)$, July 1967 , pp. 3649-3660.

Von Huene, R., Shor, G. G. and Reimnitz, E. (1967), "A Geologic Interpretation of Seismic Profiles in Prince William Sound, Alaska", Contribution to Oceanography of the Alaskan Earthquake of Narch 27 , 1964, Bulletin, Geological Society of America, Vol. 78(4), 1967.

Vorhis, R. C. (1967), "Hydrologic Effects of the Earthquake of March 27, 1964, Outside Alaska", Professional Paper 544-C, U. S. Geological Survey, Dept. of The Interior, Washington, D. C., 1967, 54 pr. 
Waller, R. M. and Stanley, K. W. (1966), "The Alaska Earthquake of March 27, 1964; Effects on Communities, Homer Area", Professional Paper 542-D, U. S. Geological Survey, Dept. of The Interior, Washington, D. C., 1966, $28 \mathrm{pp}$.

Watanabe, H. (1964), "Studies on the Tsunamis on the Sanriku Coast of the Northeastern Honshu in Japan", Geophysics Magazine, Tokyo, Japan, Vol. $32(1)$, March 1964, 64 pp.

Watkins, Captain J. B. Jr. (1966), Evidence for a Fault Movement in Resurrection Bay, Personal Communication and SEA Interview, U. S. Coast and Geodetic Survey Ship "Hodgson", Valdez, Alaska, July 1966.

Whiprle, W. and Lundy, C. (1964), "Damage Reconnaissance", File Report, Tidal Hydraulics Unit, U. S. Army Corps of Engineers, Seattle, Washington, April 1964 (unpublished).

White, W. R. H. (1966), "The Alaska Earthquake - Its Effect in Canada", Canadian Geographic Journal, Vol. $72(6)$, June 1966, pp. 210-219.

Whitham, G. B. (1955), "The Effects of Hydraulic Resistance on the DamBreak Problem", Proceedings, Royal Society, London, Vol. 227(a), 1955.

Wiegel, R. L. (1964), Oceanographical Engineering, Prentice-Hall, Inc. Englewood Cliffs, New Jersey, 1964, pp. 532.

Wiegel, R. L. (1965), "Protection of Crescent City, California, from Tsunami Waves", Report for Redevelopment Agency, Crescent City, University of California, Berkeley, M-4825, 1965, 114 pp.

Wiegel, R. L., Jennings, P. C., LéMehauté, B., Saville, T., Van Dorn, W.G., and Wilson, B. W. (1967), Report on Earthquake Engineering Research, Chapter VI, Coastal and Inland Waters, National Academy of Engineering, National Research Council, Washington, 1967 (publication pending).

Wigen, S. O. and White, W. R. H. (1964), "Tsunami of March 27-29, 1964, West Coast of Canada", Technical Report, Dept. of Mines and Technical Surveys, Victoria, B.C., Canada, Aug. 1964, 12 pp.

Wilson, B. W. (1964), "Long Wave Modification by Linear Transitions", (discussion), Proceedings, American Society of Civiz Engineers, Vol. 90 (WW 4 ), Nov. 1964, pp. 161-165.

Wilson, B. W. (1965), "Generation and Dispersion Characteristics of Tsunamis", Studies on Oceanography, University of Tokyo Press, Tokyo, Japan, 1964, pp. 413-444 (also University of Washington Press, Seattle, Washington, 1965)

Wilson, B. W. (1966), Seiche; Encyclopedia of Oceanography, Rheinhold Publishing Corp., New York, 1966. 
Wilson, B. W. Hendrickson, J. A. and Kilmer, R. E. (1965), "Feasibility Study for a Surge-Action Model of Monterey Harbor, California", Contract Report No. 2-136, Waterways Experiment Station, U. S. Army Corps of Engineers, Oct. 1965.

Wilson, B. W., LéMehauté, B., and Freeman, J. C. (1964), "Propagation and Run-up of Tsunami Waves", Technical Report No. SN-166, National Engrg Science Co., March 1964.

Wilson, B. W., Webb, L. M. and Hendrickson, J. A. (1962), "The Nature of Tsunamis: Their Generation and Dispersion in Water of Finite Depth", Technical Report No. SN-37-2, National Engineering Science Co., Pasadena, California, August 1962.

Wood, F. J., et al, (1966), "The Prince William Sound, Alaska, Earthquake of 1964 and Aftershocks", Publication 10-3, Vol. 1, Coast and Geodetic Survey, ESSA, U. S. Department of Commerce, Rockville, Ma., 1966, $263 \mathrm{pp}$.

Worthington, Skilling, Helle and Jackson (1964), "Report on Seismic Damage to the Naval Station at Kodiak, Alaska", Report to Bureau Yards and Docks, U. S. Navy, April 1964.

Zetler, B. D. (1966), "The Contribution of Earth Tides to Earthquakes", Proceedings, ESSA Symposium on Earthquake Prediction, Environmental Science Services Administration, U. S. Department of Commerce, Rockville, Md., Feb. 1966, pp. 35-37. 



\author{
APPENDIX A \\ U. S. FLEET WEATHER CENTRAL \\ KODIAK, ALASKA \\ RESUME OF ACTIVITIES COMMENCING 27 MARCH 1964
}

1732 Moderate to severe earthquake commenced.

1740 Sustained earthquake ceased. Electrical equipment in tower out of commission. Power OK. C.O. arrived.

1750 Tide Station inoperative due to earthquake damage. HO advised via seismo message DTG $280350 Z$ which was passed to FWC Alameda for relay. FAA Circuits inoperative.

1805 Seismo NR2 DTG 2804152 to HO via FWC Alameda after trying FAA Circuits.

1810 Cape Chiniak reports 30-foot tsunami. Unable to contact Station OOD, called Armed Forces Radio Station and had "Tidal Wave" warning broadcasted, resulting in evacuation to higher ground of base and city personnel. Advised Station OOD of actions later.

1820 Water rising rapidly. No recession has previously occurred within sight of Tower.

1835 Water crested 22 feet above tide staff zero. Tsunami NRI to Ho prepared, DTG 280445Z, passed via telephone to remote transmitter site for relay to HO via INAVCOMSTA San Francisco.

1836 Water ebbing.

1847 Lost electrical power.

1903 Auxiliary power supplied to tower.

1907 Maximum low ebb, estimated 15 to 18 feet below mean sea level. Tsunami NR 2 to HO prepared, DTG $280512 \mathrm{Z}$ handled same as Tsunami NRI.

1930 Water rising.

1940 Water crested at 24 feet above staff zero.

2000 Water maximum low level - elevation unknown.

2030 Water crested at 21 feet above staff zero. 
2044 Water crested again at less than 21 feet. Oscillation appears to be superimposed on tsunami period

2100 FAA Woody Island called. Discussed wave times, damages, etc.

2115 Sent Tsunami NR3 DTG 2807262 to HO via Coast Guard Radio NOJ.

2130 Water started to rise again, minimum level unknown.

2132 Slight tremor felt.

2200 Water crested 25 feet above staff zero.

2210 Water slowly ebbing. Heights unknown, small amplitude, believe seiche.

2215 Water slowly rising.)

2219 Water slowly ebbing.) Heights unknown, small amplitude,

2225 Water slowly rising.)

believe seiche.

2227 Water crested at 21 feet above staff zero. Intervening minimum height not observed.

2232 CO NAVSTA KODIAK and COMALSEAFRONT/COMI7 relocated their base operations to Fleet Weather Central in tower.

2240 Slight tremor felt.

2248 Water rapidly rising and falling. Small amplitude, believe seiche.

2300 Preliminary inspection reveals tide station inundated, having been inoperative from 1740. Record lost. GMD Bldg. inundated repeatedly. All equipment on first deck washed away or damaged and immersed.

2316 Water crested 30 feet above staff zero.

2317 Water ebbing rapidly.

2319 Water rising rapidly, crest 30 feet again. Intervening ebb level unknown.

2322 Water ebbing.

2324 Water has risen and crested at unknown level, but below 30 feet above staff zero.

280015 Minimum low water estimated about 5 feet below staff zero. 
0034 Slight tremor.

0037 Stronger tremor. Water 18 feet above staff zero and rising.

0045 Water crested at 23 feet above staff zero.

0050 Water receding.

0100 Water rising. Crested at less than 23 feet above staff zero.

0102 Water receding rapidly.

0110 Water has risen to 18 feet above staff zero, holding steady.

0120 Water rising further to 21 feet above staff zero, then holding steady.

0144 Water rising again.

0145 "Rumble" reported, water rising rapidly.

0154 Water crested at 25 feet above staff zero.

0159 Water receding rapidly. Ebb water level unknown.

0213 Water level crested 21 feet above staff zero.

0219 Water level steady at 21 feet.

0222 Slight tremor felt, water receding.

0240 Water starting to rise.

0243 Water crested at 18 feet above staff zero.

0247 Water receding rapidy.

0258 Water still receding - about 2 feet above normal.

0305 Water still receding - rate about 1 foot per minute.

0312 Sudden drop in water level.

0316 Strong sound of surf. Water appears to be being drawn from Small Boat Harbor. Moving observation party to higher ground for safety.

0318 Water rising in Crash Boat Harbor.

0320 Gradual increase in water level. 
0323 Water ebbing rapidly. No crest estimated.

0347 Water rising slowly.

0355 Water appears normal. No change in height.

0408 Water rising.

0410 Water rose about 3 more feet. Now steady, just over seawall in Crash Boat Harbor.

0415 Water back to normal level.

0422 Water receding.

0434 Light tremor.

0440 Light tremor.

0517 Strong current from northeast toward Nyman Peninsula. No apparent $r$ ise in water level.

0535 Observation party secured. Watch with field glasses posted in tower building.

0615 Water level steady.

0634 Water rising.

0641 Water ebbing.

0718 Water rising.

0815 Water ebbing.

0900 Water rising.

0942 Water ebbing.

1000 Tide staff reading 17.5 feet, water temperature 36 degrees F. 1045 Water rising.

1047 Water just over 18 feet on tide staff. Start ebb.

1200 Water rising.

1227 Water ebbing.

1300 Water rising. 
1346 Water ebbing. Crest reached 22.8 feet above staff zero.

1438 Water rising.

1530 Tide gage overhauled and placed back in operation. Staff reading 18.7 feet.

1659 Slight tremor.

1902 Slight tremor, continuing at intervals until 1930.

2030 Slight tremor.

2217 Slight tremor.

2230 Tide staff reading 16.3 feet.

290125 Received report that Cape Hinchinbrook sustained large tremors of 5 second duration in last hour. Severe shock wave reported in Prince William Sound area.

0845 Tide staff reading 12.1 feet.

1810 Received HO tsunami DTG $300351 \mathrm{Z}$.

1835 Replied to HO. Staff 13.8 feet. Maximum height past 6 hours 20.6 feet at 291400 AST.

300144 High tide estimated 22 feet above staff zero.

0212 Slight tremor.

0410 Slight tremor (rolling motion).

1700 Irregular marigram. Staff reading 17.5 feet.

310015 Coast Guard Cutter SEDGE reports tides 6 to 8 feet below normal at Cape Hinchinbrook.

0815 Staff reading 11.1 feet

AFRII,

010825 Staff reads 12.4 feet.

1543 Starf reads 18.3 feet.

2200 Staff reads 13.8 feet.

020330 Coast and Geodetic Survey set up a seismograph in Fower Bldg. 
0350 Staff reads 20.0 feet.

1020 Staff reads 12.7 feet

1031 Staff reads 12.5 feet.

031234 AST recorded earthquake on seismograph.

1245 Recorded earthquake on seismograph.

1415 Tsunami of 6-inch amplitude started on marigram.

2312 Light tremor, duration, 1 minute and 40 seconds. Seismograph indicated local quake.

040030 Tsunami of 6-inch amplitude started on marigram.

$\underline{\text { NOTES }}$

1. Unless otherwise indicated, all times are Alaska standard time $(+10)$.

2. Heights were referred to staff zero in the following manner. After each crest, a pencil mark was made at the resultant water line in a building very near the water. When it was impossible to make a pencil mark, the water level was referred to the nearest identifying feature on the building and marked in pencil after the water had ebbed. The highest mark was then measured in reference to the tide staff at the Tide Gage and the heights of all other wave heights in the building where the pencil marks were made were subtracted from this height. The building mentioned is not in the immediate vicinity of the Tide Gage.

3. Other highest water marks on cliffs and buildings were measured along a 3-mile area from Nyman Peninsula to about $1 / 2$ mile northeast of the mouth of Buskin River. All were within 2 feet of the highest water mark at the Tide Gage.

4. The Tide Gage is located on Marginal Pier, Nyman Peninsula, U. S. Naval Station, Kodiak, Alaska, and is in Womens Bay.

5. All Tidal Bench marks were connected by spirit leveling on 5-6-7 April and the relative elevations of the Tidal Staff and bench marks are unchanged from previous values.

6. An analysis of the Tide Station hourly heights for the 5-day period 2-6 April gives a mean value for the tide level of 15.8 feet referred to zero of the Tide Staff. With the assumptions that this short record is a reasonable approximation of mean sea level (MSL) 
and that MSL differs a negligible amount from the half-tide level, it is the opinion of USC\&GS that a subsidence of 5.5 feet has occurred in the Nyman Peninsula area.

7. Hydrographic surveys by USC\&GS in the Kodiak area indicate increased depths of 4 to 6 feet and give support to Note 6 .

8. All heights mentioned refer to the Tide Staff in its new elevation relative to half-tide level.

9. When water level could not be measured with any degree of accuracy, its level was estimated and is so stated, or the height was listed as unknown. Few low water levels could thus be tabulated.

10. Tides since the event of 27 March 1964 indicate that there is no change in tidal period or amplitude and that the tides are the same in all respects as they were prior to 27 March 1964. The Tide Tables therefore are still considered accurate.

11. TIDES 27 March 12399.0 feet $1853 \quad-0.2$ feet 28 March $0101 \quad 8.9$ feet $0710 \quad-0.1$ feet

12. SUNRISE MUNSET MOON RISE MOON PHASE

27 March $0522 \quad 1840 \quad 1817 \quad$ Full

28 March $0519 \quad 1842 \quad 1935$

13. Cloud cover 271800 to 280000 AST $8 / 10,280000$ to 280500 AST Clear. Wind velocity (true light and variable 271800 to 280800 AST. Visibility unrestricted 271800 to 280800 AST. 



\section{APPENDIX B}

PROPAGATION OF THE ALASKAN TSUNAMI OF MARCH 27-28, 1964 ACROSS THE PACIFIC OCEAN

TABULAR DETAILS OF ARRIVAL TIMES, RUN-UP HEIGHTS, ETC. 



\begin{tabular}{|c|c|c|c|c|c|c|c|c|c|c|}
\hline & Tide Station & Lat. & Long. & $\begin{array}{l}\text { Time of } \\
\text { Arrival }\end{array}$ & $\begin{array}{l}\text { Inftial } \\
\text { Period } \\
\text { lst to } \\
\text { 2nd Crest }\end{array}$ & $\begin{array}{l}\text { Initial } \\
\text { Rise } \\
\end{array}$ & $\begin{array}{l}\text { Follow- } \\
\text { ing } \\
\text { Fell } \\
\end{array}$ & \multicolumn{3}{|c|}{ Meximum Rise or Fall } \\
\hline & & ${ }^{\circ} \mathrm{N}$ & ${ }^{\circ} \mathrm{w}$ & $\mathrm{d}-\mathrm{h}-\mathrm{m}$ & $\min$ & ft & $f t$ & $d-h-m$ & $\min$ & $f t$ \\
\hline 36. & La Jolla, California & 3252 & 11715 & $28-09: 24$ & 33 & 1.9 & 2.2 & $28-09: 36$ & $16 \mathrm{~F}$ & 2.2 \\
\hline 37. & San Diego, California & 3243 & 11710 & $28-09: 50$ & 9 & 0.7 & 0.4 & $28-11: 31$ & $27 \mathrm{R}$ & 3.7 \\
\hline 38. & Ensenada, B.C., Mexico & 3151 & 11638 & $28-09: 42$ & 46 & 4.7 & $7.8+$ & $28-09: 52$ & $18 F$ & $7.8+$ \\
\hline 39. & La Paz, B.C., Mexico & 2410 & 11019 & $28-12: 27$ & 39 & 0.3 & 0.3 & $30-05: 39$ & $42 F$ & 1.8 \\
\hline 40. & Guaymas, Sonora, Mexico & 2755 & 11054 & $28-12: 30$ & 180 & 0.2 & 0.3 & $28-14: 00$ & $60 \mathrm{~F}$ & 0.3 \\
\hline 41. & $\begin{array}{l}\text { Topolobempo, Sinaloah, } \\
\text { Mexico }\end{array}$ & 2537 & 10903 & $28-11: 59$ & --- & -- & $s$ & ------ & $-\infty$ & 0.1 \\
\hline 42. & Mezatlan, Sinaloa, Mex. & 2311 & 10626 & $28-12: 00$ & 38 & 0.6 & 0.5 & $28-22: 56$ & $22 \mathrm{~F}$ & 1.6 \\
\hline 43. & Manzanillo, Mexico & 1903 & 10420 & $28-12: 15$ & 31 & 1.3 & 2.4 & $29-07: 20$ & $6 \mathrm{R}$ & 3.9 \\
\hline 44. & $\begin{array}{l}\text { Acapulco, Guerrero, } \\
\text { Mexico }\end{array}$ & 1651 & 9955 & $28-13: 05$ & 30 & 0.8 & 1.2 & $29-04: 09$ & $13 \mathrm{~F}$ & 3.5 \\
\hline 45. & $\begin{array}{l}\text { Salina Cruz, Oaxaca, } \\
\text { Mexico }\end{array}$ & 1610 & 9512 & $28-14: 10$ & 31 & 0.8 & 1.0 & $29-02: 07$ & $10 \mathrm{R}$ & 2.8 \\
\hline 46. & San Jose, Guatemala & 1355 & 9050 & $28-14: 52$ & 48 & 0.4 & 0.3 & $29-03: 00$ & $18 \mathrm{~F}$ & 0.6 \\
\hline 47. & Acajutla, El Salvador & 1335 & 8951 & $28-15: 18$ & 48 & 0.5 & 0.3 & $29-22: 15$ & $17 \mathrm{~F}$ & 1.0 \\
\hline 48. & La Union, El Salvador & 1320 & 8749 & c & --- & $\cdots$ & S & $-\cdots$ & $-\cdots$ & $\cdots$ \\
\hline 49. & Corinto, Nicaragua & 1228 & 8712 & $28-16: 00$ & 8 & 0.1 & 0.1 & -n- & $\cdots$ & $-\cdots$ \\
\hline 50. & Puntarenas, Costa Rica & 0958 & 8450 & $28-16: 23$ & 42 & 0.2 & 0.3 & $29-03: 50$ & $7 \mathrm{R}$ & 1.0 \\
\hline 51. & Quepos, Costa Rica & 0924 & 8410 & $28-16: 00$ & g & 0.3 & 0.2 & $29-06: 17$ & $8 \mathrm{~F}$ & 1.5 \\
\hline 52. & $\begin{array}{l}\text { Puerto Armuelles, } \\
\text { Panama }\end{array}$ & 0816 & 8252 & $28-16: 24$ & $g$ & 0.2 & 0.1 & $29-01: 12$ & $7 \mathrm{~F}$ & 0.6 \\
\hline 53. & Neos Island, Canal Zone & 0855 & 7932 & c & -- & -- & S & -n- & 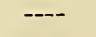 & --- \\
\hline 54. & Bahia Solano, Colombia & 0614 & 7724 & $28-17: 45$ & 11 & 0.2 & 0.1 & $29-02: 54$ & $5 \mathrm{~F}$ & 1.2 \\
\hline 55. & Buenaventura, Colombia & 0354 & 7705 & ----- & -- & -- & $\mathrm{S}$ & --1--- & $\cdots$ & --- \\
\hline 56. & Tumaco, Colombia & 0150 & 7844 & c & -- & -- & $-\infty$ & $29-03: 31$ & $15 \mathrm{R}$ & 0.3 \\
\hline 57. & $\begin{array}{l}\text { San Cristobal, Galapagos } \\
\text { Island, Ecuador }\end{array}$ & $00^{5} 54$ & $89^{W} 37$ & $28-16: 27$ & 14 & 1.7 & 2.7 & $28-17: 18$ & $6 \mathrm{H}$ & 3.8 \\
\hline 58. & La Libertad, Ecuador & 0213 & 8055 & $28-18: 09$ & 23 & 0.7 & 0.9 & $28-19: 49$ & $8 \mathrm{R}$ & 4.2 \\
\hline 59. & Talara, Peru & 0435 & 8117 & $28-17: 56$ & 15 & 1.8 & 2.9 & $28-19: 03$ & $6 \mathrm{~F}$ & 3.5 \\
\hline 60. & La Punta (Callae), Peru & 1203 & 7709 & $28-19: 11$ & 16 & 2.0 & 2.3 & $28-21: 09$ & $12 \mathrm{R}$ & 6.4 \\
\hline 61. & Sen Juan, Peru & 1521 & 7509 & $28-19: 30$ & 16 & 2.0 & 3.9 & $28-19: 40$ & $10 \mathrm{~F}$ & 3.9 \\
\hline 62. & Matarani, Peru & 1700 & 7207 & $28-19: 57$ & 12 & 0.9 & 1.2 & $29-04: 22$ & $4 \mathrm{R}$ & 2.9 \\
\hline 63. & Arica, Chile & 1828 & 7020 & $28-20: 30$ & 15 & 1.4 & 1.3 & $29-05: 09$ & $10 \mathrm{R}$ & 7.0 \\
\hline 64. & Antofagasta, Chile & 2339 & 7025 & $28-20: 39$ & 19 & 1.5 & 1.7 & $28-23: 09$ & $6 \mathrm{~F}$ & 3.3 \\
\hline 65. & Caldera, Chile & 2704 & 7050 & $28-20: 55$ & 19 & 2.4 & 4.1 & I & --- & --- \\
\hline 66. & Valparaiso, Chile & 3302 & 7138 & $28-21: 27$ & 31 & 2.8 & 3.8 & $28-22: 52$ & $14 \mathrm{R}$ & 6.2 \\
\hline 67. & Talcahueno, Chile & 3642 & 7306 & $28-22: 15$ & 12 & 2.3 & 1.0 & $29-00: 00$ & $6 \mathrm{R}$ & 5.4 \\
\hline 68. & Corral, Chile & 3952 & 7326 & $28-22: 39$ & 27 & 4.3 & 6.3 & $28-22: 54$ & $20 \mathrm{~F}$ & 6.3 \\
\hline 69. & $\begin{array}{l}\text { Ushuaia, Tierra del } \\
\text { Fuego, Argentina }\end{array}$ & $54 \quad 49$ & 6813 & c & -- & -- & --- & $29-03: 03$ & $36 \mathrm{~F}$ & 0.8 \\
\hline 70. & $\begin{array}{l}\text { Bahia Esperanza, Palmer } \\
\text { Peninsula, Antarctica }\end{array}$ & 6324 & 5700 & $29-02: 10$ & 8 & 0.1 & 0.1 & ------ & $-\cdots$ & 0.2 \\
\hline 71. & $\begin{array}{l}\text { Argentine Island, Palmer } \\
\text { Peninsula, Antarctica }\end{array}$ & 6515 & $\begin{array}{c}6416 \\
W\end{array}$ & $29-01: 25$ & 17 & 1.9 & 1.0 & $29-03: 40$ & $9 F$ & 3.2 \\
\hline 72. & Christmes Island & 0159 & 15729 & $28-11: 21$ & 12 & 0.3 & 0.1 & $28-11: 21$ & $13 \mathrm{R}$ & 0.3 \\
\hline 73. & Hilo, Hawaii Is. Hawaii & 1944 & 15503 & $28-09: 00$ & 19 & 5.7 & $11.3+$ & $28-09: 22$ & $8 \mathrm{R}$ & $12.5+$ \\
\hline & Kahului, Maui Is. Hawaii & 2054 & 15628 & $28-08: 47$ & 23 & 6.8 & $11.0+$ & $\begin{array}{c}28-09: 00^{\theta} \\
\text { to } \\
28-10: 00\end{array}$ & $12^{\mathrm{R}}$ & $11.0+$ \\
\hline
\end{tabular}


TABLE B-1 (Continued)

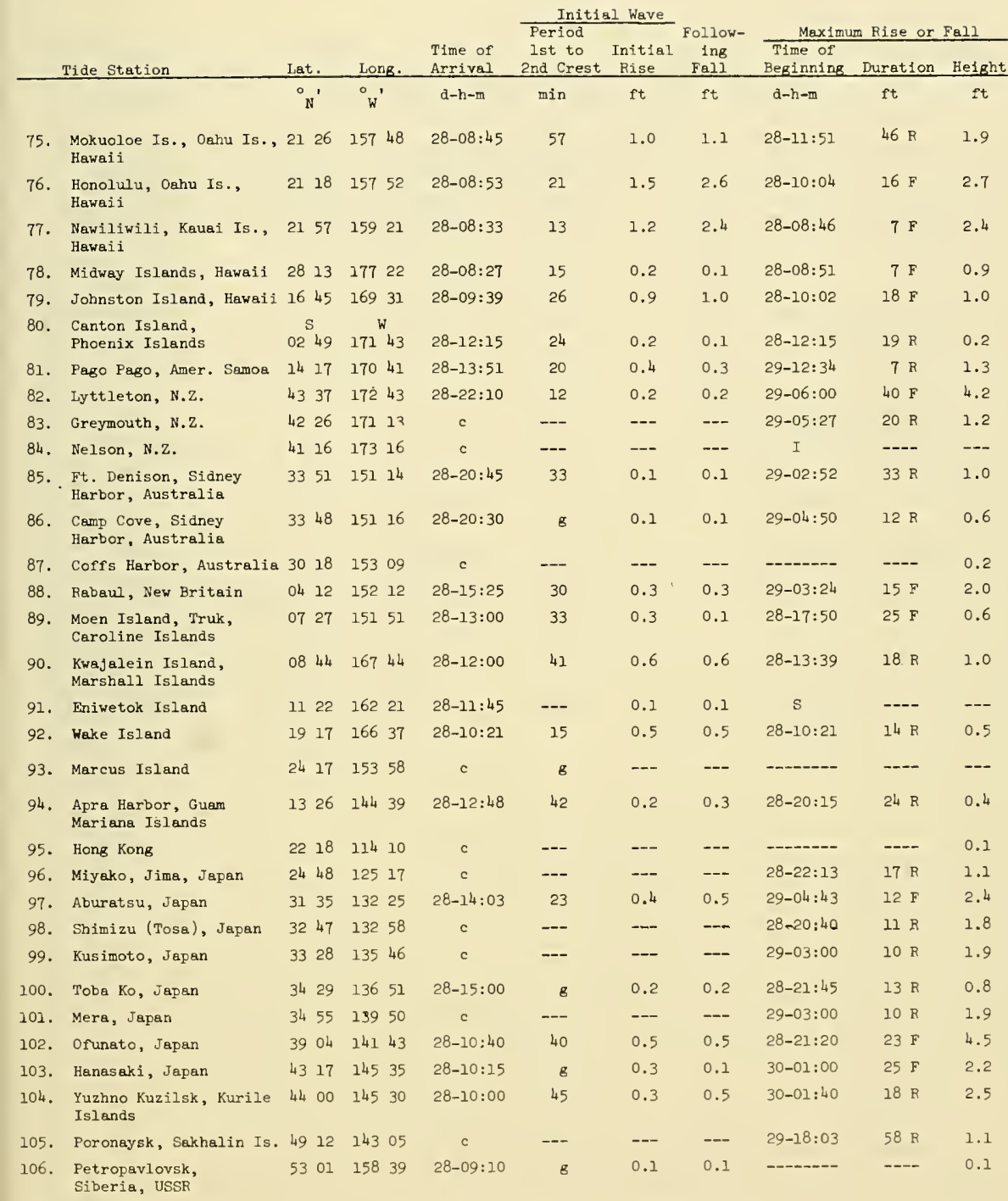

I Incomplete record

$S$ Only slight evidence on record

+ Gage limit exceeded

R Rise

F Fall

* Reproduced from Spaeth \& Berkmen, 1967 a Four waves exceeded gage limit

b Small part of record missing

c Arrival time indefinite

$f$ Initial oscillation was a fall

g Indeterminate 


\section{TABLE B-2}

Seiche Action Caused by the Prince William Sound Earthquake of March 28, 1964 as Recorded by Tide Gages* (All times are Greenwich)

\begin{tabular}{lcccc}
\hline Tide Station & Lat. & Long. & $\begin{array}{c}\text { Time of } \\
\text { Arrival }\end{array}$ & $\begin{array}{c}\text { Maximum } \\
\text { Amplitude }\end{array}$ \\
\hline & $0_{N}$ & $0_{W}^{\prime}$ & d-h-m & feet \\
a. Key West, Fla. & 2433 & 8148 & $28-04: 02$ & 0.1 \\
b. Pensacola, Fla & 3424 & 8713 & $28-04: 00$ & 0.5 \\
c. Bayou Rigaud $\quad$ (Grand Isle), La. & 2916 & 8958 & $28-04: 00$ & 0.3 \\
d. Blakely Dam, Ark. & 3430 & 9315 & $28-03: 40$ & 1.5 \\
e. Narrows Dam, Ark. & 3410 & 9345 & $28-03: 40$ & 0.5 \\
f. Freeport, Texas & 2857 & 9519 & $28-04: 00$ & 0.6 \\
g. Rockport, Texas & 2801 & 9703 & $28-04: 02$ & 0.8 \\
h. Port Mansfield, Texas & 2633 & 9726 & $28-03: 57$ & 0.2
\end{tabular}

*Reproduced from Spaeth and Berkman, 1967 


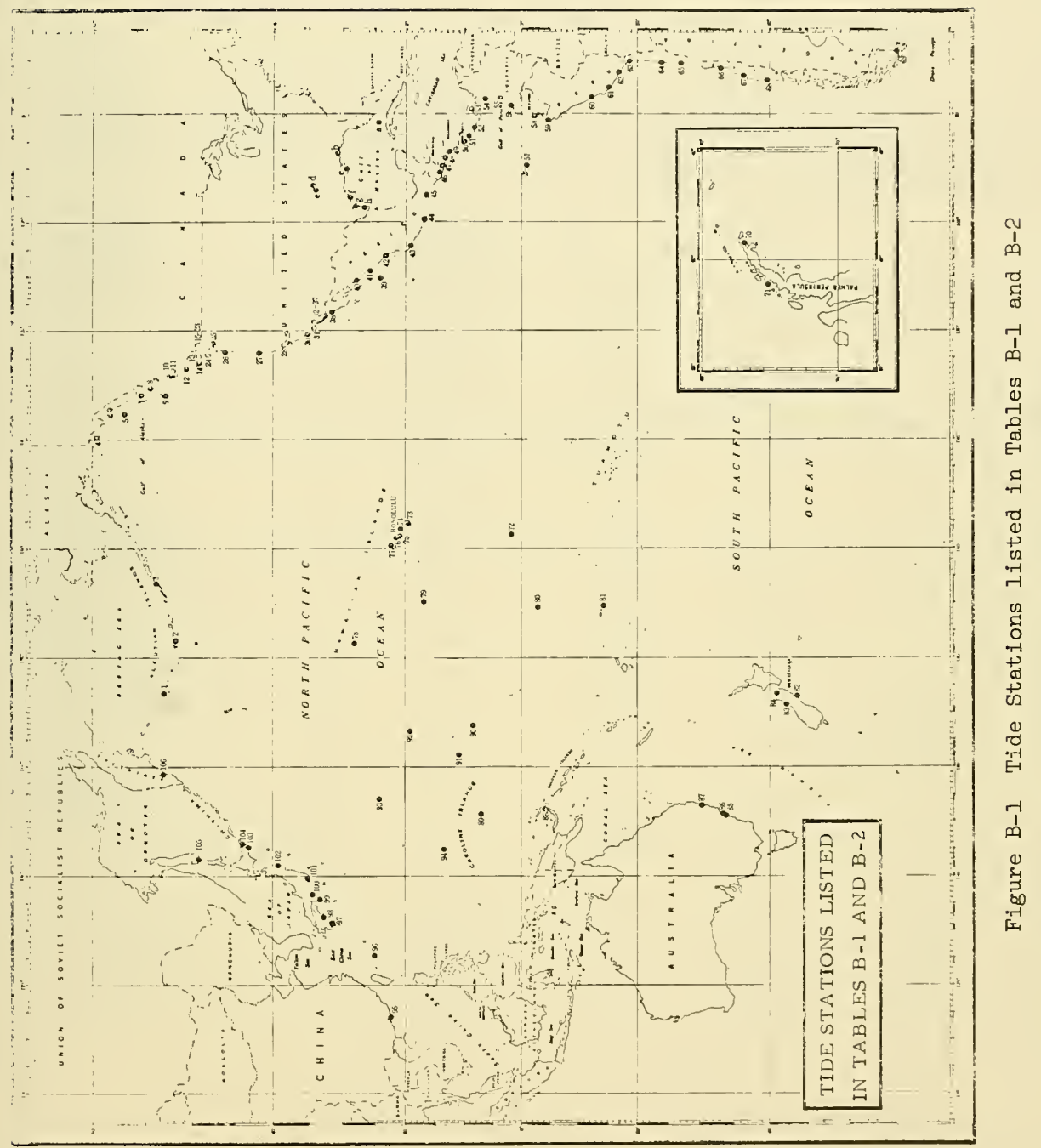




\section{TABLE B-3}

Maximum Crest Levels of the Tsunami Along the Canadian Coast*

The heights reached by the maximum tsunami wave crest at a number of Vancouver Island ports where no tide gages were operating are compared to the elevations of higher high water, large tide. Elevations at some permanent gaging stations, showing normal and extreme recorded high waters are also included for comparison.

\begin{tabular}{|c|c|c|c|c|c|c|}
\hline Port & Lat. & Long. & $\begin{array}{c}\text { Tsunami } \\
\text { Crest }\end{array}$ & H.H.W. & Diff. & $\begin{array}{c}\text { Extreme } \\
\text { High Tide } \\
\end{array}$ \\
\hline Port Alice & 5023 & 12727 & $19 \cdot 3$ & 14.0 & $+5 \cdot 3$ & \\
\hline Klaskino & 5018 & 12744 & 19.2 & 13.7 & +5.5 & \\
\hline Fair Harbour & $50 \quad 04$ & 12707 & 21.0 & 13.6 & +7.4 & \\
\hline Amai Inlet & 5006 & 12705 & 19.0 & 13.5 & +5.5 & \\
\hline Zeballos & 4959 & 12651 & 16.8 & 13.6 & +3.2 & \\
\hline Esperanza & 4952 & 12644 & 15.2 & 13.6 & +1.6 & \\
\hline Tahsis & 4955 & 12640 & 16.4 & 14.0 & +2.4 & \\
\hline Gold River & 4941 & 12607 & $17 \cdot 7$ & 14.0 & +3.7 & \\
\hline Hot Springs Cove & 4922 & 12616 & 20.5 & 13.1 & $+7 \cdot 4$ & \\
\hline Tofino & 4909 & 12555 & 14.0 & 13.2 & +0.8 & 15.60 \\
\hline Franklin River & 4906 & 12449 & 20.6 & 13.0 & +7.6 & \\
\hline Port Alberni & 4914 & $124 \quad 49$ & 20.9 & 12.2 & +8.7 & 14.8 \\
\hline Victoria & 4825 & 12324 & 8.4 & 9.6 & -1.2 & 12.10 \\
\hline Prince Rupert & 5419 & 13020 & 25.2 & 24.6 & +0.6 & 26.18 \\
\hline
\end{tabular}

*Reproduced from Wigen and White (1964). 


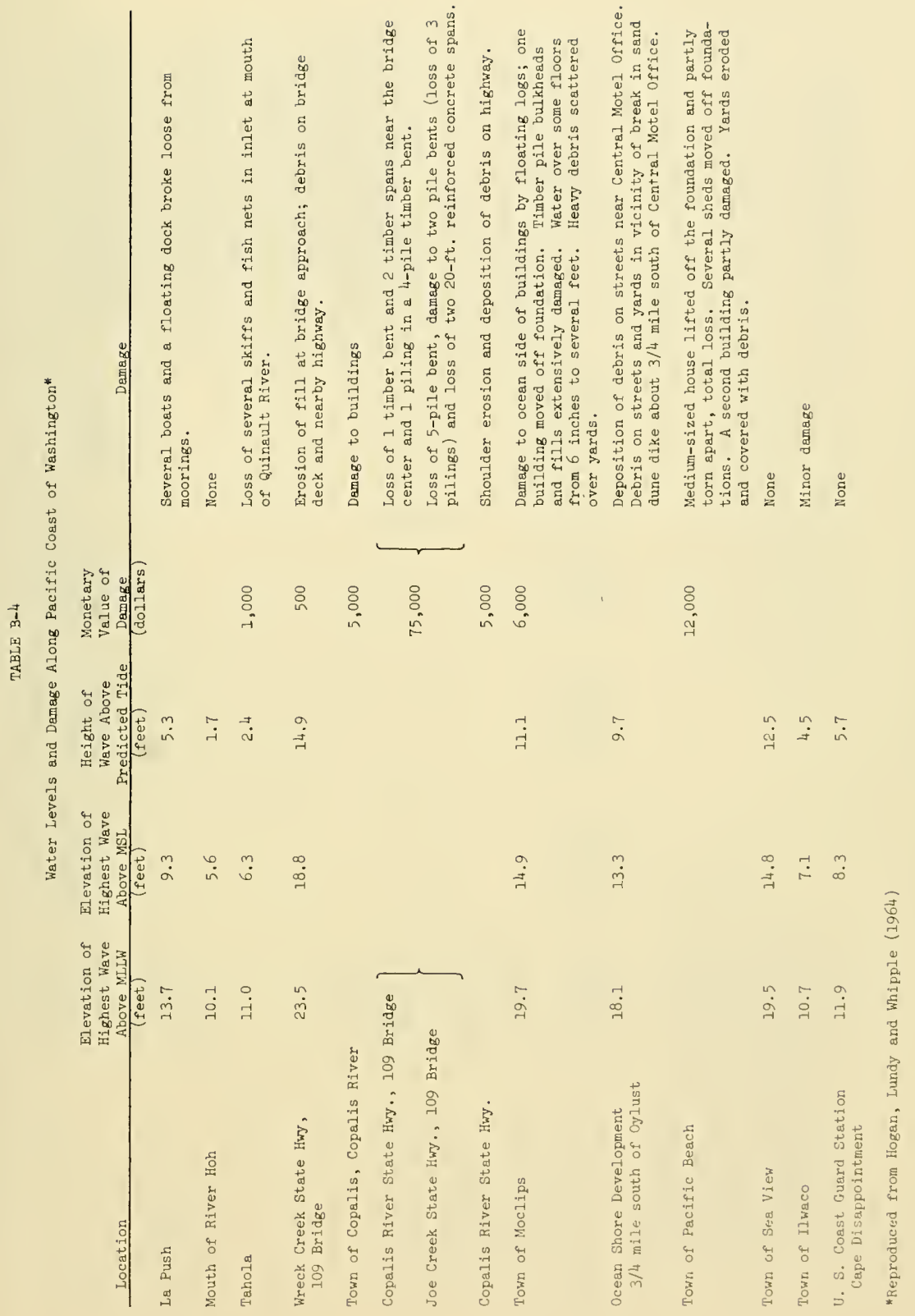




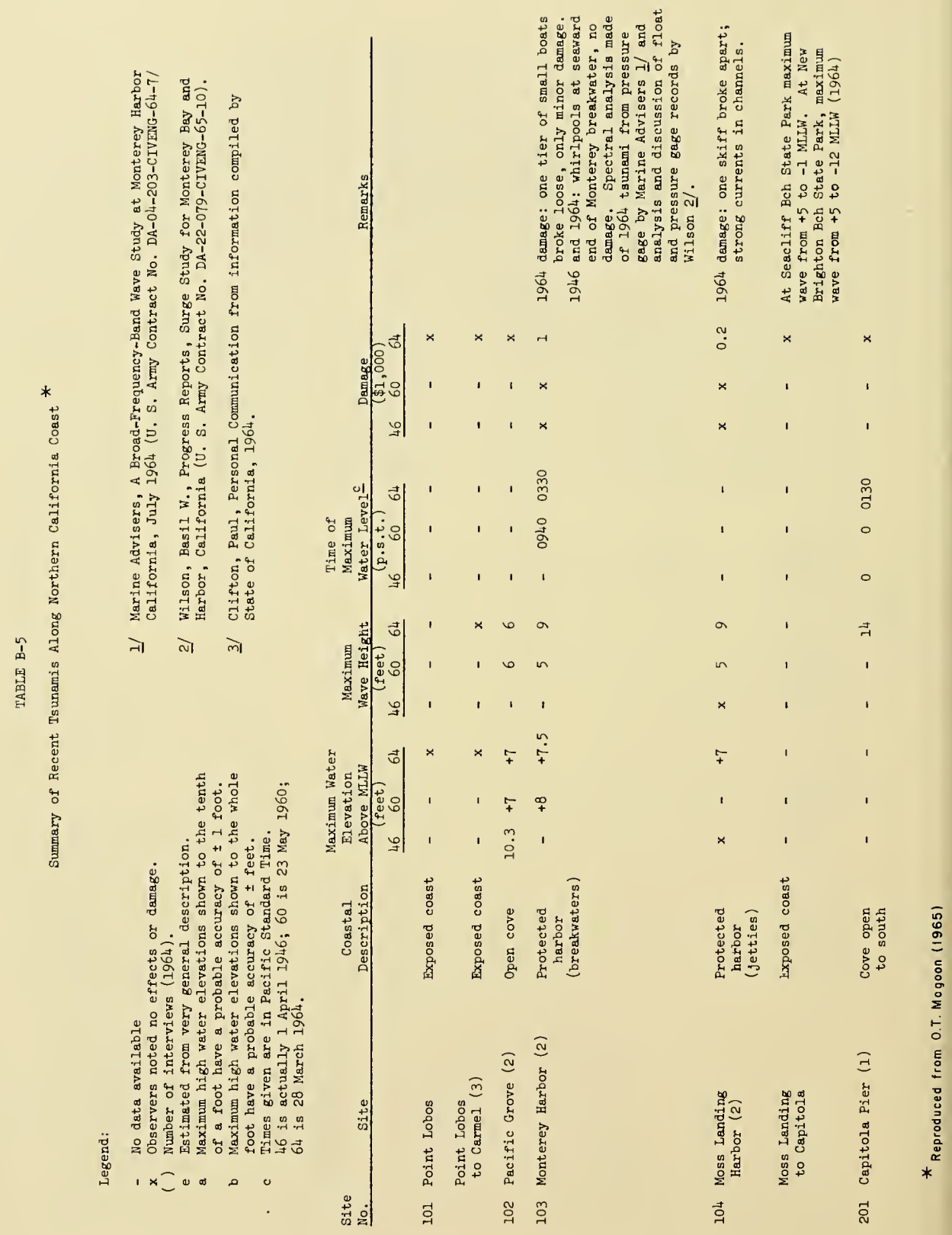




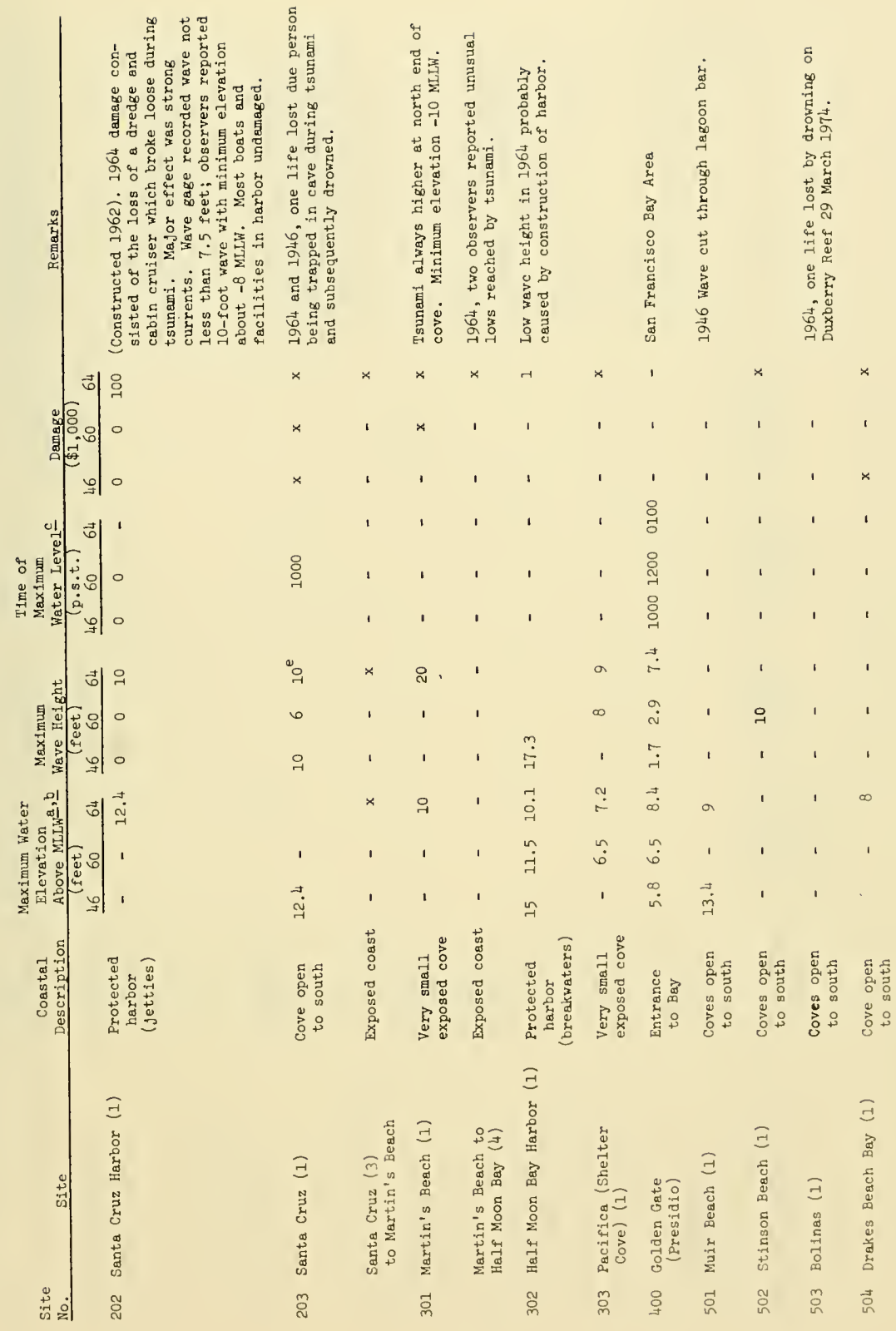




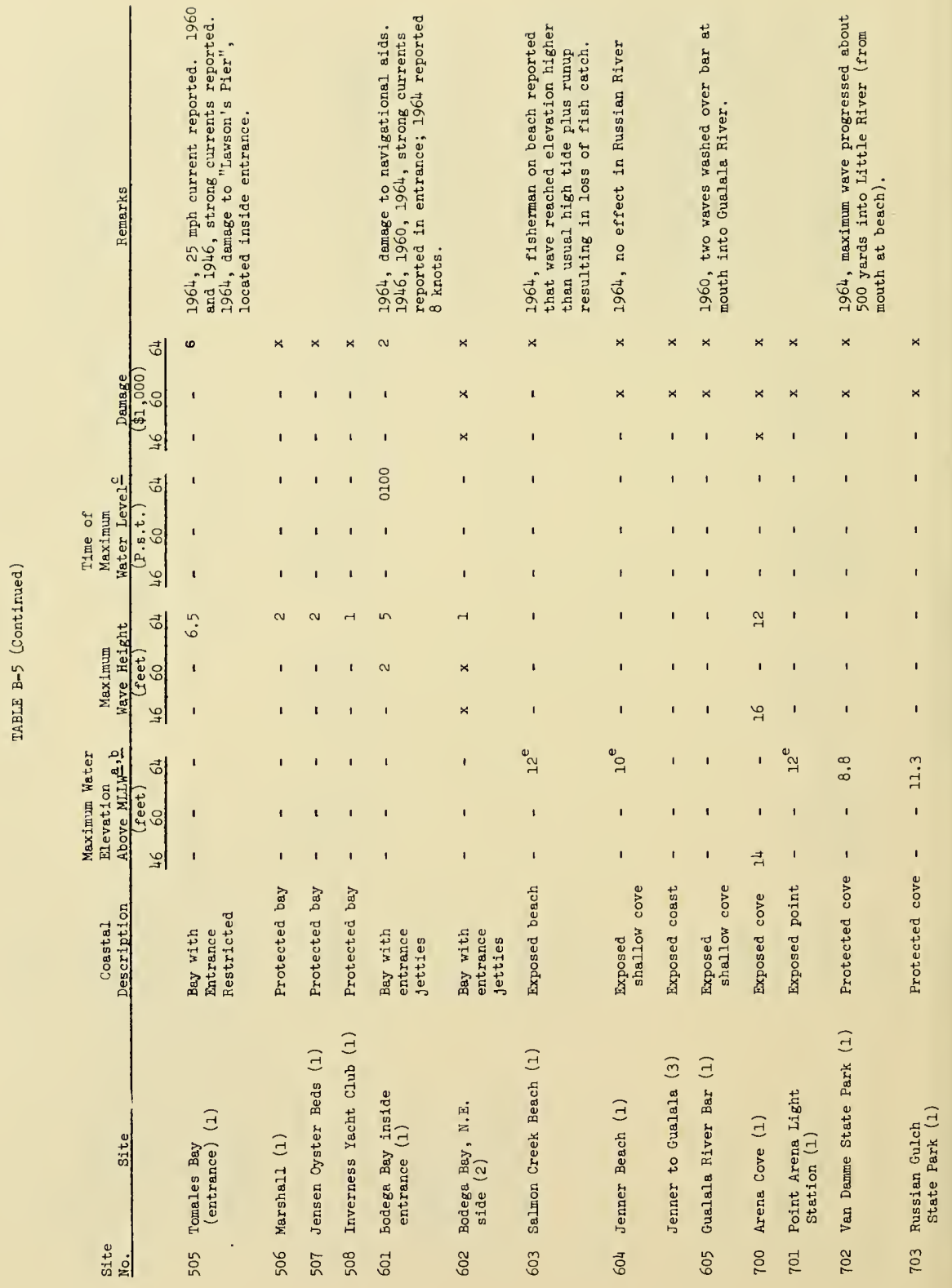




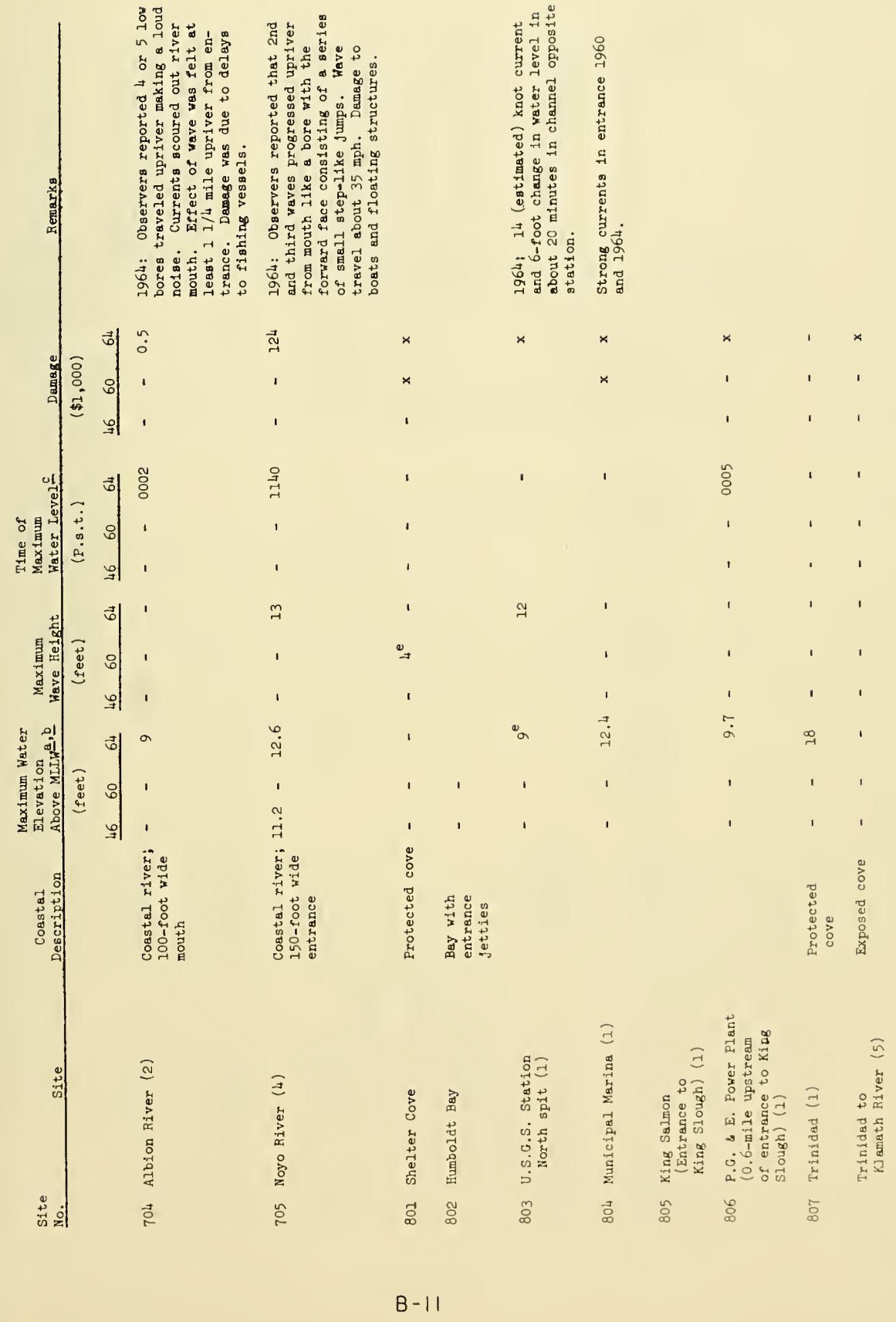




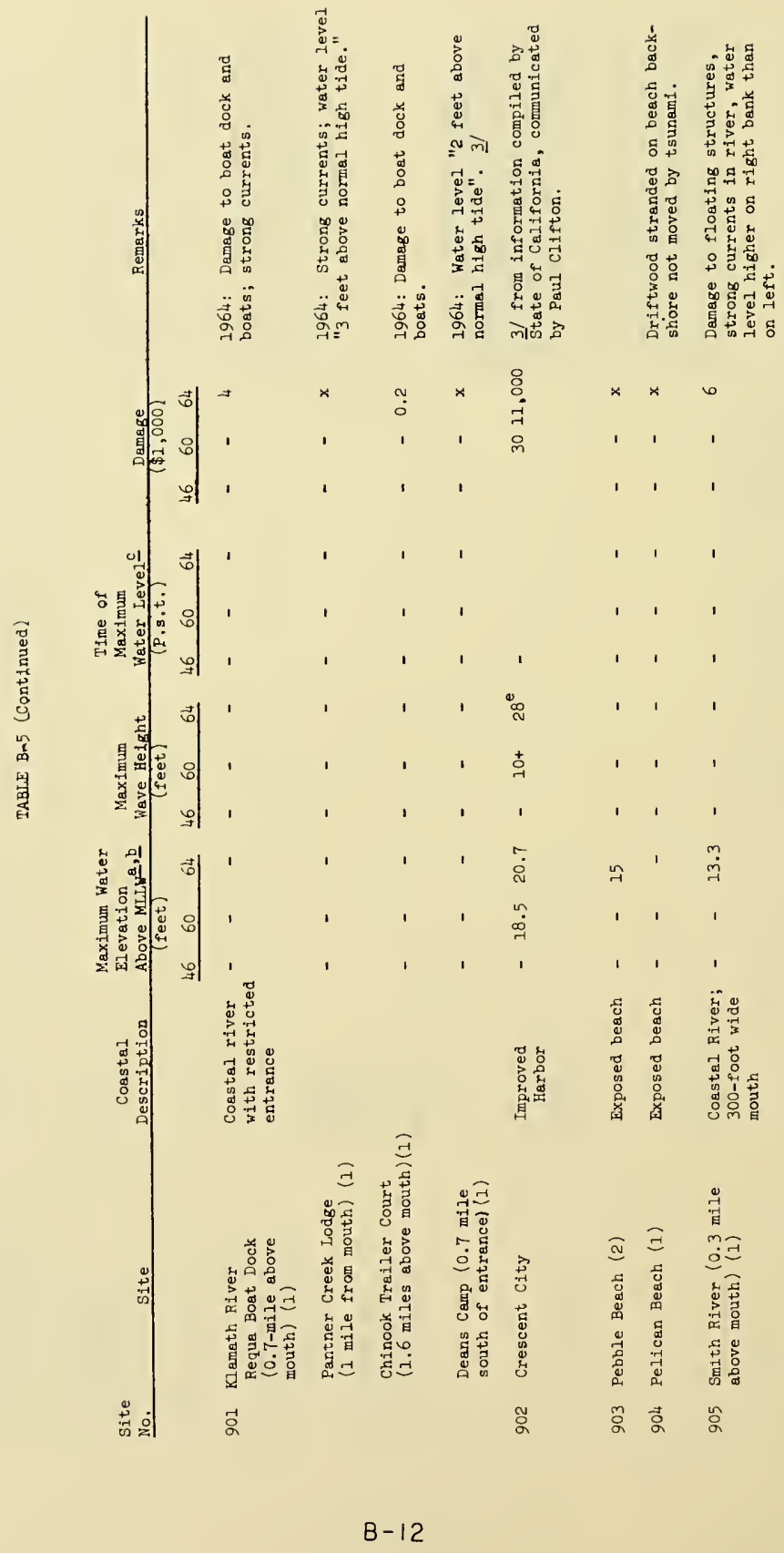


APPENDIX C

TSUNAMI CHARACTERISTICS AND RUNUP - THEIR PREDICTION

RELATED TO THE ABILITY FOR DAMAGING STRUCTURES

by

Alf T Trum

The damaging effect of tsunamis of the same wave height may vary to a great extent. Isaacs (cf. Wiegel, 1964), in regard to the damage at Oahu during the tsunami of April 1, 1946, suggested the damage caused by tsunamis may be roughly screened into the following three categories:

1. Damage or effect of tsunami did not exceed that which would be expected from an equal tidal inundation without surf. Typical houses would be floated from their foundations or merely flooded, but moved little; vegetation not disturbed greatly.

2. Damage or effect of tsunamis was intermediate between 1 and 3 conditions. Houses were moved some distance and damaged. Ground was somewhat eroded.

3. Damage or effect of the tsunami seemed disproportionately great compared with that which would be expected from a tidal inundation of similar height. Evidence of high velocity everywhere. Buildings destroyed, reef coral carried far inland, automobiles rolled about, escarpment and stripping produced, and in level regions invasion of the water for great distance inland.

These same categories are also applicable to the tsunami of the 1964 Alaskan earthquake.

What determines the category of damage seems to be primarily whether the waves break or not, and to what extent they break. A nonbreaking wave will presumably cause mostly damage according to the first category, light breaking waves cause damage according to the second, and the most violent breaking wave causes damage according to the third category.

It is not within the scope of this study to deal in detail with the problem of nonbreaking and breaking of waves and the related problem of runup. However, we would like to go into this question to the extent it shows the deficit in the theory when trying to understand the behavior of the tsunamis at different places.

If a wave does not break, its energy is assumed to be comrletely reflected when neglecting friction; while in fully breaking waves, the wave energy is assumed to be completely transformed into heat by 
turbulent friction. In partly breaking waves, some of the wave energy is reflected and some dissipated.

\section{NONBREAKING WAVES}

The approaches in theoretical treatment of breaking and nonbreaking waves and their runup have mostly been along the lines of the small amplitude wave theory and the long wave theory.

The breaking criterion for small amplitude wave theory is that the maximum water particle velocity of the wave crest exceeds the phase velocity of the wave, or that the Bernoulli equation of the free surface is not satisfied. In the long wave theory the breaking criterion is defined by the inception of a shock wave.

Based on the small amplitude wave theory, Miche (1951) has proposed the following theoretical formula for limiting conditions of nonbreaking waves.

$$
(H / L)_{\max }<\frac{2 \alpha}{\pi} \frac{\sin ^{2}}{\pi}
$$

where $\quad \mathrm{H}=$ wave height

$$
\mathrm{L}=\text { wave length }
$$$$
\alpha=\text { angle of bottom slope }
$$

Fior

$$
\begin{aligned}
& \alpha=45^{\circ},\left(\frac{H}{L}\right)_{\max }=0.112 \\
& \alpha=15^{\circ},\left(\frac{H}{L}\right)_{\max }=0.0079 \\
& \alpha=5^{\circ},\left(\frac{H}{L}\right)_{\max }=0.00057
\end{aligned}
$$

The long wave theory and the application of the method of charac-teristics is considered a better approach than the small amplitude wave theory. However, this method does not give such a simple relationship for limiting conditions as does the small amplitude wave theory. Except for some rather limited attempts at finding an analytical solution, the problem of long wave propagation over a gentle slope is largely unresolved. The most reliable method consists of applying the method of characteristics for each particular case (Wilson, et al, 1964).

Wê shall not go into any detail about different theoretical and experimental results on wave runup for nonbreaking waves, but merely include Figure $\mathrm{C}-1$ to show a trend of result.s. 


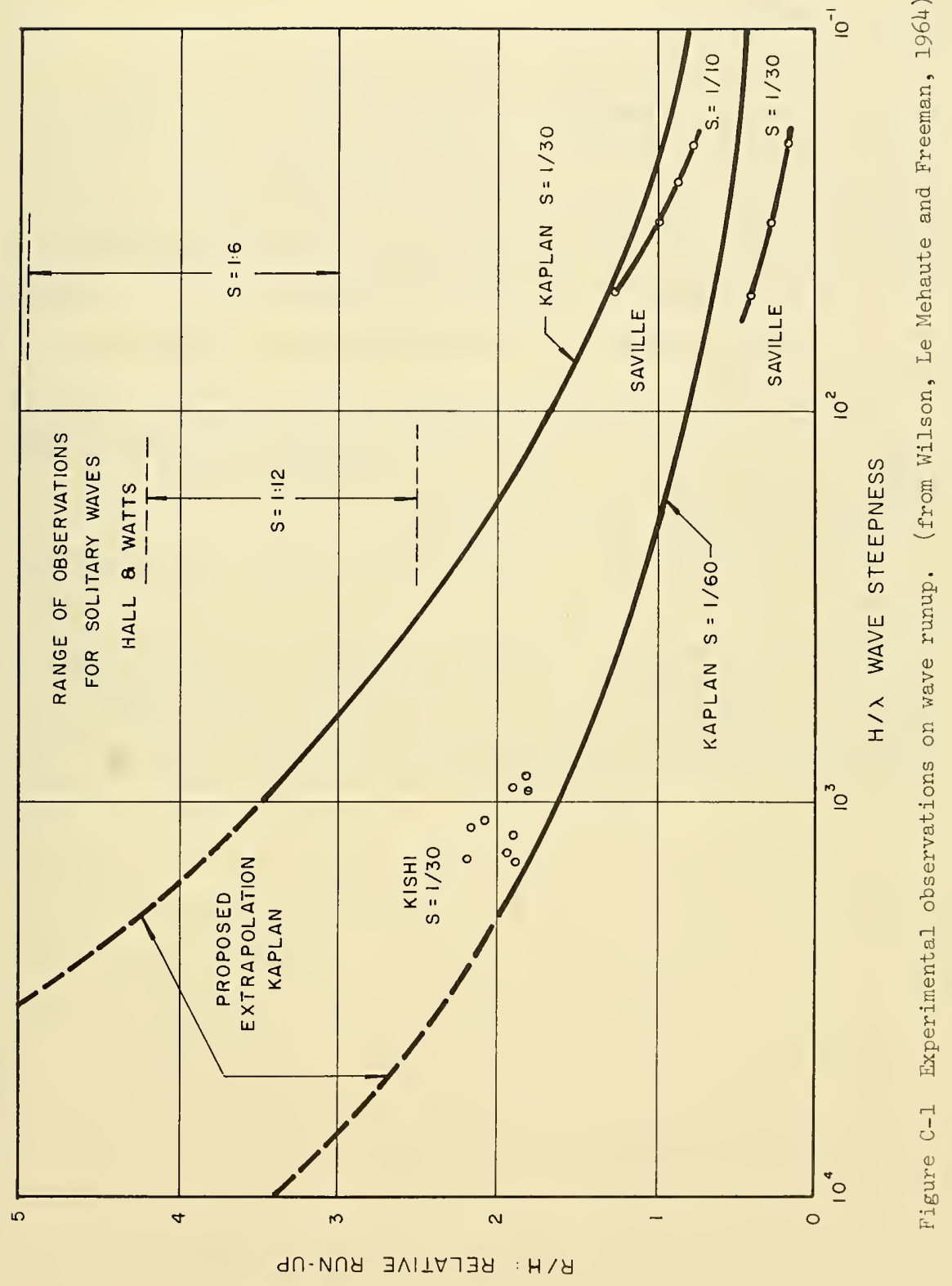


Breaking waves are usually classified into three categories: (1) spilling breakers, (2) plunging breakers, and (3) surging breakers. Spilling breakers are characterized by the appearance of white water at the crest; they break gradually. Plunging breakers are characterized by a curling over of the top of the crest and plunging down of this mass of water; the front of the crest first becomes steep and then concave. Surging breakers are observed when waves of small steepness travel on very steep slopes; they are essentially bores in character. The whole front face of such a breaker becomes unstable and "boils" all at once rather than gradually, as in a spilling breaker.

It is the wave steepness and the beach slope that determine how the wave will break.

The most reliable theory for calculating runup values of breaking long waves is the method of characteristics, applied in each particular case. This method, however, requires the profile of the wave to be known somewhere off the coast before the wave breaks. This profile then provides the input data for the calculation.

Le Mehaute (Wilson, et al, 1964) suggests the following as a rough approximation of runup calculation.

If the bottom slope $s>0.01$ at the point where the wave height water depth ratio is $\mathrm{H} / \mathrm{d}=0.78$ (McCowan's breaker limit for solitary waves), the runup is approximately twice the breaking wave height (depending on the slope). If $\mathrm{s}<0.01$, take the wave height $\mathrm{H}=0.78 \mathrm{~d}$ where the slope becomes 0.01 ; the runup then is twice this breaking wave height. This will be the maximum possible runup. 


\section{APPENDIX D}

\section{THE FLOW AND FORCE FIELD OF TSUNAMI WAVES}

By Basil W. Wilson

Recognizing that tsunami waves are of very great length and period n shallow water and also of considerable amplitude, in relation to the Jepth, by the time they reach the coast, we are led to enquire into the lature of the water velocities and the forces which these waves can bring o bear against obstacles of any kind.

Most records of tsunami waves (as, for example, Figs. 43 to 66) show that they have little resemblance to cnoidal or solitary waves, but on the contrary are strongly sinusoidal, as also are the much longer period astronomical tidal waves. The existence of what are effectively Airy waves .n such shallow water (very small values of $H / T^{2}$ and $d / T^{2}$ ) poses a problem which the writer has not at present resolved; since the dictates of shallow-water wave theories seem to prescribe otherwise.

The periods of waves found to occur as a result of the Alaskan earthquake cover the range from about 2 mins. to 5 hours. The relative capacity of these waves to produce damage is a matter of prime interest. Because of the above mentioned observation of the apparent sinusoidal character of the waves, we resort to the finite-amplitude wave theory of Lamb (1932 Edn. , pp. 278-280) which uses the Method of Characteristics to show that a long wave of elevation $\eta$ above water level of depth $d$ propagates at the velocity

$$
\left.c=\sqrt{g^{-}}-3(1+\eta / d)^{1 / 2}-2\right]
$$


with a horizontal water particle velocity, uniform over the depth, of

$$
u=2 \sqrt{g d}\left[(1+\eta / d)^{1 / 2}-1\right]
$$

These results assume a horizontal bed and negligible vertical accelerations. To the first order of $\eta / d$ the results are the same as derived by Airy in his finite amplitude, long wave theory. Evidently, since $\eta$ can be both positive or negative according to position in the wave, the crest velocity must exceed that of the trough and the wave must eventually break or form a bore. Eq. (D-1) is the same as Eq. (38), used in the text in the discussion of tidal ingress up the Columbia River.

It is of interest that if $\eta / d$ is small in Eq. (D-1), then

$$
c=\sqrt{\mathrm{gd}}\left[1+\frac{3}{2}(\eta / \mathrm{d})\right]
$$

and the velocity of progression exceeds that of a solitary wave. This result is given also by Milne-Thomson (1960, p. 418) by a different method; as also by Bouasse (1924, p. 301).

We may transform Eq. (D-2) to the form

$$
u=2 \sqrt{g \eta}\left[(1+d / \eta)^{1 / 2}-(d / \eta)^{1 / 2}\right]
$$

and hence conclude that if the wave were to run on to dry ground (for which d tends to zero), then the water velocity would approximate

$$
u \simeq 2 \sqrt{\mathrm{g} \eta}
$$

This cquation has no very special meaning because of its neglect of 
sed-friction and bottom slope, but in a general sense it supports other conclusions we shall draw regarding the velocity of the tip of a bore.

The development of a bore is usually dependent on the amplitude of the long wave, the presence of a reverse flow, upstream of the wave, and on the influences of constrictions in the path of the wave or sudden changes of bed gradient. No very simple explicit statement can be made :o define the criterion for bore formation (cf. Stoker, 1957; Freeman \& Le Mehaute, 1964), although it is possible with fair accuracy to specify the velocity $u$ of propagation of a bore of height $H$ advancing into still water of depth d.

The classical approach to this problem by consideration of continuity and momentum (see, for example, Lamb, 1932, p. 280; Rouse, 1938; Keulegan, 1949) yields the result

$$
u=\sqrt{g d}[(1+H / d)(1+H / 2 d)\urcorner 1 / 2
$$

As pointed out by Keulegan (1949), this formula tends to lose physical meaning as d approaches zero value, equivalent to a surge over a dry bed. However, Eq. (D-6) can be rendered in the form

$$
u=\sqrt{g H^{-}}[(1+d / H)(l+H / 2 d)]^{1 / 2}
$$

from which we find that when $H=6 d$

$$
\mathrm{u} \simeq 2 \sqrt{\mathrm{gH}}
$$

The significance of Eq. (D-8) derives from the fact that it also expresses the theoretical velocity of the tip of the wave over dry ground 
created by the failure of a dam of height $H$. Friction over the bed must undoubtedly play its part in reducing this velocity to some factor of $\sqrt{\mathrm{gH}}$ less than 2. Keulegan (1949) quotes the experiments of Schoklitsch (1917), which confirm quite well the dam-break theory (see Stoker, 1957), but demonstrate the friction effect. Keulegan concludes that Eq. (D-8) is nevertheless a fair approximation to the velocity of a surge over a dry bed. Here it is of interest to consider the velocity formulation of Gibson (1925, p. 405) for the speed of advance of a "wave of transmission", or intumescence of height $H$. Gibson uses Bernoulli's equation to equate energies within and beyond the wave, on the assumption that no energy is lost through friction and turbulence, and derives

$$
u=\sqrt{g d}\left[(1+H / d)^{2}(1+H / 2 d)^{-1}\right]^{1 / 2}
$$

which may be rendered in the alternative form

$$
u=\sqrt{g H}\left[(1+d / H)^{2}(1 / 2+d / H)^{-1}\right]^{1 / 2}
$$

For $\mathrm{H} / \mathrm{d}<0.25$, as pointed out by Allen (1947, p. 360), Eqs. (D-9) or (D-10) and Eqs. (D-6) or (D-7) differ by less than one percent. Allen has used Gibson's formula for studying bore propagation in models for values of $\mathrm{H} / \mathrm{d}$ up to 0.5 , and found agreement to within $\pm 3 \%$. He has, however, overlooked the possibility of using Lamb's result (Eq. (D-4) in the same sense but with an expected greater reliability for larger values of $\mathrm{H} / \mathrm{d}$. It is noteworthy that if Eq. (D-10) is forced to the limit, $d=0$, we obtain

$$
\mathrm{u} \simeq 1.41 \sqrt{\mathrm{gH}}
$$


In recent hydraulic experiments on tsunami bore propagation, Fukui, et al (1963), use a modified form of Lamb's Eq. (D-6) for comparison with their measurements. This modification takes the form

$$
u=\left[\frac{g(d+H)(2 d+H)}{2\{d+H(1-\delta)\}}\right]^{1 / 2}
$$

The "disturbance" coefficient $\delta$ is a resistance term which the author derived experimentally for a bed roughness equivalent to a Manning's n of 0.013 . Derived as a function of $d /(d+H), \delta$ was found to vary from 0.83 at $d=0$ to 1.03 for $d /(d+H)>0.5$.

It is convenient to render Eq. (D-12) in the alternative form

$$
u=\sqrt{\mathrm{dH}}\left[\frac{(1+\mathrm{d} / \mathrm{H})(1+2 \mathrm{~d} / \mathrm{H})}{2\{(1-\delta)+\mathrm{d} / \mathrm{H}\}}\right]^{1 / 2}
$$

and thence find, for the special case of interest of the propagation of a bore over a dry bed $(\mathrm{d}=0, \quad \delta=0.83)$

$$
u=1.73 \sqrt{\mathrm{gH}}
$$

A more recent series of experiments on tsunami surges has been made by Cross (1966, 1967), from whose work Fig. 99 (in the text) has been reproduced. Cross reviews some of the features we have discussed above and in his more complete report (Cross, 1966) discusses the work of Dressler (1952) and of Whitham (1955) relative to the dam-break problem. These authors results are quite similar in showing that the factor $\mathrm{u} / \sqrt{\mathrm{gH}}$ tends to decrease rather rapidly from the value 2.0 for a frictionless 
condition to about 0.7 for high bed resistance. Cross' own experiments for the case of simulated tsunami surges travelling over a relatively smooth bed (Chezy coefficient $C \simeq 98$ ), yield a consistent result for different values of surge height $H$

$$
\frac{\mathrm{u}}{\sqrt{\mathrm{gH}}} \simeq 1.41
$$

which fortuitously agrees with Eq. (D-11).

There remains to mention the work of Matlock et al (1962), recently condensed in a paper by Reese and Matlock (1967); whose post-mortem analysis of the damage caused by the Chilean tsunami at Hilo, Hawaii, in 1960, attempted to identify the forces and velocities of the bore, known to have been responsible for a great deal of the damage. In all but one case of structural failure, of the ten cases examined, the force necessary to cause failure was calculated and correlated with a force based on pure fluid drag, namely

$$
\mathrm{F}=\frac{1}{2} \mathrm{C}_{\mathrm{D}} \rho \mathrm{Au^{2 }}
$$

in which $C_{D}$ is a dimensionless drag coefficient appropriate to the fluid flow and the shape of the structural obstacle, $\rho$ the mass density of water, A the projected area of the obstacle normal to the flow, and $u$ the stream velocity bearing on the structure. The essential outcome of their study was to show that the velocities computed as being necessary to cause the structural failures were in a range consistent with water velocities for the bore based on Eq. (D-6) or its simplification for surge over a dry bed such as Eq. (D-8). 
It seems reasonable to conclude from the foregoing discussion that the velocity of the water $u_{s}$ at the front of a bore or surge advancing over dry land as an inundation, or over a channel bed that has been emptied by a preceding withdrawal of water will be fairly well represented by the formula

$$
u_{s}=K \sqrt{g_{s}}
$$

in which $d_{s}$ is the height of the general surge level above the land level at any point occupied by the front of the surge, and $K$ is a numerical coefficient with a value between say 1.5 and 2.0 . For conservative design purposes it would seem desirable to adopt the value $K=2.0$.

We return to our comment made at the beginning of this Appendix regarding the extremely wide range of periods of tsunami waves engendered by the Alaskan earthquake. The findings of this report are that for the most part the very long period waves of the tsunami merely inundated the land like fast-rising tides. Since there was neither wave-breaking nor boreformation in this action, the formulas considered above obviously do not apply. However, we need to know what velocities of flow developed in these cases.

If we consider the crest of a wave of period $T=1.8 \mathrm{hrs}$, to have reached a coastline, it is of interest to determine where its still-water level crossing point would be located, seaward of the coast. To a first approximation we may assume the wave speed to be that of Eq. (4) in the text, so that the quarter wave length $\lambda / 4$ of the wave is given by the definition formula

$$
\frac{\lambda}{4}=\frac{T}{4} \sqrt{g d}
$$


If now we assume a mean depth $\mathrm{d}$, over the quarter wave length, of $128 \mathrm{ft}$. , we find, for $\mathrm{T}=1.8 \mathrm{hrs}$.

$$
\frac{\lambda}{4} \simeq 8.6 \mathrm{n} . \mathrm{mi}
$$

These figures are consistent with a sea bed slope of about 1/200 which is fairly reasonable.

With maximum amplitude of the wave over the coastline, we find (for a sinusoidal wave) that the $1.8 \mathrm{hr}$. wave will have 95 percent of this amplitude at a distance from the crest of about $3.5 \mathrm{n}$. mi. on either side. Because inundation distances from the Alaskan tsunami never exceeded $1 / 2 \mathrm{n}$. mi., it is clear that inundation water level immediately seaward and landward of the coastline would be effectively horizontal. Further, since the surface slope of so large a wave is extremely gradual, the rise of the crest at the coast would be tantamount to the lifting of a virtually horizontal sea level in the time of the quarter wave-period. This argument may be extended successfully to wave periods of much smaller periods at least to $\mathrm{T}=30 \mathrm{mins}$.

Assuming then a $r$ ise of horizontal sea level over the land at the vertical rate $\partial \eta / \partial t$ where $\eta$ is the wave elevation of the wave above still water level at any point, and $t$ is variable time, the continuity condition governing the speed of water over dry land of slope $s$ requires a velocity of horizontal flow per unit width

$$
u=\frac{1}{s} \frac{\partial \eta}{\partial t}
$$

For a sinusoidal wave at the coastline of amplitude $A$ and angular frequency $\sigma$ 


$$
\eta=A \sin \sigma t
$$

and

$$
\frac{\partial \eta}{\partial t}=A \sigma \cos \sigma t
$$

so that from Eqs. (D-20) and (D-22) horizontal velocity per unit width becomes

$$
u=\frac{A \sigma}{s} \cos \sigma t
$$

The flow is therefore periodic and for any given amplitude $A$ and ground slope $s$ is inversely proportional to the wave period. This means, of course, that a 30-minute period wave would have four times as severe a current as a 2 -hour period wave.

In most cases of inundation investigated for the Alaskan tsunami, the flooding was brought about by a superposition of long waves of large amplitude. The nature of the superposition sometimes results in extremely rapid time rates of change of water level $\frac{\partial \eta}{\partial t}$. If tide gage or water level records are available, $\frac{d \eta}{d t}$ is directly measurable from the records and water velocities are then calculable from Eq. (D-20). Obviously if the ground slope $s$ is very slight, water velocities can attain high values. The The dictates of the flow are then governed by hydraulic considerations, as for flow in rivers and canals.

The point of overlap or criterion for which a flow of the type of Eqs. (D-20) and (D-23) can become a tsunami bore or breaking wave is at present not known to the writer and needs further research.

Eq. (D-16) for the force of the flowing water on an obstacle is obviously relevant only if the object is completely enveloped in the flow. 
It is therefore likely to be pertinent to cases of isolated objects of moderate size around which the flood water can establish a regime of flow. In the case of large objects such as continuous breakwaters, sea walls, blocks of buildings, and other objects with large frontages which are liable to deter a cascading bore and obstruct the flow, the effect of both hydrostatic and dynamic pressure and of the destruction or deflection of momentum must be taken into account. This leads to the definition of the force $F$ per unit length of wall, in the form

$$
\mathrm{F}=\frac{1}{2} \rho \mathrm{gd}_{\mathrm{W}}^{2}+\mathrm{C}_{\mathrm{F}} \rho \mathrm{d}_{\mathrm{t}} \mathrm{u}_{\mathrm{s}}^{2}
$$

where $d_{w}$ is the depth of water formed at the wall, $d_{t}$ the depth of water at the toe of the wall before deflection of the stream, $u_{s}$ the surge velocity appropriate to the height $d_{s}$ of the surge (Fig. D-l), $\rho$ the mass density of sea water and $C_{F}$ a dimensionless force coefficient.

This formula is well known in the hydraulics of river and canal flow (cf., for example, Francis, 1958), although usually without the inclusion of the coefficient $C_{F}$. Cross (1966, 1967), who introduces the equation to the study of tsunami surges has evaluated the coefficient $\mathrm{C}_{\mathrm{F}}$ on the basis of theoretical work by Cumberbatch (1960), in which the impingement of a water-wedge normal to a plane wall was analyzed. Cross finds a nonlinear dependence of $C_{F}$ on the slope of the water surface of the wedge or the angle $\phi$ (Fig. D-1) such that for $\phi=0, C_{F}=1.0 ;$ and $\phi=60^{\circ}$, $\mathrm{C}_{\mathrm{F}} \simeq 3.0$.

In his experiments on tsunami surges, Cross found that a peak force developed on the experimental wall after the initial build-up of force, 


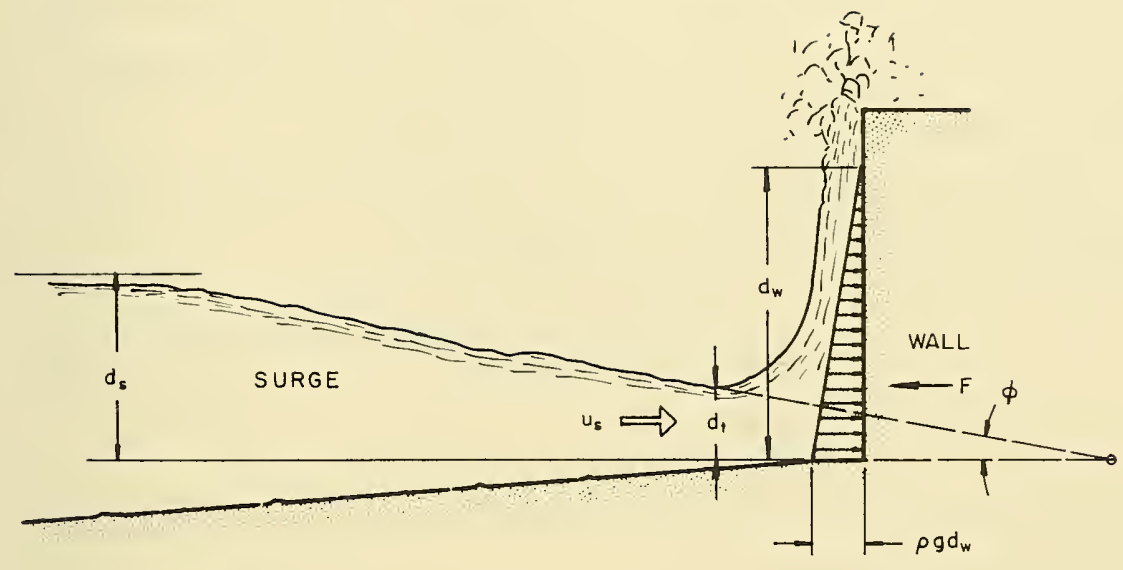

Figure D-1 Schematic Diagram of Impulsive Force of a Tsunami Surge on a Wall 
following which the force remained approximately constant or diminished slightly. The effective height of run-up $\mathrm{d}_{w}$ on the wall (Fig. D-1) showed approximate linear relationship to $u_{s}^{2} / 2 g$, as might be expected, yielding $\mathrm{d}_{\mathrm{w}} /\left(\mathrm{u}_{\mathrm{s}}^{2} / 2 \mathrm{~g}\right)$ values of about 2.0 for a wet bottom and 1.5 for a dry bed in front of the surge. The peak pressure occurred, apparently, when this run-up collapsed on the reflecting bore, which formed at that moment and moved away from the wall. The fairly quiet water left behind exerted effectively only hydrostatic pressure against the wall.

For the case of a fairly flat surge, we may take $d_{t} \simeq d_{s} ; C_{F} \simeq 1$ and apply to Eq. (D-24) the observation that

$$
\frac{\mathrm{d}_{\mathrm{w}}}{\left(\frac{\mathrm{u}_{\mathrm{s}}^{2}}{2 \mathrm{~g}}\right)}=1.5 \text { to } 2.0
$$

and the earlier conclusion of Eq. (D-17) with $K=1.5$ to 2.0. Eq. (D-24) then reduces to the simplified form

$$
\mathrm{F} \simeq 7 \rho \mathrm{gd}_{\mathrm{s}}^{2}
$$

which is quite similar to a result obtained by Wiegel (1967) by this type of reasoning. It must be noted that if $d_{s}$ exceeds the height of the wall or structure, due allowance would have to be made for the overtopping flow, which would reduce the numerical coefficient in Eq. (D-26). The latter, otherwise, says that the dynamic force per unit length on a wall-type structure is about 14 times the hydrostatic force from a tsunami surge. 
APPENDIX E

ESTIMATES OF DAMAGE

CAUSED BY THE ALASKAN TSUNAMI OF MARCH 1964 



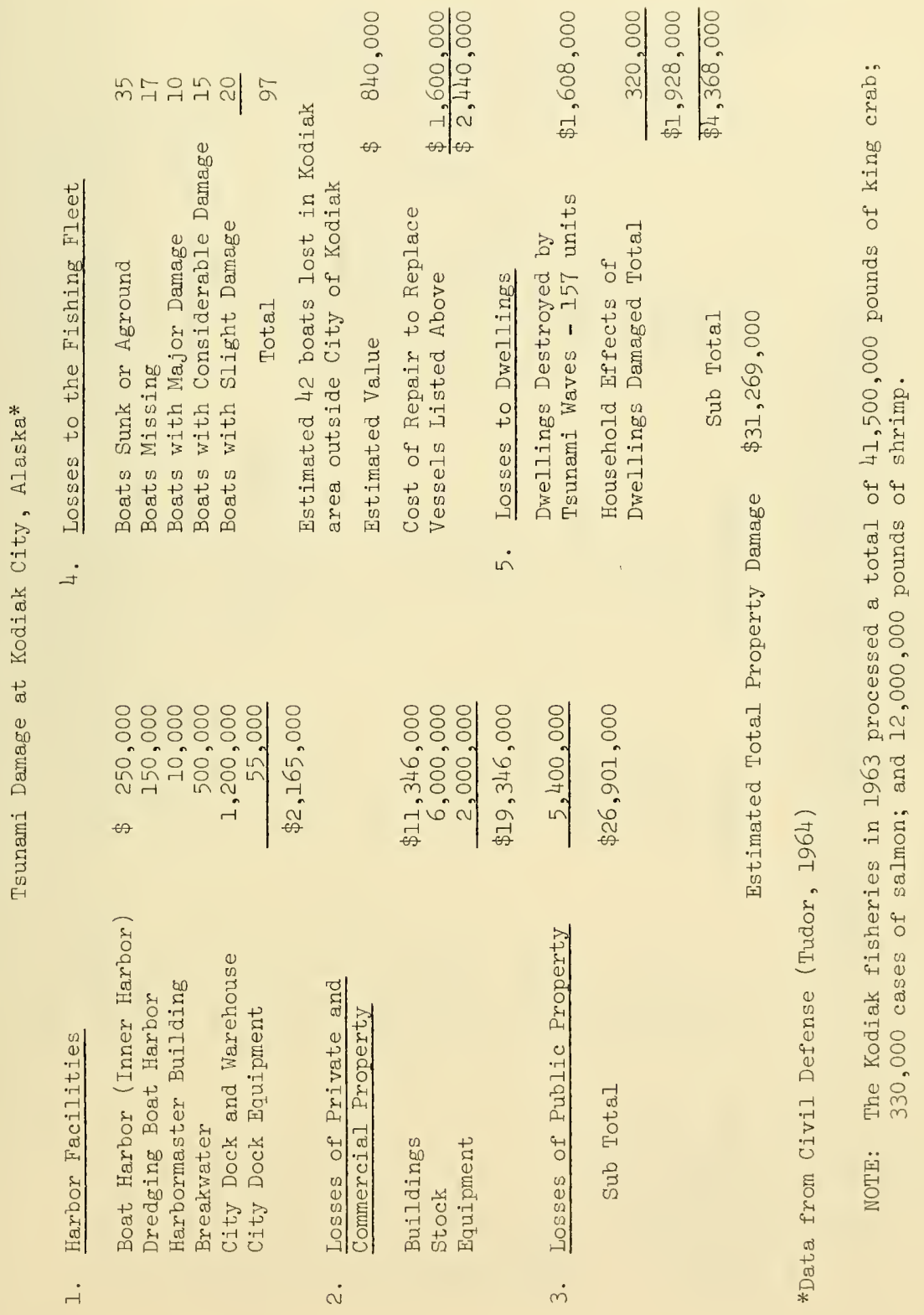




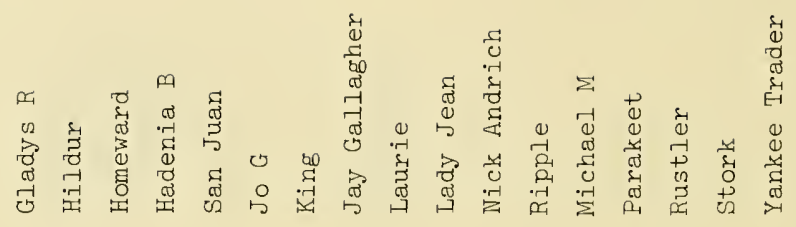

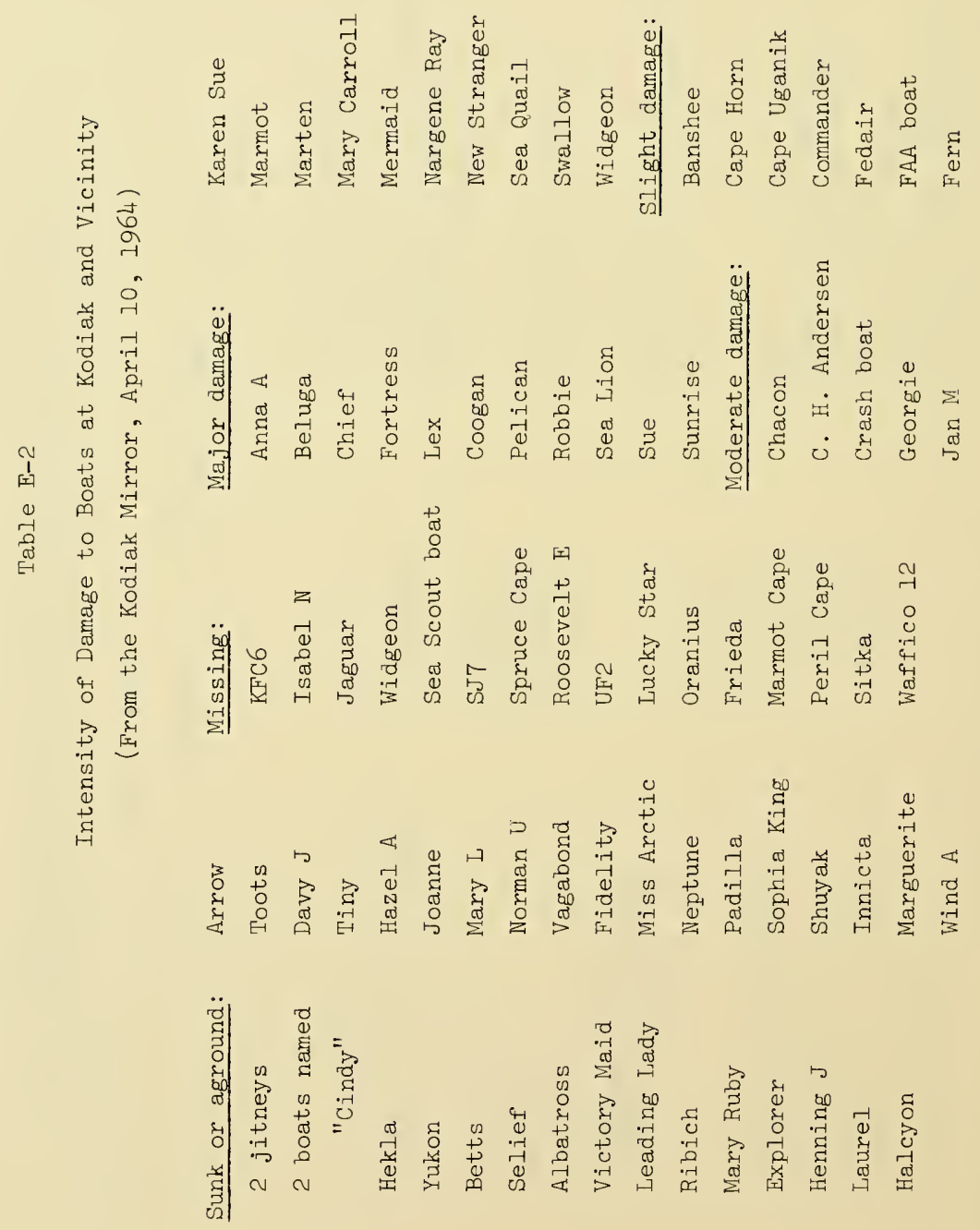



Description and Cost of Restoration or Replacement of Facilities at Kodiak Naval Station, Damaged by the Earthquake or Tsunami*

Description

Rebuild roads and bridges NAVSTA

to Holiday Beach

200 KW Generator Holiday Beach

Central Power Plant

Repair Hangars 1, 2, 3: and aprons

Repair AUW Facility

Microwave Installation

Repair Runway Ends and Shoulders

Repair Runway Lights

Replace Generators (OPCON)

Marginal Pier (new)

Repair Crash Boathouse

Diving Gear and Boathouse

Repair Station Electrical

Repair Rawin Aerological Building

Repair Fuel Pier S-40

Repair Shop (Coast Guard) \#22

Public Works Maintenance Shop

Repair Crash Fire Station

Repair Aviation Warehouse

*Data from Kachadoorian and Plafker, 1967
Estimated Cost

$\$ 1,677,000$

147,500

177,500

936,400

35,400

900,000

215,000

17,200

31,000

$1,716,000$

29,800

75,000

61,750

13,200

37,900

6,200

22,400

88,500

14,500

$\$ 6,202,250$ 
Losses of Property and Income in Communities on Kodiak Island and Nearby Islands*

Estimated Location Nature of Damage Replacement Cost

Kodiak

Afognak**

Old Harbor

Uzinki

Kaguyak**

Larsen Bay

Akhiok

All Communities

Al1 Communities

Kodiak Naval

Station

\section{Losses of private, commercial and public property}

Losses of public \& private property

"

11

$"$

"I

$"$

Vessels damaged

Loss of income to fishing industry

Damage to structures and equipment

Total Losses

$$
\begin{array}{r}
\$ 24,736,000^{(1)} \\
816,000^{(2)} \\
707,000^{(2)} \\
349,800^{(2)} \\
321,000^{(2)} \\
80,000^{(2)} \\
\text { None } \\
2,466,500^{(3)} \\
5,087,000^{(3)}
\end{array}
$$

* From Kachadoorian and Plafker, 1967

* Village site abandoned

(1) Data from Tudor (1964)

(2) Data from Bureau of Indian Affairs (9/25/64)

(3) Data from Alaska Department of Fish and Game (1965) 
TABLE E-5

List of Casualties and Major Damage due

to the Tsunami of March 1964

Location

Alaska

Cape St. Elias

Chenega

Cordova

Kaguyak

Kalsin Bay

Kodiak

Kodiak Naval Station

Old Harbor

Ouzinkie

Port Ashton

Port Nellie Juan

Port Nowell

Seldovia

Seward

Spruce Cape

Valdez

Whitshed

Whittier
8

1

12

31

1

23

$-$

3

6

$-$

$-$

1

3

1

-

3

1

13
Damage (\$)

$$
100,000
$$

$1,775,000^{\text {(a) }}$

50,000

- -

$$
150,000
$$$$
500,000^{(c)}
$$

$31,279,000^{(b)}$ (23,714,000 private;

$7,565,000$ public)

$10,300,000^{(b)}$$$
\text { - . }
$$

.




\section{Canada}

Alberni-Port Alberni

Hot Springs

Zeballos

Uregon (d)

Cannon Beach

Florence

Newport

Seaside

Waldport-Alsea

California (e)

Crescent City

Long Beach Harbor

Los Angeles

Marin County

Noyo Harbor

Hawaii (f)

Hilo

Maui
11

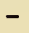

$-$

$-$

$-$ (Civil Defense estimated damage of $\$ 5$ million, excluding damage to heavy industry and private autos) 100,000 150,000 230,000 50,000

4

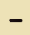

276,000 160,000 $7,414,000$ 100,000 175,000 to 275,000 $1,000,000$ 250,000 to $1,000,000$

(a) Anchorage Daily News, April 19, 1964

(b) Tudor, 1964

(c) Daily Alaska Empire, March 31, 1964

(d) Sandstrom, 1964

(e) California Disaster Office, 1964

(f) Stevenson, 1964.

$$
E-6
$$




\section{TABLE E-6}

\section{Casualties and Damage along the Oregon Coast \\ from the Tsunami of March 1964*}

The Civil Defense Agency reported that four children, who were camping with their parents on the beach near Newport, were drowned.

Location

Bandon

Cannon Beach

Chetco

Coos Bay

Iepoe Bay

Florence

Port Orford

Rogue River

Seaside Area

Tillamook

Umpqua

Waldport-Alsea Area

Warrenton

Yaquina

*From Spaeth and Berkman, 1967.

* Damage estimates supplied by Civil Defense

\section{Damage**}

Negligible

City, \$50,000; Private, $\$ 180,000$

Negligible

$\$ 20,000$

$$
5,000
$$

50,000

Negligible

$\$ 3,000$

City, \$41,000; Private, \$235,000

Negligible

$\$ 5,000$

Port Facilities, $\$ 145,000$;

Private, $\$ 15,000$

Negligible

$\$ 5,000$ 
Casualties and Damage at Crescent City, California from the Tsunami of March 1964*

Eleven persons lost their lives at Crescent City as a result of the Tsunami. Approximately 30 blocks were devastated. The California Disaster Office reported damages, excerpted from a report of the California Department of General Services, as follows:

$\begin{array}{lc}\text { Residences total loss } & 54 \\ \text { Residences sustained major damage } & 13 \\ \text { Residences sustained minor damage } & 24 \\ \text { Commercial fishing boats lost (sunk or beached) } & 21 \\ \text { House trailers total loss } & 12 \\ \text { Business houses severely damaged or destroyed } & 172\end{array}$

Estimated cost to replace and repair:

$\begin{array}{lr}\text { Public Property } & \$ 473,000 \\ \text { Private Utilities } & 68,000 \\ \text { Private Property } & \$ 6,873,000 \\ \text { Total Estimated Cost } & \$ 7,414,000\end{array}$

*From Spaeth and Berkman, 1967 
of

3

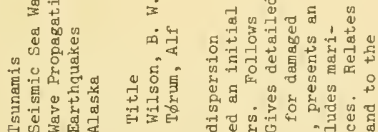

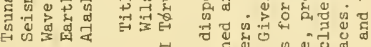

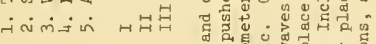

넌

on

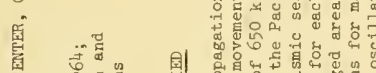

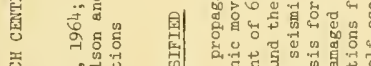

近

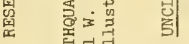

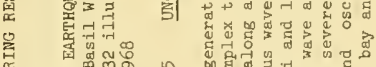

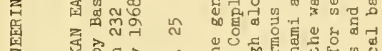

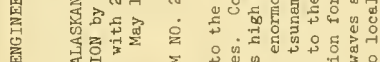

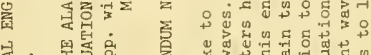

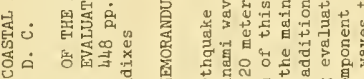

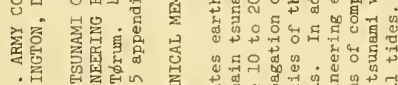

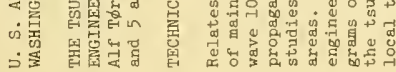

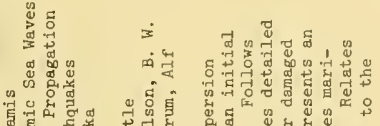

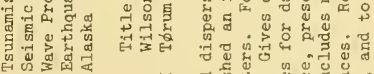

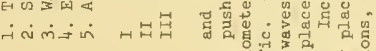

田 $\quad \ldots$ 苛

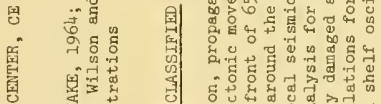

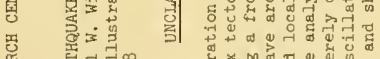

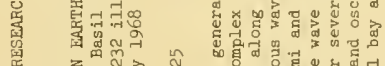

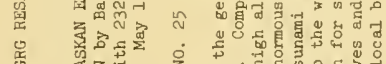

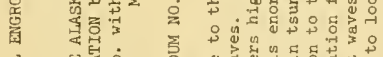

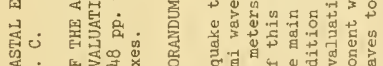

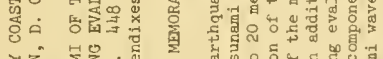

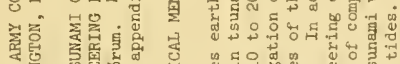

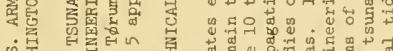

v

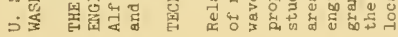

赵:

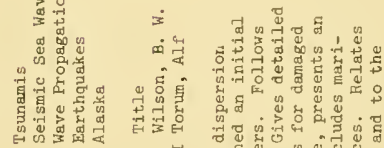
क प्रुण की

떵

鼻

鼻

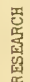

苗

密

殏

角

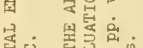

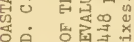

ठํ.

竞芯

的䓟

b. 这

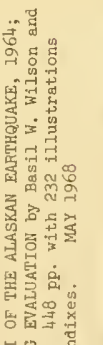
co

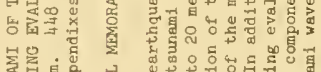

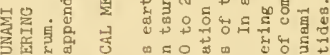

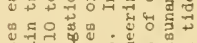

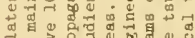
o

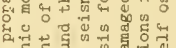
(1) ज a

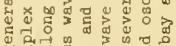

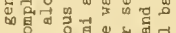

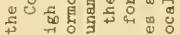

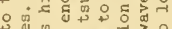
ข

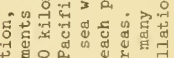

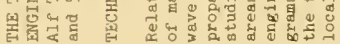


Casualties and Dame

from the Tsi

Eleven persons lost their lit Tsunami. Approximately 30 b] Disaster Office reported dame California Department of Gent

\author{
Residences total loss \\ Residences sustained majc \\ Residences sustained minc \\ Commercial fishing boats \\ House trailers total loss \\ Business houses severely
}

\author{
Estimated cost to $r t$ \\ Public Property \\ Private Utilities \\ Private Property \\ Total Estimated C
}

*From Spaeth and Berkman, 196 


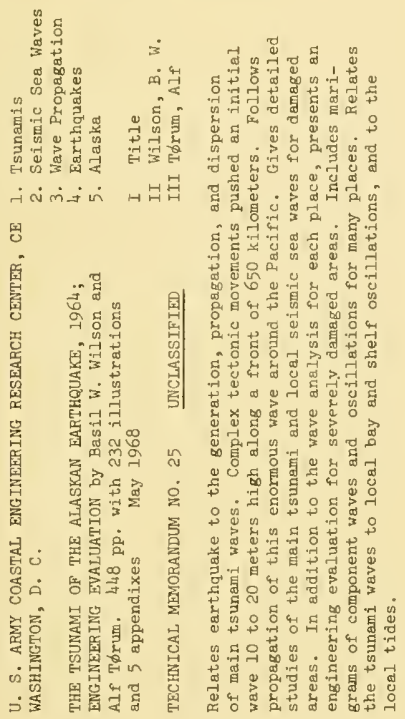

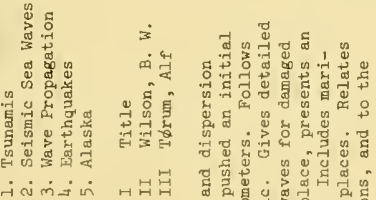

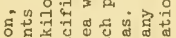

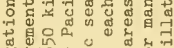

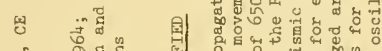

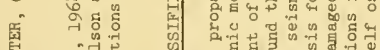
ब건

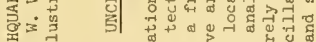

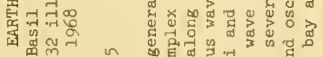

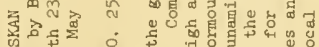

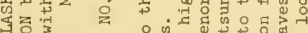

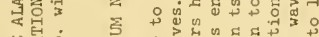

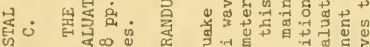

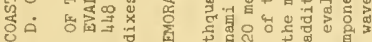

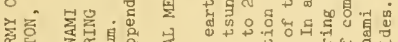

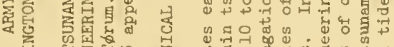

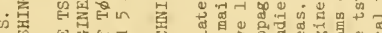

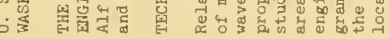

常

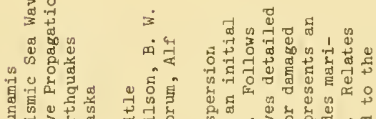

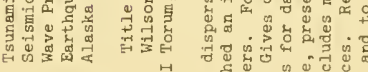

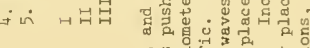
봉

嘼

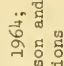
बैन 的

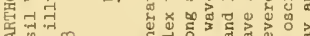

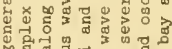

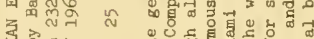

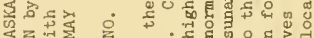

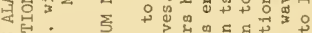

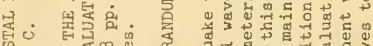

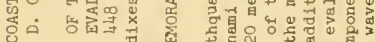

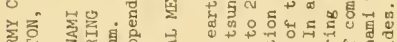

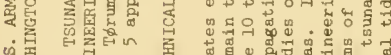
in 죾

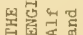


Casualties and Dam: from the Tsi

Eleven persons lost their $1 i$ T Tsunami. Approximately $30 \mathrm{~b}$. Disaster Office reported dam: California Department of Gent

Residences total loss

Residences sustained majc Residences sustained minc Commercial fishing boats House trailers total loss Business houses severely 

